
Frauke Reitemeier (ed.) Strangers, Migrants, Exiles

This work is licensed under the Creative Commons License 3.0 "by-nd", allowing you to download, distribute and print the document in a few copies for private or educational use, given that the document stays unchanged and the creator is mentioned. You are not allowed to sell copies of the free version.

\begin{tabular}{|c|}
\hline C) \\
SOLIERIGHIS RESERVED
\end{tabular} 
erschienen in der Reihe der Universitätsdrucke im Universitätsverlag Göttingen 2012 
Frauke Reitemeier (ed.)

Strangers, Migrants, Exiles

Negotiating Identity

in Literature

Göttinger Schriften zur

Englischen Philologie, Band 6

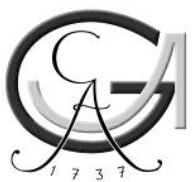

Universitätsverlag Göttingen

2012 


\section{Bibliographische Information der Deutschen Nationalbibliothek}

Die Deutsche Nationalbibliothek verzeichnet diese Publikation in der Deutschen Nationalbibliographie; detaillierte bibliographische Daten sind im Internet über $<$ http://dnb.ddb.de $>$ abrufbar.

Anschrift der Herausgeberin

Frauke Reitemeier

Seminar für Englische Philologie

Käte-Hamburger-Weg 3

37073 Göttingen

e-mail: Frauke.Reitemeier@phil.uni-goettingen.de

This work is protected by German Intellectual Property Right Law.

It is also available as an Open Access version through the publisher's homepage and the Online Catalogue of the State and University Library of Goettingen

(http://www.sub.uni-goettingen.de). Users of the free online version are invited to read, download and distribute it. Users may also print a small number for educational or private use. However they may not sell print versions of the online book.

Satz und Layout: Frauke Reitemeier

Umschlaggestaltung: Franziska Lorenz

(C) 2012 Universitätsverlag Göttingen

http:/ / univerlag.uni-goettingen.de

ISBN: 978-3-86395-033-0

ISSN: $1868-3878$ 
Table of Contents

Introduction (FRAUKE REITEMEIER) ............................................................... 7

Lord Byron's Descendants (VANESSA MANGIONE) ............................................... 11

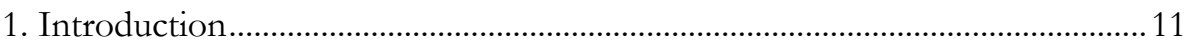

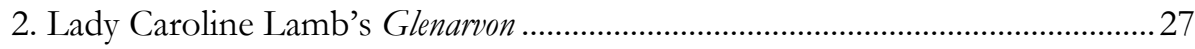

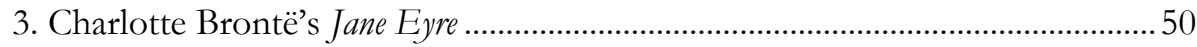

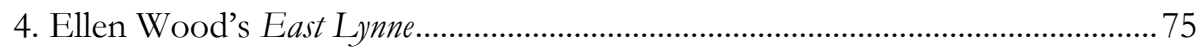

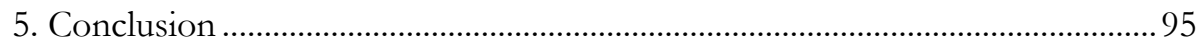

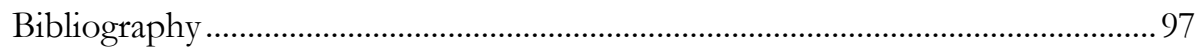

Indian Diamonds in Victorian Fiction (SABINA FAZLI) .......................................... 103

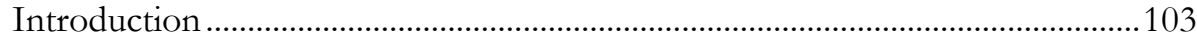

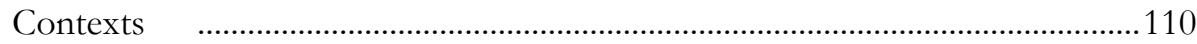

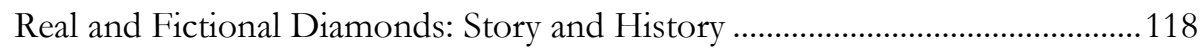

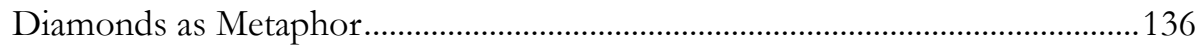

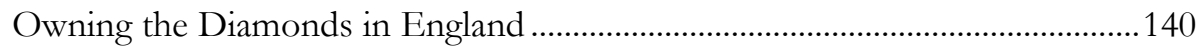

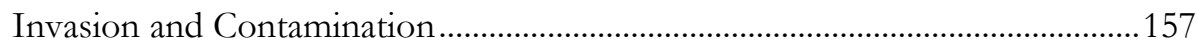

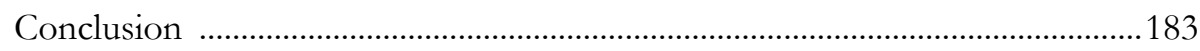

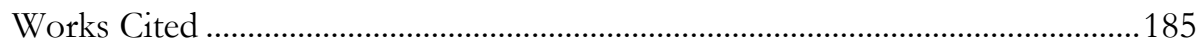

The Construction of Identity in Northern Ireland (MELANIE SWIATLOCH)..........193

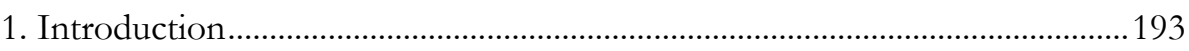

2. Language Matters in Northern Ireland..........................................................195

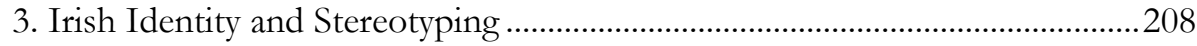

4. Conflict in Northern Ireland - The Land of Many Oranges and Greens ....244

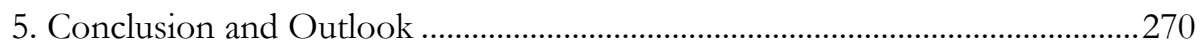

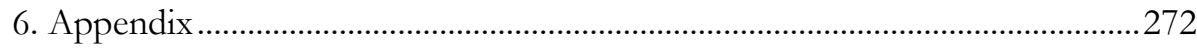

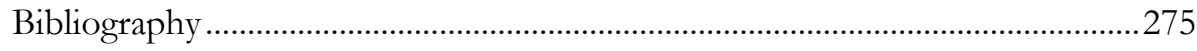

Transnational Identities in Michael Ondaatje’s Fiction (SONJA LEHMANN) .........281

1. Introduction: Transnational Identities in Michael Ondaatje’s Fiction ..........281 


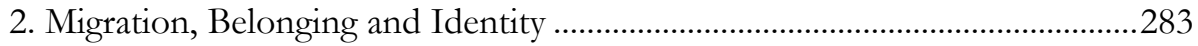

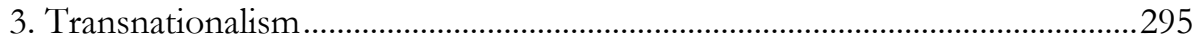

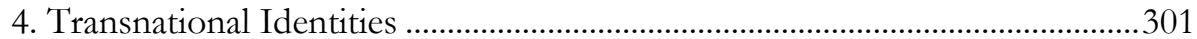

5. Transnational Identities in Ondaatje's Fiction .................................................307

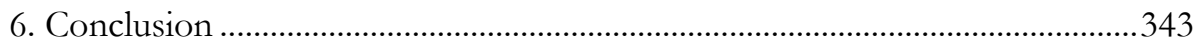

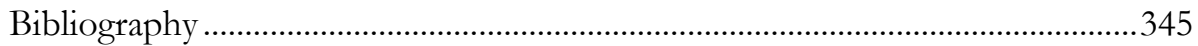

„Göttinger Schriften zur Englischen Philologie“:

Zum Konzept der Reihe (FRAUKE REITEMEIER) .............................................353 
Frauke Reitemeier

\section{Introduction}

"Who am I?" For users of Unix operating systems, whoami is a command that gives the name that the user is working under. For psychologists and psychiatrists, it is the question that many patients ask themselves, trying to pin down the main 'ingredients' of their personality. In 2009, Richard David Precht published Wer bin ich - und wenn ja, wie viele? (Who am I - and If so, How Many?), subtitled "a philosophical journey". Unlike many other self-help books Precht's deals with the important questions in life: What is truth? Where do we come from? What is it that I am morally obliged to do, and why? As such, it is a short introduction to philosophy, and the question of who one is also belongs to this area. "Who am I?", then, seems to be one of the key questions of humanity.

In philosophy, sociology, and psychology, it asks for the definition of an identity. According to the OED, 'identity' denotes

a. The sameness of a person or thing at all times or in all circumstances; the condition of being a single individual; the fact that a person or thing is itself and not something else; individuality, personality.

b. Who or what a person or thing is; a distinct impression of a single person or thing presented to or perceived by others; a set of characteristics or a description that distinguishes a person or thing from others. (OED, s.v. identity') 
Identity, then, is seen as something that is largely immutable ("sameness [...] at all times or in all circumstances") and as unique ("that distinguishes a person $[\ldots]$ from others"). The idea is that someone - or something, or even a group of someones - has features that sets him/her/them apart from everyone else, and that remain stable even if circumstances change. But just who "am" I, or who "are" we, and how do we find out?

The perception of oneself differs from the way others see us, and the selfconcept of an individual must be considered as different from the way $\mathrm{s} / \mathrm{he}$ is seen from the outside. Many aspects come into play: an individual's dreams and aspirations, his/her abilities and disabilities - real or perceived - , his/her interaction with others, his/her physical constitution, to name but a few. Sociologists have suggested that identity is created on two different levels, on an individual or personal and a social level. Essentially this describes the difference between referring to oneself as ' $\mathrm{I}$ ' as opposed to making statements about 'us', meaning 'I and others like me' and creating a group identity that is seen as distinct from the identity of 'them'.

With respect to literature and literary analysis, questions of identity matter very much: Whenever we look for characteristics of this or that fictitious character we are interested in the way his/her identity is formed and formulated, part of which is apparent in the group or groups the character belongs to. Whenever we analyse the behaviour of a narrator we try to pin down not only his/her identity as an intermediator between the reader and what happens in the story, but also investigate the relationship between narrator and fictitious characters. There is more to that, though. Many texts deal with questions of group identity; Romeo and Juliet are separated by group boundaries that are formed by kinship, for example, and novels like Sir Walter Scott's Ivanhoe or Waverley depict conflicts between groups that are delimited by belonging to a specific 'race' or political persuasion. The four essays in this volume reflect various aspects of identity and its (literary) construction.

The first two papers focus on the formation of characters, on patterns of identity, in nineteenth-century literature. Ever since the publication of Daniel Defoe's Robinson Crusoe, readers have been faced with characters that were (and are) seen to be modelled on 'real life'. In the first decades of the nineteenth century, George Gordon Lord Byron became infamous not only for his scandalous love-life but also for his poems which, in their male protagonists, largely reflected the image he created of himself. Readers were fascinated, and the 'Byronic hero' became a literary staple. Vanessa Mangione follows the variations of this very special kind of anti-hero through some of the best-known nineteenth-century novels written by female authors. Drawing on Kristeva's terminology of the symbolic and the semiotic she explains why the Byronic hero was so interesting and yet so challenging to the authors and their readers. At the same time she traces a closely related and 
very modern discussion: that on the rights and duties especially of women, but also of men.

The nineteenth century does not only witness the first novelists that can be considered as feminists, it also sees the rise of the British Empire. Sabina Fazli looks at another very modern feature of nineteenth-century literature: Authors like Arthur Conan Doyle, Wilkie Collins and Anthony Trollope use Indian diamonds to represent facets of nationality and a very specific concept of 'civilisation'. Fazli points out that diamonds have always been the subject of myths and legends, and these are taken over into sensationalist novels and the budding crime literature. They serve to characterise women as frail vessels that must be protected - because they are very good at losing the very valuable stones - , but at the same time they introduce an element of the Orient to England, and one that is directly connected to criminality as they "poison" minds (183) and make otherwise rational men commit acts of murder and treachery.

The following two papers are concerned with the creation of identity in national and transnational contexts. The early twentieth century saw the disintegration of the Empire. Discontent had long simmered in India but also closer to home, in Ireland. Throughout the nineteenth century there had been attempts to create a greater autonomy for Ireland, and in 1893 the Second Home Rule Bill was passed in the House of Commons though vetoed in the House of Lords. It was only in 1914 that the Home Rule Bill was passed by both Houses, but with the outbreak of the First World War the implementation was deferred. From 1921, Ireland was a divided country, comprising the Republic of Ireland and Northern Ireland. This also sparked a debate about the constitutional status of Northern Ireland and provoked what became known as 'the Troubles', a series of conflicts between (mainly Catholic) nationalists that were interested in a closer relationship with the Republic and (mainly Protestant) unionists intent on remaining a part of Great Britain. 'The Troubles' found their way into literature, too. Melanie Swiatloch shows how contemporary Irish novelists negotiate the difficulties of positioning their characters within the framework of religion and politics, moving between past, present and a vision of the future. Questions of how to relate to the 'Other' are raised and answered differently in the texts Swiatloch discusses; yet in all novels, some kind of national identity is created and altered through the lives of the protagonists.

The final paper in this collection is also concerned with questions of national identity, but Sonja Lehmann does not restrict herself to one geographic region. Instead she focuses on the work of a novelist whose very biography is transnational: Michael Ondaatje was born in Sri Lanka in 1943 to parents of TamilDutch origin; his family moved to England in 1954, and in 1962 Ondaatje emigrated to Canada. He holds both the Sri Lankan and the Canadian nationalities. Many of his texts focus on the experience of migration and the resulting mental and physical homelessness - another aspect of identity. 
'Them' and 'Us' are important categories, not only in theories of nationhood but also with respect to the social positioning of individuals. The papers collected in this volume illustrate how very relevant this dichotomy has been for authors and readers from 1800 onwards. Each of the papers was accepted as a master's thesis between 2009 and 2010 and was chosen for inclusion both for the authors' competence in using theories and for their unusual topics. As such, they are valuable additions to literary criticism; at the same time they show the level of competence students can attain at Göttingen university.

Bibliography

Bhabha, Homi K. The Location of Culture. London: Routledge, 1994.

"identity, n." Oxford English Dictionary 3rd edition 2010. OED Online June 2011). Oxford: Oxford UP. Retrieved Aug 16, 2011. Online at http://dictionary.oed.com.

Turner, J. C., and P. J. Oakes (1997): "The socially structured mind", in C. McGarty and S. A. Haslam (Eds.), The Message of Social Psychology: Perspectives on Mind in Society). Oxford: Blackwell, 355-373. 
Vanessa Mangione

\section{Lord Byron's Descendants \\ The Byronic Hero in Lady Caroline Lamb, Charlotte Brontë, and Ellen Wood as a Feminine Critique of Constricting Gender Roles in the Nineteenth Century}

\section{Introduction}

\subsection{The Byronic Hero}

About three things I was absolutely positive. First, Edward was a vampire. Second, there was a part of him - and I didn't know how potent that part might be - that thirsted for my blood. And third, I was unconditionally and irrevocably in love with him. (Meyer 171)

He closed his eyes, lost in his agonized confession. I listened, more eager than rational. Common sense told me I should be terrified ... [but] I was 
filled with compassion for his suffering, even now, as he confessed his craving to take my life. (Meyer 238)

In 2003, Stephenie Meyer, author of the Twilight Saga, had a dream about a girl and a vampire in a meadow. She turned her dream into a book and became one of the bestselling authors of our time (Lev Grossman). The first book was soon turned into a movie and its male lead, Robert Pattinson, became a star over night. By portraying the mysterious, handsome, guilt-ridden and tortured vampire Edward Cullen, Pattinson strongly evokes characteristics of a well-known literary persona, the Byronic hero. ${ }^{1}$ These characteristics combined with a bitter outlook on the world that has resulted from an incident against which he was powerless and can never break away from are qualities that are commonly connected to the Byronic hero. This persona seems to have struck a chord since it has aroused an intense emotional response within the female readership, precisely as it did back in 1812 when the first Byronic hero appeared in the form of Lord Byron's Childe Harold and won the public over. Henceforth, Byron's heroes dominated the literature of the Romantic period and emerged in numerous variations through the decades. Those heroes are represented in the term of the "Byronic Hero".

The Byronic hero has been a prominent figure in literary fiction since the early nineteenth century and still dominates popular modern romances. He appears, although slightly transformed, in modern vampire fiction, such as Stephenie Meyer's Twilight Saga, in novels by Anne Rice, but also as the dark lover in historical novels by authors like Barbara Cartland, Victoria Holt and Elisabeth Chadwick. They all make excessive use of the tortured hero. He appears in Margaret Mitchell's Gone with the Wind, where he emerges in the shape of Rhett Butler, a dandified version of the original dark lover. During the nineteenth century, the persona of the Byronic hero dominated sensational, Silver fork and Newgate novels. Famous authors like Oscar Wilde, Charles Dickens, Edward Bulwer-Lytton and Benjamin Disraeli are said to have been strongly influenced by Byron's creation and portrayed him in many varying and sometimes opposing forms, as the dark Gothic lover, the soulless seducer or the superficial dandy (Lutz 60).

During the Romantic period, a growing fascination with a wild and melancholy facet of nature arose. Thus the adjective "romantic" does not only refer to a specific literary genre but is attributed to the combination of beautiful and terrifying aspects of nature. Praz advocates in his book The Romantic Agony the thesis that a new erotic sensibility emerged within the Romantic period. According to him, this new sensibility was a perverse one in which contradicting sensations such as tenderness and sadism, pleasure and pain, and love and hate are inseparably connected to each other. Hence, Praz argues that the Romantics took pleasure in the

1 There has always been a notion to link Byron to vampires as Dr. Polidori's, Byron's physician, short story The Vampyre was thought to be written by Byron. Although both confirmed that this was not the case, the connection between Byron and vampires never ceased to be. 
horrid and saw beauty in the bizarre. ${ }^{2}$ Furthermore, he states that an interaction between pleasure and suffering has always existed but "became a common inheritance of the Romantic and Decadent sensibility through a particular chain of literary influences" (Praz xiv). An example of this connection between perverse sensations can be seen in Percy Bysshe Shelley's poem On the Medusa of Leonardo da Vinci: "Tis the tempestuous loveliness of terror" (1. 33). The combination of pleasure and pain is clearly demonstrated in this single line. Suddenly beauty was found in objects that actually should evoke a shudder. ${ }^{3}$

Accordingly, a novel sense of beauty arose which also changed the relationship to horror that was discovered as a new source of beauty and delight. Horror not only became a different form of beauty but also was suddenly one of its indispensable elements. Praz states that the "beautifully horrid" became "horribly beautiful" (27), and although this is not an entirely new concept, as it has existed before, only within the Romantic period has it been recognised and brought to attention. However, the concept of pain as an essential part of desire was entirely new. Another good example of this concept can be found in a different one of Shelley's works To the Skylark: "Our sweetest songs are those that tell of saddest thought" (1. 90). Praz comments on this concept of the sublime: "all through the literature of Romanticism, down to our own times, there is an insistence on this theory of the inseparability of pleasure and pain, and on the practical side, a search for themes of tormented, contaminated beauty" (28).

Within this new concept the Byronic hero was born. This literary persona is described by critics as "fatal homme" (Wilson, Introduction 7), a "passionate hero with a darkly mysterious past" (Elfenbein 9), carrying a burnt-out passion and secret sins ${ }^{4}$ He mainly appears as an immensely proud aristocrat, who tries to hide a secret and sinful past, and his tortured appearance evoked by his remorse is the very thing that attracts women. Furthermore, Thorslev states that he is primarily a lover, his passions are far more subjective and intense than those of other Romantic heroes; love is for him the one ruling passion in his life, on which he bases every other action. The Byronic lover remains faithful to his one and only love until his death. Moreover, Thorslev argues that an air of a fallen angel surrounds this persona, who is on a pilgrimage in search of relief for his past sins, for selfrestoration, although he knows that he will never find what he is seeking and that he will wander in eternal remorse $(136,148-50)$. Pesta adds that Byronic characteristics also include "warmth without light, heat without sun and a burning passion

2 Mentioned here is the sublime, a Romantic concept that describes an idea associated with awe, vastness, natural splendour and glory and strong emotion. It refers to an incomparable magnificence.

3 In A Philosophical Enquiry into the Origin of Our Ideas of the Sublime and Beautiful (1757) Edmund Burke discusses the connection between terror and the sublime and its distinction from beauty. In terror he saw obscurity, darkness, power, vastness, and solitude, while he associated beauty with light, delicacy, smallness and smoothness.

4 This notion characterizes the Romantic concept of love: Love is perpetual longing and pain. 
that is self-consuming in its intensity (62). Lutz agrees with Thorslev that the Byronic hero is primarily a lover; she adds that his whole existence is based on this all-consuming love that will however, never be fulfilled. ${ }^{5}$ Lutz defines the very essence of the Byronic hero most accurately:

The Byronic philosophy sees love as the ultimate, and only, essential truth and final resting place for one in this life. Love is the only force that still holds meaning. [...] The very foundations of love for the Byronic hero are based on failure and forgetting of what is possible. The Byronic hero in its purity can, by definition, never be redeemed by becoming a couple, he is interminably thrown back upon black despair; he is unremitting cast adrift into absence and dark night. In The Corsair, Conrad loses Medora because she pines away when she thinks he is dead. In The Giaour, Leila is murdered by her master because of her love for the Giaour, and the Giaour's life becomes one of vengeance against her murderer and then a tortured living in the past of his life. In Manfred, Astarte has died because of his unspecific sin. But finally the hero fails because this is the definition of the Byronic hero. He is the tormented melancholy failure who nears success and then fails and experiences eternal loss, the repetition of the impossibility of bliss. He retains his status as the outcast, the dangerous lover whose subjectivity is as large and as impoverished as the world. (52)

The Byronic hero has never had a chance of being either redeemed or fulfilled by his true love as his story often begins when it is already over, namely after the death of his love and he feels that his life and being have lost all meaning and purpose. Often he has been outlawed and robbed of his inheritance and status in society by envious relatives who have murdered his father. Thus, he turned him into a misanthrope who is isolated from society.

In addition, Thorslev states that "the Romantic heroes epitomized many of the most important aspects of Romanticism, and the Byronic hero shows the elements of every major type of Romantic hero" (4). Consequently, according to Thorslev, the Byronic hero is a combination of every major pre-existing type of hero. He represents characteristics of the "Child of Nature", "Hero of Sensibility", "Gothic Villain", "Faust" and "Cain" and "Prometheus". These Romantic heroes, whose genesis started in the Bible, and are then used by the likes of Shakespeare and then later Milton finally accumulate in the Romantic period in the Byronic hero. However, the question concerning the origin and development of Byron's creation continues to be debated.

Academic discussions are split into two groups. In one group, we find those who believe that Byron's heroes are direct descendants of the eighteenth-century Gothic Villain, and in the other group, we find those who position his origin

5 This concept of love is beautifully demonstrated in John Keats' Ode to an Grecian Urn. 
within the Bible, as does Thorslev. While I tend to be in agreement with the latter group, the first group does present some convincing arguments. Railo argues that Byron was mainly influenced by the works of Ann Radcliffe, seeing as her villain Schedoni in The Italian bears highly visible resemblance with Byron's protagonists in appearance. Both are described as having a high, white forehead, ebony curls, a dark piercing glance, a general beauty of countenance and a mysterious past (219). Nevertheless, he places the Byronic hero within an English tradition and claims that he is a purely English product, denying, among other things, the influence of Goethe and Schiller on Byron (219-224, 234). 6 Other critics argue that Byron's creation primarily stands in the tradition of Milton's Satan, who is a fallen angel; nevertheless a product of numerous influences, and his origins can be traced back to the bible. ${ }^{7}$

However, Byron himself gives the best description of his heroes in Lara:

There was in him a vital scorn of all:

As if the worst had fall'n which could befall

He stood a stranger in his breathing world,

An erring spirit from another hurled;

A thing of dark imaginings, that shaped

By choice the perils he by chance escaped;

But 'scaped in vain, for in their memory yet

His mind would half exult and half regret:

With more capacity for love than earth

Bestows on most of mortal mould and birth, His early dreams of good outstripped the truth,

And troubled manhood followed baffled youth;

With thought of years in phantom chase misspent,

And wasted powers for better purpose lent;

And fiery passions that had pour'd their wrath

In hurried desolation o'er his path,

And left the better feelings all at strife

In wild reflection o'er his stormy life;

But haughty still, and loth himself to blame,

He called on Nature's self to share the shame,

And charged all faults upon the fleshy form

She gave the clog the soul, and feast the worm;

'Till he at last confounded good and ill,

6 Eino Railo, 219-224, 234. However, Robert Woolf argues that Byron not only had read Goethe's Faust and was highly influenced by it, he also dedicated two of his plays to Goethe to demonstrate his admiration for him. Robert Woolf, Byron: A Dangerous Romantic? (Grasmere: Wordsworth Trust, 2003) 27.

7 For further discussion see: Andrew Elfbein, Peter Larson Thorslev, and Francis Wilson, (Introduction). 
And half mistook for fate the acts of will:

Too high for common selfishness, he could, At times resign his own or other's good,

But not in pity, not because he ought,

But in some strange perversity of thought,

That sways him onward with a secret pride

To do what few or none would do beside;

At this same impulse would in tempting time

Mislead his equally to crime;

So much he soared beyond, or sunk beneath,

And lodged by good or ill to separate

Himself from all who shared his mortal state ...

'Tis true, with other men their path he walked,

And like the rest in seeming did and talked,

Nor outraged Reason's rules by flaw nor start,

His madness was not of the head, but heart;

And rarely wandered in his speech, or drew

His thoughts so forth as to offend the view. (1. 313-348, 355-362)

The Byronic hero is here demonstrated as a mourning but simultaneously defiant man, whose characteristics as "fallen angel" are emphasised with a specific reference to Milton's Satan ("an erring spirit from another hurled", 1. 316). He has already been made cynical through occurrences outside his control and through the vice of man. He is haunted by a sense of crime, real or imagined.

In English Romantic Writers, Perkins characterises the concept of the Byronic hero as follows

The "Byronic Hero" [is] first portrayed in Cantos I and II of Childe Harold and thereafter developed variously in The Corsair, Lara, Childe Harold III and IV, Manfred and Cain. The figure had prototypes in the Gothic novels of the eighteenth century, in Chateaubriand's Réné and in the characters of Milton's Satan and of Napoleon as seen through Romantic eyes. The Byronic Hero continued to haunt nineteenth-century literature and philosophy. He is a man greater than others in emotion, capability, and suffering. Only among wild and vast forms of nature - the ocean, the precipices and glaciers of the Alps - can he find a counterpart for his own titanic passions. Driven by a demon within, he is fatal to himself and others, for no one can resist his hypnotic fascination and authority. He has committed a sin that itself expresses his superiority: lesser men could not even conceive a like transgression. Against his own suffering he brings to bear a superhuman pride and fortitude. Indeed, without the horror of his fate there could not 
be a splendour of self-assertion and self-mastery in which he experiences strange joy and triumph. (782)

Perkins expressly mentions both his fatality for others and his 'hypnotic fascination' which leads to the heroines' downfalls (in Jane's case to the necessity to flee from the Byronic power). However, like most critics, Perkins too excludes Byron's Don Juan from the concept of the Byronic hero. Thorslev argues that Don Juan seems strangely out of place when compared to Byron's other work because of its satiric style and uses this argument for leaving Don Juan out of his study (199). Railo, too, argues that Don Juan does not belong within the Byronic tradition, as the protagonist is ripped of his dark pose that is typical of the Byronic hero (241). Praz does not even mention him when he discusses the Byronic hero in his work. ${ }^{8}$ Although it might be assumed that the term "Byronic hero" refers to one specific character, this is not the case. Byron's protagonists differ immensely from each other, Elfenbein comments, "Don Juan pokes fun at the Byronic style which exhausted itself in Manfred" (40). What really lies behind the Byronic hero phenomenon and the reason why critics consider all of Byron's protagonist to be Byronic heroes, and why Don Juan also needs to be considered as a type of Byronic hero, is Lord Byron himself. The poet overshadows the characteristics of the Byronic heroes, and much of the Byronic conception is actually drawn from Byron himself and not from his heroes.

Various critics have commented on this phenomenon. Wilson, for example, supports this thesis by stating that Byron's personality was more influential than his poetry. According to Wilson, Byron not only portrayed the ultimate Romantic hero, but also hypnotised the whole of the Romantic generation and dominated the next (1). In addition, his life and scandals are still the subjects of various myths, and controversies about his life are still being discussed in a huge range of different biographies. Wilson estimates that more than 200 biographies have been written about Byron and every year new ones are published (1). This can be seen as a result of the strong connection between Byron's life and his prose. With the publication of Childe Harold's Pilgrimage in 1812, Byron became an immensely prominent figure. A downright frenzy about Byron and his work broke out which Annabell Milbank, later Lady Byron, summed up as Byromania to describe the con-

8 Furthermore, Torslev points out that Praz's focus on the Byronic hero is too narrow. He tries to demonstrate that the Byronic hero is a descendent from Milton's Satan and Ann Radcliff's villains but that he is also linked to the Marquis de Sade through his characteristics of the fatal and cruel lover. Additionally, he claims that Byron's creation is the ancestor of a long series of nineteenth-century vampires. But what he does not take into account is that Radcliffe's villains are evil through and through. They never feel redemption for their cruel deeds, where the Byronic hero is defined through his search for salvation. The connection to the Marquis de Sade is difficult to prove, too, as the Byronic hero may be a fatal lover but he is never cruel and is usually described as courteous and tender in his behavior towards women. As to the assumption concerning the vampire, there is only one reference in all of Byron's works in which one might assume that he is referring to a vampire (The Giaour l. 755). 
temporary mania for Byron and everything Byronic. His next poem The Corsair, which was published in 1814, sold 10,000 copies on its day of publication (Wilson 4). The poet Samuel Rogers commented that Byron's youth and rank combined with his "romantic wanderings in Greece" were the reasons why the world was "stark mad about Childe Harold" and its writer, for the identification of Byron with his aristocratic and world-weary hero was made straightaway (229). Nevertheless, the quality of the poetry is often left out when Byron and his success are discussed; contemporaries concentrated more on imitating his expression and style than on his poetic value. This attitude is still pursued even today; the Byronic hero as a concept and the Byronic Romantic are still being discussed, but his poetry is almost entirely left out of academic discussions. Thus, Wilson argues, the potency of his name is rather connected to a certain style and attitude than to the actual historic figure of Lord Byron (Introduction 9). In addition, Wilson reminds us that opposing concepts of the Byronic and Byron were and still are circulating:

Byronism has represented at the same time both solitary elegance and gross libertinism, physical indulgence and emaciation; the sharp dandy as well as the dishevelled wanderer are said to look "Byronic", and Byron was being erased officially at the same time as he was being recreated in the subculture of Byromania. (9)

Consequently, Byron became one with his protagonists and at the same time a figure of identification and desire in the public imagination; Byron became a star. The line between life and performance vanished, and they became the same thing. He even created a specific way to look for his self-portrayal as a Byronic hero', which numerous people tried to copy. Elfenbein adds that through his dominant Byronic character, Byron not only influenced and changed literary genres but also fashion, social manners, erotic experience, and gender roles of his time (8). He was a cultural phenomenon, one that had never existed before. He was portrayed and portrayed himself as Lord Byron as well as his protagonists, from the suffering Childe Harold to the satirical Don Juan. He played with the accusations of incestuous love for his half-sister Augusta Leigh and worked it into his poem Manfred, which only led to further speculation. Thus, as there was no distinction made between Byron and the Byronic hero, it is difficult to draw a line as to where the creator ends, and the creation begins.

Nowadays, Byronism is considered to be the first modern-style celebrity phenomenon. Nevertheless, the interest in the Byronic hero seems to have subsided in the 1960s. While during the first half of the twentieth century he was often referred to, and studies of the Byronic hero had appeared regularly, ${ }^{10}$ Thorslev

9 He would bend his head a bit and look out of the corners of his eyes to appear brooding and mysterious.

10 For discussions of the Byronic hero before the 1960s see among others: Mario Praz, The Hero in Eclipse in Victorian Fiction, (Oxford: Oxford University Press, 1959); Mario Praz, The Romantic Ag- 
wrote the last major study in 1962. Between the 1960s and 2006, Byron's creation seems to have been neglected or forgotten, and is only to be found in very few studies and articles. When mentioned in articles, critics only concentrate on specific facets of him, such as his function and appearance in works by George Eliot, Charles Dickens, Alexander Pushkin or Charlotte and Emily Brontë, but no booklength studies appeared. ${ }^{11}$ In 2006, Lutz's study The Dangerous Lover was published in which she revives the important and influential figure of the Byronic hero. Lutz notes that through the rise of feminism in the late 1960s, the literary persona of the dangerous lover, thus the Byronic hero, became an outcast within the critical literary world (12). Furthermore, the Byronic hero has always had a slightly negative connotation of marginalization, as it is thought that he appears mainly in romance novels, and that he mainly appeals to women. In any case, the romantic novel with a Byronic hero, the villain lover, at its centre, has still not been accepted as a distinct literary genre. Lutz, who argues that the dangerous lover plays a dominant role in today's romantic novels and cinema, also criticises this fact. Even if he appears mainly in female-coded genres, his existence needs to be recognised (ix). She also criticises the lack of a complete exploration of the dangerous-lover romance. Its history has not been thoroughly studied despite the fact that the villain lover, who became the Byronic hero, can be as far traced back as to the Elizabethan tragedy and is thus not only a figure that plays a part in subordinate literature but belongs to the literary canon (ix-x).

More importantly, Lutz's study is primarily a study about longing. It concentrates on the longing of the hero and scarcely considers the longing of his female counterpart, which still needs analysing. Lutz states that "Standing always under the sign of longing is the dangerous lover - the one whose eroticism lies in his dark past, his restless inquietude, his remorsefull and rebellious exile from comfortable everyday living." Furthermore, Lutz notes "When we long we encounter our own absence" (ix). According to this statement of Romantic ideas, the undefined longing of the Byronic hero is the reason why he goes out "into the anguished world in order to find, paradoxically, the self" (x). To find the "self" in an "other" and thus the wish and hope to be freed of the unbearable longing, to be redeemed through the love of this other, lies at the origin of the modern romance novel pattern. To find fulfilment and salvation in love is a privilege that has been denied to the original Byronic hero.

ony, (London: Oxford University Press, 1933); Eino Railo, The Haunted Castle: A Study of the Elements of English Romanticism (New York: Gordon Press, 1927); Jacques Barzun, "Byron and the Byronic", Atlantic Monthly (August, 1953); Charles Du Bois, Byron and the Need of Fatality, (London: Putnam, 1932).

11 See: William R. Harvey, "Charles Dickens and the Byronic Hero", Nineteenth-Century Fiction 24.3 (1969): 305-316; Sona Stephen Hoisington, "Eugene Onegin: An Inverted Byronic Poem", Comparative Literature, 27. 2 (1975), 136-152; Helen Brown, "The Influence of Byron on Emily Brontë" The Modern Language Review, 34. 3 (1939), 374-381. Sarah Wootton, "The Changing Faces of the Byronic Hero in Middlemarch and North and South, Romanticism 14.1 (2008), 25-35. 
The longing for something that cannot be achieved resembles Lacan's definition of "desire":

It is in the nature of desire to be radically torn. The very image of man brings in here a mediation which is always imaginary, always problematic, and which is therefore never completely fulfilled. It is maintained by a succession of momentary experiences, and this experience either alienates man from himself, or else ends in destruction, a negation of the object. (166)

Byron mainly places his protagonists in a situation where there is no longer hope, as the "other self", their true love, has already been lost. One of the first authors who actually placed the hero within reach of redemptive love is Charlotte Brontë, whose Mr Rochester could be saved by Jane Eyre.

Nevertheless, two questions come to mind: Why do critics believe that the Byronic hero is relegated to female-coded sub-genres only? Plus, why do they claim that this persona only appeals to female readers? As early as 1789 , Joanna Baillie argues in the "Introductionary Discourse" to her work Series of Plays on the Passions that as soon as the reader encounters someone who holds passionate feelings within him but tries to conceal them, a strong wish to reveal them overcomes us:

Let us understand, from observation or report, that any person harbours in his breast, concealed from the world's eye, some powerful rankling passion of what kind soever it may be, we will observe every word, every motion, every look, even the distant gait of such a man, with a constancy and attention bestowed upon no other. Nay, should we meet him unexpectedly on our way, a feeling will pass over our minds as though we found ourselves in the neighbourhood of some secret and fearful thing. (11)

Baillie does not differentiate between male and female reactions to these passions. Men as well as women are equally drawn to these secret feelings; they are both stimulated by them and an urge to discover them is awakened. Furthermore, the man who carries these strong passions suddenly holds an immense appeal for the people around him. Baillie continues:

If invisible, would we not follow him to his lonely haunts, into the midnight silence of his chamber? There is, perhaps, no employment which the human mind will with so much avidity pursue, as the discovery of concealed passion. (11)

Pinch comments on this passage "The very secretness of his passion not only incites people to discover it; it also makes him a strangely affecting being whose presence sends feelings to haunt us" (3).

Overall, neither Baillie nor Pinch differentiate between the wishes of men and women to discover the mystery behind those feelings. This leads to the question: Why has the need to discover the source of the guilt-ridden feelings of the By- 
ronic hero only been ascribed to women? McDayter addresses a problem that seems to lie at the root of the two previously asked questions: the division between art ("high- quality" literature) and mass culture (popular fiction). She argues that the denial of any desire in the process of academic literary criticism is the very reason why academics do not only ascribe the phenomenon of the Byronic hero but the phenomenon of Byromania itself to female hysteria (Byromania 9). Through the distinction between the male academic scholar, who analyses, and the female fan, who simply fantasises and is sometimes considered to be alarmingly enthusiastic, academic critics were able to dismiss the popularity of the Byronic hero as a female fancy. McDayter continues by stating that Byron and his poetry had as many male admirers as female, but the notion of fandom has been feminised and linked to hysteric women. Furthermore, critics in the nineteenth century tried to draw a line between critical readers, meaning men, and "hysterical readers of novels" meaning women. In order to ensure such a distinction, the whole realm of popular culture had to be ascribed to female fancies and was thus simultaneously marginalised (Byromania 15).

Knapp argues that the poet Samuel Taylor Coleridge tried very hard to "desynonymise" the perception of "enthusiasm" from "fanaticism", which was a hard task, as a differentiation was no longer made. Knapp writes that the overall opinion was that "just as enthusiasm must in a sense be quarantined, protected from social contagion that would degrade it to mere fanaticism, so poetry must be insulated from the modes of literality it both imitates and inspires" (42). However, Byron as a poet was not interested in differentiating between the enriching character of enthusiasm and proletarian fanaticism. McDayter supports Knapp's argument and adds, "On the contrary, Byron's literary fame seemed to act as a conduit for this disease, spreading his inflamed imagination to that of his readers, transforming his riotous fantasies into action" (18). This might be exactly one of the reasons for Byron's unprecedented success.

In addition, a scholar, as a critical analyst, should supposedly not only try to reveal the secret passions of the Byronic hero but also attempt to interpret them. This is apparently done by revealing the hidden sorrow, the "true" feeling of the Byronic hero could be discovered. However, McDayter states that trying to discover the truth behind the Other's passion and desire "is to conjure our own as the Other" (Byromania 13). Baillie suggests that the fascination the reader feels when he comes across such hidden passions is primarily attributed to the fact that such mysteries excite the reader's imagination to project his own truth into it. Thus, the reader draws on his own experiences, projects these into the secrets of the stranger, and only secondarily tries to discover the stranger's truth. Baillie deduces that this is an important procedure because "in examining others we know ourselves" (11). McDayter supports Baillie's argument. She states that by drawing on our own experiences to comprehend the mystery, already known passions are projected into it and thus the reader thinks he is able to understand the passions 
of the Other: "That which seduces us as a mystery is, in actuality, so very seductive because it is our desire we encounter as that of the Other" (Byromania 13). This conclusion is of great importance, as it challenges the former assumption that only women react to the Byronic hero because of some hysteric notions - it even challenges the assumption that only women are drawn to the mystery of the Byronic hero. Regardless, the Byron "fan", whether an enthusiastic reader or writer (who used Byron's literary persona) and the 'fan's' belief that there exists a hidden truth within the subject, is still looked down upon. For instance, Phyllis Grosskurth writes ironically:

The necessity to penetrate the hero's façade, to reach the sensitive heart that undeniably throbbed beneath the austere exterior became the determined purpose of every young woman who copied passages into her commonplace book. He might still be saved by a pure woman. (155)

She presents enthusiastic Byron readers as "screaming females" (159) who are naive enough to believe in the discovery of a hidden truth, while she herself declares in the introduction to her Byron biography to be a "seeker after truth" (xiii).

Where then is the line which separates the critics' and the fans' search for the truth? I suggest that the line is blurred, as already male contemporaries of Byron, learned and famous men, felt the attraction of his work and heroes and tried to identify the origin of his magnetism. In 1812, Jeffrey wrote that the secret of Byron "excited a kind of curiosity" as the "flashes of emotion and suppressed sensibility that occasionally burst through the gloom" would hit the reader like the force of the discovered truth $(2: 837)$. Walter Scott also stated that one could hardly resist the power of Byron's work "not only by many noble qualities, but by the interest of mysterious, undefined, and almost painful curiosity" that the reader feels while being confronted with the ferocity of his passions (176). Consequently, women writers who used the Byronic hero in their work were not hysterical, fanatic fans who wanted to copy his mysteriousness for "silly" romantic plots. On the contrary, female writers used the phenomenon of the Byronic hero to criticise standing gender roles and the threatening rise of the separate spheres ideology.

\subsection{The Separate Spheres Ideology}

The concept of separate spheres is based on a strict division of spheres into the domestic and the public, which developed in the late eighteenth century and dominated the whole of the nineteenth century. This artificially created concept coincides with the industrialisation and the rise of the middle class and had a huge impact on women's lives. The new invention of masculinity and femininity and the finding of new gender definitions played an important role in the confinement of the newly risen middle-class; it separated them from other classes. This separation between the sexes and their confinement to distinct spheres existed at every 
level of society and was one of the fundamental organizing characteristics of the middle-class society in the late eighteenth and early nineteenth century. ${ }^{12}$

Every part of a woman's life was affected by this ideology; she was supposed to stay at home and was not allowed to be involved in political discussion. Women were seen as "covert" humans, meaning they were perceived as "relative creatures" who were financially, emotionally, and intellectually dependent on their male relatives (Gleadle 51). Vickery writes that women have been linked to the domestic sphere since the time of Aristotle, but the term "separate spheres" emerged only recently with an entirely new character and was essential to constitute new limitations and oppression for women (383). The role of the 'Angel in the House' was ascribed to women and they were expected to live according to this image. This meant that women should be passive, sacrificing, loving, caring, silent, obedient, and submissive. ${ }^{13}$ Historians have suggested that the female education of the time was only focused on tasks that were important for domestic life. A woman's primary role was, as Morgan points out, the raising of children, as it was the mother who was supposed to transmit the current values to her offspring. A mother's influence on her children was seen as enormously important, in particular her influence on boys, as they were to become the citizens of the future. It was hoped that a strong moral influence at home would produce men with moral courage and strength (Morgan 192). Furthermore, it was thought that this "motherly" influence could eventually improve the whole of society, and it was therefore important that they kept up their moral mission. New restrictions came along through this idealization of women; they were bound to stay at home and not involve themselves in politics, because moving into the 'public sphere' could be a threat to their task and could therefore have damaging effects on the moral standards of a whole nation. There was a concern that if a woman was to involve herself in politics, she might not have enough time to concentrate on her actual duty, namely providing her husband with a safe haven from the public sphere and supervising the education of her children (Morgan 199-201). Sarah Ellis, a contemporary writer of conduct books and a self-appointed advocate of the separate spheres ideology, even declared that if a woman engages herself in the public

12 See Leonore Davidoff and Cathrine Hall, Family Fortunes: Men and Women of the Middle Class 17801850 (London: Routledge, 1987) ch. 3 for a rich discussion of domestic ideology.

13 The phrase the "Angel in the House", which aptly characterises the new role of women, was introduced in a poem by Coventry Patmore in 1854 and was next to Tennyson's "Idylls of the King" a best-selling poems at that time.. Patmore wrote the poem for his wife and the plot is rather simple, it is about the courtship and marriage of a young couple. The poem is central to the concept of the separate spheres ideology in light of how it idealises womanhood and dictates the virtues a woman should have. She should be sacrificing, loving, caring, silent, comforting, passive and should provide her husband with a domestic haven away from the severe world of business and politics. Virginia Woolf was the first one who used the term "Angel in the House" critically and turned it into an item of feminist criticism (see her essay "Professions for Women" [1929]). 
sphere (paid work, politics, etc.) she "ceases to be a lady" (qtd. in Davidoff and Hall 3). In other words, the separate spheres concept imposed bondage on women that permeated every aspect of their being. Rights and independence were denied to them, desires and passions had to be suppressed and the justification of there existence was connected entirely to their roles as mothers and wives. ${ }^{14}$

Until recently, feminism has represented Victorian sexuality in terms of opposites: Angel and fallen woman. This conception summarised the discourse of sexuality in the Victorian age, and it continues to direct the modern view of the correlation between women and sexuality in the nineteenth century. Reynolds and Humble note that:

(T)he sense of being torn between two incompatible positions typifies much twentieth century feminist criticism ... Stimulated in particular by the work of Michel Foucault, feminists have made many fruitful readings of a wide range of Victorian images which explore the relationship between femininity and sexuality. Time and again the contradictory nature of this relationship has been brought to the fore. The complexity and prolificacy of the discourses surrounding female sexuality amply support Foucault's thesis that traditional images of Victorian Britain as refusing to acknowledge sexuality have been mistaken. (1-2)

Reynolds and Humble proceed by arguing that the public discourses concerning sexuality, which state that a woman is either the angel in the house, submissive and sexually passive, or a "sexually charged and demonic mad-woman-in-theattic" (2) cannot be seen as private reality. They judge the common understanding of Victorian sexuality as a dyadic model as out-dated, since "common sense suggests that the Victorians' angelic feminine ideal is entirely suspect" (3). They allude to the fact that for women the Victorian was not a static epoch but ever changing. It started with the invention of the separate spheres notion and the creation of the angel of the house and ended with the fragile females in "bloomers, in offices, in higher education, and driving motorcars" (4-5). Still, the word "Victorian" is still associated with "prudery, repression, hypocrisy, smug confidence, and uncompromising patriarchy" (5).

Nevertheless, a tendency to set up boundaries and establish certainties through classification and categorising was commonplace during the Victorian period. This tendency is particularly evident in its application to sexuality, which led to an oppressive ideology, a division of female and male experiences ${ }^{15}$ and the categorisation of women as "pure" or "impure". However, in the approach of female sexuality within the Victorian period, tensions and contradictions were seen that easily

14 It must be mentioned that contemporary discussions result in the realization that the reality differed immensely from the idea of the separate spheres. The Angel in the House was not to be found, the concept, however, brought along restrictive conventions for women.

15 For a detailed presentation of the public sphere read Jürgen Habermas 1989. 
challenge the idea of a dyadic model. ${ }^{16}$ While it was argued that men's sexual urges were regrettable but not uncommon, women were seen as unnatural, mad, and abnormal when experiencing sexual desire (Reynolds and Humble 6-7). Within this ambivalent attitude towards sexuality, the symbolic importance of Byron and his hero becomes evident. Moglen explains that:

The ideal by which Byron attempted to define his life expressed not only personal but collective longings of psychic and social liberation. But the reality of his circumstances betrayed the potency of the forces which obstructed freedom and thwarted realization. In his own relationship with women, and in the relationships which he created for his heroes, the poet expressed the complex destructive and self-destructive attitude which refine romantic. (31)

\subsection{Julia Kristeva: The Symbolic and the Semiotic}

Kristeva's theory of the "semiotic" and the "symbolic" demonstrates that such a denial of the self and an absolute devotedness to a social construct can never be achieved. According to Kristeva "every social practice ... is articulated like a language" (author's emphasis) ("The System and the Speaking Subject" 25). Furthermore, she states:

Every social practice, as well as being the object of external (economic, political, etc.) determinates, is also determined by a set of signifying rules, by virtue of the fact that there is present an order of language; that this language has a double articulation (signifier/signified); that this duality stands in an arbitrary relation to the referent; and that all social functioning is marked by the split between referent and symbolic and by the shift from the signified to signifier coexists with it.

One may say, then, that what semiotics had discovered is the fact that there is a general social law, that this law is the symbolic dimension which is given in language and that every social practice offers a specific expression of that law. ("The System" 25)

Thus, Kristeva's interpretation of "symbolic" can be seen in the style of Lacan's technical term "Law of the Father" which belongs to his definition of the "Symbolic Order". Lacan describes it as the moment when s/he must abide to the symbol of the phallus as the embodiment of the Law of Fathers and accordingly

16 Reynolds and Humble suggest that, among others, the vast number of prostitutes, Victorian women's clothing and the rise of the "New Women" are all evidences of the overtly challenge of the dyadic model. Furthermore, representations in novels or paintings, of Victorian heroines show them as sexually powerful beings. In the course of their study, Reynolds and Humble identify various efforts to recover resume and recover female, middle-class sexuality. 
must accept the thereby accruing castration. The recognition of this castration is required in order to enter into society as an established individual; nevertheless, it simultaneously demonstrates that this society is a patriarchal and oppressive one. As Kristeva puts it:

[...] the symbolic - and therefore syntax and all linguistic categories - is a social effect of the relation to the other, established through the objective constraints of biological (including sexual) differences and concrete, historical family structure ("Revolution in Poetic Language" 97).

Thus, the symbolic is associated with authority, order, repression, and control, with family and normalcy. Furthermore, it is seen in connection with the "conscious", meaning an "orderly surface realm of strict distinctions and laid-down structures through which language works" (Barry 123-124). The symbolic function is the place of "unitary" law for the subject, the place for renouncing pleasures (drives) that come up against social censorship. It is also the place where the closed sign is established (the linear division of the sign) through the absence of the rejected or repressed object (possible signifiers).

By contrast, the semiotic aspect of language is a violent force disrupting the symbolic order. Its social practice is connected with the maternal rather than the paternal. Kristeva argues that the semiotic does not belong in the same category as logic and order, she describes it with the terms displacement, repulsion, rejection slippage and condensation ("Revolution" 97). It continuously endangers the stability of the symbolic categories, such as the law and images that sustain and support culture. She does not only link it with the feminine, in particular to the mother's body ("Revolution" 95), but also to the "poetic language", which she describes as "the semiotic disposition will be the various deviations from the grammatical rules of the language" ("The System" 28).

As Barry states, in summarizing Kristeva's idea of the semiotic: The semiotic is the "unconscious" of a text emerging into and disrupting the conscious or the surface of meaning. "[The semiotic is] a disruptive incursion into rational, previously stable structures [as] they are shown in dreams, poetry, modernist and experimental writing" (Barry 124). The semiotic is thus seen as everything that deflects from the symbolic. However, the symbolic and the semiotic cannot be considered as two different kinds of language, only as two different aspects of it, which are always connected in every given sentence.

In the following, I will draw on Kristeva's discourse of the semiotic and symbolic to present and discuss the imposed restrictions on women in nineteenthcentury Britain. Lady Caroline Lamb's Glenarvon, Charlotte Brontë's Jane Eyre and Ellen Wood's East Lynne, appear particularly suitable for the discussion. First, because they were written by women who had to live within the limits of the boundaries that were imposed on them because of their gender. Secondly, because as the novels were written in different decades of the nineteenth century, different 
interpretations of the Byronic hero are given, by the novelist. All three female novelists demonstrate considered and typical interpretations, through different responses to this literary persona, depending on the decade they wrote in and by which they were influenced. They thus offer several levels of imitation, revision, and rejection of the Byronic hero in their novels; still, they all use him to excite female emotions. Furthermore, the female character's struggle to comply only with the symbolic order will be depicted though Kristeva argues that such a compliance is not achievable. It will also be shown how the authoresses present the symbolic and semiotic in their work. Although it has been demonstrated that the Byronic hero fascinates men as well as women, the focus lies on how the literary persona excites, triggers, and catalyse repressed female desires. These tend to be enforced to such an extent that it results in an explosion of female sexual desire, which ends most of the time in disaster and eventually in death. Thus, female novelists use the Byronic hero to criticize constricting gender roles.

\section{Lady Caroline Lamb's Glenarvon}

Everybody wishes to run down and suppress the vital spark of genius I have, and truth, it is but small (about what one sees a maid gets by excessive beating on a tinder-box). I am not vain, believe me, nor selfish, nor in love with my authorship; but I am independent, as far as mite and bit of dust can be (qtd. in Douglass, Introduction xxviii).

From the moment Glenarvon was published in 1816, it has been reduced to an assumed biographical account of the scandalous affair between Lady Caroline Lamb and Lord Byron. At the time of the novel's release, Byron was not only at the height of his popularity, but had also only recently agreed to a separation from his wife Annabella Milbanke, a cousin of Lamb's. Two weeks before the publication, he had left England for a self-chosen exile, as the scandalous rumours about a sexual relationship with his half sister Augusta Leigh became more and more oppressive. Additionally, the very public affair of Lamb and Byron had stirred a craving for more savoury details. Butler notes:

Enormous curiosity about Byron's life already existed, but no biographies had appeared. Understandably, the public eagerly scanned Glenarvon for clues that would reveal the mysterious author of Childe Harold I and II and the Oriental Tales. Even Goethe, though the novel bored him dreadfully ... read it from cover to cover under the impression that he was gleaning reliable information about Byron's private life. (37)

Therefore, after Lamb's novel was published, it not only became an immediate success but was also eagerly scanned for clues that would reveal Byron's true identity. Furthermore, Glenarvon has been read as a "compulsive act of confession" 
(Douglass, Introduction xxix). Olney suggests that Lamb intended the novel "primarily as an act of contrition and humility; a public confession of $\sin$ " (275), although he is not specific as to which sins she confesses. Clubbe states that the novel "forced itself out of her: she had to write it as much as Byron had to write his confessional poems" (205). ${ }^{17}$

Glenarvon was first published on the 9th of May 1816. In June, the public had already demanded a second edition, a third edition was published in the same year and a fourth in 1817. As already mentioned Glenarvon was considered a kiss-andtell story of Lamb's and Byron's liaison, a roman à clef. ${ }^{18}$ The novel is a curious mix of different genres, including, the political and historical novel, novel of manners, literary-social satire, and Gothic romance. The plot itself is generally considered to be confused, over-complex, and absurd (Franklin xiv). Douglass even describes it as an "angst-filled tryst and overwrought exclamation of love, pain and selfrecrimination" that is "tiresome in its repetition" (Introduction xxxix). It tells the story of the married Calantha, ${ }^{19}$ a virtuous girl, who falls desperately in love with the revolutionary Lord Glenarvon. Calantha is generally viewed to reveal more about Lamb herself, sexually and biographically. Set against the backdrop of the Irish revolution in 1798, bit by bit the plot evolves around Glenarvon, who in his multiple disguises as the child-murdering Viviani and the fatalistic Glenarvon, seduces almost every female character. He betrays them and leaves them to madness and doom, just as he abandons his revolutionary followers who see him as their leader in the fight for independence. Lamb not only depicts Glenarvon's mysterious hypnotic charm but also demonstrates the resulting dilemma for women when they give into their desires.

In the following, the focus not only lies on Lamb's novel but also on her life, as she is the author who had a passionate affair with Byron and consequently with the Byronic hero. Even more, she was the first writer who used the persona of the Byronic hero in a novel. She thus started a new literary trend that is even nowa-

17 The notion of female writing forcing itself out is discussed in Hélène Cixous' "The Laugh of the Medusa". She argues with the imagery of a volcano when discussing female writing in general. She states that "a female text cannot fail to be more than subversive. It is volcanic; as it is written it brings about an upheaval of the old property crust, carrier of masculine investments; there is no other way". Cixous sees the function of the final eruption to "smash everything, to shatter the framework of institutions, to blow up the law, to break up with the "truth" with laughter" (888).

18 This is justified, to some extent, since Lamb incorporated letters of Byron into the novel that some friends of his recognized as such. As a result, it was taken as a truthful account of their affair (Duncan Wu 143).

19 The name "Calantha" originates from John Ford's The Broken Heart (1633). Evidence for this assumption can be found in Glenarvon itself when Lady Augusta says: "At this moment you put me vastly in mind of it [Ford's tragedy]. You look most woefully. Come, tell me truly, is not your heart in torture? And, like your namesake Calantha, while lightly dancing the gayest in the ring, has not the shaft already been struck, and shall you not die ere you attain the goal?" (155). The connection with Ford's work alludes to Calantha's tragic end. 
days extremely popular and successful. In addition, Lamb was the first to use him to criticise unequal power relations between men and women. Because of her affair, she can give a first-hand account of the fatality of falling in love with a Byronic hero and of his "hypnotic fascination" of which Perkins writes. Furthermore, she had to endure the criticism and condemnation of society because she was not willing to comply with an oppressive patriarchal system. A demonstration of the criticism of this system in Glenarvon that oppresses women in several ways (e.g. through an inadequate female education) and forces them to repress their natural sexual desires will be given. Lamb uses the Byronic hero in the shape of Glenarvon as a trigger of female desire, who arouses this desire to such an extent that it can neither be repressed nor ignored.

\subsection{Lady Caroline Lamb: A Love-Mad Woman}

Lady Caroline went down in history as the woman whose obsessive love for Byron drove her insane. Deeds like the sending of her pubic hair, after Byron had ended their affair, only seem to add to this assumption. Her pubic hair, which was enclosed in a small locket, was delivered with the following letter:

I asked you not to send blood but Yet do - because if it means love I like to have it. I cut the hair too close \& bled much more than you need - do not you the same \& pray put not scizzors points near where quei capelli grow - sooner take it from the arm or wrist - pray be careful - \& Byron - tell me why a few conversations with the Queen Mothers ${ }^{20}$ always change you. ... When you left me I must one night be in your arms - \& now not even see you but in presence of a witness - oh I could scold - ... I will kneel \& be torn from your feet before I will give you up - or sooner be parted with you. (qtd. in Tuite 59)

The note clearly shows that she simply refused to accept the end of their affair and continued to pursue him.

Her scandalous behaviour and her very public pursuit of Byron led to the presumption that she must be mad. Byron himself helped to create the image of her as an adulterer and persecutor; he openly mocked her pursuit of him and presented her love letters as amusement to Whig society. Wu notes that his "disparaging assessment has led some to regard her as little more than one of the more bizarre features of his love-life" (140). Byron wrote to John Moore in 1816 "It seems to me that if the authoress had written the truth, and nothing but the truth the whole truth - the romance would not only have been more romantic, but more

20 Lamb refers here to Lady Melbourne, Caroline's mother-in-law, and Lady Oxford, who both had amorous liaisons with Byron. 
entertaining". Concerning his likeness in Glenarvon he comments that it was a "bad picture" as he had "sat not long enough" for it (qtd. in Clubbe 214).

In addition, Lamb is known for coining the famous formula describing Byron as "mad, bad and dangerous to know". However, this was not her first impression of Byron but a conclusion after years of reflection. Although less known but yet still adding to her reputation of an insane woman, were Byron's comments, calling her "mad and malignant", and a "monster" who "cannot be in her senses" (Douglass, "Madness of Writing" 53). Additionally, he wrote in a letter to Lady Byron "[H]er whole disposition is a moral phenomenon (if she be not mad) it is not feminine - she has no real affection ... but everything seems perverted in her she is unlike every body I know - \& not even like herself for a week altogether" (qtd. in Douglass "Madness of Writing" 53). In other words, Byron himself helped to spread the rumour of her supposed insanity. Accordingly, Lamb's formula gets under this aspect a whole new quality.

Wilson reminds us that Lamb is still remembered as a woman who could not differentiate between fiction and reality. Her name was and is a synonym for the melodramatic to this day; it was even used by contemporaries, including Byron, as an adjective for "self-indulgent emotionalism" ("An Exaggerated Woman" 195). In addition, he points out that Caroline's behaviour applied to the "myth of desiring women" which depicts them as being "damaged and damaging", as "unnatural, theatrical, deceptive, duplicitous, witch-like" and "sexually excessive" ("Exaggerated" 199). All of those characteristics were applied to Lamb, and thus her work has merely been viewed with the focus on the sexual, rather than the political, on the scandalous affair, rather than on the critic within. McDayter states that Chew, a well-established Byron critic, evaluated Glenarvon as "the product [of Lamb's] hysteria" and therefore, McDayter argues "can be [according to Chew] summarily dismissed, aesthetically, and politically, in a single satisfying stroke. It is about sex, not a "legitimate" literary subject such as politics" ("Hysterically Speaking" 155). Chew is not alone with his poor opinion of Lamb's work. Cecil regards it as the "merely outpouring of a diseased sexuality" (qtd. in Kelsall 138) and further as "a deplorable production, an incoherent cross between a realistic novel of fashionable life and a fantastic tale of terror, made preposterous by every absurd device" (qtd. in Graham 95). Up until recently, numerous critics agreed that the only merits of the novel were the powerful depiction of the heroine Calantha and her affair with Glenarvon because of their biographical aspects. ${ }^{21}$

Tuite discusses the decade long double standard of the handling of the affair; she states that the relationship between Byron and Lamb confirmed his "seductive

21 Henry Blyth. Caro: The Fatal Passion. New York: Haper Collins, 1972. - Mabell, Countess of Airlie. In Whig Society 1775-1818, Compiled from the Hitherto Unpublished Correspondence of Elizabeth, Viscountess Melbourne, and Emily Lamb, Countess. Cambridge: Scholar Publishing, 2010. - Elizabeth Jenkins. Lady Caroline Lamb. London: Sphere, 1972. George Paston and Peter Quennell. "To Lord Byron": Feminine Profiles based upon unpublished letters 1807-1824. London: Murray, 1939. 
fatality" and her "banality" (61). Born Lady Caroline Ponsonby, her mother being Lady Bessorough and her aunt Georgiana, Duchess of Devonshire, Lamb grew up within one of the most powerful and influential circles of Regency England. Her aunt and mother were one of the few politically significant women of the time. Marie Antoinette, as well as the Prince of Wales belonged to her family's acquaintances and her future husband, William Lamb, would be Victoria's first Prime Minister. Accordingly, she belonged to England's social elite, which even enforced the public's interest in her life and scandals.

Extra-marital affairs were not uncommon in Regency England but they were only tolerated as long as they were kept private. With the publication of Glenarvon, Lamb not only violated this rule but also drew a satirical and critical picture of Regency's upper circles, only thinly disguising some of its most powerful members. This resulted in Lamb's social death. She became a social exile, mirroring Byron's self-exposed exile from England to the continent. Nevertheless, Tuite argues that their exiles varied immensely in their result as " $t$ t] he narrative and plot of exile is significant here because there is a sense in which the crossing over, as it were, from social death into literary fame or posterity, enacts a strategy of immortality that translates exile or ruin into redemption" (79). Accordingly, the aftermath of their exile differed because of their gender difference. Where Byron's short life on the continent lead to a change of his reputation from being a scandalous outlaw to having heroic fame, Lamb had to endure continued public humiliation that included a public diagnosis of insanity, and she was left no hope of posthumous redemption.

The significance of these background details lies in the critique of patriarchy and the symbolic in Glenarvon itself. Lamb's's life and reputation are examples of the consequences "desiring women" had to endure. She is one of these women who choose to give in to their passions: to object to Kristeva's repressive symbolic and indulge in the semiotic. The Byronic hero, as Lamb uses him in Glenarvon, has a very special relevance as she not only lived during the same era as Byron, but was also influenced by the same concepts and ideals as he was. ${ }^{22}$ Accordingly, Lamb's Glenarvon is closer to the original Byronic hero than those of her follower's are. In addition, she also knew the real Byron, hence she knew from firsthand experience how seductive and fascinating the "Byronic hero" was. She experienced how easily one could succumb to his charm, how short-lived his love was and how severely one was punished by society for surrendering to him. Having recognised society's double standard on sexual indiscretion, she protests it in Glenarvon:

22 On of those being the romantic longing, a longing that can and even should never be fulfilled. The fulfillment of this longing necessarily ends in tragedy and disaster as depicted in Glenarvon, as the "longing" itself is the essential expression of Romanticism. 
That which causes the tragic end of a woman's life [i.e. her reputation and social life], is often but a moment of amusement and folly in the history of a man. Women, like toys, are sought after, and trifled with, and then thrown by with every varying caprice. Another, and another still succeed; but to each thus cast away, the pang has been beyond thought, the stain indelible, and wound mortal. (278)

Neither contemporaries nor critics could appreciate Glenarvon for its critique on existing gender roles but the focus lay, as already mentioned, on the assumed insight into Byronism and Whig society. Even political events such as the Irish uprising in 1798 were not acknowledged. Critics like Solderholm, regardless of their recognition of her supposed hysteria and insanity as calumny, still do not recognise Lamb's work on its own account, but mainly in relation to Byron. Solderholm not only denies her any kind of originality, but also argues that her motivation "can be more generously understood as a spectral pursuit of her own kind of proto-Byronic, erotic-notoriety: an imitation of her ideal man" (26). Other critics follow in his steps and see Lamb's work as an imitation of Byron, as an attempt to create her own Byronic character in order to be close to him. ${ }^{23}$ Furthermore, critics who write favourably of her work and defend it against its more vehement opponents, only recognise the merits of her work in the supposed biographical and social depiction of Byron and Whig society and its confessional character. ${ }^{24}$

However, more recent critics do not agree that revenge or confessional outpouring were the motives behind Lamb's writing of Glenarvon and have recognised its critique of restricting conventions for women and hypocritical values in society. ${ }^{25}$ Douglass states that Lamb had mixed motives in writing the novel. Although agreeing that striking back at Byron and those who had humiliated her might have been one of them, he believes her main motive was that she wanted to "reveal wrapped values of society that knowingly continued to abide behaviour that was more criminal than her own" (Introduction xxx). Lamb criticises this condition by pointing to the corruption of Calantha's innocence by society, as the following paragraph shows:

Her reason by degree became convinced by the arguments which she continually heard; and all that was spoken at random, she treasured up as truth: even whilst vehemently contending and disputing in defence of her favour-

23 Among others, Barbara Judson discusses how similarities of Byron's and Lamb's work have recently been discovered and discussed but only to demonstrate the" inferiority and derivative nature of Lamb's work - her attempt to "play Byron," to appropriate his myth of personal authority for herself' (151).

24 John Clubbe suggests that Glenarvon works only when read as a satire (208) and mainly fails as a novel but could be considered as a self-analytic study oft the writer concerning her relationships with Byron, her husband William Lamb and Regency society (210).

25 To this critics belong, among others, Gishlane McDayter, Frances Wilson, Barbara Judson, Ducan Wu and Paul Douglass. 
ite tenets, she became of another opinion. So dangerous is a little knowledge - so unstable is violence. Her soul's immortal hopes seemed to be shaken by the unguarded jests of the profane ... she read till she confounded truth and falsehood, nor knew any longer what to believe: she heard folly censured till she took it to be criminal; but crime she saw tolerated if well concealed. (60)

The paragraph not only criticises society's hypocrisy but also mentions a more farreaching problem: the dangers of insufficient female education.

\subsection{Female Education; or the Fine Art of Hysteria}

Lamb is not the only woman whose personal and scandalous life has influenced the perception of her work, thus she was not the first (and not the last) to have her writing dismissed as emotional scribble. Mary Wollstonecraft, one of the most influential writers of the Romantic period commenting on the status of women, had to endure the same procedure. As Craciun comments, "Wollstonecraft's violent relationship with Imlay, and her resulting two suicide attempts in 1795 when he had moved in with another woman, dominated the reception of her work throughout the nineteenth century" (10). Lamb was not only familiar with Wollstonecraft's work, but also admired it tremendously. Glenarvon was highly influenced by Wollstonecraft's agenda which makes it particularly interesting for contemporary criticism, as feminists have discussed that "gender carries an ideology as distinctive as the political attachments highlighted by new historians" (Wu 145).

In a time in which Rousseau's Emile, or On Education (1762), an educational treatise, was immensely significant, restrictions on women because of their subordinate gender increased. Rousseau claims that men and women are fundamentally different, physically and intellectually. Furthermore, he suggests:

[T] he whole education of women ought to relate to men. To please men, to be useful to them, to make herself loved and honored by them, to raise them when young, to care for them when grown, to counsel them, to console them, to make their lives agreeable and sweet - these are the duties of women at all times, and they ought to be taught from childhood. (166)

It is obvious that Rousseau not only demands women to merely act within the sphere of what Kristeva calls the symbolic, he also strongly advises men to let their women act only within this sphere. Otherwise, severe consequences were the result, thus, he warns the male population that if women should be allowed to give in to their sexual desires:

(M)en would be tyrannized by women. For, given the ease with which women arouse men's senses and reawakening the depths of their hearts the remains of ardors which are almost extinguished, men would finally be their 
victims and would see themselves dragged to death without ever being able to defend themselves. (169)

As a result, in order to prevent female tyranny and domination, men should keep their female relatives in check and women's education should concentrate in every respect on pleasing men, and simultaneously on the repression of their own wishes.

Lamb is well aware of this agenda and criticises it vehemently in Glenarvon, demonstrating the dangers the world holds for an uneducated, and therefore easily impressed mind, as well as the effect of repressed desire on women. She agrees with the criticism Wollstonecraft expresses of such an education and sees the same dangers as Wollstonecraft did:

The education of women has, of late, more attended to than formerly; yet they are still reckoned a frivolous sex, and ridiculed or pitied by the writers who endeavour by satire or instruction to improve them. It is acknowledged that they spend many of the first years of their lives in acquiring a smattering of accomplishments; meanwhile strength of body and mind are sacrificed to libertine notions of beauty, to the desire of establishing themselves, - the only way women can rise in the world, - by marriage. And this desire making mere animals of them, when they marry they act as such children may be expected to act: - they dress; they paint, and nickname God's creatures. - Surely these weak beings are only fit for a seraglio! - Can they be expected to govern a family with judgment, to take care of the poor babes whom they bring into the world? (qtd. in Craciun 111)

Lamb adapted Wollstonecraft's critique on female education and incorporated it into Glenarvon. Accordingly, female education is often commented on in her work. Mrs Seymour, Calantha's aunt, has raised her daughters in the "proper" way and has diminished every spark of passion and desire in them. Lamb obviously attacks this manner of education through Lady Margaret, Calantha's aunt:

By these means, Sophia and Frances were already highly accomplished; their manners were formed; their opinions fixed; and any contradiction of those opinions, instead of raising doubt, or urging to inquiry, only excited in their minds astonishment at the hardihood and contempt for the folly which thus opposed itself to the final determination of the majority, and ventured to disturb the settled empire and hereditary right of their sentiments and manners ... "But, in your girls and in most of those whom we meet, how narrow are the views, how little the motives, by which they are impelled. Even granting that they act rightly, - that by blind following, where others lead, they pursue the safest course, is there any thing noble, any thing superior in the character from which such action spring?" (28-29) 
Lady Margaret criticises this conformity and inability to react to new situations, to have no opinions of your own and to bend unquestionably to society's standards. She also refers to Sophia's and Frances' lack of desire: “These are your pupils ... these paragons of propriety - these sober minded automatons ... I only wish I could shake off a little of that cold formality which petrifies me" (28). When she describes the upbringing intended for Calantha, it seems to be in the manner of Rousseau: "Now see how differently my Calantha shall appear when I have opened her mind, and formed her according to my system of education - the system which nature dictates and every feeling of the heart willingly accesses to" (28). Probably influenced by Wollstonecraft, Lamb condemns women like Lady Dartford and Sophia, who submit to the symbolic, to those "paragons of propriety" whose interests lie only in dresses and jewels. Based on Calantha's case, Lamb tries to demonstrate the dangers of an education that focuses on superficiality and not reason. She attempts to expand the world of female experiences and to extend it into the world of politics, poetry and passion and demands an improvement of the options for women.

The topic of female education, or rather the inadequacy of female education is of the utmost importance here, seeing as for Lamb the repression of desire and passion starts in the education of girls. They are not seen as reasonable beings, and reason is not exercised, they are not taught how to control their desires, only to deny them. The fate of the heroines in Glenarvon are an open attack on Rousseau's philosophy concerning female education they demonstrate the ridiculousness and the outspoken danger of an education that focuses on innocence only. Consequently, when suddenly confronted with the public sphere or "outside world" they have no guidance. McDayter points out that while these women are still girls they only appear submissive, controlled, and restrained but as soon as they mingle with the "outside" world and are confronted with passion, desire, and sexual lust "they reveal an ephemeral nature of this passivity". She continues to say that "under the seemingly calm surface is a positive torrent of repressed and denied desires only barely restrained by the enforcement of social restrictions and cultural laws" ("Hysterically Speaking" 164-165).

We are told that this is the case with Calantha: "Her feelings indeed swelled with a tide too powerful for the unequal resistance of her understanding: - her motives appeared the very best, but the action which resulted from them were absurd and exaggerated" (29). Embodying the Rousseauian idea of feminine fragility and charm, Calantha, when still a child, was spoiled by all: "[T]he wildest wishes her fancy could invent, were heard with the outmost scrupulous attention" (29). She never learned to control the always-changing "impulses of her feelings" and thus grew up to become "more than usually ignorant, backward and uninstructed" (30). McDayter comments that although Calantha's depiction as a Rousseauian heroine does not follow exactly his conventional education, she still has to live with all its restrictions and repressions, even though she is aware of how weak 
and unprepared her education has made her ("Hysterically Speaking"164). This proves Calantha's self-assessment:

"I am not like those I see: - my education, my habits, my feelings are different; I am like one uncivilized and savage; and if you place me in society, you will have to blush every hour for the faults I shall involuntarily commit.

Besides this objection, my temper - I am more violent - ..." (49)

Again, Lamb's source for this explication of education comes directly from Wollstonecraft's $A$ Vindication of the Rights of Woman. Both women have penetrated and understood the dilemma such an education beholds for women. The idea of a proper lady was a fixed concept; every female aberration that challenged this concept was scrupulously judged by society. A desiring woman violated the idea of "natural femininity", and the belief that masculinity and femininity were biological parameters of identity. Concerning their sexual identities, as Wilson states, they had two options to choose from, to be the "passive object or active subject of desire". Nevertheless, Wilson proceeds "the expression of desire was traditionally associated with the masculine and the sexual power which this position ideally represents ... any expression on the woman's part is seen as kind of theft" ("Exaggerated Woman" 204). Calantha, as Lamb herself, thus becomes "unnatural" and is judged as a disfiguration of femininity. Desiring and longing women become, in their expression of their passion for men, "unsexed" beings. Women are only expected to fulfil men's desires within the symbolic.

Contrarily, they are also raised to be sensual beings. They are explicitly taught how to use their bodily facilities to arouse men, and how to neglect their minds. As Wollstonecraft puts it:

Taught from their infancy that beauty is a woman's sceptre, the mind shapes itself to the body, and roaming around its gilt cage, only seeks to adore its prison .... . Women, confined ... having their thoughts constantly directed to the most insignificant part of themselves, seldom extended their thoughts beyond the triumph of the hour. But were their understandings once more emancipated from the slavery to which the pride and sensuality of man and their short-sighted desire, like that of a dominion in tyrants, of present sway, has subjected them, we should probably read of their weakness with surprise. (qtd. in Craciun 128)

They are intentionally kept ignorant of reason and have only their bodies to turn to whose desires they are not allowed to articulate, as it is considered as "unfeminine" and "unnatural". However, a woman's way to express her desire is over her body, as she has been taught since childhood how to use it to seduce men and eventually catch a husband.

Accordingly, using the example of Calantha and her fall, Lamb demonstrates the dangers of being forced to comply to the symbolic solely. Without being al- 
lowed to connect with the semiotic, long repressed desires break free in a destructive explosion. As men allow women to consider themselves as their queens, they put them on a pedestal of beauty and sensuality. Nevertheless, this role is shortlived, since men have the power to put them back in their place as subordinates whenever they wish to. Accordingly, women were trapped; no matter what they decided to do, they were judged for it. Depicting Calantha as a girl educated after Rousseau's conception of female education, her fall lies ahead. Lamb's feminist approach, to criticise the repressive restrictions for women in a patriarchal system, concentrates, among others, on the double standards of sexuality. Franklin points out that while society is prizing "extreme sensibility as highly "feminine", it simultaneously "punished any resulting impropriety in women while condoning outright libertinism in men" (xiv).

Moreover, women are kept intentionally innocent, and when suddenly confronted with the real world, they are not fit to cope, as Lamb demonstrates. In the first detailed description of Calantha, the narrator presents her as rather haughty and with much potential for self-destructive behaviour:

Her feelings indeed swelled with a tide too powerful for the unequal resistance of her understanding: - her motives appeared the very best, but the actions which resulted from them were absurd and exaggerated. Thoughts, swift as lightening, hurried through her brain: - projects, seducing, but visionary crowded upon her view: without a curb she followed the impulse of her feelings; and those feelings varied with every varying interest and impression ... It was thus, with bright prospects, strong love of virtue, high ideas of honour, that she entered upon life. (29)

Lord Avondale decides to deprive her of her Rousseauian innocence and open her eyes to see the world how it really is. Although having only good intentions in mind, namely to free Calantha from all her former restrains and oppression and thus to liberate her "true nature", Lord Avondale is all too radical:

Eager to oppose and conquer those opinions in his wife, which savoured as he thought of bigotry and prudish reserve, he tore the veil at once from her eyes, and opened hastily her wondering mind to a world before unknown. He foresaw not the peril to which he exposed her: - he heeded not the rapid progress of her thoughts - the boundless views of an overheated imagination. At first she shrank with pain and horror, from every feeling which to her mind appeared less chaste, less pure, than those to which she had long been accustomed; but when her principles, or rather her prejudices, yielded to the power of love, she broke from a restraint too rigid, into a liberty the most of dangerous from its novelty, its wildness and its uncertainty. (52-53) 
The description of her character and Avondale's act of "freeing" or "waking" his wife from a sheltered and simultaneously oppressive world is again pointing to the origin of the dilemma, the poor education of female sensibilities. Consequently, as McDayter states, "abruptly released without careful direction or instruction, Calantha indulges herself in an orgy of indiscretion and sensuality ..." ("Hysterically Speaking" 165). As a result, the liberation of these women from their chains of ignorance and naivety unintentionally leads to tragedy.

\subsection{Institutionalised vs. Passionate Love}

Lamb thus paves the way for the following explosion of female hysteria released by Glenarvon. She tries to explain why these women never had a chance to act any differently, how unjustifiable the condemnation of their behaviour actually was. She clearly sees the blame in the failure of society and in the demand to deny true love:

"From the deep recesses of a guilty, yet not humble heart, in the agony and the hopelessness of despair", said Calantha. "I acknowledge before God and before man, that for me there is no excuse. I have felt, I have enjoyed every happiness, every delight, the earth can offer. Its vanities, its pleasures, its transports have been mine; and in all instances I have misused the power with which I have been too much and too long entrusted ... Tell them I do not hope that my example can amend them: they will not turn from one wrong pursuit from me; they will not compare themselves with Calantha... Yet when they read my history - if amidst the severity of justice which such a narrative must excite, some feelings of forgiveness and pity should arise, perhaps the prayer of one, who has suffered much, may ascend for them, and the thanks of a broken heart be accepted in return." (279-278)

Having recognised her faults and taking full responsibility for them, Calantha nevertheless hopes that she will not be condemned too severely by women and hopes for their compassion and understanding.

The criticism proceeds in Lamb's depiction of marriage and love in Glenarvon. To be or to get married does not simultaneously mean to be in love; the bestdepicted marriages in Glenarvon are those which lack love. Lady Selwyn's relationship with her husband is described as an equally beneficial agreement for both parties, a secure kind of alliance. Lady Selwyn even speaks against a marriage based on love:

"After all, a wife is only pleasant when her husband is out of the way. She must either be in love, or outer love with him. If the latter, they wrangle; and if the former, it is ten times worse. Lovers are at all times insufferable; but when the holy laws of matrimony give them a lawful right to be so 
amazingly fond and affectionate, it makes one sick." "Which are you, in love or out of love with Mr. Selwyn?" - "Neither, my dear child, neither. He never molests me, never intrudes his dear dull personage on my society. He is the best of his race, and only married me but of pure benevolence ... [he] took me as his mate, because I let him play at cards whenever he pleased. He is fond of cheating, he never can get any one but me to play with him." (77)

Described here is what Graham calls a "mechanical marriage", obviously belonging into the realm of the symbolic. Lady Selwyn argues that a union that is based on love is bound to fail. She tries to explain to Calantha that the moulding into symbolic structures is necessary to ensure a successful marriage. However, this institutionalised love is connected to slavery throughout the novel. ${ }^{26}$ Images of masters, slaves, chains, but also of shackles, subservience, and obedience are continuously depicted in connection with this kind of love. Calantha proclaims that her marriage to Lord Avondale will neither cost her her freedom, nor turn her into a slave "dear as he was, her freedom was even dearer ... she would never become a slave and a wife" (49). What Calantha fails to understand is the fact that she was never free to begin with and that her husband is able command over her as he wishes. ${ }^{27}$ In Glenarvon, men hold an advantage when it comes to love. Graham argues that:

The problem with the Avondales' marriage ... arises in part because, for men, love is not enough. It may enslave for a time, but the world holds other fascinations: military affairs for Avondale... Women, especially married women, have no such recourses when the chains of love grow heavy. There is nothing to do but love again. (117)

Calantha later on recognises this circumstance and declares, "Marriage is the annihilation of love" (99).

The power relation between male and female characters as depicted in Glenarvon gives a demonstration of patriarchal values but reveal also ambivalence towards them. The "love" between Lord Avondale, as a representative of patriarchy, and Calantha is, accordingly, one based on the ideals of the symbolic. Kelly argues that love, passionate love as that between Calantha and Glenarvon is depicted as an

extra-social absolute, [a] timeless plane of experience which clearly must rival "virtue" ... and it is love very different from the love embodied in the social institution of marriage which Calantha has already experienced with

26 For a more detailed exploration of this interplay of love and slavery see Peter Graham, Ghislane McDayter ("Hysterically Speaking"), and Gary Kelly.

27 For a further discussion of the master/slave relationships in Glenarvon see Peter Graham and Ghishlane McDayter ("Hysterically Speaking"). 
Avondale, and found, as social experience is, to be merely a relative thing, not extra-social, not absolute, and certainly not timeless. (14)

Glenarvon, as a Byronic hero, is the embodiment of this extra-social love, or in other words, he belongs to the realm of the semiotic. Repressed passions and desires, some of which women were never even aware of, are awakened through his presence. Kelly proceeds with an explanation of his interpretation of Kristeva's symbolic and semiotic, in his words, the social and extra-social. He argues that the plot evolving around Calantha belongs to the private, extra-social world of passion, whereas she is surrounded by "a crowded, complex, confusing, and deceptive social world" (16).

With the appearance of Glenarvon, the plot of the novel is reduced to affairs of passion, be it relationships between men and women, or revolutionary acts. Passion, love and desire function as a bridge between male and female worlds of experiences; they reduce the plot to the interaction between men and women. In the novel the individual as well as everything belonging to the semiotic like passion, or a woman's world of experience, has to surrender and be repressed in order to comply with the symbolic structure of public, social and traditional patriarchal values. This is depicted in the love-triangle between Calantha, Avondale and Glenarvon, and through a clash of institutional love with passionate love. The symbolic and semiotic are treated in society as two separate orders, which are not supposed to collide. However, as Kristeva argues, the one cannot exist without the other; subordination to a dominant patriarchal system of social convention through neglect and repression of the "female world" of emotional experience is doomed to fail. Accordingly, under the calm surface, the heroines in Glenarvon are emotional time-bombs that are waiting to explode.

\subsection{The Byronic Hero: Catalyst of Repressed Desires}

Lamb uses the Byronic hero as the activator of the explosion of repressed female desire he is used as a form of criticism of institutionalised love and of the emotional oppression of women. Glenarvon is portrayed as a fatal seducer, a betrayer of the weak and oppressed, of women, and Irish rebels. He combines in equal measures Satanism and sexuality, which are both destructive for women, as the real Byron was. Braudy comments on Byron's power to activate the semiotic in women:

Byron is ... celebrated ... for the literary display of 'himself - a swirling whirlpool of almost sexual allure in which his audience might glimpse an image not of their public selves so much as those desires and aspirations that had seemed socially unfit or irrelevant, now writ large and grand. In letters that poured in to him ... spoke the voices of private loneliness and 
singularity in response to their public model and the catalyst of their own self-regard. (401)

Lamb condemns the Byronic hero as a libertine and criticises through this persona the sexual double standard (Glenarvon's social condemnation is incomparable with the women's condemnation, as it is does not exist virtually) but also brings him into play as a catalyst of female passion. Calantha's first meeting with Glenarvon is described as follows:

She gazed for a moment upon his countenance - she marked it. It was one of those faces which, having once beheld, we never afterwards forget. It seemed as if the soul of passion had been stamped and printed upon every feature. The eye beamed into life as it threw up its dark and ardent gaze, with a look nearly of inspiration, while the proud curl of the upper lip expressed haughtiness and bitter contempt; yet, even mixed with these fierce characteristic feelings, an air of melancholy and dejection shaded and softened every harsher expression. Such a countenance spoke to the heart, and filled it with one vague yet powerful interest - so strong, so undefinable, that it cold not easily be overcome. (118)

Many of the already discussed characteristics of the Byronic hero are included in this quotation, ranging from the "soul of passion", "dark and ardent gaze" to the immensely and immediate attraction women feel in his presence.

Calantha felt the power, not then alone, but evermore. She felt the empire, the charm, the peculiar charm, those features - that being must have for her. She could have knelt and prayed to heaven to realize the dreams, to bless the fallen angel in whose presence she at that moment stood, to give peace to that soul, on which was plainly stamped the heavenly image of sensibility and genius. (118)

A fallen angel, a hidden secret, from which she would like to cure him and give his 'soul [...] peace': all the imagery of the ever-longing, dark, mysterious, fatal and dangerous lover is here evoked.

McDayter writes that Byron has been depicted as a "dangerously seductive, even mesmeric figure who could lead the masses into unthinking political violence through the "sublime terror" of his words" ("Hysterically Speaking" 158). Accordingly, Glenarvon's appearance frees Calantha, from the first moment of their meeting onwards, from the limitations of feminine ideals which she is expected to act upon. He stands as an example for a revolt against authority that in this sense is not only confined within the limits of the Irish rebellion against their English oppressors but operates also on a different level; as a female revolution against an 
oppressive patriarchal system. ${ }^{28}$ Sir Everard, Elinor's uncle, points out that his female relatives have been acting in extreme and for him incomprehensible ways since Glenarvon's appearance:

that lawless gang - those licentious democrats - those rebellious libertines; have imposed on the inordinate folly of my wife and daughters, who, struck mad, like "gave in the orgies of Bacchus, are running wild about the country, their hair disheveled, their heads ornamented with green cockades ... and Lady St. Clare, to the same of her sex and me, the property of a recruiting sergeants employed by one of that nest of serpents at the abbey, to delude others, and all, I believe, occasioned by that arch fiend, Glenarvon. (109)

As an icon of the Irish revolution Glenarvon appears to women as a violent force of emancipation; that is the reason why a big part of his attraction for women lies in his political enthusiasm. As Judson puts it fittingly "he stimulates wives and daughters of the gentry to mutiny ... Glenarvon's presence spurs women to break out" (161). However, Helen Small demonstrates that he is more than a fatal seducer. He quickly becomes the leader of the Irish uprising against the oppressive English rule and his main impact on others is to "drive them to madness of one kind or another" (118).

Nonetheless, Lamb tries to demonstrate through Glenarvon's appearance how unprepared "proper" and "virtuous" women are for the world. Calantha, never having been harmed by a man before or confronted with sexual desire, sees men as harmless creatures. Being the innocent girl she was raised to be, the narrator describes her as follows:

All that was base or mean, she, from her soul despised; a fearless spirit raised her, as she fondly imagined, above the vulgar herd; self confident, she scarcely deigned to bow the knee before her God; and man, as she read about him in history, appeared too weak, too trivial to inspire either alarm or admiration. (30)

A virtuous girl who shrinks away from everything evil and wrong, Calantha, in her naiveté, has no understanding of the things which occur around her. Girls like her, kept intentionally ignorant, are defenceless when left on their own, too trusting, and too inexperienced. While she might not consider that other people would be able to harm her deliberately and just for the fun of it, Lamb shows how easily these girls can become prey in male games of which they understand nothing. Gondimar, an acquaintance of Calantha, describes her virtues to Viviani, Glenar-

28 Various critics have discussed that the Irish uprising is a metaphor for female oppression, a revolution against a tyrannical, patriarchal system (England). For further discussions of the Irish rebellion being a struggle for female independence see, among others, Caroline Franklin, Gishlane McDayter, and Gary Kelly. 
von in disguise. He declares him that there has never been a woman of more virtue and of whose integrity he is more convinced of than Calantha's. He ensures Glenarvon of her purity and her love for her husband and child and mentions that even the seductive Glenarvon could never intervene. Whereupon Glenarvon reacts as follows:

Viviani [Glenarvon] smiled in scorn. "Gondimar, this Calantha, this fair and spotless flower of a woman, and, as such, she must be frail. Besides, I know that she is so in a thousand instances, though as yet too innocent to see her danger, or to mistrust our sex. You have often described to me her excessive fondness for music. What think you of it? She does not hear it as the Miss Seymour's hear it, you tell me. She does not admire it, as one of the lovers of harmony might. Oh no; she feels it in her very soul - it awakens every sensibility - it plays upon the chords of her overheated imagination it fills her eyes with tears and strengthens and excites the passions, which it appears to soothe and to compose. There is nothing which the power of music cannot effect, when it is thus heard. Your Calantha feels to a dangerous excess. Let me see her and I will sing to her till the chaste veil of every modest feeling is thrown aside, and thoughts of fire dart into her bosom, and loosen every principle therein ... She boasts too of the most unclouded happiness, you tell me and of the most perfect state of security and bliss; they who soar above others, on the wings of romance, will fall. Oh surely they will fall." (67-68)

This passage functions as an indication of things to come. The Byronic hero has laid his eyes on Calantha and will make sure that she will be woken from her imaginary world of institutional love and patriarchal conventions, as he recognised the semiotic in her. He is eager to prove that virtue and purity are only facades dictated by society, and that the semiotic in Calantha cannot successfully be repressed. Regardless of the unavoidable negative consequences, her fall from society, Glenarvon is determined to free her repressed desires. The motives behind such an act are only secondary for Lamb; the important part is that she brings the focus to the fact that women are often unaware of their semiotic side. Nevertheless, too rash a discovery of the semiotic can easily lead to a catastrophic outcome, since she lacks the ability and experience to react to it. Furthermore, she can also be taken advantage of, where men know of and are familiar with both the symbolic and semiotic, women are kept ignorant. Lamb uses Viviani/Glenarvon as a link that connects the women in the novel with the semiotic, but she also uses him to demonstrate how helpless and exposed these women are when confronted with it.

Furthermore, Graham notes that Glenarvon and Avondale are to a certain extent the same man; both love and belittle Calantha. Although Lord Avondale is depicted as a loving husband, he corrupts, even if involuntarily, her innocence by 
educating her (104-105). Glenarvon, on the other hand, wants to seduce and destroy her intentionally and enjoys his corruptive power over her "Remember when a word or look were regarded by you as a crime," he says halfway through his seduction of her, " " - how you shuddered at the bare idea of guilt. Now you can hear its language with interest: it has lost its horror: Ah, soon it will be the only language your heart will like."' (193). Through the comparison of these two men Lamb makes an important point, by emphasizing the parallels of the finest and most evil men in Glenarvon, she "generalize[s] the corruption of Calantha, to make it resonate as a sort of archetypal act: what men, even truly loving men, do to women ..." (Graham 106). Graham continues to argue that the role of men in the novel is to wound women; they are reduced to "stealing, staining, and breaking feminine hearts" (106). Lamb captured in Glenarvon some of Byron's most prominent characteristics; starting with the description of his appearance and his attraction to women (which I have already quoted on page 29) she connects them with the Byronic legend and thus produces an entirely new form of the Byronic hero as such, she "defrock[ed] him of his revolutionary authority" (Judson 155). Accordingly, Glenarvon only bears a vague resemblance to Byron. She does not describe him one-to-one, as the general idea of Byron could never grasp the real man but was always a misconstruction of reality.

The duplicity of the characters in the novel suggests a love-hate relationship with the hero-villain Glenarvon. Douglass comments:

The novel condemns Glenarvon and yet seeks to emulate him. This approach/withdrawal response is mirrored in the personalities of its multiple heroine-victims. Condemned by the women he wrongs, Glenarvon still obsesses them. They each repeat the same tale of passion, bereavement, and self-destruction. ("Madness of Writing" 60-61)

Glenarvon, as a Byronic hero, is free from any kind of restrictions as such as conventions or the restraints of love:

This heart has never stoop'd its pride

To slavish love, or woman's wile;

This mind has trac'd its own career, ...

Nor, moved by love, or hope or fear, ...

Then hope not now to touch with love,

Or in its chains a heart to draw,...

A heart ...

Sees nought above, nor deigns to cast

A look away on aught below. (119)

The song he sings at his and Calantha's first meeting which tells that he could never become a slave to love, operates as a kind of challenge for women that they take up. Therefore, he radiates a very special attraction, as he is not only free from but also completely uncommitted to love. 
Judson notes that the driving force behind Glenarvon's actions is a "taste for power" as well as the "will to dominate" (163). By seducing Calantha twice and betraying her to her family, he demonstrates his undeniable power over her. Nonetheless, in the end he has to pay for his crimes. After Glenarvon has wounded Lord Avondale in a duel and tries to flee to England. However, the ghosts of all the women he has betrayed haunt him. In a nightmarish scenario, these female ghosts drive him, in an act of revenge, to insanity; hell awaits Glenarvon.

\subsection{Elinor: Denied Desires Run Wild}

The denial of the female semiotic is not the only criticism Lamb expresses through Glenarvon on the patriarchal order of society. Another critique is the struggle against oppression and tyranny. McDayter explains that according to Burkean ideology, unmanageable and dangerous appetites and damaging passions have their origin in the female body ("Hysterically Speaking" 156). Consequently, the female hysteria that is set loose as soon as Glenarvon appears is an expression of uncontrollable female desire, about which Rousseau has already warned men. All the same, McDayter proceeds to argue that a Wollstonecraftian reading of Glenarvon allows for a very different perspective on the female situation. She states that the origin of "unmanageable and dangerous appetites and damaging passions" is not an expression of female desire "but rather the horrific symptoms of sexual and political oppression manifested in her body" ("Hysterically Speaking" 157). Thus, since women are not allowed to speak publicly, to defend themselves against oppression and a patriarchal system, or to even interact within the public sphere to better their situation, their protest has no outlet and manifests itself through the female body. She concludes that it is "precisely in the sexual body of Glenarvon's suffering heroines that we can find the physical manifestation of oppression and unspoken rage" ("Hysterically Speaking"157). She uses Sigmund Freud's interpretation of hysteria to support this argument. According to Freud: "Hysteria is a disease defined by the manifestation of unspoken desire upon the body of the subject" (qtd. in McDayter, "Hysterically Speaking" 164). Consequently, women have been cultured in the "fine art of becoming hysterics" (McDayter, "Hysterically Speaking" 164). As I have already stated, the Byronic hero as a symbol of revolt, libertinism, and passion only releases the violence and uncontrollability within these women. He is not the origin of the violence but its trigger, as it lies in the oppressive, traditional structures that dictate the repression of desire in female education.

The most hysterical of all these women is Elinor St. Claire, a more emotional alter ego of Calantha who is also destroyed by her love for Glenarvon. Elinor, who was raised by nuns and grew up in a convent, is apparently the woman to whom restrictions and repressions of desire were applied the most. In an attempt 
to keep her innocent in all imaginable ways, she has to suffer the most from conventional and traditional rules. Accordingly, the most apparent demonstration of how unguided liberation causes tragedy and of how repressed desires function in the body is demonstrated through her:

But for the deep flushes which now and then overspread St. Clara's cheeks, and the fire which at times animated her bright dark eyes, some might have fancied her a being of a purer nature than our own - one incapable of feeling any of the fierce passions that disturb mankind; but her voice was such as to shake every fibre of the heart, and might soon have betrayed to an experienced observer the empassioned violence of her real character. (61)

Again, Glenarvon senses the violence of the oppressed semiotic in her nature and is eager to release it, but only in order to gratify his own (sexual) desire. However, he could not have guessed the indomitable power he set free in Elinor. Presenting himself as a liberator of oppressive structures for the Irish as well as for women, he soon loses all control over the now emancipated former nun and is horrified and disgusted by that which he cannot control. With astonishing speed, which can only be explained by the immense amount of previously repressed passion, Elinor transgresses from an innocent, virtuous girl into a wild, masculine Amazon. The first meeting between Calantha and the the new Elinor is described as following:

Elinor came near: she raised her full black eye, and gazed with fearless effrontery upon Calantha.

It was the same face she had seen a few years back at the convent; but alas, how changed; - the rich and vivid crimson of her cheek, the deep dark brown of the wild ringlets which waved above her brown, the bold masculine manners and dress she had assumed, contrasting with the slender beauty of her upright form. She was dressed in uniform ... Elinor appeared desperate and utterly hardened: her presence inspired Calantha with a mixed feeling of horror and commiseration ... (114)

The extreme change of Elinor even unsettles her creator Glenarvon "Oh Elinor, I tremble at the sight of so much cold depravity - so young and so abandoned. How changed from the hour I first met you at Glenna!" (255).

Unlike Calantha, who has scruples about surrendering herself to Glenarvon, Elinor openly becomes his mistress and loves him with an incommensurable, burning passion. Where Calantha could still feel social restrains and even tried to live a life according to these, although she has already surrendered herself to Glenarvon, Elinor is different. She frees herself irrevocably from all feminine restrictions and even dresses like a boy, as Lamb herself did. ${ }^{29}$ She pursues a more radi-

29 Lamb claimed that she had written Glenarvon at night within the space of one month, dressed in page attire. It is also known that she visited Byron during their affair dressed as a page. A friend of Byron, Robert Charles Dallas, mentions one of those meetings in disguise: "While I was with 
cal way than the other women do, by breaking drastically with everything symbolic and exchanging it for the semiotic. In this manner, she intentionally commits a crime that is judged by society as vile and disgraceful, she openly lives as Glenarvon's mistress; she gives herself over to female desire and becomes an "unnatural" woman. Moreover, she leads a clearly rebellious existence as the leader of the Irish peasants and the prophetess of the Irish revolution. Even after Glenarvon abandons her and his revolutionary followers, she keeps faith in the revolt, fights like a man in battle and sets Glenarvon's ancestral home on fire, as an act of revenge.

Nonetheless, contrary to the heroines who devoted themselves to Glenarvon, Elinor does not perish after he has abandoned her. She is the only female who refuses to be shattered by a failed romance or to make his abandonment the centre of her existence. She is, in this respect, the most emancipated of all women in the novel. Her rejection of old traditions activated through her passionate love for Glenarvon and his eventual abandonment of her lead to a complete emancipation of her mind, a breaking from oppressive conventions and poisonous love. There is no way back for her. She is obviously the most hysterical of all women, and Calantha asks herself:

"And can a few short years thus harden the heart?" she exclaimed, "was St. Claire innocent, happy, virtuous? can one moment of error thus have changed her? Oh, it is not possible. Long before the opportunity of evil presented itself, her uncontrouled passions must have misled her, and her imagination, wild and lawless, must have depraved her heart. Alive was innocent: he who first seduced her from peace, deceived her; but St. Clare was not of this character. I understand - I understand the feeling which impelled her to evil. Her image hounds me. I tremble with apprehension. Something within me seems to warn me, and to say that, if I wander from virtue like her, nothing will check my course ... my ungoverned will has hitherto, my only law". (116-117)

In her pursuit for freedom, Elinor is clearly depicted as a Byronic heroine. In the end, she commits a Sappphoesque suicide when she leaps on horseback over the cliff into the sea and theatrically dies. Until then, she is defiant and unbowed and vehemently refuses to go back to her existence as a passive bystander and victim of a patriarchal society that had the power to lock her up in a convent.

Judson argues that Elinor's commitment to the Irish rebellion is depicted as pitted against Glenarvon's vocation of treachery for the Irish cause and is thus an assault against Byron and Whig society. Furthermore, she states that at first ap-

[Byron], the Lady's page brought him a new letter. He was a fair-faced, delicate boy of thirteen or fourteen years old, whom one might have taken for the lady herself. He was dressed in a scarlet hussar jacket, and pantaloons... He had light hair curling about his face, and held a feathered hat in his hand which completed the scenic effect of this urchin Pandarus. I could not bust suspect at the time that it was a disguise" (qtd. in Jenkins 57-58). 
parent similarities between Elinor and Lamb herself could be noted as they both (supposedly) played Byron "because she, too, is a darkly alienated poet, known to have been Glenarvon's mistress, thus set apart by obligatory crime and guilt" (166). However, Judson continues, differences become more and more apparent. Elinor starts to function as the "authenticity of Gaelic culture in stark opposition to the mummery of the Byronic hero" (166). Correspondingly, it has been argued that Lamb empathised with the political emancipation of Ireland and its longing to liberate itself from a too domineering England, since she recognised parallels between the repression of the Irish and the female struggle for autonomy. ${ }^{30}$ Consequently, the Irish rebellion against the English in Glenarvon has been read as a metaphor for a female revolt against an oppressive patriarchal system; both have been caused by the appearance of the Byronic hero.

Elinor's function as a Byronic heroine has barely been commented on although it is noticeable. Judson states that, in a real Byronic fashion, she renounces every conventional rule, starts to wear men's clothing, shatters her obligation of filial obedience, and chooses to live under her dying father's condemnation rather than going back to old values and restrictions (167). She possesses enough passion and devotion for the Irish cause to gain the rebels' confidence and to qualify as their leader. She is, like the Byronic hero, a fighter for justice who actively considers isolating herself from society in order to gain freedom. Nevertheless, Judson concludes "where the Byronic hero's "involuntary fault" is presented as confirmed hypocrisy and self-seeking mobility, St. Clare's rebellion against the corrupt institutions of family, colonial society, and British power is commended as heroic martyrdom in the best tradition of Roman virtue" (169). Where Glenarvon functions as the Byronic hero gone berserk, Elinor is his counterbalance, a fighter for equality and against oppression; as someone who detached herself completely from everything, whether they be conventions, or even love. Thus she says to Glenarvon:

"Alice dead - Calantha discarded! I heard the tale, but it left no credit with. - Can there be hearts so weak as thus die for love? ... [B]y thyself, thy [Glenarvon's] glorious self, I swear I will never return to virtue ... by these eyes ... by these shining looks ... by these lips, which prest by yours, have felt the rapturous fire and tenderness of love - virtue and I are forsworn: and in me, whatever I may appear, henceforward know that I am your enemy." (255-256)

However, critics have commented that there was no place for such an independent woman in English Regency society and that the future "holds no place for this proleptic figure of sexual and political liberty, who remains a prophet without honor in her own country" (Judson 168). ${ }^{31}$

30 For a further discussion see Barbara Judson and Ghishlane McDayter ("Hysterically Speaking").

31 See Ghislaine McDayter and Barbara Judson among others. 
Her end is thus anticipated. Elinor's fate clearly functions as a forewarning of how women are treated in society. It demonstrates how sexual repression affects the psyche. She personifies the consequences of the explosion of too long denied desires, the violence which occurs through this release. Elinor chooses to die rather than to rehabilitate herself in the eyes of society by conforming to the expectations of society. As McDayter describes it "death is the only alternative to slavery in this brutal world ruled by the "law of father" "Hysterically Speaking", 170). After setting fire to Glenarvon's ancestral home

she pressed the spur into his sides, and galloped in haste to the edge of the cliff, from which she beheld, like a sheet of fire reddening the heavens, the blazing turrets of Belfont. She heard the crash: she gazed in triumph, as millions of sparks lightened the blue vault of heavens; and volumes of smoke, curling from the ruins, half concealed the ravages of insatiate flame ... The waves of the foaming billows now reflected a blood-red light from the scorching flames ... (349)

Seeking her watery grave voluntarily, she chooses freedom over slavery, the semiotic over the symbolic. The theatrical setting, a fire-red sky, the wild, troubled ocean symbolise the tumult of her passion, the unspoken rage within that can never be controlled again. The flames can easily be read as a flaming sexual desire, which can also never be fulfilled. Accordingly, her suicide is her own kind of victory.

Graham argues that Glenarvon's heroines are doomed to failure and death, because they have to pay for their error, and the nineteenth-century novel demands such a punishment (102). However, I agree with critics like McDayter and Judson, as they argue that Lamb recognises the dangers of the repression of desires and knows that desire, if not expressed, will articulate itself through the female body. Women's radical breaking with conventions in Glenarvon, Elinor's inconsiderate giving in to the semiotic, the self-destructiveness of Calantha's and Elinor's passion, all this points to a reflective discussion of repressed desire.

\subsection{Conclusion}

Critics have tried to depict Lady Caroline Lamb as a hysterical woman in need of mastery, a concept that is not uncommon in Romantic criticism. She has also been reduced to a love-mad woman who wrote a novel as an act of revenge. Her work has been diminished to a biographical account of a very public affair so that the social criticism on gender power relations has been ignored. However, as I have tried to demonstrate, the origin of Lamb's supposed madness lay not in her incapability to rest but in society's prohibition of the female semiotic and in Byron himself. 
Lamb demonstrates in Glenarvon how passion and desire will find a way to break free and take over the body and mind. She uses the literary persona of the Byronic hero as a trigger and catalyst of female passion. Simultaneously, she transforms him through her own personal experienced with Lord Byron, and presents him as an inconsistent, fatal and cruel, but charismatic lover, who arouses female desire to such an extent that it can neither be repressed nor ignored. She not only started a new literary tradition by using the dangerous love for the first time in a novel, her depiction of this persona would become one of the most popular Byronic features in novels. Furthermore, other female writers would use the persona to criticise gender roles.

Lamb sees the origin of the "female dilemma" in an insufficient education. Avondale's and Glenarvon's attempt to reveal the "true" woman within from artificial social and cultural restrictions such as education, law, and social class, demonstrates how the idea of femininity has been forced upon women. Lamb exposes the oppressive power of the patriarchal system and its capability to repress women's semiotic side. Thus, Lamb's interest lies not in the punishment of the heroines' failure to resist the sexual temptation through remorse but in the emotional understanding and experiences of the "female world" that is oppressed by a patriarchal rule of social convention. The women in her novel had no other chance than to fail, as their education and traditional conventions prohibited them to learn reason, so that they acted on their desires only. Accordingly, Glenarvon is a presentation of the inevitable interaction between the symbolic and semiotic, a demonstration that neither order can stand alone. It is a depiction of the relationship between conventional patriarchal social values, the private world of passionate feeling and the consequences of being forced to comply with the symbolic only.

\section{Charlotte Brontë's Jane Eyre}

\subsection{Feminist Criticism}

Since its publication in 1847, Jane Eyre has been considered to be a novel that speaks particularly to women and about womanhood. In the twentieth century it became an iconic text in feminist criticism, which reads it as a woman's quest for independence and equality. From childhood on, Jane Eyre struggles to recount her own story, in order to defend and explain her life's choices, which are far from conventional, but also to let her voice be heard at a time when women were not supposed to have a voice of their own. Jane, however, dares to talk back and thus liberates herself from the repressing symbolic order. C.Kaplan states that feminist criticism has read Jane Eyre as a "revolutionary manifesto" as Jane is able to "nar- 
rate (if not direct) her own story" (72). Traditionally, the novel is seen as a form of resistance, or, as Gilbert and Gubar state, as "a pattern for countless others ... a story of enclosure and escape of difficulties Everywoman in a patriarchal society must meet and overcome" (256). Nevertheless, Jane also has to live within a patriarchal system in which she is expected to repress her desires. Although she is one of the first heroines to recognise and admit those desires, she needs a Byronic hero before she is able to free herself from oppressive conventions and let her passions free.

One of the first critics to note the new concept of this female selfdetermination in Brontë's novel was a contemporary of Brontë, Margaret Oliphant, a Scottish novelist and historical writer. She was the earliest critic to identify Jane Eyre as a transformation within the female tradition of writing, as Jane is more aggressive, independent and demanding than any female protagonist before:

Nobody perceived that it was the new generation nailing its colours to the mast. No one would understand that this furious love-making was but a wild declaration of the 'Rights of Woman' in a new aspect. (557)

Oliphant, although she recognises the new dynamics between men and women that the novel presents, vehemently criticises Brontë's radicalism in the novel, arguing that it gives young women a wrong impression of courtship and marriage.

In "A Room of Ones Own" (1929) Virginia Woolf saw Brontë as one of the women who had set the stage for the acceptance and recognition of female writers and their work. Yet she judges Brontë's writing as containing too much anger and rage in her authorial voice that she sees as a distortion of the narration. As Showalter comments on Brontë: "[P]erhaps no other writer of her time has impressed her mark so clearly on contemporary literature, or drawn so many followers onto her own peculiar path" (87). Either way, Brontë's Jane Eyre has a special significance in feminist criticism.

At a time when women were supposed to keep strictly within the bounds of female decorum in their writing, both in style and subject, an obvious double standard in literary works can be found. Accordingly, critics judged the literary works of female writers differently than those of their male counterparts. Consequently, female writers used male pseudonyms when publishing their works. During the mid-Victorian era, women had only few opportunities for using their talents to express their true identities. It was expected that they would be content with their lives within a confined and limited sphere; when in fact these restrictions and confinements drove many of them to madness by prohibiting their selffulfilment. In Jane Eyre Brontë demonstrates that all women are symbolically disinherited in a patriarchal society and that they have only a limited number of options to come to terms with their lot. A woman could forsake all worldly aspirations and pleasures and thereby deny her self, as the examples of Helen Burns and Eliza Reed show who retreat into the promises of religion. Alternatively, they 
could try to catch a husband who would care for them, as Georgina Reed and Blanch Ingram choose to do. In contrast to those two choices, Jane finds a way to express herself and to eventually balance her desires, which become almost overbearing with the appearance of Rochester, so that she is no longer able to ignore them and act within expected norms.

When Jane Eyre appeared in 1847 critics were eager to find out if Currer Bell, Brontë's pseudonym, was a man or a woman. Showalter comments that the character of Rochester in particular provoked a whole range of negative criticism ranging "from bafflement to horror" (115). ${ }^{32}$ Even though he was a convincing character, it was argued that no decent girl could ever love this brutish hero. Still, in the novel exactly such a girl loves him. Where men saw Rochester as tyrannical, female novelists recognised the value of such a hero, since the "brute flattered the heroine's spirit by treating her as an equal rather than as sensitive, fragile fool, who must be sheltered and protected" (Showalter 117). Even though Brontë confessed to her friend James Taylor that she had had difficulties in constructing a male character, her creation is still considered to be one of the most popular male protagonists in English literature:

In delineating male character, I labour under disadvantages; intuition and theory will not adequately supply the place of observation and experience. When I write about women, I am sure of my ground - in the other case I am not so sure. (qtd. in Showalter 109)

Rochester's character, however, was not as new and innovative as Showalter depicts it to be. He is actually a remnant of the previous Romantic period, since he is a direct descendent of Lord Byron's protagonists. Byron's influence on the Brontë sisters is indisputable; various forms of the Byronic hero pervade their works. Their idea of love in particular, as vital to give meaning to life and as fatal and as burdened with guilt, is a Byronic concept. Moglen even argues that the articulated ambitions of the original Byronic hero could be considered to be "the repressed needs and feared passions of Charlotte's "other" self" (26). She continues by pointing out that when Charlotte first heard of Lord Byron he had already died and his name had been linked interchangeably with everything that was prohibited and audacious. Nevertheless, as Gérin argues, Brontë provides her heroes with

32 Brontë however defends Mr Rochester against his critics: "Mr Rochester has a thoughtful nature and a very feeling heart; he is neither selfish nor self-indulgent; he is ill-educated, misguided; errs, when he does err, through rashness and inexperience; he lives for a time as too many other men live, but being radically better than most men, he does not like that degraded life, and is never happy in it. He is taught the severe lessons of experience and has senses to learn wisdom from them. Years improve him; the effervescence of youth foamed away, what is really good in him still remains. His nature is like wine of good vintage; time cannot sour, but only mellows him.” (Charlotte's Letter to W.S. Williams 14 August 1848 in: Wise, Thomas James and John Alexander Symington (Eds), The Brontës. Their Lives, Friendships and Correspondenc. Oxford: Basil Blackwell, 1989.) 
every Byronic characteristic and theme, such as "love, jealousy, treachery, ambition, courage, pride and daring", as well as with "quality satanic ruthlessness and demonic power" (2-3).

\subsubsection{An "Unwomanly" Woman}

The presentation of female desire in Brontë's novel outraged many readers. The novel addresses the stigmatization of female desire, as it does not depict Jane as a mere passive being or as a sexual, demonic assailer. The novel raises the awareness of the difficulties women had to communicate their desire. Female novelists challenged and questioned the codes of female behaviour through their depiction of fictional female characters. They tried to create a counter motion to advice literature that tried to regulate female behaviour. Mitchell and Osland comment that during the sixteenth century

women where regarded as inherently sexually voracious, driven by bodily desires that their inferior rational powers struggled to control, advice literature emphasized ... prohibitions that would establish a system of behavioural defences, chief amongst these being the scriptural case for obedience which men saw as the basic resolution to women's wiles and weaknesses. (6)

They continue by pointing out that from the 1630s onwards, conduct books changed their course from proclaiming that the dangers of female sexuality could be avoided through submissiveness to men by focusing more on female "modesty":

A modesty that in its broadest sense is no different form the moderation earlier enjoined on women in subjugating themselves to masculine authority as a 'due master' of their inferior status, but increasingly understood, or at least increasingly discussed, more narrowly as a personal delicacy that prompts a woman to shrink from notice or self-assertion. (6)

With the help of advice literature, critics could thus reconstruct the development of the "image of woman as lustful, loquacious, and wilful to one that is naturally rather than prescriptively chaste, silent and obedient" (6). The alteration from the idea that women's sexuality should be regulated through male authority to the concept that all women are naturally delicate, sensitive and modest, and that they instinctively shrink back from sexuality did not mean that one idea of femininity replaced the other. Mitchell and Osland argue, "in the social construction of womanhood, beliefs seem to have accumulated in layers" (7). This is why women on the one hand could be condemned as demonic, voluptuous and wilful beings 
and why, on the other hand, the existence of female sexuality could be denied altogether. ${ }^{33}$

Jane Eyre questions basic institutions and concepts of a bourgeois patriarchal society and can thus be considered to be a "ringleader of a feminist revolt against its stifling conventions" (Mitchell and Osland 175). It was Jane's discontent that drew the most fervent protestation, as she seemed unable to appreciate the "simple duties and pure pleasures" of a "proper" woman. The very temperament of Jane's passions, such as falling in love with her master Mr Rochester was judged as inappropriate, and having such passions at all was considered as indecent (Mitchell and Osland 177).

In this regard, Jane Eyre is a highly unconventional novel, as Jane declares her independence as an individual who will not be governed by conventions and traditional patriarchal beliefs, but only by her own conscience. However, she only narrowly escapes the charm of the Byronic hero who almost tempts her into living like him, ignoring and flouting divine power and laws. Ewbank notes that "measured against the criterion of womanliness which states that the pure feminine mind must, even theoretically or imaginatively, know no sin, no evil, no sexual passion [Jane Eyre and even Charlotte Brontë] could not but seem 'unwomanly"' (42). The very questioning of the established gender roles was thus seen as unfeminine, improper and scandalous.

It is difficult to assign the novel to a particular genre as it unites the romance with the woman question and various other social themes, such as class, patriarchy and religion. Jane Eyre voices the female hunger for sexual experiences and tries to provide a surrounding in which the expression of these sexual desires might be made possible and in which women are not condemned as mad when experiencing sexual urges.

Brontë gives a demonstration of the symbolic and semiotic order by placing characters in either the one category or the other. She thus reveals the dangers and consequences those orders hold for women if they are forced or chose to comply with only one. Jane will be confronted with a semiotic force in form of Mr Rochester, the Byronic hero who acts as a catalyst for Jane's strong inner sexual desires. She almost loses herself in both, the semiotic and symbolic, as she has difficulties resisting male sexual power, but eventually finds a way to balance these two orders.

33 Maynard comments that Michel Foucault was one of the first critics who concluded in his History of Sexuality that the Victorians were, contrary to popular belief, rather concerned with the subject of sexuality. It had been believed that within the Victorian period, sexuality was a topic which had been completely ignored. Foucault corrects this view when he discusses that on the one hand there were those who discussed the matter of sexuality quite openly, and on the other hand were those Victorians who vehemently ignored or even denied the matter of sexuality. Either way, the Victorians were obviously engaged in a ubiquitous discourse of sexuality (vii). Yet, the term Victorianism is still connected with the idea of repressed or ignored sexuality. 


\subsection{Symbolic and Semiotic}

Jane's development into a woman in nineteenth-century England is described powerfully and is worth to be carefully looked at. From childhood on, she is unable to comply solely with the symbolic, as the semiotic always forces itself to the surface. One of the most profound innovations of Jane Eyre, however, is the depiction of the symbolic and semiotic by dividing the characters' psyche into two parts of mind and body. This is illustrated through two contrasting characters: Helen Burns and Bertha Mason. These two women can be seen as the embodiment of the "unyieldingly dualistic" Victorian attitude towards female sexuality. While Helen is a clear personification of the symbolic, her counterpart Bertha is the personification of the semiotic. While Helen and Bertha are prominently read as two faces, or alter egos, of Jane, my reading of these two female characters will be focused on their role as the embodiments of the two orders and the resulting inescapability of their demise. These polar personalities serve Jane as warning against the separation of the symbolic and semiotic.

\subsubsection{Jane’s Inner Struggle}

Although raised in a patriarchal, symbolic tradition Jane's growth from child to woman is marked by unexpected and unparalleled outbursts of the semiotic in the form of rage and revolt against her oppressors, namely her cousin John Reed and her aunt Mrs Reed. When Jane defends herself against John's violent assaults, she is locked up in the red room, where she experiences a hysterical fainting fit. Gilbert and Gubar comment that the red-room experience induces Jane to withdraw into herself. They argue that the room, which was "stately, chilly, swathed in rich crimson, with a great white bed and an easy chair 'like a pale throne' looming out of scarlet darkness, perfectly presents her vision of the society she is trapped in" (257). It appears to me, however, that, instead of forcing Jane into herself, this incident marks the end of her submission to authorial power and introduces a new chapter in her life. When she wakes up, she carries the knowledge of the absolute necessity to protect herself against the symbolic. She realises that she needs to care for herself, as nobody else will do so. Furthermore, while defending herself against her cousin, as well as in the red room she experiences a previously unknown aspect of herself, an almost animalistic rage and passion. As Moglen notes, Jane awakens to a new "capacity of moral judgment and nascent senses of the self" (111).

While Gilbert and Gubar discuss Jane's following outburst against Mrs Reed and the corresponding comments of "something burst out of me" (13) and "a sound filled my ears, which I deemed the rushing of wings; something seemed near me" (14) as a suggestion of the existence of a "dangerous double consciousness" (Gilbert and Gubar 260). I rather understand her rebellion and outburst as 
her perception that a compliance with the symbolic will end in a life full of oppression and ultimately in the loss of the self in patriarchal traditions. In order to prevent this from happening, she needs to stand up against her aunt Mrs Reed, who acts as a representative of the patriarchal system. Thus, Jane confronts her:

Speak I must; I had been trodden on severely, and must turn; but how? What strength had I to dart retaliation at my antagonist? I gathered my energies and launched them into this blunt sentence:

"I am not deceitful!"...

"I am glad you are no relation of mine ... You think I have no feelings and that I can live without one bit of love or kindness; but I cannot live so and you have no pity ... And that punishment you made me suffer because your wicked boy struck me - knocked me down for nothing ... You are deceitful!"' (31-32)

Jane tells the reader that

Ere I had finished this reply my soul began to expand, to exult, with the strangest sense of freedom, of triumph, I ever felt. It seemed as if an invisible bond had burst, and that I had struggled out into unhoped-for liberty. Not without cause was this sentiment; Mrs Reed looked frightened. (31)

The child Jane already feels that she must stand up against the injustice and discrimination that she experienced at her aunt's house, despite her youth and indoctrinated submissiveness. Jane's semiotic side cannot be fully suppressed and surfaces over and over again. A dialogue between passion and reason, feeling and judgment, impulse and conscience, fire and ice starts.

\subsubsection{Female Education: or the Oppression of Female Sexuality}

After the outburst Mrs Reed sends Jane to Lowood School; a place where female sexuality is systematically diminished and repressed. Mr Brocklehurst, the director of the school, acts as an example of tyrannical and cruel male authority. He is the embodiment of institutionalised oppression that is based on class and sexual prejudice, a representative of the symbolic. He represents the abusiveness and oppression that women have to endure in a patriarchal society.

As various critics have noticed, Brocklehurst is presented as the evil wolf in Charles Perrault's "The Little Red Riding Hood." 34 He is a mixture of the devil himself and the evil wolf, a devourer of everything innocent. Gilbert and Gubar have stated how Mr Brocklehurst is the perfect example of the "Victorian superego" (260), because of his description in evident phallic terms during Jane's and his first encounter:

34 See Sandra Gilbert and Susan Gubar, Cyndy Hendershot, and Huang Mei among others. 
The handle turned, the door unclosed, and passing through and curtseying low I looked up at - a black pillar! Such, at least, appeared to me, at first sight, the straight, narrow, sable-clad shape standing erect on the rug: the grim face at the top was like a carved masked, placed above the shaft by way of capital. (26)

Hendershot points out that the fairytale of the "Little Red Riding Hood" has been read as a tale of female sexual initiation, consequently she sees Brocklehurst's comparison to the evil wolf as an act of sexualizing him and simultaneously presenting the "image of masculine sexuality as animalistic and dangerous" (167). His sexualisation is further emphasised by an imagery of a personified erection "it was Mr Brocklehurst, buttoned up in a surtout, and looking longer, narrower, and more rigid than ever" (58). Accordingly, male sexuality is presented as threatening. His function as an oppressor of female sexuality is emphasised through his speeches, for example, when he explains his actions to Miss Temple:

I have a Master to serve whose kingdom is not of this world; my mission is to mortify in these girls the lusts of the flesh, to teach them to clothe themselves with shame-facedness and sobriety - not with braided hair and costly apparel; and each of the young persons before us has a hair twisted in plaits which vanity itself might have woven; these, I repeat, must be cut off; think of the time wasted, of - . (56)

He systematically tries to desexualise the orphans who are entrusted to his care and his "obsession with feminine sexuality fuels Jane's sexualisation of his authorial power" (Hendershot 167). Presenting himself as a pious and spiritual man, he is an example of how men used religion to justify the imposition of their worldview on women and the poor.

At Lowood, the girls are not only starved to death but they are also denied all kinds of sensual pleasures. Signs of their femininity are methodically destroyed, as they are all clothed in the same brown dresses and deprived of their hair, which is their last symbol of their femininity. At school, they are supposed to be taught the kind of chastity that their future lives will require. Brocklehurst is on a mission "to mortify in these girls the lusts of the flesh"; he tries to accomplish this task by destroying not only the girl's individuality but he simultaneously "punishes and starves their sexuality" in order to "create an intensely spiritualised creature", namely "the angel in the house" (Showalter 97) while simultaneously representing masculine sexuality.

\subsubsection{The Self-Destructiveness of the Angel in the House}

Helen Burns represents the angel in the house and is thus a "perfect ... representation of the feminine spirit in its most disembodied form" (Showalter 97). Helen 
is the ideal victim for Brocklehurst's method of education, as she is pious, patient and submits completely to the symbolic order. She endures unjust punishment uncomplainingly, forgives the teacher's cruelty and entirely acknowledges the legitimacy of their punishment. Helen appears like a living martyr; her desire for death however, demonstrates how the total compliance to the symbolic results in violence against the self. Her total submission to her oppressors eliminates any kind of self-preservation; as a result, she is convinced of her inadequacy and her guilt for not being able to live up to their expectations leads to this desire for death. Thus, Helen's submissiveness and inability to live within the symbolic order let her consider death as her only chance of happiness:

No ill usage so brands its record on my feelings ... We are, and must be, one and all, burdened with faults in this world; but the time will come soon when, I trust, we shall put them off in putting off our corruptible bodies when debasement and sin will fall from us with this cumbrous frame of flesh, and only the spark of the spirit will remain, the impalpable principle of life and thought, pure as when it left the Creator to inspire the creature: whence it came it will return - perhaps again to be communicated to some being higher than man - perhaps to pass through gradations of glory from the pale human soul to brighten to the seraph! Surely it will never, on the contrary, be suffered to degenerate from man to fiend? No; I cannot believe that; I hold another creed, which no one ever taught me, and which I seldom mention, but in which I delight, and to which I cling; for it extends hope to all; it makes Eternity a rest - a mighty home, not a terror and an abyss. Besides, with this creed, I can clearly distinguish between the criminal and his crime, I can so sincerely forgive the first while I abhor the last; with this creed, revenge never worries my heart, degradation never too deeply disgusts me, injustice never crushes me too low. I live in calm, looking to the end. (50-51)

This passage shows how completely Helen has given up, not only on herself but also on the world; consequently, she almost excessively waits for her death to come.

Jane admires Helen's attitude immensely, and it has a deep impact on her: "It was as if a martyr, a hero, had passed a slave or victim, and imparted strength in the transit" (58). Helen's martyrdom however, is presented as saintly and at the same time as self-abnegating. Although she serves also as an example to instruct Jane in the virtues of patience, endurance and selflessness, her patience implies "a rational submission to the repressive conventions of Lowood, which she does not challenge" as well as a "resigned endurance of life as a burden from which will come release" (Eagleton 15). Eagleton sees in Helen's heroism a "heroic selfaffirmation" that is "a realization of the self through its inner surrender" (16). As her name a suggest, Helen "Burns" within; her suffering and religious passion 
indicates a renunciation of the (symbolic) world. Because of the complete denial of the importance of worldly desires, her passions are forced to consume themselves and her in an inward fire. Her absolute rejection of desires results in an internal self-immolation. She complies and tries to obey the laws of the symbolic at such an excessive degree that it becomes her vanishing point. In the end, she prevails over oppressive and tyrannical conventions. Her victory, however, is won through her early death, as this is the only way for her to escape the symbolic; her death frees her from all potential suffering.

Helen is not the only one who teaches Jane self-discipline. Miss Temple, the superintendent at Lowood School, is one of the few positive female role models who treat Jane with respect and compassion. After Helen's death, she becomes Jane's only friend and as long as she stays at Lowood Jane can pretend to be content, however:

From the day she left I was no longer the same: with her was gone every settled feeling ... I had given in allegiance to duty and order; I was quiet; I believed I was content: to the eyes of others, usually even to my own, I appeared a disciplined and subdued character ... I had undergone a transforming process; my mind had put off all it had borrowed from Miss Temple - or rather that she had taken with her the serene atmosphere I had been breathing in her vicinity - and that now I was left in my natural element, and beginning to feel the stirring of old emotions. (73)

Her former calmed discontent makes itself felt again and she knows that she cannot oppress or ignore them once more: "I felt that it was not enough: I tired of the routine of eight years in one afternoon. I desired liberty; for liberty I gasped; for liberty I uttered a prayer" (74). Here she realises that she could never be content with complying to the symbolic and that she wants more from life: “'Then,' I cried, half desperate, 'grant me at least a new servitude!'” (74).

She also desires independence and the longing for and acquiring of it is another important motif of the novel. For an unmarried woman independence is, in a wider sense, a matter of status and affects her self-esteem and personal identity.

\subsubsection{Repressed Desires Run Wild: or the Mad Woman in the Attic}

Where Helen Burns is the embodiment of the symbolic, Mr Rochester's wife Bertha Mason who is confined to the third story of Thornfield because of her madness is an embodiment of the semiotic. She stands as a symbol for suppressed female sexuality and through her Brontë raises the awareness of the amalgamation between sexual suppression and its consequence, namely madness. Various critics have argued that Bertha functions as Jane's dark alter ego (Gilbert/Gubar), or as an exemplum of the dangers of sexuality (Maynard). Like Helen, Bertha represents the Victorian discourse of female sexuality; she is the supposedly dangerous side, 
the wilful female, the fallen woman whose sexual hunger drives her into madness. However, it appears useful to discuss Bertha's madness both as unregulated female desire and as a consequence of patriarchal suppression of female sexuality. She embodies everything a woman had, according to the symbolic, to suppress, but yet in Jane's own words "could neither be expelled nor subdued by the owner" (185). Furthermore, Bertha functions also as a warning against complying fully with the semiotic, as a warning against having nothing of the passion controlling symbolic within oneself.

As Showalter comments, Bertha is the incarnation of the flesh, of "female sexuality in its most irredeemably bestial and terrifying form" (98) that is "a potential dangerous force that must be punished or confined" (98). Thus, Bertha's madness can also be translated into unregulated sexual desire. Female sexual appetite was considered as something unwomanly, even bestial. When Jane meets Bertha for the first time, the later is not even considered as a human being but is associated with a wild and dangerous animal that cannot be constrained:

In the deep shade, at the further end of the room, a figure ran backwards and forwards. What it was, whether beast or human being, one could not at first sight, tell: it grovelled, seemingly, on all fours; it snatched and growled like some strange wild animal: but it was covered with clothing and a quantity of dark, grizzled hair, wild as a mane, hid its head and face ... the clothed hyena rose up, and stood tall on its hind feet. (258)

Bertha embodies the resistance and defiance of repressive, symbolic cultural notions and gives herself fully to the semiotic that is expressed through an animalistic and masculine violence against others:

The maniac bellowed: she parted her shaggy locks from her visage, and gazed wildly at her visitors. I recognized well that purple face - those bloated features ...

'Ware!' cried Grace. The three gentlemen retreated simultaneously. $\mathrm{Mr}$ Rochester flung me behind him: the lunatic sprang and grappled his throat viciously, and laid her teeth to his cheek: they struggled. She was a big woman, in stature almost equalling her husband, and corpulent besides: she showed virile force in the contest - more than once she almost throttled him, athletic as he was. He could have settled her with a well-planted blow; but he would not strike: he would only wrestle. At last he mastered her arms; Grace Pool gave him a cord, and he pinioned them behind her: with more rope, which was at hand, he bound her to a chair. (258)

The paragraph does not even depict her as a woman but as an uncontrollable, wild animal which needs to be conquered as it is otherwise a threat to society.

Bertha embodies everything that lies beneath acceptable femininity. Her animal appearance and behaviour however, are the very consequence of her impris- 
onment and not its cause; or, as Showalter argues, "after ten years of imprisonment she has become a caged beast" (100). She is presented as a being that consists so thoroughly of passions and desires that it has lost its humanness. Not being able to repress these passions and desires any longer, they plunge out of her uncontrollably. She represents everything that could disrupt the symbolic in an extent that appears abjected; she is not able to articulate herself but through eccentric murmurs, threatening growling and snapping sounds - even her laugh is preternatural. All these sounds recall Kristeva's concept of the "semiotic chora" that is an essential part of the semiotic.

Her rage is shown through an emphasis on her 'big', 'corpulent' and 'virile' body that is linked with an extreme fury and a want for vengeance against her oppressors. As Bronfen notes, Bertha presents the female body as the dangerous "Other" to men; she is described as "cunning and malignant lunatic, maniac, monster, wild beast goblin and fury" (221). Her body is described as monstrous, as polluted and "mad, bad and imbruted" because of her Creole heritage (221). She is equally excessive as Helen is and falls short of the expected code. She stands as a symbol for the pure, uninstructed, diffuse, aggressive and sexual drives that constitute the semiotic and that must be controlled and restrained. Through the fire she sets at Thornfield Bertha tries to destroy the external, the symbolic that held her captive. Bronfen argues that Bertha's death states that she had to finally give into the "exertion that [her] body is equally termed by others as socially defective and physically corrupt" (222).

That Bertha was meant to be a critique on standing social gender bias and not as a critique on female sexuality is further underlined by in a comment by Brontë herself:

[Bertha's] character is shocking... [but] profound pity ought to be the only sentiment elicited by the view of such degradation, and equally true is that I have not sufficiently dwelt on that feeling; I have erred in making horror too predominant. (qtd. in Smith, Letters 3)

Accordingly, Bertha's example reveals both the sheer impossibility to comply solely with one order, as this eventually leads to death, which she has in common with Helen. It also reveals Brontë's warning of the violent force of denied desires which will ultimately explode.

Two alternatives of behaviour have been presented to Jane in the form of Helen and Bertha. First, the angel in the house, whose required angelic innocence lead to death. Secondly, she encounters a wild and uncontrollable woman, who lost herself in the semiotic, which leads to social rejection, imprisonment and in the end to death. However, it is important to notice that Bertha's total compliance with the semiotic is a result of the symbolic, whose required sexual suppression led to Bertha's madness. 
By assigning Helen and Bertha to the two contrasting orders, Brontë is able to criticise the contemporary discourse of the polar aspects of female sexuality and to demonstrate the risk women are exposed to if forced to comply to the symbolic only. Either they die because of repressed passions devouring them from within, or their desires find a way to break out of them uncontrollably so that they become mad and destructive. These two choices are presented to Jane, and although she knows what is expected of her, namely to become a second Helen Burns, to be submissive, patient and content, she has seen the dangers of such a compliant behaviour and rejects it. The other extreme however, to become like Bertha and give into her desires, is equally daunting.

\subsection{The Byronic Hero: Catalyst of Denied Passions}

Jane's departure from Lowood is not only a change of place but also temporarily the end of the dominance of the symbolic. At her arrival at Thornfield, she enters into the semiotic realm. Standing at the battlement of Thornfield and longing for more than a woman in her position can expect, for "a power of vision which might overpass that limit; which might reach the busy world ... I desired more of practical experience than I possessed", Jane addresses the reader:

Who blames me? Many, no doubt; and I shall be called discontented. I could not help it: the restlessness was in my nature; it agitated me to pain sometimes ... It is vain to say human beings ought to be satisfied with tranquility: they must have action; they will make it if they cannot find it. Millions are condemned to a stiller doom than mine, and millions are in silent revolt against their lot. Nobody knows how many rebellions besides political rebellions ferment in the masses of life which people earth. Women are supposed to be calm generally: but women feel just as men feel; they need exercise for their faculties, and a field for their efforts as much as their brothers do; they suffer from too rigid a restrain, too absolute a stagnation, precisely as men would suffer; and it is narrow-minded in their more privileged fellow-creatures to say that they ought to confine themselves to making puddings and knitting stockings, to playing on the piano and embroidering bags. It is thoughtless to condemn them, or laugh at them, if they seek to do more or learn more than custom has pronounced necessary for their sex. When thus alone, I not unfrequently heard Grace Poole's laugh. (95)

Jane's realization that the new servitude could not slake her inner restlessness paves the way for her to experience the semiotic.

After being confined within the symbolic and refusing to surrender to it, at Thornfield she will be confronted with a semiotic force that she cannot resist and that excites her deepest desires, and passions: the Byronic hero. All through her 
stay at Thornfield, a gothic setting underlines a certain dangerous and uncanny atmosphere; yet, Jane strongly renounces her fancies by trying hard to rely on reason only. This effort is scattered by the arrival of Mr Rochester. Her already acknowledged passions and desires are catalysed through his appearance to such an extent that Jane has to struggle hard in order to not lose herself completely in the semiotic.

The first description that Mrs Fairfax, the housekeeper at Thornfield, gives Jane of her new master already establishes Rochester as a Byronic hero: "[h]is character is unimpeachable, I suppose. He is rather peculiar, perhaps: he has travelled a great deal, and seen a great deal of the world, I should think. I daresay he is clever" (92). When Jane asks her, in what way Rochester is peculiar Mrs Fairfax answers:

I don't know - it is not easy to describe - nothing striking, but you feel it when he speaks to you: you cannot be always sure whether he is in jest or earnest, whether he is pleased or the contrary; you don't thoroughly understand him, in short - at least, I don't ... (92)

As numerous critics have already pointed out, Jane's and Rochester's first meeting is constituted within the perfect fairy-tale setting, accordingly it takes place in the semiotic realm. ${ }^{35}$ The moon illuminates a cold twilight-scenery; just moments before their first actual encounter Jane contemplates about her imagination, which was nourished by the stories of her childhood that Bessie, the maid, used to tell her:

In those days I was young, and all sorts of fancies bright and dark tenanted my mind: the memories of nursery stories were there amongst other rubbish; and when they recurred, maturing youth added to them a vigour and vividness beyond what childhood could give. As this horse approached, and as I watched for it to appear through the dusk, I remembered certain of Bessie's tales, which figured a North of England spirit, called a "Gytrash;" which, in the form of a horse, mule, or large dog, haunted solitary ways, and sometimes came upon belated travellers, as this horse was now coming upon me. (98)

Through this paragraph, Brontë not only places emphasises on that Jane is already in the semiotic realm but she also demonstrates the willingness of her protagonist to leave the real world behind and to decent into a realm of romantic love. It also constitutes Rochester within the context of demonised and animalised male sexuality. As soon as Rochester appears, he lures Jane into the interior world of dreams, desires and passions:

35 For a further discussion of fairy-tale elements in Jane Eyre see, among others: Sandra Gilbert and Susan Gubar, Huang Mei, and Helen Moglen. 
He had a dark face, with stern features and a heavy brow; his eyes and gathered eyebrows looked ireful and thwarted just now ... I felt no fear of him, and but little shyness. Had he been a handsome, heroic-looking gentleman, I should not have dared to stand thus questioning him against his will, and offering my services unasked ...

If even this stranger had smiled and been good-humoured to me when I addressed him; if he had put off my offer of assistance gaily and with thanks, I would have gone on my way and not felt any vocation to renew inquiries: but the frown, the roughness of the traveller, set me at my ease. (99-100)

As Cho notes, Rochester has an "unconventional look" that contains a "kind of proud detachment and passionate energy with which she feels instinctively comfortable and familiar" (105). Cho comments that Jane's description of Rochester's physicality is an anesthetization of his masculinity:

I had hardly ever seen a handsome youth; never in my life spoke to one. I had a theoretical reverence and homage for beauty, elegance, gallantry, fascination; but had I met those qualities incarnated in masculine shape, I should have known instinctively that they neither had nor could have sympathy with anything in me, and should have shunned them as one would fire, lightning, or anything else that is bright but antipathetic. (99)

By pointing out his physical irregularities of an "un-heroic looking, middle-aged dark man" and depicting his appearance as contrary to "handsome youth[s]', it is obvious that Jane is fascinated mostly with his "lack of beauty" (105). By constituting him as a "charismatic" and not "beautiful" man, Brontë gives an entirely new definition of masculinity. Rochester, the embodiment of this new type of masculinity, strikes Jane "with such an impressive anomalous charisma as to leave an audible mark on her "gallery of memory" in an unprecedented way" (Cho 105):

The new face, too, was like a new picture introduced to the gallery of memory; and it was dissimilar to all the others hanging there; firstly, because it was masculine; and secondly, because it was dark, strong and stern. (101)

Brontë portrays Rochester as man who is aware of his shortcomings and who is torn between admitting it and trying to uphold a masquerade of masculinity. Neither Jane, nor Rochester are described as attractive in a conventional way, this "lack" of attractiveness prepares the ground for their shared appeal. Jane apparently falls under the Byronic spell, although she tries to renounce the romantic encounter as something unimportant - "[t]he incident had occurred and was gone for me; it was an incident of no moment, no romance, no interest in a sense" (101) - she cannot stop thinking about him and their meeting, and she even imagines, or hopes, to hear his horse again. 
Rochester enters the novel in a mythical light, but the illusion of masterful and powerful masculinity is undermined instantly when he falls from his horse to the ground and is unable to mount it again. This first depiction of him demonstrates that he is aware of his insufficiency, as he is unable to maintain the fantasy of his authoritative masculinity. He needs to lean on Jane physically to remount his horse. Contrary to the original Byronic hero, who chooses isolation and prefers to go alone through life to repent his sins, Rochester instantly recognises his dependency on Jane overtly (Hendershot 182). The first hint to a wholly transformed interpretation of the Byronic concept has thus been given.

Jane appears not as the typical damsel in distress but, on the contrary, as his rescuer. She insists upon helping this fallen stranger before she goes on her way. Moglen points out that from the first moment on, Rochester belongs to Jane's interior (semiotic) world, he is her "object of need", "cause of anxiety" and Jane's answer to her "restlessness which disappears with his presence" (118). Returning to Thornfield Jane discovers that the stranger turns out to be her master, $\mathrm{Mr}$ Rochester. The next day he summons her to take tea with him; Jane is redeemed quickly from her initial shyness towards him because of his impatient and slightly arrogant manner "I sat down quite disembarrassed. A reception of finished politeness would probably have confused me [...] A descent quietness, under the freak of manner gave me advantage" (105). Furthermore, Rochester also values Jane's unconventional honesty and frankness, which he considers to be part of her charm "You puzzled me [...] it would please me now [...] to learn more about you." (117). Her frankness attracts him:

"You examine me, Miss Eyre," said he: "do you think me handsome?"

I should, if I had deliberated, have replied to this question by something conventionally vague and polite; but the answer somehow slipped from my tongue before I was aware: - "No, sir." (115)

Thus, their shared unconventionality is the very essence of their attraction for each other.

An emphasis on the circumstance that the Thornfield episode is situated within the realm of the semiotic is given by several hints to the dream world of fairytales. Rochester's comments towards Jane link her instantly to the romantic world of fairy-tale fancies:

"No wonder you have rather the look of another world. I marvelled where you had got that sort of face. When you came on me in Hay Lane last night, I thought unaccountably of fairy tales, and had half a mind to demand whether you had bewitched my horse; I am not sure yet”. (107)

Moreover, it seems that he prefers to perceive her as something "otherworldly", as Moglen has argued, since he insisted upon it by continually linking her to the 
realm of fairytales by calling her "nonnette" (115), "elf" (215), "elfish" (229), "fairy" (235), his "good genii" (113). Jane's "Otherness" draws him to her.

Gilbert and Gubar argue that Jane falls in love with Rochester "not because he is her master but in spite of the fact that he is, not because he is princely in manner, but because, being in some sense her equal, he is the only qualified critic of her art and soul" (266). Rochester, in turn, needs her; when Bertha sets his bed on fire Jane rescues him; when Bertha attacks her brother Richard Mason, he entrusts him to Jane's care so that he can get the doctor. The fact that Rochester is repeatedly rescued by Jane creates their sense of equality that becomes most apparent when Jane is the only one who is not tricked by Rochester's masquerade as an old gypsy woman in the course of his party entertainment, but recognises the man behind the pretence.

Rochester's Byronic character is further accentuated by the narration of his past in which he embraces this definition of himself:

"I was your equal at eighteen - quite your equal. Nature meant me to be, on the whole, a good man, Miss Eyre, one of the better end, and you see I am not so ... Then, take my word for it, I am not a villain; you are not to suppose that - not to attribute to me any such bad eminence; but, owing, I verily believe, rather to circumstances than to my natural bent; I am a trite, common-place sinner, hackneyed in all the poor, petty dissipations, with which the rich and worthless try to put on life ... You would say, I should have been superior to circumstances; so I should - so I should; but you see I was not. When fate wronged me, I had not the wisdom to remain cool; I turned desperate; then I degenerated. Now, when any vicious simpleton excites my disgust by his paltry ribaldry, I cannot flatter myself that I am better than he; I am forced to confess that he an I are on a level. I wish I had stood firm - God knows I do! Dread remorse when you are tempted to err, Miss Eyre; remorse is the poison of life." (119-120)

He combines all of the main Byronic characteristics; although he confesses that he is a sinner, he claims not to be villain; fate alone is to be blame for his downfall: "I started, or rather (for, like other defaulters, I like to lay half the blame on ill fortune and adverse circumstances) was thrust on to a wrong tack ..." (119). As Moglen notes, he was "made desperate", "degenerated" through "the misery of an enforced marriage [to Bertha Mason, who he was forced to marry by his father because of her dowry]" (118). After the death of his father and elder brother, he still has to suffer from the consequences of their pressure to marry for money; isolated from society by his mad wife he flees to the continent and seeks pleasure, repenting his choices incessantly. When Jane asks him if he could not be cured from his current state by repentance, he answers:

"It is not a cure. Reformation may be its cure; and I could reform - I have strength yet for that - if - but where is the use of thinking of it, hampered, 
burdened, cursed as I am? Besides, since happiness is irrevocably denied to me, I have a right to get pleasure out of life; and I will get it, cost what it may." (120)

Rochester sees himself as the victim of unfortunate circumstances. He embraces the role of a rebel, by refusing to follow symbolic orders and flouts society's laws. ${ }^{36}$ He willingly ignores divine laws, such as monogamy, and tries to create his own moral commandment; he wants to make Jane his wife even though he is still married to Bertha.

Furthermore, his appearance also meets all the requirements of a true Byronic hero. Jane mentions his 'dark face', 'heavy features' and 'dark brows', which are all physical Byronic characteristics. Moreover, there is Bertha, his dark secret, his mad wife whom he has locked up on the third floor and tries to hide from society. As Millgate notes:

Rochester behaves quite deliberately and self-consciously like a Byronic hero, taking up dramatic poses, singing Corsair songs, acting arbitrarily and inscrutably; he talks of his past in Childe Harold's terms; he delights in dressing up and playing exotic roles. When such a figure is presented through the still more naively Romantic imagination of the eighteen-year-old Jane Eyre the coloration becomes positively violent. (318)

Accordingly, Jane fully succumbs to the Byronic hypnotic fascination.

Repeatedly, Rochester is connected to fire. He often sits in front of the hearth and smokes, and Jane tells the reader that "Mr Rochester would like to see a cheerful hearth when he came in" (243). Lodge points out that this element "is generally associated with the inner life of passion and sensibility" (131). In addition, Jane regularly compares him with fire itself, she mentions that "a strange fire was in his look," (133) that he "receive[d] the light of the fire on his granite-hewn features, an in his great, dark eyes," (115) and she hopes that she will not be "exiled from the sunshine of his presence" (216). Accordingly, fire is connected to both domestic idyll as well as to Byronic passion. Throughout her stay at Thornfield, Jane is confronted with the dangers of fire, literally and metaphorically. She soon sees the essential necessity to keep it under control; otherwise, she will be at risk to be burned by it, as the Byronic hero's capacity of passion makes it impossible for her to resist him.

\subsection{The Escape from the Byronic Power}

In a moment of despair, when she fears losing Rochester to another woman, Jane strips away all disguises and lets her passion free:

36 The flouting of authoritative laws is a Byronic characteristic that can be found particularly in Byron's protagonists Lara, Conrad and Cain. 
"Do you think, because I am poor, obscure, plain, and little, I am soulless and heartless? You think wrong! - I have as much soul as you,- and full as much heart! [...] I am not talking to you through the medium of custom, conventionalities, nor even of mortal flesh - it is my spirit that addresses your spirit; just if both had passed through the grave, and we stood at God's feet as equal, - as we are!"

“As we are!" repeated Mr Rochester. (222)

Rochester replies likewise by throwing away all pretences and confesses his love for her. The rhetoric of equality that is developed is based rather on a spiritual basis than a sexual one. Whereas he tried through his first marriage to comply with the symbolic and to gain status and money, his behaviour now suggests that this second marriage attempt is instructed by the semiotic and is based on love, a love which might redeem him from his inner pain.

Soon after his affirmation of equality however, his talk changes into the rhetoric of enslavement. In his intention of loading Jane with all of his family jewels and other treasuries, Lambert sees a metaphor for a "threatened submergence of Jane's identity in his" (111). His behaviour suggests that Jane cannot become his equal, and what formerly drew him to her, her frankness and independent spirit, he now tries to oppress by treating her as his property.

"I will myself put the diamond chain round your neck, and the circlet on your forehead, - which it will become: for nature, at least, has stamped her patent of nobility on his brow, Jane; and I will clasp the bracelets on these fine wrists, and load the fairy-like fingers with rings [...] I will make the world acknowledge you as a beauty too." (227)

But Jane vehemently denounces this new behaviour of his, of him trying to turn her into his possession by referring to his former affair: "Do you remember what you said of Céline Varens? - of the diamonds, the cashmeres you gave her? I will not be your English Céline Varens." (237). She insists on being and staying herself; plain Jane, the governess (237), however, she comes dangerously close to losing her own identity and integrity.

As Maynard points out, Rochester's sexuality is of a "direct and responsive nature" (110) which Jane has difficulties to resist. It becomes more and more overwhelming and Jane struggles to keep him at a distance. His Byronic character emerges once again after the failed marriage ceremony when he glares at the battlements of Thornfield and declares that he will seize happiness even if it means to write his own law. His Byronic character however, does not define his ultimate nature but provides a colour and excitement to his personality. His Byronic overreaching derives not from a need to carry a bleeding conscience, but from an intense need to have a fulfilled relationship with Jane. All of his former sins derive from sexual needs; the novel shows his weakness and vulnerability, he is sexually 
active and emotionally needy. However, with Jane he sees his chance for true love and happiness.

Chase comments that Rochester obviously serves as "Charlotte's symbolic embodiment of the masculine élan" (107). Jane's feelings for Rochester are situated always in conflict with each other, he "draws her to him with a strange fascination" but she is simultaneously "repelled by his animalism and demonism" (107). Chase proceeds by noting that she is torn between her desire to submit herself to him and the knowledge that she cannot do so. Jane is captivated by the gentleness and passion in his every trait, ranging from his masculine appearance, to the mysteriousness of his self-proclaimed guilt to his many female conquests. However, I disagree with Chase when he states that Jane flees because she could not "endure the intensity of his passions" and that she only sees two options of behaviour in this situation: "meek submission" or a "flirtatious, gently sadistic skirmishing designed to keep the love at bay" (107). Chase clearly seems to forget the fact that Jane decides to return to Rochester even before she has heard of Bertha's death and Rochester's freedom. Accordingly, she is not scared by his passion for her, but of her passion for him, since she began to lose herself in the pure semiotic. It is not her fear of Rochester's sexuality, or the limited options of behaviour she can choose from, as Chase argues, but her recognition that she is not able to keep a balance between the symbolic and semiotic that induces her to leave him eventually. In the midst of all this, as Gérin notes, Jane is still able to break free from the Byronic enchantment, from "the voice that has lulled all her senses" (18):

My future husband was becoming to me my whole world, and more than the world - almost my hope of heaven. He stood between my every thought of religion, as an eclipse intervenes between man and broad sun. I could not, in those days, see God for his creature, of whom I had made an idol. (241)

Rochester catalyzes Jane's passions and desires to such an extent that she can no longer think clearly, and is at risk to surrender her whole identity to him.

Mei argues that the failed marriage attempt can be seen as a turning point where Jane leaves the realm of the fairy tale and is for the first time at Thornfield fully driven by reason (168-170). When Rochester tries to convince her that she should stay as his mistress, since she has no one else who could care for her, Jane comes close to giving in, but in the end she finds the power to resist him. Nevertheless, after a severe inward struggle, instead of finding a balance between the symbolic and semiotic, she chooses the symbolic:

This was true; and while he spoke my very conscience and reason turned traitors against me, and charged me with crime in resisting him. They spoke almost as loud as feeling, and that clamored wildly. "Oh, comply!" it said. "Think of his misery, think of his danger, look at his state when left alone; 
remember his headlong nature, consider the recklessness following despair; soothe him, save him, love him, tell him you love him and will be his. Who in the world cares for you? Or who will be injured by what you do?"

Still indomitable was the reply, "I care for myself. The more solitary, the more friendless, the more unsustained, I am, the more I will respect myself. I will keep the law given by God, sanctioned by man. I will hold to the principles received by men when I was sane, and not mad - as I am now. Laws and principles are not for the times when there is no temptation; they are for such moments as this, when body and soul rise in mutiny against their rigor; stringent are they; inviolate they shall be. If at my individual convenience I might break them, what would be their worth? They have a worth, so I have always believed; and if I cannot believe it now, it is because I am insane, quite insane, with my veins running fire, and my heart beating faster than I can count its throbs. Preconceived opinions, foregone determinations, are all I have at this hour to stand by; there I plant my foot." (279)

When Rochester recognises Jane's strength as a power that he cannot conquer, he loses himself momentarily and tries to seize her with violence. The Byronic hero has finally met his match in her spirit: "It is you, spirit, with will and energy, and virtue and purity that I want; not alone your brittle frame" (280). However, staying with Rochester would represent the abandonment of principle for the consummation of passion, so she decides to leave.

Although Rochester tries to persuade her to flout every symbolic law, Jane resists him by declaring her faith in virtue as her only principle for conduct and asserting her independence once and for all. However, it takes all her strength to free herself from the Byronic enchantment:

I felt an inward power - a sense of influence - which supported me (266)

I was experiencing an ordeal; a hand of fiery iron grasped my vitals. Terrible moment; full of struggle, blackness, burning! Not a human being that ever lived could wish to be loved better than I was loved; and him who thus loved me I absolutely worshipped; and I must renounce love and idol. One drear word comprised my intolerable duty - "Depart!" (278)

Gérin points out that Jane's "greatness of conduct does not derive from virtue, but from the degree of her infatuation, from her susceptibility to temptation", the sense of a "higher morality" which is presented here is "shown as a quality of the mind, and not as an observance of the law" (18). Nevertheless, opposing to the other Byronic heroes (Glenarvon and Levison), Rochester's Byronic brooding does not lead to a triumphant seduction of the heroine. On the contrary, after Jane leaves him Rochester is left alone and cannot escape pondering on his mistakes. For now, he fails to make her into the wife he has "sought for twenty years, 
and never before encountered" (192) and is left with the knowledge of his errors and failure in a true Byronic manner.

\subsection{The Last Confrontation}

Jane suffers in running away from Rochester; nevertheless, it is a necessary act to escape the purely semiotic. Before she can achieve a balance of the two orders however, she is once again confronted with the symbolic in the form of her cousin St. John Rivers.

St. John Rivers is the embodiment of sexual and sensual renunciation, and thus an opposing extreme to Rochester. Even physically, there is a contrast to be found; where Rochester is depicted as the dark Byronic hero, St. John is presented as a fair avenging angel. His total repression of sexuality seems to have transformed him into something dangerous and harmful. Like Bertha, he has indications of madness, but where Bertha's madness is connected to fiery passion, his madness derives from cold repressed desires. Like Helen's inner fire, St. John's repressed passions are self-consuming. Through him, Jane moves once again into a layer of the novel that is social and moral, rather than personally and sexually characterised but demonstrates the danger of repressed emotions. This time however, not female but male sexuality is repressed through a self-imposed renunciation of desire.

The contrast of Rochester and St. John lies not only in their physical appearance but also in their characters, which is demonstrated in their behaviour towards Jane. When St. John asks Jane to marry him, she thinks: "To me, he was in reality become no longer flesh, but marble. His eye was a cold bright, blue gem; his tongue, a speaking instrument - nothing more" (361). With inhuman strength, he directs his will towards self-sacrifice and tries to pressure Jane into the same direction. Even Jane's relationship to St. John is contrasted to Rochester, whereas the latter acknowledges Jane's independence and passion, St. John, on the other hand, tries to oppress it. However, like Rochester, he exerts an inexplicable power over Jane that she finds hard to resist:

By degrees, he acquired a certain influence over me that took away my liberty of mind; his praise and notice were more restraining than his indifferences. I could no longer talk or laugh freely when he was by, because a tiresomely importunate instinct reminded me that vivacity (at least in me) was distasteful to him. I was so fully aware that only serious moods and occupations were acceptable, that in his presence every effort to sustain or follow any other became vain; I fell under a freezing spell. When he said "Go," I went; "Come," I came; "Do this," I did it. But I did not love my servitude; I wished, many a time, he had continued to neglect me." (350) 
St. John makes her fear that her "vivacity is disdainful." Once again, Jane is trapped in the symbolic and St. John's influence over her even progresses. She is unable to fight and about to surrender her will and spirit to him. She is well aware that she is constantly torn between submission and revolt in his presence:

I know no medium; I never in my life have known any medium in my dealings with positive hard characters, antagonists to my own; between absolute submission and determined revolt. I have always faithfully observed the one, up to the very moment of bursting, sometimes with volcanic vehemence, into the other; and as neither present circumstances warranted, nor my present mood inclined me to munity, I observed carful obedience to St. John's directions (352).

Jane recognises and acknowledges the interdependency between the symbolic and the semiotic in herself, between self-oblivion and self-assertion, and although she usually breaks away when one of these forces becomes too powerful, she knows that she cannot defend herself against St. John Rivers:

As for me, I daily wished more to please him; but to do so, I felt daily more and more that I must disown half my nature; stifle half my faculties, wrest my taste from their original bent, force myself to the adoption of pursuits for which I had no natural vocation. He wanted to train me to an elevation I could never reach; it racked me hourly to aspire to the standard he uplifted. (351)

St. John is preparing to go to India as a missionary and he wants Jane to go with him as his wife, although he completely rejects the perception of her as a woman. Moglen comments that "he wants her to deny her sexuality (feeling/body) to subordinate that which is most vital in her to his own spiritual quest. St. John uses his predestinarian religious belief to make her to obey him, he argues that submitting to him would mean election; a refusal would make her a "castaway"' (364). He further argues: "God and nature intended you for a missionary's wife. It is not personal but mental endowments they have given you; you are formed for labor, not for love. A missionary's wife you must - shall be. You shall be mine; I claim you" (354). She rejects his judgement: "I am not fit for it; I have no vocation" (354). When she offers to accompany him as a sister, he refuses: "I, too, do not want a sister; a sister might any day be taken from me. I want a wife; the sole helpmeet I can influence efficiently in life, and retain absolutely till death" (357). He wants the power to completely control her as his wife. He wants to make her his property and turn her into an object. Jane recognises that being in a loveless marriage, being with St. John would be her death: "if I were to marry you, you would kill me. You are killing me now" (363).

She tries to resist the assumption that he is an agent of God but the temptation to give in is strong: 
I was tempted to cease struggling with him - to rush down the torrent of his will into the gulf of his existence, and there lose my self. I was almost as hard beset by him now as I had been once before, in a different way, by another. I was a fool both ties. To have yielded then would have been an error of principle; to have yielded now would have been an error of judgment. (368)

Nevertheless, in the end, she can resist him and the confrontation ends with a sharp attack on St. John's hypocrisy, arrogance and idea of love:

"I scorn your idea of love," I could not help saying, as I rose up and stood before him, leaning my back against the rock. "I scorn the counterfeit sentiment you offer; yes, St. John, and I scorn you when you offer it.” (359)

Jane finally recognises that St. John's heroic image is nothing more than a masquerade; he is merely a fallible, imperfect human being. Moglen argues that Jane was under the influence of St. John's sexual power but that her final refusal "yields awareness and self-discovery instead of dread annihilation" (139). Furthermore:

Much of the dangerous appeal of Rochester's sexuality had derived from a similar charisma power (a charisma not completely lacking, as masculine force, even in Brocklehurst and John Reed). That appeal is experienced by here fully - and finally, absolutely rejected. (139)

\subsection{An Independent Woman}

When the dangerous appeal of sexual power is finally broken, Jane can withstand and explore it without running into the danger of losing herself. She consciously chooses the semiotic, she chooses Rochester. The inner struggle between the symbolic and semiotic is ended and she once again can enter the semiotic, but this time with a new strength and on her own terms. Jane needed to resist the force of the symbolic power once again to be able to choose freely between the two orders. Rochester's call thus comes as a response of the need in herself for the semiotic: "I heard a voice somewhere cry, 'Jane! Jane! Jane!' noting more ... it spoke in pain and in woe - wildly, eerily, urgently" (369). From this moment on the temptation which St. John constitutes is forgotten and Jane hurries back to Thornfield to be with Rochester, even though she has not yet learned of Bertha's death.

When she arrives at Thornfield she finds it a ruin. She is told that Bertha set the mansion on fire and although Rochester tried to rescue her, died from a jump of the roof. After the destruction of Thornfield, Rochester has retreated to Ferndean, where Jane finds him maimed and blinded by the fire. The Byronic hero is broken and does no longer exist. Rochester's threatening sexual power is 
gone; he is now desexualised but redeemed through Jane's return by love. Whereas he was before a rebel, he is now Christianised and believes in the divine law. A true fairy-tale ending is now possible. When Rochester is courting Jane, she tells him that when they are married

"for a little while you will perhaps be as you are now, - a very little while; and then you will turn cool; and then you will be capricious; and then you will be stern, and I shall have much ado to please you: but when you get well used to me, you will perhaps like me again, - like me, I say, not love me. I suppose your love will effervesce in six months, or less" (228).

This is a reasonable and realistic conclusion when considering a union of dominance and submissiveness: the male, who is more powerful, will eventually tire of the weaker female. She will then be unable to satisfy him. The reversal of these gender roles is brought about by the decline of Rochester's dominant position, through the breaking of his Byronic power. In the end they are equals, Rochester now depends on Jane and she realises that "I love you better now, when I can really be useful to you, than I did in your state of proud independence, when you disdained every part but that of the giver and protector" (392). Rochester's reduction of power is precipitated by Brontë's realisation that, within the constraints of a common constellation of the male as a subject and the female as an object, a happy ending is impossible. Towards the end of the novel, in the face of traumatic events it becomes apparent that Jane and Rochester depend on each other, recognise their equality. When Rochester touches Jane now it is not motivated by sexual desire but because he perceives her as his "prop and guide" (395).

She returns to Rochester as a free individual, constrained neither by the symbolic or semiotic, but as her own woman who chooses for herself. She is completely independent and in every way his equal, if not even his superior. Thus, she announces to the reader "Reader, I married him" (395) as a sign of her emancipation. Now that the war of the orders within her has ended, she eventually embraces "woman's work". She reminds the reader that domesticity in itself is not the culprit, she has been given the opportunity to put higher duties of life before passionate love, but decided against it.

\subsection{Conclusion}

Jane is one of the first heroines in nineteenth-century literature who does not pretend to be content with her restricted role as a woman. She is torn perpetually between reason and emotion, the symbolic and semiotic, and in her search for equality and independence; she wants to find a means of balancing the dictates of both. By the examples of Helen, whose desire for death demonstrates how a total compliance with the symbolic results in violence against the self, and Bertha, 
whose fate raises the awareness of an amalgamation between sexual suppression and its consequence: madness, Jane is warned to comply solely with one order.

The Byronic hero catalyzes Jane's feminine desire for the male subject. Brontë knew that there could be no happy-ending where a Byronic hero was concerned, since he is too powerful and oppressive a character. Consequently, the hero needs to be broken, stripped of his power and crippled, in order to ensure a relationship of equality between Rochester and Jane. In the end, Rochester has to atone for his sins, which results in the loss of the role of the dominant male leader. Nevertheless, through his love for Jane, he is able to admit his dependence on her; he has discarded every sign of self-righteousness and pride. One of the first authors who actually placed the hero within reach of redemptive love is Charlotte Brontë, whose Mr Rochester could be saved by Jane Eyre. He accepts the existence of a higher power and loses his threatening power, with which he has put Jane's identity at risk. His blindness, from which he will eventually recover, is a symbolic immersion of the male hero in a feminine experience; men must learn how it feels to be helpless and to be forced into dependency.

Jane has eventually found a way to balance the two orders, an unconventional circumstance which forces her to live withdrawn from society at Ferndean in the forest, since society would not accept such an arrangement.

\section{Ellen Wood's East Lynne}

\subsection{Ellen Wood: Firm Moralist or Cultural Critic}

East Lynne by Ellen Wood was serialised from 1861 to 1862 in William Harrison Ainsworth's New Monthly Magazine and became an instant hit. When it was reprinted in three-decker form, it became an immediate success. It is said to have been sold more than two and a half million times by the end of the century and has been translated into various languages (Jay xxxviii). However, in the twentieth century it fell out of print and became forgotten. It underwent what Light calls "cultural squint" a result of the literary institution's "obsession with [...] elites" (11).

The novel depicts unequal power relations between men and women by focusing on Lady Isabel Vane, who after the death of her father, Lord Mount Severn, marries the country lawyer Archibald Carlyle. Carlyle purchases her father's estate East Lynne. Isabel marries Carlyle out of necessity as her father died without making any provisions for his daughter. Her love for Sir Francis Levison leads her to elope with him to Franc. When he abandons her she is once again homeless and penniless. Disguised as Mme Vine she returns home to become a governess to her own children. The total dependency of women on men and the demand to put institutionalised and before passionate love is clearly criticised. 
Critics have argued that East Lynne's powerful attraction to Victorian readers lay not only in the subject matter but in that she reinvented the "conventions of domestic realism but also employs seemingly anti-realistic devices roofed in the Gothic in order to convey a darker vision of the home" (Introduction: Ellen Wood, Writer 151). Thus, the sacred home suddenly became a place of secrets and lies. The consequence of placing the home within a Gothic setting "led to Wood rather than Wilkie Collins - being labelled as "the originator and chief of the sensational school" by commentators" (Introduction: Ellen Wood, Writer 151). Sensational novels describe a literary genre that was popular in the 1860s and 1870s. They have been characterized as "novels with a secret".

This genre was regarded as a completely new form of fiction by contemporary reviewers of the mid-Victorian literary scene that replaced the stereotypical form of the the domestic novel, the only proper one for female readers, from its position of dominance as it indulged the public craving for scandal. In this new novelistic mode, the heroines of the complicated plots about crime, bigamy, or adultery evolve in a passionate, devious and dangerous manner. The novels evoke the Victorian public's lust for scandal as they situated murders, mysteries, and social improprieties within respectable middle class or aristocratic homes. The sanctity of the family, as well as the stability of middle-class mores, was put into question, their narratives parallelizing the daily newspapers' contents of the newly instituted divorce courts. Furthermore, the stability of individual identity was challenged frequently by showing that a person's outer appearance and status could not be taken as proof of personality and motives.

To express both feminine desire and fears that were otherwise ignored by contemporary discourses, Wood used the supernatural which found a way into the home. Jaquet notes that the "non-realistic mode of the supernatural becomes a strategic choice for female authors in order to represent the often marginalized experiences of Victorian women" (245). She continues by pointing out that Wood "illuminates the operations of the supernatural ... as a form of investigation and redefinition of the domestic sphere" (245). Accordingly, the supernatural in Wood that is demonstrated, among others, through uncanny dreams and shadows, is connected to the domestic sphere, thus the author is able to present the various and different experiences of women. Dickerson argues that "the supernatural tale allows for play, speculation, investigation and redefinition" and is thus "presenting an important avenue for female writers to comment on their society" (148). The new motif of the family threatened from the outside, in this case by an aristocratic, dangerous male seducer, evoked both indignation and curiosity.

Many established critics thought that the primary function of art was to "elevate or purify" and as sensational novels did no such thing, they responded with moral outrage and dismay at the public approval of this new genre. Sensational novels exhibit a variety of characteristics of genres, such as melodrama, romance, gothic, realism, and Newgate fiction and thus can be seen as generic hybrids that 
are related to both sensational journalism and melodramatic theatre. They are mainly described as being "plot-driven" in contrast to "character driven". Therefore, they are often regarded as inferior to Victorian realism, both artistically and morally and as a sub-genre that is peculiarly feminine and mostly written by women to women (Harrison and Richard xii). Mitchell comments that sensational novels were and still are easily dismissed by critics as they lack reality. However, by dismissing them, she warns, one does not understand "the function of women's recreational reading", as "these books do not provide pictures of the contemporary scene" they "can be read to indicate the way women felt about the society they lived in" ("Sentiment and Suffering" 31).

Nevertheless, recent studies have shown that sensational novels were devoured by men and women alike. Mitchell explains East Lynne's immense success in that "readers were tired of the inane and impossible goodness in heroines. Really interesting women - and women worth writing a whole book about - had sexual experiences" (The Fallen Angel 74). The first novel to be critically dubbed "sensational" was Wood's East Lynne (1861). It eventually started a new literary trend, whose main exponents also included Wilkie Collins (The Woman in White, 1859; The Moonstone, 1868), Charles Reade (The Cloister and the Hearth, 1861) and Mary Elizabeth Braddon (Lady Audley's Secret, 1862). Though judged as heavily sentimental and crudely melodramatic, Wood's novel in particular enjoyed immense popularity due to the detailed and quite accurate representation of the worldview of its middle-class audience.

Another dominant discourse of East Lynne, apart from the woman question, is a panorama discussion of society which supposedly added to the novel's appeal for the middle-class reader. Wagner notes that East Lynne "forms a charting of the social and cultural competition between gentility in decline and [the middle class]", thus, it contains "increasingly complex representations of the aristocracy and landed gentry" and that Wood "seek[s] to negotiate shifts in the social construction of gentility as a cultural enterprise in the nineteenth century" (200). In other words, Wood contrasts the aristocratic and the middle class to demonstrate the moral superiority of the latter. The aristocracy in East Lynne is presented in a bad light; Lady Isabel's whole family, for example, has been nearly erased because of indulgence, decadence and wastefulness. Through her marriage with Carlyle, Isabel's transgression from one class into the other "symbolizes the failure of aristocracy" (A. Kaplan 45) and depicts the middle class as a new representative of morality and the law. Wynne argues that Wood demonstrates the middle-class's superiority by their way of obtaining prestige, namely through "discipline, determination, and disarmingly genial manners [they] inherit the power, property, and status of a class group she publicly emulates, but secretly envies and despises" (68). 


\subsubsection{The Byronic Hero's Transformation}

In the Victorian age, a new concept of Byronism was invented, as the Victorians applied their moral code to him. As a result, several interpretations of this hero and different emphasis on topics regarding the Byronic hero evolved. Accordingly, Carlyle used the concept in his work to focus on class issues, Brontë to focus on gender roles, Tennyson to discuss popularity and Bulwer-Lytton, Disraeli, and Wild to focus on sexuality (Elfenbein 10). Elfenbein notes that in the 1840s the romantic had to give way to the realistic novel, as Byron and his literary persona were connected to Romanticism, the rise of realism simultaneously entailed a rejection of the Byronic hero (146). Thus, a dualism of the Byronic perception evolved; although he did not lose his appeal to the reading audience, novelists (like Eliot and Wood) dealt with him more critically. His overtly sexual attractiveness becomes a reason of rejection, as morality and proper behaviour develop into conventions that were to be followed strictly. Accordingly, Wood presents the Byronic hero in form of Sir Francis Levison as an Iago-like character. He is a heartless, evil seducer; a vilified dandy, whose force of meaningless malevolence destroys lives. He is stripped of all "attractive" Byronic attributes, like mysteriousness, broodiness and obvious remorse; instead, he embodies negative, aristocratic characteristics, such as arrogance, indifference and extravagance.

\subsubsection{Differences of Opinion in Wood Scholarship}

Wood as a writer of sensation novels is perceived to be one of the most conservative and domestic writers. It has been argued that the narrator, who is strongly associated with Wood herself, favours the new middle-class family and thus serves the symbolic as she supports with patriarchal ideas through her harsh critique of female sexual desire and passion. ${ }^{37}$ A. Kaplan argues that "she [the narrator] can vividly appreciate the attractions of desire, but self-righteously sets itself against it in "lectures" to the reader" (46). She adds that "like Wood herself, the narrator cannot think outside of the discourse available within the fictive world and thus cannot conceive a world in which female desire would not destabilize the entire system" (46). Wynne comments that East Lynne is a "product of a conservative, rather old fashioned magazine" and that it "promoted views which blended comfortably with the magazine's house style" (64). However, she also points out that the only source of Wood's life is "her dutiful son's unsatisfactory biography" that "obscures and mythologizes one of the most prolific writers of the Victorian Period" (65). The picture of Wood, which is presented by her son Charles in his Memorial of Mrs Henry Wood (1894), is that of a "conservative, passive, nervous and domestic" woman. The contrasting picture of Wood however, that emerges more

37 For such an interpretation of Wood's intention see A. Kaplan. 
and more, is that of a "self-promoting, hard-working writer and editor" (65). For more than twenty years, she was the editor of The Argosy magazine and produced almost 40 novels and more than 300 short stories and articles. This suggest that Wood was herself a more interesting woman than she has been given credit for. Her son presents her writing not as a kind of work but as a peaceful hobby of a flawless, moral woman writer and his account "overlooks some of the more complicated elements of Wood's writing career to assure readers that her femininity was never compromised by her fame" (Introduction: Ellen Wood 153). Her son obviously realised the importance of presenting his mother as a delicate woman, in order to disguise her "unfeminine" energy of management skills and literary aspirations.

Critics like Maunder judge East Lynne to be "a host of contemporary moral, social and scientific anxieties to the fore" and comment that the "moral contamination of the wife and mother gone mad with uncontrolled sexual longing" is severely punished, as Wood presents it as a "threat to the individual family unit and broader morality of the nation as a whole" (59). Nevertheless, critics like Showalter argue that Wood had a "powerful appeal to the female audience by subverting the traditions of feminine fiction to suit their own imaginative impulses, by expressing a wide range of suppressed female emotions, and by trapping and satisfying fantasies of protest and escape" ((1977) 158). Accordingly, the character of Wood-criticism is dualistic, as she is either depicted as a stern moralist or as "the emancipated daughter of Charlotte Brontë and a cultural critic" (Introduction: Ellen Wood, Writer 152).

\subsubsection{Feminist Criticism}

In the second half of the twentieth century, feminist criticism discovered a new interest in the novel, as it powerfully describes a maternal melodrama and is concerned with the restrictions imposed on women in order to become the perfect woman. Wynne comments that nowadays East Lynne is considered as "the archetypal woman's novel, its mixture of sentiment and sensation forming a model for later examples of popular romantic fiction" (61). She continues to argue that, "Wood's famous address to the reader as "Lady - wife - mother" is an exhortation to women to bear any burden in the cause of domestic unity and appears to establish East Lynne firmly as women's fiction" (61).

Feminist criticism has put its focus on Lady Isabel as exemplifying the "tensions and restrictions associated with Victorian codes of femininity" (67). However, feminist critics have mainly emphasised Isabel's role as a mother and read East Lynne as a maternal melodrama. Thus, A. Kaplan sees Isabel's story as a melodramatic warning against disproportionate feelings for her children. Cvetkovich also focuses on the melodramatic plot surrounding Isabel by describing East Lynne as a "drama of effects" that "transforms a narrative of female 
transgression into a lavish story about female suffering that seems to exceed any moral or didactic requirement that the heroine be punished for her sins" (98-99). Cvetkovich joins the group of critics who perceive Wood's excessive punishment for Isabel as a means to demonstrate her adultery and abandonment of her family as unpardonable. Wynne also argues that the "enjoyment for readers [lies] more in Barbara's triumph over Isabel rather than its capacity to generate tears" (67). Here she disagrees with Langbauer who perceives it to be a "weepy melodramatic" novel and comments that "all female characters cry hysterically throughout it" (227). All these feminist critics lay their focus on either Isabel's excessive maternal feelings, the appeal of the novel to female readers because of its melodramatic mood and the ability to 'generate tears' or on Isabel's excessive suffering as a warning for the female population to stay within their assigned sphere. What they fail to mention is what Showalter points to: that Wood "expressed female anger, frustration, and sexual energy more directly than had been done previously" (1999, 158).

Moreover, a closer reading of Wood's works suggests that her novels and East Lynne in particular, are concerned with the exposure (supposedly unconsciously, as has been argued) of the difficulties, economic and ideological, women had to endure. While excessive women are always severely punished in her works (usually through imprisonment or death) this is done in a way "which some critics have suggested smack "of rebellion against constraints of the respectable plot" (Introduction: Ellen Wood, Writer 151).

To read Wood's East Lynne as a pure condemnation of the fallen Isabel and thus a propagating of middle-class values is too simplistic a reading, as the novel is more complex than that. It is also possible to read the text as both a critique on the emotional restrictions imposed on women in the nineteenth century and the shortcomings of bourgeois masculinity. The Byronic hero, here stripped of any positive quality and presented as a pure seductive villain, acts again as a catalyst of desire that induces the heroine to flee the restrictions of the passionless, symbolic sphere.

\subsection{Lady Isabel: Propriety vs. Desire}

East Lynne differs in its structure from Glenarvon and Jane Eyre. Where in the latter two novels the heroines meet the Byronic hero and are confronted with the temptation to give in to the semiotic only after their lives within the symbolic has been presented, Lady Isabel encounters the Byronic hero right from the start. Thus, she is immediately torn between sexual desire and decorum, as she meets Sir Francis Levison only shortly after her very first meeting with Archibald Carlyle, a fact on which the narrator comments: 
Strange - strange that she should make the acquaintance of those two men in the same day, almost in the same hour: the two, of all the human race, who were to exercise so powerful an influence over her future life! (15)

Accordingly, she is confronted from the very beginning with the temptation of the semiotic but is still too firmly positioned within the symbolic to act on it.

In the first part of the novel, she is presented as the lucky, successful heroine, who is at the heart of love and domesticity. Carlyle meets Lady Isabel Vane for the first time when he visits her father, Lord Mount Severn, in order to enquire about the opportunity to buy his country estate East Lynne. His first impression of Lady Isabel is described as follows:

Who - what - was it? Mr Carlyle looked, not quite sure whether it was a human being: he almost thought it more like an angel.

A light, graceful, girlish form, a face of surpassing beauty, beauty that is rarely seen, save from the imagination of a painter, dark shining curls falling on her neck and shoulders smooth as a child's, fair delicate arms decorated with pearls, and a flowing dress of costly white lace. Altogether, the vision did indeed look to the lawyer as one from a fairer world than this ... Mr Carlyle had not deemed himself a particular admirer of woman's beauty, but the extraordinary loveliness of the young girl before him nearly took away his senses and his self-possession. (11)

Representing the perfect, delicate, fragile attributes of femininity, Isabel is already depicted as a dependant, childlike woman. She is the embodiment of the ideal notion of femininity. Immediately after her meeting with Mr Carlyle, she sets out to visit old Mrs Levison, where she is introduced to Captain Francis Levison. He is described as a "young and elegant man" (14). The narrator continues:

He was deemed handsome, with his clearly-cut features, his dark eyes, his raven hair, and his white teeth: but, to a keen observer, those features had not an attractive expression, and the dark eyes had a great knack of looking away while he spoke to you ...

Few men were so fascinating in manners (at times and seasons), in face, and in form, few men won so completely upon their hearer's ear, and few were so heartless in their heart of hearts. The world courted him, and society humoured him: for, though he was a graceless spendthrift, and it was known that he was, he was the presumptive heir to the old and rich Sir Peter Levison. (14-15)

While the outward characteristics, as the dark hair and eyes, and his masculine features are still depicted as attractive and mesmerising, the repugnance and dangerousness of this character is instantly established. Isabel cannot elude his charm. A. Kaplan comments that a Christian undertone is used to demonstrate her dilemma; thus, Isabel is linked to "the figure of Eve in the Garden of Eden and 
perused by 'snake' Levison" (35). This becomes apparent when Levison breaks her cross on her necklace that had been given to her by her mother. Her mother gave it to her as a talisman on her deathbed and told her to look at it when in "distress, or in need of counsel" (17). Not only can the breaking of the cross by Levison be seen as a premonition of things to come, but A. Kaplan argues that the "breaking signals Isabel's aloneness and vulnerability to the 'snake' Levison" and that he is "ready to step into the gap left by her mother's death" (36). Accordingly, she points out that "right from the start she experiences a merging sensation with Sir Levison" (36). The Byronic hero evokes unknown desires in Isabel and she succumbs to his charm completely, as the following paragraph demonstrates:

He spoke in a tone of thrilling gentleness, gratifying to the ear but dangerous to the heart. Lady Isabel glanced up, and caught his eyes fixed upon her with the deepest tenderness, a language hers had never yet encountered. A vivid blush rose to her cheek, her eyelids fell, and her timid words died away in silence. (19)

Levison is able to arouse sexual desires in her that she has never experienced with Carlyle. The difficulties to favour an institutionalised for a passionate love are thus anticipated.

\subsubsection{The Fading Angel in the House}

When Isabel is left homeless, penniless and dependant on relatives who do not want and dislike her, she marries Carlyle, as he is able to offer her a stable home that was once her own, East Lynne. Yet, when he proposes, Isabel is not sure if she can accept his offer:

It was a perplexing debate that Lady Isabel held with herself in the solitude of her cambers ... Isabel was little more than a child, and as a child she reasoned, looking neither far nor deep: the shallow, palpable aspect of affairs alone presenting itself to her view. That Mr Carlyle was not of rank equal to her own, she scarcely remembered: East Lynne seemed a very fair settlement in life, and in point of seize, beauty, and importance, it was superior to the home she was now in. She forgot that her position at East Lynne as Mr Carlyle's wife, would not be what it had been as Lord Mount Severn's daughter; she forgot that she would be tied to a quiet home, shut out from the great world, from the pomps and vanities to which she was born. She liked Mr Carlyle much, she liked to be with him, she experienced pleasure in conversing with him; in short, but for that ill-omened fancy which had 
crept over her, there would have been danger of falling in love with $\mathrm{Mr}$ Carlyle. $(120-121)^{38}$

Isabella muses:

"So far it looks favourable," mentally exclaimed poor Isabel, "but there is the other side of the question. It is only that I do not love Mr Carlyle, but I fear I do love, or very nearly love, Francis Levison. I wish he would ask me to be his wife! - oh that I had never seen him.” (121)

The difficulties to follow are all presented in these two paragraphs: Isabel's childlike character hinders her ability to perceive things more clearly. In a society where women are not supposed to act for themselves, she has never learned how to take care of herself. She has neither home nor friends to turn to, consequently, accepting Mr Carlyle's proposal would get her out of her dilemma. Although a quiet home suits her, she is not prepared for the eventual boredom, uselessness and powerlessness that awaits her at East Lynne. In addition, she does not love her husband but yearns for another man. With so many obstacles already in the way, Isabel is bound to fail.

Throughout her marriage with Carlyle, she remains a child-like woman, a passive angel and decorative object. In order to support her he invites his brusque half-sister Cornelia to live with them at East Lynne to help Isabel run the household. However, the strong-minded unmarried woman soon takes over. Consequently, Isabel is miserable, she is unable to defend herself against Cornelia's subtle abuses or tell her husband about it; she is homeless and powerless within her own home. At the first meeting of the two women, Cornelia's dominance and Isabel's helplessness is already established. After Isabel and Carlyle have arrived home from their honeymoon, and the two women have been introduced to each other, Isabel asks if she could have some tea but Cornelia denies it to her:

“Tea!" ejaculated Miss Corny. "So late as this! I don't know that they have boiling water. You'd never sleep a wink all night, ma'am, if you took tea at eleven o'clock."

"Oh - then never mind," replied Lady Isabel. "It is of no consequence. Do not let me give you trouble." ...

Meanwhile, Lady Isabel sat down and burst into tears and sobs. A chill had come over her: it did not seem like coming home to East Lynne. $\mathrm{Mr}$ Carlyle entered and witnessed the grief.

38 Although my focus does not lie on the class discourse, I have to point out that Isabel's shortcomings, which have been contrasted to Barbara Hare's abilities, and which are ascribed to her aristocratic ancestry, are enforced by middle-class notions. It is Carlyle, the middle-class lawyer, who is responsible for Isabel's inability to develop. Through his overprotective manner (letting his sister run his household), his inability to perceive Isabel's unhappiness, and his secretiveness which let to her elopement, he is responsible for her fall. 
"Isabel!" he uttered in amazement, as he hastened up to her. "My darling, what ails you?"

"I am tired, I think," she gently answered; "and coming into the house again made me think of papa. I should like to go to my rooms, Archibald, but I don't know which they are." (142)

Through her child-like character, Isabel is unable to voice her wishes; she feels her powerlessness and has no other means to express it than through tears.

Although she has been idyllically happy in the beginning of her marriage, Isabel regresses more and more into dependency, childlike behaviour, and idleness neither her character nor her abilities have the chance to develop, as she is treated like a naive girl. She feels hurt because her husband pays her less attention as soon as the honeymoon is over. It is her only wish to be with Carlyle but since he has to attend to his business he is gone most of the day. Mitchell suggests that Isabel thought it was a woman's business to maintain a perfect relationship with her husband, and as she is unable to do that, she perceives herself as a failure. This feeling of inferiority originates in Isabel's idea that "if she were a better woman, somehow, he would love her more" (The Fallen Angel 81). Furthermore, Mitchell argues that since their betrothal the "marriage and husband are the focus of her feelings of inferiority" and through her ultimate elopement "she strikes at [him] by using the weapon which is most effective in the battle of sexes" "Sentiment" 42). Isabel has nothing else to do than to wait for him; thus, she gets bored, listless and feels empty without him. Even though she is loved and cherished by him, she is not allowed to grow up. Mitchell points out that she "stands to him as a child to a parent" (The Fallen Angel, 80) as the marriage advances, the feeling of emptiness and a need to be loved becomes her normal condition. She spends her time with reading novels, and painfully bears Carlyle three children, which weakens her to such an extent that she becomes an invalid. Sick, faint, fragile and oppressed by her sister in law, Isabel slowly pines away in her own home. Accordingly, the suppression and repression of her desires and her inability to communicate her unrest to her husband, leads to an endless downward spiral, resulting in her fading away and would eventually have lead to her death, as angels were supposed be content no matter what.

In addition, she is tortured by an irrational and unfounded jealousy of her husband's friend Barbara Hare. As already mentioned, Barbara's brother Richard is involved in a murder case and the suspected murderer. Barbara, who is convinced of his innocence, turns to Carlyle for help. Isabel sees Barbara as a rival for his affections since she is actually is deeply in love with Carlyle. Isabel overhears a conversation between two servants, in which they discuss Barbara's love for Carlyle; she is convinced that he has never loved her:

[The overheard conversation] might not, indeed would not, have made so great an impression upon her had she been in strong health, but she was 
weak, feverish, in a state of partial delirium; and she hastily took up the idea that Archibald Carlyle had never loved her, that he admired her and made her his wife in his ambition, but that his heart had been given to Barbara Hare.

A pretty state of excitement she worked herself into as she lay there, jealousy and fever, ay, and love too, playing pranks with her brain ... her pallid cheeks were burning with a red hectic, and her eyes glistened with fever. (180)

Again, the state Isabel is kept in is clearly criticised by Wood. If the people around her had some confidence in her and her abilities, she would have the chance to grow up and would not work herself into such a fit. However, there is nothing else for her than to lie down, and as a result, her jealousy runs wild. A Kaplan points out the dilemma in which Lady Isabel is situated within the symbolic. While she completes Carlyle's world, she herself is quite incomplete. She is even deprived of the action and power of her domestic role. Thus, "she is left in a position of lack and as the object of the male gaze [Carlyle/Levison] and of the jealous female gaze [Barbara/Cornelia]" (38).

Isabel's doctor recommends that she should be send to France to recover, as he is concerned for her life. Isabel, who sees the sending away as a means for Carlyle to be with Barbara, is anxious to leave home and wishes to at least take her children with her, as she cannot stand the idea to be parted from them. Cornelia, however, denies her that wish. She makes her feel guilty about the expenses Carlyle had to spend, and since Isabel is already a high cost factor, she suggests Isabel should be content and stop being presumptuous. Thus, miserable, jealous, and lonely Isabel leaves for France, where she meets upon Sir Levison. A. Kaplan notes that Isabel's longing to take her children with her originates in a "fear of separation, individuation and emotional autonomy" which she is not used to. Consequently, Isabel's repressed desire for Levison quickly emerges again and he fills the emotional gap left by her isolation. Ann Kaplan continues to argue, "her desire forced itself upon her physically, in a way rare in fictional representations of female characters" since "the novel locates Isabel within the power relations of patriarchy, she cannot consciously accept herself as a desiring subject" (37). Consequently, her desire expresses itself through her body:

After an interval, there appeared another, a tall, handsome, gentlemanly man. Her eyes fell upon him; and - what caused it that caused every nerve in her frame to vibrate, every pulse to quicken? Whose form was it that was thus advancing, and changing the monotony of her mind into tumult? It was one of whom she was soon to find had never been entirely forgotten [Captain Levison]. (205) 
Through his presence and the attention he pays her, Isabel quickly recovers. She is well aware of her feelings for him. Even more, the Byronic power has such an effect on her that she starts to feel like a young and happy girl again:

She did not dare to analyse her feelings, but she was conscious that all the fresh emotions of her youth had come again. The blue sky seemed as of the sweetest sapphire, the green fields and the waving trees were of an emerald brightness, the perfume of the flowers was more fragrant than any perfume had yet seemed. She knew that the sky, that the grassy plains, the leafy trees, the brilliant flowers were but as they ever had been ... and she knew that the change, the sensation of ecstasy, was in her own heart. No wonder that she shrank from self-examination.

The change from listless languor to her present feelings brought the hue and contour of health to her face far sooner than anything else could have done. (209)

In case of Lady Isabel, the appearance of the Byronic hero does not only generate repressed sexual passion, which she does not feel for her husband, but it simultaneously seems to save her life. Where she did not improve under her husband's care, the mere presence of Sir Levison heals her.

For Isabel, Carlyle and Levison are representatives of the symbolic and semiotic; her compliance with the symbolic almost led to her death. Repressed desire, idleness, powerlessness, helplessness turn her into a mere shadow, a decorative object, a child-like woman. Her inability to withstand Cornelia's tyranny add to her fading away. Wood obviously uses Isabel as an example of what happens to women if they are too weak and incapable to defend themselves in an oppressive patriarchal system; they turn into shadowy victims. Thus, the encounter with the semiotic immediately revives Isabel's will to live. However, Isabel is not yet willing to give into the semiotic and to leave the symbolic; on the contrary, she tries to fight it:

She knew - and she could not stifle the knowledge, however she might wish to do so - that it was not the place or the sea-air which had renovated her heart and her countenance. But she clasped her husband's arm the closer, and inwardly prayed for strength and power to thrust away from her this dangerous foe, that was creeping on in guise so insidious. (210)

Wood obviously criticises the idea of the angel in the house and demonstrates how impossible it is to fulfil this role. Through the example of Isabel, Wood reveals the dangers if women are not allowed or not able to express themselves. Isabel had married without love, because there was no other choice for a woman in her position. As a married woman, she suffers not only from jealousy, but also from isolation, boredom, lack of money, and powerlessness. "Her frustration and 
depression is obviously enforced by the strictness of her role, which prohibits women from expressing their sexual feelings." (Sterner 201-202)

By taking away from them any chance to keep themselves busy with useful tasks, by forcing them to comply with the symbolic, they ultimately take away their will to live. They settle for convenience and repressed feelings, by putting them on a pedestal and keeping them as a decorative object: the angel in the house fades away and eventually dies. She also points out that to comply with the symbolic inevitable results in a shadowy existence for women. Thus, Isabel's biggest flaw in the first half of the book is to marry out of convenience and not out of love. Wood hints that where passion is absent, mere goodness is not enough. Accordingly, the main criticism is of oppressive, social conventions and of Carlyle who fails to perceive her misery.

\subsection{Carlyle: Failing of Patriarchy}

As various critics have already pointed out Carlyle stands for the epitome of Victorian middle-class values. He has been described as "uncomplicated, sensible, rational, cautious, moderate" as a "good citizen" who is "kind and involved in his work" (A. Kaplan 40). Furthermore, his "solid, respectable manliness, rationality, calmness in the face of turmoil, control in face of loss and crisis, dedication to work and service to community" constitute him as a rational rather than emotional man (A. Kaplan 44). Wood describes him as follows:

He was a very tall man of seven-and-twenty, of remarkable noble presence. He was somewhat given to stooping his head when he spoke to any one shorter than himself; it was a peculiar habit, almost to be called a bowing habit, and his father had possessed it before him, when told of it, he would laugh, and say he was unconscious of doing it. His features were good, his complexion was pale and clear, his hair dark, and his full eye-lids drooped over his deep grey eyes. Altogether it was a countenance that both men and women liked to look upon, the index of an honourable, sincere nature; not that it would have been called a handsome face, so much a pleasing and distinguished one. (7)

Where Levison is described as attractive and beautiful, Carlyle's advantages lie in his character. Pykett, however, points out that "although he is the very model of "manly" honour and restraint, he occupies an ambiguous gender position", since he is "initially dominated by his competent, combative and masculine half-sister Cornelia" (120). Moreover, he is "consistently blind to the tension in his own home" (120). Pykett defines two reasons that explain his blindness and reveals his share of blame on Isabel's fate: 
This [blindness] is partly, because he is, as a man, presumed to be inherently incapable of fathoming the mysteries of the domestic sphere, and partly because he is frequently absent from it and habitually preoccupied with the concerns of the masculine world of work. In other words, Carlyle demonstrates a structural masculine incomprehension of the domestic: the novel implies that men's position within the family simply does not equip them to read the signs of the domestic sphere ... . In this respect he is seen as, to some extent, responsible (through ignorance and inefficacy) for Isabel's dilemma. (120)

Pykett concludes: "The well-intentioned, but ignorant and hence unsympathetic husband, is in part responsible for a difficult domestic situation for which his wife pays the price of banishment and exile" (120).

McCusky comments that East Lynne warns of the dangers of the separate spheres, as Carlyle's strict separation of the public and domestic sphere eventually results in the destruction of his family. This destruction is brought upon through the privacy that is thus gained, as it produces "secrecy, silence, and reserve" that "too often upset the personal relations upon which the community itself depends on" (372). His professional reserve estranges him from his wife. Although his secret meetings with Barbara are innocent, Mangham notes, "his resolution to keep his private and professional lives separated (by not telling Isabel) leads his wife to suspect he is having an affair" (134) which results in her running off with Levison. He hardly ever expresses his emotion a fact that makes Isabel insecure of his love to her. She tries to confront him:

"What is it that she wants with you so much, that Barbara Hare?"

"It is a private business, Isabel. She has to bring me messages from her mother."

"Must this business be kept from me?"

He was silent for a moment, considering whether he might tell her. (258)

He eventually decides against it and thus gives Isabel ground for questioning his faithfulness:

She did not put faith in a word of the reply. She believed he could not tell her because her feelings, as his wife, would be outraged by the confession: and it goaded her anger into recklessness. Mr Carlyle, on his part, never gave a thought to the supposition that she might be jealous: he had believed that nonsense at an end years ago. He was perfectly honourable and true, giving her no shadow of cause or reason to be jealous of him: and, being a practical, matter-of-fact man, it did not occur to him that she could be so. (258)

Wood obviously questions the strict division of the spheres and the resulting lack of complicity between men and women. She points to its dangers, as misunder- 
standings can easily occur. Mangham continues by pointing out that although Carlyle is "hardly the deceptive tyrant" the "lack of communication between him and Isabel (as augmented by his professional status) is a significant factor in the breakdown of his marriage" (136).

Furthermore, A. Kaplan argues that Isabel seeks a "satisfaction of a passionate, merging feeling" that she experiences a "desire for the loss of the self in the Other" (38). Carlyle's calm, distanced and rational character prevent such a kind of merging. Levison's seductiveness, on the other hand, and "his own desire to possess [her] make such a projection easy" (38). As Isabel stands to Carlyle as a child to a wise and overawing father, she is afraid of telling Carlyle of her attraction to Levison or of Cornelia's abuses; she is unable to reveal her secrets:

[His] strong arm of shelter round her; a powerful pillar of protection, him upon whom she leaned; why did she not confide herself to him as trustingly as a little child? Simply because her courage failed. Once, twice, the opining words were upon her lips, but come forth they did not; and then the carriage stopped at East Lynne, and the opportunity was over. (225)

McCusky comments here that "again and again the failure to speak candidly, even from the best of motives, ultimately erodes individual trust and leads to disaster" (372).

Langbauer also notes Carlyle's shortcomings, although Wood obviously tried to create the "perfect" male, which she "pieced together by changing emphasis on old literary clichés of gender", thus, she "makes him authoritative, say, rather than overbearing" (240). Although Carlyle fails in the end to live up to the idea of the 'perfect' male, Wood's attempt to create a different character demonstrates the need to do so: "[The] attempt to transform what may be an inevitable patriarchal grammar through new inflections reveals the oppressiveness of its categories even while failing to transform them" (240). Thus, East Lynne implies that Carlyle's bourgeois standard of living is the true cause of Isabel's fall. Pykett comments that in sensation fiction "men and women are shown as being foreign countries to each other ... In such narratives marriage, the presumed site of union and mutual understanding, is revealed as, in fact, a state of mutual isolation, secrecy, and misunderstanding" (50). This notion can obviously be applied to Carlyle's and Isabel's marriage.

\subsection{The Byronic Hero as the Seductive Villain}

When Isabel finally gives in to her passion for Levison, she is governed by enraged feelings of jealousy and revenge on seeing Carlyle and Barbara together in the dark. Levison, who is with Isabel, finally reveals his true colours by supporting Isabel's suspicion through lies. He tells her that he saw her husband and Barbara Hare enjoying a tête-à-tête by moonlight (271). His role as an evil seducer, a vilified 
dandy, becomes now apparent. In contrast to other Regency dandies in the Silverfork novels, however, Levison tastelessly overdresses: "He would wear diamond shirt-studs, diamond pins; brilliants, all, of the first water" (55). Additionally, he would put perfume on his gloves; he is a man full of excesses.

The following passage characterises Isabel's feelings as explosive and energetic; accordingly, at that moment of uncontrolled passion, she stands in the semiotic realm.

Lady Isabel almost gnashed her teeth; jealous doubts which had been tormenting her all evening were confirmed. That the man who she hated - yes, in her blind anger, she hated him then - should so impose upon her, should excuse himself by lies, lies base and false, from accompanying her, on purpose to surpass the hours with Barbara Hare! Had she been alone in the carriage, a torrent of passion had probably escaped her. (271)

Isabel's feelings are portrayed as a 'torrent' that requires an explosive outlet. Levison takes advantage of the situation and begins his seduction of Lady Isabel; in this scene his dangerous nature is described at length:

$\mathrm{He}$, that bold bad man, dared to put his arm around her; to draw her to his side; to whisper that his love was left to her, if another's was withdrawn. She was most assuredly out of her senses that night or she never would have listened.

A jealous woman is mad; an outraged woman is doubly mad; and the illfated Lady Isabel truly believed that every sacred feeling which ought to exist between man and wife was betrayed by Carlyle.

"Be avenged on that false hound, Isabel. He was never worthy of you. Leave your life of misery, and come to happiness."

In her bitter distress and wrath, she broke into a storm of sobs. Were they caused by passion against her husband, or by these bold and shameless words? Alas! alas! Francis Levison applied himself to soothe her with all the sweet and dangerous sophistry of his crafty nature. (271)

Consequently, Isabel does both: she listens to Levison's false promises and gives in to her own sexual desires. The affair however, is only short lived. After he conquers her, he loses all interest in Isabel. They elope to France where he leaves her alone for most of the time, and Isabel quickly starts to regret her action. Her sexual desire soon dies away and is replaced by a growing repulsion. In his meaningless cruelty, he confesses that he has lied to her and that she had never really had a reason to doubt her husband's faithfulness. Although he had promised to marry her when she got pregnant, she finds out that he has no intention to do so and that her child will be illegitimate. As soon as Levison inherits his long awaited title and fortune, he abandons Isabel completely. At this point, she has already stopped caring for herself but she still hopes that he will be willing to marry her for their 
child's sake. When her hope is crushed, she finally decides to leave him. Wood thus demonstrates how differently the power relations between men and women are apportioned. Isabel depends solely on Levison's willingness to marry her in order to be able to be rehabilitated and to legitimaize their child. Levison, on the other hand, has neither responsibility nor obligations towards Isabel.

Lutz notes that the persona of the purely evil seducer is the Victorian version of the dangerous lover. In the middle of the century, the evil seducer was a very prominent figure in stories serialised in magazines. Usually, the narrative would present an aristocrat who would seduce a lower-class girl, generally to ruin and leave her. Where a typical Byronic hero would feel remorse after his evil deed and seek repentance, the newly evolved evil seducer is stripped of any Byronic characteristics except for his appearance and his fatality. Moreover, unquestionably he does not regret his malicious deeds. Lutz argues that this development can clearly be seen a "class allegory and certainly as a reaction against the Byronic hero" (76). She continues by pointing out that the "narratives represent the dangerous lover not as an unquiet soul searching for absolution or death, but rather as only dangerous (but still titillating in his dangerousness)" (76). He ultimately becomes a mere source of harm for those around him.

Lucas' review of East Lynne in The Times focuses upon Wood's representation of Sir Francis Levison, rather than on Lady Isabel's story. Lucas argues that this is one of the better sensation novels, yet is puzzled as to why Wood should heap so much ignominy on Levison's head:

$[\mathrm{H}] \mathrm{e}$ is hated and despised by all his acquaintance, not expecting even the woman he espouses [...] All this crime and retribution for an ordinary performer who is merely up to the standard of a walking gentleman is excessively onerous, and we know of few cases in fiction of such rigorous treatment as that of Sir Francis Levison.(6)

One expects Levison to be punished for his seduction of Lady Isabel, yet the extensive list of humiliations he faces before he finally ends his days in prison is, as Lucas suggests, unusual in fiction. The didactic undertone of Levison's seduction of Lady Isabel reveals that the idleness, wastefulness and cruelty of such men are harmful to society as a whole; his punishment needs to make an example. There is no purpose behind his seduction of women which leads to the destruction of families. Lutz comments that he

does these things without any sort of magnetism, personal power, or clear desire. As a purely transgressive force, he still does not create a serious rift or interruption in given norms, as a rebellious Romantic would seek but rather serves to uphold the generally understood moral structure based on heterosexual marriage and monogamy. (76-77) 
In contrast to the Romantic rebel, the evil seducer does not want to change social norms:

The Victorian antihero, on the contrary, can always be recuperated into a heterosexual discourse of crime and punishment. He may stand out starkly in his dangerous eroticism initially, but as the novel draws to a close, he is punished, chastened, and somehow brought under the shadow of propriety. (77)

Thus, in the end Levison is convicted of the murder he tried to pin on Richard Hare and is sentenced to be shipped overseas where he is condemned to hard labour. Although he cannot be legally punished for his seduction of Lady Isabel, he is hated by all for his evil deed and shunned by society; even his own wife is not sorry to have seen the last of him. Wynne points out that Levison's downfall and humiliation is completed when he is "denied the "dignity" of death when he is found guilty of murder" but punished to hard work (77).

Accordingly, unlike the original Byronic hero who falls and survives as failure, the evil-seducer character, like Levison, must be punished when confronted with his crimes.

\subsection{Madam Vine: The Suffering Heroine}

Through her elopement, Isabel forfeits not only home and family, but also her social position, and self-respect as well. She learns in a devastating way that her desire for sexual fulfilment is impossible, as Levison emerges as the villain. Her punishment for giving in to her sexual desires and forgetting any morality is instantaneous, as Levison soon starts to neglect her, refuses to marry Isabel and to make their child legitimate. The overt didacticism and moral implication used by the narrator to tell the second part of Isabel's story, a story of suffering and remorse has been interpreted in different ways. Thus Wynne argues that "Isabel's downfall gives Wood and middle-class readers a pretext to gloat over the downfall of aristocracy" (67). She continuous by arguing that "Barbara, with her bourgeois values of prudence and propriety, eventually replaces the frail, childlike Lady Isabel" and although

the reader is encouraged to feel sympathy for her dilemma [nevertheless] Wood's focus upon her suffering and in particular the obvious delight she takes in detailing her mutilated body and agonies of remorse, lets suggest that she experienced a range of complex response to Isabel, including a covert satisfaction in witnessing the downfall of aristocracy. (69)

Wynne reduces Isabel's story to Wood's aversion against the aristocracy and her delight in portraying its downfall. However, this is too simplistic a reading of East Lynne, as there is much more to it than class rivalry. 
Critics like Mangham argue that one of the main motifs of the novel is the failure of the family, which "appears to hinge, almost entirely, on the ungovernable passions of the wife and mother Isabel" (129) and the threat Isabel's elopement presents to the nuclear family. Furthermore, he comments that the moral tone of the narrator "echoes mid-Victorian, conformist claims that the control of female emotion is crucial to the health and preservation of the middle-class way of life" (132). A. Kaplan joins Mangham and Wynne when she argues both that the narrator clearly "serves patriarchy in her severe critique of female desire" and at the same time endorses the new middle-class family" (46). She continues by pointing out that only the middle class is able to keep a balance between desire and its release in the novel. Furthermore, she argues that the main critique lies on desire and "the necessity of control a socially inscribed desire"; more specifically "it is especially female desire that is the problem and in the case of Isabel ... [her] desire brings about disaster" (47). A. Kaplan does not perceive Levison as the evil seducer who takes advantage of Isabel's misery but merely as "the willing and available vessel for evoking and receiving their sexual desire" (47). As has been demonstrated, those readings of the novel are obviously too partial and alternatives need to be considered.

Isabel loses her illegitimate child in a train accident and is herself disfigured beyond recognition. She is wounded so severely that the doctors have no hope for recovery and a notice containing the announcement of her death is sent to the papers. Taking the name of Madam Vine, she supports herself as a governess. Overwhelmed with the longing for her children, she returns to England to take up the position as governess to her own children. In England, at her old home, is where her punishment really starts. She does not only suffer from the loss of place in her family but she has to watch the Carlyle's and Barbara's marital bliss, and instead of motherly love she has to give her own children the cool attention of a governess.

The narrator explicitly urges the audience to learn from her mistake:

Never had she experienced a moment's calm or peace, or happiness, since the fatal night of quitting her home. She had taken a blind leap in a moment of wild passion; when, instead of the garden of roses it had been her persuader's pleasure to promise her, (but which, in truth, she had barely glanced at, for that had not been her moving motive), she had found herself plunged into an abyss of horror from which there was never more any escape... a lively remorse, a never-dying anguish, took possession of her soul forever. O reader, believe me! Lady - wife - mother! should you ever be tempted to abandon your home, so you will awake! Whatever trials may be the lot of your married life, though they may magnify themselves to your crushed spirit as beyond the endurance of woman to bear, resolve to bear them; fall down on your knees and pray to be enabled to bear them: pray for patience: pray for strength to resist the demon that would urge you so 
to escape; bear unto death, rather than forfeit your fair name and your good conscience; for be assured that the alternative, if you rush on to it, will be found far worse than death. (283, my emphasis).

This moral prescription of purity, duty, obedience, and conformity describes the constricted role of the Victorian woman. Consequently, the urgency of this message suggests that "she felt herself speaking to a large and desperate audience" (Showalter 1999, 172). The sympathy and identification female readers felt with Lady Isabel led simultaneously to a rejection of the "perfect" Barbara. Margaret Oliphant, for example, could far more identify with Isabel's plight than with Barbara's propriety:

When [Isabel] returns to her former home under disguise of the poor governess, there is not a reader who does not feel disposed to turn her virtuous successor to the door, and reinstate the suffering heroine, to the glorious confusion of all morality. (170)

Furthermore, it has been argued that Wood intended her pitiable heroine as an object lesson to other women. Although a sympathetic, it is nevertheless a powerful one, as it is considered as a lesson "in the necessity of suppressing sexual desire and passion" (Introduction to Ellen Wood, 152). Critics argue that Wood's attitude towards this subject is apparent: a woman who leaves her husband for another man must necessarily suffer the consequences. This is part of a providentially designed pattern, in which good is repaid and evil punished. Isabel's misfortunes are an accurate representation of the dilemma of Victorian women. According to Showalter, the story:

expresses the sense of hopeless dependency, the lack of alternatives in the lives of Victorian gentlewomen. Detail by detail, Mrs. Wood builds up her case study of women's position in a patriarchal society ... Mrs. Wood condemns her heroine's weakness and folly, but also gives the reader a sympathetic documentary of Lady Isabel's empty hours, her loneliness, isolation, and hopelessness ... ("Family Secrets" 110)

Showalter continues by pointing out that although Wood "adopts a moral and prudential tone" she nevertheless "clearly sympathizes with the wife who is neither deceived nor mistreated but sexually frustrated and bored to death" (1999, 172). Sterner supports this statement when he argues: "[Isabel] falls due to her own feminine weakness, her inability to live up to the Victorian woman's idealization" (200). Thus, unrealizable demands were the reason for her failure. 


\subsection{Conclusion}

To argue that East Lynne is intended as an example for women to demonstrate the necessity to suppress their sexual desires as their acting out would only end in disaster is to disregard Wood's obviously sympathetic treatment of Isabel's dilemma. Although Isabel's passions are the reasons for the destruction of her family, the text implies that the shortcomings of Carlyle, embodiment of the ideal of bourgeois masculinity, are responsible for Isabel's fall. Even though readers should reject Isabel for her actions, both the description of her marital misery and the detailed depiction of her repentance lead to a questioning of the restricting social convention. Her fading away within the symbolic left her no choice than to break out, as it would have led to her certain death.

The representation of masculinity in East Lynne is reduced to only two models. Firstly, the good but morally overwhelming father, up to which standards Isabel cannot live. Secondly, the villainous lover, who ruins her. The Byronic hero, although the trigger and catalyst of her sexual desire, is here stripped of every Romantic notion and presented as a shallow, evil seducer, whose villainy knows no end. In the second part of the novel, Levison's villainy is emphasised. He is portrayed as an experienced seducer and eventually revealed as a murderer. Thus, Isabel is more and more perceived as a victim. Wood's portrait of Isabel's character and the description of her marital relationship lead to sympathy and pity, not to a condemnation of the heroine.

The dialogism of the text, meaning the subversive sub-text that arises from the circumstance that Wood wants the reader to think two contradictory things at once, to condemn and to identify with Lady Isabel, is clearly intended as a critique on the patriarchal system. This points to Wood's intentions, both to criticise the strict social conventions for women and the shortcomings of masculinity. In this way, East Lynne challenges the very norms it seems to support and pictures the contradictions of the ideal woman.

\section{Conclusion}

Through their novels, Lady Caroline Lamb, Charlotte Brontë and Ellen Wood, three female writers, partake in the chief debate of their age, the debate between rights and duties. By means of characters and plot, these women writers express their view in the debate. They criticise and condemn ideals and values of a society dominated by the ideology of patriarchy and its oppressive stance towards women. All three demonstrate, in similar ways, the severe consequences of an ideology that demands the repression of female desire and total female submissiveness. Where Lamb and Wood reveal by the examples of Calantha and Isabel how under the surface a torrent of repressed and denied desire is only barely re- 
strained, Brontë creates a heroine who refuses to be dominated by a tyrannical ideology.

Julia Kristeva's declaration of the interdependency of the symbolic and symbiotic is correct, as none of the female characters is able to comply with one order only. The attempt either leads to self-destruction (Helen), madness (Bertha), or an unrestrained shift to the semiotic (Calantha, Elinor, and Isabel), which eventually ends in death. Even Jane, the most emancipated and independent of these women and the only one who is able to balance the two orders and therefore rewarded with a happy ending, has difficulties in not losing her identity in the semiotic (Rochester) or symbolic (St. John River).

A notable parallel between the novels is the means by which women are confronted with the semiotic; namely through the appearance of the Byronic hero. The interpretation of this literary persona depends on which image of Lord Byron influenced the novelists, such as the real man Byron, the heroes of his poetry, his myth, or a mixture of the three. It also depends on the decade the writer was living in. Where Lamb and Brontë approach the Byronic hero from a more Romantic view, Wood applies a strict moral code on him, strips him of anything Romantic and depicts him as a shallow, evil seducer. Nevertheless, each of these female writers use the Byronic hero as a critique on restricting gender roles, as his appearance presents the hopelessness of the situation in which women are located in. Within the dominant ideology of patriarchy, female sexuality, which simply cannot be repressed completely, is considered unsustainable and unacceptable. There is no place for desiring women in society, thus the only consequences for them are either isolation (Jane) or death, as the examples of Calantha, Elinor, Helen, Bertha, and Isabel clearly demonstrate. Lamb, Brontë, and Wood draw on the Byronic hero's function as a fatal lover, who overpowers and in most cases destroys the women he encounters, to draw attention to the female dilemma.

The popularity of the Byronic hero nowadays is indisputable; he is found in a vast number of novels and movies, all resulting in a happy ending. Most notably, his role as a brooding vampire is steadily gaining popularity. However, he is no longer used as a means of criticism but as a romantic object of female desire. This transformation still needs to be explored. 


\section{Bibliography}

Primary Literature

Baillie, Joanna. A Series of Plays: In Which It Is Attempted to Delineate the Stronger Passions of the Mind. London, 1789

Brontë, Charlotte. Jane Eyre. Ed. Richard J. Dunn. New York: W.W. Norton \& Company, 1987.

Byron, George Gordon Noel, Baron (2009). Byron's Poetry and Prose. Select. nd ed. Alice Levine. New York: W.W. Norton, 2009.

Lamb, Lady Caroline. The Whole Disgraceful Truth: Selected Letters Lady Caroline Lamb. Ed. Paul Douglass. New York: Palgrave McMillain, 2006.

Shelley, Percy. "On the Medusa of Leonardo da Vinci", "To the Skylark."The Complete Poems of Percy Bysshe Shelley. New York:The Modern Library of New York, 1994. 621; 640.

Wood, Ellen. East Lynne. Ed. Jay, Elisabeth. New York: Oxford University Press, 2008.

Secundary Literature

Airlie, Mabell Countess of. In Whig Society 1775-1818, Compiled from the Hitherto Unpublished Correspondence of Elizabeth, Viscountess Melbourne, and Emily Lamb, Countess. Cambridge: Scholar Publishing, 2010.

Barry, Peter. Beginning Theory: An Introduction to Literary and Cultural Theory. Manchester: Manchester UP, 2009.

Henry Blyth. Caro: The Fatal Passion. New York: Haper Collins, 1972.

Braudy, Leo. The Frensy of Renown: Fame and its History. Oxford: Oxford UP, 1986

Bronfen, Elisabeth. Over Her Dead Body: Death; Femininity and the Aesthetic. Manchester: Manchester UP, 1992

Butler, Eliza Marian. Byron and Goethe: Analysis of a Passion. Nottingham: Nottingham University College, 1992.

Chase, Richard. "The Brontës, or Myth Domesticated." in Forms of Modern Fiction. Essays Collected in Honor of Joseph Warren Beach. Ed. William Van O'Connor. Minneapolis: Univ. of Minnesota Press, 1948.102-119.

Cho, Sonjeong. An Ethics of Becoming: Configuration of Feminine Sexuality in Jane Austen, Charlotte Brontë and George Eliot. New York: Routledge, 2006. 
Cixous, Hélène. "The Laugh of the Medusa," trans. Keith Cohen and Paula Cohen, Signs 1.4 (1976).

Clarke, Michael M.. “Brontë's Jane Eyre and the Grimm's 'Cinderella”'. Studies in English Literature, 1500-1900. 40.4 (Autumn 2000): 695-710.

Clubbe, John. "Glenarvon Revised - and Revisited". The Wordsworth Circle 10.2 (1979): 205-217.

Craciun, Adriane, ed. Mary Wollstonecraft's A Vindication of the Right of Woman: $A$ Sourcebook. London: Routledge, 2000.

Cvetkovich, Ann. Mixed Feelings: Feminism, Mass Culture, and Victorian Sensationalism. New Brunswick: Rutgers UP, 1992.

Davidoff, Leonore, Catherine Hall. Family Fortunes: Men and Women of the Middle Class 1780-1850. London: Routledge, 1987.

Dickerson, Vanessa. Victorian Ghosts in the Noontide: Women Writers and the Supernatural. Columbia, Mo: UP of Missouuri, 1996.

Douglass, Paul. “The Madness of Writing: Lady Caroline Lamb’s Byronic Identity". Pacific Coast Philology 34.1, (1999). 53-71.

— "Introduction." The Works of Lady Caroline Lamb. Pickering \& Chatto, 2009. xxvii-xlv.

Eagleton, Terry. Myths of Power. Basingstoke: Palgrave Macmillan, 1975.

Elfenbein, Andrew. Byron and the Victorians. Cambridge: Cambridge UP, 1966.

Ewbank, Inga-Stina. Their Proper Spheres: A sSudy of the Brontë Sisters as early- Victorian Female Novelists. London: Arnold, 1966.

Francis, Jeffrey. The Romantics Reviewed. Contemporary Reviews of British Romantic Writers. Part B. 5 vols. Ed. Donald H. Reiman. New York: Garland, 1972. 2:837.

Franklin, Caroline. "Introduction.” Glenarvon: Volume I, by Lady Caroline Lamb. London: Routledge/Thoemmes Press, 1995: v-xxii.

Gérin, Winifred. “Byron's Influence on the Brontë's." Keats-Shelley Memorial Bulletin 15,(1966): 1-20.

Gilbert, Sandra and Susan Gubar. "A Dialouge of Self and Soul: Plain Jane’s Progress." The Brontë Sisters: Critical Assessments.3 vols. Evaluation of the Novels: Agnes Grey, Wuthering Heights and The Tenant of Wildfell Hall. Ed. Eleanor McNees. Mountfield: Helm Information, 1996. 254-283.

Gleadle, Kathryn. British Women in the Nineteenth Century. Basingstoke: Palgrave Macmillan, 2001.

Graham, Pete. Don Juan and Regency England. Charlottesville: UP of Virginia, 1990.

Grosskurth, Phyillis. Byron: The Flawed Angel. London: Hodder \& Stoughton, 1997.

Grossman, Lev. "Stephenie Meyer: A New J.K. Rowling?" Time U.S. Online, n.pag. 24. April 2008. 
Habermas, Jürgen. The Structural Transformation of the Public Sphere: An Inquiry into a Category of Bourgeois Society. Cambridge, Massachusetts: The MIT Press, 1989.

Harrison, Kimberly and Richard Fantina, eds. Victorian Sensations: Essays on a Scandalous Genre. Columbus, Ohio: Ohio State UP, 2006.

Hendershot, Cyndy. The Animal Within: Masculinity and the Gothic. Ann Arbor, Mich.: UP of Michigan, 1998.

Jaquet, Alison. "The Disturbed Domestic: Supernatural Spaces in Ellen Wood's Fiction." Women' Writing 15:2 (2008): 244-258.

Jenkins, Elisabeth. Lady Caroline Lamb. London: Cardinal, 1974.

Judson, Barbara. "Roman à Clef and the Dynamics of Betrayal: The Case of Glenarvon." Genre: Forms of Discourse and Culture 33.2 (2000): 151-69.

Kaplan, Ann. "The Political Unconscious in the Maternal Melodrama: Ellen Wood's East Lynne." Gender, Genre and Narrative Pleasure. Ed. Derek Longhurst. London: Unwin Hyman, 1989. 31-50.

Kaplan, Carla. The Erotics of Talk: Women's Writing and Feminist Paradigms. New York: Oxford University Press, 1996.

Kelly, Gary. Women, Writing, and Revolution 1790-1827. London: Clarendon Press, 1993.

Kelsall, Malcolm. "The Byronic Hero and Revolution in Ireland: The Politics of Glenarvon.” Byron: Poetry and Politics: Seventh International Byron Symposium, Salzburg 1980. Ed. Erwin A. Stürzl and James Hogg. Salzburg: Inst. für Anglistik \& Amerikanistik, Univ. Salzburg, 1981. 137-151.

Knapp, Steven. Personification and the Sublime: Milton to Coleridge. Cambridge: Harvard University Press, 1985.

Kristeva, Julia. "The System and the Speaking Subject." The Kristeva Reader. Ed. Toril Moi. New York: Columbia UP, 1986. 24-34.

— "Revolution in Poetic Language." The Kristeva Reader. Ed. Toril Moi. New York: Columbia UP, 1986. 89-137.

Lacan, Jacques. The Seminar of Jaques Lacan, Book II: The Ego in Freud's Theory and in the Technique of Psychoanalysis, 1954-1955. Ed Jaques-Alain Miller. New York: Norton, 1985.

Lamb, Lady Caroline. Glenarvon. Ed. Deborah Lutz. Kansas City: Valancourt Books, 2007.

Lambert, Elisabeth Zetzel. The Face of Love: Feminism and the Beauty Question. Boston: Beacon Press, 1995.

Langbauer, Laurie. "Women in White, Men in Feminism." Yale Journal of Criticism, 2:2 (1989 Spring): 219-243.

Liggins, Emma, and Andrew Maunder. "Introduction: Ellen Wood, Writer." Women's Writing, 15:2 (2008): 149-156. 
Light, Alison. Forever England: Femininity, Literature and Conservatism between the $W$ ars. London: Routledge, 1991.

Lodge, David. Language of Fiction. London: Routledge, 1966.

Lucas, Samuel. "Review of East Lynne.” Times, 25 January 1862, 6.

Lutz, Deborah. The Dangerous Lover: Gothic Villains, Byronism, and the NineteenthCentury Seduction Narrative. Columbus: Ohio State University Press, 2006.Mangham, Andrew. Violent Women and Sensation Fiction: Crime, Medicine and Victorian Popular Culture. Basingstoke: Palgrave Macmillan, 2007.Maunder, Andrew. "'Stepchildren of Nature': East Lynne and the Spectre of Female Degeneracy, 1860-1861." Victorian Crime, Madness and Sensation. Ed. Andrew Maunder and Grace Moore. Aldershot: Ashgate, 2004. 59-71.

Maynard, John. Charlotte Brontë and Sexuality. Cambridge: Cambridge University Press, 1984.

McCuskey, Brian W. "The Kitchen Police: Servant Surveillance and Middle-Class Transgression." Victorian Literature and Culture 28.2 (2000): 359-75.

McDayter, Ghislaine. Byromania and the Birth of Celebrity Culture. Albany, NY: State University of New York Press, 2009.

— "Hysterically speaking: Lady Caroline Lamb's Glenarvon.” Romantic Generations: Essays in Honor of Robert F. Gleckner. Ed. Ghislaine McDayter, et al. London, England: Associated UP, 2001. 155-77.

Mei, Huang. From Fanny Burney to Charlotte Brontë: The Transformation of a Dream. Ann Abhor, Mich.: Univ. Microfilms Internat., 1989.

Meyer, Stephenie. Twilight. London: Atom, 2007.

Millgate, Jane. "Narrative Distance in Jane Eyre: The Relevance of the Picture." Modern Language Review, 63 (1968): 315-319.

Mitchell, Maera, and Dianne Osland. Representing Women and Female Desire from Arcadia to Jane Eyre. Basingstoke: Palgrave Macmillan, 2005.

Mitchell, Sally. The Fallen Angel: Chastity, Class and Women's Reading 1835-1880. Bowling Green: Bowling Green University Popular Press, 1981.

— "Sentiment and Suffering: Women's Recreational Reading in the 1860s." Victorian Studies, 21:1 (1977:Autumn):29-45.

Moglen, Helene. Charlotte Brontë: The Self Conceived. New York: Norton, 1976.

Morgan, Simon, “'A Sort of Land Debatable': Female Influence, Civic Virtue and

Middle-Class Identity, c.1830-c.1860.” Women's History Review 13, 2 (2004), 183-209.

Oliphant, Margaret. "Modern Novelists-Great and Small." Blackwood's Edinburgh Magazine, 77 May (1855): 557-59.

— “Novels.” Blackwood's Magazine, 94, (August 1863): 170.

Olney, Clarke. "Glenarvon Revisited." University of Kansas City Review, 22 (1956): 271-276. 
Paston, George and Peter Quennell. "To Lord Byron”: Feminine Profiles based upon unpublished letters 1807-1824. London: Murray, 1939.

Perkins, David. English Romantic Writers. New York: Harcourt \& World, 1967.

Pesta, Duke. "Darkness Visible': Byron and the Romantic Anti-Hero." Lord Byron. Ed. Harold Bloom. Philadelphia: Chelsea House Publishers, 2004.. 5985.

Pinch, Adela. Strange Fits of Passion. Epistemologies of Emotion, Hume to Austen. Stanford: Stanford University Press, 1996.

Praz, Mario. The Romantic Agony. London: Oxford University Press, 1933.

Pykett, Lyn. The Improper Feminine. London: Routledge, 1992.

Railo, Eino. The Haunted Castle: A Study of the Elements of English Romanticism. New York: Gordon Press, 1927.

Reynolds, Kimberly and Nicola Humble. Victorian Heroines: Representation of Femininity in Nineteenth-Century Literature and Art. New York: New York Press, 1993.

Rogers, Samuel. Table Talk. New York: Appleton, 1856.

Rousseau, Jean-Jaques. Emile, or On Education (1762). Translated and introduced by Allan Bloom. New York: Basic Books, 1979.

Scott, Walter, "Review of Childe Harold's Pilgrimage, Canto III", in The Quarterly Review 16 (October 1816-January 1817): 172-206.

Showalter, Elaine. "Family Secrets and the Domestic Subversion." The Victorian Family. Ed. Anthony S. Wohl. London: Croon Helm, 1978.

- A Literature of Their Own: From Charlotte Brontë to Doris Lessing. London: Virago, 1999.

- A Literature of Their Own: From Charlotte Brontë to Doris Lessing. London: Virago, 2009.

Smith, Margaret, ed. The Letters of Charlotte Brontë: With a Selection of Letters by Family and Friends, Volume II. 1816-1855. Oxford: Clarendon Press, 2000.

Solderholm, James. "Lady Caroline Lamb: Byron's Miniature Writ Large.” KeatsShelley Journal: Keats, Shelley, Byron, Hunt, and Their Circles, 40 (1991): 24-46.

Sterner,Mark. "The Changing Status of Women in Late Victorian Darama." Within the Dramatic Spectrum. Ed. Karelisa Hartigan. Lenham: University Press of America, 1986. 199-212.

Tuite, Clara. "Tainted Love and Romantic Literary Celebrity." ELH 74.1 (2007): 59-88.

Torslev, Peter Larson. The Byronic Hero: Types and Prototypes. Minneapolis, Minn.: University of Minnesota Press, 1962. 

Sabina Fazli

\section{Indian Diamonds in Victorian Fiction \\ Wilkie Collins' The Moonstone, Anthony Trollope's The Eustace Diamonds, R. L. Stevenson's “The Rajah's Diamond" and Arthur Conan Doyle's The Sign of Four}

\section{Introduction}

If there is one object in nature, more interesting to buman beings than another, it is the Diamond. Why this should be so, Philosophy might perhaps be able to tell if we consulted her; but it is not surprising that Poetry, who is always more or less inclined to superstition, should refer the influence of the stone over our judgments and imaginations to some occult talismanic power working upon us like fascination. (L.R. 49)

The arrival of the Koh-i-Noor in England incited widespread interest, and the fascination with the diamond which the anonymous writer of the 1849 article "The Koh-i-noor, or Mountain of Light" expresses is by no means short-lived. James Bond is equally amazed a hundred years later in Ian Fleming's novel Diamonds are Forever:

Now he could understand the passion that diamonds had inspired through the centuries, the almost sexual love they aroused among those who han- 
dled them and cut them and traded in them. It was domination by a beauty so pure that it held a kind of truth, a divine authority before which all other material things turned, like the bit of quartz, to clay. In these few minutes Bond understood the myth of diamonds, and he knew that he would never forget what he had suddenly seen inside the heart of this stone. (Fleming 13)

Wilkie Collins' The Moonstone, published in 1868, was an instant success and is today viewed as the first detective novel written in English. Apart from inaugurating a new genre, The Moonstone influenced a number of successors which take up the idea of an Indian diamond as the focus of the plot and the object of detection. Other literary diamonds which followed the Moonstone are Arthur Conan Doyle's Great Mogul in The Sign of Four, R.L. Stevenson's Rajah's Diamond in the New Arabian Nights, and Anthony Trollope's Eustace Diamonds in the novel of the same name. Although The Eustace Diamonds is usually regarded as a realist domestic novel, it still boasts two burglaries and a police investigation with no less than three officers in search of the stolen diamonds, so that here again the diamonds are the objects of detection.

Diamonds are present in literary texts as solid objects, as the focus of detection. In this position they are naturally central to the plot. The detective discourse, Elaine Freedgood asserts, is the area where things have to be read and are expected to have a meaning as evidence and clue to the solution of the case (150). It is therefore possible to read the diamond narratives as significantly shaped by the diamonds and attendant connections which they introduce to the text. With the precious stones not only the discourse of detection enters the stories but also their place of origin in India. Although by the middle of the nineteenth century, other sources of diamonds had been opened up, and the Indian mines had lost their significance in the international diamond trade, the novels retain the idea of historical diamonds with an identifiable Oriental aura.

On the other hand, diamonds work as vehicle for metaphor. Coventry Patmore expresses the Victorian reverence for the 'Angel in the House' through a comparison of Honoria with the Koh-i-Noor. In his metaphor, Patmore combines the sacred domestic space and its representative with the ultimate symbol of colonial rule in India, the 'Jewel in the Crown' of British imperialism. This yoking together of the domestic and the imperial points to the multifaceted way diamonds figure in literary texts, often uniting opposing qualities. The different interpretative possibilities partly owe to the fact that, over time, diamonds have been associated with different ideas. The Moonstone and its successors are imagined as bearing a curse, while in folklore, diamonds have been thought of as a charm against evil, possessing magical and healing properties) since the Middle Ages (Harlow, "History of Diamonds" 127-128. This notion can be traced back to ancient Indian sources which enumerate the beneficial use of diamonds as talismans (Tolansky 747). The formerly positive properties of diamonds are hence turned 
into the negative, although the basic assumption remains that an object of such immense value, rarity and often age, must exert some kind of unexplainable influence.

The "poetry" of the journal article and Fleming's "myth" evoke the otherworldly and romantic associations of diamonds. The otherworldly quality of diamonds surfaces in their connection with the Oriental 'treasure trove'. Diamonds serve as an ideal romanticised stand-in for this imaginary region through their association with luxury, abundant and presumably ownerless treasure.

Diamonds as such have always been the centre of legends and myths: In Hindu mythology they come into existence through the sacrifice of a god (Harlow, "History of Diamonds" 119), and the famous fable of the valley of diamonds, featuring either Sindbad or Alexander the Great as its principle hero, has been transmitted in innumerable versions. Real historical diamonds, too, seem to have attracted stories like hardly any other objects (Proctor 287). The stories especially those about the history of the Koh-i-Noor captured the attention of the Victorian public on its arrival in England.

Famous historical diamonds have a more or less thoroughly documented history; it is usually a mingling of fact and fiction which also often features different crimes. As the object of such a narrative, the diamond is individualised and identifiable by name. Such a legendary diamond presents the twofold allure of a mythical object and a financial asset. A singular and often named diamond, however, lacks the interchangeable quality and anonymity of cash or any precious metal. In turn, the individualised diamond is the centre and instigator of stories.

It should by now have become clear, I think, that diamonds in fiction and detective fiction cannot be regarded as a mere "MacGuffin" to keep the plot in motion (Hennelly 27) or as the plug for a text with "a hole in the middle" as Patrick Brantlinger described The Moonstone (Brantlinger, "What is Sensational" 22, qtd. in Hennelly 28). I would rather argue that the diamonds in The Moonstone and the later texts cannotbe exchanged with any other objects. They are integral to the texts and as they are identified as Indian their Otherness must be significant. I propose to analyse the diamonds as Indian objects in texts which are concerned with detection, either very overtly as in Doyle and Collins, or more peripherally as in Trollope.

I will look at the fictional diamonds from different angles and concentrate first of all on their stories which partly draw on existing and famous contemporary diamonds. In the next step, I will consider the contexts which the diamonds appear in in England, namely possession and inheritance, which are naturally central themes of detective fiction. In a separate chapter the focus will be on the intricate web of significances and metaphors which connect diamonds and women and their ownership of diamonds. The introduction of romance into the detective plot also provides a frame to analyse the endings of the stories and relies on diamonds as distinctly Orientalised objects. A mode of writing termed the "Imperial Gothic" 
by Patrick Brantlinger articulates the fears surrounding the contact with the colonies towards the end of the nineteenth century. Images of contamination and invasion inform the description of diamonds as well as the depiction of opium, another ambiguous colonial product, which already appears alongside the Moonstone. Both the Oriental drug and the diamonds are perceived as uncanny.

The texts I will rely on for in-depth analysis are Wilkie Collins' The Moonstone, Robert Louis Stevenson "The Rajah's Diamond", Anthony Trollope's The Eustace Diamonds and Arthur Conan Doyle's The Sign of Four. My criteria for choosing these texts are their focus on identifiably Indian diamonds as the focus of crime.

The Moonstone first appeared in serialised form in Charles Dickens' All the Year Round in 1868. It is conceived as an epistolary novel in which the theft of the Moonstone in India, its bequest and second theft in England and its return to India are narrated in letters and diary entries assembled to document and solve the crimes. The Moonstone has attracted a lot of critical attention and has been variously evaluated. T.S. Eliot famously hailed it as the "first and greatest of English detective novels" (Eliot 377, qtd. from Gruner 127) while Brantlinger complained of its "hole in the middle" thus obsessively circling a void (Brantlinger "What is "Sensational"” 22, qtd. in Hennelly 28). John R. Reed proposed the first postcolonial analysis of The Moonstone (Free 345) and reads the novel as an indictment of imperialism (Reed 281).

The Eustace Diamonds (serialised 1871-1873) by Anthony Trollope presents a decidedly domestic take on the plot of The Moonstone and has even been called a "parody" (Milley 656) or mere rewriting of the former (Daly 69). Lizzie Eustace insists on keeping her deceased husband's diamonds while the Eustace family's lawyers try to reclaim them for his family. At the bottom of the dispute is the diamonds' legal status as either heirloom or paraphernalia. While Lizzie is in possession of the diamonds, she is on the one hand an eligible match due to her wealth, but on the other hand her retention of the diamonds gives rise to rumours. At an inn the diamonds' box is stolen; Lizzie keeps it from the police that the box had been empty, and that she is still in possession of the diamonds. In a second burglary, her diamonds are really stolen and it transpires that she has lied. This damage to her reputation appals all her former suitors, and she has to marry below her station. Although Trollope's novel is often classed as domestic, it has colonial connections. The Eustace diamonds are stated to come from Golconda, the famous Indian mines (Trollope 138), and they appear in England in 1799, the year of the Fourth Anglo-Mysore War which is also the site of the plundering of the Moonstone (Daly 75). In a sub-plot another legal case concerning stolen property complements Lizzie's endeavours to keep the diamonds: An Indian prince, the fictional Sawab of Mygawb, claims back his land, and two of Lizzie's suitors are engaged in the case on opposite sides.

In 1875, a short-story in two instalments appeared in Charles Dickens' All the Year Round, by an anonymous contributor. It is called "The Rajah's Diamond" and 
tells of a diamond miner in southern Africa who travels to Borneo to obtain the "largest and finest diamond in the world" (2: 155) from a local rajah. The diamond is cursed and every single rajah who had guarded it had died a violent death (1: 138). It does lend itself to a comparison with the other texts, though, as the action is mostly set in Borneo and not in Europe. The story, nevertheless, is interesting because, like The Datchet Diamonds ${ }^{1}$, it juxtaposes southern African and Oriental wealth. Furthermore, Stevenson chose the same title for his short-story three years later.

R. L. Stevenson's “The Rajah's Diamond” was published in The London Magazine in 1878 before it appeared in the collection of the New Arabian Nights (1882). The collection was published in two volumes with "The Suicide Club" and "The Rajah's Diamond" making up the first. Both stories feature the pair of Prince Florizel of Bohemia and his faithful servant Colonel Geraldine. "The Rajah's Diamond" tells of the eponymous diamond's passage from one owner to the next in a succession of intentional and unintentional thefts and recoveries. "The Suicide Club" and "The Rajah's Diamond" are embedded in a frame narrative of an editor recounting these stories from an Oriental manuscript and mediating the "Oriental's" voice (Stevenson, "Suicide" 68). This frame narrative imitates the Arabian Nights of the title in connecting the different stories.

Arthur Conan Doyle admired Stevenson's "The Pavilion on the Links" in the second volume of the New Arabian Nights (Gray 90). Doyle produced his own diamond narrative in The Sign of Four, published in 1890 in Lippincott's Monthly Magazine. It marks the second appearance of Sherlock Holmes and his friend, biographer and sometime co-lodger Dr. John Watson, following their first adventure in A Study in Scarlet (1887). Both novels split their action between London and a colony so that Holmes investigates colonial crimes which follow their perpetrators back to England, a device which recurs several times in the Holmes canon. Doyle references The Moonstone in the plot of his novel and also in the name of "Able White" (Doyle, Sign 214), an Anglo-Indian planter. Three other Sherlock Holmes stories involve the theft of diamonds, "The Adventure of the Beryl Coronet" (1892), "The Adventure of the Blue Carbuncle" (1892) and "The Adventure of the Mazarin Stone" (1921). "The Adventure of the Beryl Coronet" identifies the diamonds as presumably colonial. The beryl coronet is "[o]ne of the most precious public possessions of the empire" (Doyle, "Beryl" 470) and thus evokes objects like the crown jewels and a range of historical diamonds. The plotalso shows some resemblance to The Moonstone, but Doyle does not so much focus the description on the Indianness of the diamond but on the scene of the theft of the Moonstone in Rachel's room, although with reversed roles. In Doyle's version, Arthur watches his cousin Mary steal the coronet to run away with her lover. He snatches part of it back, but he is caught by his father when he puts it into the

1 See p. 108. 
cabinet and is thus falsely accused of the theft. As he does not want to incriminate his cousin, he refuses to testify. Consequently, an innocent maid servant is suspected of the theft, and Holmes has to clear up the case on the grounds of circumstantial evidence.

"The Adventure of the Mazarin Stone"2 (1921) revolves around the theft of the "Crown Diamond" ("Mazarin" 559), "the great yellow Mazarin Stone" (562). The thief is the Italian Count Negretto Sylvius, a big-game hunter in Algeria (566).

In criticism, the dependence of The Sign of Four on The Moonstone has often been remarked and the two texts have been viewed togetherfor example, by Jaya Mehta who links both texts to colonialism abroad and the "detective romance" at home (613). Suzanne Daly and John Plotz point out the connection between the realist domestic novel by Trollope and the detective mystery by Collins. Arndt Mersmann groups together The Moonstone, The Eustace Diamonds and The Sign of Four as texts which focus on "the absence of diamonds or jewels" (187). In his discussion of The Moonstone, Jean Pierre Naugrette also includes The Sign of Four and briefly touches upon Stevenson's "The Rajah's Diamond". The New Arabian Nights as a whole seem to have been eclipsed by Stevenson's other more famous texts, and critics seem to have largely ignored it. The only other instance in which "The Rajah's Diamond" is mentioned together with The Moonstone seems to be Bhupal Singh's Survey of Anglo-Indian Fiction of 1934. Singh identifies a set of texts which centre on "Jewel hunting", and he lists Stevenson's short-story as an emulation of The Moonstone (268). Singh further concentrates on popular adaptations of the theme in the 1920 s and 30 s.

A lowbrow forerunner of these can be found in Richard Marsh's ${ }^{3}$ The Datchet Diamonds (1898). Its plot again consists of the search for diamonds. The Duchess of Datchet's diamonds are stolen and ultimately retrieved by detective John Ireland. Cyril Paxton, a stockbroker, accidentally picks up the wrong suitcase in a train restaurant and finds himself in possession of the stolen diamonds. He plans to keep them as he has lost money in his investment in shares and plans to marry. From then on, he is on the run both from the police and from the original thieves. In a happy-ending the diamonds are restored to the Duchess, Cyril is pardoned, and he can marry as a company he holds shares in has discovered gold in southern Africa. The diamonds are set in "the Begum's brooch" and "the Rani's bracelet" (46) and thus again identified as originally Indian possessions.

2 In the short-story, a "French modeller" named Tavernier is mentioned. He fashions a figure of Holmes in wax which he places at the window to mislead Sylvius ("Mazarin" 564). Jean-Baptiste Tavernier, a French eighteenth-century traveller and diamond trader, is one of the most famous and widely quoted references on historical Indian diamonds. The bulk of information on the history of diamonds from Persia and India goes back to his descriptions and drawings. The name might thus be a side-effect of Doyle's research on diamonds as it is impossible to read up on diamonds without encountering Tavernier.

3 Pseudonym of Richard Bernard Heldmann. 
It is obvious, I think, that the theft of diamonds which are more or less clearly identified as Indian, is the feature of a number of texts, at least from the publication of The Moonstone onwards. Through the diamonds as stolen goods, India enters the text and invariably connects the domestic problem with the reality of British imperial possessions. It is therefore necessary to look at the underlying pattern of imperialist discourse and the extent to which the domestic genre of detective fiction is concerned with and dependent on imperial relations.

\section{Orientalism in Literature}

Empire relies on "cultural representations" (Boehmer 5) to persist in imagination and reality. Geographical expansion has to be supplemented by a general cultural climate which sustains imperial domination and supports its foundation. Literature in general, and in the nineteenth century the novel in particular, supported and perpetuated imperialist ideology (Said, Culture 74). The representation of the colony and the metropolis as realms of the Other and the self transports the intrinsic difference between the two spaces. The writing of empire rationalises and justifies domination by ascribing a set of notions to these spaces which are presented as natural and unchanging. Orientalism as a discipline and system of ideas defines the Orient as the utter and deviant opposite of the Occident and western civilisation (Said, Orientalism 58). In the logic of binary oppositions the Other comprises the deviances from the colonisers' auto-stereotype of masculinity, rationality, civilisation and individuality. The Other is imagined as deficient, as "less human, less civilized, as child or savage, wild man, animal, or headless mass" (Boehmer 76). These ascriptions feed on projections and imaginations which are, in the example of the Victorian novel, continually bequeathed as a rigid structure to later texts. Edward Said argues that this ideology is taken for granted and underlies even the most domestic plots as a silent and basic assumption (Culture 74-75). This system of ascriptions is not confined to the Orient, but any culture or social group can be thus othered and understood as inferior and opposite to one's own.

Orientalism as an academic discipline was directly implicated in the imperial project. Amassing knowledge on the Other and ordering it along western scientific models is essential in governing them. Accordingly, Said describes the writing of the Déscription de l'Égypte in the wake of Napoleon's conquest as the quintessential Orientalist project. It achieves the retelling of history from a western point of view and consolidates power through a renaming and reinterpretation of the other culture (86-87).

In my analysis of the texts, I will draw on Said's thesis that the idea of empire is an all-pervading element in Victorian novels and constitutes an integral, albeit muted element. The importance of knowing and charting the Oriental Other in order to gain power over them, which Said points out, also surfaces in studies on the literary detective and his imperial predecessors. The specialised and scrutinis- 
ing ethnographic knowledge is supposed to make the Other knowable and to exert control over the criminal who is himself always othered (A.D. Miller 36).

\section{Contexts}

Before I will look at the texts themselves I will briefly sketch the historical and cultural background. The Victorian attitudes towards India as well as their articulation in the literature of the time, are a complex topic. As already said, the diamonds are the centre of plots of detection. Detective fiction, the genre which The Moonstone arguably initiated, heavily relies on the writing of empire. The British view of India painted a picture of the colony as a hotbed of crime. Caroline Reitz contends that even at the beginning of the century this notion intrinsically influenced the formation of detective fiction. The constellation of the detective, crime and India is a common denominator of my chosen texts and therefore deserves prior consideration.

Lastly, I will briefly outline the significance of diamonds in Indian culture and their introduction into Britain as a colonial product and the growing interest in stories and legends surrounding them.

India in Literature: The Fashioning of India as 'Criminal'

The image of 'criminal' India came up in the late eighteenth century and informs the discourse on India in the Victorian period (Mukherjee 23). The expansion of empire relied on the justificatory myth of spreading civilisation and progress. It brought "order, justice, and legality" to a place which was in turn imagined as lacking all of these, a site of unchecked crime and injustice (25). This constellation was repeated in further violent encounters where Indian rebellion was not viewed as politically motivated but as the expression of an innate tendency to crime. The first and enduring instance may be the infamous 'Black hole', the prison where the inhabitants of the British settlement in Calcutta were held, in 1756. While contemporary texts were more concerned with the emasculating effect of having been defeated by a people that was considered to be inferior, the construction of Indians as 'criminal' emerged in later accounts of the 'Black hole' when the East India Company began to establish wider political domination and could make ideological use of the stereotype (26-27).

\section{Thuggee and the Detective}

The idea of innate criminality infused British contempt for Indian religions. Hindu iconography was condemned as immoral in its depiction of sexuality and as exalting not only deviant but criminal behaviour (Mukherjee 33). An influential in- 
stance which depicts the conflation of religion and crime and then generalises the idea to comprise the whole of the population was the popularity of narratives of Thuggee. At the beginning of the nineteenth century, the figure of the Thug became an important symbol for Indian cruelty and immorality. Thugee came to stand for crime rooted in religion, social organisation and culture (Reitz 25). The sect drew its legitimation from the devotion to the goddess of destruction, Kali, and her decree to provide her with human sacrifices (Rapoport 662). Thuggee was perceived as widespread but hidden from imperial eyes. Deception could also be detected in the way Thugs murdered: they used a sash which could be concealed on the body (Reitz 28). Disguise and - murder were seen as the hallmarks of Thuggee and applied to India as a whole. An important aspect of Thuggee is its wide literary dissemination in Britain as representative of India through the success of Philip Meadows Taylor's Confessions of a Thug (1839). In the discussion of Thuggee as an omnipresent phenomenon, it should be noted that actual numbers of stranglers and victims are unknown (Rapaport 661-662) and that the allegation was also used to discredit resistance to British rule in general as during the Indian Mutiny ${ }^{4}$ in particular. Considering the uncertainties surrounding the historical existence of Thuggee, critics even speak of an invention and "manufacturing" to justify rule and provide the colonial administration with a success story in exterminating crime (Mukherjee 103). The conflation of religion and crime, however, also entails the idea of criminal castes, which gained impetus especially after the Mutiny. The conviction that criminal behaviour is inevitably tied to certain castes actually turns into law in the 'Criminal Tribes Act' of 1871. The distinction between caste and tribe was blurry at best but nevertheless strengthened the notion of a systematic and deeply rooted social leaning to crime (Yang 109).

The depiction of William Sleeman and the work of the colonial 'Thagi and Dakaiti Department' figures in a number of texts from the 1830 s onwards and informed the public's image of the upright policeman and colonial administrator. His opponents, the sect of Thugs, served to provide a neat "compartmentalization" of "English cops and Indian robbers" (Reitz 23) 5 . The excessive secrecy of Thuggee demands an emphasis on detection and confession which often provided the only chance to penetrate the Thug network. The main strategies employed were the use of spies and approvers as witnesses were generally unwilling to testify

4 I will use the term Mutiny as this was the designation used in Victorian writing and carries the connotations which I am interested in with regard to the texts, although more appropriate terms such as First Indian War of Independence, the Great Revolt or Uprising, etc. are used by historians to account for the Indian perspective.

5 The colonial setting naturally highlighted the Englishness of the detective. This was important as the reform of the police in England was widely opposed. The presentation of an English detective in India helped disperse these reservations and cleared the way for the acceptance of new forms of policing in England. The colonial detective furthermore rallied the imperial project as the spread of justice and law. The police as benevolent reformers was more readily accepted and supported as colonial agents than the military or the East India Company. (Reitz 29) 
(28). These new and inventive means, often original and sometimes barely legal, also proved fertile for the literary detective (Perera 112). The same form of police intelligence, which had hitherto been rejected or at least been frowned upon in England, was implemented in London in the wake of its colonial success (Reitz 28). As Caroline Reitz argues that the birth of the whole genre of detective fiction heavily relied on India as the site of crime, the pedigree of crime fiction includes Taylor as an important and influential contributor (22). The type of the Thug as representative of India and the conventional literary villain congealed into a repeatable literary stereotype. The close intertwining of the colonial adventure story and the rise of the literary detective in England, Reitz suggests, make Dickens and Collins not so much into inventors of the genre but inheritors of an imperial tradition (45). In situating the birth of the detective in India, she also explains the conflation of colony and crime which is to become a fertile impetus for detective literature and refutes the traditional histories of the genre which posit the detective novel as purely "homegrown" (46). Detective fiction is thus one mode which perpetuated the image of the criminal colony .

Meadows Taylor immortalised another Indian 'criminal' in his novel on the Mysore wars, in Tippoo Sultaun (1840). The figure of Tipu was made famous, primarily, through captivity narratives which showed him as a despotic and cruel ruler (Mukherjee 110). His 'fame' was definitely comparable to Nana Sahib, the icon of the Mutiny.

\section{The Mutiny}

The Indian Mutinyof 1857/8 consolidated this image and again saw the indiscriminate labelling of the colony as inherently prone to crime. The great outrage the Mutiny had incited in Britain is impressively mirrored in the literary output. Fifty novels on the Mutiny were written before 1900 and another 30 before World War II (Brantlinger, Rule 199). The Mutiny was the subject of countless other texts: "[t]here was a deluge of eyewitness accounts, journal articles, histories, poems and plays dealing with the 1857-58 rebellion" (199). The Indian Mutiny was the defining moment in the mid-Victorian attitude to British colonisation of India and India itself and caused a boost in public interest in the colony (Pionke 109)

Writings on the Mutiny signalled a change in the attitudes towards India. Although, before the Mutiny, India was represented in Orientalist stereotypes, many writersstill expressed the possibility that Indians could be 'civilised' and 'elevated' from their state of 'barbarism'. The discourse which underpinned British rule in India posited the mild and passive Hindu as longing for and consenting to British rule and reformation (Sharpe 58). The possibility of change for the better, in British eyes, is rendered impossible after 1858. The trope of India as unchanging and forever caught in the same "superstition and violence" (Brantlinger, Rule 200) supersedes the ethnocentric and philanthropic, though racist, aspirations of earlier 
times. The stereotype of the Indian now includes innate and unreformable savagery to explain the Mutiny (Sharpe 201). Post-Mutiny writing is thus governed by binary oppositions of "good and evil, innocence and guilt, justice and injustice, moral restraint and sexual depravity, civilisation and barbarism" (Brantlinger, Rule 200).

Nana Sahib's massacre of women and children in Cawnpore is the most enduring moment of the Mutiny in British fiction and came to stand for the Mutiny as a whole, with Nana Sahib representing the quintessence of Indian cunning and Oriental cruelty (Brantlinger, Rule 204; 222). In the British public, the fact was suppressed that Nana Sahib's massacre at Cawnpore might not have been an act of gratuitous violence, but a retaliatory action for atrocities the British had committed in Benares and Allahabad (201). Patrick Brantlinger argues that the preeminence of Cawnpore in the British imagination of the Mutiny is a symptom of a much larger reduction of the Mutiny. Crime rather than politics is seen to be at the root of the rebellion, and Cawnpore supersedes all other accounts of the $\mathrm{Mu}$ tiny, including British violence and actions of revenge (201-204). The massacre at Cawnpore also confirmed and propagated the fear that English women especially are in danger of being the victims of Indian violence and sexual predation (Free 357-358). Rumours of mass rape were readily accepted as truth in England and entered official history (Sharpe 65). In the criminalisation of the Mutiny, the figure of the rebel was conflated with the earlier image of the Thug as representing the natural criminality of Indians (Mukherjee 102-103, ftn. 26).

For imperial ideology, the protection of innocent women and children after the Cawnpore massacre played an important role as it provided a just cause for action: The call for revenge for the murdered women and children was used to justify the extreme violence of the 'devil's wind', and in presenting the political cause of the Mutiny as a (sex) crime, it became devoid of any political intent (Sharpe 65-66).

\section{Opium}

Partly coinciding with the Mutiny, Britain fought another colonial war with China. China had tried to stop the influx of opium, and enforced restrictions which led to the 'Opium Wars' fought in 1839-42 and 1856-58, to force the Chinese market open to British opium from India. After the second war, which Great Britain fought in alliance with France, China was forced to completely legalise the import of opium. Other European colonial powers also profited from the sale of opium: France established a government-held monopoly in Indo-China, an example which the Netherlands copied in Indonesia in the late nineteenth century (Van Ours 141).

By the middle of the century opium was, alongside tea, one of the most important products imported from India and was sold profitably abroad and consumed 
in Britain itself (Keep and Randall 207). The East India Company held a monopoly on opium cultivation in Bengal and exported the product to China and Asian regions with Chinese minorities.

Until the 1860s, opium was freely available in Britain, and both opium and alcohol were the "favourite drugs of the Victorians" (McCormack 139). Both alcohol and opium, pure or mixed as laudanum were not only recreational drugs but also a staple medicine used for all kinds of complaints. The consumption of opium was not yet regarded as morally dubious. After the middle of the century, however, the danger of addiction began to be emphasised over the drug's usefulness as a medicine and tranquilliser so that the Pharmacy Act of 1868 checked the availability of opium (139-140). The excesses of Romantic culture at the beginning of the century were now frowned upon and what had been regarded as a "moral weakness" eventually came to be viewed as a "disease" (139). The first society which promoted the ban of opium and a cessation of opium trade to China had been founded in 1840, but their cause gained renewed impetus after the Opium Wars with the "Anglo-Indian Society for the Suppression of the Opium Trade" in the 1880s. By this time, under the impression of the Opium Wars, demands for further outlawing of the drug were helped by a decline in the opium trade. With the financial gains diminishing, as China herself had started to cultivate opium poppies, the moral arguments against opium found more supporters (Foxcroft 67). Furthermore, with the discovery of alternative drugs as narcotics and painkillers, the use of and need for opium in medicine dwindled (Van Ours 141).

The attitude towards opium (and alcohol) in Victorian literature was marked by a growing severity as the century advanced, directed against all threats to the Victorian ideals of "sobriety, responsibility, self reliance, chastity, moderation, perception, and domesticity" (McCormack 143). With the growing demonisation of opium it came to be viewed as a poison rather than a medicine and thus perceived as criminal and especially connected to the criminalised East as part of its huge repertoire of murderous substances (Harris 455). The effects of opium, too, were imagined as a tropical disease, contagious and dangerous, issuing from the land itself (454).

The Orientalisation of opium in literature goes back to Thomas De Quincey's Confessions of an English Opium-Eater, the origin of a set of recurring motifs such as the "exotic and sinister foreigners who smoke, eat, drink, convey and dispense opium to decent Englishmen" (McCormack 142). Doyle's opium dens as in "The Man with the Twisted Lip" (1891) have been prefigured by Dickens' The Mystery of Edwin Drood (1870). With the suggestion that the empire enters the nineteenthcentury novel primarily in the shape of its products (Boehmer 26) opium comes to represent exotic and negative aspects associated with India and the Orient which infect the imperial centre. An interest in opium and also in its criminal potential was incited by James Esdaile's Mesmerism in India (1866) and other works in the same vein detailing the way mesmerism in combination with opium is used to 
commit crimes (Ascari 71). Opium is one of the products of empire which incited discussion, and it is closely linked to imperial history through the Opium Wars. The fact that it also highlights the economic interrelatedness of Britain and its colonies will be the basis for my analysis of how the perceived relation between opium and diamonds informs the texts.

\section{"Imperial Gothic"}

If the literary detective is imagined as originating from the encounter with the Other and their criminality, detective fiction provides a frame which contains and regulates the foreign elements in England. The reliance on science and rationality which the Holmes stories propagate contrasts with another tendency in mid- and late Victorian literature which describes the encounter with the Other as threatening and uncontrollable.

When the British Empire was at its height, the optimistic belief in its stability and progress was undermined by visions of imminent decay and danger for the nation as a whole and the individual. The celebration of British imperialism in Queen Victoria's Gold and Diamond Jubilees in 1887 and 1897 is thus contemporary with the mode of imperial Gothic in Victorian fiction. An interest in the occult in connection with the exotic and mysticism had existed since mid-Victorian years, but it produced a specific tone through the rise of a pessimist outlook on empire. Occultism and imperialism, separately and mixed, stood in for a loss of religious certainties and faith. Several themes and motifs, attendant on the consolidation of empire in the last decades of the century, address a sense of insecurity and fear surrounding Britain's expansion. The mode of imperial Gothic transforms the progressive belief in the superiority of science and Darwinian ideology into their darker undersides of occultism and the possibility of regression (Brantlinger, Rule 227-228).

Patrick Brantlinger identifies three distinct themes in imperial Gothic: The fear of "going native" as reversed evolution in an individual and the regression to an earlier stage of civilisation expresses an awareness of just how thin the dividing line between coloniser and colonised was. From the middle of the century onwards, the superiority of the British over their colonial subjects had been based on race (David 88-89), a concept which could now be contested. The fear of invasion and the appearance of "barbarism" and "demonism" far from their assigned places on the periphery in the middle of British society is another recurrent theme. These occult forces were imagined to follow homecoming colonials to England. Lastly, Brantlinger cites the waning of "opportunities for adventure and heroism in the modern world". The "Colonial Adventure Story" thus propagated an image which had lost its credibility.(Rule 230-231).

The imperial Gothic draws its unsettling quality from the assumed diminution of distance between the self and the Other. While the sensational novel had al- 
ready depicted crime in the domestic sphere, it is now colonial spectres that appear in the metropolis. In reading the diamonds as Indian, their intrusion can be analysed through the categories Brantlinger defines.

\section{Diamonds in India and Britain}

\section{Diamonds in Nineteenth-Century Britain}

The history of diamond trade to Europe can be divided into three phases according to their places of import. From ancient times until the 1730s, diamonds were imported from India, from then on until the 1860s they mainly came from Brazilian mines, and the third phase sees the dominance of southern Africa in the international diamond trade (Gaggio 76-77).

India is the oldest export region for diamonds, but little is known about its first mines. Pliny the Elder in the first century and Ptolemy in the secondcentury $\mathrm{CE}$ both mention Benares as the place from which diamonds are brought to Europe. In the thirteenth century, Marco Polo reports new mines in Golconda. In the fifteenth century, the Portuguese from their base in Goa, began to dominate the diamond trade with Europe - which also became more organised - and they were followed by the British and the Dutch based in Madras (Gaggio 76). The output of the Indian mines was limited, and only a small percentage of stones reached Europe, as the local rulers often claimed the largest stones for themselves and only allowed minor diamonds to be exported. India was succeeded by Brazil as the main source of diamonds in the $1730 \mathrm{~s}$, when the Indian mines showed the first signs of exhaustion, until, in 1866, diamonds were discovered in southern Africa (Levinson 73-75).

With the turn to Brazil for the import of stones and the increasing output of the South American mines, a growing middle-class in Great Britain was able to afford diamonds. The quite uncontrolled output of the Brazilian mines led to a crash in prices, and traders contrived to ship their diamonds to India whence they could be sold as more expensive and rare Indian stones (Proctor 388). This practice is also mentioned by King who asserts that Brazilian diamonds sold as Indian had more of "a character" in European eyes (34). Even when hardly any diamonds were imported from India, Indian diamonds were still thought to be more desirable than Brazilian ones and retained a special allure. The availability of diamonds was further facilitated by the discovery of deposits in Africa, whose mines topped the output of the Brazilian ones. In England, the luxury of a diamond purchase was consequently democratised (Levinson 78-79; Proctor 390).

An interest in the history of diamonds was also emerging, and diamonds as the focus of ancient legends and history naturally aroused interest. The rise of different historical sciences additionally fed the interest in objects and their histories (Goetsch 68). Kurt Tetzeli von Rosador observes that "from the middle of the 
[nineteenth] century onwards a steady stream of books on gems and jewels appears," which perpetuates anecdotes and scientific information read by a wide public (300). The increasing availability of diamonds thus also spawned a rising interest in texts on and about the subject. C.W. King explicitly refers to this interest in the preface of The Natural History, Ancient and Modern, of Precious Stones and Gems and of the Precious Metals (1865), the text which Wilkie Collins studied in preparation for the writing of The Moonstone (Hennelly 29). King introduces his text by claiming that "the owner of a jewel, however insignificant, is naturally desirous to know something of its character and value" (v), testifying to the spreading ownership of diamonds. The rise in the interest in diamonds might also have been occasioned by the presentation of the Koh-i-Noor in the Great Exhibition of 1851. Since Victoria was proclaimed Queen and, in 1876, Empress of India, the colony came to be called the 'Jewel in the Crown', connecting the land and the symbol of rule. Furthermore, the stories surrounding the Koh-i-Noor, and what King called "its character" and reputation, made it a must-see object.

\section{Diamonds in Hinduism}

References to diamonds in Sanskrit sources date back to 300 BCE. It cannot, however, be ultimately verified whether all the precious stones mentioned there are actually diamonds in today's sense of the word or comprised of other very hard material (Proctor 385). The words most often used for 'diamond', vajra and indrayudha, denote 'thunderbolt' (Platts, "Vajra") and 'Indra's weapon', Indra being the Vedic god of war (Harlow, "History of Diamonds" 119).

The Ratnapariksa by Buddha Bhatta, from the fifth century CE, contains the diamonds' myth of origin: According to this legend, the gods were unable to overcome the king Bala. To avert defeat they ask him to offer himself in sacrifice in a ritual to their honour. Bala is too proud to refuse, and his body is torn to pieces. Because of the valour and purity of his voluntary death, his remains turn into diamonds. Gods, serpents and the minor divinities of Siddhas and Yakshas pick them up and, in flying over the land, let them fall to the earth and there create diamond deposits. From their origin in Bala's noble act, diamonds in Hinduism possess divine powers which can be used to benefit or harm their owner ("History of Diamonds" 118-119).

The Râǵanighantu, a medical dictionary written in the thirteenth century CE by the physician Narahari, ranks diamonds according to colour (Garbe vi), a classification in which it concurs with the Ratnapariksa (Harlow, "History of Diamonds" 120). The appearance of diamonds in a dictionary of medical terms also highlights the medieval Indian view of diamonds as medicines and beneficial. Narahari distinguishes four different colours, white, red, yellow and blue-black (Garbe 82). Diamonds of these colours correspond to different castes (varna) and can only be worn by their respective members. Brahmins are allowed to wear white, Kshatri- 
yas (warriors) red, Vaisyas (merchants) yellow and Sudras (craftsmen) black diamonds. If a diamond is worn by the member of a wrong caste, it brings bad luck and even death. Yet, as long as the rules are observed, the diamonds are supposed to grant wealth and social esteem (82). White diamonds bestow power, wealth and friends, red ones grant health and prevent old age, yellow ones bestow success and the blue-black diamonds provide for good fortune. The donation of a diamond to a temple assured the giver of eternal life (Anon, "Diamond"). In the iconographical depiction of Hindu gods, especially in temples, a recurrent element is a "jewelled girdle" as in the different avatars of Vishnu and Shiva (Bunce, "Vişņu"; Bunce, "Shiva").

Narahari further details the medical usefulness of different diamonds, and he emphasises that only unflawed diamonds are auspicious (Garbe 81). The earlier Ratnapariksa further stipulates the privilege of kings to wear diamonds of all colours. Buddha Bhatta also asserts that a flawed or damaged diamond is sure to bring misfortune and death to its owner (Harlow, "History of Diamonds" 120).

Although sources on Hindu views on diamonds are rare, it seems clear that they were valued as talismans and their influence regarded so highly that their wearing was strictly regulated. In accounts of the diamond trade to Europe, it is further remarkable that only smaller stones where traded west, as Indian kings had the right to the bigger diamonds found in their lands (Levinson 72). In the stories which centre on historical Indian diamonds their association with Indian religions almost forms a staple ingredient.

\section{Real and Fictional Diamonds: Story and History}

The Models: Famous Indian Diamonds and their Stories

In the preface of the 1868 edition of The Moonstone, Wilkie Collins gives the Koh-iNoor and the Orlov as sources on which he modelled the Moonstone. Both diamonds, he asserts, used to be part of Hindu cults:

With reference to the story of the Diamond, as here set forth, I have to acknowledge that it is founded, in some important particulars, on the stories of the royal diamonds of Europe. The magnificent [Orlov] stone which adorns the top of the Russian Imperial Sceptre was once the eye of an Indian idol. The famous Koh-i-Noor is also supposed to have been one of the sacred gems of India; and, more than this, to have been the subject of a prediction which prophesied certain misfortune to the persons who should divert it from its ancient uses. (Collins, Preface 5)

Jaya Mehta adds three other diamonds as possible sources for the Moonstone: "Charles Reed's moonstone; the Pitt diamond, which [...] proved a curse to its owner; and the Sancy $[\ldots]$ believed to have been returned to India" (ftn.6, 649). In 
the following I will look in detail at the stories of the Koh-i-Noor and the Orlov. I will include other famous diamonds whose histories and legends might have contributed to the plot of The Moonstone and other texts centring on Indian diamonds. Given the general interest in diamonds from the middle of the nineteenth century onwards and Collins' own well-known research into diamonds, it is more than likely that he would have been familiar with these stories as well as his Victorian readers. The existence of these stories, more widely known in the nineteenth century than today, may also refute the claim that the Moonstone is an interchangeable and meaningless item to trigger the detective plot and actually evokes a range of associations with existing diamonds.

C. W. King describes the transmission of the legends surrounding diamonds as conspicuously unreliable: "[T] here is no class of relics (except sacred) whose whole history swarms with confused and conflicting stories, re-copied and reblundered by careless writers, $[. .$.$] and these fictions [...] obtrude themselves into$ newspaper paragraphs" (King vii). The layer of fiction, which constitutes parts of these stories, feeds on Orientalist stereotypes. As many of the stories were collected and edited for a growing interested Victorian reading public (Rosador 300) the image of India which is conveyed oscillates between excessive violence, excessive riches and the occultism of an unknown religion. This becomes evident in the recurring motif of the theft of diamonds from a temple or statue of a god and the idea of a curse laid on the diamond. While the disregard for native "superstition" establishes the thief as superior and immune to "heathen" beliefs, the theft also holds the possibility of an Oriental revenge in the form of a curse which reflects the interest in occultism (Brantlinger, Rule 227). The original function of diamonds in Hinduism as talismanic and generally auspicious is suppressed in these stories.

When the Koh-i-Noor reached England in 1850, it could already boast a documented history of many centuries. According to legend, the diamond was mounted in a statue of Shiva as his third eye. Its earliest known owner was the Rajah of Malawah (Harlow, "Great Diamonds" 109). His kingdom was conquered by the first Mogul emperor of India, Barbur, who obtained the Koh-i-Noor as loot after his taking of Agra in 1526. It became a symbol of omnipotence and power (Balfour 15-16) and thus remained in the hands of Humayun, Barbur's son and successor to the throne. In the reign of Aurangzeb, it passed to Persia after the sacking of Dehli in 1739. Nadir Shah there named it the Koh-i-Noor, the 'Mountain of light' (Mersmann 178). The last Persian owner of the diamond was Shah Shuja, who traded it to Maharajah Ranjit Singh of the Punjab for protection in Lahore after he had been driven out of his country. Ranjit Singh, at one point, intended to dedicate the diamond to the temple of Jaganath in Puri, but was dissuaded by his treasurer (Balfour 23). This episode, however, was to become the basis of one of India's claims for restitution. The British took the Koh-i-Noor from Ranjit Singh's son Dalip Singh after the conquest of the Punjab in the Second Anglo-Sikh War of 1849. The peace treaty which was drawn up between the 
Punjab and the East India Company minutely regulated the ownership of the Koh-i-Noor and made it over to Queen Victoria, thus providing a "legalistic façade" in an attempt to erase its history as an object of plunder (Mersmann 178). The greater part of the history of the Koh-i-Noor so far, as Mersmann remarks, had been distinguished by "violence, dispossession, torture, extortion, [and] cruelty" (177). On its arrival in England, rumours spread that the diamond was illfated and even cursed. When Queen Victoria was attacked, shortly after the diamond's arrival in Britain, the public was quick to blame the cursed Koh-i-Noor for the incident (Balfour 25; 28).

The almost magical properties which were ascribed to the diamond and its association with India posed specific problems in its appropriation in England. The Koh-i-Noor's distinct biography was determined by its prestige as a symbol of rule and power. Its new owners in England coped with these problems by containing the diamond in a controllable frame. It was first presented to the public at the Great Exhibition of 1851, providing a very particular space for the reinterpretation: It was on display in the British department rather than in the Indian Court (Mersmann 179-180). The Koh-i-Noor actually presented an antithesis to the underlying idea of the Exhibition which was devoted to the display of neatly arranged "classes of commodities". The Koh-i-Noor stood apart as a symbol of a pre-modern, Orientalist economy, of social and political concepts completely at odds with those propagated by the Great Exhibition (180). It served as the symbolic opposite of industrial mass production, which was imagined as democratic and morally superior. The Koh-i-Noor was the fascinating but detestable exponent of a society imagined as feudal and backward including aristocratic luxury and over-consumption built on ruthless tyranny (182-183).

Before its exhibition, Queen Victoria had the diamond re-cut to remove a yellow tinge, and its size was significantly reduced in the process (Balfour 27). In the 1850s Dalip Singh, its last owner in India, came to live at Queen Victoria's court and again presented the diamond to her as a gift. Both Arndt Mersmann and Jaya Mehta emphasise this as an "element of subaltern resistance" (Mersmann 186; Mehta 615). The gesture turned the diamond from a symbol of conquest into a generous personal gift fashioning the giver as an equal to the Queen. In any case, Dalip Singh's token gesture renewed the public discussion on the Koh-i-Noor, its alleged curse and also the legitimacy of its seizure, as Singh presented it as a personal possession and not as property of state, which could have been confiscated in war (Balfour 28).

The Koh-i-Noor was set in a circlet for Queen Victoria and later reset for Queen Mary and Queen Elizabeth, the Queen Mother, but it was only rarely worn. Mersmann argues that at the bottom of this could be the Indian Mutiny of $1857 / 58$ together with the - perhaps unconscious - realisation of guilt as to its 
theft from Singh and India (186). Thus the Orientalist aura and history seems to have proven too persistent an element in the domestication of the diamond ${ }^{6}$.

Ellenborough's attempt to restore the Gates of Ghazni to their original site in Somnath was also widely debated at the time. The plundering of Somnath by the Afghan Muslims in 1024 is mentioned in the prologue of The Moonstone. Ellenborough seized the famous gates during the Afghan campaign which ended in 1842. He suggested restoring them to the Hindu temple in Somnath whence they had presumably been stolen by Mahmud. The act was supposed to cover the otherwise disastrous results of the war and to ingratiate themselves with the Hindu population. The plan was, however, fiercely rejected by Ellenborough's contemporaries and marked the end of his career (Jasanoff 129-130). The Sancy offers an interesting instance of an Indian diamond which actually found its way back to India and thus upset the connotation of historical Indian diamonds as loot, trophy and a representation of the splendour of a subjugated colony. It presumably came to Europe in the sixteenth century through Portuguese trade and was henceforth in French possession. The diamond was bought by a Bombay merchant in 1865, who then sold it on to the Maharajah of Patiala two years later, or, according to another version, kept it until the late 1880s (Balfour 34).

The second diamond mentioned by Collins is the Orlov which is also supposed to have been a sacred stone, set in a statue of Vishnu in Srirangam, in southern India. It was supposedly stolen from the shrine by a French soldier, who had deserted from his regiment and feigned his conversion to Hinduism. The priests of the temple eventually granted him access to its inner precincts where he stole the diamond and escaped to a British station. It was purchased in Amsterdam by Prince Orlov and presented to Catherine the Great of Russia. According to legend, when Napoleon invaded Russia and searched for the diamond, he opened the tomb of a priest where it lay hidden. The ghost of the priest then appeared and cursed anyone who dared touch the diamond (Balfour 79-80).

The diamond in The Sign of Four evokes two historical stones. Doyle names it after the existing Great Mogul which is now lost (Balfour 44). The setting in Agra, the capital of the Mogul emperors, also suggests the Agra diamond which was smuggled by British soldiers out of India, at exactly the time of Small's story, i.e. during the Mutiny in 1857. In its history as a trophy of war, it too, had been in the possession of Humayun, perhaps together with the Koh-i-Noor (Balfour 37).

"The Adventure of the Mazarin Stone" also draws on an existing diamond, or rather a collection of diamonds: The diamonds which Cardinal Jules Mazarin (1602-61) bequeathed to Louis XIV included the celebrated Sancy, and the whole

6 The Koh-i-Noor continued to spark controversy when the Indian government claimed the return of the diamond in 1947. India was followed by Pakistan and Iran to ask for restitution. Additionally, the Indian federal state of Orissa demanded that the diamond ought to be given back to its rightful owner, the god Jaganath (Balfour 28). 
collection was named the 'Mazarins'. In a spectacular heist they were stolen in 1792, and only some have since been recovered (Balfour 60-61).

The diamond which is today known as the Regent was formerly named after its owner Pitt. Thomas Pitt was the East India Company's president of Fort Madras and also traded in diamonds. In this function, he somehow obtained the diamond and, on his return to England, rumours spread that he had used foul play. During his lifetime, Pitt not only suffered from the slander, but he was also constantly afraid that his diamond might be stolen and desperately tried to sell it. Philippe II, the Regent of France finally bought it and incorporated it into the French crown jewels (Balfour 61-66).

Obviously, a range of motives in fictional texts have their parallels in the legends and histories of existing diamonds. While the Koh-i-Noor furnishes the archetypal story, some of the factual and legendary instances in the histories of other diamonds also have inspired the histories of fictional stones. The slander surrounding the acquisition of a valuable diamond and misbehaviour in the colony is prefigured in the story of the Regent and also appears in The Moonstone and "The Rajah' Diamond". The curse is a recurring element in many stories and is associated with the Koh-i-Noor and the Orlov and its ghostly guardian. The story of the Frenchman serving the Hindu priests to get near the diamond bears resemblance to "The Rajah's Diamond" and Thomas Vandeleur's services to the Rajah of Kashgar. The disguised three Brahmins of The Moonstone - who are, moreover, supposed to have converted to Islam -, also recall the Orlov and its history. Apart from the Koh-i-Noor and the Orlov, other precious stones like the Nassak, too, were believed to have been part of a statue of a god and hence stolen in an act of sacrilege (Balfour 97).

The legends surrounding the historical Indian diamonds unanimously suggest that objects of such great value invariably boast a history of violence and theft. The abundance of legends and fables testifies to the diamonds' propensity to generate stories and especially crimes and to stand at their centre with owners as well as crimes revolving around them. They are, furthermore, associated with distinctly Indian episodes, the recurrence of Hindu temples and deities and the violence of the Mutiny in the legend of the Agra posit them as positively Oriental.

\section{The Description of the Fictional Diamonds}

Most of the texts I am concerned with give the diamonds an individual name. The implication is that these share the individuality and history of their real-life counterparts. Furthermore, the names already signal their Indian origins. The Rajah's Diamond's other appellation, the "Eye of Light" (Stevenson, "Rajah's" 88) echoes the Koh-i-Noor, the 'Mountain of Light' and the Nur-ul-ain, the 'Light of the Eye', a famous diamond in the Persian crown jewels (Balfour 51). Richard Marsh, too, refers to the diamonds' putative previous owners, as the Datchet diamonds 
are set in "the Begum's brooch, the Rani's Bracelet" (Marsh 46). Without any further explanation, these designations co-exist with the collective name of the jewels as "Datchet Diamonds". Doyle calls his diamond after the once existent Great Mogul but changes its history. This diamond, of course, also evokes Indian rule through the Mogul dynasty. Its last descendant, Bahadur Shah II, was briefly installed as Indian emperor during the Mutiny but disposed of after the rebellion had failed (Mehta 616). The Hindu and Muslim honorifics 'rajah', 'rani', 'begum' and 'Mogul' in the diamonds' names evoke their Indian owners and a history of aristocratic possession, however indistinct.

The Koh-i-Noor's name changed at least once, when Nadir Shah gave it the present name instead of its older designation as Babur's Diamond (Mersmann 178). Only in the Datchet Diamonds does the name of the English owners overwrite the former possessive claims. In the Eustace Diamonds all former ownership is erased.

While the Moonstone alone forms the centre in Collins' novel, the other diamonds are part of larger treasures. In Stevenson, however, the treasure gradually disintegrates, and the diamond is the last and most representative item that is left in the end. In The Sign of Four the treasure stays intact, but the diamond again represents and chrystallises its significance into one single object. They are both elevated from the unnamed mass of lesser diamonds which highlights their special status.

The direct descriptions of the Moonstone and the Rajah's Diamond draw on a similar vocabulary and imagery. In The Moonstone, the paramount impression which is evoked through its depiction is its "unfathomable" nature. It is described in greatest detail by Betteredge:

As large, or nearly, as a plover's egg! The light that streamed from it was like the light of the harvest moon. When you looked down into the stone, you looked into a yellow deep that drew your eyes into it so that they saw nothing else. It seemed unfathomable: this jewel, that you could hold between your finger and thumb, seemed unfathomable as the heavens themselves. We set it to the sun, and then shut the light out of the room, and it shone awfully out of the depth of its own brightness, with a moony gleam, in the dark. (Collins, Moonstone 70)

The diamond's property to glow in the dark possibly shows that Collins knew King's study (Hennelly 29) who, after all, asserts that the diamond "alone among gems has the peculiarity of becoming phosphorescent in the dark, after long exposure to the sun's rays" (King 37). The radiance of the diamond is described as "awful", which foreshadows the sublime in the scene of its restitution. Furthermore, it turns the light of the sun into a "moony gleam" which also lights its restitution in the "dark, [...] awful [and] mystic" light of the moon in India (Collins, Moonstone 464). 
According to Hennelly, Collins' use of King as a source can also be seen in the Moonstone's "flaw, in the very heart of the stone" (Collins, Moonstone 46) (Hennelly 29) which links it to the Koh-i-Noor. Additionally, the Hindu sources unanimously suggest that a flawed diamond is the most dangerous of all. The flaw in the diamond bears on its interpretability in the English context as a potential cash item: Together with its uniqueness, its imperfection makes it hard to estimate the Moonstone's price on the market as "[t]he question of accurately valuing it presented some serious difficulty. Its size made it a phenomenon [...]; its colour placed it in a category by itself, and, [...] there was a defect [...]" (Collins, Moonstone 46). Betteredge expresses the same uncertainty when he repeatedly states the Moonstone's "unfathomable" nature.

The seemingly abysmal depth of the diamond has a mesmerizing quality and captivates the attention of even an unwilling onlooker. Through Betteredge's description, the Moonstone is twinned with the Shivering Sands' "unfathomable depths" (Collins, Moonstone 308) (Mehta 629) and their allure for Rosanna (Collins, Moonstone 34). In both cases, the objects are both fascinating and at the same time destructive. Another inbuilt contradiction is evident in the diamond's physical size comparable to a "plover's egg" which contradicts its ability to conjure the illusion of infinity in its lustre, creating a disparity between its material existence and the mirage of an "unfathomable" inner depth.

The imagery in the description oscillates between extremes: The lunar brilliancy and the infinity of heaven have their counterpart in the "yellow deep". The recurrence to these extremes mirrors Betteredge's insistence on the impossibility to fathom the Moonstone and the fact that its character defies expression. The prosaic problem of estimating the Moonstone's worth in terms of cash is thus complemented by the impossibility to grasp it in words and evaluate its significance. The Moonstone can neither be defined in terms of cash nor in words which adds to the "elements of uncertainty" surrounding it (46).

The description of the Rajah's Diamond is in some points similar to the Moonstone's. Before Prince Florizel throws the diamond into the Seine, he muses:

'We have spoken of corruption,' said the Prince. 'To me this nugget of bright crystal is as loathsome as though it were crawling with the worms of death; it is as shocking as though it were compacted out of innocent blood. I see it here in my hand, and I know it is shining with hell-fire. I have told you but a hundredth part of its story; what passed in former ages, to what crimes and treacheries it incited men of yore, the imagination trembles to conceive, for years and years it has faithfully served the powers of hell; [...] enough of broken friendships; all things come to an end, the evil like the good; pestilence as well as beautiful music; [...] its empire ends tonight' [...] 'Amen,' said Florizel with gravity. 'I have slain a cockatrice!' (Stevenson, "Rajah's" 131) 
The juxtaposition of physical size and "unfathomable" allure links the two diamonds. Prince Florizel can hold the Rajah's Diamond in his hand, and yet it shines "with hell-fire". While Prince Florizel asserts its extraordinary beauty (130), it is associated with everything satanic. Its dual nature is expressed in the image of the "cockatrice", illustrating its two contradictory qualities, beauty and destructive power, in the hybrid mythological creature. It also draws attention to the allure of the visual as the cockatrice kills through its stare.

The Moonstone, likened to the devil (Collins, Moonstone 43; 78), resembles the "satanic" Rajah's Diamond in its association with ultimate evil. Its treachery has its equivalent in the Moonstone which "has misguided everyone who has come near it" (300). Both diamonds are thus imagined as wilfully deceptive. Furthermore, they destroy friendships and disrupt social relations. The "broken friendships" find their counterpart in the Moonstone's ability to "poison" the rapport between people and scatter a household which before had been presented as cohesive (186).

Prince Florizel's speech combines the accusation of the treacheries with their history, which is presumably long but remains unknown. The dimension of the long procession of crimes is unconceivable and evokes the diamond's age. The Moonstone ends on a similar note emphasising the diamond's durability with an assertion of the eternal "cycles of time" which might bring more adventures of the Moonstone in endless repetitions (464).

The Rajah's Diamond is further characterised as a misfit on two levels. Firstly, it is perceived as "monstrous" (Stevenson, "Rajah's" 121) by Frank Scrymgeour. The monstrosity of the diamond may on the one hand be attributed to its excessive and 'monstrous' value. On the other hand Indian diamonds actually did appear as monstrous due to the Indian way of cutting which aimed at preserving the greatest possible size in the diamonds. The European fashion demanded lustre rather than size and was content with smaller diamonds which showed more brilliancy (Mersmann 185-186). C. W. King calls the Koh-i-Noor a "monster diamond" before its size and weight were reduced (36). The same notion is taken up again when Simon Rolles carries the diamond around with him: "The diamond in his pocket occasioned him a sensible physical distress. It burned, it was too large, it bruised his ribs" (Stevenson, "Rajah's" 99). Harry Hartley thinks of the diamond as an "incubus" (76) and believes that the possession of the stone brings "most uneasy dreams" (99) to Simon Rolles. This shows the diamond's uncanny propensity to influence its owner.

Secondly, the possession of the Rajah's Diamond is alien to the political system or at least perceived as an anachronism: Prince Florizel expresses the aristocratic and basically undemocratic nature of the Rajah's Diamond when he claims that "[j] ewels so valuable should be reserved for the collection of a Prince or the treasury of a great nation. To hand them about among the common sort of men is to set a price on Virtue's head" (97). His speech reiterates the notion of the Koh-i- 
Noor as the antipode of the British democratic mass-production of commodities as presented at the Great Exhibition of 1851. Additionally, handing around the diamond among common men exactly describes the plot of "The Rajah's Diamond". According to Prince Florizel, it has therefore entered a system alien to it. Ironically, Prince Florizel is of course not a "common man", yet he eventually also falls prey to the diamonds' influence (129).

To sum up, the basic idea which both texts convey is the Otherness of the diamonds. This is expressed in their ability to escape definition. Their effect on the onlooker as well as their appearance has to be compressed in indistinct and sometimes contradictory images. Moreover, their price cannot be securely set and adds to their elusiveness. The flaw in the Moonstone and the assertion by Prince Florizel that the Rajah's Diamond was not meant to circulate in the market defines them as alien and disruptive to the economic and social system. The excessive worth concentrated in a small stone cannot be securely contained by society and, as John Plotz argues, "threatens to become illegible" (34) and thus also indescribable in familiar terms. The recourse to the vast but indistinct images of heaven and hell reflects this impossibility of finding precise and moderate terms. Moreover, it removes the diamonds from the everyday sphere and contributes to the mystification of their nature which places them in romance rather than reality. The monstrosity of their value is complemented by their monstrous age which also has to remain undefined.

\section{Diamonds as Cash}

While the Moonstone's singular nature is expressed through its religious significance, the Rajah's Diamond and the Great Mogul are set apart from the lesser diamonds through their exceptional size and value. The Rajah's Diamond is "the sixth known [sic] diamond in the world" (Stevenson, "Rajah's" 71) and the Great Mogul "is said to be the second largest stone in existence" (Doyle, Sign 224). The once existent Mogul was ranked as the largest stone ever to have been discovered in India (King 34-35).

The Agra Treasure as a whole is worth "not less than half a million sterling" (Doyle, Sign 150). The Moonstone's worth is, as already mentioned, hard to pin down because of the flaw in its middle. Franklin and Mr. Luker both deposit it in the safe of a bank as "a valuable of great price" (Collins, Moonstone 55; 204). Ablewhite has Mr. Luker estimate the worth of the Moonstone at thirty thousand pounds (450), while it has been valued at twenty thousand before (89). As a cut-up "marketable commodity" $(452 ; 454)$ it is worth even more. Ablewhite then draws two thousand pounds on the diamond to cover his embezzlements and the expenses for keeping his mistress. The value of the Eustace Diamonds is put down as ten thousand or twenty thousand pounds (Trollope 130; 194). The Datchet Diamonds are worth a quarter of a million: 
The value of their [the Dukes of Datchet's] collection is fabulous - the intrinsic value of the stones [...] was a quarter of a million of money! [...] This was the net value [...] and quite apart from any adventitious value which they might possess, from [...] the point of view of historical association.” (Marsh 21)

The Mazarin stone, a "Crown diamond", is worth a hundred thousand pounds ("Mazarin" 559). Marsh's text sets off the trade value against the historical value of the diamonds, which cannot be expressed through money and recognises an invaluable aspect in the existence of the diamond. The always impending cutting of the diamonds is prefigured in the history of the Koh-i-Noor. C. W. King criticised its reduction in size. He calls it "[a] most ill-advised proceeding, which has deprived the stone of all its historical and mineralogical value" (36). The historical value, then, depends on wholeness and invests the diamonds with symbolical meaning. As in the instances of historical diamonds, they symbolise power, and as the witness of conquests they are the lasting trophy of victory. The Moonstone, however, combines its existence as a trophy of war with its religious significance.

\section{The Sacred Gem: The Moonstone}

The Moonstone follows the pattern of stories of historical diamonds in its description as a sacred part of a statue of a god. Originally, it was set in the forehead of the "moon-god" (Collins, Moonstone 12), Soma7. The historical temple of Somnath was dedicated to Shiva in his incarnation as 'Soma's Lord', Som-näth (Platts "Soma"). The temple held a linga beset with jewels (Thapar 31). Lingas are the common emblems used to represent Shiva in temples and are usually preferred to figurative depictions (Michell 38). Somnath was, at the time of its sacking by Mahmud of Ghazni, known for its wealth and several kilograms of jewels which adorned its statues (Thapar 31).

The depiction of Soma mounted on an antelope in The Moonstone (464) references the traditional iconographic representation of Soma with a three-wheeled chariot drawn by an antelope (Bunce, "Soma"). In The Moonstone, the association with Shiva is abandoned in favour of "Vishnu the Preserver" (Collins, Moonstone 12), who guards the diamond. He is a much more benign god than Shiva, who is also associated with the legend of the Koh-i-Noor. Shiva is worshipped as the deity of destruction and chaos, and the god of battlefields and cremation (Michell 25). Vishnu, on the other hand, represents the life affirming elements of creation and preservation. He also maintains the order of the universe and, in myth, res-

7 Indra, who wields the 'thunderbolt', vajra, is allied with Soma in mythology (York 807). Vajra is Sanskrit for 'diamond'. 
cues mankind from destruction (26). The Moonstone is dedicated ${ }^{8}$ to Soma because of its propensity to mirror the phases of the moon. It is thus believed to have an organic connection with the god and wax and wane independently. The colour yellow is also associated with the god Soma and either present as the colour of his skin or garments (Bunce, "Soma"). Soma has a twofold meaning as it first denoted the Vedic drug and only later came to stand for the moon. The Moonstone thus also represents the juice of Soma which was won from the "moon-plant" and is, in the Vedas, described as drunk at sacrifices (Bunce, "Soma").

The sanctity of the Moonstone relies on its wholeness. The destruction of its "sacred identity" (Collins, Moonstone 82) puts an end to its existence as a religious symbol. The cutting of the diamond turns it from a holy relic into brilliants, but these would be worth more than the uncut diamond (47). Its spiritual significance is thus distinctly set off against the value for which it is admired in England. Its significance as a whole but worthless sacred symbol and cut but valuable cash item constitutes another paradox in its existence.

The anonymous narrator of the prologue compares the practice of donating a diamond to a shrine to customs of antiquity. In this respect, Indians, ancient Romans and Greeks, his comparison concludes, share the same superstitions (Collins, Moonstone 11). This idea may partly rely on King's chapter "Sacred Gems" (406-409) which enumerates such customs from Greek antiquity to the Middle Ages. The parallel between antiquity and India, where diamonds are revered as holy objects, also throws into relief the similarity of the British and Mogul interpretations of the diamond as plunder. Additionally, the comparison of Greece, Rome and India creates a cultural intimacy between India and Europe and at the same time a temporal gap because the ancient superstitions, long abandoned in the west, still flourish in the East, which is thus imagined as stuck in time and development.

While the prologue is set in India it is also located in an apparently timeless and "romantic" (Collins, Moonstone 462) space. The emphasis is on the age of the Moonstone and the long and uninterrupted line of Brahmins who guard it: "One age followed another" (repeated twice on the same page), "generation after generation", "the generations succeeded each other" (12). The specific indications of time only occur in connection with conquests that interrupt the customs which had existed "for centuries" (12). Mahmoud of Ghazni in the "eleventh century of the Christian era" and Aurangzeb in the "first years of the eighteenth century of the Christian era" (12) interrupt this flow of time and are granted an approximate dating. Together with its guardians the Moonstone is the unchanging witness of different violent conquests. The Moonstone is raised from the indistinct and unmarked flow of time, it is suggested, on the "4th of May 1799" (11) when John

8 Given the Hindu conviction that flawed diamonds are singularly inauspicious, the dedication of such a diamond to a god is rather unlikely. 
Herncastle steals it and, at the same time, elevates it into the realm of precise historicity. The exact dating, in contrast to the blurry history before, reflects the notion that history arrived in India only with the East India Company's aggression (Mukherjee 25). In the same way, the history of the Moonstone is framed as myth, called "[o]ne of the wildest of these stories" (11), "the fanciful story", "a fable" (13), and "the fantastic Indian legend" (16).

When the Moonstone is reinterpreted as a religious object it also again enters the same cyclical pattern of history as the ending of Murthwaite's letter affirms its reimmersion in the "cycles of time" (Collins, Moonstone 464). This conception of history also refers to the Hindu belief in continual rebirths. The virtually indestructible diamond aptly figures eternal repetition.

The Acquisition of Trophies: The Moonstone, the Rajah's Diamond and the Agra Treasure

The history of the Moonstone especially emphasises its status as a trophy. The Muslim invaders of Benares carry away the diamond which then passes from one of Aurabgzeb's officers to Tipu. The Moonstone is removed from its place in the statue and set in the pommel of a dagger (Collins, Moonstone 13). It is thus changed from a religious artefact which adorns a god into a symbol of power and rule and into a trophy of war which remembers a historical event. The diamond as a receptacle of memory is prefigured in the history of the Koh-i-Noor whose passage marks the transition of power.

The acquisition of the diamonds in India relies on the notion of the East as 'treasure trove' and the ready availability of these treasures. The adventure story set in the colony propagates the imperial right to the apparently ownerless riches. The idea of the colony as a huge treasury is, according to Elleke Boehmer, one of the central images of imperialism at its height (23). "A prime way of 'selling' empire was to portray it not as a scheme of financial gain, but as thrilling adventure" (45), Diane Simmons contends. The reward for the adventurer is "some final prize: victory against the native, wealth, the achievement of identity, personal or national honour and withal, status as a Briton and a man" (Boehmer 73). The texts, however, describe the 'earning' of treasure as problematic and as inevitably bound up with crime and criminals, undermining this notion.

Herncastle steals the Moonstone in the plundering, after Seringapatam has been stormed, in a battle which became notoriously famous for the undisciplined looting (GoGwilt 68). The "riot and confusion" (Collins, Moonstone 14) allows Herncastle to reach the treasury where he commits the crimes which, however, cannot be ultimately proven. His entrance with "a torch in one hand, and a dagger dripping with blood in the other" (14) can be read as a denunciation of the supposedly enlightened civilising mission, which provides the respectable veneer for plunder and murder (GoGwilt 65). Called the "Honourable John" (Collins, Moon- 
stone 40) by Betteredge, Collins puns on the title used with the East India Company combining it with its slang designation as "John Company" (GoGwilt 65). The allegorical light of progress and the pun on his name suggest that not the individual crime is at stake but its enmeshing in the wider context of British expansionism. The Moonstone remains a trophy in the hands of Herncastle as its passage again marks the transition of power from the Indian ruler to the European power.

The provenance of the Rajah's Diamond is only revealed in the last story entitled "The Adventure of Prince Florizel and a Detective". An allusion to Thomas Vandeleur's crime relating to the diamond appears early on in the story in a rather sketchy version: "For some reason, some service the nature of which had been often whispered and repeatedly denied, the Rajah of Kashgar ${ }^{9}$ had presented this officer with the sixth known diamond of the world." (Stevenson, "Rajah's" 71) Only in the end can Prince Florizel give a coherent account. He narrates the whole story of the diamond and also names the "service which had been often whispered" (Stevenson, "Rajah's" 71):

'An officer,' began Prince Florizel, 'a man of courage and conduct, who had already risen by merit to an eminent rank, and won not only admiration but respect, visited in an unfortunate hour for his peace of mind, the collections of an Indian Prince. Here he beheld a diamond so extraordinary for size and beauty that from that instant he had only one desire in life: honour, reputation, friendship, the love of country, he was ready to sacrifice all for this lump of sparkling crystal. For three years he served this semi-barbarian potentate as Jacob served Laban; he falsified frontiers, he connived at murders, he unjustly condemned and executed a brother-officer who had the misfortune to displease the Rajah by some honest freedoms; lastly, at a time of great danger to his native land, he betrayed a body of his fellow-soldiers, and suffered them to be defeated and massacred by thousands. In the end, he had amassed a magnificent fortune, and brought home with him the coveted diamond.' (130)

The "time of great danger" may be identified with the Mutiny which would set Stevenson's text even more firmly in the same line of tradition as The Moonstone. The motif of labouring for the diamond, as it is suggested by the reference to the biblical story of Jacob and Laban, also appears in The Sign of Four. Thomas Van-

9 Kashgar is now part of the Sinkiang Uigur Autonomous Region of China. From 1755 to 1862 the Muslim population was under Chinese rule. From 1862 until 1875 a rebellion established a Muslim as king of Kashgar (Anon., "Kashgar"). I do not know I do not know? Assess wird in solchen Kontexten eigentlich gar nicht gebraucht. if this actually is the reason for wie wärs denn mal mit "is the reason for"? you inform very often! the choice in Stevenson's text, but 'rajah' is not a title used by Muslim rulers. I would rather think that the Rajah of Kashgar is just a standin for some-exotic sounding Indian prince and place. The link with the Mutiny which the text suggests rules out any actual significance of the historical Kashgar apart from the name. 
deleur'scorruption is directly brought about by the diamond and exploited by the "semi-barbarian potentate"10, who seduces him to violence and treason. In his violence and cunning he 'turns Indian', forsaking his "courage and conduct" and also his fellow countrymen. Although Thomas Vandeleur does not steal the diamond, he commits crimes to possess it, and in these crimes, he is in league with an Indian prince. The diamond is the direct reward for immoral and supposedly Oriental treachery. The crime is the "skeleton in the house" (Stevenson, "Rajah's" 75), as Lady Vandeleur's excesses in luxury cover this more substantial secret. The skeleton aptly represents his actions in the service of the Rajah of Kashgar so that the crime of overindulgence at home and the crime of excessive greed in India overlap.

Two of these aspects recur in The Moonstone, namely the "unspeakable" crimes which consist in disloyal behaviour, and alienation. John Herncastle's desire to keep the diamond makes him disregard his superiors' orders which prohibit looting. Like Thomas Vandeleur, he scorns former loyalties to gain possession of the diamond. He also turns against his cousin and, in order to keep the diamond, he refuses to attempt reconciliation with his relatives and is ostracised by society. The coveting and eventual theft of the diamonds goes hand in hand with an alienation from former loyalties. The obsession which compels the English characters to forsake everything to own the diamond is a common denominator in these two texts. Prince Florizel highlights the diamonds' propensity to destroy social bonds when he compares it to the "apple of discord" (Stevenson, "Rajah's" 97), dissolving an assumed previous harmony at home. In the same way, the Moonstone sows discord as part of its nature as a tool of vengeance (Collins, Moonstone 186) and scatters the household. Thomas Vandeleur is in league with the rajah while John Herncastle takes up the habit of smoking opium and dabbling in arcane sciences (40-41). The dangerously diminished distance between the English protagonists and the Indians and Indianness are a common hallmark in the hunt for the diamonds which is repeated in The Sign of Four.

In The Sign of Four Jonathan Small is in the same way seduced to violence by Indians as Thomas Vandeleur is by the rajah. The agents of his seduction are the Sikhs of his watch party. His account of the theft of the "Great Agra Treasure" is given by himself and narrated to Sherlock Holmes. The first sentence resembles Prince Florizel's account of Thomas Vandeleur's story: “It was an evil day for me when first I clapped eyes upon the merchant Achmet and had to do with the Agra treasure" (Doyle, Sign 207). Both characters' desires are focused on the treasures "in an unfortunate hour" (Stevenson, "Rajah's" 130) when they see the diamond for the first time. Jonathan Small also labours to "earn" (Doyle, Sign 213) the

10 At another point in the story, the Rajah of Kashgar is termed a "prince of great enlightenment" (Stevenson, "Rajah's" 97). The statement could be ironic; perhaps it draws on the character of Tipu Sultan who founded a Jacobin club in Seringapatam and admired the French Revolution. These sympathies also led to the British invasion of Mysore (Jasanoff 125). 
treasure in "slavery" (207) and thus justifies his right to ownership by his suffering for the coveted treasure like Thomas Vandeleur.

In a British fort, besieged by Indian mutineers, Jonathan Small enters into a close relation with the Sikhs, who, as Jeffrey Richards points out, bear "impossible Moslem names" (17) which they soon exchange for "The Sign of Four", the appellation of their secret pact. By "the threefold oath which no Sikh was ever known to break" Jonathan Small becomes one of them (Doyle, Sign 219). As in The Moonstone and "The Rajah's Diamond", in view of the diamonds, loyalties shift and Jonathan Small adheres to the pact's principles. His scruples about murder are waived by Abdullah Khan's unmasking comment that he must only "do that which your countrymen came to this land for [...] to be rich" (219). The Sikh Khan unmasks the hypocritical nature of colonialism where the hunt for treasure is hidden under the mask of the civilising mission and other myths of empire. As this is voiced by a native and a criminal the impact and credibility of this statement is lessened. However, it is noteworthy that the imperial maxim of gain in the colony is perpetuated and acted upon by the Sikhs themselves, the colonial subjects. The implication is that they assume the exploitative stance of the coloniser, thus exculpating Small who has been seduced by the stereotypical arguments for empire voiced by the colonised themselves. Jonathan Small only has to consent to "be rich", and he becomes part of the Indian plot of "the Four" and is subsumed under the strange signature, which erases racial differences in the commitment to crime. He agrees to his accomplices' murder of Achmet, the carrier of the treasure and becomes involved in colonial crime like John Herncastle and Thomas Vandeleur.

While "the Four" pursue the treasure in the labyrinth of the old Agra fort the Mutiny rages outside the walls. The Mutiny, the quintessential manifestation of Indian cruelty and violence serves as the background for British crimes in The Sign of Four and "The Rajah's Diamond" which aligns the perpetrators with their Indian accomplices.

In both "The Rajah's Diamond" and The Moonstone the British crimes in India, which surround the diamonds, are unspeakable: "It was said he [John Herncastle] had got possession of his Indian jewel by means which, bold as he was, he didn't dare acknowledge" (Collins, Moonstone 40) and Thomas Vandeleur rendered a "service which had been often whispered" (Stevenson, "Rajah's" 71). The initial silence around the circumstances under which the diamonds have been acquired mirrors the unspeakability which surrounded the Mutiny in contemporary British discourse. Despite an outpouring of texts on the subject, Christopher Herbert observes, many of them refer to the "unspeakable horror" (Herbert 21; also Sharpe 66) which can only be hinted at but not fully expressed. Thomas' brother John Vandeleur served the government in the Mutiny through "services, by which the Government profited, but which the Government dared not recognise" (Stevenson, "Rajah's" 96). The second-hand account of the Moonstone's theft em- 
phasises the uncertainty of the "rumours" as John Herncastle's nameless cousin admits: "I have not only no proof that he killed the two men at the door; I cannot even declare that he killed the third man inside - for I cannot say that my own eyes saw the deed committed" (Collins, Moonstone 15). The events connected with violence in the colony and the acquisition of the diamonds is shrouded in a mystery which is perpetuated in England and transforms into rumours and slander. The attempted silencing, which mirrors the reactions to the Mutiny, implies a sense of guilt and its repression.

In "The Rajah's Diamond" another context for the interpretation of the diamonds as trophies is opened up: The hunt for treasure which also underlies the adventure story is discredited in the character of John Vandeleur. "He sees the colony as the legitimate hunting ground: "I have hunted most things, from men and women down to mosquitos; I have dived for coral; I have followed both whales and tigers; and a diamond is the tallest quarry of the lot." (Stevenson, "Rajah's" 127) Similarly, in the Sherlock Holmes short-story "The Adventure of the Mazarin Stone", the villain Count Negretto Sylvius is a big-game and diamond hunter in Algeria, the colonial possession of France (Doyle, "Mazarin" 566). Hunting as the trope of subjection and exploitation of a country formed an important part in imperial self-fashioning (Siddiqi 241). Its importance grew especially after the Mutiny when hunting stood in for the "civilising" of India and at the same time displayed untainted British prowess (Nayar 133). The diamonds are, in "The Rajah's Diamond", the reward for a successful hunt and aligned with big game. At the same time this notion is discredited in the unscrupulous character of the adventurer John Vandeleur who hunts men as well as beasts.

The crimes committed in India mark the diamonds' transition into British ownership. The acquisition of the diamonds always must be regarded before a more comprehensive backdrop of violence and politics. The silences which mark the accounts of the Moonstone and the Rajah's Diamond enforce the connection with the historical event. The Mutiny and the siege of Seringapatam serve as the foil on which the crimes are enacted. Both events significantly determined the relationship between Britain and India. Through this association with events that relate to British domination over India, the diamonds acquire the status as trophies of war and thus signify rule as prefigured in the Koh-i-Noor and its symbolic incorporation into the crown jewels. While this status as a trophy is plausible in the context of untroubled British victories, the diamonds which are associated with the Mutiny are not so much trophies but mnemonic objects of insecurity and almost-defeat. This property vies with the traditional view of the Indian diamond as, in a synecdoche, figuring the possession of India.

India thus is not only the treasure trove of 'Adventure Literature' but also a place replete with violence and crime. While the rumours about the Moonstone captivate John Herncastle and instigate him to murder its guardians and steal the diamond, it is Indians who, in the two later texts, seduce the English protagonists 
to commit murder for the acquisition of the treasures. The allure of the diamonds makes them into instruments of natives and thus reverses their loyalties. While Thomas Vandeleur turns against his own countrymen, both Jonathan Small and John Herncastle disobey orders to seek advantage for themselves. The slander, which follows them to England, socially censures their behaviour. The Mutiny which was framed as an outburst of Indian criminality rather than a politically motivated anti-colonial uprising is thus complemented by British crime. The Moonstone is a special case as the reference to the Mutiny is somewhat obscure. Nevertheless, the siege of Seringapatam can be read as a stand in for the more topical rebellion.

\section{The Mutiny and The Moonstone}

The event which Collins puts at the beginning of the story is the siege of Seringapatam in 1799. The conquest of Mysore and the death of Tipu are significant in Anglo-Indian history as they marked the rise of British power in India (Free 347) and the halt of French influence through Tipu's alliance with France.

The notorious large-scale plundering of Tipu Sultan's extensive treasures led to an unprecedented influx of Indian artefacts into Britain. One of the most famous was a mechanical toy, 'the tiger of Mysore', which, when displayed in London, attracted a wide public. Other objects appeared in the salons and drawing-rooms all over the country as trophies of the Company's victory (Jasanoff 124-125). John Herncastle's acquisition of the Moonstone thus turns it into another of these trophies which found their way to England in the wake of the conquest. In the context of the victory over Tipu Sultan, the theft of the Moonstone appears quite realistic as yet another Indian curiosity which comes to Britain.

Sir David Baird's widow commissioned Collins' godfather Sir David Wilkie with a painting to commemorate her husband's victory. Wilkie Collins probably knew the painting which shows Baird triumphing over Tipu's stripped and plundered body (GoGwilt 68). In the painting, General Baird strikes a pose as if giving orders. In front of the stripped Sultan's body this gesture might well refer to the controversy which ensued around the British troops' uninhibited plunder. The inclusion of Baird's effort to halt the plunderers would then amount to an attempt of exculpation of the General (68). This recurs in The Moonstone when Herncastle's cousin describes the scene: "It was [...] after General Baird himself had found the dead body of Tipu under a heap of the slain, that Herncastle and I met. We were each attached to a party sent out by the General's orders to prevent the plunder and confusion that followed our conquest" (Collins, Moonstone 13). When the painting was exhibited in 1839, it seems to have failed its purpose of glorifying the British triumph because viewers also sympathised with the vanquished Tipu (Mehta 620). 
The choice of Seringapatam as the background for the prologue situates the Moonstone in the flow of objects that reached England as plunder and at the same time references the ambivalent stance towards Tipu, who was depicted as both villain and victim. Tipu Sultan had inspired great interest at the beginning of the nineteenth century when he was cast as a "popular villain of cult status" (Mehta 618). Yet, his fate also elicited sympathy, not the least because of the excesses of the campaign and his depiction in Wilkie's painting (GoGwilt 69).

In the siege of Seringapatam, the situation is reverse to that of the Mutiny: In The Moonstone the British besiege and finally capture the city in which Tipu Sultan holds out (Mehta 618) while narratives of the Mutiny focus on the British as victims of the Indian onslaught as in descriptions of the siege of Lucknow. Nevertheless, Collins uses Seringapatam as a guise for the Mutiny: The Moonstone was written in 1868, and the story starts on the Verinder estate in 1848, the same year that saw revolutions on the continent, Chartist agitation in Britain as well as the British invasion of the Punjab (622). The last letter in the novel, written by Murthwaite in 1850, marks the year when Dalip Singh, the last Indian ruler of the Punjab, surrenders the Koh-i-Noor to the East India Company (Pionke 124). The Indian Mutiny, "the most significant and horrific event in the history of British India, [...] took place precisely at the mean of those two dates" (Mehta 617), i.e. ten years before Collins began writing the novel and ten years after the Moonstone arrives on the Verinder estate. Moreover, the impression of the Mutiny was still vivid in Victorian minds in the 1860s when Collins wrote the novel, and the topicality of the rebellion would always let it resonate with readers. If the siege of Seringapatam recalls the Mutiny, the casting of the Indians as victims and the British as unchecked criminals also draws attention to the often suppressed violent retaliation after the Mutiny, the "Devil's Wind" (Free 350) and British aggression in India. Collins alludes to the rebellion but never names it, yet, with its images still present; the reversal of the roles of aggressor and victim must be evident to the reader through the evocation of one important historical battle in the conquest of India and the submerged presence of another more recent one.

Wilkie Collins wrote on the Mutiny for Dickens' Household Words and expressed a much more moderate and conciliatory view than his friend. Dickens, more in tune with the public opinion, demanded the eradication of India's whole population (Nayder, "Collins and Empire" 144). The depiction of British crime in the Mutiny would thus have been a hotly disputed topic which Collins avoids through the cover of another battle.

The Moonstone suggests British aggression as the crime in the background of the theft of the diamond, while both "The Rajah's Diamond" and The Sign of Four paint a picture of Indian aggression which underlies the acquisition of the diamonds. They are consequently viewed as trophies of war, such as the Koh-i-Noor actually is. A trophy of war is a mnemonic symbol of victory inextricably linked with the site of its acquisition, but in the fictional diamonds' stories the Mutiny 
and the siege of Seringapatam are not heroic conquests but fraught with crime. These always include disloyalty and treachery, the very quality which is later ascribed to the diamonds themselves (Stevenson, "Rajah's" 131; Moonstone 300). The idea of crimes as the basis of colonial wealth leads to these stories being repressed in England or censured through slander. The diamond as trophy is a decidedly imperial reading. Diamonds, however, also figure as a domestic metaphor.

\section{Diamonds as Metaphor}

"The Angel in the House" and Promiscuous Paraphernalia

Originally, diamonds were exclusively worn by men. In the Middle Ages, when they began to appear in the crowns of European kings, Louis IX of France decreed that women were not allowed to wear diamonds. This seems to have changed in the fifteenth century when diamonds began to be worn at court by both men and women (Harlow, "History of Diamonds" 130-131).

In the analysis of the complex imagery relating to women and diamonds, Suzanne Daly offers a helpful point of departure in her differentiation between the domestic and colonial imagery attached to jewels which accounts for a range of contradictions. She argues that there are

[...] two strands of gendered imagery that tend to be disconnected in Victorian literature [...] jewelry as identification or identity found in the domestic novel, in which gems are understood to be property, and the colonial treasure trove, found in the novel of adventure, in which gems are understood to be plunder. (Daly 70)

Daly further argues that these two strands can overlap, but I will, first look at, what she terms, the "domestic strand". Kurt Tetzeli von Rosador focuses on Daly's first category, the function of diamonds in domestic fiction. There, he argues, diamonds are used as a means of characterisation, drawing on a wide range of shared knowledge of their attributes and appropriateness in certain social contexts. These diamonds can also expose their wearers to moral judgment and imply that a woman may be immodest and lacking appropriate Christian contempt for material wealth (292). Diamonds as a means of characterisation have to be fixed property. Tetzeli von Rosador refers to the literal use of jewellery as a means of characterisation, but there is also a metaphorical use of diamonds.

The wearing of diamonds makes women the object of the male gaze by which they are themselves objectified so that the object which had been used to characterise now supersedes character (Tetzeli 284) and turns them into the focus of lust and gazing (Menikoff 349). In the novels, Lizzie Eustacefor example, relies on the Eustace Diamonds for social representation and the construction of her identity 
(Lindner 76). Lord George's desire confuses Lizzie and her diamonds; he is equally covetous of both and drops Lizzie when she loses the diamonds.

The metaphor of diamonds as a stand-in for female sexuality relies on the equation of women and diamonds as cash items, as valuably marketable in marriage. In their function as heirlooms, the Eustace Diamonds confer identity because an heirloom presupposes fixity. As a bequest they are bound to the male line. As paraphernalia, however, they are regarded as female and can be tendered and "circulate promiscuously through the commodity marketplace" (Lindner 83). As a commodity which is traded and coveted, they can be read to stand for female sexuality. This also provides the psychoanalytical reading of the Moonstone before the first postcolonial interpretation by John R. Reed (1973). The Moonstone as a symbol of Rachel's virginity is kept in her bedroom and stolen by night, only leaving a stained nightgown. As long as the diamond remains uncut, Rachel, as a virgin, is a valuable object to trade (Gruner 135). The same conflation of illicit sexual encounter and diamonds figures in the Sherlock Holmes short story "The Beryl Coronet", where the taking of the diamonds coincides with the girl's elopement. The theft of the Eustace Diamonds from Lizzie's bedroom mirrors The Moonstone and lends itself to the same interpretation. "The Rajah's Diamond", as Barry Menikoff observes, revolves around interactions which are either sexual or economic (348). The primary object which connects people in the story is, of course, the diamonds which combine both associations. The potentially adulterous Lady Vandeleur is a "gem of the first water" (Stevenson, "Rajah's" 90). The joy which Harry derives from the sight of the diamonds and which Francis experiences in the presence of the dictator's daughter elicit the same reaction: Both see "all the colours of the rainbow" (111; 84).

As a commodity for purchase, diamonds lose their positive ascriptions, and as they are "tendered openly in the market" they, just like women, "lose their [...] most alluring charms of feminine grace" (Trollope 523). According to this reading, diamonds as free floating objects are thus gendered as female, and the image they confer on their wearers is negative as they are associated with moving and sellable goods.

This imagery is usually opposed to the "sentimental" or "affective" (Plotz 334; 337) use of the trope of the virtuous woman as diamond (Daly 74). If diamonds represent fickleness and eroticism as moving objects, their absence connotes simplicity and naturalness. Lizzie's opposite is the poor governess Lucy, wholly devoid of any kind of jewellery comparable to the Eustace Diamonds. Yet, the narrator constantly evokes the tear in Lucy's eye, sparkling like a diamond: "[...] in her eye, too, a tear would sparkle, the smallest drop, a bright liquid diamond that never fell" (Trollope 212). Although in criticism, Lizzie is always compared to her diamonds, Trollope's narrator states that Lucy is a treasure (61) and a diamond: "Lucy held her ground because she was real. You may knock about a diamond, and not even scratch it; whereas paste in rough usage betrays itself. Lizzie [...] 
knew that she was paste, and knew that Lucy was real stone" (628). In her simplicity and moral uprightness she is everything which Lizzie is not: "She was not beautiful. She had none of the charms of fashion. [...] There was a reality and a truth about her [...]" (151). To a certain extent Miss Morstan falls into the same category: "There was, however, a plainness and simplicity about her costume which bore with it a suggestion of limited means. The dress was sombre grayish, beige, untrimmed and unbraided [...]" (Doyle, Sign 131). Miss Morstan, as well, in the end, is the true reward for Watson, the socially acceptable substitute for the immense riches of the Agra treasure. Both Lucy and Mary Morstan are described as plain so that the metaphor of the diamond-like virtuous woman can be conferred on them.

The most telling use of the sentimental image of the diamond can be found in Coventry Patmore's The Angel in the House of 1856: Felix compares Honoria, the idealised wife, to the Koh-i-Noor (Patmore 185) (Hancock 8). Canto XIII of Book II, "The Espousals", is titled "The Koh-i-Noor" and praises Honoria's submissiveness, but also her cunning and lying in pleasing her husband: "She joins the cunning of the snake, / to rivet and exalt his love; / Her mode of candour is deceit" (Patmore 181). It is probably no coincidence that Patmore associates Honoria's "cunning" with the diamond. It is, of course, unintentional and comes to her naturally, "[t]o the sweet folly of the dove" (181). The Canto ends asserting that "A woman, like the Koh-i-noor, / Mounts to the price that's put on her" (185). Canto IX, "The Friends", directly following "The Koh-i-noor", contains the related imagery of empire: "A woman is a foreign land, / Of which, though there he settle young, / A man will ne'er quite understand / The customs, politics and tongue" (186). While Patmore obviously draws on what Plotz terms the sentimental or affective image of woman as diamond, he inevitably leads over to a comparison of woman and a colonised land. The explicit naming of the Koh-iNoor already introduces empire and the diamond as a symbol of possession.

I will look at this connection in a separate chapter and begin by showing that it is possible to distinguish two currents of imagery in the narratives of diamonds where there are "two very different circulatory systems, one affective, the other fiscal" (Plotz 337) both subsumed under Daly's domestic (70) strand. The diamond which moves around, like money, which is paraphernalia as the Eustace Diamonds, highlights its material worth and its evasiveness as a possession. It represents female sexuality as "tendered openly in the market" (Trollope 523). The diamond as a sentimental metaphor, as applied to Lucy or as in Patmore's poem, retains the view of women as objects of desire, minus the fiscal considerations of material but rather sentimental worth, as the unassuming "Angel in the House". 
Gendering the 'Jewel in the Crown'

India is the space primarily associated with diamonds, regardless of the decline in its exports since the early eighteenth century. With the seizure of the Koh-i-Noor, its representative in the English crown is a diamond, and the appellation of 'Jewel in the Crown' captures the combination of the object and its source. India is thus closely associated with diamonds, but it is also perceived as a female space.

Coventry Patmore who celebrates the domestic virtues of Honoria compares "a woman" to a "foreign land" which has to be discovered, just after having likened her to the Koh-i-Noor (Patmore 186). He draws on the prevalent imperial notion that "whole continents and worlds exist as mysteries to be solved by Europeans [...]" (Mehta 612), meaning European men. In the logic of binary oppositions, woman is thus othered as alien, and non-European spaces are in turn gendered as female.

The colonial counterpart to Daly's domestic imagery of diamonds is the "treasure trove", a female space where male adventurers conquer diamonds as prize and reward for endured hardship (Daly 71). The active male colonialist can thus seize and dominate the passive,female land by maintaining a neat binary opposition

[i]n that colonization was a struggle for supremacy, not only white against black, but between European nations, the scramble for territory took on the aspect of a conflict between competing virilities. From this it becomes clear how the ranking of cultures relative to a dominant and warlike Europe might have led to the feminization of other peoples [...]. The people of India, especially of Bengal, were typically characterized as passive, soft, seductive, languid, and generally effeminate [...]. (Boehmer 82)

The diamonds as imperial objects and symbols of rule are thus gendered as female as they are the stand-in for a female space. They furthermore enforce the view of the colonised as effeminate as they are associated with the luxury and decadence which the diamond suggests.

The feminisation of diamonds as objects with colonial connotations and as plunder can be illustrated with Stevenson's "The Rajah's Diamond." Sir Thomas Vandeleur has to earn the Rajah's Diamond: "For three years he served this semibarbarous potentate as Jacob served Laban" (Stevenson, "Rajah's" 130). Thomas Vandeleur is cast into the male role of the wooer and the Indian diamond is the reward he hopes to earn.

The gendering of the colony as female (as well as its representative, the diamond) then leads to "[t]he geography of rape as a dominant trope for the act of 
imperialism" (Suleri 17) ${ }^{11}$ in which the diamonds are again taken to signify female sexuality. However, Nancy L Paxton points out that the trope of rape in imperial discourse differs in pre- and post-Mutiny narratives. While, before 1857, in more sympathetic accounts of India, the exploitation by the East India Company was criticised as a "rape" of the land, after the Mutiny, the idea of the native-as-rapist and Englishwoman-as-victim prevails (Paxton 5-7). With reference to The Moonstone, critics have remarked on the parallel thefts of the diamond from Tipu's treasury and from Rachel's "Indian cabinet" in her bedroom, so that plunder and metaphorical rape are conflated (Nayder, Wilkie Collins 118). This scene therefore rather conforms to Paxton's pre-Mutiny cast of the metaphor. Nevertheless, in the direct confrontation with the Brahmins, the image of Indians threatening English womanhood is confirmed. Rachel is the subject of their scrutiny as she is wearing the diamond on her dress (Collins, Moonstone 78).

It has become apparent that the two realms of imagery, the domestic and colonial are linked in the gendering of diamonds. This naturally leads to a multilayeredness of diamond narratives where diamonds as sentimental and sexual imagery always bear Orientalist overtones.

\section{Owning the Diamonds in England}

\section{Relocation of Agency}

\section{Indian Revenge and Imperial Forgetfulness}

Jaya Mehta argues that "imperial violence, originally wrought on the colony by the English, [is] subsequently represented as springing from the colony" (613). This can be clearly seen in the reactions to the Mutiny. It was not understood as an uprising against colonial suppression, but as originating in Indian society and its proneness for crime and violence which had to be checked.

The idea that the diamonds have actively been 'sent' to Europe, that they are part of some deliberately designed plan to work revenge on an innocent and harmonious society is explicitly expressed in "The Rajah's Diamond". It is Prince Florizel, the detective figure, who is able to suggest this plan: " [] $\mathrm{f}$ the Rajah of Kashgar [...] desired vengeance upon the men of Europe, he could hardly have gone more efficaciously about his purpose than by sending us this apple of discord" (Stevenson, "Rajah's" 126). The revenge, it is implied, consists of sowing distrust and inciting "discord" in an otherwise peaceful and cohesive society. It is

11 Sara Suleri goes on to argue that the colony frequently is not gendered as female at all, but as masculine, albeit effeminate. The encounter then takes on homosexual connotations (16). The main point, though, is that it has to be gendered as deviant in relation to the male coloniser. 
deliberately suppressed that Thomas Vandeleur desired the diamond and brought it to London himself.

In The Moonstone, Colonel John Herncastle turns the curse of the diamond into the weapon of his personal revenge on his sister. Yet, in the following, agency is attributed to the diamond itself (Free 154). Betteredge exclaims: "I wish to God the Diamond had never found its way into this house!" (Collins, Moonstone 147), and "here was our quiet English house suddenly invaded by a devilish Indian Diamond bringing after it a conspiracy of living rogues" (43), "blame the Diamond!" (147). Even more explicitly, he accuses the diamond of deception: "That cursed jewel has misguided everybody who has come near it" (300). Herncastle's malignant intentions are reflected onto the diamond and he, the actual agent, seems to have no part in the events. In the same manner, Prince Florizel accuses the Rajah's Diamond of having "faithfully served the powers of hell" (Stevenson, "Rajah's" 131) with the same sense of independent agency which brings the diamond from India to England. The Eustace Diamonds contains the same idea of the diamonds as malevolent agents when Lizzy deplores that "[t]hose ill-starred jewels have been almost as unkind to him [Benjamin] as to me" (Trollope 760).

The diamonds as agents and the covetous English as victims of the diamonds' power cover the initial plundering in India. The crimes are imagined as emanating from India in the form of Indian objects and infecting England so that " $t]$ he crime of colonialism," as Jaya Mehta argues, "is replaced by colonial crime" (634).

The assigning of an agency to the diamond also contributes to their perception as an uncanny presence. Freud identifies the uncertainty whether an object is alive or not as the point of departure for his own theory of the uncanny (Freud 157). The descriptions of the diamonds as being uncannily alive and animated by a curse illustrate this idea. Another source which feeds into their perception as animate is the manner of their passage from one owner to the next.

\section{Fetishes and Chance}

The most prominent and unifying feature in the English main protagonists in The Moonstone, "The Rajah's Diamond" and also in The Datchet Diamonds is the almost accidental acquisition of the diamonds. In "The Rajah's Diamond", Harry Hartley carries a band-box without knowing what it actually contains and unwittingly becomes an accomplice in Lady Vandeleur's plot. Simon Rolles chances upon the diamonds in a flower-bed, and Miss Vandeleur hands Francis Scrymgeour the diamond wrapped in a handkerchief. When he unwraps it together with Prince Florizel, he maintains that "I possess no stolen property" (Stevenson, "Rajah's" 122).

In The Datchet Diamonds the initial innocence of the protagonist and the unpremeditated theft of the diamonds are stressed through the mere coincidence of the events. Cyril Paxton comes into the possession of the stones as he picks up 
the wrong suitcase in a train restaurant (Marsh 251) after the diamonds had already been stolen, and he maintains his innocence: "The diamonds came into my possession owing to an accident" (294), "he had but found them" (48).

Franklin Blake unconsciously steals the Moonstone while he is under the influence of opium. Dr Candy, as well, suffers from a "mysterious amnesia" after he has dosed Franklin (Duncan 314). The reason for the restaging of the theft in the novel is not to determine the identity of the thief but to clear Blake of guilt, as Melissa Free remarks that opium serves to divest Blake of any guilt whatsoever (354). Similarly, Godfrey Ablewhite, the true villain does not himself take out the diamond from Rachel's chest, but Franklin presents it to him so that, although Ablewhite acts consciously, he is helped by Blake who actually takes the diamond from the cabinet. Sergeant Cuff's statement that "[n]obody has stolen the Diamond" (Collins, Moonstone 113) appears as a very lucid remark. At the same time, as opium exculpates Franklin Blake from the theft, his attitude reiterates the attribution of an agency to the diamond. The denial of blame for having plundered mirrors Herncastle's looting and perpetuates the same view in England (Free 154).

Not only The Moonstone, but other texts, as well, exhibit this tendency to transfer agency from the diamonds' owners onto the diamonds. Prince Florizel's remark, that the slipping of the diamond from one owner to the next can only be explained by providence (Stevenson, "Rajah's" 128) points to the notion that the human agent is directed by some other power. None of the characters set out with the intention of stealing the stones but each was 'accidentally' made into thieves by circumstance. This unintentional acquisition of the diamonds, however, is restricted to their passage within England.

The transference of agency from person to object is that of a fetish, as Ian Duncan suggests with reference to the Moonstone: "The fetishistic displacement of agency from persons onto the relic of an apocalyptic collectivity constitutes The Moonstone's figure of mystery [...]" (318). Christopher Lindner observes the same in The Eustace Diamonds: "What Trollope is essentially showcasing is commodity culture's fetishistic tendency. More precisely, [...] Trollope exhibits a distortion of vision in which the commodity appears to erase all trace of human presence that animates it" (76). Lindner and Duncan base their analyses on Marx's definition of a fetishistic relation between people, "the social relation between people looks like a relation mediated by things" (Lindner, 76, italics in the original). The fetish in Marx is a product which takes on religious dimensions turning products into agents:

Hier [in der Religion] scheinen die Produkte des menschlichen Kopfes mit eigenem Leben begabte, unter einander und mit den Menschen in Verhältnis stehende selbstständige Gestalten. So in der Waarenwelt die Produkte der menschlichen Hand. Dies nenne ich den Fetischismus, der den Arbeitsprodukten anklebt [...]. (Marx 103) 
In "The Rajah's Diamond", the diamond is described as such a fetish demanding veneration: "[A] savage would prostrate himself in adoration before so imposing a fetish" (Stevenson, "Rajah's" 92). Lizzie, in her room with the boxed diamonds prays in front of them: "Some short prayer she said, with her knees close to the iron box [containing the necklace]" (Trollope 440).

Both the labelling and presenting of the diamonds as fetishes and the circumstances of their theft in England serve to exculpate the thieves. They are victims, if not of the diamonds, then at any rate of circumstance. It also highlights the crimes committed before the diamonds reached England. Both Colonel Herncastle and General Vandeleur actively plot and labour to gain possession of the diamonds. Although the action of theft establishes parallels between the colonial and the domestic crimes, the circumstances of these crimes separate them and suggest discontinuity as the thefts in England are presented as unintentional. While Melissa Free suggests that this denial includes the thefts in India (352-353), I would argue that the innocent thieves in England are at first glance in opposition to the imperial plunderers while they are still, and very visibly living on the spoils of empire which are disguised as the product of chance and situation. A dividing line is drawn between the evil exertions of plunderers and the innocent and unintentional thefts at home. The distinction, however, cannot be drawn sharply as the parallels between the theft of the Moonstone from the Indian treasury and the Indian cabinet obviously invite a comparison. Once in England, the diamonds figure in contexts which are designed to turn them into domestic objects and to 'fix' them.

\section{Diamonds as 'Curiosities': Collection and Greed}

Collecting was a nineteenth-century obsession fuelled largely by natural philosophy and Darwinism (Whitworth 111). In the context of empire 'curiosities' were brought from all parts of the world and exhibited in Britain. Exploring, collecting and classifying the Other defined the boundaries between the colonisers and the colonised in an important imperial practice (Jasanoff 113). The presentation of the Koh-i-Noor in the Great Exhibition of 1851 provides a telling example of the effectiveness of exhibiting items in a different frame and, as objects of curiosity, in a controlled context. As curios, oriental objects have long been part of European collections, one of the contexts diamonds would figure in in the West. The image of the collector in literature, grew decidedly more negative towards the end of the century. Paul Goetsch observes that

[i]n the late-Victorian period, collectors in literature were often seen as selfish adventurers, unscrupulous scientists or capitalists, criminals, amoral aesthetes and decadents. Concomitantly, collecting is frequently associated with exploitation, violence, and crime. (Goetsch 68) 
Collecting means ownership for the sake of owning without any considerations of usefulness. The aim of a collection therefore is not gain but completeness. The prime motive among the collectors of diamonds in the texts is possession rather than realising wealth from the stone. This practice bears negative connotations as it aligns the English protagonists with Indians or exposes them as greedy and Orientalised.

John Herncastle owns the Moonstone just for the sake of owning: "He never gave it away; he never even showed it to any living soul" (Collins, Moonstone 40) for fear of his persecutors. The Moonstone is an object known among collectors and a valuable item. For John Herncastle, the possession of the diamond goes along with "smoking opium and collecting old books, [...] trying strange things in chemistry" (40-41). The Orientalising aspect is alluded to in paralleling John Vandeleur and the Rajah of Kashgar as collectors (Stevenson, "Rajah's" 97; 130). In “The Rajah's Diamond", Prince Florizel describes John Vandeleur's motif for stealing his brother's diamonds: "Not to be richer, nor to have more comforts or more respect, but simply to call this diamond yours for a year or two until you die, and now and again to open a safe and look at it as one looks at a picture" (97). The Rajah of Kashgar, as well, owns not only the diamond but a whole "collection" (130). John Vandeleur is a collector of diamonds which he brings "from all parts of the world" (110) and hoards in his house. This passion is complemented by his hunting: "I have hunted most things, from men and women down to mosquitos; I have dived for coral; I have followed both whales and tigers", (97) he professes. The hunting of "men and women" highlights John Vandeleur's personality. Francis Scrymgeour catches John Vandeleur in the act of robbing Reverend Rolles surrounded by these collections, which form part of the crime scene: "In a small apartment, carpeted with matting and surrounded by glazed cabinets full of rare and costly curios, Mr. Vandeleur was stooping over the body of Mr. Rolles" (117).

The connection between collector and crime which the setting highlights can also be found in The Sign of Four. John Sholto is too greedy to share the treasure with its other 'rightful owners', and he withholds it from Miss Morstan. On his deathbed he confesses to his sons:

The cursed greed which has been my besetting sin through life has withheld from her [Miss Morstan] the treasure, half at least of which should have been hers. And yet I have made no use of it myself, so blind and foolish a thing is avarice. The mere feeling of possession has been so dear to me that I could not bear to share it with another. (Doyle, Sign 145)

In this handling of the treasure, John Sholto directly parallels its original owner, the Indian rajah, "who is of a low nature and hoards his gold rather than spend it" (Doyle, Sign 220). Even Lizzie owns the Eustace Diamonds just for the pleasure 
of possession as she admits that they will probably always be locked up in an iron box because of the danger of showing them in public (Trollope 81).

The collecting for the pleasure of possession is thus presented as an Oriental trait which is spelled out in the character of Bartholomew Sholto, John's son. He is a greedy decadent who lives in "Eastern luxury" (Doyle, Sign 142) complete with a "Hindoo servant" (141). Furthermore, he is a collector of art, both Indian and European (143). The interior of his house compared to its exterior "looked as out of place as a diamond of first water in a setting of brass" (141). The same picture of mismatch and incongruity is created by his Indian servant "standing in the commonplace doorway" (141). Collecting and the pleasure of possessing the diamonds or anything valuable, as presented in the texts, is Oriental and inherently distasteful and also alien to Englishness as the mismatch of outside and inside of the house suggests. Thaddeus Sholto, too, lives in a "House full of Indian curiosities" (164), Pondicherry Lodge, which he has inherited from his father. The image of the Orient as an immense 'treasure trove', as mediated in the Arabian Nights is mirrored in its interior. Both Bartholomew and Thaddeus are collectors of Indian curiosities and perpetuate the greed of their father in initially withholding the Agra treasure from Mary Morstan.

Mere owning of value is harmful for a market economy. Possession is unproductive and dangerous and testifies to a "low nature" (Doyle, Sign 220). "To sustain commodity culture," Christopher Lindner argues, "it is necessary to circulate and consume commodities" (Lindner 10). The diamonds which incite greed represent inert and unproductive ownership. In the Sholtos and John Vandeleur, the refined collectors of art and the ruthless hunter of treasure respectively, the collecting of Indian 'curiosities' is represented as abnormal and socially disruptive. The misgivings about the diamonds as objects of vanity are founded on the same notions that were expressed about the Koh-i-Noor during the Great Exhibition of 1851. The diamond then came to represent a "premodern, Orientalist economy" (Mersmann 180) which is at odds with the modern market economy of Great Britain. The diamonds bring about a relapse into this more ancient structure. Likewise, Prince Florizel asserts that the Rajah's Diamond is an aristocratic possession which cannot be handed around "among the common sort of men" (Stevenson, "Rajah's" 97). Not even in the context of inheritance can the diamonds be integrated in the existing system; they represent an alien force.

\section{Diamonds as Inheritance}

Allan Hepburn suggests that inheritance automatically creates a plot. It assumes a past and points into the future and thus creates expectation. Property changing hands automatically devises a "narrative sequence". He argues that "[i]nheritances change destinies and instigate stories" (3). Inheritance was commonly used as a plot device especially in Victorian novels (GoGwilt 60). Like detective fiction, the 
plot of inheritance highlights objects. It also proposes a specific model for detective fiction as a temporal trajectory into the past is opened up, and previous events have to be discovered to explain their influence on the present.

The subject of inheritance turns up most prominently in The Moonstone and The Eustace Diamonds, but also in The Sign of Four and "The Rajah's Diamond" in which colonial riches are juxtaposed with native English inheritances. Yet, the inheritances are treated before the foil of the crimes surrounding the diamonds so that a comparison between the two modes of gaining wealth seems to be implied: The inheritance of land and money in England and the inheritance of colonial wealth from India.

I will first turn to the English inheritances. In the earliest novel, The Moonstone, Franklin Blake is called back from his travels "in the East [...] camped on the borders of a desert" (Collins, Moonstone 292) when he is informed that his father has died and that he has inherited "his great fortune" (292). This English inheritance naturally draws him home, back from a place almost at the edge of civilisation where the diamond, Rachel's Indian inheritance, has lured him. This solves the debts he had run up on the continent and for which the Moonstone loomed as a possible solution. It also again calls to attention that Franklin, too, is denied an inheritance (Dolin 76):

Hearing what I [Betteredge] now tell you, you will naturally ask how it was that Mr Franklin should have past all the years, from the time when he was a boy to the time when he was a man, out of his own country. I answer, because his father had the misfortune to be next heir to a Dukedom, and not to be able to prove it. (Collins, Moonstone 24)

Betteredge here points to the connection between the disinheritance of Franklin's father and his vagabonding life which has given him, in Betteredge's view, several un-English identities. Franklin's internationalism is thus only cured through the marriage to Rachel and his acquisition of landed property, a rightful English inheritance.

In "The Rajah's Diamond", Harry Hartley loses the diamonds he was entrusted with, but is compensated for the loss by an inheritance from "a maiden aunt in Worcestershire" (89). In The Sign of Four, the chapter entitled "The Science of Deduction" contains a number of minute facts which foreshadow the following story and lay the foundation of Holmes' deductions later on. Holmes is shown to have completed studies on different subjects from which he will conclude the solution of the one to come. The "lunkah smoker" and the "diamond polisher" are already mentioned (Doyle, Sign 126), and at the beginning of the story, Holmes is presented as a user of Oriental drugs. Similarly, the subject of inheritance is touched upon (128-130) which will also become prominent through Mary Morstan's appeal for help. In the context of the other items foreshadowing the case to follow, the mention of an heirloom, too, has to be regarded as a prolepsis. Watson 
wants to test Holmes' abilities of deduction and presents a watch (128). Just by examining it, Holmes infers that it is an heirloom which has come down to Watson from his father through the death of his older brother. "Jewellery usually descends to the eldest son," (128) he concludes alongside other observations on the brother's character and habits, which are all inscribed on the watch.

With these heirlooms, Franklin's and Harry's money and Watson's watch, wealth and memory are passed on in a regulated and official manner. They provide stability and continuity over many generations. In the case of Franklin, being denied the inheritance of the dukedom and his ensuing exile, the destabilising effect of the denial shows in his unstable identity, as described by Betteredge. In The Moonstone and The Sign of Four these inheritances are juxtaposed with the Indian diamonds which are also passed on as bequests. Yet they do not function in the same stabilising manner.

The Moonstone is left to Rachel by her uncle John Herncastle, and it is made clear that it is intended as a revenge on her mother. Franklin Blake pointedly questions "the Colonel's motive in leaving this legacy to his niece, for my aunt's sake" (Collins, Moonstone 49). The diamond and the will are used to wreak vengeance on the relatives as John Herncastle knew well that the possession of the diamond is dangerous (44). The diamond also threatens the Verinder's property in that it upsets Lady Julia's provisions in her own will. Rachel is only entitled to a life-long interest in her property to avert fortune-hunting suitors like Godfrey Ablewhite who would squander the property. Through the inheritance of the Moonstone, she is again exposed to the risk her mother wanted to avert and whose legal precautions are nullified (Dolin 78). Thus the inheritance of the Moonstone confers both an alleged Oriental curse and social and economic vulnerability.

The same danger of prosecution impends on the owner and heir of the Great Agra Treasure. Bartholomew and Thaddeus Sholto inherit the treasure from their father John Sholto. One half of the treasure was supposed to go to his accomplice Arthur Morstan, but is withheld from his daughter, Mary Morstan. The recovery of the treasure would make her "the richest heiress in England" (Doyle, Sign 150). As in The Moonstone the owner of the diamonds is threatened by a mysterious third party that follows it. In The Sign of Four it is Jonathan Small and Tonga, who are responsible for the deaths of John and Thaddeus Sholto. They go where the treasure is and represent the inheritance's threatening side.

Anthony Trollope's The Eustace Diamonds is another example of Indian diamonds bequeathed in England and a young woman claiming them. The emphasis is on the legal status of the diamonds, and the question of ownership is paramount as Lizzie refuses to give them up. The legal battle which is fought over the diamonds concerns the possibility of their status as an heirloom of the Eustace family, which would force Lizzie to give them back to her husband's family. Their great value is cited as an argument to the negative which actually confirms Lizzie's claim that they are paraphernalia, but this information is withheld from her. The 
legal complications and her lies estrange her from her late husband's family and gain Lizzie Eustace a bad reputation in society. In the end, the diamonds do not secure her social status but destroy it.

In the texts, inheritance is addressed as an unproblematic and positive way of securing a place in society. An heirloom is exempt from "the world of commodity exchange" (Lindner 83) and gains a special and fixed status. As such it confers identity, it becomes "domestic" (Daly 70) and thus characterises its wearer (Tetzeli 299). The incorporation of the diamonds into this same pattern marks, as Christopher GoGwilt observes, "the disintegration of (Indian) culture into (British) goods" (81). Yet, the diamonds' history of theft and murder is contrary to the 'English' inheritances. Furthermore, they cannot stand for uninterrupted succession. Their legal status is as insecure as their ownership and they disrupt the stabilising effect of the domestic bequests.

The strong link between material inheritance and national economy is stressed by Allan Hepburn: "Especially in nineteenth-century novels, property ownership functions within the dual framework of personal and national heritages" (9). Together with the diamonds their history is inherited, the nation's involvement in colonialism. Considered as national rather than private objects, the possession of the diamonds raises the question whether, "a nation inherit[s] the evil of its forebears if it accepts the benefits derived from the crime?" (Reed 287) The texts unanimously suggest that the inheritance of colonial wealth is problematic and potentially threatening.

In addition, the diamonds' heirs are all women - a fact which further seems to stress the insecurity of the transference of wealth - and their inability to keep them is emphasised. Women are not only more prone to lose the diamonds to a third party, but the pattern that an heirloom "usually descends to the eldest son" is disturbed. The presence of future male heirs in The Moonstone and The Eustace Diamonds relieves this anxiety.

\section{Women as Owners of Diamonds}

Mary Morstan and Rachel Verinder are the inheritors of the Moonstone and the Agra treasure respectively. Lizzie Eustace styles herself as the wronged widow who fights for her inheritance of the Eustace Diamonds, and she tries to manipulate her intermediaries to argue for her ownership of the diamonds. Eventually, all her attempts are in vain when the diamonds are stolen. Mary Morstan's and Rachel's inheritances, as well, are stolen from them or their claims are refused. In all of these texts, women are the victims of theft, and their ownership of the diamonds is presented as insecure and contested which is partly due to the disruption of male inheritance which I have already discussed. Yet, Mary Morstan and Rachel Verinder are threatened in their inheritance and ownership of the treasures by 
some lurking dark forces represented by the three Indians and Jonathan Small and Tonga who break into their domestic security.

In The Moonstone and The Sign of Four the history of the diamonds is bound up with the Mutiny. The most enduring image of the Mutiny was the Well of Cawnpore. The event influenced the ideological discourse and underpinned counter insurgent aggression. The representation of women and children as the major victims of the Mutiny and the depiction of the rebels as criminal sexual perverts directed the focus on the endangered ideal of the peaceful Victorian home as the main point of attack. The lasting theme in writing on the Mutiny became "white womanhood threatened by dark natives" (Mehta 646) and the projection of devilish and deviant impulses on Indians (Brantlinger, Rule 210). The diamonds bring the violence and irrationality of the Mutiny to England, in their history and their surrounding conspiracies. In threatening domesticity in their eruption into the "quiet English house" (Collins, Moonstone 43), they first and foremost threaten women in their position as keepers of the Victorian ideal of the peaceful home. The constellation, moreover, reflects the preset stereotypical depiction of Mutiny violence. In The Moonstone, the danger which Rachel incurs is spelled out: First Murthwaite affirms that she would be in great danger in India (74) and later, she actually is the object of the Indians' threatening gaze: "[T] here she stood, innocent of all knowledge of the truth, showing the Indians the Diamond in the bosom of her dress" (78). It is suggested that Rachel is especially vulnerable and thus unable to securely guard her diamond as property. The Sign of Four addresses the Mutiny directly, and Jonathan Small, in his confession, describes the violence of the rebels in their assault on the Indigo farm: The book-keeper's wife is "all cut into ribbons, and half eaten by jackals and native dogs" (Doyle, Sign 215). He also mentions Cawnpore and the danger that women and children incur (218) in the hands of the mutineers.

The Eustace Diamonds alludes to another Indian crime against women which attracted sensational coverage in the nineteenth century. "Suttee propensities of all sorts, from burning alive down to bombazine and hideous forms of clothing, are becoming less and less popular among the nations," (Trollope 229) the narrator ironically comments on Lizzie's longing for entertainment. Frank Greystock also refers to "suttee" when he explains "the burning of Indian widows" with the unconscious Indian realisation of the "unfitness of women for solitude" (258). Lizzie's situation as a young widow thus evokes sati, phrased ironically by the narrator and more seriously by Frank. Lizzie, however, obviously wants to avoid the renunciation which society demands from her, symbolised through sati, the mourning and giving up of the jewels, which are so important to her identity. The association of Lizzie's situation with sati articulates the threat to her life and identity, which rests in the diamonds. This threat is represented through an Indian practise. 
In her legally contested property Lizzie is linked to the Sawab of Mygawb ${ }^{12}$. The parallelism of his case and her own is enforced by the Orientalising of Lizzie's widowhood. He is in a similar situation as Lizzie as the court decides whether he "should have twenty millions of rupees paid to him and be placed upon a throne, or whether he should be kept in prison all his life" (63). Lucy Morris, depicted as morally superior to Lizzie, defends the cause of the Sawab when she complains that "the prince is being used very ill $-[\ldots]$ he is being deprived of his own property, $[\ldots]$ he is being kept out of his rights, just because he is weak" (102). Although Lizzie's claim for the diamonds rests on lies, she, too, is deliberately kept in ignorance of her rights (273) and thus remains at the mercy of men in power.

The emphasis on the legal status of the Eustace Diamonds points to another context for the discussion of women as owners, topical in the 1870s, which is detached from the diamonds as Oriental objects. The first 'Married Women's Property Act' had, even long before it was passed in 1870, stirred a discussion on the subject. The underlying intention was to improve the standing of workingclass women who had to hand over their wages to their husbands. The controversy, however, also exposed the injustices women faced in the middle and upper classes (Dolin 68-70). Before the act was passed, all property owned by a woman automatically passed to her husband on marriage, and she lost all rights to income and revenue from her property.

The insecurity of women's possession of objects of great value which the texts address is illustrated by the immediate danger through some Oriental design. In The Eustace Diamonds the reference is more obliquely introduced in the disempowered state of widows through sati and the parallels to the Sawab of Mygawb's case. Lizzie is in the first instance threatened because of her unprotected and, according to Frank, unnatural state as a widow. In the comparison with the Indian prince, her precarious position is likened to his as both of them depend on the intervention of men in power like Lord Fawn and Frank Greystock, both involved in the case. Frank Greystock pleads in the Sawab's favour and also supports Lizzie's claim of the diamonds while Lord Fawn opposes both.

Women appear as unable to hold possession of the diamonds but are at the same time bound up in the imagery of metaphors and similes conferring the corrupting or desirable qualities of diamonds on the female protagonists. In the plots, women and diamonds also occupy a usually mutually exclusive position as reward for successful detection in the reestablishment of order at the end of the stories. I

12 The name alludes to the long-running court case of the insolvent Maharajah of Mysore (Trollope 773 note 6). Krishnarajah Wodeyar ascended the throne after the defeat of Tipu, 1799. He was removed in 1831 because he had incurred heavy debt and the British government took over the administration of the state. In 1867 it was decided that Mysore should again be ruled by an Indian prince, and in 1881 Krishnarajah's successor ascended the throne (Anon., "Mysore"). The novel's action is set in 1865-66 (Sutherland 24) when the question of native rule was debated before the decree took effect one year later. 
will therefore consider the aspect of romance as a necessary substitute for the failure of the detective to effect order.

\section{The Failure of Order and Detection}

In detective fiction the ending imposes order on a chaotic and unintelligible world (Siddiqi 244). It involves the reconstruction of significant past events which make sense of the present:

Eigen schließlich ist zum dritten jenes entscheidenste Kriterium, das den Detektivroman von allen anderen Erzäblformen trennt, so eben sein Unerzäbltes und dessen Rekonstruktion [...] das Herausfinden eines bereits Geschebenen ante rem. (Bloch 334, italics in the original)

The aim of detection, in all of the stories, is the recovery of the diamonds. In The Sign of Four and "The Rajah's Diamond", which share a similar ending, the finding of the diamonds and their sinking is accompanied by the discovery of their history in India and the crimes which had been committed long before. Thomas Vandeleur's services to the Rajah of Kashgar had only been rumours, but Prince Florizel can offer their details in a coherent narrative together with the diamond. He presents the diamond to the startled detective together with the account of its appropriation by Thomas Vandeleur in India and its passage to Paris (Stevenson, "Rajah's" 130-131). His position of near omniscience has aptly been prefigured in the impression he had made on Simon Rolles: "[T] he man who seemed, like a god, to know all things and to have suffered nothing" (96) can oversee both Indian and metropolitan crime.

In The Sign of Four, Jonathan Small who has been arrested as the thief narrates the theft of the treasure in India in his confession. His revelations thus not only include the solving of the immediate crime in England, but the discovery of the crimes' pre-history. Sergeant Cuff, however, ignores the Moonstone's Indian prehistory and, one could argue, fails in his task (Free 342). Keep and Randall suggest, with reference to The Sign of Four, that "[n]arrative thus substitutes itself for the unrecuperated aspect of the case" (218), which also holds true for "The Rajah's Diamond". In both instances, however, the momentous recovery of the treasures is followed by their loss in the rivers Thames and Seine respectively.

The Moonstone is also lost to its English owners. It is not sunk but returns to India as the three Brahmins manage to outwit the police. The restitution of the diamond to its place in a statue in Somnauth undoes not only the British plundering of Seringapatam, but also the earlier conquest of Somnauth by the Moguls, 800 years ago, so that the time arc of the story reaches back before the beginning of the prologue. The English, however, do not have a hand in this restitution. Yet, the narrative as substitute for a failed recovery does play a role. Murthwaite's surveillance of the scene and his reporting back of the discovery constitutes such a 
compensation. His presence and knowledge reassert the perspective of empire over the success of the nameless Indians (Nayder, "Collins and Empire" 148).

Another aim of detection, the identification of the culprit, is equally difficult to achieve in the three stories as they present a whole array of thieves. Yumna Siddiqi argues that the "assigning of guilt purifies the community as a whole" (244). As already discussed, the accidental passages of the diamonds in England explicitly avoid the concentration of guilt in one individual. According to Siddiqi, the exculpation of the community (244) is impossible without determining the culprit and thus constitutes another problem in the closure of the detective plot.

From the perspective of the detective plot, the fact remains that complete closure is impossible because the objects cannot be restored by the detective and vanish into the water or back to India. I will relate the failure of the detective to the element of romance which enters the detective discourse and suggest that the latter works as a substitute for a satisfactory closure through detection. The element of romance pervades the whole of the texts in The Moonstone, The Eustace Diamonds, "The Rajah's Diamond" The Sign of Four and The Datchet Diamonds. Before assessing its relevance in the resolution of the narrative of detection, I will point out the conspicuous references to romance, their origin and effect.

\section{Romance as Substitute Closure and the Arabian Nights' Entertainment}

"Here was romance indeed!" (Anon., 1: 155) The hero of “The Rajah's Diamond", a short story, which appeared in two instalments in Dickens' All the Year Round in 1878, identifies his situation as romantic. He pursues "the largest and finest diamond in the world" (Anon., 2: 155), the property of an Oriental rajah. The narrator later on affirms that " $[\mathrm{t}]$ he mystery and romance of his position worked their spell" (2: 156). The diamond is, of course, old (1:135) and he is distracted from diamond hunting by the rajah's daughter (1: 137).

Romance has a twofold meaning: It denotes both "the oriental, the exotic, the occult, the dangerous and the mysterious" and "the domestic story of wooing, winning and wedding" (Mehta 611). The Oriental aspect clearly influnces the novels in the shape of the diamonds which evoke the quintessential European fantasy of the Orient, the Arabian Nights.

Antoine Gallard's French translation of the Nights appeared between 1704 and 1717 and exerted a strong influence on European literature. An English translation followed very quickly, and the editions of Edward William Lane's and Richard Burton's further popularised the Nights (Mack 470). The stories played a major role in shaping the western image of the Orient. In describing and understanding the Orient the Arabian Nights furnished the vocabulary for fictional and nonfictional texts. They present "an instance of Orientalist thought: the way in which the West perceived the East as taking the form of its own fantasies of a paradisical Orient" (Boehmer 43). An important part of the Nights is their setting in a rich 
and urban environment which adds to the 'treasure trove' image of the Orient. The "domestic romance" which culminates in marriages upon the loss of the diamonds and the exotic romance of a removed fairy-tale like Orient, as represented in the Arabian Nights, are entwined in the narratives.

The romance element is highlighted in all of the stories, which is especially conspicuous in The Sign of Four as the Sherlock Holmes stories usually do not include romance in the domestic sense. The insistence on romance contrasts with the analytical and 'modern' prerogative of detective fiction. This reservation is voiced in The Sign of Four and "The Rajah's Diamond". Romance in detective plots is contrary to readers' expectations. Simon Rolles, in his role as a reader of detective fiction in "The Rajah's Diamond", is frustrated with Gaboriau's narrative: "He [Rolles] was annoyed, moreover, to find the information scattered amongst romantic story-telling" (Stevenson, "Rajah's" 95). Similarly, Holmes rebukes Watson for his writing of $A$ Study in Scarlet:

'Detection is, or ought to be, an exact science and should be treated in the same cold and unemotional manner. You have attempted to tinge it with romanticism, which produces much the same effect as if you worked a love-story or an elopement into the fifth proposition of Euclid.' (Doyle, Sign 125)

In The Sign of Four, however, the romance plot like the stock characters of fairy-tale are deliberately mentioned: "'It is a romance!' cried Mrs. Forster. 'An injured lady, half a million in treasure, a black cannibal, and a wooden-legged ruffian. They take the place of the conventional dragon or wicked earl."' (188) Similarly, in The Eustace Diamonds, Lizzie imagines herself as the hero or heroine of such an exotic romance as Mrs. Forster envisions. She chooses the Arabian Nights as a fitting frame because it unites romance and romantic treasure:

'I do feel so like some naughty person in the Arabian Nights,' she said, 'who has got some great treasure that always brings him into trouble; but he can't get rid of it, because some spirit has given it to him. At last, some morning it turns into slate stone, and then he has to be a water carrier, and is happy ever afterwards, and marries the king's daughter. What sort of king's son will there be for me when this turns into slate stones?' (Trollope $323-324)^{13}$

As a story from the Arabian Nights, Lizzie imagines the plot of Collins' and Doyle's novels: The possession of the diamonds turns into a curse, and marriage compensates for the renunciation and loss of the treasure, a hope which is disap-

13 This forms part of Lizzie's frequent attempts to imagine her life in terms of romance: She fashions Lord George as her Byronic "Corsair" (Trollope 371), and alludes to Frank's position as resembling Lancelot between two women through Tennyson's Idylls of the King (209) (Trollope 778 , ftn. 1). 
pointed for Lizzie as she will not find a "king's son" but only a scheming preacher. The bad outcome could already be prefigured in the reversed gender roles of her imagined romance indicating that Lizzie's life does not correspond to the Oriental model she dreams up. In The Datchet Diamonds, too, Cyril Paxton wonders whether he was "the victim of some extraordinary hallucination or the hero of a fairy tale" (Marsh 42).

As part of the New Arabian Nights, "The Rajah's Diamond" is framed as the recounting of such a story from the Orient: In situating half of the action in Paris, Stevenson references at the same time Poe's Dupin (Ascari 99) and the intertext, the Arabian Nights of the title. Stevenson invents an Oriental source from which a narrator copied the stories. The fairy-tale quality of the text is highlighted by the hero's very name, Prince Florizel, which is taken from Shakespeare's romance The Winter's Tale. A prince who walks in disguise among the common people also references the 'original' Arabian Nights. The stories which are set in London and Paris are thus embedded in an Oriental frame and controlled by a western editor relying on an Oriental source. The original stories are told by an omniscient narrator, the "Arabian author" (Stevenson, "Suicide" 31) ${ }^{14}$ or "this Oriental" (68), providing a frame-narrative. Yet, the setting and characters are European so that an ironic tension is created between the occidental story and setting and the Oriental frame. The stories are mediated by the voice of an editor who comments on the narrative behaviour of the "Arabian Author" and occasionally disapproves of it, for example when the "Arabian Author breaks off the story of THE YOUNG MAN IN HOLY ORDERs" (Stevenson, "Rajah's" 102), and the editor "regret $[s]$ and condemn $[s]$ such practices", or the editor admits to changes in the text, "[o]mitting some reflections on the power of Providence, highly pertinent in the original, but little suited to our occidental taste" (Stevenson, "Suicide" 65). The few allusions to the editor's changes contrast with the overall transformation of a supposed Oriental original and its impossible setting in London. The discrepancy creates the text's irony and also introduces the editor/narrator as unreliable or at least misrepresenting his source. The exotic romance of the New Arabian Nights is present in these allusions to its generic model. Thus "The Rajah's Diamond", too, frames the story of the diamonds as belonging to the world of romance. The close connection between the diamond and the Oriental frame is evident in the simultaneous discarding of the diamond into the Seine and the Oriental author "into space" (Stevenson, "Rajah's" 132).

Two different aspects drive the romance plot. One is the European text of the Arabian Nights. As a model for romance it unites the two disparage strands of romance, exoticism and chivalric love, and at the same time it includes the diamonds. The chivalric romance draws on narratives of the Mutiny which is more or less obliquely referenced in the texts by Collins, Stevenson and Doyle. The influence could be Mutiny narratives which highlighted the threat of Oriental lechery

14 The passages in which the editor takes over from the Oriental source and comments on the "Arabian Author" or provides summaries are set off by italics from the rest of the text. 
to helpless white women and resurrect the "chivalric code" (Paxton 9). The male protagonist would then, of course, be rewarded for his feats by marriage. The years following $1857 / 8$ saw a wave of such texts in which this motif turned into a staple ingredient (6).

In a brief summary I will give an overview on the couples that marry upon the loss of the treasures and for whom the loss of the diamonds is a prerequisite for marriage: Obviously, Rachel and Franklin in The Moonstone can only get together after the Moonstone has been found and Franklin has been cleared of guilt. In The Sign of Four Mary Morstan and Watson fall in love during the investigation. If Mary would have come into the possession of the treasure, she would have been too rich a bride for Watson. He brings her the chest, presumably filled with the Agra Treasure. When they find out that it is empty, Watson confesses his love, now that "the golden barrier was gone from between us" (Doyle, Sign 211). In "The Rajah's Diamond", the diamonds pass through several hands. The first "thief" is Harry Hartley, who, on his flight, meets Prudence, a maidservant. He manages to lose all of the diamonds and subsequently marries Prudence on "a sum of money [inherited] from a maiden aunt in Worcestershire" (Stevenson, "Rajah's" 89). Francis Scrymgeour gives up the diamond to Prince Florizel who arranges the longed-for marriage to Miss Vandeleur and induces John Vandeleur to give her a dowry of one thousand pounds. In The Datchet Diamonds Cyril Paxton has to give up the diamonds and can finally marry Daisy Strong on money he earns from his soaring shares in a southern African gold mine. The loss of the diamonds is compensated by more secure financial means and the texts close with marriage.

On the one hand, the persistence of romance in these detective plots points to the lack of an alternative closure through successful detection and restoration of the stolen property, the natural and satisfying ending of detective fiction which reinstates order. Additionally, it also owes to the Victorian preoccupation with domesticity. This has also moral implications as the young male heroes renounce the worldly wealth of the dangerous Indian diamonds and opt for the quiet Victorian house. The diamonds themselves, as insecure colonial possession or domestic fiscal objects, are then traded for the reified sentimental image of the "Angel of the House", Patmore's Koh-i-Noor. The idea is evident in the exchange of treasure for love that underlies the endings which follow this plot as Watson exclaims: "Whoever had lost a treasure, I knew that night that I had gained one" (Doyle, Sign 211). The evil Agra Treasure has to disappear to clear the way for the romantic metaphor of Mary Morstan as treasure.

On the other hand, the diamonds seem to press the connection not only with the Orient in general but with a fairy-tale like version of it, modelled on the Arabian Nights in their European editions. The recurrence to a fairy-tale Orient as the provenance of the diamonds renders the "romantic regions" (Collins, Moonstone 462) of India as ahistorical and unchanging as the prologue to The Moonstone sug- 
gests (12). The history of the diamond in India is consequently presented as "a fable" (12) and, as Matthew Bruff, the solicitor puts it, as the "romance of the diamond" (278). This phrase as well as Lizzie's "spirit" (Trollope 323) who unconditionally gives away a treasure, obliterates the actual provenance of the diamonds. Jonathan Small can immediately identify the gems of the Agra treasure as something he has "read and thought about" when he was "a little lad at Pershore" (Doyle, Sign 224). He understands and frames it as literary rather than real. The notion of the fairy-tale treasure propagates the same idea as the colonial adventure story, the existence of ownerless Oriental wealth (Boehmer 23).

Romance, in particular Oriental romance, not only offers a conclusion to the story of an insoluble crime, but also produces a frame for the diamonds which is less threatening and more removed, more literary and less real than their actual history and origin.

\section{Insecure Possessions}

The passage from one owner to the next through chance and/or theft points to the problems of secure possession of the diamonds. Another variation of the same idea is the abundance of empty boxes, the "focus on the absence of diamonds or jewels" (Mersmann 187) through their empty containers, which makes them the subject of the discourse of detection. The empty Indian cabinet in Rachel's room stood "wide open. One of the drawers inside was pulled out $[\ldots]$ " (Collins, Moonstone 87). In the scene of Godfrey's murder, as well, "[a] small box was found $[\ldots]$ open and empty" (445). The box of "Indian workmanship" (Doyle, Sign 205) in The Sign of the Four only seems to hold the diamonds because of its weight, but when found, "[t]he box was empty!" (211)! In The Eustace Diamonds, as well, the box that is supposed to hold the jewels, is empty and the thieves in the first burglary escape with this "iron emblem of their [the diamonds'] absence" (A.H. Miller 163). The Datchet Diamonds, too, disappear from their box: "When the box was opened, it was empty! There was nothing of any sort to show that the diamonds had ever been in it - they had vanished into air" (Marsh 23-24). The "impossibility of fixing these stones" (Mersmann 187) is not only emphasised through their empty containers but also through multiple thefts. The diamonds in The Moonstone, The Sign of Four, The Eustace Diamonds, The Datchet Diamonds and "The Rajah's Diamond" are stolen at least twice. The initial crime committed in India is multiplied in England, and it is impossible to identify one single thief.

The theft of objects in detective fiction necessarily draws attention to the question of ownership: The detective not only has to find the stolen objects but also to return them to the rightful owner to restore order. But ownership of the diamonds is precarious and uncertain. The Rajah's Diamond is devoid of a fixed status: it is not "stolen property" (Stevenson, "Rajah's" 122) in the hands of Francis, and Harry replies to Raeburn, the gardener: "The jewels are not mine, and I 
cannot share what is another's, no matter with whom, nor in what proportions" (86). Jonathan Small tentatively asks: "Whose loot is this, if it is not ours?" (Doyle, Sign 213) In Marsh's The Datchet Diamonds, the thief Lawrence answers to Cyril's question, why he supposed that he was the "rightful owner of the Datchet diamonds": "By right of conquest" (Marsh 252). The legal status of the Eustace Diamonds is never fully resolved: Lizzie keeps/steals them claiming them as a present from her late husband in Scotland. Mr. Dove asserts that they are "paraphernalia" rather than an "heirloom" (Trollope 263-264), a fact that is kept from Lizzie. Thus, as long as Lizzie insists on keeping up her lie, the true owner of the Eustace Diamonds cannot be determined. The question of the whereabouts of the owner is further complicated by determining the original owner. At the basis of this question the original theft of the diamonds from India introduces a complication.

The never-ending passage from one potential owner to the next emphasises their mobility. This contrasts with the secure inheritance of land as in The Moonstone. "The Moonstone seems to embody this shift from land to capital, with the diamond itself objectifying the intrusion of capital into the landed estate." (GoGwilt 63). The diamond, consequently, cannot confer identity as the inheritance of land does. The substitution of marriage and domestic inheritance for the recovery of the diamonds compensates for the loss and also corresponds to the Victorian reverence for domesticity.

The problems of the unresolved detective plot are partly accommodated by assigning the diamonds to the realm of romance. Objects from this fairy-tale Orient are devoid of historical and political implications as their status as trophies would suggest. They thus belong to an imaginary place without the threatening connotations of Mutiny violence and colonial exploitation.

The romantic version of the diamonds, however, does not erase their geographical and historical provenance. The colonial implications raise specific fears of infiltration which intensify in late Victorian times. I will now look at the ways in which this fear is expressed and framed in the texts. The most obvious elements of invasion are the foreigners who follow the diamonds.

\section{Invasion and Contamination}

The Intrusion of the Periphery

\section{The Inside: The Quiet Country House}

While The Moonstone is set in the country side and the Verinder's belong to the landed gentry, The Sign of Four and "The Rajah's Diamond" transplant the action to urban settings. Both London and Paris are the capitals of empires and important gateways to the colonies. London is infused with colonial goods and subjects 
that bring the colony home to England and carry among them the spoils of war of the diamonds. The Vandeleur brothers as well as the abundance of characters in The Sign of Four - Jonathan Small and Tonga, Captain Morstan, the Sholtos and Dr. Watson - testify to the literary interest in the "flotsam and jetsam of Empire" (Siddiqi 233) and also to the possible disturbance they impose. However, the description of the "tranquil English home" (Doyle, Sign 167-168) is a staple in both The Sign of Four and The Moonstone (Collins, Moonstone 296) (Mehta 612).

One of the hallmarks of sensational fiction, the genre Wilkie Collins wrote in, is the proximity of crime to the domestic (Mukherjee 166). This also holds true for The Moonstone which grew out of this tradition and is concerned with the immediate impact of colonial crime on the domestic sphere and the intrusion of Others into the home. The proximity of the Other is suggested through the presence of the Shivering Sands in the English landscape of Yorkshire (Carens 248). It implies that the English Yorkshire landscape is much closer to the colonial Other than might be evident at first glance. The interior of the Verinders' house itself betrays its long involvement with the East. Rachel puts the Indian diamond into the Indian cabinet, for the purpose of "two beautiful native productions to admire each other" (Collins, Moonstone 84-85). Her Indian cabinet belongs to the furniture and forms part of the English interior. Similarly, the crimes of the Rajah's Diamond, Mrs. Vandeleur's unchecked spending, covered by the diamond as well as Thomas Vandeleur's desertion in India belong to the inside of the London house as the proverbial "skeleton" ( Stevenson, "Rajah's" 75) in the cupboard.

The country house, on the other hand, is a metonymic representation of a selfsufficient and ordered national community (Kenny 204). Since the beginning of industrialisation, the urban centres overtook the countryside in importance so that the image of the country house is a nostalgic remnant. It is nevertheless used to set off the peaceful rural areas from the mysterious imperial regions. Prince Florizel unravels the story of the Rajah's Diamond on the bank of the Seine which, however, seems like "some country river" (Stevenson, "Rajah's" 130) in her tranquillity. Through the sinking of the diamond he tries to restore the purely rural which is supposedly untainted by and independent of imperialism.

In both The Moonstone and "The Rajah's Diamond", the contrast between roses and flowers and the diamonds is stressed, to juxtapose the exotic and the domestic rural. Sergeant Cuff explicitly states: "I also think a rose much better worth looking at than a diamond" (Collins, Moonstone 177). Instead of probing into the unsolved case of the Moonstone he prefers a discussion of the "dog rose" with the Verinder's gardener (177) ${ }^{15}$. After retirement, he devotes himself to his true pas-

15 In the context of the establishment of the detective police the depiction of policemen as something thoroughly English harks back to Dickens' attempts to popularise detectives in London. In Detecting the Nation Caroline Reitz argues that the detective police was only slowly accepted in England and was formerly regarded as outright un-English. Sergeant Cuff therefore has to "forge relationships with those figures who initially set themselves against him" (Reitz 60). 
sion, not the pursuit of mysterious Orientals in an imperial city but the cultivation of the national flower: "Far from the crimes and the mysteries of the great city, the illustrious thief-taker was placidly living out the last Sybarite years of his life smothered in roses!" (354). In "The Rajah's Diamond" the diamonds are "rolling here and there among the rosebushes like drops of morning dew" (84). The picture of innocence evoked through the flowers and diamonds as fresh dew stand in stark contrast to the description of the Rajah's Diamond as "crawling with the worms of death" and "compacted out of innocent blood" (Stevenson, "Rajah's" 131). The contrast which is established here pits the roses as a symbol of the domestic against the diamond. The value and exotic splendour of the one is juxtaposed with the native, natural but invaluable beauty of the other. In the face of the ancient and "unfathomable" (Collins, Moonstone 70) Moonstone the roses are the natural and unrefined answer that promise simplicity. In the same vein, the "little nosegay" reminds Ezra Jennings of pleasant experiences in England as opposed to his 'unspeakable' upbringing in the unnamed colony: “How beautiful they are!' he said simply, showing this little nosegay to me [Franklin Blake]" (366). The presentation of England as rural assumes that it is not involved in colonialism and also untainted by crime.

Betteredge with his "English ideas" (81) and long service in the Verinder family stands for the decidedly English values which are also present in the setting of the country house. His constant reading of Robinson Crusoe exemplifies his representation of Englishnesss. The religious reverence with which he treats it, however, rather evokes the Indian "hocus-pocus" that he condemns. He mimics Robinson Crusoe's use of the Bible during his isolation on the island so that Betteredge perpetuates the practise found in Robinson Crusoe using the narrative of European colonialism in the Caribbean to find answers in the use of Crusoe as "a combination Bible and Ouija board" (Mehta 622) in the present. Duncan asserts that Betteredge's domestic leisure pursuit is downright imperialist: "Robinson Crusoe is the founding fable of a modern, economic, and colonial formation of British identity, while tobacco is one of England's original imperial commodities" (Duncan 309-310). Betteredge's reading of Robinson Crusoe and his tobacco pipe brings together one of the earliest ideological founding texts of imperialism and its contemporary economic result. The substitution of Robinson Crusoe for the Bible already suggests the stand-in of imperialism for faith which marks the late-Victorian times (Brantlinger, Rule 228). Betteredge's ignorance of the connection between the theft of the Moonstone and the colonial implications of Robinson Crusoe is illustrated in his checking his digression on Crusoe with the words: "Still this don't look much like starting the story of the Diamond, does it" (Collins, Moonstone 19), when the colonial text clearly is a very good starting point for "the story of the Diamond." Gabriel Betteredge and Sergeant Cuff, who represent 'Englishness, are united by their ignorance of colonial connections to their respective situations. Cuff ignores the Indian origin of the Moonstone, and Betteredge equally unre- 
flectingly uses Robinson Crusoe. This denial ties in with the haze of forgetting and repressing which surrounds the theft of the Moonstone from Rachel's cabinet. In the following I will look at the way the intrusion of the Other is depicted and how contact with the Other is framed.

\section{The Moonstone: The Three Indians}

As the Indians do not speak, their characterisation relies on the perception of the diverse cast of letter writers. This strategy first and foremost characterises the people who describe the Indians rather than the Indians themselves. They function as a foil on which the different writers project their fears and expectations. The anonymous cousin's account of the siege of Seringapatam which forms the Moonstone's prologue, describes the ancestors of the Brahmins and depicts the custom of their watch over the diamond since the eleventh-century. The most striking characteristic in the Indians is the absence of any individual trait. Not only are the three Indians who follow the Moonstone to England undistinguishable, they have also been devoted to the same cause in the same manner over many generations. The lack of distinctive traits among the three Brahmins is complemented by their featurelessness as compared with their ancestors in Tipu Sultan's palace: "They are indistinguishable from each other, a unitary sign of India: as reliable and as persistent as ants, unchanged across generations, outside of history" (Dolin 77). For ages, the same task has been fulfilled by an undistinguishable procession of descendants of the Brahmins from Somnauth. While, in this case, the Brahmins belong to the realm of "fable" and "fanciful story" (Collins, Moonstone 13), determined by the nameless cousin's "superstition" (16) surrounding the Moonstone, they step out of the fairy-tale frame in Betteredge's description: For him they are not mythical agents of Vishnu's will but a threat to the Verinders family silver, while asserting that he would not "distrust another person because he happens to be a few shades darker than myself" (26). After the legend of the prologue, down-to-earth Betteredge relates the Indians only to his narrowly confined realm of the house. Apart from the comic effect, Betteredge's character is established as practical and unconsciously hypocritical. Betteredge who had earlier admitted to the Indians' superior manners later describes them as "snaky" and possessing a "tigerish quickness" (79). He further remarks that the Brahmins" pursuit of the diamond "didn't at all square with my [Betteredge's] English ideas" (81). The juxtaposition of the English and the Indian runs through other remarks by Betteredge: "Here was our quiet English house suddenly invaded by a devilish Indian Diamond - bringing after it a conspiracy of living rogues" (43). He furthermore condemns the Indians as practicing "hocus-pocus" (28) and later applies the same term to Ezra Jennings' experiment (403). For Betteredge, the alleged epitome of sound Englishness, "the Hindu priests [...] represent dangerous tropical animality that has encroached upon the temperate and familiar regions of Eng- 
lish country life." (Carens 247) However, the parallels between his own use of Robinson Crusoe for divination and his 'belief' in "that immortal book" (Collins, Moonstone 178) is not too far removed from the Brahmins' practice of clairvoyance (Mehta 622).

Murthwaite shares Betteredge's stereotypical assumptions, but he bases them on "his superior knowledge of the Indian character" (Collins, Moonstone 287) which he has acquired in "the wild places of the East" (74). He also describes the Indians as having the "patience of cats" and the "ferocity of tigers" (80), reiterating Betteredge's image of their "tigerish quickness" (79). Yet, Murthwaite's description of the Indians largely relies on generalisations of pseudo-science: He knows that "no Indian [...] ever runs an unnecessary risk" (286). Through his knowledge he rationalises their séance with the English boy: "The clairvoyance in this case is simply a development of the romantic side of the Indian character [...] We have nothing whatever to do with clairvoyance, or with mesmerism, or with anything else that is hard of belief to a practical man" (285-286). Rather than dismissing mesmerism as "hocus-pocus", Murthwaite offers Bruff an explanation for the Indians' behaviour, distinguishing the Brahmins' efforts at detection from his own rational method, which "trace[s] results back, by rational means, to natural causes" (286). For Murthwaite the Brahmins present the confirmation of preset rules, similar to the description of Tonga in The Sign of Four. But Murthwaite is also sympathetic to them, calling them "a wonderful people", while Betteredge insists on "murdering thieves" (81-82).

The evangelical Miss Drusilla Clack fashions the Indians into protagonists of her religious allegory: "How soon may our own evil passions prove to be Oriental noblemen who pounce on us unawares!" (203) For her, they are evil personified as opposed to the "Christian Hero" Godfrey Ablewhite and his natural antagonists. Through the satiric representation of Miss Clack these ascription have to be immediately questioned by the reader.

The Indians are further present in the text by the things they carry into London: In their assaults on Mr. Luker and Godfrey Ablewhite the Brahmins engage their attention through "two unusual things" (201): A manuscript laid out on a table and the smell of "musk and camphour" (201). Both evoke a mysterious and sensual Oriental atmosphere. The manuscript, "richly illuminated with Indian figures and devices" (201), seems to mesmerise the onlooker in a similar way as the Moonstone which draws all attention to it on its first presentation (70). Furthermore, the manuscripts are a symbol for the Indians' silence in the text which is constituted of letters but only contains one short written note by one of the Brahmins' collaborators in London (288). The manuscripts belong to the group of writing which remains unreadable like Franklin's "hieroglyphics" (178). Another signifier of the Indians' presence is a "morsel of torn gold thread [...] which persons expert in such matters declare to be of Indian manufacture, and to be a species of gold thread not known in England" (446) at the site of Godfrey Able- 
white's killing, which serves to indicate the Brahmins to be Godfrey's murderers. Together with the sound of their drums (78) which announces the arrival of the jugglers at the Verinders house, the Indians are surrounded by everything Oriental: The luxury of musk, the mystery of the manuscripts, the wealth suggested by the gold thread and the archaic and mesmerising beat of the drum. They thus represent the "romantic regions" (462) which are the origin of the Moonstone. The gold thread especially evokes the luxury of the eastern 'treasure trove' but it is, like the Moonstone, subject to the scrutiny of a detective.

Critics differ in their evaluation of Collins' presentation of the Indians. John R. Reed contends that the description of the Indians is absolutely positive. He sees them as "heroic figures, while the representatives of Western Culture are plunderers" (283). In the decades when the Indian Mutiny still loomed large in British fiction on India, the favourable depiction of Indians would be the more remarkable. Other critics foreground the negative stereotyping and marginal position the Brahmins occupy and the fact that the ultimate restitution of the diamond can only happen under British surveillance (Mukherjee 178). In comparison with the texts that took up the idea of The Moonstone in later years, Collins' treatment of the Indians is certainly more positive. The ambiguity he creates through the use of multiple perspectives through the epistolary mode stands in stark contrast to the description of Tonga by the authoritative voices of Sherlock Holmes and Watson.

\section{The Sign of Four: Tonga}

Tonga does not first and foremost exist as an individual but as an exemplary specimen of his race as he is described through the article of an encyclopaedia, which minutely defines him and prefigures his actions. The ability of "forming most devoted friendships when their confidence has once been gained" as well as the use of "their poisonous arrows" (Doyle, Sign 186) apply to Tonga and, predictably, will be confirmed by Jonathan Small. Similarly, the mention of "misshapen heads" (186), intractability and fierceness are confirmed in the rest of the story. The encyclopaedia thus provides an almost exhaustive image of Tonga who conforms to all the criteria set down for him. This is Orientalism in the narrower sense as defined by Edward Said: The Other has been made an object of study, scrutiny and knowledge. "The object of such knowledge is inherently vulnerable to scrutiny; this object is a fact [...] To have such a knowledge of such a thing means to dominate it, to have authority over it" (Said, Orientalism 32). Furthermore, the "fact" cannot change. Thus Tonga has to make use of his poisonous arrow, kill and generally display his fierceness and morosity. Holmes, in this instance, perpetuates what Caroline Reitz calls "the imperial gaze", the foundation of empire (Reitz xxiii). Holmes' all-encompassing knowledge of imperial subjects is already introduced in the beginning of the story. Among the "monographs" of which he "pleads guilty" are ones on distinguishing the hands of a diamond pol- 
isher and on different types of ashes to identify a lunkah-smoker. Together with another work on the tracing of footsteps a number of events in the story are already foreshadowed in writing (Doyle, Sign 126).

Christopher Keep and Don Randall observe that the description of Tonga's deformity evokes "contemporary accounts of the murderous rage exhibited by the Sepoys during the Mutiny, the maddened features of the cocaine addict, and late nineteenth-century fears concerning devolution and degeneration" (214). Tonga can be read as impersonating the curse of the treasure and as functioning as its evil spirit. The Mutiny, poison and going native are equally evoked through the Agra treasure, its theft and its intoxicating quality. The danger that emanates from both leads to Tonga and the treasure being sunk in the Thames together (Doyle, Sign 205), which further emphasises their connection. Yet Tonga does not only display every imaginable trait of barbarism, but he is also described as "a black cannibal" (188). Although he is a native from the Andamanese islands, his name connotes the South Seas and thus links him even closer to a region which was long thought to be inhabited by cannibals.

Tonga's main action is the murder of Bartholomew Sholto. The episode is a nod to E.A. Poe's "Murders in the Rue Morgue", which introduced the lockedroom mystery. Tonga shoots Bartholomew with a poisoned arrow and leaves traces which first leads the reader in the same direction as in Poe's version of the mystery: Holmes observes that Tonga's toes are "each distinctly divided" (170) and evokes the ape that turns out to be the murderer in Poe's story. After his escape, Tonga is then traced by a dog through the scent of creosote, another hint at his animal rather than human nature as he is turned into game $(160)^{16}$. Tonga's murder of Bartholomew Sholto additionally associates him with "Senegambia" in Holmes encyclopaedic knowledge of "parallel cases" (159). Tonga thus signifies more than just India but the generally dangerous and exotic Other capable of and importing crimes that have previously been unknown in England and must necessarily originate in some 'barbarous' region.

While both novels draw on the fear of infiltration, the Brahmins and Tonga as representatives of India paint two very different pictures. The Moonstone's Indians are the agents of an alien culture while Tonga is the personification of a threatening wilderness. The Brahmins, by their designation as such alone testify to the existence of a whole civilisation. This strange culture imbues the Moonstone with its meaning as a religious artefact. Tonga, by contrast, is not represented as the exponent of a native Andamanese society but as the embodiment of wilderness,. The image of India as such a wilderness also informs "The Rajah's Diamond" and John Vandeleur's character as a hunter (Stevenson, "Rajah's" 127). This presupposes the colony as jungle, a view which the two later texts share.

16 "The Crooked Man" is a Sherlock Holmes story with a locked-room mystery and a monkey as the alleged suspect. 
The Moonstone and The Sign of Four, nevertheless, frame fears of intrusion and invasion in a similar manner and draw on the popular perception of the Mutiny as a conspiracy against British dominion.

\section{Secret Societies and Thuggee}

The idea of a murderous and secretive India is largely based on two sources. The immense interest in Thuggee at the beginning of the century and its popularisation and fictionalisation in Philip Meadows Taylor's successful Confessions of a Thug (1839) almost certainly shaped the image of India as the site of murder which is rooted in religion but underpins the whole of society (Mukherjee 108). The problems which arose in the attempts to suppress Thuggee made for popular plots and secured it an afterlife detective fiction. The sensationalist press coverage of Thuggee also nurtured the belief that Thugs could appear in the middle of London or Paris, and motifs and figures from Thug narratives found their way into all kinds of crime fiction in the latter half of the century (níFlathuín 35-36).

The outbreak of the Mutiny revived the notion of Indian conspiracies as contemporary explanations centred on the existence of secret societies, which aimed to overthrow British rule in India. Again, it was thus possible to reduce the popular basis of the rebellion and deny a more widespread discontent with British rule. Furthermore, the theory also paid off ideologically, as British resistance and retribution was directed against the secret and cowardly plans of ungrateful conspirators (Pionke 114-118). Patrick Brantlinger also acknowledges the Victorian resorting to these theories and sees Nana Sahib cast into the role of prime conspirator, while at the same time Indians as a whole were held to be incapable of acting on an organised scheme (203).

Deception is therefore rooted not in personal ability but in religion which encompasses the whole of society. Thus concealment and murder are hallmarks of Indian rather than Thug culture (Reitz 25). Consequently, the Indians in The Moonstone and The Sign of Four, who allegedly conspire to harm English persons, appear as secret societies. The Moonstone might have been the "object of a conspiracy in India" (Collins, Moonstone 43) and Murthwaite remarks that "a Hindoo diamond is often part of a Hindoo religion" (74) and that there was "a conspiracy then in existence to get possession of the gem" (461). These instances show that the elements of the discourse of secrecy and conspiracy recur in The Moonstone with reference to the diamond itself. The depiction of the Indians, of course, follows the same lines. First of all, their "modest little Indian organisation" (284) conflates the image of the gang of wandering murderers with the emphasis on their religion. Their voluntary forfeiture of cast obliquely evokes the affair of the greased cartridges (Pionke 126). The mutineers in The Sign of Four are accordingly described as "fanatics" and "devil-worshippers" (Doyle, Sign 216). This also transports the underlying notion that they are completely determined by their religion and em- 
phasises the point that their actions directly grow out of their religious devotion in the same way as the Brahmins murder Ablewhite to fulfil their vow to Vishnu. Franklin Blake consequently ascribes their behaviour to the well-known "influence of oriental religions" (Collins, Moonstone 48).

The assaults on Mr. Luker and Godfrey Ablewhite can be read as oblique allusions to Thuggee. The assertion that human lives are irrelevant for them further stresses the connection (81). The Indians' method of strangling their victims leads Suvendrini Perera to the assumption that Collins derived them directly from Taylor's novel (113). The Brahmins' devotion to Vishnu and fulfilling of the god's command is reminiscent of the worship of Kali which is at the core of Thuggee. However, rather than directly drawing on Taylor, Collins might as well have used the most prominent stereotypes of his times which grew from Taylor's influential depictions as well as the more recent events of the Mutiny.

The mysterious "Indian plot" (Collins, Moonstone 283) at the centre of English society also articulates undefined fears of infiltration. It is as Caroline Reitz remarks the original constellation from which the English detective figure evolved and accordingly casts the conspiratorial pacts as his antagonist The "Indian plot" (283) suggests that there must be a hidden network of conspirators to support the pursuit of the diamond. The edges of this network are visible in the worker in Mr. Luker's shop, the letter the Indians receive in prison and the dummy who hires their rooms. Their dealings, however, remain hidden and impenetrable. The depiction of the Indians as subversive and invisible also leads to their perception as "spies"17 (285) by Bruffsuggesting invisibility but uncanny omnipresence. At the centre of this conspiracy is the diamond imbued with a secret meaning generated by a secret society which the English characters cannot read or even misread.

The motif of an Indian diamond at the centre of an Indian conspiracy is taken up again two decades later in The Sign of Four. Jonathan enters the secret pact to murder and steal the Agra treasure. When "the Four" are betrayed by John Sholto and Captain Morstan, Small seeks vengeance for his accomplices. It is further suggested that Small's implication in the otherwise exclusively Indian pact is part of his corruption and downfall in the colony, which, in the end, sees him in the place of a typical native guarded by white guards.

Doyle's novel explicitly links the Mutiny with the pact, but he might also have drawn on the contemporary fear of European secret societies which were thought to be imported to Britain by emigrant revolutionaries from the continent. The myth of Indian Thuggee is thus complemented by a literary current in novels of the end of the century to revolve around repentant terrorists who cannot escape their ex-comrades and are bound by an unbreakable oath (Ascari 54). Doyle alludes to this notion in his first novel A Study in Scarlet, where the obvious but

17 The method of spying, however, opens another interesting parallel as Betteredge confesses that the "natural occupations of people situated as we [Betteredge and Rosanna]" are "prying, and peeping, and listening" (Collins, Moonstone 149). 
wrong suspects are continental secret societies and German revolutionaries who hide out in London (Doyle, Scarlet 33). Major Sholto and Thaddeus Sholto, although not directly bound by the pact of "the Four", still break their promise and are consequently sought out by Small. Thus Thaddeus Sholto sees "secret agencies at work all around us" (Sign 147) and assumes the same omnipresent and deceptive plot as in The Moonstone. Both texts, however, assume different attitudes towards the secretive pacts. The opacity of the Brahmins' dealings juxtaposes Small's complete confession of the conspirators' deeds so that The Sign of Four presents a conspiracy that is finally unravelled. The diamonds instigate these conspiracies and function as the bond which draws the alien characters to England. They are associated with the obscure, criminal invasive.

The 'Close' Other

\section{The Eustace Diamonds: Harter, Benjamin and Emilius}

The mysterious Indians who follow the Moonstone and who are perceived as a threat to Rachel have somewhat less sensational counterparts in The Eustace Diamonds. The firm of Harter and Benjamin, Jewish moneylenders and jewellers, is responsible for the two burglaries to steal Lizzie's diamonds, one attempted and the other successful. As Jews they represent a version of the 'close' Other, alongside the racial hybrid as represented in Ezra Jennings.

The stereotypical depiction of Jews in nineteenth-century realist literature shifts from the mythical arch-villain to the economic criminal. His relation to the rest of society is structured by his economic activity and his exaggerated embracing of capitalism and casts him as a new threat to the established and especially to the landed society. This stereotype is backed by the much older stereotype of Jews as usurers (Schuhmacher 44-45).

In The Eustace Diamonds, Benjamin and Harter are from the beginning introduced as shady and dishonest, as they knowingly accept Lizzie's lies about her age and upcoming marriage and agree to support her scheme of letting Sir Florian pay her debts after their marriage (Trollope 40-41; 46). Mr. Benjamin's desire for the Eustace Diamonds surfaces very early on when Lizzie presumes that "if Mr. Benjamin got them into his hands, Mr Benjamin might perhaps not return them" (79), and "she was wise enough to know that [...] Harter and Benjamin were not trustworthy" (80), that they were not "as firm as rocks" (80). Respectability and honesty described as adamant firmness are also attributed to Lucy but not to Lizzie, who knows that she is "paste" (628).

According to Lord George, who is in debt to Benjamin, he has "'that greasy, Israelitish smile" (494). Harter and Benjamin are immediately suspected by the police to have stolen the diamonds (474): "That there was nothing 'too hot or too heavy' for Messrs. Harter and Benjamin was quite a creed with the police of the 
West-end of London" (475) and also by Lord George (493). Mr. Benjamin's involvement is finally proven, and he is sentenced to fifteen years of penal service (753). In the end Lizzie feels pity for Mr. Benjamin and tries to differentiate between his desire for the diamonds and her own, clinging to her self-deception: " $[\mathrm{H}] \mathrm{e}$ [Mr. Benjamin] coveted them. I never coveted them, Mr. Emilius, though I clung to them because they were my darling husband's last gift to me." (760) Lizzie's greed for the diamonds then is rendered even more repulsive as it connects her with Mr. Benjamin, who is ironically termed "her old friend" (478).

Lizzie's downfall is illustrated by her marriage to Mr. Emilius, who is "a renegade Jew" (639) with a "hooky nose" (759) whom the narrator disqualifies as a "scheming hypocrite, craving her [Lizzie's] money" (762), perpetuating the traits attributed to Mr. Benjamin. Mr. Emilius, a converted Jew, is additionally described as an impostor and a bigamist. While the narrator in The Eustace Diamonds only hints at Mr. Emilius' being married (636), later novels, in which Lizzie returns, confirm his bigamy (Sutherland 14). The descriptions of Mr. Benjamin and Mr. Emilius rely on a stereotyped image of Jewishness. The Jews in The Eustace Diamonds are united by their desire for Lizzie's diamonds and money. To get them Benjamin and Harter cooperate with the thieves Smiler and Billy Cann, and Emilius ingratiates himself with Lizzie and marries her. They are furthermore criminalized by their occupation as money-lenders, conforming to another established prejudice. Unlike the Brahmins in The Moonstone, they are not granted a redeeming excuse. Mr. Benjamin and Lizzie are both thieves and resort to lies and scheming to possess the diamonds. By introducing Benjamin into the story, greed is presented as an alien passion from which Lizzie suffers, too. It is a general "Jewish" fault as all three of the Jews in the novel, Mr. Harter, Mr. Benjamin and Mr. Emilius, are caught up in the pursuit of other people's wealth.

Jews who covet "English" diamonds also reference a contemporary colonial context. From the late 1860s onward, southern Africa supplied the bulk of diamonds on the market (Levinson 73-75). British and Jewish traders fought over the rights to claims in Kimberley, most notably Cecil Rhodes and the Jew Barney Barnato (Kaufman 518). Cecil Rhodes prevailed with the founding of De Beers which still controls the diamond industry and trade in Africa. Press and literature, too, depicted Jews who tried to secure a share of the market as inferior ${ }^{18}$ (Kaufman 519).

The Jews here function as another version of the Other: the Oriental "rogues" who follow the diamonds appear in their domestic version as greedy and deceiving Jews. Greed is thus dispersed and deflected. The Moonstone, however, features a character who is not involved in the pursuit of the diamond, but still represents the 'close' Other: the appearance of the colonial in the metropolis.

18 According to Heidi Kaufman, the anti-Semitic sub-text of H. Rider Haggard's King Solomon's Mines (1885) feeds on these historical circumstances and fictionalises the British conquest of Jewish diamonds in Africa (528). 


\section{The Moonstone: Ezra Jennings}

Ezra Jennings acts as an intermediary figure in the novel. Born to an English father and a foreign mother he personifies another version of the 'close' Other and "performs a link between the Indian frame and the English center" (Mehta 628). Three times Franklin Blake describes Ezra Jennings as "remarkable-looking" (Collins, Moonstone 321; 332; 356), thus constantly drawing attention not only to his racial markedness. The other "remarkable-looking man" in the novel is the chief of the Indians, who sees Mr. Bruff at his office. He speaks "in an excellent selection of English words" and appears in "European costume" (278). The adjective thus seems to be reserved for the more or less hybrid characters and emphasises their visibility without approving of their appearance which imitates English norms. The behaviour is similar to Homi K. Bhabha's concept of "mimicry" (Bhabha 86), which necessarily disturbs imperial self-fashioning and accounts for the excessive repetition of the "remarkable" appearances which finds the narrators lost for words.

In Franklin Blake's description Ezra Jennings' appearance seems inexplicably incongruent. He is neither young nor old and has piebald hair: "Over the top of his head it was still of the deep black which was its natural colour. Round the sides of his head - without the slightest gradation of grey to break the force of the extraordinary contrast - it had turned completely white" (321). To Franklin he "look[s] old and young together" (364). Furthermore, Jennings describes his own character as hysteric and alleges that "Physiology says, and says truly, that some men are born with female constitutions - and I am one of them" (369). His psyche, too, is described as indeterminate. His mental instability is further stressed by his opium use because of "an incurable internal complaint": "My nervous system is shattered; my nights are nights of horror" (375). Physical and mental illness are thus paired. The indeterminacy in his character stems from the "mixture of some foreign race in his English blood" (367) which Franklin Blake detects in his physiognomy, where he can "read" "[t] he story $[\ldots]$ in his face" (366):

His complexion was of a gypsy darkness; his fleshless cheeks had fallen into deep hollows, over which the bone projected like a pent-house. His nose presented the fine shape and modelling so often found among the ancient people of the East, so seldom visible among the newer races of the West. (Collins, Moonstone 321)

As in his bicoloured hair and indefinable age, Franklin's reading of Jennings' face shows that Jennings" body is the key to his "remarkable" position.

Ezra Jennings himself allegedly has an indistinct criminal past which is never fully explained and follows him as slander which he cannot set right (Collins, 
Moonstone 374). It is equally "a blank" (455) as his origin ${ }^{19}$. In the discovery of the diamond, he translates and completes Mr. Candy's confession spoken in delirium. Ezra Jennings functions as a medium because of his own opium usage and his intermediate and indeterminate position due to his mixed racial heritage. Through the mediation of Dr. Candy's delirious words, and in helping Blake to identify opium as the true cause for the theft, he is in both instances a "mysterious intersection point" (Thomas 71) situated on the borderline between sanity and insanity, the domestic and the Other. It also accounts for his access to Dr. Candy's irrationality. Both in Dr. Candy's delirious speech and in the revelation of Franklin Blake's involvement in the theft, Ezra Jennings interprets the subconscious to solve the crime. The regular representatives of the police, Superintendent Seegrave and Sergeant Cuff, at least partially fail at this task (Ascari 71).

Ezra Jennings offers an alternative method of detection, as many critics argue: "Jennings then is a man of faith as opposed to reason" (Murfin 663). Yet the opium experiment is conducted as a scientific undertaking and Ezra Jennings can finally offer the explanation for Franklin's theft, not the least because he is a professional physician and scientist (Thomas 70). His detection combines science with methods reminiscent of the Brahmins' mesmerism in his use of opium, and its success thus "unsettles imperial dichotomies" (Carens 257) as the combination proves successful. In criticism, Jennings' behaviour is seen as either proof of his role as "serving" Franklin and thus as a deliberate assertion of the existing imperial order (Nayder, Wilkie Collins 122) or as a subversive and triumphant undermining of racial stereotypes (Carens 256). Although Jennings is depicted as a wreck whose misfortunes, it is indicated, are at least partly caused by his heritage, he nevertheless assumes a position of power: Ronald R. Thomas argues that, in solving the crime, Jennings relies on the latest forensic research and applies it to turn Franklin Blake's body into the evidence for his guilt (67). The solution demands the scientific scrutiny of Franklin's body so that he finds himself in the same position as Ezra Jennings before him: Ezra's "remarkable" appearance, , speaks against him and makes him a suspect. The same scrutiny applied to Franklin's body, its "reading" proves his complicity albeit an unconscious one, in a crime.

All Others are first perceived as perpetrators and as inherently suspicious. The image of the "criminal who is by definition the "other"" (A.D. Miller 36) is turned around in The Moonstone. The potentially thieving Indians of Betteredge's narrative (Collins, Moonstone 26), later suspected of having stolen the diamond, are pronounced to be "as innocent as the babe unborn" (91; also 154). Following in the same vein, Ezra Jennings first elicits the expected reaction of distrust from Betteredge: "We none of us liked him or trusted him" (153; also 322) and Franklin admits that "his appearance [...] was against him" (364). Nevertheless, Ezra

19 Ronald R. Thomas takes it for granted that Jennings' mother is Indian (71), but this is never clarified in the text. 
Jennings turns out to hold the key to the mystery. The initial anticipation of an alien thief is turned around in the conviction of Godfrey Ablewhite. The Moonstone as the earliest of the texts discussed here thus presents the most ambivalent picture in the description of its racial Others, while in The Sign of Four and The Eustace Diamonds the stereotypical characters fulfil their role as villain. Ezra Jennings is further set off from the other outlandish characters because he does not desire the diamond.

The desire of the English protagonists for the diamonds is represented as infectuous and addictive. The intrusion of the Other is imagined as the spread of poison and the effect on the individual is a contamination. The diamonds are caught up in the same imagery and thus complement the invasion by a foreign people.

Oriental Contaminants and "the intoxicating chrystal"

A discussion of poison and drugs in the stories has become necessary for two reasons: The diamonds and their passing from India to Britain and through many hands suggests an image of imperial economy in which goods and raw material are hauled from the colony to the centre for profit and consumption. Drugs formed an important part in the economic relation with the colonies. Opium was harvested in India and profitably passed on to the Chinese market. Yet, addiction also became a problem in Britain itself and the potential dangers of the drug were realised. Opium and diamonds share a violent history, and a history of exploitation. Opium, according to Keep and Randall, is an "uncanny" element in British culture (207) which has not shaken off its imperial associations and as such resembles the diamonds as products which still remember the violence of their history. The opium traffic draws attention to the imperial economy and the close interrelatedness of the markets of India and Britain. It also exposes the suffering this market produces as the opium addicts appear in the heart of London itself.

Secondly, imported to and consumed in Britain, opium furnishes a powerful image of contamination:

Cultivated in India for export throughout the empire, $[. .$.$] opium above all$ other substances represented the global penetration and ontological contamination of a modern imperial economy. The commodity in its pure state as all-pervading, all subverting fluid, opium enthralls the inner subject to an alien, Asiatic identity. (Duncan 310)

Elleke Boehmer asserts that, especially towards the end of the century, the perceived threat of degeneration was articulated in images of contamination (66). Ezra Jennings serves as the prime example of mental contamination through opium addiction in combination with "the mixture of some foreign race" (Collins, Moonstone 367). 
In combination with the secret societies of The Moonstone and The Sign of Four, the image of opium metaphorically articulates the fear of infiltration. Opium shares this ascription with the diamonds in The Moonstone and The Sign of Four as the "quiet English house" (Collins, Moonstone 43) is colonised by the diamonds. In "The Rajah's Diamond" Prince Florizel actually uses the vocabulary of poison and drugs to describe the influence of the diamond when he says: "I myself, Mr Vandeleur, could scarce handle the intoxicating crystal and be safe" (Stevenson, "Rajah" 97 ${ }^{20}$. In the same way, Franklin describes the influence of the Moonstone: "Scattered, disunited - the very air of the place poisoned with mystery and suspicion [...] The Moonstone has served the Colonel's vengeance" (Collins, Moonstone 186). The influence of the diamond works to spread fear and disharmony and poisons relations. Their influence, analogous to the drug, is perceived as corrupting. The diamonds are, analogous to opium, described as addictive: The Rajah's Diamond casts a spell (Stevenson, "Rajah's" 130) and binds Thomas Vandeleur to the Rajah of Kashgar almost as a slave. His "peace of mind" is gone and the desire for the diamond replaces "honor, reputation, friendship, the love of country" (Stevenson, "Rajah's" 130). John Herncastle, too, obsessively pursues the Moonstone and refuses to give it up, although its possession is dangerous.

The diamonds present a condensed version of the process of Othering. The properties which are imposed upon them display Orientalist notions current in nineteenth-century Britain. At this point in time, when anxieties about the future of the empire grew, the fear and threat of the Other was imagined as contamination, especially in racial terms: "Despite efforts at containment, the fear of other cultures, or of the primitive, found its way into texts, cropping up in all manner of images of contamination, infection, and bewitching" (Boehmer 66, italics in the original). Opium thus also functions as a metaphor for the fear of corruption through alien influences.

Oriental substances then not only embody the infection with the native and Other, but also imply a grander scale than the single body as the site in danger as they circulate in the national economy. Society as a whole can be infected and disrupted by being poisoned, a threat ultimately growing from the expansion of the empire. With the 'body politic' as the target of Oriental poison and poisoners, the reach of this metaphor explains its persistence (Harris 452).

\section{Poison and Murder}

In nineteenth-century Britain, poisoning was regarded as a thoroughly Oriental way of murder. It was perceived as rooted in the eastern flora and fauna which

20 Jean-Pierre Naugrette suggests an etymological reading of the Moonstone as a 'gift', a present and poison at the same time. Opium has the same ambiguous properties as a medicinal and addictive drug (Nougrette 410-411). 
was, as such, thought to be harmful to Europeans. The land itself, it was believed, produces sicknesses and tropical plants which yield lethal poisons. The inhabitants, naturally and inevitably, use these poisons while it was thought that the use of Oriental poison by Englishmen was very unusual. This view of the poisonous East was so pervasive that scientific texts of the time frequently cite an undetectable Indian poison, the perfect but imaginary weapon for professional murder (Harris 447; 450). It was especially India that served to supply hideous and secret ways to commit murder (Reitz 25). Again, the influence of Meadow Taylor's Confessions of a Thug (1839) and his depiction of the strangling and secretive sect might have reinforced the image of deceitful and skilled murderers. This notion is combined with the general perception of India as naturally unhealthy for Europeans.

The definitive association of poison with the Other is evident at the scene of Sholto's murder in The Sign of Four. Holmes' reasoning depends on the assumption that no Englishman would commit a murder using such an Oriental weapon as Tonga's poisoned arrow. The identification of the poison with the land it comes from is apparent, as in Jonathan Small's account the Andamans are described as "dreary, fever-stricken" (Doyle, Sign 226), surrounded by shark-infested waters (186), and Tonga is "as venomous as a young snake" (231). Thus, naturally, it is he who brings the deadly poison to England.

Another case of poisoning can be found in "The Rajah's Diamond". John Vandeleur, who has been introduced as completely reckless in the hunt for diamonds, poisons Simon Rolles to steal the Rajah's Diamond (115). It is suggested that John Vandeleur has not only acquired riches in the colonies but also poison and, more importantly, the inclination to use it. The "transmission pattern" (Harris 452) is the same as in many Sherlock Holmes stories which revolve around the return of Englishmen from the colony, who bring with them an exotic poison and a mind to use it. This is attributed to their prolonged contact with an alien and corrupting environment. The other culture is thus presented as both morally and physically unhealthy (452). The motive for both the murder of Bartholomew Sholto and the poisoning of Simon Rolles is greed for the Indian diamond. The influence of the diamond on the mind has already been described in terms of a poison (Stevenson, "Rajah's" 97) and subsequently leads to poisoning, presumably with an Oriental toxic.

There is yet another way to link poison and diamonds: in their respective connections to alchemy. It has been suggested that, in earlier times, Indians considered diamonds to be poisonous when swallowed (King 37). Transmitted to Europe in the Middle Ages, this lore was turned upside down and diamonds were used as a cure against poison. C.W. King, Collins' source, reiterates the ancient association of diamonds and alchemy (Hennelly 31) (King 6; 10) which must have arisen from these earlier beliefs. The texts, consequently, link diamonds and chemistry as in John Herncastle who intends to found a professorship of experimental chemistry, should the Moonstone be cut up (Collins, Moonstone 47) (Thomas 72). 
The Agra Treasure is hidden above Bartholomew Sholto's rooms which are, not purely by chance, outfitted as a laboratory (Doyle, Sign 233). The belief in the magical alchemistic properties of diamonds is translated into the scientific interest in chemistry which, nevertheless, investigates invisible influences and potentially harmful substances. It is noteworthy that both Herncastle and Sholto are presented to have acquired this interest in India.

\section{Opium and Contamination in The Moonstone and The Sign of Four}

In the texts, opium and cocaine are presented as both controllable and threatening forces. A connection between the diamond and opium is established almost from the beginning of The Moonstone. The history of the Moonstone includes its theft from the city of Somnauth (12), named after the Hindu god of the moon but also the ritualistic Vedic drug (Mehta 629). This link with another Indian drug ${ }^{21}$ paves the way for the entwining of opium and diamond. The linking of opium and the Moonstone is evident very early on when, in Betteredge's account, Herncastle is described to be "given up to smoking opium" after his return from India (Collins, Moonstone 40) (Mehta 630) and Betteredge implies that the story of the Moonstone might just be a product of his imagination, "a matter of opium" (45).

Opium also figures in Jonathan Small's narrative of his theft of the Agra treasure during the Mutiny, albeit imbued with different connotations. The rebelling sepoys outside the besieged fort are described as drugged: "The beating of drums, the rattle of tomtoms, and the yells and howls of the rebels, drunk with opium and with bang" (Doyle, Sign 218). The connection of the Mutiny and opium heightens the perception of the rebellion as irrational and thus unjustified. The evocation of drums and inarticulate yells suggests primitivism and a lack of restraint. It is these aspects which Keep and Randall see embodied in Tonga (214). Patrick Brantlinger's remark on the Mutiny that "[m]ost Victorian accounts insistently mystify the causes of the Mutiny, treating the motives of the rebels as wholly irrational, at once childish and diabolical" (Rule 222) also provides the adjectives which apply to Tonga, who is first thought to be a child and then a simian (Doyle, Sign 160). The introduction of "opium and bang" into the narrative thus serves the same effect as the accusation of secret societies at work in instigating rebellion in "Indian plots" (Pionke 115). Another such image without mention of opium consists of "the black fiends [...] dancing and howling round the burning house" (Doyle, Sign 216). Uncontrollable ecstasy connected to drugs and the violence of the Mutiny are brought together and form the backdrop for the theft of the Agra Treasure. With both Tonga and Herncastle, opium finds its way to England in the wake of the diamonds. The connection between opium and diamonds, Hennelly suggests,

21 The actual plant that yields Soma cannot be ultimately identified in Vedic scripture but probably was hallucigenic (Hillebrandt 4). 
thus lies in their shared "irrationality" (31) so that both can also stand in for the event which escapes all attempts at rationalising, the Mutiny.

In the theft of the Moonstone in England, opium has a twofold function: Superficially, it leads Franklin Blake to theft, but it also exculpates him. Collins wrote The Moonstone under the influence of strong doses of laudanum and claimed that he did not recognise what he had been dictating before as his own invention (Hayter 255). In fact this is exactly what Alethea Hayter has identified as a common characteristic in descriptions of the effects of opium usage (333). She furthermore describes the genesis and content of the novel as "the actions of an opium-dosed man $[. .$.$] described by an opium addict who is the invention of a writer heavily$ dosed with opium" (159). The inability to recall actions under the influence of opium is pivotal to the plot of The Moonstone. The accidental dosing of Franklin sets in motion the theft and quest for the Moonstone. It is assumed that opium brings about a split of personality with a sober and a drugged conscience functioning independently of each other. For this reason the detection of the diamond is only successful when Blake is dosed again. The experiment Jennings conducts with Franklin draws on an assumed regularity and predictability of the effect of opium under similar circumstances. The trust in the ultimate rationality of the working of the drug informs the use of opium in the detection of the diamond in The Moonstone and turns it into a tool. The "irrational" which Hennelly assumes as the connecting property between diamond and opium lets Franklin steal the Moonstone while the second dosing harnesses the drug for a controlled scientific experiment.

Dr. Candy's "mysterious amnesia" after he has dosed Franklin (Duncan, 314) and Franklin's own inability to remember, tie in with the denial of agency which informs many of the texts discussed here. The emphasis on forgetting also implies repression which I will deal with later. If opium is read as an Oriental contaminant, Franklin under its influence reveals a formerly repressed side of his character (310). The appearance of the Indians in the countryside and the presence of opium in his body all threaten the stability of the country house community and the possession of the Moonstone. It should, however, be noted that Dr. Candy's administration of opium is connected to another colonial product. He wants to cure Franklin's insomnia induced by his weaning from the smoking of cigarettes, the fashionable addiction of the day (310). Tobacco in The Moonstone is the inevitable accompaniment of Betteredge's reading of Robinson Crusoe. As a colonial product from the West Indies it is as permanently connected with colonialism as opium (GoGwilt 78). One colonial substance is thus replaced by another suggesting that the overt intrusion of opium into the English house is by no means an unparalleled or singular event.

The Sign Four begins with Sherlock Holmes' injecting himself with cocaine. Although cocaine originates in South America it came to be regarded as resembling opium. It was first used and discussed as a valuable medicine. By the 1890s, how- 
ever, its addictive nature, colonial origin and degenerative effects led to its association with opium (Keep and Randall 209). The conflation of the two went even further as cocaine was classified as "a sub-category of opium" which obscured its chemical and geographical origins (210). Both Tonga's poison and Holmes' cocaine are actually derivatives of alkaline. ${ }^{22}$ In the description of the rebels mad with opium, Sherlock Holmes' sobriety when under the influence of the drug is juxtaposed with their irrationality. He methodically uses it to bridge the ennui between his intellectual engagements.

The treatment of opium and opiate derivatives in The Moonstone and The Sign of Four is ambiguous. Yet, the association of opium and the Mutiny provides a much more threatening image in the later text. Remarkably, although the effect of opium turns the Indian mutineers into an irrational mob, the English users of the drug can turn it into a tool for detection and apparently even control it. In The Moonstone, the unreliability of Herncastle's story is based on his having been "a notorious opium-eater for the years past" (Collins, Moonstone 45), while the detection of the diamond demands "accepting a matter of opium as a matter of fact" (45). Opium, in the ending of The Moonstone is not the substance to cloud but to lighten. While Louise Foxcroft and Kathleen McCormack assert that generally in Victorian fiction the negative and immoral aspects of the drug are emphasised (McCormack 138; Foxcroft 58), The Moonstone reflects the early Victorian stance towards opium as a medicine. In addition, Collins' own attitude certainly also led to a more favourable depiction.

Contrarily, The Sign of Four explicitly aligns opium with the violence of the Mutiny and assigns it to the periphery of the story and the empire. In The Moonstone, on the other hand, opium takes centre-stage in the crime and its solution.

Doyle's Sherlock Holmes represents the fin-de-siècle aesthete for whom opium alone is "too quotidian a drug" (Foxcroft 57). In the use of cocaine, the drug does not have the same uncontrollable effect on Holmes as opium has on the Indians. Unlike The Moonstone, The Sign of Four shows the different effects the drugs have on the white and contained character of Sherlock Holmes, and the uncontrolled Indians in Small's narrative of the Mutiny.

\section{Going Native}

One of the fears surrounding empire which found expression in imperial Gothic was the anxiety about an atavistic backslide into "barbarism" through contact with the Other (Brantlinger, Rule 229). The idea is based on an earlier turn in imperial attitudes towards race: From about the middle of the century onwards, supremacy over subject peoples was not imagined to be grounded in a superior culture and

22 Morphine, Holmes' alternative to cocaine, is a derivative of opium and subject to the same process of Orientalisation. 
rapid industrial progress any more, but in race. Before the 1860s, racial others could still be 'civilised'. With the turn to Darwinian explanations of supremacy, race and the purity of race become the defining markers of superior civilisation and the legitimation for rule (David 88-89).

In the texts discussed, there are several different images which draw on this theme. In all of them the influence of the colony is depicted as deforming and asserts itself as deviation in body and/or mind. The body which is deformed and altered through contact with the Other highlights the notion of racial difference. Contamination through Otherness therefore also shows in the body and also points to a mind tainted by the other:

[T] he coloring, physique, physiognomy, and vestments of the European body all bespoke the puissance of a ruling race, as it was celebrated in public rituals of social power, whether on parade or on a hunt. But at the same time Europeans were continually aware of the weakness and vulnerability of their bodies. Influenced by the theories of degeneration that were popular in the late Victorian period, English people believed that imperial location had harmful effects upon European bodies, passions, and intellects. (Siddiqi 241)

What I will look at first is the deformed body in "The Rajah's Diamond" and The Sign of Four. The Sherlock Holmes stories swarm with "returned colonials"23 and the concept is ever present in Holmes' co-lodger and biographer John Watson. In A Study in Scarlet, Watson introduces himself as a former army surgeon. He was "struck on the shoulder by a Jezail bullet" (Doyle, Scarlet 3), followed by "enteric fever, that curse of our Indian possessions" and his "health [was] irretrievably ruined" (4). The colony here appears as a place of both human and natural violence from which Watson barely escapes. In The Sign of Four Jonathan Small suffers very similar afflictions: A crocodile bites off his leg in the Ganges (Doyle, Sign 214) and he serves his sentence on the Andamans, a "dreary, fever-stricken place" (226). As if to emphasise the connection between the two characters, Watson's wound, located in his shoulder in A Study in Scarlet, suddenly wanders to his leg in The Sign of Four (Doyle, Sign 125) (Mehta 636).

Jonathan Small's mutilation has to be connected with his involvement with the "Sign of Four", the Indian secret pact, which also transfigures him morally ${ }^{24}$. To-

23 One of the most conspicuous is Henry Wood in "The Cooked Man": Tortured by Indian rebels during the Mutiny he is deformed, "carried his head low and walked with his knees bent", "he spoke in a strange tongue sometimes" (Doyle, "Crooked" 656), "living and crawling with a stick like a chimpanzee" he has lived among Indians rather than return to England (660). India obviously has reduced Wood, who was once "the smartest man in the One Hundred and Seventeenth Foot" (658) to a more animal-like creature, an association which is driven home by his only companion, a mongoose.

24 Thomas Vandeleur in "The Rajah's Diamond", induced by greed, also enters a pact with an Indian and serves him against his own countrymen during the Mutiny. He "betrayed a body of 
gether with the three Sikhs, Jonathan Small swears the oath that makes him one of "the Four", an Indian conspiracy to murder for greed. The oath is taken in the Agra fort which is divided into two parts: "[A] modern part, which took all our garrison, women, children, [...]" and an "old quarter, where nobody goes, and which is given over to the scorpions and the centipedes" (Doyle, Sign 216-217). The old part is "a labyrinth of passages and corridors" and "it is easy for folk to get lost in it" (217) and it is here that Small agrees to enter the pact. The fort thus figures as the wilderness and the uncivilised. The labyrinth is exactly the place where Small gets lost morally. This is the place where the treasure is buried (225), in the wilderness of a ruined hall.

Small stays true to his oath and seeks revenge for his Sikh accomplices. The racial difference in this pact is dangerously blurred and following racist logic, overstepping the line leads Jonathan Small to crime. On the Andamans, he is then guarded as a prisoner by Sholto and Morstan, the reversal of his employment as supervisor on the indigo plantation before the Mutiny. In his change from supervisor to supervised, Small's descent is apparent as he has left the white and ruling class of the guards and is classed with captives and criminals, the natives. Furthermore, the white officers are not the only people who have power over him now, but the camp is also guarded by "a vile Pathan who had never missed a chance of insulting and injuring [Small]" (232) and Small is being "bullied by every cursed black-faced policeman who loved to take it out of a white man" $(213)^{25}$. Jonathan Small's pairing with Tonga offers another instance of his native character. While Tonga is implicitly dehumanised, Small, too, is described as "monkeyfaced" (180). The connection between the two, however, is revised after Tonga's death. Small confesses that his friend killed Sholto and claims, in an attempt to win favour, that he himself would never have committed this deed.

Driven by greed, Thomas Vandeleur in "The Rajah's Diamond" also enters a pact with an Indian and serves him against his own countrymen during the $\mathrm{Mu}$ tiny. He "betrayed a body of his fellow-soldiers, and suffered them to be defeated and massacred by thousands" (Stevenson, "Rajah's" 175). John Vandeleur, "the biggest adventurer" and some-time "Dictator of Paraguay" is known for "his exploits and atrocities" in America and "services in the Indian Mutiny" (96).

$[\mathrm{H}]$ is whole appearance that of a swift, violent, unscrupulous man of action; and his copious white hair and the deep sabre-cut that traversed his nose and temple added a note of savagery to a head already remarkable and menacing in itself. (96)

his fellow-soldiers, and suffered them to be defeated and massacred by thousands" (Stevenson, "Rajah's" 175).

25 Yumna Siddiqi argues that it was especially colonial working-class characters like Jonathan Small who worked in direct contact with the natives, as on the indigo plantation, that threatened the clear division between the rulers and the ruled (239). 
In John Vandeleur, even more so than in his brother, the colony is connected with amorality and crime. Prince Florizel insinuates that he has no scruples in the pursuit of diamonds (97). Here again moral depravity is marked on the body, the scar which makes Jack Vandeleur look savage and serves as a visual reminder of the disfiguring influence of the colony. In his love for the diamond he parallels his brother, but Thomas is not so much interested in the hunt for diamonds as in climbing the social ladder through wealth. Jack Vandeleur has his double in the original owner of the diamond, the Rajah of Kashgar, who is a "semi-barbarian potentate" and in Prince Florizel's story of the diamond, evidently a tyrant (130), very much like the despotic Dictator.

Godfrey Ablewhite and Murthwaite, the traveller, are examples of Europeans trying to pass as natives. In The Moonstone, which is not as obsessed with anxieties of contagion as the Sherlock Holmes stories, two versions of disguise exist: Murthwaite is the "celebrated Indian traveller [...] who, at risk of his life, had penetrated where no European had ever set foot before" (Collins, Moonstone 74), "beyond the civilized limits" (81). He at once detects the Brahmins' disguise as jugglers (79) because of his "superior knowledge of the Indian character" (287). In his conversation with Matthew Bruff, he is able to partly explain the "Indian plot" just through the information the solicitor gives him. In this rational reasoning on the grounds of second-hand information, he employs the favourite method of Sherlock Holmes (Mehta 633). Although Murthwaite can "pass" "undetected" (Collins, Moonstone 462) among the Indians, he is not in the same danger of losing his English identity as Jonathan Small or Thomas Vandeleur. "Murthwaite demonstrates the detective's unromantic "English mind" (Reitz 62) as opposed to "the romantic side of the Indian character" (Collins, Moonstone 285). In Caroline Reitz' study on the colonial origin of the English detective, Murthwaite is paired with Sergeant Cuff, the epitome of Englishness (Reitz 61). In The Moonstone's last chapter, Murthwaite assumes the "imperial gaze", separated from, aloof and superior to the Indians and the Hindu ceremony he surveys (Reitz xxiii). The comparison of his position with Jonathan Small's direct involvement shows the security of the one and the precariousness of the other's white identity.

The principle that the criminal is always the Other (A.D. Miller 36) is played with in the character of Godfrey Ablewhite. To escape, he also uses a disguise. He dresses as a lascar and darkens his face. Sergeant Cuff discovers "the whiteness of the thief' (Nayder, Wilkie Collins 119) when he washes off the paint and at the same time undermines the notion that the perpetrator always has to be Other.

The characters whose English identity is thus threatened are Godfrey Ablewhite, John Herncastle, the Vandeleur brothers and Jonathan Small26. They are 'infected' by contact with the Other but also by contact with the diamonds. "[G]reed [...] has been my besetting sin" (Doyle, Sign 145), John Sholto avows. In

26 I leave out Thaddeus and Bartholomew Sholto as they seem to have 'contracted' their decadence and Orientalness from their father, John Sholto, in a curious instance of heredity. 
different forms, the characters desire the diamonds and are consequently disfigured by the contact with the Orientalising vice of greed. They are obsessed with the idea that the diamonds are valuables which have to be obtained at all costs. The Sholtos, John Vandeleur and John Herncastle are, accordingly, in relation to the diamond, depicted as unscrupulous collectors of treasure. The presence of the diamond as a collectible thus leads to the discourse of degeneration through the appropriation of an Oriental practice.

\section{The Return of the Repressed: The Diamonds as Uncanny Spectres}

In his essay "The Uncanny" (1919), Sigmund Freud defines the uncanny by reiterating the etymology of its German equivalent and the relation between things beimlich and things unbeimlich. He explains the etymological relation by stating that the uncanny is "something repressed which recurs" (Freud 166, italics in the original) and which is intrinsically known. The known and beimlich fact turns unheimlich when it reappears in an altered form from the state of repression to which it had been banned (166). The imperial gothic, like the gothic, is preoccupied with this kind of return and the uncanny effect of the altered revenant.

The most obvious instances of repression are the sinking of the Rajah's Diamond in the Seine and of the Agra Treasure and the Great Mogul in the Thames. In both instances the irretrievability of the diamonds is emphasised. Jonathan Small throws the Agra treasure into the Thames because he insists that "no living man has a right to it, unless it is three men who are in the Andaman convict barracks and myself' (Doyle, Sign 212). He distributes the treasure over a great stretch of the riverbed so that it is impossible to retrieve it. Tonga, too, lies on the bottom of the Thames, and in describing his resting place, Watson conspicuously employs the present tense when he says that "[s]omewhere in the dark ooze at the bottom of the Thames lie the bones of that strange visitor to our shores" (Sign 205) (Keep and Randall 217). The impossibility of recovering the treasures and Tonga's body assures their continuing existence in the rivers.

Prince Florizel throws the Rajah's Diamond into the Seine to end "its empire" (Stevenson, "Rajah's" 131). The sinking of the Rajah's Diamond collides with the discarding of the "Arabian author": In the end of "The Rajah's Diamond", the editor takes his place in finishing the story and sends the "Arabian author" "topsy-turvy into space" (131-132). In discarding the "Arabian author" of the presumed 'original', Stevenson turns around the hierarchies which have been established in the text before, as the narrator/editor professed that he "must follow [his] original" (Stevenson, "Rajah's" 102). Thus in the final paragraph, "the outside narrator, by the merest succession of words and sentences, can turn the Arabian author into an invention and the narrator into a reality" (Menikoff 343). While the "Arabian Author" is exposed as literary, the editor meets Prince Florizel in a metalepsis which bridges frame and nested narrative. The authority of the Oriental 
original text and the "empire" of the diamond are both discarded in the same moment. The Rajah's Diamond, too, is unlikely to be recovered as its exact position in the Seine is unknown (Stevenson, "Rajah's" 131).

Both the Rajah's Diamond and the Great Mogul of the Agra treasure cannot be recovered from the rivers. While this on the surface denotes their 'destruction', this happens without touching their integrity and destroying their identity. At the bottom of the rivers they thus continue their existence as mnemonics, which is a more threatening prospect than the actual destruction of their identity through cutting. It is noteworthy that both texts emphasise the impossibility to recover the diamonds so that they will have an continuing presence. Both the Thames and the Seine are gateways of imperial cities to their overseas colonies. The interrelatedness of metropolis and colony through the transportation of goods and people takes place through this connection (Keep and Randall 217).

Repressed colonial history also informs the description of the Moonstone. The appearance of its lustre as unfathomable depth links it to the Shivering Sands, the close site of repression in the Yorkshire landscape. Rosanna Spearman feels drawn to the quicksand, which has "laid a spell on [her]" (Collins, Moonstone 34) and exercises an irrational power. It literally functions as a place of suppression when Rosanna destroys evidence of Franklin Blake's guilt by throwing the stained nightgown in the quicksand.

Moreover, the Shivering Sands visualise colonial violence. The anthropomorphic description of the quicksand as a "broad brown face" (35) alludes to the racial Other. Rosanna further describes the Shivering Sands as concealing "hundreds of suffocating people under it - all struggling to get to the surface, and all sinking lower and lower in the dreadful deeps!" (35). The suffocating and amorphous multitude represents colonial upheaval (Mehta 625) and can be related to the Black Hole of Calcutta, the Well of Cawnpore and the Mutiny, or Morant Bay (Mehta 623; GoGwilt 67). Yet the image is ambiguous enough to merely suggest violent subversive turmoil suspended before the outbreak. The indistinct movements are half hidden with an intact surface concealing their true nature. The repressed still stays in place but shows that repression is precarious. The presence of the Shivering Sands close to the Verinders country house reveals the proximity of the perceived Other. The quicksand is furthermore situated between land and sea and at high tide lies underwater (Collins, Moonstone 49). The tidelands are a liminal landscape only temporarily exposed and a threshold between land and sea. Franklin travels to such a place when he camps "on the borders of a desert" (292). These "borders" are a similarly indefinable landscape between civilisation and wilderness. Both sites then suggest the theme of possible transgression.

Catherine Wynne traces a whole sequence of such instances of "unstable grounds" (76) in Doyle's works ${ }^{27}$ which are, or so she contends, an image of the

27 The bog in Doyle's The Hound of the Baskervilles, another story of a troubled imperial inheritance, also belongs to this category. 
uncivilised in the midst of civilisation (77). The Andamanese swamps and the Thames marshes in The Sign of Four as well as The Moonstone's Shivering Sands, are representations of treacherous ambiguity. They are not only physically but also psychologically threatening (77) as a landscape which exists both in the colony and in England. The "fever-ridden swamps" (Doyle, Sign 213) on the Andamans and the "melancholy Plumstead Marshes" (204) are the sites where the struggle for the treasure takes place and which are thus linked (Wynne 78).

The common denominator which connects the quicksand as a site of repression with the rivers is the spatial dimension. The repressed is topographically situated at the bottom and imagined as buried which reflects its psychological place in the sub-conscious. Suppression can thus be visualised as 'sinking', through permeable surfaces. This place below the suface is assigned to the diamonds and to Rosanna Spearman and Tonga. While Rosanna carries with her revolutionary ideas as voiced by her friend Limping Lucy, Tonga is the diabolic personification of the Mutiny.

Forgetting and silencing, too, are markers of repression and accompany the acquisition of the Rajah's Diamond and the Moonstone. The unspeakable nature of Thomas Vandeleur's services, which, are the true "skeleton in the house" (Stevenson, "Rajah's" 75), and John Herncastle's silence mirror the discourse of the Mutiny. As "The Rajah's Diamond", The Moonstone and The Sign of Four all emphasise the historical background of the hunt for the diamonds, the diamonds are associated with colonial violence and colonial history. While both are confined to the far-away periphery, the diamonds bring these events uncannily close. Like real diamonds which are typically invested with some legendary history, the fictional diamonds reveal the violence behind the flow of wealth to Britain. The protagonists in Britain thus have to be absolved from this guilt so that acquisition by chance becomes a common feature. The amnesia in Dr Candy and Franklin Blake equally bears traces of repressing guilt.

In the same way that opium turns Blake into a thief by activating a buried identity, the diamonds animate "dark and irrational passions" (Carens 240-241), which was projected on the Other but actually exist in the middle of English society. Greed and criminal intentions are constantly ascribed to Others, as the Rajah of Kashgar in "The Rajah's Diamond", the Sikhs in The Sign of Four, the three Indians in The Moonstone and the Jews in The Eustace Diamonds, but actually motivate the Vandeleur and Sholto brothers, Godfrey Ablewhite and Lizzie Eustace. The repressed thus also comes to reside in the Others as the "evil passions" as evangelical Miss Clack warns: "How soon may our evil passions prove to be Oriental noblemen who pounce on us unawares!" (Collins, Moonstone 203) 


\section{The Curse}

The curse that the diamonds carry is a hallmark of all the stones in the texts. It implies a malignant supernatural influence which has been wilfully bestowed on the diamonds to turn the pleasure of their possession into punishment. The curse which rests on the Moonstone is conditional. Only if the stone is taken from Soma's statue will the taker be cursed. Vishnu's prediction is turned into a curse by the dying Brahmin. In folklore, gods and persons close to death are believed to have special powers in cursing so that Collins evokes an extremely powerful invocation in combining the two (Anon., "Curse"). While in The Moonstone, the pronouncing of the curse is described, the other diamonds are perceived as cursed because of the misfortunes which are seen as an effect of a curse. The curse, then, is fashioned from crimes attributed to a single root and follows the logic of gothic fiction: "[F]ollowing the psychological mechanism of cause and effect $[\ldots]$ evil is rooted in previous evil" (Ascari 53). The biblical idea and the new interest in heredity combine in the plot so that the curse can be passed on over generations (58). This is illustrated in the emphasis on the diamonds as inheritance which shows the hold of the dead over the living and the ongoing influence of the past. The diamonds not only function as the focus of a chain procession of crimes but as uncanny agents implying "that the history of this particular commodity informs and even determines that of its possessor" (Lindner 74) as it conforms to and repeats past events. The belief in a supernatural phenomenon is contingent on the diamonds belonging to the east, the realm of romance, where the 'cursing', as Collins describes it, seems possible.

In The Moonstone, the diamond is under the protection of Vishnu. The god promises to destroy those who violate his decree. In the first chapter of The Moonstone, two sources for the curse are thus given. One arises from the breach of a religious law and the profaning of the diamond. The stories of historical diamonds provide ample sources for diamonds being stolen from temples and statures.

The other source as perceived by the letter writer, stems from Herncastle's crime of manslaughter. According to the anonymous cousin, it is not Vishnu's curse which will prove dangerous but Herncastle's crime of theft and murder, when he asserts "that crime brings its own fatality with it" (16). This guilt shares the curse's longevity and will pass from one owner to the next (16). The old age of the Moonstone and the accumulated crimes also play an important part in its curse. Its historicity alone serves to characterise it as evil, as Sara Suleri argues that Indian pre-colonial history was uniformly regarded as "evil" (34).

The cursed diamonds form part of a larger discourse on uncanny colonial objects. Very successful later examples of the same notion are mummy narratives which also rely on the sensational appeal of exoticism and occultism. Like the diamonds, they are the remnants of a colonised culture. Their removal, however, is perceived as the same sacrilege as the one attached to the theft of diamonds, and leads to the curse. Mummy narratives, too, draw on the uncanny effect of the 
reappearance of the Other in the metropolis and thus spell out fears of invasion. As dead bodies uncannily preserved, they also suggest the confusion of animacy and inanimacy which is perceived as uncanny (Freud 157). Both are strange objects which come to life again to invade the familiar space with their colonial presence. All in all, the perception of the diamonds as uncanny remnant relies on their association with unacknowledged crime and the revelation of the brittleness of boundaries between the Other and the Self.

\section{Conclusion}

Looking at the diamonds in the texts from many different angles shows that diamonds as objects of detection are singular in many respects. They combine a multi-layered imagery with a highly topical interest of the Victorian period. As Indian objects, the fictional diamonds evoke their real life counterparts which are themselves the subjects of story and legend. As objects, the fictional diamonds find numerous parallels in named and unnamed diamonds in collections and trophies of war, the most important being the Koh-i-Noor. Hence, the diamonds are not a self-referential 'MacGuffin' but open up a large area of colonial objects with their own stories.

In the discourse of detection, the diamonds appear as criminal as the thieves themselves. In fact, one of the hallmarks of the diamond narratives is the confusion surrounding the crime. Thefts depend often entirely on chance or on accidents while the diamonds themselves are blamed for their 'poisonous' influence. The problem posed by the circulating commodity in England is augmented by the diamonds as individualised Indian artefacts with a distinct history of their own. The multiple thefts and owners testify to the uncertainty and fear surrounding the diamond. The detective's presence owes to the Otherness of the diamond and the impossibility of their smooth integration into imperial possession. They individualise the otherwise anonymous flow of goods through their singular identity and history, fashioned on existing stones. The diamonds' socially and economically disruptive presence is evident in their role as inheritances, a practice that is supposed to grant stability and continuity but achieves the opposite. The diamonds are imagined as parallel to opium, as sharing not only their provenance but also their effect on society.

The social disturbance which the diamonds create is supplemented by foreign intrusion in the form of Others who also desire the diamond. They threaten possession and transport colonial crime into English society. The Jews in Trollope's realist novel fill the same place of the opposing party. The greed which motivates the English characters finds its counterpart in the Orientals and depicts the desire for the diamonds as a potentially corrosive and un-English threat.

Diamonds inevitably invite references to fairy tale and the intertext of the Arabian Nights. These texts offer patterns of narratives revolving around treasures, 
and the Arabian Nights is at the source of European imaginations of the Orient as luxurious and decadently wealthy. The immense value of the diamonds is thus framed by references to their unreal quality and their being part of timeless legend rather than the present. The fictional geography of a literary Orient, however, overlaps and contrasts with the history of British India and the diamonds as colonial objects. The notion of a curse laid on a treasure points to the imagined origin of the diamonds in a world apart. This image exists side by side with the very real association of the diamonds with the violence of the Indian Mutiny.

The Mutiny which forms the backdrop of the theft of jewels from India in The Moonstone, The Sign of Four and Stevenson's "The Rajah's Diamond" conveys the notion that the far-off events in the colony do have a bearing on presumably innocent subjects at home. The fictional diamonds, like their real-life counterparts, are inevitably bound up with important events in the colonisation of India. The traditional function of diamonds as mnemonic trophies now transports threat and trauma instead of images of a glorious victory. The long-lasting influence of the Mutiny on the perception of India is evident in the persistence of its depiction from The Moonstone to The Sign of Four. The Mutiny thus already introduces crime as lying at the root of the plots.

In their attitudes towards colonial products, the texts also address the change of the image of the colony from being a site of heroic and financially rewarding adventures to a more troubled view of the 'treasure trove' as the origin of crimes and curses. The extraction of wealth, which was formerly framed only as adventure, is now a crime. The image of India as criminal is supplemented by the idea that it also converts Englishmen to criminals and exports crime. Threatening natives and drugs appear accompany the diamonds. The prominence of drugs in The Moonstone and The Sign of Four is complemented by metaphorically imbuing the diamonds with a contagious disease. Like the diamonds, opium is acolonial product which still retains its Oriental character. It likewise shares the Orientalisation of the commodity.

Apart from the realms of history and romance, diamonds unite the disparate spaces of the domestic and the colonial. They are a stock metaphor in the Victorian praise of the dutiful "Angel in the House". Coventry Patmore,deliberately chooses the Koh-i-Noor, the figuration of India, to describe Honoria. Accordingly, in the texts the woman and the diamond are linked, but the material Indian diamond and the metaphor of domestic bliss are mutually exclusive. Only when the treasures disappear from England can the male protagonist be rewarded with marriage. The prerequisite to reinstall domesticity is the destruction of the diamonds and their history as loot. This however, is only partly successful as the Rajah's Diamond and the Great Mogul lie irrecoverably at the bottom of rivers where their uncanny presence continues. The Moonstone, too, ends on a similar note, promising more adventures in the future. In these endings, the diamonds have again evaded control and exhibit the same resistance to appropriation. 
Diamonds are thus ambiguous objects in fiction which contain numerous contradictions. In a domestic context they can retain their Otherness, they are on the one hand singular and individualised as mythical or historical objects, and on the other hand they are a potential cash item. They transport both a fantastic and a historical imperialist version of India.

\section{Works Cited}

Primary Literature

Anon. “The Rajah's Diamond." Part 1. All the Year Round. 15.362 (1875): 134-138.

Anon. "The Rajah's Diamond." Part 2. All the Year Round. 15.363 (1875): 155-159.

Collins, William Wilkie. The Moonstone. London: Penguin, 1994.

Doyle, Arthur Conan. A Study in Scarlet. Sherlock Holmes: The Complete Novels and Stories. Vol. 1. New York: Bantam, 2003. 1-120.

- . "The Adventure of the Beryl Coronet." Sherlock Holmes: The Complete Novels and Stories. Vol. 1. New York: Bantam, 2003. 467-492.

- ."The Adventure of the Mazarin Stone." Sherlock Holmes: The Complete Novels and Stories. Vol. 2. New York: Bantam, 2003. 558-575.

- . "The Crooked Man." Sherlock Holmes: The Complete Novels and Stories. Vol. 1. New York: Bantam, 2003. 644-662.

- . The Sign of Four. Sherlock Holmes: The Complete Novels and Stories. Vol. 1. New York: Bantam, 2003. 123-236.

Fleming, Ian. Diamonds are Forever. London: Penguin, 2006.

Marsh, Richard. The Datchet Diamonds. London, 1898.

Patmore, Coventry. The Poems of Coventry Patmore. Ed. Fredrick Page. London and New York: Oxford UP, 1949.

"R., L". "The Koh-i-Noor, or Mountain of Light." Chamber's Edinburgh Journal 291 (1849): 49-52.

Stevenson, Robert Louis. "The Rajah's Diamond." New Arabian Nights. Northridge, CA: Aegypan, 2005. 71-132.

- “"The Suicide Club.” New Arabian Nights. Northridge, CA: Aegypan, 2005. 9-70.

Trollope, Anthony. The Eustace Diamonds. London: Penguin, 2004.

Secondary Sources

Anon. "Curse.” Dictionary of Anthropology. Ed. Charles Winick. New York: Philosophical Library, 1956. 
Anon. "Diamond." Standard Dictionary of Folklore, Myth, and Legend. 2 vols. Ed. Maria Leach. New York: Funk and Wagnalls, 1949.

Anon. "Kashgar." Encyclopaedia Britannica: Micropaedia. 15th ed. 12 vols. Chicago: Encyclopaedia Britannica. 2002.

Anon. "Mysore." Encyclopaedia Britannica. 23 vols. Ed. Harry Scott Ashmore. Chicago: Encyclopaedia Britannica, 1962.

Anon. "Somnath." Encyclopaedia Britannica. 23 vols. Ed. Harry Scott Ashmore. Chicago: Encyclopaedia Britannica, 1962.

Ascari, Maurizio. A Counter-History of Crime Fiction. Basingstoke: Palgrave Macmillan, 2007.

Balfour, Ian. Famous Diamonds. London: Collins, 1987.

Bhabha, Homi K. The Location of Culture. London: Routledge, 1994.

Bloch, Ernst. "Philosophische Ansicht des Detektivromans." Der Kriminalroman. Zur Theorie und Geschichte einer Gattung. Vol. 2. Ed. Jochen Vogt. München: Fink, 1971. 322-343.

Boehmer, Elleke. Colonial and Postcolonial Literature: Migrant Metaphors. Oxford: OUP, 2005.

Brantlinger, Patrick. Rule of Darkness: British Literature and Imperialism, 1830-1914. Ithaca: Cornell UP, 1988.

- . "What is 'Sensational' about the 'Sensational Novel'?” Nineteenth-Century Fiction 37 (1982). Quoted in Mark M. Hennelly, Jr. "Detecting Collins' Diamond: From Serpentstone to Moonstone." Nineteenth-Century Fiction 39.1 (1984): 25-47.

Bunce, Fredrick W. "Shiva." An Encyclopaedia of Hindu Deities, Demi-Gods, Godlings, Demons and Heroes. With Special Focus on Iconographic Attributes. 3 vols. Ed. Fredrick W. Bunce. New Delhi: Printworld, 2000.

Bunce, Fredrick. "Soma." An Encyclopaedia of Hindu Deities, Demi-Gods, Godlings, Demons and Heroes. With Special Focus on Iconographic attributes. 3 vols. Ed. Fredrick W. Bunce. New Delhi: Printworld, 2000.

Bunce, Fredrick W. "Vişņu." An Encyclopaedia of Hindu Deities, Demi-Gods, Godlings, Demons and Heroes. With Special Focus on Iconographic Attributes. 3 vols. Ed. Fredrick W. Bunce. New Delhi: Printworld, 2000.

Carens, Timothy L. "Outlandish English Subjects in The Moonstone.” Reality's Dark Light. The Sensational Wilkie Collins. Ed. Maria K. Bachman, and Richard Cox. Knoxville, TN: U of Tennessee P, 2003. 239-265.

Collins, William Wilkie. Preface. The Moonstone. By Collins. London: Penguin, 1994. 5.

Daly, Suzanne. "Indiscreet Jewels: The Eustace Diamonds." Nineteenth Century Studies 19 (2005): 69-82. 
David, Deirdre. "Empire, Race, and the Victorian Novel." A Companion to the Victorian Novel. Ed. Patrick Brantlinger and William B. Thesing. Malden, MA: Blackwell, 2002. 84-100.

Dolin, Tim. Mistress of the House: Women of Property in the Victorian Novel. Aldershot: Ashgate, 1997.

Duncan, Ian. "The Moonstone, the Victorian Novel, and Imperialist Panic." MLQ 55.3 (1994): 297-319.

Eliot, T. S. "Wilkie Collins and Dickens." Selected Essays, 1917-1932. New York: Harcourt, 1932. 313-382. Quoted in Elizabeth Rose Gruner. "Family Secrets and the Mysteries of The Moonstone." Victorian Literature and Culture 21 (1993): 127-145.

Foxcroft, Louise. The Making of Addiction: The 'Use and Abuse' of Opium in NineteenthCentury Britain. Aldershot: Ashgate, 2007.

Free, Melissa. "Dirty Linen': Legacies of Empire in Wilkie Collins's The Moonstone." Texas Studies in Literature and Language 48.4 (2006): 340-371.

Freedgood, Elaine. The Ideas in Things: Fugitive Meaning in the Victorian Novel. Chicago: U of Chicago Press, 2006.

Freud, Sigmund. "The Uncanny." Trans. by James Strachey. Literary Theory: $A n$ Anthology. Ed. Julie Rivkin and Michael Ryan. Malden, MASS: Blackwell, 1998. 154-167.

Gaggio, Dario: "Diamond Industry." The Oxford Encyclopaedia of Economic History. Oxford: OUP, 2003. 76-81.

Garbe, Richard. Die indischen Mineralien, ibre Namen und die ibnen zugeschriebenen Kräfte. Narahari's Râǵanighantu Varga XIII: Sanskrit und Deutsch, mit kritischen und erläuternden Anmerkungen. Leipzig, 1882.

Goetsch, Paul. "Uncanny Collectors and Collections." Magical Objects: Things and Beyond. Ed. Elmar Schenkel and Stefan Welz. Berlin: Galda, 2007. 67-90.

GoGwilt, Christopher. The Fiction of Geopolitics: Afterimages of Culture, from Wilkie Collins to Alfred Hitchcock. Stanford: Stanford UP, 2000.

Gray, William. Robert Louis Stevenson: A Literary Life. Houndmills: Palgrave Macmillian, 2004.

Gruner, Elizabeth Rose. "Family Secrets and the Mysteries of The Moonstone." Victorian Literature and Culture 21 (1993): 127-145.

Hancock, Michael W. "The Stones in the Sword: Tennyson's Crown Jewels." Victorian Poetry 39.1 (2001): 1-24.

Harlow, George E. "Following the History of Diamonds." The Nature of Diamonds. Ed. George E. Harlow. Cambridge: CUP, 1998. 116-135.

- . "The World's Great Diamonds." The Nature of Diamonds. Ed. George E. Harlow. Cambridge: CUP, 1998. 105-115. 
Harris, Susanne Cannon. "Pathological Possibilities: Contagion and Empire in Doyle's Sherlock Holmes Stories." Victorian Literature and Culture 31.2 (2003): 447-466.

Hayter, Alethea. Opium and the Romantic Imagination. Berkeley: U of California P, 1968.

Hennelly, Mark M. Jr. 'Detecting Collins' Diamond: From Serpentstone to Moonstone." Nineteenth-Century Fiction 39.1(1984): 25-47.

Hepburn, Allan. "Introduction: Inheritance and Disinheritance in the Novel." Troubled Legacies: Narrative and Inheritance. Ed. Allan Hepburn. Toronto: U of Toronto P, 2007. 3-25.

Herbert, Christopher. W ar of no Pity: The Indian Mutiny and Victorian Trauma. Princeton, NJ: Princeton UP, 2008.

Hillebrandt, Alfred. Soma und verwandte Götter. Breslau: Koebner, 1891.

Jasanoff, Maya. "Collectors of Empire: Objects, Conquests and Imperial SelfFashioning." Past and Present 184 (2004): 109-135.

Kaufman, Heidi. "King Solomon's Mines?: African Jewry, British Imperialism, and H. Rider Haggard's Diamonds." Victorian Literature and Culture 33 (2005): 517-539.

Keep, Christopher, and Don Randall. "Addiction, Empire, and Narrative in Arthur Conan Doyle's The Sign of Four.” Novel 32.2 (1999): 207-221.

Kenny, Virgina C. The Country-House Ethos in English Literature 1688-1750: Themes of Personal Retreat and National Expansion. Brighton: Harvester, 1984.

King, C.W. The Natural History, Ancient and Modern, of Precious Stones and Gems, and of the Precious Metals. London: n.p., 1865.

Levinson, Alfred A. "Diamond Sources and their Discovery." The Nature of Diamonds. Ed. George E. Harlow. Cambridge: CUP, 1998. 72-104.

Lindner, Christoph. Fictions of Commodity Culture: From the Victorian to the Postmodern. Aldershot: Ashgate, 2003.

Mack, Robert. "The Arabian Nights' Entertainment and Other 'Oriental' Tales." The Oxford History of Literary Translation in English. Vol 3. Ed. Stuart Gillespie and David Hopkins. Oxford: OUP, 2005. 470-475.

Marx, Karl, and Friedrich Engels. „Das Kapital“ und Vorarbeiten. Karl Marx, Friedrich Engels Gesamtausgabe. Vol. 6. Berlin: Dietz, 1987.

McCormack, Kathleen. "Intoxication and the Victorian Novel." A Companion to the Victorian Novel. Ed. William Baker and Kenneth Womack. Westport, CT: Greenwood, 2002. 137-150.

Mehta, Jaya. "English Romance, Indian Violence.” Centennial Review 39.3 (1995): 611-658.

Menikoff, Barry. 'New Arabian Nights: Stevenson's Experiment in Fiction." Nineteenth- Century Literature 45.3 (1990): 339-362. 
Mersmann, Arndt. "'Diamonds are forever' - Appropriations of the Koh-i-Noor: An Object Biography." Journal for the Study of British Cultures 8.2 (2001): 175-193.

Michell, George. The Hindu Temple: An Introduction to its Meaning and Forms. Chicago: U of Chicago P, 1988.

Miller, A.D. The Novel and the Police. Berkeley: U of California P, 1988.

Miller, Andrew H. Novels behind Glass: Commodity Culture and Victorian Narrative. Cambridge: CUP, 1995.

Milley, James Wye. "The Eustace Diamonds and The Moonstone." Studies in Philology 36 (1939): 651-663.

Mukherjee, Upamanyu Pablo. Crime and Empire: The Colony in Nineteenth-Century Fictions of Crime. Oxford: OUP, 2003.

Murfin, Ross C. 'The Art of Representation: Collins' Moonstone and Dickens' Example." English Literary History 49.3 (1982): 653-672.

Naugrette, Jean-Pierre. "The Moonstone: Signes Indiens." Études Anglaises 48.4 (1995): 407-418.

Nayar, Pramod K. English Writing and India, 1600-1920: Colonizing Aesthetics. London: Routledge, 2008.

Nayder, Lilian. Wilkie Collins. New York: Twaine, 1997.

- . "Collins and Empire." The Cambridge Companion to Wilkie Collins. Ed. Jenny Bourne Taylor. Cambridge: CUP, 2006. 139-152.

níFhlathúin, Máire. "The Making of a Master Criminal: The 'Chief of the Thugs' in Victorian Writings on Crime." Victorian Crime, Madness and Sensation. Ed. Andrew Maunder and Grace Moore. Aldershot: Ashgate, 2004.

Paxton, Nancy L. "Mobilizing Chivalry: Rape in British Novels about the Indian Uprising of 1857." Victorian Studies 36 (1992): 5-29.

Perera, Suvendrini. Reaches of Empire: The English Novel from Edgeworth to Dickens. New York: Columbia UP, 1991.

Pionke, Albert D. "Secreting Rebellion: From the Mutiny to The Moonstone." Victorians Institute Journal 28 (2000): 109-141.

Platts, John T. "Soma." A Dictionary of Urdu, Classical Hindi and English. Lahore: Sang-e-Meel, 2003.

- . "Vajra." A Dictionary of Urdu, Classical Hindi and English. Lahore: Sang-e-Meel, 2003.

Plotz, John. "Discreet Jewels: Victorian Diamond Narratives and the Problem of Sentimental Value." The Secret Life of Things: Animals, Objects, and It-Narratives in Eighteenth-Century England. Ed. Mark Blackwell. Lewisburg, PA: Bucknell UP, 2007. 327-354. 
Rapoport, David C. "Fear and Trembling: Terrorism in Three Religious Traditions." The American Political Science Review 78.3 (1984): 658-677.

Proctor, Robert N. "Anti-Agate: The Great Diamond Hoax and the Semiprecious Stone Scam.” Configurations 9 (2001): 381-412.

Reed, John R. "English Imperialism and the unacknowledged Crime of The Moonstone." Clio 2.3 (1973): 281-290.

Reitz, Caroline. Detecting the Nation: Fictions of Detection and the Imperial Venture. Columbus: Ohio State UP, 2004.

Richards, Jeffrey. Sherlock Holmes, Conan Doyle and the British Empire: An Investigation into Conan Doyle's Links with the British Empire as expressed through his Sherlockian and other Literature. Huddersfield: Musgrave, 1997.

Rosador, Kurt Tetzeli von. "Gems and Jewellery in Victorian Fiction." REAL 2 (1984). 275-317.

Said, Edward. Culture and Imperialism. New York: Vintage, 1994.

- . Orientalism. London: Penguin, 2003.

Schuhmacher, Manfred. Barabas' Enkel: Juden-Bilder in der englischen Literatur bis zur Moderne. Frankfurt a. M.: Lang, 2000.

Sharpe, Jenny. Allegories of Empire: The Figure of Woman in the Colonial Text. Minneapolis: U of Minneapolis P, 1993.

Siddiqi, Yumna. "The Cesspool of Empire: Sherlock Holmes and the Return of the Repressed." Victorian Literature and Culture 34.1 (2006). 233-247.

Simmons, Diane. The Narcissism of Empire. Loss, Rage and Revenge in Thomas DeQuincey, Robert Louis Stevenson, Arthur Conan Doyle, Rudyard Kipling, and Isak Dinesen. Eastbourne: Sussex Academic, 2007.

Singh, Bhupal. A Survey of Anglo-Indian Fiction. London: Curzon, 1975.

Smith, Travis L. "Śiva." Encyclopaedia of Hinduism. Ed. Denise Cush and Catherine Robinson. London: Routledge, 2008. 799-803.

Suleri, Sara. The Rhetoric of English India. Chicago: U of Chicago P, 1992.

Sutherland, John, and Stephen Gill. Introduction. The Eustace Diamonds. By Anthony Trollope. London: Penguin, 2004. 7-28.

Thapar, Romila. "Somanātha: Narratives of a History." Narratives and the Making of History: Two Lectures. Oxford: OUP, 2000. 24-51.

Thomas, Ronald R. "The Moonstone: Detective Fiction and Forensic Science." The Cambridge Companion to Wilkie Collins. Ed. Jenny Bourne Taylor. Cambridge: CUP, 2006. 65-78.

Tolansky, S. "Some Folklore and History of Diamonds." Royal Society of Arts Journal 109 (1961): 743-763.

Van Ours, J.C. "Opium and Narcotics." The Oxford Encyclopaedia of Economic History. Oxford: OUP, 2003. 141. 
Whitworth, Michael H. "Science and the Scientist in Victorian Fiction." A Companion to the Victorian Novel. Ed. William Baker and Kenneth Womack. Westport: Greenwood, 2002. 111-122.

Wynne, Catherine. The Colonial Conan Doyle: British Imperialism, Irish Nationalism, and the Gothic. Westport: Greenwood, 2002.

York, Michael. "Soma." Encyclopaedia of Hinduism. Ed. Denise Cush and Catherine Robinson. London: Routledge, 2008. 807-808.

Yang, Anand A. "Dangerous Castes and Tribes: The Criminal Tribes Act and the Magahiya Doms of Northeast India." Crime and Criminality in British India. Ed. Anand A. Yang. Tucson: U of Arizona P, 1985. 108-127. 

Melanie Swiatloch

\title{
The Construction of Identity in Northern Ireland Hybrid States, Nationalism, and Images of Violence in Contemporary Northern Irish Novels
}

\author{
And the battle's just begun \\ There's many lost but tell me who has won \\ The trench is dug within our hearts \\ And mothers, children, brothers, \\ sisters torn apart \\ "Sunday Bloody Sunday" by U2 (1983)
}

\section{Introduction}

Thirty-eight years after what became known as the Bloody Sunday Great Britain's Prime Minister David Cameron made a formal apology for the killings of fourteen demonstrators in Derry ${ }^{1}$. His apology was grounded on the results of the Saville

1 Nationalists rather refer to the city as Derry while unionists prefer to call it Londonderry. Throughout this paper the shorter form Derry is used, which is not supposed to take a political stand, however. See also note 36 in this paper (p. 254). 
report. This report was meant to clarify the exact circumstances of the events on 30 January 1972 that lead to the deaths of fourteen innocents as the examination unfolded. Still this declaration of guilt does not mark the end of years of bloodshed. "The absence of conflict at one point in time should not imply that this is a permanent state of affairs," A.M. Gallagher warned as well (9). On Saturday, 14 August 2010, according to national and international news a bomb exploded in a residential area in Lurgan, Northern Ireland, injuring three children. It went off during a Protestant parade. Another bomb in the same district luckily failed to detonate. Although officially settled - the Provisional IRA was disbanded in 2006, British military presence was ended and a power-sharing government has been established in 2007 (Keating-Miller 58) - these incidents show that the Northern Ireland conflict, also referred to as 'the Troubles', has not come to a final, peaceful resolution yet. Although by far less severe than in the hottest phases of the 1970s and 1980s, remnants of the old conflict are still up to date.

Many contemporary Northern Irish authors have been dealing with major and minor effects the conflict has brought. Thousands of people saw their family and friends die in bomb attacks planted by paramilitary groups, experienced tensions between Catholics and Protestants and saw how prejudice and group belonging reorganised whole neighbourhoods. These sides of the Troubles are focused on in manifold ways, thereby showing different possible identities. In addition, attitudes have changed during the course of the time. While authors of the 1920s and 1930s put a stronger emphasis on nationalist aspects, authors of the 1980s and 1990s try to give a larger picture of society and highlight the miseries of the conflict itself, and not so much the struggle for independence. Eve Patten ascribes this change to the emergence of a new generation.

In recent years, however, fiction from Northern Ireland has begun to change dramatically. This is a manifestation, firstly, of the emergence of a new generation of writers who have come of age since the beginning of the Troubles and whose reconstructions of childhood experience effectively undercut the moral baggage and creative paralysis of their predecessors. Secondly, it marks the overdue exploitation of literary strategies such as perspectivism, ambiguity and displacement which, though categorically post-modern, may also be perceived as attributes of a sustained constitutional and psychological identity crisis germane to any representations of a contemporary Northern Irish self-image (Patten 129-130).

These new strategies necessary for the depiction of a Northern Irish identity she talks of - perspectivism, ambiguity and displacement - are also made use of by the authors talked about in this paper: Robert McLiam Wilson (Eureka Street), Deirdre Madden (One by One in the Darkness), and Lucy Caldwell (Where They Were Missed). Very different characters such as Protestant profit seekers, Catholic radicals or people without a certain standpoint are given a voice here. The resulting multiper- 
spectivity and ambiguous identities allow the authors to create possible images of the "New Irish" the Catholic Jake Jackson from Eureka Street is dreaming of:

In my early years, I had often hoped that the future would be different. That from out of the dark mists of Ireland's past and present a new breed would arise. The New Irish. When all the old creeds and permutations in people would be contradicted. We would see the Loyalist Catholic. The liberal Protestant. The honest politician. The intelligent poet. But, as I sat and listened to my workmates, I decided I wasn't going to hold my hand in my arse waiting for any Utopia (McLiam Wilson 164).

As intoxicating and tempting Jake's vision may sound, its ironic undertone suggests that there is still a long way to go to achieve it.

In order to discuss what exactly has changed in Northern Irish identity in recent years it becomes necessary to throw a glance into the past and thus on postcolonial aspects as well as the loss of the native language. Also contemporary aspects such as living in a both divided and violent city as Belfast must be taken into account. Important questions will be how society is depicted in the novels and what changes concerning identity issues have taken place. In how far does a new intelligentsia play a decisive factor for contemporary Northern Irish society? How do Protestants and Catholics interact and how do they form an identity in contrast or in unison with each other? What kind of images of the New Irish do the authors propose? Is the current peace a final peace? This paper thus tries to show how Northern Irish identity is made up, by what it has been influenced as well as how the characters in the novels are depicted in contrast to stereotypical assumptions of the Northern Irish resident that is often linked to IRA ${ }^{2}$ or $\mathrm{UVF}^{3}$ propaganda.

\section{Language Matters in Northern Ireland}

The investigation of language in relationship to identity is a wide field that would exceed the scope of this paper. In the following only a few aspects of language and ethnic consciousness are therefore discussed. The loss of the Irish language or rather the absence of it will be foregrounded as only very few native speakers of Irish can be found in Northern Ireland today. Still, Irish has a special meaning to those who are capable of speaking or understanding it. The inspection of language

2 The Irish Republican Army (IRA) was established in 1919 as a descendant from the Irish Volunteers that had been created in 1913 and had been involved in the Easter Rising in 1916. Its goal was the achievement of an independent Ireland. Although this was also pursued by the Irish nationalist party Sinn Féin the IRA acted independently from them (Britannica 386).

3 The Ulster Volunteer Force was founded in 1966 in opposition to the IRA. Its name was taken from a Protestant loyal organisation which at the beginning of the twentieth century had successfully resisted Home Rule (Britannica 117). 
will not be undertaken in a linguistic way but is rather used as a means to show correlations between language differences and possible means for identity.

\subsection{A Note on the Irish Language: Developments From the Past Until Today}

When it comes to identity issues language plays an important role, particularly when the native language - as in the case of the Irish - has largely been taken away from a people. While the government of the Republic of Ireland nowadays officially promotes the Irish language in several ways (school, radio, television), the North is lacking any official support. But even in the South this was not always the case. Official support and the recognition of the Irish language as the official language of the Gaeltacht ${ }^{4}$ only started shortly after the foundation of the Irish Free State 5 .

The invasion of Ireland began quite early in the twelfth century when Henry II with the permission of Pope Adrian IV marched into the country due to religious reasons $^{6}$ (Hickey 30). Dublin, which is the anglicised form of Baile Átha Cliath, became a popular place to settle for the English. Following the Charter of Dublin in 1172, "English has existed continuously in Dublin" as Raymond Hickey, professor of linguistics, points out, since Dublin had a promising position on the east coast (31). Still, the Irish language resisted further invasions during the fourteenth and fifteenth centuries. Only another century later, in the sixteenth and seventeenth centuries, did the English extend their place of residence over the whole of Ireland. With the so-called plantations, a well-planned settlement strategy, the English occupation reached its climax ${ }^{7}$. While Irish, for example, was still the language of the court when at least one Irish person was involved, this changed completely from the seventeenth century onwards when Irish was "banned from public life" (Hickey 33ff). During the eighteenth century the Penal Laws ${ }^{8}$ completed the exclusion of the Catholic Irish from the political as well as the social

4 The Gaeltacht or An Ghaeltacht is a region where Irish is the dominating language. The term here refers to Irish-speaking regions in Ireland (Britannica 1001).

5 The Irish Free State was founded in 1922 under the Anglo-Irish Treaty signed 6 December, 1921 by David Lloyd George (GB), Arthur Griffith, and Michael Collins (IE). It came to an end in 1937 when Éamon de Valera introduced proposals for a new constitution. The Irish Free State from then on was termed Éire. It was succeeded by the Republic of Ireland in 1949 (Britannica 1015ff).

6 The argument was that the church in Ireland "had fallen into a state of disarray" (Hickey 30).

7 The first known plantations took place in the counties Offaly and Laois during $1549-1557$ (Hickey 35).

8 The Penal Laws were a series of laws that were aiming at the restriction of Catholic religion. They imposed civil disabilities of a severe degree on Catholics in the $16^{\text {th }}$ and $17^{\text {th }}$ centuries. Punishments for living out the Catholic faith included imprisonment, fines but also death for those priests practicing their ministry in Great Britain or Ireland. Other laws included, for example, the ban from voting, holding public offices, owning land or teaching (Britannica 254). 
sphere. As a general education was denied to the Irish, only hedge schools ${ }^{9}$ allowed some of the native population a small account of instruction (ibid. 41).

Two influential factors increased the further decline of the Irish language: In 1831 National Schools helped to diminish the rate of illiteracy, but as tuition was held in English as well a radical shift in language opened the floodgates. Furthermore, the nineteenth century was marked by the Great Famine (1845-8) which resulted in about one million victims. Many of those who did not die emigrated to North America or elsewhere (ibid. 46). According to Raymond Hickey the nineteenth century thus had to face the loss of about two million native speakers of Irish, which made up about a quarter of the total Irish population (47). The remaining part of the inhabitants was now exposed to the English language more strongly than ever before. He stresses the fact that Irish "has receded greatly over the past 150 years and continues to do so" (ibid. 22). Hence, Hickey speaks of an ambivalent feeling the Irish have towards the English language today. Although most Irish people continue to speak English as their native language they face this fact with certain reluctance as Irish is considered being a carrier of native culture (Hickey 22). English, by contrast, is the language of the former occupier. To give an example, between 1801 and 181145 per cent of the population were Irish speakers, between 1831 and 1841 the number decreased to only 28 per cent of Irish speakers (Mac Póilin 1996, 138). Hickey has also pointed out: "To accord English equal status with Irish in the consciousness of the people would be somehow to openly acknowledge the language of the former colonisers" (22). In Northern Ireland the relation to language looks a bit different, however.

In the North nowadays Irish is not accepted as an official language at all, although it had been the native language of a majority of Ulster's ${ }^{10}$ inhabitants before the seventeenth century (Hickey 94). The Good Friday Agreement ${ }^{11}$ ensures the "tolerance of linguistic diversity" (Chríost 45) including the Irish language but no official promotion is taking place. Due to the immigration of English and Scottish settlers to that area the Irish language became almost extinct as the Irish were relocated to areas where no immigrants lodged, thus disconnecting them from their former lives (ibid 94). All of Ireland, but especially the North, had to suffer from the Tudor invasion during the sixteenth century. Following the Nine Years' War $^{12}$ (1594-1603) in which the English defeated Irish and Spanish resistance

9 As Catholics were forbidden to teach, hedge schools were the only possibility for Catholics to get at least some education. As the name implies hedge schools were mainly situated in rural areas where "migrant teachers offered tuition to individuals or small groups" (Hickey 41).

10 The province of Ulster consists actually of nine counties: Antrim, Down, Armagh, Derry, Tyrone and Fermanagh, all of which make up Northern Ireland, plus Donegal, Monaghan and Cavan that lie in the South (Hickey 85).

11 The Good Friday Agreement was signed on 10 April 1998. It launched a new system of powersharing in the context of a devolved Northern Ireland Assembly (Mitchel xi).

12 Before the Nine Years' War the O'Neill clan was the leading force in the province of Ulster. As resistance against English rule had formed in this area, the Spanish agreed to support the Irish 
quite a number of Gaelic leaders left Ireland in 1607, which became known as the Flight of the Earls. After their leave their lands were obtained by James I and the plantation of Ulster was decided in 1609. Other than in the case of the South, however, the North was settled by Scots and Englishmen from the north of England. Hickey thus argues that "due to the Scottish and English background of these immigrants the division of Ireland came to be as much linguistic as political and confessional" (Hickey 87). Nevertheless some areas remained in which Irish was still spoken into the early twentieth century ${ }^{13}$.

In the region of Belfast there has been a strong coming back of the Irish language recently. In 1969 eleven West Belfast families established their own Gaeltacht Community. Having learned Irish themselves as a second language their children should be brought up similar to native Irish speakers. Thus, Irish should become the language of home, neighbourhood and school. Therefore these families founded their own Bunscoil Ghaelach, an Irish-medium Primary School (Maguire 72ff). The main reason for this undertaking was that they wanted to "give their children something of value which they had missed" (ibid. 74). Undoubtedly, also many people in the North still count the Irish language to their cultural background. The phenomenon of a native Irish speaking community is one that remains connected mainly to the South, though.

\subsection{Constructing a Community - Northern Ireland: One Nation, Two National Identities}

By taking a closer look on Northern Ireland we find a society that is deeply divided on various grounds, which this paper will investigate. Among other things this is reflected in the many political parties that stand for diverse and opposing opinions and beliefs like the two best known Sinn Féin ${ }^{14}$ and the Ulster Unionist Party ${ }^{15}$, the latter one supporting the union with Great Britain while Sinn Féin still promotes a united Ireland. Generally speaking one will find two larger religious communities - Catholics and Protestants - that have been living together in the same place for almost four hundred years and that have been struggling with each

rebellion in 1601 by sending an army of over 3000. In the battle of Kinsale (1601) both armies were defeated (Hickey 87).

13 (1) West Ulster in Co. Fermanagh, (2) South-east Ulster in north Co. Louth, (3) Mid Ulster in north Co. Tyrone, (4) North-east Ulster on Rathlin Island (Hickey 94).

14 Sinn Féin (Irish for "We Ourselves") is a nationalist party and the political wing of the IRA. The two are frequently referred to as "the republican movement". Its aim has always been the end of the union with Great Britain and instead an Irish Republic containing all thirty-two counties (Mitchel xii).

15 The Ulster Unionist Party was the major unionist party in Northern Ireland up until 2003 before it was outrun by the Democratic Unionist Party (now Northern Ireland's largest Unionist party, founded by Ian Paisley and currently led by Peter Robinson). It governed the land from 1921 to 1972 ("Northern Ireland Political Parties", Whyte). 
other for almost as long, resulting in suffering and losses on both sides. The twentieth century, especially the times of the recent Troubles that began in the late 1960s and lasted well into the 1990s, put the Northern Irish people to the test. Only the Good Friday Agreement of 1998 has offered the possibility of a lasting peace process. But why have these two communities had such problems living peacefully together, and why does it seem to be impossible for them to fuse into one nation? Certainly religion has played an important aspect here but this is clearly not the main reason for division. What has changed over the years that made peace possible, and is it really going to be a final peace?

When talking about a community or a nation it should at first be made clear what such a construct is, what it can contain and what it is built of. Benedict Anderson offers some key reasons for the development of group belonging and feeling in his influential work Imagined Communities. His first definition of a nation in general is the following:

It is an imagined political community - and imagined as both inherently limited and sovereign. It is imagined because the members of even the smallest nation will never know most of their fellow-members, meet them, or even hear of them, yet in the minds of each lives the image of their communion (Anderson 5-6).

In the case of Northern Ireland this principle of the nation does not seem to work properly, though. Communion can be understood both in a religious way or in a more general way in the sense of a collective. But neither do most of the Northern Irish inhabitants share a common feeling of community nor a feeling of shared faiths. It appears to be not only one coherent nation but rather two nations encompassed by a larger one that is called Northern Ireland. This assumption is backed by Anderson's argument that the imagined community is formed of a "horizontal comradeship" and fraternal feelings (7) with people willing to die for their beliefs and for their fellow citizens. During the course of history it could be seen that people in Northern Ireland were indeed willing to die for their nation (and some of them still are) only that the nation was not Northern Ireland but recollections of the Republic of Ireland or Great Britain respectively, depending on which side of the divided community one stood. On the level of each individual religious community, however - that is the Catholic community and the Protestant community - Anderson's theory can be applied. The same applies for radical political groups like the Irish Republican Army or the Ulster Volunteer Force, who time and again proved that they were ready to die for their own interpretation of a greater cause, although one also has to take into account that their primary goal was actually harming members of the other group instead of becoming martyrs themselves. Cathal McCall, who is engaged with nationalism and identity in Europe, describes the nation as a "politically self-aware ethnic community" (19), 
which supports the assumption that Northern Ireland indeed consists of two nations, one ethnically Irish the other ethnically English/Scottish.

In 1880 the French philosopher Ernest Renan offered the following description of a community in his essay "Qu'est-ce qu'une nation?":

The nation, even as the individual, is the end product of a long period of work, sacrifice and devotion. The worship of ancestors is understandably justifiable, since our ancestors have made us what we are [...] To have common glories in the past, a common will in the present; to have accomplished great things together, to wish to do so again, that is the essential condition for being a nation (Renan 17).

Renan's point of view of the nation was thus much simpler than Anderson's. For him the nation consisted of a "soul, a spiritual principle" (ibid. 17). The only two terms that were essential for this assumption were the past and the present, namely what a people had shared together and that they were also inclined to continue to do so. This concept might have been valid at some point in the past but it does not seem to be the only adequate source for the present day as most nations indeed remember their history but do not solely live on it anymore. Still, some of these aspects are important to understand why people share a common sense of belonging. Max Weber then in 1948 supposed the idea that nations were a concept that meant to "exact from certain groups of men a specific sentiment of solidarity in the face of other groups" (Weber 21-22) In this sense Weber rather talks about a value system that forms a nation.

Today we speak of nations and nation states as a matter of course. But according to Anderson, national feelings arose much earlier and can be traced back to the eighteenth century; to a time when ideas of Enlightenment and rationalist secularism spread throughout Europe. Religion lost part of its importance; values and morals changed. Before the term nationalism came up, however, in Anderson's opinion the two dominating powers that made up a sense of belonging together were the religious community and the dynastic realm. Christendom for instance united people by a sacred language and a written script (Anderson 11ff).

Latin was the language of the church in the European world, thus it was the only language taught in medieval times and also the only language that books were published in. In the sixteenth century, however, this gradually changed and Latin began to lose its ubiquity. On the one hand Great Britain was reaching out for new territories. The exploration of the non-European world led to a new geographical but also cultural knowledge. On the other hand publishing in the vernacular languages instead of Latin had become popular by the seventeenth century (Anderson 16ff). As Anderson notes, "the fall of Latin exemplified a larger process in which the sacred communities integrated by old sacred languages were gradually fragmented, pluralized, and territorialized" (18). In a word, the international community held up by Latin lost its base. Instead, and as a result of that "a 
focus on individual identity and its place within the wider community came under scrutiny" as McCall has observed (29).

Subsequently, print-capitalism opened up new ways for the imagined community. What followed were smaller communities that from then on were united by superior forms of spoken languages. Anderson describes three paradigms that "laid the basis for national consciousness" (44). First of all print-languages formed an intermediate level between the spoken vernaculars and Church Latin.

Speakers of the huge variety of Frenches, Englishes, or Spanishes, who might find it difficult or even impossible to understand one another in conversation, became capable of comprehending one another via print and paper. In the process, they gradually became aware of the hundreds of thousands, even millions, of people in their particular language-field, and at the same time that only those hundreds of thousands, or millions, so belonged. These fellow-readers, to whom they were connected through print, formed, in their secular, particular, visible invisibility, the embryo of the nationally imagined community (Anderson 44).

What Anderson is essentially saying here is that print-media tied people together in a new way. While many people could not understand each other properly due to different vernaculars they now could due to a shared language in printed form.

Secondly, Anderson argues that print-capitalism distinctly fixed languages and thirdly, that print-capitalism helped to produce "languages-of-power" (44). With the latter he refers to vernacular languages that were closer to the print-language than others. Speakers of these forms of languages were thus in advantage while others lost their prestige. This "new form of imagined community", in Anderson's terms, "set the stage for the modern nation" (46).

In the case of Ireland - both North and South - one can see that Anderson's concept is easily applicable. On the one hand Irish ceased to exist due to the reasons already explained and English became the superior language on the island both in everyday speech and writing (and the only language taught in schools). This clearly shows how one language was superseded by another one and is evidence for the "languages-of-power" theory. On the other hand on a different level Irish served as a marker for cultural belonging that united those who wanted to set themselves apart from the British. Print-media here again served as a means to reinstall the forgotten language. Hence, with the foundation of the Gaelic League in 1893, Gaelic Irish regained its importance in print-media as well as concerning identity issues. Several bilingual newspapers were published by them. With the help of these newspapers and most notably the Nation journalists "promoted the aim of an independent, rural, Gaelic Ireland, free from the colonial rule of an alien, industrial, English neighbor." Other newspapers like the Connaught Telegraph or the Kerry Sentinel delivered information about a national identity to the smaller rural communities (McCall 30). In the latter half of the twentieth century televi- 
sion became a further factor to spread messages strengthening the Catholic community during the Civil Rights Marches in Northern Ireland (ibid. 30/31). These first approaches to re-establish an Irish identity show how print-media (and later other forms of media) can strengthen a smaller community both via messages partly written in Irish but also to make nationalist approaches public. Thus, printmedia not only supports languages-of-power but also language communities that want to express their common belonging. As language in general and languages used in print-media form a central part of Anderson's theory the next chapter will deal with the significance that language has played in Ireland.

Identity and identity construction in relation to culture are one of the major topics of this paper which makes a short definition necessary as well. Chris Barker describes a difference between the two terms in that culture is a form of process whereas cultural identity refers to ethnicity, class, race and so forth (Barker 382). Stuart Hall furthermore argues that there are at least two ways in which cultural identity may be described. On the one hand it can be seen as "one, shared culture, a sort of collective 'one true self', hiding inside the many other, more superficial or artificially imposed 'selves', which people with a shared history and ancestry hold in common" (Hall 1999, 393). Cultural identities thus "reflect the common historical experiences" (ibid. 393). On the other hand, according to Hall, difference also plays an important role for the creation of identity (ibid. 394). Besides, identities are never fixed entities but constantly undergo changes and are "always in progress" (Hall 1998, 2). This twofold cultural imprint is also stressed by Homi K. Bhabha in the terms of "baffling alikeness" and "banal divergence" that constitute the cultural hybrid (Bhabha 1998, 54) which is discussed further in chapter 3.3.2.

Máiréad Nic Craith in addition stresses the fact that identity is always multilayered and not two-dimensional as often depicted in the case of Northern Ireland. In this sense she refers to Michael Billig's term "pastiche personality" which assumes that identity adapts to different contexts (Nic Craith 2003, 5), as for example Jake in Eureka Street who belongs to the Catholic community but not to the Irish-speaking or republican community, or Saoirse in Where They Were Missed who belongs to the Catholic and Irish-speaking community but is not fully accepted as such as she in the eyes of her classmates in the South belongs to the Northern Irish community. As identities are progress-like this means for Northern Ireland that "identities are being reshaped" and "new significant others emerge" (ibid. 6). At the same time Nic Craith points out that there are not simply two communities, either. Instead, the two larger groups of Protestants and Catholics consist of many "competing factions and interest-groups." Many people are even members of a number of communities. Thus the two larger groups are divided into the nationalist community, the Irish-speaking community, the Catholic community, et cetera (ibid. 8). Conflict in Northern Ireland, in her view, results in the fact that "groups [...] essentialize cultures, exaggerate differences and usually construct them where they do not exist" (ibid. 10). Although Nic Craith is right when talk- 
ing about the many different communities there are existing and the perception of pastiche personalities, this paper mainly refers to the two largest groups of Catholics and Protestants for reasons of simplicity and to make things graspable. Nevertheless, sub-groups such as nationalists or Irish speakers are considered as well as they appear throughout the examined novels.

\subsection{On National Consciousness}

"The language spoken by somebody and his or her identity as a speaker of this language are inseparable: This is surely a piece of knowledge as old as human speech itself. Language acts are acts of identity" (Tabouret-Keller 315), asserts Andrée Tabouret-Keller. This statement surely seems to make sense, especially if one thinks of oneself and the languages one speaks. Most people have one mother tongue and are able to speak one or more second languages. Usually the language acquired during childhood is the language with which a person identifies the most. Furthermore, this is also commonly the same language relatives, friends, acquaintances and neighbours speak. Language thus connects a person to the people around him/herself and therefore creates a certain feeling of community. If one remembers the families who tried to reinstall an Irish language community in Belfast one also sees how important even a once lost language can become for one's cultural background and identity.

Tabouret-Keller's argument continues as follows: "The link between language and identity is often so strong that a single feature of language use suffices to identify someone's membership in a given group" (317). This can both happen in positive and in negative ways. Born in Belfast Saoirse Pentland, the narrator in Lucy Caldwell's Where They Were Missed, is living in the Republic of Ireland where she is learning Irish at school. Although she is receiving very good marks and is one of the best Irish speakers in class she time and again has to experience that she is actually an outsider because everybody knows she is from the North. Talking about a new girl in class she says:

It doesn't seem to matter that I've lived here for nearly ten years; it doesn't seem to matter that I'm almost always top of the class in Irish, or that I go to Mass just like the rest of them; none of it matters, because when it comes down to it, even after a couple of months - a matter of weeks, really - Clodagh Mulcahy is less of an outsider than I'll ever be (Caldwell 116).

No matter how hard Saoirse tries, in the south of Ireland she will always be perceived as a member of another community although she has Irish roots as well. Nevertheless her aunt and uncle seem to be especially proud of her good marks in Irish. This is stressed when Saoirse tells her uncle she came second in an Irish test she took: "You did? He beams. That's my girl, ey" (ibid. 90). Other school subjects do not seem as important as the Irish lessons. Saoirse is in a conflict here. 
Although she feels Irish she does not belong to her classmates and friends in the way other Irish girls do. Being the daughter of a Protestant father from the North and a Catholic mother from the southern Gaeltacht, Saoirse's background does not allow her to be fully integrated in neither the group of Irish people nor the community of Protestant Northern Irish people. When she drives back to the North in order to visit her father Saoirse stops at a newsagent's in a Protestant area to ask for directions. She suddenly realises her accent's Southern Irish touch and is carefully observed by two women in the shop. "I am glad to hurry on. I am a Greyabbey Pentland, I want to say; I belong here, too; but like Derry, this isn't a familiar place, either" (Caldwell 224).

Belonging to two different communities Saoirse at the same time does not belong to either of the two, so Tabouret-Keller's claim is reversed in this case. Membership seems to be only valid for people coming from one group, not for people of mixed descent as this feature rather turns the individual into an outsider who is observed with mixed feelings than into an insider who is welcomed by both communities.

That the Irish language is an "indicator of cultural identity" is also stressed by linguist Diarmait MacGiolla Chríost (45). Still the majority of the population believes "that the Irish language is an integral part of the ideology of Irish Republicanism and Nationalist separatism" (ibid. 46). In Robert McLiam Wilson's Eureka Street this conviction is used to mark off nationalists from non-nationalist inhabitants of Belfast. The only characters speaking the native language here are people promoting their Irish character. Aoirghe Jenkins, for instance, strongly believes that Northern Ireland should be reunited with the Republic (McLiam Wilson 98). She also sympathises with the Just Us, a group of nationalists who sometimes uses violence to make its goals plain. When there is a demonstration against the IRA planting bombs on the Belfast to Dublin line it is the Just Us who turn the peaceful event into a violent scenario with "peaceful heads [...] being kicked" (ibid. 195). When Jake Jackson, one of the main characters and part-time narrator of the book, meets Aoirghe for the first time he at first cannot understand her name and even thinks she is coughing when introducing herself, which leads to a tense atmosphere between them (ibid. 92). For Aoirghe her English surname "Jenkins" is a bit of a problem. Jake, however, finds it hilarious: "I passionately wanted not to laugh - but Jenkins. Aoirghe Jenkins. It must have broken her republican heart that she wasn't called something Irish like Ghoarghthgbk or Na Goomhnhnle. I laughed. Like a drain" (ibid. 292). In this scene the difference between Jake and Aoirghe is underlined once more. For Aoirghe her English surname is a burden that stands against everything she is fighting for. Yet, it makes up a part of her that she cannot deny. Jake in contrast can only think of strange sounding Irish surnames that are impossible to pronounce, thus mocking Aoirghe's longing for a true Irish heritage. 
A young waitress who chats up Jake in a bar whispers the words "Tiocfaidh ar La" in his ear, which is ironically said to sound like Chuckie's name, Chuckie Lurgan. As Jake explains, it is a nationalist rallying cry and means "Our day will come" (ibid. 150). Because naming in Northern Ireland very often bears the mark of the British occupier this example turns the table: Protestant Chuckie's name suddenly resembles more the Irish than the British, an additional hint that both Catholics and Protestants in Northern Ireland unite parts of both Ireland and Great Britain. Another time the waitress greets the guys with "Slan" and continues to talk in Irish to Jake. Although everybody at the table is of Catholic origin nobody understands the "nationalist waitress" (ibid. 295) and "freedom-fighting waitress" as Jake calls her (ibid. 296).

These scenes already hint at the ambiguous characters Patten is talking about (see introduction). By giving Aoirghe an English surname and making Chuckie's name sound like an Irish rallying cry McLiam Wilson stresses the fact that Northern Ireland does not consist of a black-and-white society but that multiculturalism and the merging of identities has been there for ages. It is the same with Saoirse Pentland whose name is a blending of her mother Deirde O'Conor's Irish heritage and her father Colin Pentland's English/Scottish origin. As these approaches easily lead to theories of hybridity they are going to be further investigated in chapter three.

Conflict in Northern Ireland is rooted deeply in society in manifold ways. While language on the one hand can serve as a marker for a positive communal consciousness it on the other hand can also lead to misunderstandings and hostilities towards another group. For Protestants there can develop a strange situation when fellow Northern Irish citizens are able to speak another language that sounds as foreign to them as for example Japanese. As English is still the first language of most of the Northern Irish people the conflict here results in an imagined language conflict, to use Anderson's term. Aodán Mac Póilin argues that conflict arises by ways of definition:

Unlike other societies, linguistic conflict here does not involve two communities speaking different languages. Instead, it reflects a conflict between two mainly English-speaking political blocks which define themselves in relation to their aspirational or emblematic linguistic identity, ultimately traceable to their sense of origin (Mac Póilin 1999, 109).

Referring back to Anderson the Catholic and the Protestant community are imagined language communities because each group defines itself with the help of certain aspects - in this case the aspect of language - and thus conceives the community as an "horizontal comradeship" (Anderson 7) as mentioned earlier. It is important to notice, however, that the position that language takes is an aspect that results from the past (a quick reminder: Irish has lost its importance as a community language rapidly since the $18^{\text {th }}$ and early $19^{\text {th }}$ centuries $[$ Mac Póilin 
1999, 113]). As Mac Póilin has stated correctly, Irish has become a matter of identity for many Northern Irish Catholics as Ulster-Scots has become for a couple of Protestants. Irish especially has a strong connotation to Catholic nationalism in the North. Ulster-Scots thus became the Protestant answer to a non-Irish but unionist cultural identity (Mac Póilin 1999, 109). A survey undertaken by Eddie Kerr on behalf of Naíscoil na Rinne in Derry in 1994 gives an interesting insight to what Protestants think of the usage of the Irish language:

A nineteen-year old youth thought that all Irish-speakers were 'Taigs' (Catholics), that the Irish language was 'Taig-talk', and that everybody who spoke it was in the IRA. A 51-year old unemployed shipyard worker said: I mean it's a Catholic thing and to me it says it's theirs and nothing to do with us. It's a political statement made by those who speak it (Mac Póilin 1999, 109).

Mac Póilin notes that the interviewed persons categorically made no distinction between Catholicism and nationalism. The statements rather reveal a strong generalisation.

Interestingly, Eureka Street takes a similar point of view as all Irish speaking characters in the book have an affiliation towards nationalist ideas. The proposal here only works in one way, however. While everybody speaking Irish is of Catholic origin, not everybody being Catholic automatically is interested in the Irish language. Jake and his friends, although being Catholic, are neither able to speak Irish, nor do they insist on a united Ireland. Aoirghe Jenkins, Shague Ghinthoss, an anti-English Catholic poet from Tyrone who is nevertheless loved by the English (McLiam Wilson 173), and the Irish speaking waitress in contrast refer to the worldview as presented by the interviewees above as they combine Catholicism and nationalism alike and indeed try to make a political statement by using Irish.

Yet, in Eureka Street the language conflicts arise not only between Protestants and Catholics but also amongst Catholics themselves. For instance, Jake's observations of the Irish language and of Irishness generally have an underlying sense of irony. One night he and his friends accidentally take part in an Irish poetry reading: "An Evening of Irish Poetry Tonight 8 p.m. [a sign in the bar] said. Oh, fuck, I replied" (McLiam Wilson 172). The poems are all about the natural beauties of the country but Jake notices "that these were all nationalist hedges, republican berries, unProtestant flowers and extremely Irish spades" (ibid. 175). Not everybody present is able to understand the Irish texts, however, and they are translated into English (a hint that Irish is not really the main language of all Catholics). Finally, Jake expects boos and catcalls for the sentimental tone but the audience loves the poems. "Weren't there any Protestants here?" (ibid. 176), he wonders. Eve Patten argues that the underlying and "pervasive" irony in Eureka Street thus offers the characters a "distance from which to survey and destabilize the configurations of home" (Patten 130). One could say that Jake has evolved 
from the communal Northern Irish world and is able to see the old conflict from a different perspective.

The language aspect raised here shows a connection between the usage of Irish and the nationalist topics raised within the poetry. It also proves Anderson's argument that communities are united by the same language. Those in Eureka Street who share an Irish identity and (unlike Jake) want to express it, feel they belong together when listening to Irish poetry. Although many people are not able to understand it the printed aspect of this old cultural marker - namely the Gaelic language - confirms this particular Irish community in their identity. Nevertheless, it also demonstrates Anderson's point that certain vernacular languages in the past became superior to others, in this case English.

It is important to note, however, that Irish generally is more of a symbol to artificially uphold an Irish identity. In everyday life English is the tool to communicate for most people. "Any influence from Irish almost certainly derives from historical, rather than contemporary, contact between the two languages," observes Alison Henry (7). When speaking English, all Belfastians use the same dialect and it cannot be told to which ethnic community the speaker belongs. "Although Belfast is known to be in many ways a divided society, with often little contact between the Protestant and Catholic communities, Belfast English is not distinguished, either phonologically or grammatically, along religious lines" (ibid. 8). If any difference occurs at all it is between classes (working and middle-class) or generations (older and younger speakers) (ibid. 8). So, even if there is hardly anything those two communities share, they are united by a common dialect of English, one that is different from the English spoken in Britain or elsewhere. At the same time this form of dialect is considered showing "a lack of education", and in working life standard English is to be preferred (ibid. 8). When Saoirse is in the south of Ireland, shortly after having left the North, the cleaning lady of the school asks her where she is from due to her "funny accent" (Caldwell 138). The feature of the dialect's bad reputation is also expressed by Chuckie although he uses the same dialect as everybody else: "Chuckie was ashamed of the way his fellow citizens spoke. The accents of his city appalled him [...] He longed for elocutionary elegance" (McLiam Wilson 36ff). On another level this could also mean that Chuckie does not agree with the situation in Belfast. Although people try to make opposing political stands it all amounts to the same 'language', the language of sectarianism. Chuckie in contrast like Jake expects something better to come, still he himself at the beginning is not much different from everybody else.

Considering Anderson's community theory and definitions of identity it thus can be seen that Northern Ireland indeed incorporates two 'nations'. Although the whole population belongs to the English-speaking community some people mostly Catholics - have also referred back to traditional Irish community facets such as the Irish language in order to define an identity. Obviously, identity is not 
only arranged through language. Further aspects will be considered in chapter three.

\section{Irish Identity and Stereotyping}

“Taigs! Filthy stinking Ta-igs!"

Where They Were Missed, Lucy Caldwell

$(2006,22)$

Like many colonised peoples the Catholics in Northern Ireland have come into a diasporic situation (although in 2001 Catholics made up 40 per cent of Northern Irish population and are losing their minority status (Mitchell 2006, 22)). This situation surely differs from that of African slaves brought to North and South America and it differs much from the Jewish history of living outside the Holy Land, but in the case of the Irish it is possible to speak of diaspora as well, as they were indeed not taken forcefully away from their homeland but their homeland was occupied, altered and gradually transferred into a country with a generally British lifestyle. Consequently, the Irish had to adapt to a different mode of living. However, the question remains whether Northern Ireland can be included in the field of British colonialism. There are several aspects that speak for this assumption, which will be discussed in the following chapters.

\subsection{The Colonial Discourse - "England's Oldest Colony" \\ "It's like a war." \\ One by One in the Darkness, Deirde Madden (1996, 95)}

"More than three-quarters of the people living in the world today have had their lives shaped by the experience of colonialism" state Bill Ashcroft, Gareth Griffiths and Helen Tiffin in their joint work The Empire Writes Back (1). This is also valid for Ireland. Since the beginning of its early conquest in 1171 Ireland has been time and again subject to British intrusions. As one of the first colonies Ireland thus stands at the beginning of a long era of British imperialism and could theoretically be grouped together with for instance India, the Caribbean, Japan, Australia and parts of Africa, to name just a few. Simultaneously, critics for a long time had to face the problem whether to include Irish literature in the series of postcolonial writing at all, since the Irish as "functionaries" of the British had also been engaged in colonial affairs overseas (Döring 97). Ashcroft, Griffith and Tiffin for example do not include Ireland in their list of postcolonial literatures though they acknowledge it is worth examining Ireland in these terms (Ashcroft 24). That it 
should not be left out completely of the postcolonial context is one aspect this paper aims at showing in reference to contemporary Northern Irish fiction.

Alongside Malta, Gibraltar and Minorca, Ireland takes a special position as it is one of the few European places of British colonisation and thus was excluded from the prevailing Eurocentrism described by Edward Said (221). While the great European imperial powers put on the role of observers that "studied, classified and verified" (ibid. 221/222) other peoples Ireland belonged to that very group studied itself. The system "subordinated them by banishing their identities, except as a lower order of being, from the culture and indeed the very idea of white Christian Europe" (ibid. 221/222). In the eyes of the British colonisers Ireland never fitted into this "white Christian Europe".

British writers such as Edmund Spenser have repeatedly put the Irish on a lower level. In his essay $A$ View of the Present State of Ireland Spenser describes the Irish as descendants of the Scythians ${ }^{16}$ and that they were once every year turned into wolves: "Also the Scythians sayd, that they were once every yere turned into wolves, and soe it is wrighten of the Irish" (R. Morris 634). Tobias Döring also points to Charles Kingsley who, while on a journey through Ireland, portrayed the Irish in a letter to his wife as "white chimpanzees", clearly perturbed by the fact that the Irish did not look any different from their British occupiers (Döring 98). The comparison to animals thus subordinated the Irish to their British occupiers and reminds of the treatment of American natives or Indians as savages. "It is important to note how Ireland has been specifically positioned over many centuries as an Other against which a British state formulated itself' (127), Sabina Sharkey notices. This state of otherness prevailed well into the twentieth century and still has not vanished completely. Many Northern Irish Protestants still feel unfamiliar with their Catholic fellow citizens (and the Irish living in the Republic) although they have been living next to each other for centuries. Asked in an interview about their notions towards the Irish a Protestant woman from County Down answered: "I don't feel anything in common with my Irish counterparts they feel like strangers to me" (Mitchell 2006, 65).

Said argues that one way of opposition for a colonised people lies in developing a nationalism that unites the people by a common history, religion and language against the occupying power. A problem occurring here is the fact that resistance was led by the better educated classes who in turn were educated or "produced" by the oppressor (Said 223). Said also mentions two political moments that can enable the way to resistance: The first point is the realisation of Western or European imperialism. Out of this new gained consciousness the oppressed are now able to claim the end of imperial power. The second moment then occurred after World War II when "conventional nationalism was revealed to be both insufficient and crucial." Out of this a stronger urge for liberation arose that even

16 Scythians: An ancient nomadic people of Iranian descent living in central Asia and later southern Russia in the $8^{\text {th }}$ and $7^{\text {th }}$ centuries BC (Britannica 576). 
included the use of military revolt (ibid. 224) as it can also be seen in the case of Northern Ireland during the Troubles. Concerning the whole of Ireland one can take the Irish Renaissance, which came into being around 1890, as the moment when the Irish realised the importance of their long subjugated culture and that it was time to stand up against British rule and change the current state of affairs. Said describes how a colonised people have to rediscover their own identity:

For the native, the history of colonial servitude is inaugurated by loss of the locality to the outsider; its geographical identity must thereafter be searched for and somehow restored. Because of the presence of the colonizing outsider, the land is recoverable at first only through the imagination (Said 225).

Hence, before the south of Ireland gained its independence in 1921-2 the Irish had to reinvent their culture by invoking the Gaelic language and the old myths in order to mark themselves off from the British as these traditions had been connected to their country for centuries. Its revival is what is expressed by Said with the term imagination. To stick to the old language and myths again united the Irishmen in a new form, Anderson's imagined community (see chapter 2.2). For the excluded brothers in the North the struggle for an independent self continued, however.

Ashcroft, Griffiths and Tiffin illustrate several stages of literary production in the postcolonial development. As a first stage they mention colonial writings during the imperial period. These writings were done by an "elite whose primary identification is with the colonizing power" (Ashcroft 5), like travellers or settlers. It is important to notice here that these writings should not be mistaken for cultural writings by natives of the invaded country. As a second important stage they refer to the emergence of literary works by the natives themselves. "The producers signify by the very fact of writing in the language of the dominant culture that they have temporarily or permanently entered a specific and privileged class endowed with the language" (ibid. 5). However, these works were not fully developed yet, due to the censorship of colonial control. Only the people in charge decided what was to be published and what not (ibid. 6). In the case of Ireland this development is somewhat more difficult to locate than in other colonial territories as the process of colonisation began so early and the Irish language and customs were gradually superseded by British ones. Yet, as Döring has observed, in Ireland these stages took place, too. He mentions Oscar Wilde as a prominent example who by taking on the air of a British gentleman showed that British attitudes were not superior at all but accessible to theoretically everyone:

[...] By taking on the idiom and guises of the English aristocracy, like in a cultural masquerade, and by making them his chosen medium of mimicry and self-invention, Wilde can be seen to undermine their status of superiority and rob them of exclusive claims (Döring 99). 
In dressing and writing Wilde was as English as the English themselves, if not even more so.

When it comes to Northern Ireland, however, one cannot simply talk about the postcolonial as the North still belongs to the realm of the United Kingdom. The process of independence, whether territorially or in terms of selfconsciousness, has not been completed, yet, and it is uncertain if it ever will be. Regarding literature both Catholic and Protestant writers have largely dealt with problems that are neither particularly Irish or British, but with Northern Irish topics. Central here is not always the fight for Irish independence or continuing British rule but the results of that: conflict, personal loss and grief. The novels dealt with in this paper, Eureka Street, Where They Were Missed, and One by One in the Darkness, do not take stands for either a Protestant or a Catholic side but deal with the sorrows those concerned have to face.

\subsection{Hints of Nationalism in a Changing Society}

"She sings one last song, the song that Emer-of-theYellow-Hair sings to Cüchulainn whom she loves and whose heart she knows is leaving her. Mammy sings it softly, like a lullaby, and her green eyes are big and dark and shining."

Where They Were Missed, Lucy Caldwell $(2006,19)$

"Two cultures, two identities, inhabiting the same spot but travelling in their hearts towards different destinations" (Longley and Kiberd vii): This quotation by Mary McAleese nicely sums up what many (but not all) people living in Northern Ireland have experienced at one point in history. The two cultures she speaks of furthermore have a different concept of belonging. While for example Catholics in Northern Ireland put a strong emphasis on communality, Protestants rather believe in the individual citizen, as has been observed by Nic Craith $(2004,111)$.

Nationalism in Ireland as well as in Northern Ireland has a long tradition and becomes easier to understand when reconsidering Said's argument that nationalism is a form of resistance, delimitation and, in a sense, liberation from the colonial power. As the Northern Irish Protestants were representing relics of that subjugation the divide became almost insurmountable. Between 1900 and the 1916 Easter Rising the Irish Parliamentary Party was the leading political party of the time. Its goal was a united Ireland. Shortly after, Sinn Féin emerged in 1912 for two reasons, unionist resistance towards a Home Rule ${ }^{17}$ Ireland and the Irish

17 Home rule means the achievement of self-government by a dependent political unit of a central government. In Irish history Home Rule became a movement to secure Irish independence from Great Britain within the British Empire (Britannica 23). 
Parliamentary Party's readiness to accept the exclusion of the six northern counties out of a united Ireland. During the Anglo-Irish War of 1919-22 the IRA was founded. Despite their seemingly dominant presence during the conflicts - especially in the news abroad - the IRA was never supported either by the majority of the Northern Irish population or by the majority of nationalists, although it was connected to its political wing Sinn Féin.

The stagnating political process in Northern Ireland was reactivated in 1967 when Catholic protestors of the Northern Ireland Civil Rights Association (NICRA) paraded the streets with their slogan "British rights for British subjects." The rest of the world was shocked when it saw the use of police batons on a peaceful demonstrating crowd, which lead the British government to pass a reform package. In 1970 the Social Democratic and Labour Party (SDLP) was founded by Civil Rights Movement supporting MPs. The SDLP now stood for a moderate nationalist approach to politics. With the fail of the Sunningdale Agreement ${ }^{18}$, increasing IRA and loyalist violence during the 1980 s and the objection of unionists to accept their Irish fellow citizens, Sinn Féin reemerged as a serious political force in $1982^{19}$. Six years later the SDLP repeated their attempts for a peaceful resolution of the conflict. Its party leader John Hume together with Sinn Féin's top man Gerry Adams entered talks that lead to the Downing Street declaration $^{20}$ of 1993 and the paramilitary ceasefires of 1994, and that finally resulted in the Good Friday agreement (Mallon and Phoenix 4ff). Similar movements and political parties developed equally on the Protestant unionist side.

This short historical outline of Irish nationalism shows most clearly the fact that almost everything connected to Northern Irish identity has political roots. "Nationalism [...] must be regarded as a core factor in any interpretation of the Northern Ireland conflict", Patrick Mitchel contends (17). Although I agree with Mitchel it is at the same time quite hart to find a coherent approach towards the

18 In 1973 an assembly formed by UUP, SDLP, and moderate Alliance Party members agreed on a devolved government for Northern Ireland with a power-sharing executive. For the first time since 1925 parties of Britain, southern Ireland and Northern Ireland met at Sunningdale, Great Britain to agree on a Council of Ireland in which ministers from both Irish governments should be present. In addition both members from the Irish Dáil and the Northern Irish Assembly should form a consultive assembly. Loyalist opposition in form of the anti-Sunningdale United Ulster Unionist Council (UUUP) that was formed by three main loyalist parties, followed by a general strike by the loyalist Ulster Worker's Council caused the downfall of the agreement in 1974 (Mulholland 94ff).

19 Sinn Féin gained 10 per cent of the vote in the 1982 Northern Ireland Assembly elections (Mallon and Phoenix 8).

20 On 15 December 1993 both the British and the Irish government signed the Downing Street Declaration which promised "to foster agreement and reconciliation, leading to a new political framework [...] within Northern Ireland, for the whole island, and between these islands." How to convince most Protestants of this proposal was not mentioned, though. A first Downing Street Declaration had been issued by Britain's Prime Minister Harold Wilson in 1969, which stated "that only Northern Ireland could determine for itself whether the union with Britain be ended" (Mulholland 92, 132). 
term nationalism. Besides Anderson's theory of print-capitalism, sharing the same myths and culture, living in the same area or territory, knowing about the same symbols and rituals or speaking the same language are just some characteristics that unite people of one nation and separate them from another (ibid. 48). These key factors are also mentioned by Nic Craith who summarises that "the national community portrays itself as a distinct people with a unique history, language, religion and homeland" which "demands the loyalty of its people in the form of ethnic loyalty" (Nic Craith 2003, 37). Frederick Boal and David Livingstone, too, regard ethnicity as a source for nationalism and conclude that "the process of ethnic elaboration became part of the process of nation building" (Boal, Livingstone $163 \mathrm{ff})$.

It is the nature of the human being to want to belong to something or to some group. The group implies security, acceptance, perhaps respect. Being completely on one's own can cause severe problems for the concerned individual. But the levels of belonging vary. This can begin with what family one belongs to, what friends one chooses, what school one goes to, what sports team one prefers, what country or even what continent one comes from. "The formation of national identity is one component of the search for personal identity and an essential function of nationalism is to interpret and make sense of the modern world" Mitchel argues (49).

The search for belonging goes much deeper, however. Finding an identity does not only mean finding a certain group one likes and that accepts one in return but to share a deeper meaning of a common culture. While Anderson speaks of the imagined community of the nation, Mitchel adds that the whole world is an imagined construct "consisting of a host of independent nation states in which each nation seeks recognition and acceptance" (51). He also alludes to a point made by Montserrat Guibernau when he says that belonging to a nation makes a person feel being part of something that "transcends their own existence" and that the advancement of the nation was normally seen as something important and special (ibid.51). Northern Ireland had always been in the dilemma that its inhabitants, caught between the opposing powers of Catholic Nationalism and Protestant Unionism, have never acted in concert:

Unionists view themselves as part of the UK whereas nationalists see themselves in the context of a thirty-two county Ireland. Liberal unionists imagine themselves as members of the Great British State whereas nationalists think in terms of the Irish cultural nation. Not only do unionists and nationalists think in terms of different geographical territories, there are different senses of nation-state for each. Unionists primarily think in terms of an imagined political community, whereas nationalists have a stronger sense of cultural nationhood (Nic Craith 2004, 115/116). 
Nic Craith here argues that unionists conceive themselves to belong to the realm of Great Britain because they share the same ideas of politics and the same world view. Nationalists on the contrary rely much stronger on Irish cultural elements, which is also another form of imagined community, if an imagined cultural community. So politics and culture basically clash in conflict.

As already mentioned above, Mitchel names five aspects that are significant for forming a nation and thus nationalism. They are the worlds of nations, myths, culture, territory and symbols/rituals (Mitchel 50ff). Within Northern Irish society many of these aspects are received differently and are of different origins as well. Beginning with the world of nations the nation thus normally represents the will of the people who ideally all share a collective identity. It thus receives its legitimacy and can also represent the will of the people internationally, continues Mitchel to explain (ibid. 51). But what happens if a nation is not able to represent a consistent will because its people are not unified in their beliefs and do not share a common culture? In this respect Northern Ireland has failed for a long time as both Catholic and Protestant needs were neglected by the governing parties. By contrast, myth - as for instance in Where They Were Missed - links a nation to its imagined past and opens new ways for the future. Like the West Belfast families that thought it important to give their children back what they felt was missing (the Irish language), Saoirse's mother tells her children the tales of the legendary hero Cúchulainn because she thinks it is "important that the stories are told" (Caldwell 14). Although Deirdre Pentland is not a typical nationalist it here can be seen that she strongly clings to aspects of cultural nationhood as described by Nic Craith.

Two of the most obvious Protestant and Catholic myths in Northern Irish history are those of William of Orange and Cúchulainn. "Orange culture is central to the ideology of loyalism and marching is a particularly significant emblem of their sense of belonging to the region" (Nic Craith 2003, 38). Both the myth of Cúchulainn and the historical figure of William of Orange demonstrate Nic Craith's assertion that unionists identify with Great Britain and nationalists with their cultural background, as William of Orange stands for a political change in the history of Britain while Cúchulainn is a legendary Irish cultural hero. Nevertheless they have also something in common: The function of these historical myths and the commemoration of bygone days is to equip people with a "meaning beyond individual existence" (Mitchel 53). By celebrating the Orange Parades each and every year as by telling the stories of Cúchulainn and other Celtic heroes, people uphold a common past. It still remains imagined in the sense Anderson uses the term as it is a past nobody alive today has experienced in reality. In that sense I would argue that the cultural nationhood Nic Craith mentions also belongs to the realm of the imagined community (which has already been assumed in this paper but this is the positive proof). Culture remains an abstract notion by which thousands of people that have never seen each other feel united. It is just the image of a past that is 
passed onwards. Culture then connects the individual to present values and patterns. Home, schools and churches communicate the necessary elements of cultural values and thus "culture has the capacity to form identity; it mediates the way people relate to themselves, others and to the world" (ibid. 54). A strong sense of loyalty to that cultural identity is the result. If nation and state are not congruent people are likely to set up cultural markers for their identity. Sources can be among others religion, language, music or folk traditions. The stress will be put on uniqueness and distinctiveness (ibid. 54). If people start overdoing this, the cultural clash will become too deep, however, and deep-rooted aversion as in the case between Catholics and Protestants in Northern Ireland may be the result.

One of the stories Saoirse is told even reminds of the torn apart state of Ireland: Cúchulainn who is in love with Emer comes under the spell of Fand and is "going to betray Emer, and throw away everything that he has, for a love which isn't love, for a love which is like a sickness, a mist that descends and chokes reason" (Caldwell 16). Emer here is presented as Ireland that loses part of itself to Fand, which resembles Great Britain. The union between Fand and Cúchulainn only causes an ill condition like the union of Irish and British elements in Northern Ireland.

Mystic and historic figures also used to prove of significance for nationalist wall murals. For this reason, Cúchulainn and Celtic warriors were frequently depicted in Belfast such as King Nuada depicted in figure 1.

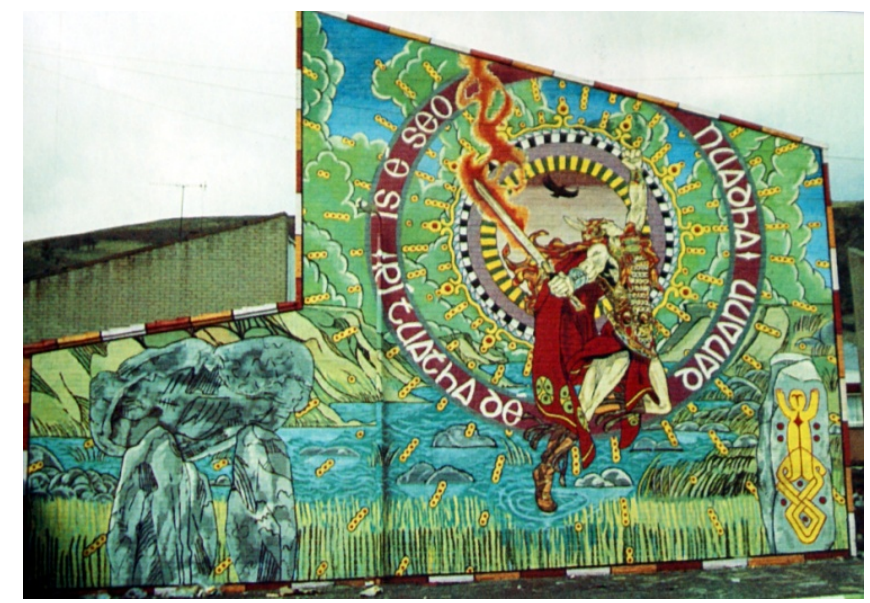

Figure 1: King Nuada, mythological warrior of the Tuatha de Danaan, Springhill Avenue, Belfast 1987 (Rolston 57).

"Heroes and myths of bygone ages are used to provide a coherent and satisfying story of origins and history that act to unite group identity in the present" Mitchel stresses (52). For Saoirse's mother Deirdre the stories of Cúchulainn provide her with a sense of her Irish background while living among Protestants who contrast 
sharply in their way of celebrating William of Orange. As "unionists have relatively few myths" (McCall 23) the Williamite reorganisation of Ireland and for instance the Siege of Derry 1689 are central themes for them. For unionists the marching season thus represents the revolt against Catholic intrusions on hegemonic rights - "compromise would be to surrender" McCall explains (ibid. 23). In Where They Were Missed the Orange culture and Celtic myths clash time and again. For the older generation as Saoirse's mother, myth makes up a vital part of their cultural kinship. Manus Dennehy, a farmer living nearby Saoirse's aunt and uncle, is also a great story teller. Saoirse loves him for that and because "he knows all the stories of Donegal, and he knows all about the Síde" (Caldwell 121). He tells stories of Roan Inish (Seal Island), a small island outside of Gweebarra Bay and a selchie, a seal-girl, and knows a great deal about Tir-nan-Og, the otherworld in which Saoirse assumes her sister Daisy to be (ibid. 123ff). These stories always have a special meaning to the story-teller or the listener. Manus, for instance, connects the selchie to his dead mother who drowned in the sea when he was still a child (ibid.127), Saoirse on the other hand wants to bring back Daisy from the "castle in the sky" in Tir-nan-Og where she believes Daisy to be residing after her death (ibid. 126). Generally, these myths also represent a connection to the countryside and the old traditions.

This leads directly to the aspect of territory which is often accompanied with strong emotional reactions. In times of war, for example, people are even willing to sacrifice their own lives for the nation. The reason for this is a strong bonding of the individual to the land and the existing beliefs (Mitchel 55ff). In Northern Ireland this is again a difficult case as the supposed enemy is living within the same territory. While republicans want to reunite the North with the South and thus incorporate the territory into the rest of Ireland, unionists rather want to maintain the boundaries of 1922 and stay in connection with the British motherland. Anderson's imagined community by contrast focuses mainly on the aspect of language and therefore fits modern times better. The days of the nation are not over, yet, as nations are still needed to provide people with political stability and personal security but nationality has lost its climax. Other people can thus also be "invited into the language community" (Anderson 145). In One by One in the Darkness, for instance, territory or the place of home, makes up an essential part of the sisters' lives. The novel begins at their home in the country and it also ends there. Inbetween many references to nature are made. Cate remembers places such as the Glens of Antrim or the Giant's Causeway they often visited during childhood (Madden 82). Even when grown up Cate enjoys driving without aim through the countryside. "Swatragh and Draperstown; Magherafelt and Toome; Plumbridge and Castledawson: her family couldn't understand her interest in these places" (ibid. 82). All these places, no matter how beautiful they are, always show the other side of Northern Ireland, too. People have marked these places to demon- 
strate their presence and Cate sees "footpaths [...] painted red, white and blue", "Republican graffiti" and "INLA21 rule" letterings (ibid. 82ff).

Finally, symbols and rituals serve individuals both as aggressive markers and as uniting factors for each community. As has already been said, typical symbols and rituals in the Northern Ireland context are wall murals, flags and religion (Mitchel 57). Protestant and Catholic housing areas were thus clearly separated from each other. The practice of rituals "reminds participants of their common belief system" and at the same time "renews the link between past and present" (ibid. 58). Both Catholic and Protestant nationalism/unionism thereby exclude each other. In Helen's memory the Orange Parades were always a faraway event and certainly not meant for any Catholics to participate in:

And yet for all this they knew that their lives, so complete in themselves, were off centre in relation to the society beyond those fields and houses. They recognised this most acutely every July, when they were often taken to the Antrim coast for the day, and as they went through Ballymena and Broughshane, they would see all the Union Jacks flying at the houses, and the red, white and blue bunting across the streets. They thought that the Orange arches which spanned the roads in the towns were ugly, and creepy, too, with their strange symbols: a ladder, a set square and compass, a fivepointed star. They knew that they weren't supposed to be able to understand what these things meant; and they knew, too, without having to be told that the motto painted on the arches: 'Welcome here, Brethren!' didn't include the Quinn family [...] They never, in all their childhood, actually saw an Orange march taking place, for their parents always made a point of staying at home on that day, complaining bitterly that you were made a prisoner in your own home whether you liked it or not (Madden 75).

One of the major problems of humanity has long since been the stubbornness of people. Conflicts cannot be solved if one cannot compromise. An example here is Aoirghe from Eureka Street who fights for a united Ireland during most of the novel. After a violent escalation caused by the Just Us, a republican group, she argues with Jake advocating the nationalist side and calling Jake a fascist because he attacked one of her friends in the confusion:

I stopped. 'T'm a fascist?! What were you all there for? You're the people with all the ordnance. You were looking for trouble'. She snorted scornfully. 'Those middle-class shitheads wanted to have their pathetic little protest. We just thought we should have one as well.' 'All they were doing was asking for peace.' She snorted again. 'Don't you want peace?' I asked. 'Not

21 INLA: Irish National Liberation Party, a republican paramilitary group founded by the Irish Republican Socialist Party, which was a Marxist and militarist splinter group of the IRA (Aughey 162). 
on their terms', she replied. 'On what terms, then?' 'On our own terms.' I laughed. 'That's a constructive position. Your folks must really dote on you.' 'We'll win in the end.' I opened the Wreck door. 'Change the record, please' (McLiam Wilson 200).

The contrasting views of Jake and Aoirghe mirror what society thinks about the state of Northern Ireland, some being more radical, others less radical in their attitude. Also a decisive point is made: Aoirghe only wants to accept peace if all nationalist requests are fulfilled. It is exactly this stubbornness that is representative for the problematic peace process. Jake is already one step further ahead because he realises that Aoirghe's gridlocked nationalism is going to lead nowhere.

In One by One in the Darkness nationalism leads to something but this is only death. Charlie Quinn and his brothers Brain and Peter stand for different political opinions. While Charlie and Peter are very moderate in their views, Brian embraces nationalist initiatives and also asks his brothers to come to the Civil Rights Marches (Madden 64). Charlie does not want to go at first but his mother convinces him: "When you think of what people have to put up with in this country, well, we have to make a start somewhere in telling them that we've had enough of that" (ibid. 65). In the end Charlie does not go because "one of the cattle fell sick" (ibid. 65). This shows where his priorities are. He joins Brian at another march in Derry, however, the one that ended in rioting. Later he says angrily: "There was no sense in what happened today" (ibid. 71). Brian on the other hand becomes more and more drawn to nationalist ideas, especially after it has been decided that British troops are to be sent to Northern Ireland. His argument is that it "would have been better if our own had been able to look after us [...] Dublin has let us down badly" (ibid. 95ff). Charlie even fears Brian has joined the IRA, which he denies (ibid. 101). However, Brian becomes a member of Sinn Féin and even distributes the Republican News, a newspaper published by them (ibid. 163). Although it is not Brian's fault that Charlie is executed by unionists he blames himself because he knows it should have been him instead (ibid. 142). The second generation of Helen, Cate and Sally does only show minimised traits of nationalism, if any. Sally is a member of the SDLP but more out of convention than out of conviction. She joined because she was asked by the headmaster of the school she teaches and thought it embarrassing to refuse (ibid. 141). Nevertheless she says: "I do support their principles, with a few reservations; but they're as good as you're going to get. And I know that there are lots of people who support Sinn Féin in a similar vein" (ibid. 141). Hence, nationalism seems to have changed in some way. While earlier generations were more supportive of nationalist goals younger people like Sally seem to have become uncertain if all of the purposes are justifiable. Aoirghe, of course, is a good example for the contrary but even Aoirghe will change in the end.

Another character that even exceeds the realms of nationalism and is more of a racist in general is Jake's colleague Ronnie Clay who "had been suffering from 
chronic insomnia for some years" and "attributed it to the Anglo-Irish Agreement and the creeping suspicion that this country would soon be in the hands of the filthy Roman Catholic Church" (McLiam Wilson 280). Apart from his strong dislike of Catholics he also hates black people and dreams of various possibilities of "ridding the planet of all its dark-skinned humans" (ibid. 280). Ironically he has to work with both a Catholic, Jake, and an Indian, Rajinder, and cannot do anything about it. Furthermore, he is fantasising about a "hybrid dog, a vicious superdog, which ate only black people" (ibid. 281): Without noticing it, Ronnie acknowledges that a hybrid being is capable of doing far better things than a nonhybrid. What he is actually dreaming of - a pure world of only white Protestant people - in his vision only becomes possible by using the opposite, a being that is not pure in that sense because it is unites different qualities.

\title{
3.3. The Colonised Body: Postcolonialism and Postmodernism
}

\subsubsection{The Literary Postcolonial Moment}

\author{
"T know Cúchulainn, I said. - But can you speak \\ Gaelic?" \\ Where They Were Missed, Lucy Caldwell \\ $(2006,139)$
}

With respect to literature, the late nineteenth century saw a counter-movement against British policies in the form of the Irish Renaissance, also termed the Celtic Revival, which is generally dated from 1890 to 1920. The Home Rule movement, led by Charles Stewart Parnell, as well as the Land League were just two developments on the political and social level. Disillusioned by Parnell's failure after his affair with married Katharine O'Shea and his inevitable fall, and because an independent Ireland seemed to be out of reach, people were in need of an Irish identity more than ever. In order to realise this, the Irish Literary Movement, the Irish Dramatic Movement and the already mentioned Gaelic League came into being. The latter movement opted for a revival of the Irish (Gaelic) language with the aim to use it both in everyday speech and writing (Imhof 61ff). It also provided the literary movement with the material necessary for inventing a typical Irish character, such as Celtic mythology and the revaluation of simple country life. One of the major spokesmen for the Irish Literary Movement was William Butler Yeats who ensured that these Irish folk tales and works by Irish writers became accessible to the public, both nationally and internationally (Kosok 146). The key characteristic for this literature is the blending of traditional Celtic topics with contemporary Irish problems as for instance shown in Yeat's poem The Wanderings of Oisin (1889), in which the Irish hero Oisin stands in dialogue with St. Patrick. 
Here Ireland's pagan past and the existing Catholic morals and values meet in a central conflict. Another important feature is the coming back to aspects of traditional Gaelic poetry like rhyme scheme, stanza and metre. In contrast to supporters of the Gaelic Revival authors of the Irish Literary Movement did not choose Irish as their form of writing (many writers were just not able to speak or write it) but Hiberno-English ${ }^{22}$, a specific variant of English as spoken by the rural population, and adapted it to their artistic means (ibid. 148ff). At the same time, we find militant republican writers like Patrick Pearse ${ }^{23}$ whose radical approach was soon questioned by Yeats and later Frank O'Connor and Sean O'Faolain. Their firsthand experiences - O'Connor, having witnessed both the Anglo-Irish War and the Civil War, and O'Faolain, having been involved in the IRA himself, allowed these writers to take a critical look on Troubles policies (Kennedy-Andrews 2006, 239).

The Anglo-Irish Treaty of 1921-2 changed quite a lot: What the Irish Renaissance had aimed at was now at least partially achieved - political independence. Still, the solution was not satisfying for everyone. The separation of Northern Ireland induced what still eighty-nine years later is clearly visible: a deeply divided population. In Troubles fiction the focus was now put on the North, and many Republican writers of the eighties (unlike James Joyce, John Millington Synge or Lady Gregory) "wrote from positions of defense", showing the human side of IRA killers (Keating-Miller 63). At the same time also English writers engaged in the theme of Northern Irish conflict, mostly in the form of the thriller. In contrast to the novels from the North, the IRA man here, however, was "simplified and diabolised" (Kennedy-Andrews 2006, 241). As Elmer Kennedy-Andrews has noted, "these novelists tended to reproduce the cultural and political views of the British establishment, thereby reinforcing the hegemonic British discourse regarding Northern Ireland" (ibid. 241).

Patten describes two trends that took place in Northern Irish fiction. One is the convention to use realism, the other the "expansion to documentary", which according to her are the "result [...] of the desire for legitimate or authentic representation distinguishable from the mass of pulp sensationalism" (Patten 131). Eureka Street, One by One in the Darkness and Where They Were Missed, written in 1996, 1996 and 2006, feature this documentary style as well. Both McLiam Wilson and Deirdre Madden were born in the 1960s (1964 and 1960 to be precise), Lucy Caldwell in 1981, and all belong to the group of postmodern writers Patten men-

22 The origins of Hiberno-English lie in the sixteenth century when the English settled Ireland. Like all languages of colonial situations also Hiberno-English shows traces of the then dominant language, Elizabethan English. Furthermore, the English spoken in Ireland adopted many Gaelic language patterns (vocabulary, loan structures of syntax). Nevertheless, the HibernoEnglish used by Irish poets should not be confused with the actual Irish vernacular (Kosok 149).

23 Patrick Pearse was one of the leaders of the 1916 Easter Rising. He advocated "a myth of blood sacrifice and mystical notions of Gaelic Ireland" (Kennedy-Andrews 2006, 239). 
tions (see my introduction). What all three novels have in common is a very personal narrative style that creates the impression of an eye-witness report of the Troubles. In the terms of Gérard Genette and Franz K. Stanzel Where They Were Missed features an autodiegetic first-person narrator, Saoirse Pentland. The first eleven chapters deal with her childhood in a Protestant area of Belfast while the following eleven chapters deal with her growing up in the Republic of Ireland. The last three chapters are again set in the North when Saoirse for the first time in ten years returns to her place of birth. One by One in the Darkness tells the story of the three sisters Helen, Cate, Sally and their mother Emily. The fourteen chapters are told by a heterodiegetic figural narrator with varying internal focalization. The chapters are thus shown through the eyes of the four women and give impressions of various stages of the past and the present, that is, from the 1960s onwards to 1994, just before the start of the IRA ceasefires. Eureka Street presents both a homodiegetic first-person narrator in the form of Jake Jackson and a heterodiegetic figural narrator who relates the Chuckie Lurgan chapters. Of the nineteen chapters sixteen are evenly distributed among Jake and Chuckie, whereas chapters ten, eleven and twelve mark an exception as they deal with the city of Belfast, a bomb explosion and the perception of its aftermath by different characters.

One of the reasons that make the re-evaluation of identity necessary is the colonial/postcolonial aspect of both the Republic of Ireland and Northern Ireland. According to Ashcroft, Griffith and Tiffin a central theme of postcolonial literature is the topic of place and displacement: "It is here that the special postcolonial crisis of identity comes into being; the concern with the development or recovery of an effective identifying relationship between self and place" (Ashcroft 8ff). As this paper only deals with Ireland and chiefly the North of it, dislocation in the sense of some Irish migrating to faraway places like the United States of America will not be discussed.

Out of the four major models of postcolonial literatures they mention (1. national or regional models, 2. race-based models, 3. comparative models, 4. hybridity and syncreticity models; see Ashcroft 15) the national and the hybridity/syncreticity model are of special interest for Northern Ireland. While the USA is considered as the first postcolonial society that created its own national literature, other countries such as India, Nigeria or Australia followed this example and started dealing with their own histories (Ashcroft 17). "The study of national traditions is the first and most vital stage of the process of rejecting the claims of the centre to exclusivity", Ashcroft, Griffiths and Tiffin argue and they refer to the Nigerian writer Wole Soyinka who saw in this the beginning "process of selfapprehension" (ibid. 17). Whereas the earlier famous Irish writers such as Oliver Goldsmith, William Butler Yeats, James Joyce or Samuel Beckett wrote in the European and foremost in the British tradition, younger Northern Irish writers like Glenn Patterson, Deirdre Madden, Robert McLiam Wilson or Seamus Deane 
are nowadays paying attention to Northern Irish themes in which mostly the conflict between Protestants and Catholics and also the impact of belonging to one of these communities is dealt with, concerning themselves with Northern Ireland's tradition of the Troubles in the latter half of the twentieth century.

Critics were also eager to know whether a complete decolonisation of culture was possible. This question, however, is as controversial as discussions in postcolonial studies and elsewhere have always been. Hence, some critics have argued the age of colonisation was only a passing event that could be ignored once independence was achieved. Objecting to this others have argued that it was impossible to overcome this stage once colonisation had taken place in the past (ibid. 30). When looking at Northern Ireland it is indeed hard to imagine that colonisation can be left entirely behind when the dimension of the division between Catholics and Protestants in some parts of the country, especially in Belfast, is still clearly visible.

In some countries, like in India, the trend goes to primarily writing in the native languages again (ibid. 30). Although there are nowadays some authors writing in Irish like Nuala Ní Dhomhnaill it is almost unthinkable that no books are produced in English anymore as English is still the dominating language. Ireland's colonial past cannot be forgotten and a pre-colonial Ireland not reconstructed. Therefore in my opinion syncreticists' views are to be preferred who argue that peoples with a colonial past will always remain "cross-cultural hybrids" (ibid. 30). The influence of the colonising power will always linger in the background, not only culturally but also literally.

In literature language is an influential tool for transporting certain data from the author to the reader. As language is also considered as a "medium of power" (Ashcroft 38), it is of greatest importance for the colonised entity to find a way through this medium to step out of coercion. Ashcroft, Griffith and Tiffin in this respect speak of the "abrogation and appropriation" (ibid. 38) of language. With abrogation they mean the "refusal of the categories of the imperial culture, its aesthetic, its illusory standard of normative or 'correct' usage, and its assumption of a traditional and fixed meaning 'inscribed' in the words" and with appropriation "the process by which the language is taken and made to 'bear the burden' of one's own cultural experience" (ibid. 38). This set of abrogation and appropriation is not new to Irish literature but still in use.

The Irish twentieth century was marked by conflict with a first climax in the 1916 Easter Rising, the following Anglo-Irish War, the Civil War and the final outbreak of the ongoing conflict in Northern Ireland. Michael Storey has argued that early writers of Troubles fiction ${ }^{24}$, such as Daniel Corkery, Frank O'Connor and Sean O'Faolain, used to write in a postcolonial tradition (Storey 63). Aspects of place and displacement and the creation of a specific Irish cultural identity

24 Storey defines stories of the Troubles as a kind of fiction that deals with any conflict that occurred in Ireland during the twentieth century (Storey 63). 
played an important role with them and were treated with utter great care. Although all the mentioned authors were familiar with the Irish language they chose to write in English and did not put a special emphasis on Catholicism or the Irish language as crucial Irish elements (ibid. 65). These early writers instead chose "to appropriate English and reconstitute it as Anglo-Irish, a process that postcolonial critics argue is effective in establishing a national identity by distancing the postcolonial text from the imperial culture" (ibid. 66). As tools to achieve this goal Storey mentions cultural allusions, allegory, native glossed or unglossed words and the syntactic blending of native and colonial language into what became known as Anglo-Irish. Thus lots of Gaelic names and words as well as lyrics from Irish songs and references to Irish myths found their way into these writings (ibid. $66 \mathrm{ff})$.

Moreover, O'Connor's, O'Faolain's and O'Flaherty's writings were much influenced by their Catholic nationalist backgrounds and their commitment to the revolution and thus a political attitude can be found in their texts. Later writers such as Fiona Barr or Anne Devlin lack this political judgment (Storey 71). In addition Storey stresses a change in the setting of the novels. "Another difference between the early stories and the later ones is the shift in setting, from the South, where most of the Troubles of 1916-23 took place, to the North, where most of the violence since the 1960 s has occurred", that is a change from the regions of Munster to the city of Belfast (ibid. 71).

To come back to language it can be said that Ireland is in an inbetween state of a monoglossic and a diglossic society. Whereas the South can be described as a diglossic society with English as well as Irish as official languages, the North although there are still some native speakers of Irish as stated before - is rather a monoglossic culture since official bilingualism does not exist. Still, writers from the North incorporate the Irish language in their works in order to illustrate group affiliations or heritage. In order to separate and break free from the colonising power, or "the centre" as Ashcroft, Griffith and Tiffin call it, a reconstruction of the language, in this case English, has to take place (ibid. 38).

One way of marking difference in the text and thus using both abrogation and appropriation is the employment of untranslated words, something Lucy Caldwell in Where They Were Missed makes use of. She often includes Irish words in the text like "Sláinte25", "céadsearc26" or the untranslated title of an Irish saga "Táin Bó Cúailnge 27 " (Caldwell 19, 35, 44). As stated by Ashcroft, Griffiths and Tiffin this is done to demonstrate difference (Ashcroft 53) and cultural Otherness (ibid. 64).

\footnotetext{
Meaning "cheers".

"First love" or a "beloved one".

Meaning "The Cattle Raid of Cooley", a legendary tale in which Cúchulainn also appears. It tells the story of Maeve and Ailill, the queen and king of Connacht, who try to catch the Brown Bull (Cooley) in the land of the Ulaid (Ulstermen) in County Louth. The Ulstermen and their king Conchobar fall under a harmful spell, though. Only Cúchulainn remains to fight Maeve's and Ailill's attempts (Gribben 279).
} 
Caldwell, being herself from the North of Ireland, delimits the Catholic identity of Saoirse, Daisy and their mother from that of their Protestant neighbours and of course also from the girls' Protestant father who does not like his wife to tell the children Irish stories by incorporating these Irish words. It is important that no translation is given: a sense of familiarity or distance is created, dependent on the fact if the reader is an Irish speaker or not. At the same time these words not only function as delimiters. They also demonstrate the part of Saoirse that comes from a Catholic Irish background and thus stress a communal belonging. The usage of Anglo-Irish vernacular also finds a way into the text as for example in the form of "Yer ma's a Taig28" or "What are youse havin'?" (Caldwell 68, 79). As already brought up earlier certain regions like Belfast have easily recognisable dialects. By using the vernacular forms of language the sense of place and belonging is thus strengthened and readers from the same or nearby regions can identify with the characters.

As an important feature of postcolonial writing, Storey also mentions the usage of allegory. Most crucial here is the image of Ireland being a woman who needs the help of a young rebel in order to save her lands lost to foreign invaders, a story that has also been taken up by William Butler Yeats in Cathleen ni Houlihan (1902). In several of Daniel Corkery's stories the main character falls in love with a young woman who stands in some relation to the nationalist movement. The rebel is held back from his beloved, however, a union will only be possible if the Irish nation is created (Storey 68). This theme is also repeated in McLiam Wilson's Eureka Street where Jake is attracted to the radical Aoirghe. She believes in everything that stands for a truly Irish culture and is even ready to accept violence as a means to achieve Northern Irish independence from Great Britain. The allegory works a bit different here as Jake and Aoirghe are united in the end. An Irish nation is not established but Aoirghe's eyes are opened when she finally recognises that violence cannot bring peace but only sacrifices innocent victims like the young Roche. It is not an Irish state that is built but rather the acceptance of the Northern Irish state. In the end there is peace as well in the form of the ceasefires of 1994.

To come back to the authors Storey chose as an example it can be seen that they were not completely positive about nationalism, either. Frank O'Connor, Sean O'Faolain and Liam O'Flaherty were dedicated to the negative effects of violence as well and questioned the use of it. Storey thus describes the central theme of their stories ${ }^{29}$ as stories of disillusionment that feature a "deep disappointment in the nationalist movement" and points out "the theme of betrayal" (Storey 69). Storey in reference to that stresses a very important fact: "There is a

28 An offensive term to describe a Catholic Irish person.

29 The stories referred to are: O'Faolain's "The Patriot", "The Small Lady", "The Death of Stevey Long”, O’Connor's "Guests of the Nation", “Jo", “Alec”, "Jumbo's Wife”, O’Flaherty's "The Mountain Tavern", "Civil War", "The Sniper” (Storey 69). 
terrible irony evoked by the theme of betrayal. Cultural and political identity, the very means by which the nation-state is to be established, becomes the greatest liability for the members of the state" (ibid. 70). As an example he gives O'Flaherty's "The Sniper", which I would like to mention here, too, as it shows an interesting parallel to Deirde Madden's One by One in the Darkness. "The Sniper" tells the story of a republican sniper who finally kills his strongest rival who in turn is a Free State sniper. What he then discovers is quite disturbing as he has actually killed his own brother (ibid. 70). One by One in the Darkness retells the story of the destruction of family bonds due to taking political stands as already shown in chapter 3.2. While father Charlie is quite reasonable and against violence, his brother Brian sympathises with the IRA and is also a member of Sinn Féin. One day Charlie sits in his brother's kitchen waiting for him when a Protestant commando attacks the house and kills him mistakenly. The family is traumatized after that and Brian has to live with the guilt that he should have died instead of his brother. These two examples show well that history seems to be repeating itself continuously. What happened during the civil war in Ireland occurred again roughly eighty years later in Northern Ireland.

Besides these many similarities writers of the latter half of the twentieth century work with many distinctive methods as well. In contrast to those writers who were born and worked before the recurring Troubles of the 1960s-1990s, a younger generation of writers has been trying to reconfigure "accepted notions of what constitutes the individual and his world" (Kennedy-Andrews 2003, 92). Similarly to Patten, Kennedy-Andrews names dislocation, fragmentation and reconfigurations of the postmodern era as decisive attributes of the younger writers' works (Patten called attention to ambiguity, displacement, and perspectivism) and thus groups authors such as McLiam Wilson and Madden in the realm of postmodern humanism, "a world in which diverse cultures and symbols are flowing together in curious ways" (ibid. 92).

Multiperspectivity is an inherent characteristic of Eureka Street and One by One in the Darkness. The equal division of story-telling between Protestant Chuckie Lurgan and Catholic Jake Jackson in Eureka Street already hints at the fact that there is always more than one point of view. Furthermore, it seems to make sense to give a voice to both Protestant and Catholic residents. Chuckie and Jake do not remain the only characters who the reader is given insight to, however. Republican and unionist views are also presented through Aoirghe Jenkins and Ronnie Clay whose racism and hate against everything that is not white and Protestant has been already mentioned in chapter 3.2 (see p. 218). One by One in the Darkness gives a comparable amount of different perspectives. Besides the three sisters and their mother Emily who tell the story through flashbacks and present events other (political) views are shown through Charlie Quinn and his brothers or for example the two nuns Sister Philomena and Sister Benedict who are teaching at Helen's school. In Where They Were Missed the reader finds only one narrator in the form of 
Saoirse. Nevertheless, different perspectives are presented by her parents Deirdre and Colin as well as through other minor characters like Johnny Mahon or Manus Dennehy.

Fragmentation and ambiguity in the novels are both used stylistically as well as within the stories. Kennedy-Andrews has noted that One by One in the Darkness can best be called a trauma narrative. It is "the struggle of the four women to recompose themselves after the Troubles have invaded the vulnerable space of family and ordinary life" (Kennedy-Andrews 2003, 152-153). The death of husband and father Charlie thereby marks a crucial event which is marked by repression. Only in the end does the reader learn what really happened to him and is Helen able to confront herself with his violent death (ibid. 153). Prior to this, the reader only learns bits and pieces about the incident. Kennedy-Andrews also points to the theory that only through talking about a cruel event the concerned person can learn to deal with the results. The process of remembering, of reconstructing the past experience takes time and "does not produce a rational, linear narrative" (ibid. 153). Thus, Cate, Helen, Sally and Emily remember various stages of the past in mixed order - happy childhood days as well as disturbing events linked to the Troubles like the intrusion into their home by the British armed forces. Other signs of repression include dreams and nightmares, which make up a "prominent element of the text" (ibid. 154). Almost everyone in the novel refers to a dream sooner or later. Emily, for example, dreams both about the threat to her family in the form of a raft heading for a waterfall and of her husband's murder (Madden 124/125). Cate's dreams are less threatening but equally concerned with repressed fears. One is about her baby and the father "denouncing her loudly" for her decision; another one shows her baby in an "adult posture" and a skeptical look on its face (ibid. 89/90). Her whole family is a somewhat doubtful about the baby at first, especially her mother. So, Cate's uncertainty about her decision is mirrored in her dreams. Nevertheless she knows she did the right thing. In a world in which families and homes can easily be destroyed having children to Cate means having "something real" (ibid. 93).

In One by One in the Darkness as well as in Eureka Street and Where They Were Missed, fragmentation seems to be the result of a huge bomb exploding directly into lives of the characters. Like pieces of shrapnel the family is blown apart after Charlie's death. In Eureka Street the physical and real bomb is dedicated a whole chapter, which brings the characters' inner fragmentation to the surface. The most obvious sign for fragmentation again becomes visible in family relations, though. After "the cops and the social workers had nabbed [him]" Jake grew up with his foster-folks Matt and Mamie (McLiam Wilson 103). Chuckie equally grew up in a fragmented family as his father left his mother and ended as an alcoholic "in a docker's bar that never closed" (ibid. 29). Like the sisters in One by One in the Darkness the two of them are always feeling that something is missing. Love (also in the form of empathy as elaborated on in chapter 3.3.2.) and again children ap- 
pear as the only solutions to their uncertain lives. "Chuckie wanted to be lost in someone. Chuckie wanted a girl who would make life burn in his heart like a heavy meal. Chuckie wanted to discover the secret of true love" (ibid. 45). He soon finds his true love in Max. When he learns about her pregnancy everything changes for him: "The child made it all right in some complete way he barely understood" (ibid. 278). Jake by contrast has to endure some pain before he in the end gets together with Aoirghe. In the beginning the reader learns that Jake was left by his long-term girlfriend Sarah. Later Jake finds out she had an abortion without him even knowing about the baby, something that deeply hurts him (ibid. 74). Always searching for love Jake sometimes finds companionship in his cat. The cat could be interpreted as a wish for security, love or even a child.

Lucy Caldwell's heroine Saoirse is affected by a fragmented family, too. Like in One by One in the Darkeness this fragmentation is clearly caused by the conflict in Northern Ireland. Her mother Deirdre cannot deal with the violent state of affairs that is unfolding itself outside their home. Because her husband Colin is working for the RUC ${ }^{30}$ she slowly begins to project the cause of all problems happening in the country on him. Normally their "mammy never swears", says Saoirse (Caldwell 6) but because Colin comes late for Daisy's birthday Deirde's mood is changing: "Blame your father [...] Blame this bloody country" (ibid. 6). This marks the beginning of the catastrophe that is awaiting Saoirse's family. The quarrels between Colin and Deirde get worse as when talking about the death of one of Deirdre's friends who was killed by Protestants. Colin mentions that the brother of the offender and the former's wife were killed by a bomb planted underneath their car. Deirde thinks he tries to justify the deed, which he denies (ibid. 40ff). Still, discussions as this one continue driving a wedge between them and lead to their separation. Deirde little by little becomes an alcoholic, then Daisy dies in a bomb explosion. Finally, Deirde leaves Saoirse with her sister Bernadette in the south of Ireland because she just cannot cope with the situation. In her anger and grief about Daisy's death she even blames Saoirse for not watching over her sister. Even ten years after the accident her mother's words still ring in Saoirse's head: "What have you done? How could you? Get away from me, go on, get away, I can't bear to touch you [...] What have you done?" (ibid. 72/191).

In contrast to earlier Troubles writing the "conflict between innocence and involvement" or "innocence and complicity" (Patten 132) can be named as another factor that became important for the generation of writers who grew up during the 1970s and 1980s. Innocence and complicity are also relevant for the discussed novels. The innocence of the two children is again expressed by Saoirse Pentland and her sister Daisy in part one of Where They Were Missed. Still unable to under-

30 The Royal Ulster Constabulary used to be the state police force in Northern Ireland. It was established in 1922. Together with the British army and the Ulster Defence Regiment (UDR) the RUC was responsible to keep peace in Northern Ireland during the Troubles. It was renamed the Police Service of Northern Ireland in 2001 (Britannica 220). 
stand the outbreak of violence in its full extend six-year-old Saoirse and four-yearold Daisy perceive what happens in a rather naïve way. They cannot understand, for example, why they are forbidden to wave at the British Army when all the other children in their street are doing so (Caldwell 4ff). Their mother in contrast, although she has her reasons, becomes an accomplice in the segregated society by forbidding her children to behave as the other children: "How many times have I told you youse're not to be waving and being all friendly to the British Army vans" (ibid. 4). She also gives a hint as to why she reacts so strongly: "They've no business to be installing themselves in this street" (ibid. 5).

The question of innocence and complicity is also significant in the case of Helen. As a solicitor specialised in terrorist cases she first and foremost intends to help innocently accused Catholics. Nevertheless, not in all cases can Helen be sure if the accused really has done nothing wrong. The Oliver Maguire case thus makes it quite hard for Helen (Madden 171ff): By defending someone she knows has killed for sectarian reasons she will always be reminded of the murder of her father. In turn there must be someone out there defending his murderers. It truly is a difficult situation. This leads to the assumption that everybody could easily become an accomplice in the dirty policies of the Troubles even though having the opposite in mind, namely doing good.

\subsubsection{Cultural Hybridization and the New Irish}

"Ye shall never be free until the woman from the south be united to the man from the north."

Where They Were Missed, Lucy Caldwell (2006, 186)

Homi Bhabha has set new standards in the fields of postcolonial identity. Terms like 'hybridity', 'third space' and 'mimicry' are strongly connected to his theories. In the introduction to his essay collection The Location of Culture Bhabha introduces the reader to one of the central issues of his notions of culture:

It is the trope of our times to locate the question of culture in the realm of the beyond [...] The 'beyond' is neither a new horizon, nor a leaving behind of the past $[\ldots]$. Beginnings and endings may be the sustaining myths of the middle years; but in the fin de siècle, we find ourselves in the moment of transit where space and time cross to produce complex figures of difference and identity, past and present, inside and outside, inclusion and exclusion. For there is a sense of disorientation, a disturbance of direction, in the 'beyond': an exploratory, restless movement caught so well in the French rendition of the words au-delà - here and there, on all sides, fort / da, hither and thither, back and forth (Bhabha 1994, 1). 
What is already hinted at here is that a new field has opened up that has not existed in this sense before. It is not a "new horizon", however, as it is connected with what was already there in the past. The "beyond" directly leads to what Bhabha calls hybridity; an identity that lies in the inbetween. In line with postcolonialism it describes a new or different state of the once colonised and his or her materialisation in a mixture of pre- and postcolonial self. Bhabha stresses the fact that it is necessary to "think beyond narratives of originary and initial subjectivities and to focus on those moments or processes that are produced in the articulation of cultural differences" (ibid. 1ff). In this way new forms of identity are made available. To make his theory more vivid Bhabha evokes the image of a liminal stairwell, which is situated inbetween identities and serves as a connection by allowing passage and movement. At the same time it symbolises the differences between fixed identities and in consequence brings about the generation of cultural hybridity (ibid. 4).

For Bhabha hybridity is "a difference "within" or "a subject that inhabits the rim of an 'in-between' reality" (ibid. 13). The cultural hybrid is therefore a complex building that both resembles and differs from the colonising agent. The hybrid resembles an effigy of the subjugator but not quite, for "what is disavowed is not repressed but repeated as something different - a mutation, a hybrid" (ibid. 111). By creating hybrid characters the colonisers allow themselves to maintain their "identity of authority" through discriminatory acts (ibid. 112). Bhabha also calls this "strategic disavowal" (ibid. 112). Lawrence Grossberg shares this opinion of the third space, that is, the cultural hybrid living in an inbetween place. Apart from that he also refers to the image of liminality. Here the colonised is moved from an inbetween place directly to the border itself (Grossberg $91 \mathrm{ff}$ ). The hybrid thus is neither coloniser nor precolonial subject any longer.

Antony Easthope sees in Bhabha's descriptions a relation to the theories of Jacques Derrida: “Bhabha's hybridity is essentially Derridean difference applied to colonialist texts - the presence of a dominant meaning in a dominant culture can be called into question by referring to the hybridity or difference from which it emerges" (Easthope 343). All things considered Easthope argues mainly against Bhabha's as well as Derrida's theory. The terms hybridity and difference in his view are too vague and can be applied anywhere and anytime. The term hybridity leads him to ask the legitimate question whether the two joined identities were formerly pure in themselves (ibid. 342). The borders of where hybridity can be applied blur in Easthope's understanding and he asks himself if he, the child of an English father and an Irish mother, will also count as a hybrid. "Who or what is not hybrid?" he asks (ibid. 342).

Easthope calls Bhabha's desire to put fixed identities aside in order to "entertain difference without an assumed or imposed hierarchy" (Bhabha 1994, 4) a "wishful thinking" (Easthope 346). In his point of view "speaking subjects must have a coherent identity", everything else would lead to instability (ibid. 346). But 
a counter-question could be: Why does everything have to be defined in strict orders? Is one not able to speak without perfectly knowing what or who one is? It will not be implied here that the world would work without any rules. Rules and definitions are certainly helpful to provide stability and security. Nevertheless, Bhabha's considerations of a difference without hierarchy would not remain utopian if people could accept difference more easily. The point I would like to make here is that through the act of speaking an identity can be created. The "coherent identity" Easthope demands can become concrete through speech acts even though the hybrid is not yet fully aware of it. A good example here would be Saoirse Pentland. In the second half of the novel she is sixteen years old - a teenager on its climax - and begins to question her own identity. Above all she is interested in the disappearance of her mother. She is asking a lot of questions and demands to be told the truth by her aunt and uncle. The story of initiation thus serves the novel in a double way as it supports Saoirse's longing for finding an identity: On the one hand she needs to know about certain things that happened in the past in order to come to terms with her current situation - that is, why her mother left her and where she has gone to - on the other hand all the discoveries she makes are connected to the context of Northern Irish history and help her to make up her mind about her Irish identities (I use the plural here because Saoirse is the daughter of two opposing Northern Irish strands). Saoirse does not yet have a coherent identity as demanded by Easthope. Still, she does not remain silent. Although her aunt Bernadette wants to protect her from the truth Saoirse insists on her right to know everything:

Nobody's ever straight with me [...] There's all of this scheming, and secrets; there's all of these secrets, and going behind people's backs, and pretending, and not telling the real reasons for things, and I'm sick of it. It's not fair [...] I'm not a little girl any more. And because it's to do with me, all right, it's to do with me and I have a right to know (Caldwell 111).

Saoirse's case therefore runs directly counter to Easthope's argumentation. While he claims "a coherent, speaking subject cannot live in the gaps between identities" (Easthope 347) I would contend that just that - the inbetween identity - leads a person to question him- or herself, thus the very questioning leads to a speaking subject and this in turn to an awareness of one's identity.

For this reason, Bhabha's reflections on hybridity are especially suitable for the Northern Irish crisis of identity. In order to find answers to the question about what has changed in Northern Ireland one can also take a closer look on the protagonists Madden and McLiam Wilson create. All of them share aspects of the 'New Irish' who is a little more cosmopolitan, a little more educated and a little more non-Irish than the characters of Frank O'Connor and other twentiethcentury authors were a couple of years ago. To show up the differences it is help- 
ful to look on the overall attitude of Northern Irish inhabitants towards their identities.

In their 1991 paper Neil Waddell and Ed Cairns examine which ethnopolitical identities people in Northern Ireland chose. They compared their findings with those of two other research studies carried out by Richard Rose in 1968 and by Edward Moxon-Browne in 1978 respectively. The task for the participants was to choose the identity which they felt they most belonged to. Among the answers to choose from were terms like "British", "Irish", "Ulster", "Anglo-Irish", "sometimes British / sometimes Irish" and "other" (Waddell and Cairns 206). In the decade between 1968 and 1978 significant changes took place. Whereas many Protestants embraced Irishness in 1968 (20 per cent), in 1978 only eight per cent felt themselves to be "Irish". The "Ulster" identity lost also in popularity. Instead the "British" identity was chosen by 67 per cent. Waddell and Cairns attributed these changes to the conflict that had begun in 1969. "For Protestants, seeing the union with Britain threatened by Republican violence, the need was probably felt to make a clear uncompromising statement of national allegiance to Britain. Any other identity [...] would fail to do this" (ibid. 206). Among Catholics the preference for an Irish identity remained relatively stable (70 per cent), however.

Waddell and Cairns felt that something was missing and included the identity "Northern Irish" in their own research questionnaire, so that people now could choose between the following identities: "British", "Irish", "Ulster" and "Northern Irish". Participants were 475 sixth form students of whom 60 per cent were Protestant, 40 per cent Catholic, 37 per cent male and 63 per cent female (ibid. 207). Protestants' answers were distributed among the "British", "Northern Irish" and "Ulster" identities, whereas Catholics mainly chose "Irish" and "Northern Irish" identities of which "Irish" was favoured. Among Catholics the "British" identity received a zero position, the "Ulster" identity was also disliked (ibid. 209ff). Waddell and Cairns concluded that Ulster by Catholics is assumed as something British or Protestant (ibid. 210):

There may be several reasons for this Catholic dislike of the Ulster label. Before partition, Ulster was always the term used to describe that area of "loyal" Ireland that was largely inhabited by Protestants. After partition, the name stuck even though it was now geographically incorrect - the old Ulster consisted of nine counties, the new Northern Ireland has only six - and subsequently the term seems to have become synonymous with Loyalism (210).

They further assumed that an "Ulster" identity would not distinguish Catholics from Protestants sufficiently as in a conflict situation such as the Troubles "opposing groups seek to develop and maintain psychological group distinctiveness" (ibid. 211). 
Despite these quite clear arrangements of rather British or rather Irish identities not every person that considers himself/herself Irish prefers the reunion with Ireland. According to Mulholland 41 per cent of Catholics were against it and six per cent said they would abstain from voting in 1972. In 2001, however, 59 per cent of Catholics were in favour of a reunion. By comparison only two per cent of Protestants would prefer that option (Mulholland 147). Concerning politics on both Protestant and Catholic sides almost 90 per cent vote for unionist or nationalist parties respectively (ibid. 148).

Waddell's and Cairn's surveys cover the period between 1968 until the end of the 1980s and early 1990s. Caldwell, Madden and McLiam Wilson continue analysing the development of Northern Irish identities, however, in the sense that clear statements concerning community belonging as shown in Waddell's and Cairn's surveys are no longer that easy to make. People are subject to transformation and community structures are beginning to adjust gradually. Thereby, each author puts a different emphasis of change of identity on the characters. Jake, for instance, calls himself a "reformed character" (McLiam Wilson 193), which indicates a conversion he has undergone. Having experienced a bad childhood with "povertystuff" and "Irishstuff" (ibid. 103) which Jake does not explain any further, his foster-parents Matt and Mamie have turned him into a "human being" (ibid. 105). He used to be involved in fighting but has given it up (ibid. 86). Instead, Jake has become quite a sympathetic character who not only cares for his cat (although he often expresses his dislike for it) but also for the twelve year old Roche. He believes in "Rousseau and the Social Contract, the natural right and the social right" instead of people going out and getting what they want (ibid. 181). Danine Farquharson talks about an "ethical drive that underlies the story" of Eureka Street; namely that "empathy can stop violence" (Farquharson 66). This idea leads her to Immanuel Kant's categorical imperative and that "empathy is a way of identifying with as many fellow humans as possible in order to participate in a common moral sense" (ibid. 72). Jake thus undoubtedly has found a way out of the sectarian stubbornness that accompanied the Troubles. With his best friend Chuckie being a Protestant he is on the right way of becoming the "New Irish" (McLiam Wilson 164) he imagines (see quotation in the introduction). In terms of identity as described by Waddell and Cairns he still thinks of himself as being Irish although not as openly as Aoirghe does (ibid. 98). Asked by her "Don't you consider yourself Irish?" he simply answers, "Sweetheart, I don't consider myself at all" (ibid. 98). But a few lines below he says "being Irish" (ibid. 98). This again indicates an inbetween state of identity. On the one hand Jake is aware of his Irish roots but on the other hand he is not willing to live solely with this identity. For him times of radical nationalism and fanatic unionism are over. This becomes also clear in the poetry reading he attends (which has been already mentioned earlier in a different context). Again Jake is highly cynic about the happenings. Although being Irish himself he cannot hear anymore about a romanticised Ireland. His 
ironic summary of a poem entitled 'Poem to a British Soldier About to Die' is the following:

The poem told the young British soldier (about to die) why he was about to die, why it was his fault, how it had been his fault for eight hundred years and would probably be his fault for another eight hundred, why the man who was going to shoot him was a fine Irishman who loved his children and never beat his wife and believed firmly in democracy and freedom for all, regardless of race or creed, and why such beliefs gave him no option but to murder the young British soldier (about to die) (ibid. 175).

Jake's depiction of the poem expresses a wish for his fellow Northern Irishmen, no matter if Catholic or Protestant, to overcome history and start into a new future that leaves the old behind. History has to stop repeating itself. The reason for all the wrong in the world according to Jake is politics, which he basically sees as an "antibiotic, i.e., an agent capable of killing or injuring living organisms" (ibid. 96). People think him to be a Protestant because he openly criticises the reading, and so he gets thrown out. Another example for Jake's new Irishness might be the fact that he does not report an RUC officer who attacks him violently because he knows the man's real motives: Jake has had an affair with his fiancée Mary. Aoirghe in contrast tries to persuade him to report the incident as in her eyes "assaults by the RUC" are "always political" (ibid. 97ff). Only Jake's ability to feel empathy breaks the cycle of sectarian hatred here. His urge for a clean front shield is symbolic for Jake's ability to see beyond certain things Aoirghe and others do not see at first. Although his car is a mess he undertakes a remarkable effort to keep the windows clean: "It was a hugely shitty vehicle but it had incredibly clean windows. Rusty bodywork covered in three-year-old filth but the windows gleamed. I cleaned them every day so that I could see my city when I drove" (ibid. 16).

Eureka Street, which according to Elke D'hoker is "reminiscent of the allinclusive Victorian novel" due to the many different characters and their stories (31), uses the model of hybridity to show new possible forms of living together that seem almost impossible at first. As the characters differ in their intentions and perceptions of the world this pluralism is used to "reflect some of the novel's important moral and political concerns" (ibid. 31). Both Chuckie and Jake are presented as hybrid characters who live in the inbetween of Protestant Britishness and Catholic Irishness. What sets them off from other rather traditional thinking characters such as Ronnie, Crab or Aoirghe is their ability to think outside the box (in different ways however). As has been noted by D'hoker Jake incorporates both sets of Protestant and Catholic stereotypes and by displaying them becomes able to transcend them in order to form an individual identity (D'hoker 32). Chuckie by contrast leaves his one-sided identity behind by cheating on both Protestant and Catholic people alike. Jake even calls him a "pan-cultural exploiter" (McLiam Wilson 307) and calls his greed "ecumenical" (ibid. 168). He does this by utilising 
clichés (D’hoker 32). He receives a grant of eight hundred thousand pounds from the Industrial Resources Board for invented and non-existent projects. "Chuckie had simply made it up as he went along" (McLiam Wilson 118) such as persuading the Ulster Development Board to give him money for a business that "would bring the Catholic nationalist sports of Gaelic football and hurling to Protestants, and the English Protestant pursuits of rugby and cricket to Catholics" for "these sports were sharply divided and a significant emblem of the apartheid in Northern Ireland" (ibid. 153). It is quite amusing that Chuckie, though initially driven by greed, suddenly overcomes his own pretensions by making a good point. In an interview with the republican Jimmy Eve he highlights capitalism and globalisation and puts them over sectarian issues, which leaves the politician rather speechless: "What America understands is what I understand - making a dollar, cutting a deal. There are no nationalities, only rich and poor. Who gives a shit about nationhood if there's no jobs and no money? Bread before flags, that's what I say" (ibid. 331). He even calls to do business "the real peace" (ibid. 331).

In the end of Eureka Street various relationships have developed:

The antipolitical Jake and Republican Aoirghe, the Muslim Rajinder and the Jew Rachel, the Englishman Luke Findlater and his Catholic working-class waitress, the socialist Slat and Wincey, his right-wing middle-aged Protestant fiancée, the Protestant lesbian housewives Peggy and Caroline (D'hoker 33).

D'hoker sees in these relationships a "reconciliation of opposites or a marriage of different perspectives" (ibid. 33). She concludes that they "represent the impossible New Irish Jake has dreamt of" (ibid. 33). Thus this working pluralism also suggests that the New Irish has already become reality.

Hybridity in One by One in the Darkness is most strongly articulated in Cate. Although each of the sisters has chosen her very own way of life after their father Charlie's death it is only Cate who leaves the country. As Jerry White has argued Madden shows how hybridity can be successful in a postcolonial Northern Ireland thus challenging Declan Kiberd's denial of a working hybrid (White 459). At this point he refers to the posh Cate who has moved to London to work as a journalist for a fashion magazine. "Even as Cate leaves her marginal community for the metropolitan/imperial center of London [...] she retains central parts of her marginal identity and manages to update them and make them relevant to her condition" (ibid. 459). This is done by Cate's still existing religiosity. Although Helen suspects her sister of having left her faith behind she learns that Cate still is a "regular churchgoer" and even has a "religious picture hanging in her apartement" (Madden 22). White calls this "the ability to form a new life without completely depending on the old existence or completely leaving it behind" (White 459). She also changed her name from Kate to Cate because "it was too Irish, $[\ldots]$ too country" (Madden 4). Her family is very hurt by this but her change of name also 
designates her inbetween state. Cate likes the London life and would not miss it; still she clings to certain family traditions as well as the Catholic faith.

Caldwell's solution for the "New Irish" lies in Saoirse's heritage. With her mother a Catholic from the South and her father a Protestant RUC officer she unites Northern Ireland's problematic past. Her name is also of significance as it means "freedom" (Caldwell 211). Both her name and her family tradition thus evoke the assumption that only a reconciliation between Catholic and Protestant beliefs and the mutual acceptance of both can lead to freedom and peace. Saoirse stands for all that Northern Ireland consists of: the conflict between her parents when she was still a child - a conflict between Catholic and Protestant, between Civil Rights marcher and RUC man - the pain of lost relatives and friends. This becomes also evident in her half Irish, half Scottish/English name, Saoirse Pentland. She combines two identities in one and in the end accepts her lot: "All my life here I've wanted so badly to be the same. But now, I'm kind of proud to be an Ulster Pentland as well as an O'Conor from the Gaeltacht" (Caldwell 214). As she unites these two characteristics in one personality she is not afraid to go to the North, either. Asked if she was not scared to go there she just says: "I can't be scared [...] I'm half from there. I can't be scared"' (Caldwell 215).

Further studies of contemporary Northern Irish literature also include how theories of multiculturalism and citizenship are incorporated in the new developments. While citizenship for a long time had been seen standing in context of nationality this has changed recently. "New conceptions and practices of citizenship point to something considerably more differentiated and multifaceted than nationality," explains Gerard Delanty (183). Thus globalisation has been a decisive factor for widening the political community into a more cosmopolitan community in which "the nation-state is no longer the primary reference for loyalties, identities and democracy" (Delanty 184). Delanty here stresses a pluralised nation that is welcoming "new imaginaries about belonging, community and identity" (ibid. 184). He mentions several fields that have been studied among others by Lurry, Stevenson, Parekh, and Touraine, in which it becomes clear how modernisations have exceeded the nation-state. Civic and social rights, for instance, are regulated by the place of residence and not by birth. Nationality here is not decisive for one's exertion of rights. Secondly, progress in technology (communication, natural sciences, and military) dispense the individual from the state because they are addressing the population itself, not the state. Furthermore, cultural rights are gaining importance over individual rights. Instead of equality as a primary aim the upholding of group differences is now a decisive factor of citizenship (as the cultural diversity programme well shows). Finally, the separation of public and private life is outdated (ibid. 186ff). Thus "citizenship is increasingly about the right to express one's identity, as in for example gay marriages [or] rights for disabled people" (ibid. 188). Deirde Madden and Robert McLiam Wilson also feature homosexual love relationships in their novels. Helen's best friend David is gay and 
has a brief relationship with Steven. Chuckie's mother Peggy after years of deep friendship finally recognises her love for her neighbour Caroline who in turn leaves her husband and moves in with Peggy. While for Helen and David's friends his homosexuality is quite a normal thing Peggy's new life as a lesbian causes an uproar in Eureka Street.

Peggy Lurgan was now a lesbian living with Caroline Causton. This was spectacular news. People had called press conferences. Peggy and Caroline were the most Protestant and the most working-class women I had ever met. Such women did not normally end up munching blissfully at each other, or so everyone had believed (McLiam Wilson 341).

After this news also Chuckie's and Jake's friend Deasely comes out as a gay (ibid. 342). As these ways of life do not stand in the traditional, or old-fashioned, lifestyle Caroline, Peggy, Deasely and David also represent types of the New Irish. Although they do not unite Protestant and Catholic ingredients in themselves they nevertheless leave nationalism behind and dedicate themselves to their own lives in the form of citizenship. Thus, they express their identities like Jake, Chuckie, Cate and Saoirse in other ways that do not aim at upholding the Northern Ireland conflict.

\subsection{The Other in the North: Stereotypes and Discrimination}

"When someone sets out for no good reason to try to bumiliate you or make you feel ill at ease in a social setting, you're often so taken aback that you don't know how to respond; and it's hard to be able to put them down without sinking to their level."

One by One in the Darkness, Deirdre Madden $(1996,167)$

Human beings have always been fascinated by things that are different from what they know. Even today people book expensive flights to travel to up to this point unseen countries and unfamiliar cultures. Tourism has thus become the modern way of 'invading' foreign countries in order to experience a different world. Few people will have the chance of actually living in another country in the way the native inhabitants do; as a result, travelling in most cases has a certain voyeuristic touch. Of course, travelling is not to be equated with occupying a foreign nation by force, making its people subaltern and taking over the sole government of the country. Despite this fact the point of wanting to see the unknown remains a common feature. While the example should not be taken too seriously I would nevertheless like to point out that the fascination with the unfamiliar, the mysterious, the 'Other' is an underlying character trait of the human soul. Homi Bhabha 
describes the latter term as something "which is at once an object of desire and derision, an articulation of difference contained within the fantasy of origin and identity" (Bhabha 1994, 67). To come back to the comparison with tourism one can see that "desire and derision" can be found there, too. How often do people take a trip abroad to still their desire to see breathtaking features of nature, colourful birds and strange animals, different people and unique customs just to come home and feel vaguely disappointed by some aspects that are just so different from the well-known that one would never want to live like that. Derision might be a bit too harsh a word in this case, but I think the point becomes clear. The unknown is ever so often accompanied by mistrust and disapproval.

Colonialism was partly justified by this so-called Other. "The objective of colonial discourse is to construe the colonized as a population of degenerate types on the basis of racial origin, in order to justify conquest and to establish systems of administration and instruction" argues Bhabha $(1994,70)$. Only the deconstruction of the colonised into uncivilised and uncultivated savages justifies the occupation of their land. Yet, the other is not completely unknown. The aim of imperialist invaders was to mould the unfinished subject into a less perfect imitation. The product was something which was "at once an 'Other' and yet entirely knowable and visible (ibid. 70ff). In this context Bhabha also speaks of a concept of "fixity" which he explains to be a sign of cultural, historical and racial difference. In connection with postcolonialism "it connotes rigidity and an unchanging order as well as disorder, degeneracy and daemonic repetition" (ibid. 66). The stereotype then, according to Bhabha, serves as a means of strategy. "It is a form of knowledge and identification that vacillates between what is always 'in place', already known, and something that must be anxiously repeated" (ibid. 66). Nevertheless the stereotype remains to be an untrue depiction of what is real, thereby denying difference (ibid. 75). For Bhabha the stereotype is also closely linked to fetishism. "The recognition of sexual difference $[\ldots]$ is disavowed by the fixation on an object that masks that difference and restores an original presence" (ibid. 74). Fetishism thus is a balancing act between similarity and the fear of difference, to put it simple. Bhabha's key words here are metaphor, the masking act, and metonymy, the lack of sameness. The fetish itself masks its difference in order to achieve a pure origin. Bhabha is referring to Fanon when he argues that this disavowal of difference can lead to severe consequences of "grotesque mimicry", which in turn threatens to destroy the colonised subject (ibid. 75). To complete the picture Bhabha is talking about the Imaginary:

The imaginary is the transformation that takes place in the subject at the formative mirror phase, when it assumes a discrete image which allows it to postulate a series of equivalences, samenesses, identities, between the objects of the surrounding world. However, this positioning is itself problematic, for the subject finds or recognizes itself through an image which is simultaneously alienating and hence potentially confrontational. This is the 
basis of the close relation between the two forms of identification complicit with the Imaginary - narcissism and aggressivity. It is precisely these two forms of identification that constitute the dominant strategy of colonial power exercised in relation to the stereotype which, as a form of multiple and contradictory belief, gives knowledge of difference and simultaneously disavows or masks it. Like the mirror phase 'the fullness' of the stereotype - its image as identity - is always threatened by 'lack' (ibid. 77).

Bhabha connects these four elements to what he calls the four-term strategy. Thus the metaphoric aspect combines with the narcissistic object-choice as does the metonymic outline of lack with the aggressive part of the Imaginary (ibid. 77). Optically, the colour of skin constitutes the most significant feature of racial difference and discrimination (ibid. 78ff). This goes even so far that skin becomes the "natural identity" (ibid. 80) of the stereotype. In case of the Irish the colour of skin does not serve as a marker of difference for there is no visible difference. The Irish subject thus is able to mask itself even better.

In Eureka Street the depiction of Northern Irish stereotypes and the Other is best transmitted through the perception of non-Northern Irish people such as US citizens or the foreign press. Bhabha's theory of the Other thus can be best seen when taking a closer look on Chuckie's business associate Luke Findlater, an Englishman. He represents the typical young urban high-flyer who comes from London to Northern Ireland. His first visit to Derry during a business trip changes everything for him as soon as he sets foot on the "crooked Irish pavement" (McLiam Wilson 349). While taking a look round the town he only meets "overweight", "unhealthy" and all in all "ugly" men drinking on the street (ibid. 349ff). Dressed well in a tweed suit with "handsome hair and kissable face" (ibid. 349) he in contrast sees himself as "Helen of Troy or Rudolph Valentino"; "stupidly handsome [and] arrestably beautiful amongst these troglodytic Hibernian halfmen" (ibid. 350). Only the women seem to be acceptable to him although they are different in Northern Ireland from where he comes from with "more make-up" and "their hair [...] stiff with unguents and sprays" (ibid. 350).

Luke's perceptions of the Northern Irish people thus resemble Bhabha's theory of the Other and simultaneously the subjugation of the Irish by the British. By degrading the men to uncivilised and uncultivated savages Luke gains the right to "invade" the country and to seduce the women. His almost godlike appearance in his view gives him the right to do that. The men he sees are a less perfect imitation of him as are the women of the familiar English women. Their use of makeup here at the same time highlights the masking of the colonised subject. The narcissism and aggressiveness that are closely related to the imaginary described by Bhabha are expressed in Luke's abuse of the women. "After a week there had been Saoirse, Siobhan and Deirdre. By a fortnight, Sinead and Aofie had added their contributions, the third saw the advent of Orla, Una and Roisin" (ibid. 350). Aggressiveness is conveyed in Luke's ferocity to date women, narcissism in the 
way he behaves and it is constantly fuelled by the women's behaviour towards Luke: "But the best thing they gave him was their version of him. For them, he was something special, something unique. He knew that, to them, it must have seemed really great to be him" (ibid. 352). Like the earlier colonisers Luke is spreading his territory and dates women all over the country in "Belfast, Derry, Lurgan, Antrim, Ballymena, Enniskillen, Portadown” (ibid. 352) and he briefly nourishes the idea of "going to South Africa to scour the townships and see how he fared amongst the surprised and grateful black girls" (ibid. 351). Hence, Luke embodies all the traits of a colonial power.

The stereotype itself as described by John Morris is in essence the "judgment of other people by placing them in groups which relate predetermined behaviour to physical, racial, class, or other, types" and uses methods of "prejudice, anticipation and systematization of human behaviour" (Morris 1). This kind of stereotyping is experienced by Chuckie during a trip to the United States. On his way through New York together with the private eye Dave Bannon Chuckie gets in trouble with some New York hoodlums who want to rob them. Bannon uses Chuckie's origin to scare the boys away by telling them Chuckie would be a member of the IRA. Of course, they do not believe them: "'He don't sound Irish to me.' 'He's a Brit or Scotch or something"' (McLiam Wilson 263). When Chuckie starts imitating the Reverend Dr Ian Paisley with set phrases such as "No Pope here", "Home Rule is Rome Rule 31 " and "Ulshter will fight", however, the boys are suddenly convinced of Chuckie's ruthlessness (ibid. 263). With the words "Power to the people, man. Down with the King and everything"" (ibid. 263) they run off. This passage is as full of stereotypes as it is with irony as all of the events are actually mixed up. The boys obviously do not know much about Northern Ireland and the ongoing conflict. They cannot distinguish a Northern Irish accent from a Scottish or British one (on top there is no single British accent). Only the mentioning of the IRA and Chuckie's usage of the Paisleyian assertions make them believe them. Finally, they do not realise that Chuckie's statement of "Home Rule is Rome Rule" completely contradicts any IRA philosophy but rather supports the unionist counter-movement. In an underlying tone of irony that almost never wears off in Eureka Street the narrator hints at the blended realities shown in this passage. What the New York boys have in mind is one of the Northern Irish stereotypes that indicate that every Irish Catholic citizen belongs to a radical group fighting against the British monarch and who at the same time stops at nothing. They judge Chuckie by placing him into a group that could be called 'Irish = IRA = dangerous'. By doing this they assume Chuckie to be a violent political activist. "The strength of stereotypes lies in [the] combination of validity and distortion" stresses Morris (ibid. 6). Although people do exist in Northern Ireland that might fit the boys' assumption only a minority actually comes into consideration.

31 The term was first used by unionists during the introduction of the first Home Rule Bill in 1886 (Mulholland 14ff). 
Chuckie certainly contradicts this stereotype but in this case instead of being discriminated against, this saves him a lot of trouble.

Helen's colleague at work in One by One in the Darkness, Owen, has experienced discrimination as well but in a less 'positive' way than Chuckie. While going out with a group of people who are at the same Law Society as Owen the others start harassing him. Apparently knowing that he is a Catholic they let slip remarks that begin to upset Owen. Although having had a little drink he knows it is not only the alcohol to blame for their behaviour: "What they did was deliberate. I could see them looking at me from time to time, they would say things that were getting close to the bone, and then look to see how I was taking it. And then suddenly, I felt afraid, really afraid; and they could see it" (Madden 166). One of the stories they tell is about a college in the nineteen fifties and a teacher who was in the B Specials ${ }^{32}$. At that time Catholics were admitted to the college for the first time. One night the teacher came to the storyteller dressed up in his full uniform and said "Do you know what this means? [...] It means I'll have to teach them by day and shoot them by night" (ibid. 166ff). Everybody thinks it hilarious except Owen. He feels afraid, angry and even ashamed that people in 1994 can still do this to him. It could be argued in this example that the masking described by Bhabha works the other way round. In this case it is Owen's colleagues who behave 'normally' during the day and wearing the disguise of tolerance at work. Only in their time off after work "the masks [start] to slip" as Owen calls it (ibid. 166). In the security of 'their' Protestant group they feel free to express what they really think.

\subsection{Changes in Education}

"Work hard, girls, because you have more to give society than you can perhaps realise. We need our Catholic doctors and nurses and university lecturers; our Catholic lawyers and civil servants."

One by One in the Darkness, Deirdre Madden $(1996,60)$

The question remains what role a new intelligentsia might have played in the Northern Irish conflict. Education in Ireland was strongly marked by the attempt of the British to anglicise the country as stated in chapter 2; see for example the introduction of National Schools in 1831 that largely ignored the existence of the Irish language and taught entirely in English. In Anderson's terms this was supposed to strengthen the imagined British community by means of the English language as the only language available. Nic Craith has stated that "the emphasis

32 A paramilitary police force that had been entirely Protestant. They were disbanded in 1970 (Mulholland 58). 
on English was designated to establish homogeneity and commonality within the British Empire and to lessen 'regional' differences" (Nic Craith 2003, 98). In 1870 the Education Act promoted "a homogenous English print community and sounded a death knell for all British Celtic regions" (ibid. 98). Thus, for example Welsh and Scottish Gaelic were deleted from the curriculum of Welsh and Scottish schools (ibid. 98). The intention was to establish a "print community in the language of the colonizer" (ibid. 100).

While some scholars have argued that national education merely offered the chance to learn English and did not force the Irish to abandon their native language, Nic Craith points out that "the desire for education" of the Irish was underestimated (ibid. 100). She also calls attention to the colonial pressure and the wish to assimilate to the superior power. "The 'native' perceives his own cultural style as inferior and abandons traditional cultural forms and language endeavours to appropriate the whole way of life of his oppressor" (ibid. 102), she argues. Besides, it was necessary to speak, read and write English if one wanted to partake in the economic world (ibid. 101). So, both the introduction of English in schools and the colonial presence put the further decline of Irish into effect. At the same time education should enable children to rise above their parents' social status and equip them with the knowledge necessary to partake in British life. However, the contrary happened; all they learned was about their Irish inferiority (ibid. 102).

Although Eureka Street and also Where They Were Missed illustrate education as important properties in this chapter I would like to focus on One by One in the Darkness as there are many good examples of educational change. Jake and his friends all have benefited from a rather good education. Jake has studied politics, Slat is a lawyer, Donal works for the Government and Septic Ted is selling insurance (McLiam Wilson 139ff). Aoirghe has studied history (ibid. 94), Saoirse is doing good at school.

As one can see the development and importance of education in general has taken a significant position in Northern Ireland like in the rest of Europe. In Madden's One by One in the Darkness the change in the educational system in the second half of the twentieth century and the perception of value of education is illustrated well by means of the two generations that appear in the novel. Cate's, Sally's and Helen's parents, Emily and Charlie Quinn, grew up in an age that highlighted the meaning of education at every moment. The reason for this lies in the history of Northern Ireland as already stated above. In her remembrances of bygone days of the 1950s Emily recounts Northern Irish politics: "At that time "politics' meant Stormont, meant a Protestant government for a Protestant people, so if you happened to be a Catholic, the message was clear" (Madden 115). Indeed, unionist fears of a "Catholic infiltration" (Mulholland 45) was accompanied by the attempt to keep politics in unionist hands. As Mulholland has remarked, "throughout the Stormont era there was consistent and largely successful pressure from the unionist grassroots to keep Catholics out of senior public employment 
positions" (ibid. 45). Consequently, education became for many Catholics the only way to be somebody in a biased society.

Education was the only hope, it was like a rope that you struggled to cling to, in the hope of pulling yourself up to a position less disadvantaged than the one in which you started out. Keep your head down, look to your own, and don't expect too much in any case: nobody ever said those words explicitly to her, but then nobody needed to, because the world around her wordlessly insisted on this every single day of her life (Madden 115).

What Emily feels in this passage goes as far back as to the introduction of national schools in the nineteenth century. Although the main focus does not lie on the acquirement of English anymore, education is still seen as the only option to transcend the as inferior perceived Irishness.

As a young teacher Emily encounters children whose future is still unclear. Many of them have unemployed fathers and Emily even thinks it a blessing they do not have high aspirations because this would only leave them frustrated (Madden 119). In a time of economic hardships and an unemployment rate five per cent higher than in Great Britain (Mulholland 42) Emily's pupils dream of driving horses for the local brewery or working in the linen mills as their mothers do (Madden 119). These fields of traditional Northern Irish economy - agriculture, textiles and engineering (Mulholland 42) - in addition represent the traditional Irish country life as celebrated by the Irish Literary Movement. That most of the parents are unemployed and look to an uncertain future also symbolises the slowly vanishing traditional Irish life. By contrast Emily stands for a Catholic woman who enjoys a rather independent work life (at least until her marriage) and who will pass this new way of life on to her children.

Yet, Emily's life is not as independent as that of her daughters is going to be. Because she wants to marry Charlie she is supposed to quit her job as "it wasn't seen as right for women to go on working when they were married" (Madden 121). At that time a married woman should not take jobs from unmarried women or from men who needed to support their families as expressed in a newspaper article Emily reads (ibid.122). Whereas she had to choose between a family and her job, Emily's daughters Sally, Helen and Cate are no longer forced to decide on one option. Still, the importance of education is very strong in Emily's mind and she is constantly worrying that Cate in her teenage years might get pregnant. In an argument she says: "What if you get into trouble and have a baby, what then? That'll be your life ruined; and all your education lost" (ibid. 109).

In terms of images of the New Irish Emily stands somewhere inbetween. Her daughters, however, are able to lead new and different lives. All three of them are educated well and rather successful in their jobs, Sally as a teacher like her mother, Helen a lawyer specialising in terrorist cases, and Cate working as a journalist for a fashion magazine. All three of them are still unmarried, and Cate is even having a 
baby. One could argue that Cate's future life as a single mother does not represent something typically Irish or new-Irish because it at first glance appears to be a phenomenon of the modern age. Nevertheless, I would like to place this in the Northern Irish context and take it as an argument for the depiction of the New Irish: Cate did not get pregnant by accident or ends up being a single mother because her boyfriend left her. Instead, having a baby on her own for Cate is a deliberate decision. She does not even want any help or support from the father. The child is just for her without any obligations. In contrast to the fears of her mother her education is not lost because she is pregnant and single. Cate still leads a very religious life, but she breaks with the rules of the Catholic Church in favour of the baby. Still, she does not give up her Catholic Irish identity because she sticks to the religious traditions she grew up with. By being a successful London journalist she has transcended the stereotype of the uneducated, rural Irish peasant. Simultaneously, the baby stands for a better future, a third generation, hopefully growing up in a time without the continuation of the Troubles.

It is also important to note that the Civil Rights Marches were attended by great numbers of students. Charlie took part in one of the marches and can say only good things about them:

I can tell you that I thought them admirable people. They're not involved in this for themselves. They're concerned about the people in this country who haven't had their chances, and who aren't going to be helped in any way unless somebody makes a stand and gets things moving, unless the people who do have something begin to speak out for those who have nothing (Madden 79).

Although the Civil Rights Marches resulted in violence its initial goals were peaceful and nonpolitical. It simply drew on the aims of the civil rights movement developed by blacks in America and demanded rights for the Catholic people in Northern Ireland (Mulholland 50). So, as Charlie says here, the educated tried to embark on a new way to improve the situation of Catholics. Charlie's daughter Helen develops similar ideas of helping people by means of education, not by means of violence.

Helen is the first in their family to go to university. When she discusses her career plans with principal Sister Benedict who signs the students' university application forms, this aspect of education is shown. Helen decides to study law because "our educated Catholics have a role to play in this society. We need our Catholic teachers and doctors and nurses and lawyers", as she explains (Madden 158). Her intentions are not only to do something important to her but also to help others. Having seen and experienced the unfair treatment of Catholics in Northern Ireland she wants to make a difference and help those wrongly accused. Sister Benedict in contrast sees this as a waste of time and tries to convince her do something else: "I don't want to see you throwing your life away, staying in this - this horri- 
ble place." For Helen her future is clear though. "Helen flinched at this last phrase, as if she'd been struck in the face. 'I like it here,' she said. 'This is where I'm from. This is my home"' (Madden 159). For Helen education means to enable her to work actively on the ill conditions in her home country. The same is preached by Sister Philomena who "was always bringing politics into education" (ibid.155). As she grew up in Derry she knows a great deal about life as a Catholic in Northern Ireland. She therefore advises her students to step out of a passive role of suffering and do something against it: "This is your society, and don't forget it. You have as much right to be in it as anyone else, and I want you all to get out there and claim the place that's waiting for you, the place you deserve" (ibid. 154). Claiming a place in society only works if one knows its rules. Education again is a key factor for Catholics to participate equally in Northern Irish society and alter their situation. Nic Craith has pointed to the fact that "education [...] rationalized difference" and "legitimated the relationship between the dominant and the dominated" (Nic Craith 2003, 103). By deciding to study law Helen can break this legitimisation. On the one hand she increasingly becomes aware of her own rights, on the other hand she can use her knowledge to help other 'dominated' Catholics. Talking with her friend David about the beginnings of the Troubles she asks: "What do you think is the biggest difference between now and then?" David replies: "We are. The educated Catholic middle class" (Madden 60).

\title{
4. Conflict in Northern Ireland - The Land of Many Oranges and Greens
}

\author{
"There are two norths, \\ One is defined, ruled, \\ agreed. \\ The other lies hidden, \\ troubles the compass, \\ is not drawn in the maps." \\ Donnelly, "North" (87)
}

Concerning colonialism Fanon remarks: "The colonial world is a world divided into compartments. [...] The colonial world is a world cut in two. The dividing line, the frontiers are shown by barracks and police stations" (Fanon 31ff). A similar scene could be found in Northern Ireland during the times of the Troubles well after the age of colonialism. The conflict that had simmered for centuries among the population finally escalated in 1969. In this context Joseph Ruane and Jennifer Todd highlight three socio-cultural dimensions of conflict: "religion (Catholicism vs. various strands of Protestantism), ethnicity (originally Gaelic-Irish, Old English, New English, Scottish) and colonialism (native vs. settler)" (10). All of these are parameters of the outbreak of violence but they are also part of a 
higher criterion: the formation of groups. While colonialism and ethnicity have already been discussed, religion remains as a parameter of conflict to be examined which will be done in chapter 4.3. At first, however, other aspects of conflict, like group dynamics and places of hostility will be looked at.

It has already been argued that in order to form an identity individuals very often look out for what they are not. The same principle applies to group identity within the studies of Social Identity Theory (SIT) as A.M. Gallagher notes (8). People always try to achieve a positive social identity which can be achieved either by comparison to so-called ingroup members or between the group and a socalled outgroup. Conflict is not mandatory, for example, when the outgroup is not recognised as being dangerous by the ingroup. Conflict can also be avoided as long as one group dominates the other group, which occurs when "the context is seen as legitimate or alternatives to the status quo are not seen as possible" (ibid. 8). By contrast change becomes possible "when a group excluded from power comes to see its inferior status as illegitimate" (ibid. 9).

Furthermore, Gallagher names several group strategies in dealing with such situations: assimilationist strategies, reformist strategies, radical attempts or the prevention of social change (ibid. 10), which political parties in Northern Ireland made use of one time or another. Whilst the SDLP followed a reformist strategy by endeavouring to legitimise aspects of Irishness, Sinn Féin opted for the radical alteration and abolishment of British authority (ibid. 9). Another point observed by Gallagher is the "over-simplification" (ibid. 13) of group members when talking about the other group in each case. "For the moment it is enough to know that 'they' are wrong, and are likely to remain wrong for the foreseeable future" (ibid. 13). This indicates that group dynamics are much harder to overcome than those of individuals. The protagonists in all three novels Eureka Street, One by One in the Darkness, and Where They Were Missed do not participate in the classical Northern Irish radical groups (Republicanism vs. Loyalism, Nationalism vs. Unionism) and thus have it easier to make up their own minds because they are not subject to psychological pressure and influences carried out by individual social groups. Most of the time the novels' protagonists even abhor the actions of those groups that use violence to make their standpoints clear. Saoirse's aunt for example complains about what she is seeing on TV: "It's a few fanatics [...] A few fanatics terrorizing the country and giving Irish folk everywhere a bad reputation," to what Saoirse replies: "That's what my father says [...] But he says it about Ulster and the Protestants" (Caldwell 94). This already indicates that people of both religious communities do not perforce believe in what paramilitary groups in their name try to achieve.

By contrast, the depiction of those clinging to traditional nationalist versus unionist or Catholic versus Protestant views always takes place in relation to groups. Accordingly, Owen in One by One in the Darkness (as described in chapter 3.4) has to confront a whole bunch of colleagues who only feel safe to harass him as a 
Catholic because they are in a group of similar thinking individuals. In Eureka Street Aoirghe is also backed up by a group in form of the Just Us (although she has the guts to say what she thinks when she is on her own, too). Ronnie knows he can run down other people like Catholics and people with a migration background because he is supported by his Protestant colleagues. Jake and Rajinder can hardly speak up to him because they are simply outnumbered by them. The Irish poetry reading Jake and his friends attend is also of relevance because here the aim is to identify as a group that shares the same myths in contrast to the Protestant residents of Northern Ireland. All these examples illustrate ingroup members comparing themselves as a group to an outgroup as described by Gallagher.

In Where They Were Missed both scenarios are shown. While living in Belfast Saoirse and Daisy are bullied by the other children in their street because Saoirse and Daisy are the only ones with a Catholic background. After having moved to the south of Ireland one could assume that Saoirse would now belong to the ingroup of Catholics living there. Instead, she feels as an outsider again. As already stated the difference of Jake, Chuckie, Saoirse and Cate lies in the fact that they do not join either nationalist or unionist groups and thus do not take a clear stand. This detail allows them to think beyond their own cultural horizon and paves the way for Jake's vision of the New Irish.

\subsection{Areas of Conflict}

"Cities are simple things. They are conglomerations of people. Cities are complex things. They are the geographical and emotional distillations of whole nations." Eureka Street, Robert McLiam Wilson

$(1996,215)$

Segregation in Northern Ireland is largely an urban conflict that arose already in the nineteenth century. Concerning the twentieth century Boal and Livingstone on the basis of data illustrating the percentage distribution of Protestants and Catholics in Belfast show that in 191159 per cent of the citizens were living in almost completely segregated areas with an increase in numbers to 67 per cent in 1969 and 77 per cent in 1972. By contrast to general models of urban social relationships between interethnic groups the numbers do not show an expected decline; the source seems evidently to be the harsh outbreak of intensified unrest during the time of the Civil Rights Marches and afterwards (164ff).

One of the Belfast areas best known for conflict is the zone between the Protestant Shankill area to the north and the Catholic Falls area to the south (both are situated in West Belfast). Dispute and tension in this part of town - where two 
working-class districts clash - have been ongoing for more than one hundred years (ibid. 165).
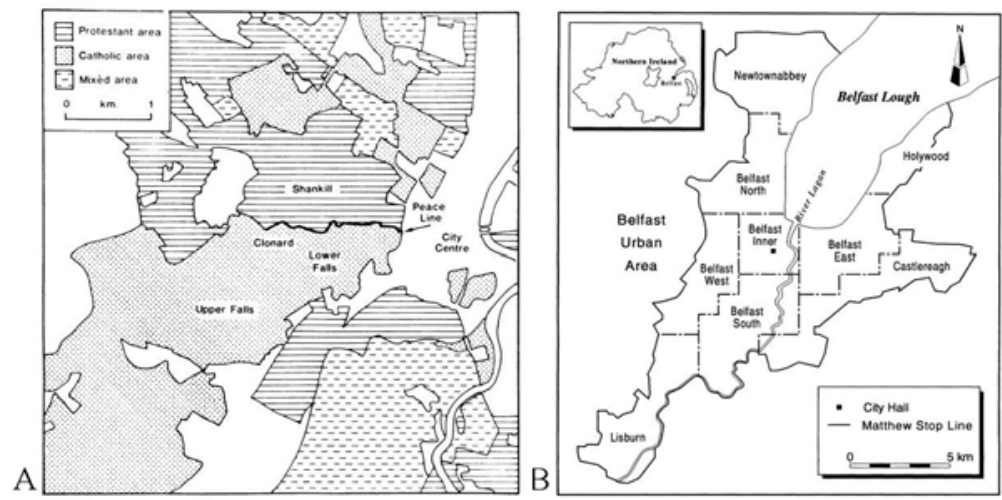

Figure 2: A - Distribution of Protestant, Roman Catholic and "Mixed" Residential Areas in West Belfast, 1976 (Boal and Livingstone 166). B - Subunits of the Belfast Urban Area (Doherty and Poole 524).

During the hottest phase of the Troubles (1969-81) the boundary line lay along Cupar Street (ibid. 171) and became the official Peace Line when the British Army intervened in September 1969 (ibid. 174). Boal and Livingstone term this area "microcosm of national division" (ibid. 175). It is also in West Belfast that young Roche in Eureka Street is living. When Jake drives him home one day it becomes clear that the segregated districts still bear some significance in the nineties: "I turned right down Sandy Row and headed for Beechmount. I should have known. Upper Falls gamin, he was typical” (McLiam Wilson 203). That Jake having grown up in West Belfast himself knows where Beechmount is situated, is also telling for Roche: "I knew you were a Taig" (ibid. 203). Jake realises that hardly anything has changed. The walls are still covered with murals that show the good sides of Catholics, the bad sides of Protestants and what is more, "large numbers of British soldiers [...] maimed and killed" (ibid. 205). As the figure on the right shows, the numbers of segregation in West Belfast in 1991 (A) were still almost the same as they had been twenty years earlier. South Belfast in contrast was a relatively mixed area. Although Derry (B) is not of the main concern here it is nevertheless quite interesting to see that Derry in 1991 was also an almost completely segregated town. Derry bears meaning because it was here that the first violent outbreaks of civil unrest took place in 1969 in the famous bogside situated in the southern part of the Catholic West (and through which Saoirse is driving at the end of Where They Were Missed). 


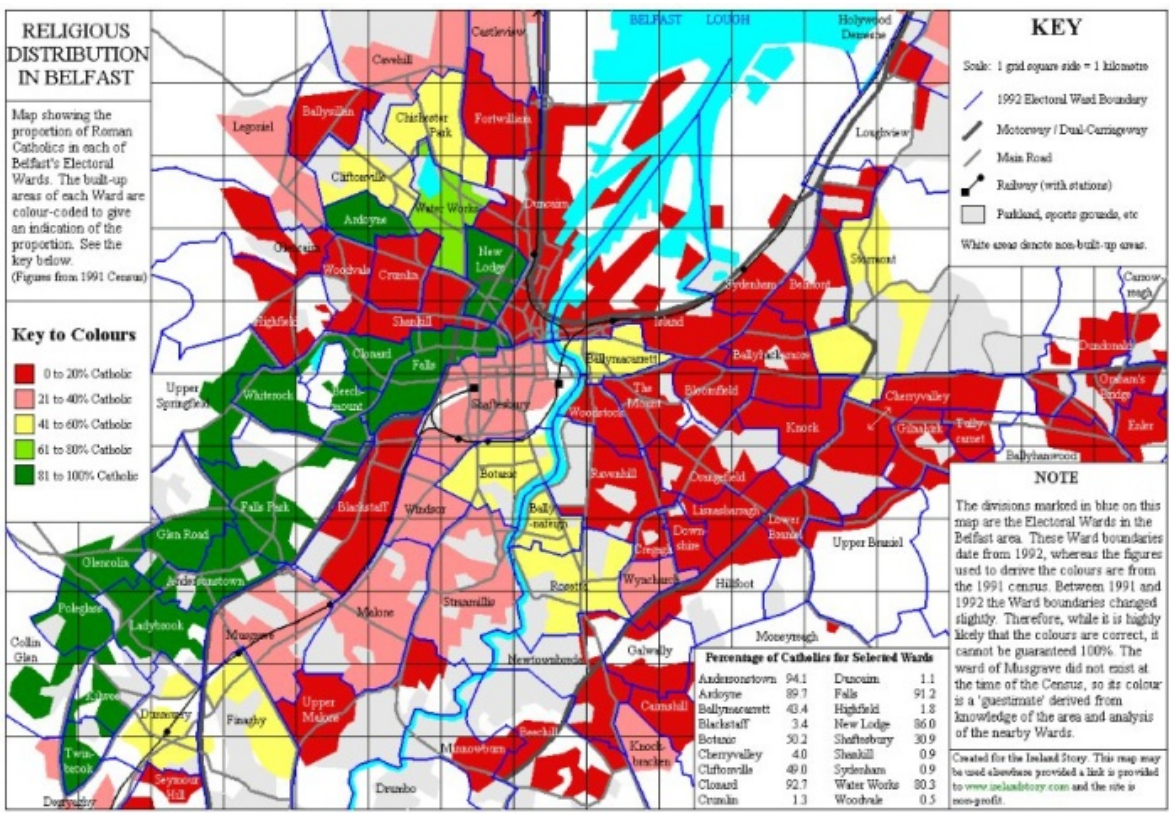

A

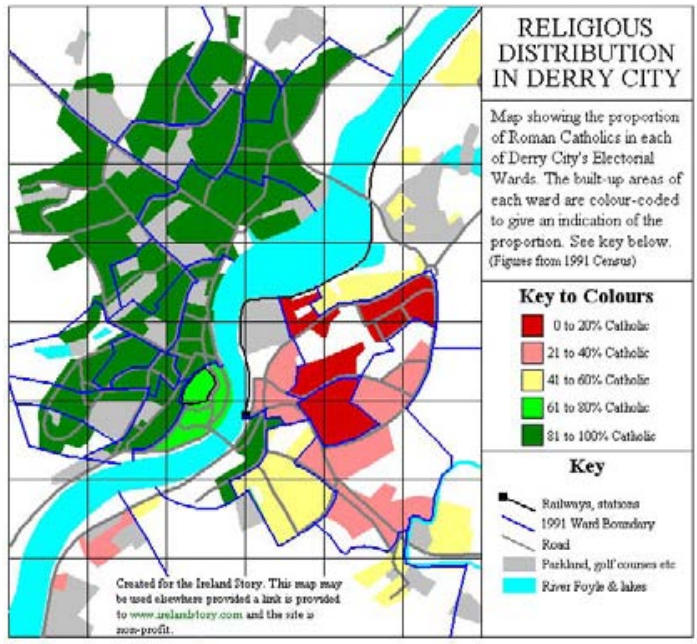

B

Figure 3: A - Religious distribution in Belfast in 1991. B - Religious distribution in Derry in 1991 (Irelandstory.com).

Jake has managed to escape his rough past, however, and now lives in South Belfast in fictive Poetry Street. His chosen area of living is again evidence for Jake's new Irishness. It reflects Jake's attitude towards an integrated society and his re- 
sentment of nationalist or unionist ideas (otherwise he might as well have chosen to live in a Catholic area). Helen in One by One in the Darkness equally chose to live in a mixed area. Like Jake she is living in South Belfast just off the Ormeau Road (Madden 44). Jake's friend Chuckie is living in Eureka Street, another fictive street in the novel (there is a Eureka Drive in Belfast, however); "Eureka" meaning "I have found [it]" (Duden 552). The street's name that is at the same time the title of the book thereby is representative for the development of a number of characters in the novel. Both Chuckie and Jake find love, Chuckie on top finds a way to earn money. Aoirghe finds a way to leave her nationalist views behind and look into the future with "clear eyes" (McLiam Wilson 396). Chuckie's mother Peggy and his friend Deasely find new ways of living by outing themselves as homosexuals. Finally, they all have found a way to live in a city like Belfast without despairing by the city's agony.

\subsection{The City Mirroring Northern Irish Society}

"In this city, the natives live in a broken world - broken but beautiful."

Eureka Street, Robert McLiam Wilson $(1996,215)$

Depictions of the city and urban life have always been of great importance to authors such as James Joyce, John Dos Passos, Virginia Woolf or Paul Auster ${ }^{33}$. Worthy to remember is Woolf's Mrs. Dalloway's walk through London while preparing for a party that same evening. The reader accompanies her through Westminster, hearing the strikes of Big Ben and crosses with her Victoria Street (Woolf 6). "I love walking in London", Mrs. Dalloway says, "Really, it's better than walking in the country" (ibid. 8). While Joyce's Dublin is converted into a scene that resembles the journeys of Odysseus, Auster's New York illustrates the city's anonymity and John Dos Passos gives a convincing picture of urban life in New York before the Great Depression. The city thus invokes different associations, whether pictures of consumerism, anonymous masses or a declaration of love. While One by One in the Darkness and Where They Were Missed engage with the city mainly as a contrast to the countryside and depict Belfast as a place predominantly associated with fear, hatred and violence, Eureka Street grants the city a more detailed report and even dedicates a whole chapter to it. For Wim Tigges Belfast is thus the true protagonist of the novel (187). In consequence he compares the portrayal of Belfast to that of Joyce's Dublin: "The physique of the city is vitalized in Eureka Street by the mention of street names, for instance when fol-

33 James Joyce, Ulysses (published 1922). John Dos Passos, Manhattan Transfer (published 1925). Virginia Woolf, Mrs. Dalloway (published 1925). Paul Auster, The New York Trilogy (published 1987 in one volume). 
lowing in some detail the trajectories of car drives or long walks made by its major characters, somewhat in the manner of James Joyce`s Ulysses" (Tigges 186). Indeed, the reader of Eureka Street learns about many of the streets of Belfast. Already on the second page Jake and the waitress Mary walk past Hope Street, on the next page they pass Lisburn Road and the reader finds out that Jake is living in Poetry Street (McLiam Wilson 2ff). Not all of the streets mentioned really exist. However, those that are invented like Hope Street, Poetry Street, Democracy Street or Constitution Street (ibid. 2, 3, 24, 25) opt for a positive feeling and thus stand in contrast to the otherwise rather upsetting depictions of the city.

Frederik Tygstrup, places emphasis on the observation that the nation-state and the novel stood in close relationship in the nineteenth century; a construction that continued well into the twentieth century. The protagonists of those novels thus live mainly in national capitals, which according to Tygstrup serve as "metaphorical images" and symbolise the "head of the national organism" (Tygstrup 225). The city in the twentieth century novel on the other hand no longer serves as a representative of the whole nation but more like an "integral universe" (ibid. 225), an area that acts rather autonomous from the nation. Accordingly the city in the twentieth-century novel has lost the requirement of being a specific or real city (ibid. 225). Many authors use the image of the city as an exemplary model for any city in the world. Sometimes cities are invented to stress the universality of their illustration even more. This new mode of writing, caused by World War I, resulted in the feeling that not only single nations were concerned by it but the entire world. Modernist writers therefore chose the city as setting in order to find "a place in time" rather than a local one (ibid. 227). The scene of demolition in almost all of Europe and other places and the feeling of forsakenness furthermore caused them to lose the "inherited image of the city embedded in a national and urban environment" (ibid. 227). According to Tygstrup national literature thus morphed into world literature. "The literary world map no longer consists of nation states, each characterized by a certain relationship between city and country, centre and periphery, but of a system of metropolizes" (ibid. 226). He continues by arguing that these metropolises form a closer connection among each other than each metropolis and its national context do.

Interestingly, the novels by Caldwell, Madden and McLiam Wilson appear to stand in the older nation-state tradition or at least in an inbetween state of the two methods. The depiction of the city - mainly Belfast but also Derry - serves to give a specific picture of the Troubles in Northern Ireland between 1969 and 1994. It does not describe the everyday problems of any people in any city anywhere in the world, but focuses particularly on the life of people who were affected by the occurrence of violence and sectarianism in a concrete period of time. City and national context are closely linked here, and the correlation of country and city also plays an important role. 
According to Joachim von der Thüsen three linguistic operations are of significance for portraying the city. They are necessary for "image-making" and are the symbolic, the metaphoric and the metonymic (1). He describes it in the following way: "Image-making of the city is concerned with the assignment of meaning to an otherwise meaningless medley of heterogeneous phenomena" (ibid.1). The city thus receives a certain value because its citizens or visitors connect particular remembrances, associations or general knowledge with single parts of the city. On the symbolic level Van der Thüsen describes the city as an icon that is actually larger than the city itself. A more general truth results from this assumption. This "truth" can either be an ultimate truth or a more neutral one; that is the city can be elevated to an ideal or it can be represented in a rather unbiased way. The city can also be associated with a specified culture or phase of civilization. While in the nineteenth century London was one of the central cities in literature, the twentieth century is rather linked to New York (ibid. 2).

Metaphorically the city is presented in terms of a definite construct, which is normally not associated with urbanity. As examples Van der Thüsen mentions images of a body, monster, ocean or jungle (ibid. 2). These metaphoric connections can be regarded in positive, negative or neutral ways depending on what a person - traveller or reader - might associate with the city and how he or she perceives it.

"On the metonymic level of image-making, a totally different procedure emerges. Here, the image of a city is made up of the customs, structures and buildings which are specific to that particular city" (ibid. 3). Most people link certain objects that are particular for a city with it. Prominent examples might be London and the Houses of Parliament, especially Big Ben, or San Francisco and the Golden Gate Bridge. In case of Belfast the Stormont where the government is situated and the river Lagan are noteworthy.

In the case of Belfast as depicted in the novels it can be seen that all three of these image-making tools apply. Symbolically Belfast is strongly associated with the violent outbreaks of a Protestant and Catholic paramilitary war. In the eyes of many foreign nations Belfast became the decisive scene of the Troubles in the second half of the twentieth century. On the metonymic level Belfast's customs, traditions and buildings stand in correlation with Protestant and Catholic murals that can be found all over the city as well as the acronyms of various organisations such as the UVF or the IRA as depicted in Eureka Street in the form of the mysterious acronym "OTG" (McLiam Wilson 22). Names like the Shankill Road or the Shankill Butchers ${ }^{34}$ also became synonymous for Belfast during the Troubles. Van der Thüsen describes this phenomenon as "markers of the city" (ibid. 3). Citizens experience the cityscape by typical buildings and preconceived images about neighbourhoods. In Belfast for example each citizen knows which areas are rather

34 A Protestant gang using butcher's knives in order to kill Catholics during the 1970s (Mulholland 89). 
Protestant areas and which are rather Catholic ones. Tigges goes one step further: "The streets, and squares, statues and public buildings in a city are a constant reminder of the past, to those that have to live in the present, and to survive into the future" (179). For those who lived to see the outbreaks of violence in Belfast the city will most certainly never lose its touch of sadness, especially for those who lost friends and relatives during this time.

Where They Were Missed introduces Belfast right on the first page and closes with Saoirse entering the city on the last page. It thus embeds Saoirse's story that for the most part plays in the Irish countryside both giving a picture of the heyday of the Troubles and later a return to Saoirse's roots. Using Van der Thüsen's concept of metaphor one observes that Belfast is depicted as a place of torment: "Belfast is hot. Belfast is never hot. But Belfast is hot this summer. [...] It's hot as hell" (Caldwell 3). The comparison to hell suggests a double meaning. On the one hand it really is a hot summer and everybody suffers from the hot weather, on the other hand it marks the ongoing outbreaks of violence as it is 1977 and the conflict is at its height. Belfast indeed becomes a place of hell for the whole family. Not only will the marriage between Saoirse's parents Deirdre and Colin break up but also her younger sister Daisy will die in a bomb explosion.

Another metaphor for Belfast is the image of a jungle that is full of threatening danger. Certain areas must not be left in order to be safe, which creates the image of the territories of wild animals that will fight for it, always ready to kill or die for it as well. Civilisation seems to have left Belfast. Saoirse, Daisy and their mother, for instance, are not allowed to visit friends in a Catholic area as their father fears for their lives. "Daddy says that for the foreseeable future, while there's cars being burned and milk bottles being thrown, Mammy is not to take us across town to visit the Antoney-oney-os and their ice-cream parlour" (Caldwell 31). Saoirse's mother nevertheless takes them to the Antonini's, an Italian family. In order to get to the Catholic Falls area they have to take a bus that is surrounded by metal mesh, "just in case anyone throws a stone" (ibid. 32). The image of the cage that is supposed to protect civilisation from a wild animal here works the other way round. Civilisation in the form of harmless citizens is this time pent up while the wilderness rages outside. Both, the cage and the hot summer, point to anomalies that will turn into an enduring state.

In Eureka Street another metaphorical dimension enters the stage. The novel begins with "All stories are love stories" (McLiam Wilson 1) and it ends with "She smiles and she looks at me with clear eyes" (ibid. 396). As Jake is so gripped with love Belfast, too, becomes a room for love although it "has lost its heart" itself (ibid. 215). Like in One by One in the Darkness the loss of the traditional economy is mourned (see chapter 3.5): "A shipbuilding, rope-making, linen-weaving town. It builds no ships, makes no rope and weaves no linen. Those trades died. A city can't survive without something to do with itself' (ibid. 215). This could be interpreted as a request for Belfast's citizens to give the city its heart back by concen- 
trating on more important things than fighting like, for example, love or empathy. The city itself is depicted as being alive, rising and falling like music or like breathing (ibid. 212) but it is also compared to a novel telling the histories of thousands of people, "present tense, past tense or future" (ibid. 215).

Symbolically, Belfast is connected to rather sad images. Bunches of flowers remind the reader of the Troubles' victims and stand for the lives lost in the war (ibid. 213). Similar symbolic images can be found in Where They Were Missed. At the beginning of Saoirse's story it is marching season ${ }^{35}$ and the Orangemen are parading in her street (Caldwell 3). The Pentland's obviously live in a Protestant area but never participate in the festivities because Saoirse's mother as a Catholic from Ireland cannot stand the segregated activities. Furthermore, helicopters are another crucial image of the unhinged city. "The hot air is cracking with the sound of helicopters rack-a-tack-a-tack-a-tacking through it. Daddy says the helicopters have special cameras to see into houses so that the Army can watch what people are doing" (ibid. 4), Saoirse informs the reader, the onomatopoeia not only imitating the sound of the helicopter but also promising a threat in terms of the resemblance to the word 'attack'. Helicopters and other instruments of the British Army thus are a symbol for the omnipresent threat both of British intrusions as well as dangerous projects of paramilitary groups. Jake's view of the city in Eureka Street also features the sight of helicopters and army personnel many times (McLiam Wilson 160).

On the metonymic level wall murals and flags showing Protestant or Catholic emblems can be found all over Belfast. Derry, too, another central part of the Troubles, bears signs of the separated country. In Saoirse's street they are the only Catholic inhabitants if we ignore her Protestant father. Neighbours have started painting their houses and installing flags on their premises. As Saoirse and her family do not participate in these actions their neighbours soon begin avoiding them.

I can see down the street as far as Wee Man's house. His house has a flag and a Red Hand of Ulster. The gate of his house is painted red, white and blue to match the red, white and blue kerbs and the red, white and blue bunting that's strung up between the lampposts. [...] We were the only ones not allowed to do the painting, and that's when Jennifer across the road started swinging on our gate and shouting that our eyes were too close together (Caldwell 73).

35 Marching season is a series of parades that celebrate the Protestant Dutch William of Orange. The "Twelfth of July" commemorates William's victory over Catholic King James II in 1689 in the so-called Glorious Revolution (Mulholland 3ff). 
Later in the novel when Saoirse and her mother leave Belfast to stay with Saoirse's aunt and uncle in the South she notices further wall murals in Stroke City ${ }^{36}$, a witty name for Derry. Under the paintings she reads the words "FREE DERRY", "BRITISH OUT" and "INLA" (ibid. 78).

Ten years later Saoirse decides to go back to Northern Ireland to visit her father for the first time. Still the problematic situation between Catholics and Protestants has not cooled down. She has to pass Derry in order to get to Belfast. Saoirse's uncle Brendan advises her not to go directly through Derry as he is aware of the lurking dangers. "Don't drive through, was the last thing he said. [...] You don't want to be lost in the Waterside (or was it Bogside ${ }^{37}$, did he say?) with Southern number plates" (ibid. 219). But Saoirse is curious to see the city where her mother marched and where her parents fell in love. The picture of the city is still a disturbing one even nineteen years after the first eruptions of violence. Saoirse sees an Army Observatory Tower, barbed wire, metal grilles and CCTV cameras (ibid. 220). She describes the city and its people as dull and grey; the only marks of colour are red, blue and yellow splashes of paint on the road but even these bear the signs of fighting: "The marks of paint bombs, they must be, I realize with a shock, but what it looks like is as if giant-sized little children have gone mad finger-painting" (ibid. 220). A bit further Saoirse sees Republican insignia such as Tricolour flags and "murals of dancing girls and balaclava'd men brandishing guns" (ibid. 220) and on the edge of the city the famous sign "You are Now entering Free Derry" (ibid. 221). Arriving in Belfast she notes almost the same signs, strings of bunting from the July parades hanging between lampposts, purple-and-orange UDA flags, and again the Red Hand of Ulster (ibid. 224). Both Derry and Belfast thus reflect the lives of its citizens, mostly being characterised by the sectarian strifes.

These images are repeated in Eureka Street. Almost all of them very often amount to the same thing, the markings of the two communities. On the walls it says "IRA, INLA, UVF, UFF, OTG" and "like a diary" (McLiam Wilson 212). The sentence "qui a terre a guerre" (ibid. 212) is mentioned, too, which roughly means "he who has land is at war". All these graffiti symbolise the conflict between nationalists and unionists. This is also shown by the "green, white, gold, red and blue" flags, also called "the two three-coloured emblems of difference" (ibid. 213). The distinctive feature of the acronym OTG is that it bears no actual meaning. It only has meaning in the sense that it is there. Throughout the city people

36 The naming of Derry/Londonderry has been problematic among the two communities. During the Troubles unionists rather referred to the city as Londonderry while nationalists used to call it Derry. Due to the written form Derry/Londonderry (Derry-stroke-Londonderry) the radio presenter Gerry Anderson invented the term Stroke City (Kerrigan 60).

37 Bogside: Catholic area in Derry where the British army was installed. In 1972 26,000 soldiers were sent there including tanks, bulldozers, Saracens, and helicopters known as Operation Motorman. Up to then it was the biggest military operation since Suez (Mulholland 86). Saoirse apparently is not aware of the significance of this area because she is too young to remember. 
are aware of all the acronyms standing for unionist and nationalist groups but when the OTG graffiti start appearing nobody knows what group is hiding behind it. The letterings itself mean war, not only in their messages but also because it is a war between the people painting them on the walls and "a civic-minded person" (ibid. 22) who paints it over again. In the end one of Jake's friends, Donal, comes up with the theory that OTG stands for nothing: "I think it's entirely random. It could be any three letters of the alphabet. It doesn't really matter what they are. This is the city of the three-letter initial written on walls. I think someone's satirizing us" (ibid. 356). Apparently, the person responsible for the OTG's just wants to indicate the senselessness and insanity of the three-letter war and the Northern Irish conflict in general, and this quite successfully.

The marching season becomes also visible in One by One in the Darkness. When London-based Cate Quinn returns home to visit her family she cannot but notice the Protestant messages on the outskirts of Antrim. Union Jacks and Ulster flags announce the twelfth of July although it is only mid June and red, white and blue coloured buntings are decorating the streets (Madden 6). Although two of the three sisters have chosen to live in the city - Helen in Belfast and Cate in London - all three of them consider the countryside as their true home. The city and the country thus stand in clear contrast to each other, the one depicting the familiar native land, the other one a place of estrangement and crisis. Helen for example has not furnished her house in Belfast as she feels "no particular attachment" to it (ibid. 24). Her home in the city serves more as a necessity, she never feels belonging to Belfast at all. "She'd needed a roof over her head, there was no more to it than that. [...] She'd bought furniture and curtains in the same frame of mind in which most people bought pints of milk and loaves of bread: she needed them" (ibid. 24). Nevertheless her home in Belfast functions as a safety mode for Helen. Her father being killed by Protestants in her uncle Brian's house she has lost her feeling of security and now welcomes "the sterility of the place in Belfast" where no bitter memories accompany her (ibid. 44). "It was, psychically, a blank" (ibid. 44).

Belfast itself is depicted as a two-faced city. A friend of Helen's, David, is expecting a visit from his London boyfriend Steve. Being afraid that he will be disappointed by the city David takes Steve only to the nice places that let Belfast appear less harmful than it really is. So he shows him the Belfast Lough, the Mournes and a nice pub in town (ibid. 56ff). On his second visit Steve gets to know the real Belfast, however. "This time, when David collected him at the airport, he didn't drive into Belfast by the motorway, but went over the Divis mountain, through Turf Lodge and then down the Falls Road, pointing out the heavily fortified barracks" (ibid. 57). Steve even meets an army foot patrol, sees the Republican murals in the lower Falls and the Loyalist murals in the Shankill area. "The 'Peace Line', an ugly structure of corrugated iron and barbed wire, which separated the two communities, apparently shocked Steve more than anything else 
he saw" (ibid. 58). Their trip is crowned by an army helicopter that watches over the city. This is contrasted by the opening of the first chapter which states the sisters' true feeling about home:

Home was a huge sky; it was flat fields of poor land fringed with hawthorn and alder. It was birds in flight; it was columns of midges like smoke in a summer dusk. It was grey water; it was a mad wind; it was a solid stone house where the silence was uncanny (ibid. 1).

That Belfast is not only a place of evil has been noted by Laura Pelaschiar, too. She has observed that Belfast in the 1970s and the 1980s was "initially portrayed as a home to alienation, confusion and violence" (Pelaschiar 117). She has realised a change in the 1990s, however:

In the nineteen nineties Belfast has gradually become a new, fertile urban location, no longer a place from which escape is necessary, but rather a laboratory for opportunities, a post-modern place depicted as the only space where it is possible to build and articulate a (post)national conscience, the only location for any possible encyclopaedic, multivoiced and multiethnic development of Northern society (ibid. 117).

A first indication that the North might not only be a place of melancholy is shown in Where They Were Missed, too. Before entering the city Saoirse realises an unexpected beauty of the Strangford Lough area around it:

It's pretty, really pretty. When you think of the North you don't think of it as being pretty; you tend to think only of bombs and things like barbed wire and concrete barriers in the rain, but here by the edge of the Lough is one of the prettiest places I've seen (ibid. 223).

This postmodern pulsation is felt by Tigges, too, who describes McLiam Wilson's Eureka Street as "demotic" and with a breath of "postmodern flair" (Tigges 180). That Belfast is no longer a place from which one wants to escape is also illustrated by Jake and his friends. Except for Chuckie everyone has been away for some time. Slat Sloane spent some years in Manchester. Donal Deasely was in Bayeux, Bremen and Barcelona. Septic Ted experienced living in Scotland. Finally, Jake was in America for several years before he went to London. Nevertheless, everybody has returned to the old home: “They'd gone away, they'd come back. It used to be that Northern Ireland's diaspora was permanent, poor denuded Ireland. But everyone had started coming back. Everyone was returning" (McLiam Wilson 141).

What all five of them experience is a certain attraction to Northern Ireland although they all have seen the evils produced there. This sensation is also described by Pelaschiar who argues that Belfast resembles a cage or a labyrinth, that is, a place one wants to escape from but cannot do so. At the same time the city has a 
captivating atmosphere and an "irresistible "fatal attraction", as Pelaschiar calls it, and she concludes that "the writers from the North seem to show symptoms both of topophobia and of topophilia", a love-hate relationship to Northern Ireland (122). That all of Jake's friends have returned to the city confirms the magnetism of it. Even strangers are somehow spellbound by it as in case of Steve. Luckily the return or visit to Belfast is for none of the characters actually fatal. They all seem to be drawn by the innate pain the city conveys, though. Chuckie's girlfriend Max, for instance, has lost her father in Belfast. As a negotiator who "persuaded people in foreign countries not to kill each other" (McLiam Wilson 120) he was killed by Protestant and Catholic paramilitaries after being only twenty minutes in Belfast. A new interesting statement enters the novel: "The IRA and the UVF both claimed responsibility. An American newscaster told the camera that [Max's] father had been executed because he was too good at his job. The Irish didn't want him persuading them away from their war. The Irish liked their war" (ibid. 122).

As the city is every now and then depicted in quite positive pictures - whereas the countryside is always connected to happy remembrances - one can assume that the city is not bad by itself. It is made a bad place by the people living there. Once sectarian issues have been solved Belfast, or even Derry, also has the potential to become a likeable place again. First signs thereof are already there. The positive feelings Jake and Saoirse sometimes have when looking at Belfast are again signs of 'New Irish' beginnings. At times it even seems as if the city wanted to tell its citizens that the times of war were over and that it was time for a change. "In Belfast, in all cities, it is always present tense and all the streets are Poetry Streets" (McLiam Wilson 217), it is said in Eureka Street. Indeed, the city waits for its people to make something out of it. This can turn into a disturbing poem in modernist style but also into a love poem.

\subsection{A Sectarian Society - The Significance of Religion}

"For there they stood, Pope and Chuckie, arms still outstretched towards one another, a whisky bottle in the Pope's hand, a glass in Chuckie's." Eureka Street, Robert McLiam Wilson $(1996,35)$

This quotation taken from Eureka Street deals with Protestant Chuckie Lurgan whose clan "had historically loved fame" (McLiam Wilson 26) - who is depicted in a painting together with the Pope. Originally a photo taken of a crowd of people surrounding the Pope during one of his visits to Belfast, a friend of Chuckie's, Dex, "an alcoholic one-time commercial artist" (ibid. 32), has redesigned the picture to show only what is important to Chuckie: him and a famous person. That 
of all people the Pope, "the evil Kommandant of all the Romish hordes" (ibid. 29) becomes on object of Chuckie's desire does not matter to him.

All his life Chuckie had been capable of shouting 'Fuck the Pope', with the hardest and most Protestant of his friends. But when he heard that the man in question, the new Polish Pope, was coming to Ireland, he was in a quandary. Sure, the guy was a Taig, a Fenian, the logical extension of all that was Catholic in the world. But no one could deny that he was famous (ibid. 29).

Because Chuckie loves fame more than his religion he is able to overcome one of the problems that is still very strong in Northern Ireland: to stick always to one's own crowd. The picture seems to say 'Let's have a drink and be friends', Catholic and Protestant forget their old dispute; an idea that works in Eureka Street but that is not yet the rule in Northern Ireland.

The conflict in Northern Ireland is not only a religious one but as Duncan Morrow points out "the specific conditions" are that "political and religious movements in Northern Ireland resulted in ingrained communal divisions, where the lines of religious rivalry ran almost parallel to political divisions" (Aughey and Morrow 190). Claire Mitchell, too, stresses the social and political significance of the church in Northern Ireland and that conflict "has not been, is not and never will be a holy war" (Mitchell 2006, 1). Reasons for this intertwining of social, political and religious factors is that the Catholic Church itself - having to endure the same misery during the Penal Laws period (see chapter 1.1) in the eighteenth century as the Catholic population - became sort of an advocate for the people against British authorities. Social and economic issues were thus always foregrounded, not theological ones. At the same time the church became a presence in managing schools, social institutions and economic initiatives (ibid. 192).

Unlike the Catholic Church, the Protestant Church has never been unified in Northern Ireland. Morrow stresses that in this case "institutional unity [...] is provided by political and cultural groups such as the unionist parties and the Orange Order and not by the churches" (ibid. 193). The religious part remains a strong "boundary marker" (Mitchell 2006, 60), however. Instead of belonging to one single church Protestants are divided up into Presbyterians, Anglicans, Methodists and other separate denominations (ibid. 191), which for Jake is another reason to make fun of the churches in Northern Ireland:

I walked up the Lisburn Road and passed the Anabaptist Church - or double-duckers as we called them - the South Belfast Gospel Hall, the Windsor Tabernacle, the Elim Pentecostal, the Methodist Mission, the Presbyterian Presbytery, and the Unitarian Church of Protestant Mnemonists or something like that. [...] I tried not to look like a Catholic (McLiam Wilson 170).

The satiric element is created here by various methods. While the Anabaptist Church sounds like an ordinary church at first the reader learns what Jake and his 
friends think of it by the nickname they use. 'Double-duckers' could stress the church's intensified religiosity, while at the same time it could also mean a sexual allusion. Although using religious terms in their names, other churches like the Windsor Tabernacle sound more like pubs or places of amusement instead of piety. Finally the alliterations in Methodist Mission and Presbyterian Presbytery and the latter's repetition of root (figura etymologica) seem to ridicule the church's authority.

However, the church in general plays a crucial role in Northern Irish society. Morrow claims that only pubs do have a similar central role in social life (consequently the peculiar church names mentioned by Jake). Thus, the church among others offers space for women's groups, charities, sports clubs and young people. During times of high unemployment rates - as in the 1970s - the church even provided for job training and employment schemes (ibid. 195).

Duncan calls attention to the fact that "in communities which regard one another with suspicion or hostility, in which the fact of being a Protestant or being a Catholic may be grounds for apprehension or fear, the avoidance of such situations of fear [...] is a matter of common sense" (ibid. 196). These situations are also familiar to Jake in Eureka Street. In a bar he frequently attends he encounters one night a "big Protestant bouncer" with UVF tattoos. Jake is afraid of talking to him because he might say "something too Catholic" (McLiam Wilson 2). The next time he goes there the bouncer on duty wears Republican tattoos and Jake is "scared of not seeming Catholic enough" (ibid. 18). This shows how important the religious background for some people is. Of course, this is a merely superficial perception. Ronnie, a Protestant colleague of Jake's, likes him as long as he believes him to be a Methodist (ibid. 162).

Both Morrow and Mitchell have recognised a change in religious behaviour. In the 1991 census, for example, the number of those not stating a religion and of those claiming no religion rose while the numbers of Protestant believers fell (Presbyterians: from 31 per cent to 21 per cent, Church of Ireland: from 27 per cent to 18 per cent) (Aughey and Morrow 191). In 1991 thus 38 per cent stated to be Roman Catholics and 51 per cent belonged to one of the Protestant churches while 11 per cent stated no religion (ibid. 1991). In 2001 the number of Catholics counted 40 per cent; that of Protestants had sunk to 46 per cent. The number of population having no religion or not stating it now counted 14 per cent (Mitchell 2006, 22).

Although there is a trend of decline concerning the importance of religion it is very small and "religious belonging remains strong amongst the young" as Mitchell points out (ibid. 23). In a 2003 survey 15-17 year olds were asked several questions about their religious identity. When asked the importance of their religion 70 per cent of Catholics and 59 per cent of Protestants agreed. The question "Do you see yourself as part of a religious community?" was answered by 91 per cent of Catholics and by 88 per cent of Protestants in the affirmative, though 
(ibid. 23). Mitchell concludes that for young people their religious identity is as important to them as to their parents, but she also assumes that they deal with it in different ways (ibid. 23).

An example for the onset of change when dealing with religion can be seen in One by One in the Darkness. All three of the sisters - Cate, Helen, and Sally - used to go to church regularly during childhood. While growing up they choose different ways of dealing with their religion, however. Sally's faith continues to run in "a straight and unfractured line" "like much else in her life" (Madden 22/23). To Cate her Catholic faith is of no less importance although Helen assumed she would quit going to church once having moved to London (ibid. 22). Cate's faith is less straightforward than Sally's, though. It is more of a "ramshackle thing, a mixture of hope, dread, superstition and doubt" (ibid. 22). Only Helen stopped going to church after she started university, which is not that easy to deal with for her family. In one of her father's notebooks she finds a reference that he hoped for two things: "That there would be peace in Northern Ireland, and that Helen would return to the Church" (ibid. 23). While faith is more of a personal thing for the sisters, their parents and relatives by contrast perceive it in a more universal way and regard it both as important and almost mandatory for every Catholic to stay connected to the church.

It has been mentioned already that religion serves as a boundary marker. One of the most persistent ways in maintaining it begins quite early in childhood, namely during school. In 2003 the majority of pupils still attended segregated schools: Protestant and Catholic. Although there do exist integrated schools (47 in 2003) with Lagan College being the first one that opened in 1981, only four per cent of the total school age population attended these schools in 2003 (Mitchell 2006, 60). Both Protestant and Catholic schools still did little to teach their pupils about the other community. Thus "knowledge of the other community's religion is weak, and $[\ldots]$ many religious and historical myths fill in gaps of knowledge about the "other side"' (ibid. 61). Due to this practice prejudice is almost inevitable. It is furthermore quite problematic as school children can get a false impression of religion. Mitchell refers to B. Lambkin who found out that pupils believed the conflict to be the result of religious differences. Without contact to children of other religions this division could even be perceived as being a natural separation (ibid. 61).

Difference and the Other become again important for religion as well, for "identity is intrinsically relational" as Mitchell points out (ibid. 64). One's own religious identity is largely defined by what one is not. This happens by looking at others. "People arrive at self-awareness by observing difference - whether this is football tops, school uniforms, cultural traditions such as going to watch Orange Order marches nor not going", Mitchell contends (ibid. 64). In Where They Were Missed Saoirse's identity is largely formed by her family's difference towards others, too. When it is marching season everybody living in their street goes cheering 
on the marchers, that is, everyone except Saoirse and Daisy who have to stay in the garden (Caldwell 3); and they do not go to church, "not even at Christmas, when everybody else goes" (ibid. 51). For Saoirse's father the church is just "Magicking Nonsense" and for her mother going to church is more dangerous than staying away from it as she has advised her daughters to say "We don't go to church" in case anybody should ask (ibid. 51). Only when the Pentlands' marriage breaks up does Deirdre return to her faith. The church appears to be like a prison to Saoirse and Daisy, however, mainly because of the black bars across the windows (ibid. 52). What serves as a protection against attacks from radical activists here at the same time becomes a metaphor for the religious situation in Northern Ireland: Religion becomes a prison itself as it is quite hard for anybody to flee from its stigmatising effects. Even if one is not an active Christian one will always be considered being a Catholic or a Protestant in the North. Religion thus becomes an "ethnic marker" and justifies delimitation (Mitchell 2005, 8).

In 2000 and 2001 interviews with 35 people were taken by Mitchell, among them with a young woman called Niamh who claimed to be a non-practicing Catholic. Although she did not go to church and did not believe in anything told by it she would have her children christened. Furthermore, it was important to her that her children went to a Catholic school, learned Irish and played Gaelic sports. "Thus the import of Catholicism for Niamh is that it is not Protestantism", Mitchell claims (ibid. 8). For her religion itself does not play a major role but the cultural difference it implies. Another interviewee, Joe, recounted how he was beaten up for being Catholic and had problems finding a job (ibid. 9). These examples show the importance to identify oneself in Northern Irish society and to mark oneself off the 'enemy' and it also illustrates the prison again from which one cannot escape; according to the motto once a Catholic, always a Catholic.

Nic Craith has observed that although it seems to result from difference conflict between groups very often actually has much in common. The groups involved artificially create distinction by making use of the same sources and applying analogous tactics. "Where communities are remarkably alike, it is similarities, rather than differences that generate conflict as great creativity is required to construct cultural boundaries when the cultural other is very alike" (Nic Craith 2003, 1). Jake poignantly summarises this problematic socio-religious situation in Northern Ireland:

The tragedy was that Northern Ireland (Scottish) Protestants thought themselves like the British. Northern Ireland (Irish) Catholics thought themselves like Eireans (proper Irish). The comedy was that any oncestrong difference had long melted away and they resembled no one now as much as they resembled each other. The world saw this and mostly wondered, but round these parts folk were blind (McLiam Wilson 163). 
It is different with Jake and Chuckie, though. While the outside world sees them as Catholic and Protestant they see each other as friends. This is where a new aspect sets in. Because Jake and Chuckie have different value systems they indeed can be real friends. They do not lose themselves in reasons why they should dislike the respective other. Both Jake and Chuckie at some point indeed accepted the fact that they are not any different from the rest of Belfast society or Northern Ireland in general (here one should also remember that they are all speaking the same thick dialect). They try to make the best out of it, however. The key to mutual understanding thereby is moderateness and to remain with both feet on the ground. Jake's colleague Rajinder, for instance, can be together with the Jew Rachel because he is a Sunni Muslim. "We're very moderate" he adds (McLiam Wilson 345). If these two religions, that in the eyes of the western world follow quite strict rules, can find together then one could also expect Northern Irish Protestants and Catholics to find a way to communicate. That people like Chuckie and Jake, Helen or Saoirse find ways not to be touched by the stigmatising effects of sectarian insanity gives hope for the future, though.

\title{
4.4. Signs of Violence
}

\author{
"He grabbed my collar, called me a Prod fucker \\ and took his swing." \\ Eureka Street, Robert McLiam Wilson \\ (1996, 196)
}

Violence, most notably in the form of 'terrorism', has been one of the major parts of life for Northern Irish citizens. But then the term terrorism is sometimes situated in a grey area. David Miller remarks that terrorism means the "systematic use of murder or other physical violence for political ends" and it is "indiscriminate or mostly targets civilians or both" (Miller 4). Nevertheless the term is always used to describe the actions of the enemy, never for the actions of allies or oneself (ibid. 4). Miller demonstrates the problem with the help of the following example. If the killings of civilians were taken as the decisive factor for terrorism then the IRA could not be termed as terrorist group since only a minority (37 per cent) of its victims were civilians between 1969 and 1989, whereas the army and the RUC in Northern Ireland could be called terrorists as a majority killed by them (54 per cent) were civilians. In addition, both parties would say they did not kill civilians deliberately (ibid. 4). Thus, Miller concludes terrorism is rather a term used for non-state or non-Western state induced acts of violence (ibid. 5). Otherwise many other acts such as the killings on Bloody Sunday in Derry 1972 undoubtedly would have to be called an act of terror as well (ibid. 6ff). The whole subjugation of Ireland by the British would lose ground then. 
According to numbers of 2001 statistics, thus more than 3,600 people have died in the Northern Ireland conflict. Nearly 90 per cent thereof were killed by paramilitary activists. The IRA alone killed more than 1,800 people up to 1998 . Another 231 were killed by republican factions. Loyalist activists killed 990 people, most of them Catholic civilians (708 to be exact). In contrast the IRA 'only' killed 133 Protestant civilians. Other victims included British Army soldiers, members of the RUC and of the Ulster Defence Regiment (later the Royal Irish Regiment). British government forces killed a total of 363 people. In Belfast alone over 1,500 people fell victim to the war. Another 40,000 were injured during the violent conflict (Mulholland 76).

The depiction of violence has changed over the years in Troubles writing, most notably if considering novels from the 1920s and 1930s and from the 1980s and 1990s.

In the early stories violence is usually in the background and always palatable. It is there as a necessary concomitant of the struggle for nationhood. In contemporary stories, the violence is brutal, random, senseless, pervasive, and most often resented front and center. It often happens to innocent civilians. The victims are both Catholic and Protestant, from the South and the North, and usually with no active allegiance to either nationalism or Unionism (Storey 73).

Hence, the writers mentioned earlier like O'Faolain and O'Connor in their novels made use of violence in order to show a nationalist standpoint whereas nowadays violence is presented in a barbaric and anarchic way (ibid. 75). Both One by One in the Darkness and Where They Were Missed make violence look ugly and certainly neither functional nor effective. In both novels the narrators lose a close person who dies innocently and randomly in an act of violence. Thereby, the authors are not afraid to depict things as they are. The scenes are frankly cruel. Because none of the daughters was there when their father Brian was murdered by terrorists Cate, Helen and Sally can only imagine the scene.

Then Helen's father saw them himself as they came into the kitchen, two men in parkas with the hoods pulled up, Halloween masks on their faces. He saw the guns, too, and he knew what they were going to do to him. The sound of a chair scraping back on the tiles, 'Ah no, Christ Jesus no,' and then they shot him at point-blank range, blowing half his head away (Madden 181).

The Halloween masks add a special harshness to the scene as they are worn by loyalists who abuse the originally Celtic tradition. Mother Emily is haunted by a dream in which she faces Charlie's murderer in the kitchen. On the floor her husband lies covered by a check table cloth "two feet sticking out at one end", the other end of it being "dark and wet". The whole place is filled with a "stench of 
blood and excrement" (ibid. 125). Cate is also haunted by her father's death in the sense that her childhood remembrances of her uncle's kitchen are overshadowed by the images of her father lying dead on the floor where they had cracked nuts as children. But the refurnished kitchen is no solution either as the refurnishing has destroyed her childhood memories. "She had always thought of her childhood not principally in terms of time, but as a place to which she could always return. Now that was over" (ibid. 143). Instead the place has become "desecrated" to her (ibid. 143).

In Where They Were Missed the death of Daisy is represented in a reduced amount of clearly given images. Nevertheless, the portrayal is not less cruel in the impressions it evokes. By only hinting at the possible outcome of a car explosion in front of the Pentlands' house Caldwell at the same time manages to create a concrete picture. The reader is almost forced to envision what has happened to Daisy: "A car horn blasts suddenly and it goes on and on the noise of it tearing through the air and on top of the car horn a shrieking noise a bang then: there is nothing" (Caldwell 66). Saoirse and her mother run out of the house, Deirdre calling: "Jesus Christ, Saoirse, where's your sister?" (ibid. 66). The words "blast", "tearing", "shrieking" and "nothing" induce violent images of Daisy being hit by the exploding bomb and the remains of her motionless body. She is not dead instantly but dies several days later in hospital. Again the reader learns about her death only by the emotions of Daisy's family. When Saoirse's father Colin comes to pick her up from a hospital room, where a nurse has been looking after her, the reader knows the outcome from his only standing in the door and staring (ibid. 71).

Eureka Street, by contrast, generally uses quite ironical language to describe violent acts, as for instance when Jake sits on the Peace Train to Belfast: "Here I was riding a Peace Train from Belfast to Dublin to protest against the IRA planting bombs on the Belfast to Dublin line. [...] But we didn't get to Dublin. There was a bomb on the Belfast to Dublin line. Boom boom" (McLiam Wilson 187). Here, too, a whole chapter deals with lost lives (chapter eleven). The method chosen evokes huge sympathies in the reader. In this scene the ironic mode is not applied, however, and it thus serves as an exception to the rest of the novel. Consequently, the chapter gains a special importance. It begins with Rosemary Daye who is looking forward to a date. More than four pages are used to introduce her to the reader during her coffee break strolling through the city. The reader accompanies her shopping at the Royal Avenue in Belfast's city centre, follows her into her favourite shop and learns about her peculiarities and how she met her latest sweetheart (McLiam Wilson 218ff). But then the scenery suddenly changes. Rosemary steps into a sandwich shop, flirts with a young man holding the door open for her and "stops existing" (ibid. 222): An exploding bomb takes her life and that of several other people who are also introduced only briefly. The descrip- 
tion of her death is very detailed and matter-of-fact and breaks with the airy atmosphere created before.

The largest part of one of the glass display cases blasted in her direction. Though fragmented before it reached her, the pieces of shrapnel and glass were still large enough to kill her instantly. Her left arm was torn off by sheeted glass and most of her head and face destroyed by the twisted mass of a metal tray. The rim of the display case, which was in three large sections, sliced through or embedded in her recently praised hips and some heavy glass jars impacted on her chest and stomach, pulverizing her major organs. Indeed, one substantial chunk of glass whipped through her midriff, taking her inner stuff half-way through the large hole in her back (ibid. 222).

Martin O'Hare, Kevin McCafferty, Natalie Crawford, her sister Liz and their mother Margaret plus further twelve people die in the bomb attack, and many more are injured severely (ibid. 225). A number of times the narrator stresses that they all had stories (ibid. 223, 224, 231). By giving the victims' names and short introductions into their lives McLiam Wilson manages to create an understanding in the reader that those people who died during the Troubles were really quite normal people with quite normal lives and that none of them deserved to die.

This disturbing scene is contrasted with Jake's statement from the beginning of the novel in which he emphasises the routine of bomb explosions in the city: "As Belfast bombs go, it went. [...] It was dull stuff. Nobody really noticed. What had happened to us here? Since when had detonations in the neighbourhood barely raised a grumble" (McLiam Wilson 15)? Farquharson rightly points out that the things Jake is talking about are "made more important than Jake seems to suggest; as McLiam Wilson shows, we are meant to be horrified" (ibid. 72). This is achieved by Jake's "sarcastic, critical and cynical” language (ibid. 71). Indeed Jake cares a lot what is happening around him, especially when Roche, a twelve-yearold kid he has met in the streets, is injured in a riot. Jake loses control screaming at the reporters around and saying mean things to Aoirghe who has always been a supporter of nationalist views (McLiam Wilson 363ff).

As the figures mentioned at the beginning of this chapter undoubtedly show, most deaths were caused by paramilitary groups, the republican IRA and the loyalist UDA and UVF being the most prominent ones. Among scholars the question has been raised how to deal with these paramilitary groups. Are they politically legitimate or merely criminals (Aughey and Morrow 159)? Alain Bairner emphasises the fact that these paramilitary groups in the 25 years of conflict "had the weaponry, the organization and the will to continue their violent activities for an unlimited period of time." He continues by noting that at first few people believed the ceasefires called in 1994 to last very long (ibid. 159). Jake for example is one of those people who eyes the ceasefires skeptically when his friend Slat tells him 
about them: "My initial deep surprise faded. 'They've had plenty of ceasefires before." The Troubles had only been the most recent outbreak of violence. Violence itself has been an element of Irish political life for much longer. Jake's doubts are definitely justified. Why should the ceasefires of 1994 have been the ultimate end?

It is interesting to take a short look on the motives of paramilitary groups at this point. Both republican and loyalist paramilitaries saw themselves not as criminals but as defenders of their political aims. Hence, republican violence in their view was legitimised by the constitution of the Irish Republic and that of loyalists by the British government (ibid. 161). Republicans also referred to the Palestine Liberation Organisation (PLO) and the African National Congress (ANC) in order to support their arguments for a legitimate fight for freedom and a united Ireland (ibid. 162). Supporters of a united Ireland faced protectors of the union. The British government in contrast considered all paramilitary factions as being terrorist groups and proscribed their existence (ibid. 160). To fund paramilitary actions, however, it was unavoidable to engage in criminal activities such as armed robberies or racketeering (ibid. 161).

Both Caldwell and Madden refer to members of paramilitary groups in their novels. The point of perception is a critical one, though. At the age of 16 Saoirse is dating Johnny Mahon whose "uncles from Derry are in the Maze prison ${ }^{38}$ up North doing short sentences for possession of firearms and suspected paramilitary involvement" (Caldwell 93). For that reason her aunt Bernadette does not want to get Saoirse involved with him (which she as a teenager of course does nevertheless). However, Johnny uses her only as an alibi for his illegal paramilitary activities when he asks her to lie about them having been to the cinema (ibid. 97). He and three of his companions finally get arrested for having stored weapons and ammonium nitrate in a nearby barn and for being suspected in paramilitary involvement with the "Provos"39 (ibid. 159ff).

38 Maze prison, officially named Her Majesty's Prison, and referred to as Long Kesh or just "the Kesh" by both loyalists and republicans, was located near Belfast outside the city of Lisburn. Opened in 1971 with the introduction of internment, it became a symbol for the division of Northern Ireland during the Troubles. Since 1976 the most dreaded paramilitary activists were housed here in the so-called H blocks until the endorsement of the Good Friday Agreement. Around 430 prisoners were released early on license then. In 1980/81 the famous hunger strikes were carried out in Maze prison. Finally, "in September 2000 the last four prisoners were transferred and the prison closed" (Gillespie 158-159).

39 Provisional Irish Republican Army: A faction that developed out of the split with the IRA in 1969. Whereas the official wing eschewed violence after 1972, the Provisionals believed that violence was the only way to achieve their goals. The IRA's tradition of physical force can be traced back to Wolfe Tone's revolutionary movement of 1798 and to the Irish Republican Brotherhood (IRB) of 1858. While the IRB acted secretly, the Irish Volunteers, a Nationalist paramilitary body, were established in 1912 to support openly the cause of Irish Home Rule. When the IRB took control over the Irish Volunteers, the IRA was formed, which proclaimed 
In One by One in the Darkeness the brother of an old friend of Helen's, Tony Larkin, dies planting a bomb near Magherafelt at the age of 19 (Madden 103). Although he dies himself as the initiator and no innocents are concerned his death leaves an awkward feeling among neighbours and friends: "A strange atmosphere hung over everyone and everything at the time of Tony's death, a hushed and grieved air, and there was a distance between people, as though no matter how much they talked, they remained deeply isolated from each other" (Madden 104), a clear sign of the confusion and disturbance the war - no matter in which way caused for families and friends. At Tony's funeral several paramilitaries are present which leaves mixed feelings among the rest of the funeral attendants. Father Black for example who speaks the sermon forbids Tony's companions to put a beret, black gloves and the tricolour flag on top of the coffin; typical insignia of an IRA funeral ritual (ibid. 104). Six men and women all dressed in black with black berets, and dark glasses bid their deceased comrade a last farewell: "[They] produced guns, and when someone gave orders in Irish, they raised their arms and fired a volley of shots over the open grave. Many of the mourners applauded loudly; some of the men even whistled and cheered" (ibid. 105). While Helen's uncle Brian is among the applauders who "clapped hardest of all" (ibid. 105) their father remains silent. Like many others Charlie cannot make sense of the IRA methods and advises his daughters to remember what they have just witnessed: "Never forget what you saw today; and never let anybody try to tell you that it was anything other than a life wasted, and lives destroyed" (ibid. 105). In the present story of the novel Helen has to defend Oliver Maguire, a young man who is suspected of having murdered a taxi driver. Although Helen chose her job deliberately this time she begins to have doubts about her clients. This time she suddenly knows Oliver really did kill the man. Images of the deed pass vividly right in front of her eyes (ibid. 173). For the first time she sees the insanity of the sectarian killings she as a solicitor has to deal with and begins to remember her father's unnecessary death.

In all three examples a deep insight into the minds of the IRA men is not given but they are not depicted as evil monsters, either. The focus is rather set on the families of the delinquents and the consequences they have to deal with. Not every family was standing in the republican tradition, thus relatives were normally as shocked by the facts as the world outside. Mrs. Larkin is said to look "as if she were locked into some terrible dream, from which she didn't have the energy to struggle to awaken" (ibid. 104). Mrs. Maguire refuses to believe her son to be a murderer at first, too. "Oliver couldn't have done what they're accusing him of. I know, because I'm his mother” (ibid. 175), but secretly Helen knows Mrs. Larkin knows the truth as well. In the end she admits: "It's all like a dream, so it is [...] All like a terrible dream" (ibid. 176). Helen is also familiar with the feelings those

an Irish provisional government in 1916. From this action the PIRA took its name (Aughey $161 \mathrm{ff})$. 
families have when leaving the court after the verdict: "They hid their faces in shame" (ibid. 174). These passages confirm that the majority of Northern Ireland's people were not interested in killing each other but were equally victims of their relatives and the whole country's situation. The guilt of their sons and daughters, brothers and sisters hit them as hard as the delinquents themselves. Questions of complicity must have tortured them. The comparison to a terrible dream of which one tries to awaken in vain thus becomes an adequate image.

\subsection{The Role of the Media}

'I switched on my Wreck-radio, caught the words 'two suspect devices', and switched it off again. I drove on, musicless. As I turned up Bedford Street, I decided to sing to myself."

Eureka Street, Robert McLiam Wilson

$(1996,201)$

Until recently, violent attacks within Northern Ireland not only threatened people in the streets but also accompanied them in the daily news. A good example here is Jake who cannot listen to the radio anymore as it is always the same news he hears (see also citation above). He is so fed up with hearing bad news all the time and conditioned to switch off the radio as soon as the news are on that he misses the only good news the radio broadcasts in the whole novel: the declaration of the ceasefires (McLiam Wilson 306). Saoirse's father Colin in Where They Were Missed shows a similar reaction to the news: "Daddy buys the Belfast Telegraph as well but he doesn't read it, he only looks at the front page and then he shakes his head and folds it all up so you can't see the photos on the front" (Caldwell 24). Violence surrounds these people everywhere they go, so their reaction is trying to ignore violence reported in the media. Unfortunately, they do not manage to do so as they encounter it outside their homes each single day.

Some of the characters' grief is yet harder to bear due to the media. Helen is full of anger at the media as she experienced the journalists' hunger for sensationalism herself. Although her father died innocently in an attack that actually was supposed to kill her uncle, the media treats the case without any decency:

Worst of all had been the British tabloids, where the death was reported coldly and without sympathy, much being made of Brian's Sinn Féin membership, and the murder having taken place in his house. The inference was that he had only got what was coming to him (Madden 47).

Helen's friend David also lost his father in an act of violence. As in Helen's case the newspapers do not make much of a distinction between two man killed in a car, one being in the IRA, the other one just being in the wrong place at the 
wrong time. Instead they both are depicted as terrorists who "got what they deserved" (ibid. 49). The novel thus suggests that violence strikes the relatives of innocent victims, which most of them were, in a double way. On the one hand they have to deal with the loss of a beloved person, on the other hand they feel the pain that the whole world believes yet another terrorist died because he deserved it.

This form of disrespect for the dead is also taken up in Where They Were Missed. Shortly after the husband of Saoirse's mother's friend has died the BBC besiege the house of the family filming them. "It's a disgrace, so it is, coming to juke at us like we're animals in a zoo, they've no respect, so they haven't, no respect at all', a relative of the deceased critises the journalists (Caldwell 38).

The media without doubt have a wide range of influence on people watching, reading, or listening to the news. A true, neutral and objective report is even for the most professional journalist a hard task. News coverage thus almost always bears the mark of the author. In the examples shown above the media even seems to lose its representative mode. The accounts of what has happened receive a touch of propaganda in order to fuel people's aversion towards the other community or the British government respectively. People who died guiltless suddenly become connected to terrorism.

That the media took their share in worsening the conflict is also stated by Alain Bairner. He stresses two schools of thought that treat the influence of the media in the conflict. One of them deals with the importance of propaganda made by the British government; the other one with the assistance of propaganda made by paramilitary activists and their supporters. Nevertheless, both have contributed to the persistence of the Northern Irish political crisis (Aughey and Morrow 173). In addition foreign news coverage is supposed to have added little to the crisis. "Instead, it is suggested that the local media in Northern Ireland have played a significant part in supporting the rival perspectives around which the politics of division have been centred" (ibid. 173). The expected neutrality of journalists and broadcasters has also lapsed as the observance of media actors has shown that they themselves very often were politically involved. Several factors such as the "economic context of media production, indirect censorship through intimidation and the threat of legal sanctions, direct censorship and, finally, self-censorship" are named by Bairner as reasons for non-detached news reports (ibid. 174ff). The British government thus partly made use of the press in their fight against terrorism. The "banning, censorship and delays in showing of over 100 television programmes about Northern Ireland between 1969 and 1993" have been the result of this policy (ibid. 175). 


\section{Conclusion and Outlook}

"It's not our business to turn Orange and Green into a sludgy brown", remarked one of the founding members of the cultural diversity programme ${ }^{40}$ in Northern Ireland (Crozier 38). Instead of mixing the cultural backgrounds of Catholics and Protestants the cultural diversity programme's aim in the first place was to join both parties in dialogue so that they could learn about the 'Other' but never "to overrule or eliminate difference" (ibid. 38). That a mutual understanding without giving up one's own identity is possible is also shown in the novels discussed. Although the protagonists have not participated and do not participate in any of the cultural diversity programmes they nevertheless develop, or already have developed, a certain degree of openness towards their fellow countrymen. By looking at different aspects that are important for Northern Irish identity, such as the Irish language, the postcolonial background, and the effects of war, it can be seen how characters are affected by both their past and present situations and how a new way in contemporary literature has been pursued. Models like Anderson's imagined community as well as more traditional models of the nation and Bhabha's theory of hybridity help to understand the building of communities as well as why some people become able to abandon old ways of thinking.

Hence, it becomes understandable why nationalism still is important to a great number of people as colonial aspects have been affecting the country. Characters like Aoirghe or Brian use this to make up great parts of their identities. Other characters like Johnny Mahon or Tony Larkin are proof of how far people were willing to go and even engaged in paramilitary activities. This is contrasted by the vision of Jake's 'New Irish' who can look very different as depicted by the three novels but who also leaves the old quarrels behind and turns to a brighter and more promising future. This model of the 'New Irish' can primarily be applied to Jake himself but also to Chuckie and their close circle of friends. Even Aoirghe at the end of the novel seems to have changed from the stereotypical nationalist to a more moderate type who is able to follow Jake on the path of new Irishness. Beyond the novel Eureka Street that has introduced the term of the 'New Irish', characters of this type can be found in both One by One in the Darkness and Where They Were Missed. Cate embodies the 'New Irish' because she both clings to her Catholic faith but also manages to lead her life free from restrictions. Saoirse inherits

40 As there had been no government initiatives to abolish the divisions between the Catholic and the Protestant community the Cultural Traditions Group was founded in 1988, which later was changed to the Cultural Diversity Group. The immediate aim of the group was to bring children of segregated schools together and give them the opportunity to meet members of the other community. Several programmes for shared projects were thus initiated. Also the "wider community" in the form of the family was not left out. Later various other courses to encourage mutual understanding were introduced like television and radio programmes, which promoted CDs and films. Also history societies, resident groups and women's and youth organizations were created (Crozier 36ff). 
both sides of the Troubles and therefore also has to deal with both facets of these personalities. She cannot take stands because she actually functions as a link between Catholic and Protestant fronts. Thus, Saoirse is the ultimate Northern Irish who represents in one person what the country consists of. She becomes the personified mosaic of Northern Ireland that does not blend orange and green into brown but that shines in both colours.

Education, for example, seems to be an important factor for change. All of the protagonists in Eureka Street, One by One in the Darkness, and Were They Were Missed are rather intelligent and educated people or in the case of Saoirse are on their way of becoming so. Education is no guarantee for tolerance and cultural openness but it is indicated that it certainly has helped in making Catholic and Protestant inhabitants equal in their social status. The aspect of education therefore would be a point for further investigation. It might be of interest at this point to pay attention to changes in numbers of graduates obtaining a university degree or a higher training. It also would be worthwhile to examine the role of education in paramilitary groups and to find out whether people in the IRA, UVF and other groupings were of mixed educational backgrounds or if a tendency to higher or lower school-leaving certificates can be observed.

In addition to this economic aspects are worthy to examine as well. During the 1970s and 1980s Northern Ireland was affected by high unemployment rates and thus it should be looked at the correlations between unemployment and the readiness to join paramilitary groups, if there are any. As it turned out, up until now peace has been rather permanent. Yet, one must not forget that time and again splinter groups are trying to destabilise the peace by planting bombs and planning other violent attacks as in the Lurgan occurrence. Although these appear to be in the minority the danger of a new escalation always poses a possible threat to the people. If there were indeed correlations between job loss and the arising of propensity to violence new financial crises in the future could destabilise the balance or even revive the bygone status.

It remains yet to be seen whether the images of the 'New Irish' will become manifest in society and gradually eliminate stereotypes of unionist and nationalist activists or whether it will remain on the fringes of society. Concerning literature it is also fascinating to see what will come after the 'New Irish'. Falling back to stereotypical descriptions of IRA killers and UVF butchers is certainly not a desirable goal once these new hybrid images were opened up by contemporary novelists. 


\section{Appendix}

\section{Summary of Discussed Texts}

\section{Robert McLiam Wilson, Eureka Street (1996)}

Eureka Street tells the stories of the Catholic Jake Jackson and one of his best friends, the Protestant Chuckie Lurgan. The setting is Belfast around the time of the ceasefires of 1994. Left by his English girlfriend Sarah who has had an abortion Jake is constantly looking for love. In the beginning he is having a short affair with the waitress Mary who is the fiancée of the RUC officer Paul. Paul finds out about Jake and one night appears at his door beating him up. Jake refrains from reporting Paul, however, because he understands Paul's motivation being merely out of jealousy. Although having studied politics in London Jake works for a repossession company together with the two Protestants Hally and Crab. He does not like the task and his brutal workmates, quits and starts working on a construction site. Meanwhile Chuckie falls in love with the American Max who he has met in a bar. Max came to Northern Ireland because her father was shot there. Working as a diplomat he was denied the chance to bring peace to the North and was killed almost instantly as soon as he had set foot on Northern Irish ground. During a double date with Max and Chuckie, Jake gets to know Max's friend Aoirghe, a radical defender of Irishness, and a dispute breaks out between them because Jake is bored with this "bullshit" as he calls it. It comes to various quarreling encounters between Jake and Aoirghe during the course of the novel. Being fed up with having no money Chuckie decides to set up a business himself. By constantly cheating on people in the most artistic manners he achieves his goal and becomes immensely rich. Seeking help from a financial adviser he meets Luke Findlater who, overwhelmed by Chuckie's skill to persuade people to give him money, wants to work for him assisting him expanding his business. Later also Jake joins Chuckie's business. The novel contains manifold strands of plot. The reader thus also learns about Chuckie's mother Peggy, her encounter with a bomb explosion in the city centre and her love relationship with her neighbour and old friend Caroline. Furthermore, Jake meets the twelve-year-old Roche, a kid from the West Belfast. Because he avoids school and comes from a home that reminds Jake of his own past he feels kind of responsible for Roche although he is crept over with fear that people might think him to be a paedophile. Throughout the novel people keep seeing the letters OTG being sprayed across Belfast wondering what it might mean. During a business trip to America the OTG signs become even handy for Chuckie. He gets invited to a TV show in which also Jimmy Eve, a man showing some similarities to the Irish republican politician Gerry Adams, is supposed to talk. In another following TV show Chuckie loses himself in his talking and even 
acknowledges plans of setting up his own non-sectarian political party, which he would like to call OTG. In the end everybody has found love, mostly in the opposite of his or her own world view.

\section{Deirde Madden, One by One in the Darkness (1996)}

One by One in the Darkness like Eureka Street is set in 1994 shortly before the IRA ceasefire. It deals with the lives of the sisters Helen, Cate and Sally Quinn and their mother Emily who lost their beloved father and husband Charlie Quinn in a sectarian murder. The story begins with Cate visiting her family in the Northern Irish countryside. Cate herself is living in London working for a fashion magazine. Actually her name is spelled with a ' $\mathrm{K}$ ', Kate, but she has changed it to Cate because this seems to sound less Irish in her eyes. The reason for her visit is that she is having a baby, which comes as a shock for her mother. Cate keeps it a secret that she decided to have the baby on purpose although being unmarried and with no prospect to marry the father in the future. Sally is working as a teacher for the local primary school, the same school the three sisters went to themselves. She is the only one who has almost continuously stayed near their home and who was there to help their mother through her bereavement. Helen by contrast works as a solicitor who is specialised in terrorist cases defending IRA men. Although she chose this career to help those unjustly accused, one of her current cases somehow unnerves her. She has to defend Oliver Maguire, a young man in his twenties, who is accused of having murdered a taxi driver. Worst of all she believes he really did it. All three of the sisters are living single lives. The present story is undercut with remembrances of the sisters and their mother's past. Gradually the reader learns about the girls' childhood in the 1960s and 1970s and about their relatives, especially their uncle Brian and uncle Peter. Although the sisters were still too young to fully understand the dimension of the outbreak of the Troubles they remember discussions about politics and the civil rights marches. While Brian was often defending some of the IRA tactics Charlie and Peter always were against violence in any form and strongly condemned the sectarian killings on both sides. On top Peter did not believe in any of the religious principles, neither Catholic nor Protestant. The readers also learn how the British Army invaded their neighbourhood and their homes and made them feel like strangers in their own country. During the course of the novel the exact circumstances of their father's death is also revealed. While waiting for his brother Brian in the latter's kitchen two masked men stormed the house and shot him mistaking Charlie for Brian. In the end Emily slowly begins to accept the baby and they all look forward to a better future for "nothing can ever be so bad again" as what has happened in the past to them. 
Lucy Caldwell, Where They Were Missed (2006)

Where They Were Missed is told in two parts by Saoirse Pentland. The first part is set in the 1970s during the first heavy unloading of the Troubles in Belfast. Saoirse is six by then, her sister Daisy is only four. Their mother Deirdre, originally an O'Conor, is from the Gaeltacht in the South of Ireland. Their father by contrast is a Protestant Northerner working for the RUC. Told through the eyes of a child the readers learn how the girls' mother despairs more and more of the conflict arising around them as well as their father's role in the game. Having a Catholic mother Saoirse and Daisy are treated as outsiders in their Protestant neighbourhood. One day Daisy gets hit by an exploding bomb in their street. She succumbs to her injuries in the hospital. This breaks Deirde completely and she decides to bring Saoirse to her sister Bernadette and her husband Brendan in the South. The second part is set ten years later during the 1980s. Saoirse is 16 by then, soon turning 17 and living in Gweebarra Sands with her aunt and uncle. Although her aunt strongly disapproves of it Saoirse dates Johnny Mahon who later turns out being involved in terrorist activities. Aunt Bernadette is always concerned that Saoirse might end up an alcoholic as her mother did. Saoirse does not know where her mother is currently situated and she begins to ask question about her disappearance. Meanwhile her father has moved on from the past and is awaiting a baby. He is still living in the North and visits Saoirse from time to time. He tells Saoirse how he met her mother in 1968 in Derry during the Civil Rights Marches. This fuels Saoirse's appetite to learn more about the past and she searches the local newspaper archives for material. She is rewarded with a picture showing her mother in 1967 at one of the marches. When she asks her father for more information he also tells her about her Protestant background. Saoirse's great-grandpa was an Orangeman in the $36^{\text {th }}$ Ulster Division and was killed on the Somme. He will not tell her more about her mother's whereabouts, however. Aunt Bernadette finally tells her her mother's story and arranges a meeting. Deirde lives in La Retraite, a place run by nuns where she has found peace. She talks to Saoirse but it becomes clear she is still having problems dealing with the past and she cannot really open up towards Saoirse. In the end Saoirse decides to travel up north to visit her father and her little baby sister. She makes a detour, however, to see the places of their parents' and her own past driving through Derry and visiting places of her childhood. 


\section{Bibliography}

Primary Literature

Caldwell, Lucy. Where They Were Missed. London: Penguin Books, 2007.

Madden, Deirdre (1997). One by One in the Darkness. London: Faber and Faber.

McLiam Wilson, Robert (1998). Eureka Street. London: Vintage.

Woolf, Virginia (2003). Mrs Dalloway. London: Collector's Library.

Secondary Literature

Anderson, Benedict (2006). Imagined Communities. London: Versobooks.

Ashcroft, Bill, Gareth Griffiths and Helen Tiffin (1989). The Empire Writes Back. London: Routledge.

Aughey, Arthur and Duncan Morrow (Ed.) (1996). Northern Ireland Politics. London: Longman Group Limited.

Barker, Chris (2000). Cultural Studies: Theory and Practice. London: SAGE.

Bhabha, Homi K. (1994). The Location of Culture. London: Routledge.

- (1998): “Culture's In-Between.” Questions of Cultural Identity. Ed. Stuart Hall and Paul du Gay. London: Sage Publications, 53-60.

Boal, Frederick W. and David N. Livingstone (1984). "The Frontier in the City: Ethnonationalism in Belfast.” International Political Science Review / Revue Internationale de Science Politique Vol. 5, No. 2, Freedom and Boundaries 161-179.

Chríost, D. MacGiolla (2000). The Irish Language and Current Policy in Northern Ireland. Irish Studies Review. 8, 45-55.

Crozier, Maurna (2004). "Pre-Political Groundwork and Cultural Identity: the Northern Ireland Experience." Nationalism and Multiculturalism: Irish Identity, Citizenship and the Peace Process. Ed. Andrew Finlay. Münster: LITVerlag, 33-42.

Delanty, Gerard (2004). "From Nationality to Citizenship: Cultural Identity and Cosmopolitan Challenges in Ireland." Nationalism and Multiculturalism: Irish Identity, Citizenship and the Peace Process. Ed. Andrew Finlay. Münster: LIT-Verlag, 183-206. 
D’hoker, Elke (2005) “'Ripley Irish British Bogle' and 'The New Irish': Hybrid Identities in the Fiction of Robert McLiam Wilson.” Belgian Journal of English Language and Literature 3, 23-34.

Doherty, Paul and Michael A. Poole (1997). "Ethnic Residential Segregation in Belfast, Northern Ireland, 1971-1991.” Geographical Review, Vol. 87, No. 4, 520-536.

Donnelly, Brendan. "North." The Irish Review 4 (1988): 87.

Döring, Tobias (2008). Postcolonial Literatures in English. Stuttgart: Klett UniWissen.

Easthope, Antony (1998). Bhabha, Hybridity and Identity. Textual Practice 12, 341-348.

Fanon, Frantz (1968). The Wretched of the Earth. New York: Grove.

Farquharson, Danine (2005). "The Language of Violence in Robert McLiam Wilson's Eureka Street.” New Hibernia Review / Iris Éireannach Nua, 9, 65-78.

Gallagher, A.M. (1988). "Identity and Ideology in Northern Ireland: A Psychological Perspective." The Irish Review 4, 7-14.

Gillespie, Gordon (2008). Historical Dictionary of the Northern Ireland Conflict. Lanham, Maryland: Scarecrow Press.

Gribben, Arthur (1990). "Táin Bó Cuailnge: A Place on the Map, a Place in the Mind.” Western Folklore, Vol. 49, No. 3, 277-291.

Grossberg, Lawrence (1998). "Identity and Cultural Studies: Is That All There Is?” Questions of Cultural Identity. Ed. Stuart Hall and Paul du Gay. London: Sage Publications, 87-107.

Hall, Stuart (1998). "Who Needs 'Identity?” Questions of Cultural Identity. Ed. Stuart Hall and Paul du Gay. London: Sage Publications, 1-18.

- (1999): “Cultural Identity and Diaspora." Colonial Discourse and Post-Colonial Theory, A Reader. Ed. Patrick Williams and Laura Chrisman. New York: Harvester Wheatsheaf, 392-403.

Henry, Alison (1995). Belfast English and Standard English. Dialect Variation and Parameter Setting. Oxford: Oxford University Press.

Hickey, Raymond (2007). Irish English. Cambridge: Cambridge University Press.

"Home Rule." The New Encyclopedia Britannica. 15 th ed. 6 ${ }^{\text {th }}$ vol. (2007). 23-24.

Imhof, Rüdiger (2002). A Short History of Irish Literature. Stuttgart: Klett.

"Ireland." The New Encyclopedia Britannica. 15th ed. vol. 21 2007. 997-1018.

Irelandstory. Ed. Wesley Johnston, Patrick Abbot. 2001. March 1998. <http://www.wesleyjohnston.com/users/ireland/maps/towns/belfast_religi on.gif $>$, http://www.wesleyjohnston.com/users/ireland/maps/towns/der ry_religion.gif 
"Irish Republican Army." The New Encyclopedia Britannica. 15 $5^{\text {th }}$ ed. vol. 6. 2007. 385-386.

Jahn, Manfred (2005). "Narratology: A Guide to the Theory of Narrative." English Department, University of Cologne. 28 May 2005 http://www.unikoeln.de/ ame02/pppn.htm.

Keating-Miller, Jennifer (2009). Language, Identity and Liberation in Contemporary Irish Literature. Basingstoke: Palgrave Macmillan.

Kennedy-Andrews, Elmer (2003). Fiction and the Northern Ireland Troubles since 1969: (De-) Constructing the North. Dublin: Four Courts Press.

- (2006): "The Novel and the Northern Troubles." The Cambridge Companion to the Irish Novel. Ed. John Wilson Foster. Cambridge: Cambridge University Press, 238-258.

Kerrigan, John (2008). Archipelagic English: Literature, History, and Politics 1603-1707. Oxford: Oxford University Press.

Kosok, Heinz (1990). Geschichte der anglo-irischen Literatur. Berlin: Erich Schmidt Verlag.

Longley, Edna and Declan Kiberd (2001). Multi-Culturalism: The View From the Two Irelands. Cork: Cork University Press.

Mac Póilin, Aodán (1996). "Aspects of the Irish Language Movement in Northern Ireland." Watching One's Tongue, Aspects of Romance and Celtic Languages. Ed. Máiréad Nic Craith. Liverpool: Liverpool University Press, 13762.

- (1999): "Language, Identity and Politics in Northern Ireland." Ulster Folklife 45, 108-132.

Maguire, Gabrielle (1987). "Language Revival in an Urban Neo-Gaeltacht." Third International Conference on Minority Languages: Celtic Papers. Ed. Gearóid Mac Eoin, Anders Ahlqvist and Donna O hAodha. Clevedon: Multilingual Matters LTD, 72-88.

Mallon, Seamus and Éamon Phoenix (2003). Nationalism in Northern Ireland. From Partition to the Belfast Agreement. A Political Perspective / An Academic Perspective. Dublin: IBIS Working Paper No. 29.

McCall, Cathal (1999). Identity in Northern Ireland: Communities, Politics and Change. Basingstoke: MacMillan Press.

McGrattan, Cillian (2010). Northern Ireland 1968-2008. The Politics of Entrenchment. Basingstoke: Palgrave MacMillan.

Miller, David (1994). Don't Mention the War: Northern Ireland, Propaganda and the Media. London: Pluto Press.

Mitchel, Patrick (2003). Evangelism and National Identity in Ulster 1921-1998. Oxford: Oxford University Press. 
Mitchell, Claire (2005). "Behind the Ethnic Marker: Religion and Social Identification in Northern Ireland." Sociology of Religion. Vol. 66, No. 1, 3-21.

- (2006): Religion, Identity and Politics in Northern Ireland: Boundaries of Belonging and Belief. Aldershot, Hants: Ashgate.

Morris, John (1993). "Introduction: On Stereotypes and Stereotyping." Exploring Stereotyped Images in Victorian and Twentieth-Century Literature and Society. Ed. John Morris. Lewisten: Mellen 1-26.

Morris, Richard (Ed.) (1877). The Complete Works of Edmund Spenser. The Globe Edition. London: Macmillan.

Mulholland, Marc (2002). Northern Ireland. A Very Short Introduction. Oxford: Oxford University Press.

Nelde, Peter Hans (1997). "Language Conflict." The Handbook of Sociolinguistics. Ed. Florian Coulmas. Oxford: Blackwell, 285-300.

Nic Craith, Máiréad, and Ian Shuttleworth (1996). "Irish in Northern Ireland: The 1991 Census.” Watching One's Tongue, Aspects of Romance and Celtic Languages. Ed. Máiréad Nic Craith. Liverpool: Liverpool University Press, 163175.

Nic Craith, Máiréad (2003). Culture and Identity Politics in Northern Ireland. Basingstoke: Palgrave Macmillan.

- (2004):“CConceptions of Equality: The Case of Northern Ireland.” Nationalism and Multiculturalism: Irish Identity, Citizenship and the Peace Process. Ed. Andrew Finlay. Münster: LIT-Verlag, 111-130.

"Northern Ireland Political Parties." Northern Ireland Elections. Ed. Nicholas Whyte. 28 February 2007. <http://www.ark.ac.uk/elections/gparties.htm>.

Patten, Eve (1995). "Fiction in Conflict: Northern Ireland's Prodigal Novelists." Peripheral Visions: Images of Nationhood in Contemporary British Fiction. Ed. Ian A. Bell. Cardiff: University of Wales Press, 128-148.

Pelaschiar, Laura (2000). "Transforming Belfast: The Evolving Role of the City in Northern Irish Fiction.” Irish University Review Vol. 30, No. 1, Special Issue: Contemporary Irish Fiction, 117-131.

"Penal Laws." The New Encyclopedia Britannica. 15th ed. vol. 9. 2007. 254.

Renan, Ernest (1994). “Qu'est-ce qu'une nation?” Nationalism. Ed. John Hutchinson and Anthony D. Smith. Oxford: Oxford University Press, 17-18.

Rolston, Bill (1998). Murals of War and Peace. Belfast: Beyond the Pale Publications.

"Royal Ulster Constabulary." The New Encyclopedia Britannica. 15th ed. vol. 10. 2007. 220.

Ruane, Joseph and Jennifer Todd (1996). The Dynamics of Conflict in Northern Ireland: Power, Conflict and Emancipation. Cambridge: Cambridge University Press. 
Said, Edward W. (1994). Culture and Imperialism. New York: Vintage Books. "Scythians." The New Encyclopedia Britannica. 15th ed. vol. 10. 2007. 576-577.

Sharkey, Sabina (1997). "A View of the Present State of Irish Studies." Studying British Cultures: An Introduction. Ed. Susan Bassnett. London: Routledge, 113-134.

Storey, Michael (1998). "Postcolonialism and Stories of the Irish Troubles." New Hibernia Review 2, Vol. 3, 63-77.

Tabouret-Keller, Andrée (1997). "Language and Identity." The Handbook of Sociolinguistics. Ed. Florian Coulmas. Oxford: Blackwell, 315-326.

Tigges, Wim (1994). "Facing the Truth: Two Belfast Novels." Babylon or New Jerusalem? Perceptions of the City in Literature. Ed. Valeria Tinkler-Villani. Amsterdam: Rodopi, 179-193.

Tygstrup, Frederik (1994). "The Literary City: Between System and Sensation." Babylon or New Jerusalem? Perceptions of the City in Literature. Ed. Valeria Tinkler-Villani. Amsterdam: Rodopi, 225-238.

“Ulster Volunteer Force." The New Encyclopedia Britannica. 15 th ed. 12 $2^{\text {th }}$ vol. 2007. 117.

Von der Thüsen, Joachim (1994). "The City as Metaphor, Metonym and Symbol." Babylon or New Jerusalem? Perceptions of the City in Literature. Ed. Valeria Tinkler-Villani. Amsterdam: Rodopi, 1-11.

Waddell, Neil and Ed Cairns (1991). "Identity Preference in Northern Ireland." Political Psychology vol. 12, No. 2, 205-213.

Weber, Max (1994). “The Nation.” Nationalism. Ed. John Hutchinson and Anthony D. Smith. Oxford: Oxford University Press, 21-25.

White, Jerry (1999). "Europe, Ireland, and Deirdre Madden." World Literature Today: A Literary Quarterly of the University of Oklahoma 73.3, 451-460. 

Sonja Lehmann

\section{Transnational Identities in Michael Ondaatje's Fiction}

\section{Introduction: Transnational Identities in Michael Ondaatje's Fiction}

Ever since his 1982 fictionalized memoir Running in the Family, Michael Ondaatje's fiction has been characterized by a concern for the lives of migrants. More precisely, it predominantly focuses on the questions of identity that result from the characters' migrations. Thus, the narrator of Running in the Family travels to Sri Lanka trying to come to terms with how his long neglected Sri Lankan heritage influences his identity. Anil, the protagonist of Anil's Ghost, faces similar questions and likewise returns to her country of origin to reconnect with her past in wartorn Sri Lanka. In the Skin of a Lion's hero, Patrick Lewis, undertakes a more metaphorical kind of migration by becoming part of Toronto's Macedonian diaspora in the first half of the $20^{\text {th }}$ century, which is contrasted with the Macedonian Nicholas Temelcoff's immigration to Canada. Both of them accordingly have to adjust to their new environment and adjust their self-understanding in the process. The English Patient's eponymous protagonist calls himself an "international bastard" (The English Patient 188) and in a somewhat questionable move extends this label to the Indian sapper, Kip, who like the patient is part of a multinational commu- 
nity in Italy at the end of World War II, but has a quite different understanding of identity and belonging. Finally, Anna, the central character of Divisadero, sees her life as a network that surpasses the boundaries between nations, characters, fiction and reality, and even time. As a result "[e]verything is collage" (Divisadero 16), even Anna's identity, as she imagines herself to belong to and identifies with all the different story lines in the novel.

While all these texts differ greatly in plot and setting they nevertheless depict a set of characters whose identities are equally influenced by multiple affiliations and affinities that cut across national and cultural boundaries. Even though Ondaatje's fiction stresses that such identities are not always easy to live with, especially in conditions where one's environment does not welcome them, there is still almost always some sense of reconciliation in the texts which makes simultaneously taking part in several cultures and nations seem possible. The sense of loss and displacement that all characters at one point feel as a result of their migrations mostly gives way to at least a little hope for a more positive and empowering sense of belonging to several places.

This sets Ondaatje's fiction apart from other forms of postcolonial migrant writing which often emphasizes the displacement and in-betweenness of migrants. Accordingly, Pico Iyer states, "Ondaatje is harder to place than many of his fellow exile writers, and there is always a sense in his books that he is trying to create a new kind of mongrel fiction that leaves old categories behind" ("Mongrel Fiction" no pag.). Iyer presents an interesting hypothesis here that I will attempt to answer with my thesis: whether Ondaatje's fiction is a new kind of migrant writing that requires a different theoretical approach compared to more traditional migrant literature.

The topic of transnational identities is ideal for this endeavour since transnational migration is a rather new phenomenon that is not well established in theories of postcolonial migrant writing yet. However, transnational theories appear very apt to describe the workings of Ondaatje's fiction since they emphasize simultaneity, the dissolution of boundaries and the importance of spaces in the formation of transnational identities. All these aspects can repeatedly be found in Ondaatje's writings as my brief introduction to the works to be analyzed in this study has already shown.

I will therefore at first summarize how identity is dealt with in postcolonial theory and compare this to sociological and anthropological studies on transnational migration in order to propose a theory on the formation of transnational identities and analyze Ondaatje's fiction in terms of this. This should not only prove useful for an analysis of the treatment of identities in Ondaatje's works but also point out how cultural globalization has affected the kind of literature that is produced in our times. 


\section{Migration, Belonging and Identity}

\subsection{Migrant Writing and Contemporary International Migration}

Migration is a recurrent topic in postcolonial literature. This is hardly surprising since many of the most prominent postcolonial authors are migrants themselves, such as Salman Rushdie, Ben Okri, Jamaica Kincaid, Michael Ondaatje and many others. However, migration is not only the matter of many literary works but it also a source for of theoretical reflections on the migrant condition. As John McLeod says, "[t]he experiences of migrancy and living in a diaspora have animated much recent postcolonial literature, criticism and theory" (207). Especially its effects on migrants' identities are explored extensively. These identities are generally seen as "doubled, or hybrid, or unstable" (Barry 196) and the protagonists of migrant literature are often portrayed as being unsure of who they are, where they belong and how to reconcile their location between several cultures and countries. This perception of identities is closely connected with the notions of place, displacement and exile in postcolonial theory. Bill Ashcroft, Gareth Griffiths and Helen Tiffin explain this in the following way:

A major feature of post-colonial literatures is the concern with place and displacement. It is here that the special post-colonial crisis of identity comes into being; the concern with the development or recovery of an effective identifying relationship between self and place. (Empire 8)

Their emphasis on the interrelationship of "place" and "self" is striking. It implies that in order to not suffer from a crisis of identity one has to somehow be connected to and identify with the place one inhabits. To be separated from this place - or to be otherwise alienated from it through the effects of colonization - consequently is not only a change of location but is also accompanied by a sense of displacement and a "crisis of identity". Displacement hence appears to be a necessary consequence of migration which is therefore also frequently referred to as a form of "exile", "from either a literal homeland or from a cultural and ethnic origin" (Ashcroft, Griffiths and Tiffin, "Exile" 92). To say where such migrants and diasporeans are at home is considered very difficult: "Where is the place of 'home' to be located for such people or such groups? In the place of birth (nateo), in the displaced cultural community into which the person is born, or the nation-state in which this diasporic community is located?" (Ashcroft, Griffiths and Tiffin, "Exile" 93; emphasis in original).

This sentiment is most famously expressed by Rushdie in his essay "Imaginary Homelands" in which he refers to migrant writers as "exiles or emigrants or expatriates, [who] are haunted by some sense of loss, some urge to reclaim, to look back" which leads to "physical alienation" and "profound uncertainties" (10). He emphasizes that this alienation does not only apply to the country of immigration 
but also to the country left behind which turns into an "imaginary homeland" that has little to do with the reality anymore (10). Rushdie's migrant seems perpetually stuck in-between these two while not belonging to either one. The migrant relies on his imagination to achieve a sense of belonging, but this turns out to be "notoriously unreliable and capricious" and as a consequence a "plenitudinous sense of home" is moved out of reach because "a sense of displacement always remains" (McLeod 211). Stuart Hall sums this up concisely by saying, "Migration is a one way trip. There is no 'home' to go back to" (qutd. in Chambers 9).

Accordingly, the migrant is considered to be neither here nor there. He is alienated from his origins but does not fit in with his new environment either. His sense of belonging to a place is either disturbed or lost altogether and he is not sure of his identity anymore as a result of this. Even scholars such as Paul White who admit to the possibility that migrants can actually live in several "worlds" (3) still come to the conclusion that their experience is nevertheless marked by "dislocation" and "alienation" (6) and that "amongst all the literature of migration the highest proportion deals in some way with ideas of return, whether actualised or remaining imaginary" (14). Iain Chambers even claims that "[ $t$ he migrant's sense of being rootless, of living between worlds, between a lost past and a nonintegrated present, is perhaps the most fitting metaphor of this (post)modern condition" (27).

More recent works on postcolonial literature and theory still adhere to that view. For example, Elleke Boehmer describes migrants as people who "live as minorities, in states of unbelonging" (226). ${ }^{1}$ Echoing Ashcroft, Griffiths and Tiffin she declares that "[c]ultural expatriation is now widely regarded as intrinsic to the postcolonial literary experience" (226). Of the migrant writer she says that at present he or she is "is more likely to be a cultural traveller, or an 'extra-territorial', than a national" who most often lives in a Western country and simultaneously still keeps some "connections" to "a national, ethnic, or regional background" but whom she clearly sees as not belonging to either country (Boehmer 227). Diasporic writing by writers of the next generation who did not even migrate themselves falls in the same category for her, being "a literature that is necessarily transplanted, displaced" and even though situated in the West still not completely part of it (Boehmer 230; emphasis in original). McLeod likewise speaks of a "perilous intermediate position that both migrants and their children are deemed to occupy" because of which they are "unable to indulge in sentiments of belonging to either place" (214; emphasis in original). The repercussions of migration thus even extend to people who did not migrate themselves and it seems that having a cultural background, which spans several nations is enough to evoke inevitable feelings of dislocation.

1 Boehmer's study was admittedly first published in 1995, however the revised edition of 2005 nevertheless still emphasizes the in-betweenness of the migrant experience. 
When prominent migrants such as Rushdie or Edward Said describe their migrant experience as not only alienating but also empowering and full of new possibilities (Rushdie 15; Said xxvii), this is often criticized as an elitist attitude. For example, Boehmer states that such feelings only apply to a small number of welleducated migrants who profited from moving to a "more comfortable location in the wider neo-colonial world" (231; see also Griem 269). She further claims that such migrant literature is characterized by "historical "weightlessness" as the following quote details:

In summary, postcolonial migrant literature can be described as a literature written by élites, and defined and canonized by élites. It is writing which foregrounds and celebrates a national or historical rootlessness - what the migrant Czech writer Milan Kundera might call lightness - sometimes accentuated by political cynicism. Yet, viewed from a different angle, weightlessness could also be interpreted as an evacuation of commitment, or as a dilution of those fiery concerns which originally distinguished postindependence writing. To define a literature of migrant floating as the culmination of the postcolonial must inevitably represent a diminution in a long tradition of self-consciously political writing. (Boehmer 233)

For Boehmer, current postcolonial migrant writing is clearly inferior to earlier postcolonial literature that was engaged with national concerns (Boehmer 225). For her, not showing a rootedness in specific nations appears to equal a transition to apolitical and weightless writing. ${ }^{2}$ Moreover, she claims, its weightlessness is what makes this literature much more popular in the West than postcolonial writing with "a more national focus" (Boehmer 233). This echoes a general criticism towards recent postcolonial literature that it is supposedly marked by inauthenticity (Innes 197-98) and "centred on, and largely catering to, the West" (Huggan, qtd. in Innes 199). Such postcolonial writing is accused of being of little importance to readers in the authors' countries of origin since its focus on topics such as hybridity and alienation through migration supposedly does not concern nonWestern readers without a migrant background. However, it is assumed that this particular subject matter in turn opens up possibilities of publication and recognition in the West (Huggan, qtd. in Innes 198). While a critique of such selective publishing and funding is certainly not unjustified, C.L. Innes doubts the generality of such claims by pointing out that Chinua Achebe's Things Fall Apart, which has a clear national focus and is nevertheless a canonical postcolonial text, is also

2 Boehmer nevertheless admits that there are political cosmopolitan fictions, naming Arundhati Roy's The God of Small Things as one of them, and says that she overdramatized the situation in the above quote to point out the "basic distinctions" (233). 
most often sold to readers in Africa (199) so that the choice of topics in recent postcolonial writing seems to be more complex. ${ }^{3}$

Michael Ondaatje's writing has also been included in this debate. On the one hand, his fiction has been described as being marked by "a series of international influences where cultures blend into one another with the continuous movement and accidental meetings of peoples across the globe" (Bowers 153). On the other hand, Ondaatje could easily be found guilty of weightlessness and lack of commitment because of that and his work be seen as a celebration of rootlessness. In fact, Arun P. Mukherjee accuses him of exactly this and asks, "[H] ow has Ondaatje managed to remain silent about his experience of displacement or otherness in Canada when it is generally known to be quite a traumatic experience?" (50). Mukherjee unites both strands of criticism towards postcolonial migrant writing in this: Ondaatje is seen guilty of betraying his Sri Lankan roots because he does not write about his alienation in the West. In addition, Mukherjee's criticism that Ondaatje does not address typical migrant concerns oddly emphasizes the stereotypical restriction of acceptable topics in literature by migrants. It is surprising that Mukherjee does not also explicitly accuse him of being elitist which would not be far-fetched considering Ondaatje's celebration of his family as part of a Ceylonese elite in Running in the Family. ${ }^{4}$ In any case, Mukherjee's critique exemplifies the rigid nature of the debate about migrant writing in postcolonial literary studies: writers like Ondaatje who do not adhere to an accepted way of writing about the experience of migration are ruthlessly criticized. This is not to say that it is justified to read such a literature as a celebration of the effortless blending of different cultures as Maggie Ann Bowers appears to be doing. Neither extreme does these texts justice. It appears that there are texts that do not fit the conventional categorization and that new perspectives are needed to analyze such writing.

In order to escape these dichotomous approaches it is necessary to focus on the subtleties of these texts and to consider literature from a cultural studies perspective and not only a political one. As White argues, literature echoes "the circumstances that lead to its creation" (15). Debbie Lisle also supports this claim, stating "a cultural product cannot be understood in isolation from its social and political environment" (17). This necessarily leads to the question of whether this kind of migrant literature was created in a different context altogether in which there was no dominant "traumatic experience" and that it maybe does not celebrate the rootlessness of a displaced, unbelonging migrant but that it reflects de-

3 For a discussion of the influence of market forces on topics in and publishing and funding of minority literatures see for example Mahlete-Tsigé Getachew's essay "Marginalia: Black Literature and the Problem of Recognition" (332 ff.), and Barbara Godard's analysis of the marketing of minority literatures in Canada (226 ff.).

4 Admittedly, Mukherjee only addresses the lack of attention to migrant concerns in Ondaatje's early writing. While Ondaatje's later texts increasingly focus on migrants and their questions of displacement and identity, he nevertheless still avoids talking directly about his immigration experience so that Mukherjee's criticism would most likely still apply. 
velopments of the time of its creation. One must therefore transcend disciplinary boundaries and examine this literature's background: contemporary migration.

International migration is continually on the rise. The United Nation's Department of Economic and Social Affairs listed an estimated 191 million international migrants in its 2005 population stock database, which constitutes an increase of 115 million since 1965 (United Nations, "Estimated"). In other words, at present three percent of the world's population are international migrants which makes it the highest since the beginning of the UN's recordings (United Nations, "International Migrants"). The number of migrants would "constitute the fifth most populous country in the world" ("Global Estimates"). Accordingly, the International Organization for Migration calls migration "one of the defining issues of the twenty-first century" since "more people are on the move today than an an other point in human history" ("About Migration"). Scholars predict that international migration will continue to rise in the future (Hollifield 77; Castles and Miller 8) and have even gone as far as calling the present age "The Age of Migration" (Castles and Miller). Migration clearly is an important aspect of more and more people's lives.

Necessarily, such a huge number of migrants will lead to diverse migrant experiences. For a start, there are many different incentives for migration, which do not always make it a voluntary endeavour. Many of today's international migrants are refugees ("Global Estimates"). An even larger number of people will have migrated because of economic necessity, which accounts for the fact that 15-20 percent of all migrants are "unauthorized migrants" and also the "large increase" of migrants to Western countries ("Global Estimates"). Such migrants might certainly be influenced by neocolonial tendencies as Boehmer indicated (231) and their negative experience may not be reflected in a migrant literature of a writer such as Rushdie who celebrates the positive aspects of his exile (s.a.). ${ }^{5}$ In addition, the influence of all these migrants on the countries of immigration must not be underestimated as Innes remarks (193). Thus, for example "Britishness" is altered to include aspects of the immigrants' culture (Innes 196). Insisting on the inevitable displacement and unbelonging of migrants seems dubious in this context.

I therefore agree with McLeod that "conventional ways we use to think about ideas such as 'belonging' no longer work" because they are based on "clearlydefined, static notions of being 'in place', firmly rooted in a community or a particular geographical location" (214). Nevertheless, I do not share his conclusion that migrants are always "in-between" for whom "[h]ome is a problematic concept" (216) because another trend in contemporary migration, namely the "[e]mergence of transnational migration" ("About migration"), considerably changes conceptions of home, identity and belonging for those affected by it so

5 The destructive influence of neocolonial forces is nevertheless not completely absent from recent migrant literature. Kiran Desai's The Inheritance of Loss and Hari Kunzru's Transmission, for example, are very critical of the neocolonial influences on contemporary migrants' lives. 
that there is no longer a focus on the in-betweenness and displacement of migrants but their transnational identities, which in turn is also reflected in migrant writing. To illustrate these changes it is, however, at first necessary to elaborate on the concept 'identity' and new transnational perspectives of migration.

\subsection{Identity}

Identity is a term notoriously difficult to define. As Rogers Brubaker and Frederick Cooper say, it "tends to mean too much (when understood in a strong sense), too little (when understood in a weak sense), or nothing at all (because of its sheer ambiguity)" (1). "As a tool for analysis, 'identity' thus becomes hardly usable because the concept has become so vague (Brubaker and Cooper 6). This stems mostly from the mingling of 'identity' as a "category of analysis" and as a "category of practice" with the latter comprising the usage of the term "by "lay" actors in some [...] everyday settings to make sense of themselves, of their activities, of what they share with, and how they differ from, others" (Brubaker and Cooper 4). Unfortunately, when it comes to analytic categories, the two categories are often mixed up which results in "an uneasy amalgam of constructivist language and essentialist argumentation" so that even many of those theorists who reject the notion of a fixed identity at the same time nevertheless use it as a practical category (Brubaker and Cooper 6$).{ }^{7}$ Some unravelling of the term 'identity' is therefore in order to make it usable as an analytical term.

To clarify the many different meanings that can be encompassed by 'identity' Brubaker and Cooper attempt to classify different types of it and finally differentiate between five "key uses" of 'identity' (6). I will quote three of them in full since they apply distinctly to the problematic formations of transnational identities that I am going to focus on and illustrate the complexity of the problem. These are defined as follows:

2. Understood as a specifically collective phenomenon, "identity" denotes a fundamental and consequential sameness among members of a group or category. This may be understood objectively (as a sameness "in itself") or subjectively (as an experienced, felt, or perceived sameness). This sameness is expected to manifest itself in solidarity, in shared dispositions or con-

6 "Strong" and "weak" here refer to understandings of the term 'identity' as "essentialist" or "constructivist" respectively (Brubaker and Cooper 2). "Strong" notions of identity thus presume that it is marked by "sameness over time or across persons" (Brubaker and Cooper 10) whereas "weak" notions describe it as "multiple, unstable, in flux, contingent, fragmented, constructed, negotiated" (Brubaker and Cooper 11). For the history of the change of usage of 'identity' see Brubaker and Cooper, 2-4.

7 Unfortunately this is also the case in postcolonial theory. I will discuss this below in connection with Bhabha's notion of hybridity. 
sciousness, or in collective action. This usage is found especially in the literature on social movements; on gender; and on race, ethnicity, and nationalism. In this usage, the line between "identity" as a category of analysis and as a category of practice is often blurred.

3. Understood as a core aspect of (individual or collective) "selfhood" or as a fundamental condition of social being, "identity" is invoked to point to something allegedly deep, basic, abiding, or foundational. This is distinguished from more superficial, accidental, fleeting, or contingent aspects or attributes of the self, and is understood as something to be valued, cultivated, supported, recognized, and preserved. This usage is characteristic of certain strands of the psychological (or psychologizing) literature, especially as influenced by Erikson, ${ }^{8}$ though it also appears in the literature on race, ethnicity, and nationalism. Here too the practical and analytical uses of "identity" are frequently conflated.

$[\ldots]$

5. Understood as the evanescent product of multiple and competing discourses, "identity" is invoked to highlight the unstable, multiple, fluctuating, and fragmented nature of the contemporary "self." This usage is found especially in the literature influenced by Foucault, post-structuralism, and postmodernism. In somewhat different form, without the post-structuralist trappings, it is also found in certain strands of the literature on ethnicity notably in "situationalist" or "contextualist" accounts of ethnicity. (Brubaker and Cooper 7-8; emphasis in original) ${ }^{9}$

The problem is obvious: all these definitions claim to stand for the term 'identity' but they clearly describe very different and even mutually exclusive things. While the second definition argues that 'identity' is something that always stays the same and never changes this is already negated to some extent in the third, which states that only some aspects never change. The fifth definition then defines 'identity' as not at all stable but as a constant process so that there appears to be hardly any sameness at all from one moment to the next, which clearly contradicts the second definition. It also becomes apparent that the use of identity with regard to nations is usually one that stresses continuity. It is thus clearly the kind of perception of identity which leads to the assumption that migration and its accompanying disruption of said sameness necessarily leads to a crisis of identity as previously mentioned.

8 Erik Erikson, mentioned in a previous passage as the theorist who "was responsible, among other things, for coining the term 'identity crisis"' (Brubaker and Cooper 2).

9 The first and fourth definitions stress the use of 'identity' as "the basis of social or political action" (Brubaker and Cooper 6) and to describe group solidarities that lead to "collective action" (Brubaker and Cooper 7-8) neither of which I will be concerned with in the following. 
Furthermore, 'identity' is used to describe group as well as individual conditions since definition two speaks of a "collective phenomenon" whereas definition five focuses on the "contemporary "self" and definition three unites both aspects. ${ }^{10}$ This is especially problematic as one's personal identity is often linked to a collective identity, such as nationality or a certain culture (Horatschek 276) but not necessarily in the same definition of identity. One can easily imagine that one admits the possibility that someone's personal identity is somewhat fluid as described in definition five but that they are part of a collective identity which stresses a "perceived sameness" among its members as in definition two. Yet, the term 'identity' is used for all of these different definitions alike so that if one comes across it in some theoretical text one can often only guess at which sense and which category is used and what exactly is meant by it.

To circumvent this confusing usage and have better analytical tools, Brubaker and Cooper therefore propose three groups of "alternative terms" which capture aspects that are generally covered by the term 'identity' (14). 'Identity' can thus stand for processes of "identification and categorization" (Brubaker and Cooper 14). This encompasses identification and categorization of oneself and of or by other people as well as "by powerful, authoritative institutions", for example a nation-state (Brubaker and Cooper 15). In this sense 'identity' appears to be mainly concerned with the act of naming or being named and the (self-) ascription of certain facts to an individual.

This is quite different from the second group under which Brubaker and Cooper subsume the terms "self-understanding and social location" (17). 'Selfunderstanding" is defined as "one's sense of who one is, of one's social location, and of how (given the first two) one is prepared to act" (Brubaker and Cooper 17). The emphasis on "social location" here is important since people define and understand themselves in relation to social connections of varying intensity surrounding them, for example via religious practices and other traditions (Brubaker and Cooper 17-18). This group differs from the first by stressing more "subjective" understandings people have about "themselves and their social world" (Brubaker and Cooper 17). It may, however, be influenced by identification and categorization by others and is not necessarily stable over time (Brubaker and Cooper 18). The second group therefore brings with it new facets of an individual's behaviour in relation to their environment and how they feel about themselves in relation to the place they inhabit in their social world. McLeod sums this

10 One might add that the condition described in the fifth definition is clearly not only used to describe individuals' identities but also that of larger groups. For example, Stuart Hall's definition of cultural identity describes it as "not a fixed essence at all, lying unchanged outside history and culture" but on the contrary as something which "is always constructed through memory, fantasy, narrative and myth. Cultural identities are the points of identification, the unstable points of identification or suture, which are made, within the discourses of history and culture. Not an essence but a positioning" (226; emphasis in original). Hall clearly speaks of a group phenomenon here. 
up succinctly: "Individual and collective identities are things which we fashion for ourselves to a degree; but they are also fashioned by others for us, whether we like it or not" (226).

Brubaker and Cooper's third group further stresses the aspect of interaction between oneself and others to form one's identity. It is made up of the terms "commonality", "connectedness" and "groupness" (Brubaker and Cooper 19). In Brubaker and Cooper's definitions commonality indicates having "some common attribute" while connectedness is meant to describe "the relational ties that link people" (20). Together these two can give rise to groupness, which is characterized by "the sense of belonging to a distinctive, bounded, solidary group" and is supposed to convey a stronger attachment than connectedness or commonality alone (Brubaker and Cooper 20). The focus of this last group is clearly on collective identities and attempts to explain what makes people feel that they belong to one specific group but not another and also the extent of such a sense of belonging as the interdependence of connectedness, groupness and commonality points out.

Brubaker and Cooper stress that none of the groups alone signifies what is usually covered by 'identity' (14). However, reversing their perspective, these three groups can be seen as building blocks of what is generally called 'identity.' In addition, cut down to their basics, they obviously address the very topics much migrant writing is concerned with when it speaks of migrants' problems with their identities: the sense of self, the relationship one has to the place one inhabits, and the sense of belonging to a bigger group one is a part of such as a specific culture or nation. In addition, the fact that 'identity' is not merely something that just is but also something that is ascribed to you by others will offer a useful tool for analyzing the more problematic aspects of transnational identities. Therefore, Brubaker and Cooper's alternatives to 'identity' are very helpful since they are much more specific and make it easier to focus on certain aspects that are usually rolled up in the term 'identity.' They furthermore also make it possible to speak of 'identity' in more than one definition without being forced to add lengthy qualifications of the term to specify what is meant. It is hence now possible to clearly analyse the problems that result from migration and transnationalism and be more specific than only speak of a crisis of identity or a changing sense of self.

Nevertheless, I am still going to speak of 'transnational identities' in the following and I will do this deliberately. I completely agree with Brubaker and Cooper that "[c]onceptualizing all affinities and affiliations, all forms of belonging, all experiences of commonality, connectedness, and cohesion, all self-understandings and self-identifications in the idiom of 'identity' saddles us with a blunt, flat, undifferentiated vocabulary" (Brubaker and Cooper 2). However, when it comes to the changes wrought by transnationalism and migration the term 'identity' is nonetheless useful as an umbrella term to sum up all the different processes that consequently occur in order to comprehend the magnitude of the phenomenon. There- 
fore, whenever the term 'identity' is used from now on it will denote the changes of all the above aspects of 'identity' combined.

\subsection{Identity and the Nation-State}

When speaking of transnational identities it is inevitable to think about nations first. After all, a transnational activity not only transcends the nation but it is also where they begin as people live in nation-states. However, a nation-state is not only a starting point for migratory movements, it can also function as a source of identity as the following quote by Steven Vertovec points out in which he describes a commonplace, more traditional understanding of the nation-state concept:

[A]s with the conventional model of the nation-state, some sense of identity is presumed to characterize a people; this identity/people is believed to be contiguous with a territory, demarcated by a border; within the border, laws underpin a specific social and political order or system; this social order which is conceived to be different from orders outside the border - both draws upon and reinforces the sense of collective identity. Identitiesborders-orders are legitimated and reproduced through a system of narratives, public rituals and institutions, educational materials, formal state bureaucracies and informal social relationships, written and unwritten regulations, sets of assumptions, and expectations of civility and public behaviour[.] ("Migrant Transnationalism" 158) 11

The nation-state here categorizes its members by imposing laws and social orders and by influencing them through education and expected norms. This categorization and identification in addition stresses the commonality of the people within the state and leads to the conclusion that people within the state differ from those outside its borders because those have different norms, rules and social behaviour. The nation-state's members accordingly develop a sense of belonging and are thus linked to their respective nation-state by "ties of sentiment" (Vertovec, "Migrant Transnationalism" 156). In more everyday terms, the nation-state becomes their home.

Ulf Hedetoft and Mette Hjort extensively reflect on the emotional implications of what it means to feel at home somewhere. Similarly to Vertovec they state that "home is where we belong, territorially, existentially, and culturally, where our own community is, where our family and loved ones reside, where we can identify our roots, and where we long to return to when we are elsewhere in the world"

11 Vertovec here sums up the findings of Civil Enculturation: Nation-State, Schools and Ethnic Difference in Four European Countries, a compilation of essays he edited along with Werner Schiffauer, Gerd Baumann and Riva Kastoryan. 
(Hedetoft and Hjort vii).12 The nation-state's relation to such notions becomes even clearer in Ulf Hannerz' definition of the term 'home.' He speaks of 'home' as being a "familiar social space because we have it quite well mapped - even the people we do not know personally act in more or less expected ways" (219). For him, it is marked by "relative transparency in social traffic" for the one whose home it is and to which, because of time spent there, we "develop a sense of belonging" (219). 'Home' in this sense is clearly marked by commonality with and connectedness to the people in one's social location. Because of this, being home is to experience a certain feeling of groupness and since this groupness is furthermore linked to a specific territory because of "identities-borders-orders", 'home' is located in the nation-state.

It is obvious that this groupness stems in part from the "narratives, public rituals and institutions" and so forth mentioned above. However, all this is not simply imposed by the nation-state in order to strengthen a "sense of collective identity" but the state also "draws upon" it according to Vertovec's definition. This implies that there is a "collective identity", which seems to precede and justify the formation of the nation-state. Ernest Renan refers to this when he stresses that a nation is made up of two aspects of which one is "a rich legacy of memories" and the other "present-day consent, the desire to live together, the will to perpetuate the value of the heritage that one has received" (19). These memories and heritage clearly indicate that the nation-state is accordingly not only understood as a person's home but also becomes an entity which encloses a group of people joined together by common traditions or a shared culture, which unites its members because its commonality stresses their similarities. This in turn allows them to connect to one another and evoke feelings of groupness. Since this groupness is, however, also confined to a specific geographic area, the nation-state thus becomes congruent with a specific culture, which can be seen best in the way the words 'nation' and 'nation-state' are used interchangeably (Brennan 45).

The nation-state thus has a powerful influence on people's sense of who they are and where they belong since according to such a definition it turns into an allencompassing source of all aspects of identity. After all, in this understanding of a nation, the nation-state is formed because its members already have a sense of collective identity prior to its formation which is strengthened after its formation because it then reiterates and reinforces what already brought this group together by identifying and categorizing its members. The inhabitants in turn can hardly escape being influenced in their self-understanding by these surroundings. It is therefore not surprising that it is frequently pointed out that in the twentieth century the nation came to be seen as home, and people's sense of belonging was generated by nation-states (J. Hall 55; Löfgren 259).

12 However, they admit that this definition only "delineates the contours of an ideal state of affairs" and that home and belonging are much more complicated in reality since the aforementioned notions can be in conflict with each other (Hedetoft and Hjort vii-viii). 
Nevertheless, it is also obvious that this understanding of the nation-state centres only on one very specific notion of identity, which is marked by commonality and sameness and disregards all other possibilities, which do not fit this theory and has been increasingly subject to criticism. Especially postcolonial and feminist critics have pointed out that such definitions of nation-states neglect to mention minorities and marginalized groups and construct a homogeneous view, which does not actually exist (Horatschek 276). Furthermore, it has been pointed out that from a historical perspective the existence of nation-states is a rather new phenomenon with its starting point located in Europe between the late eighteenth and early twentieth century (Anderson 4; Beck, "Globalisierung" 51-52; During 139). ${ }^{13}$ Especially Benedict Anderson has pointed out the socially constructed nature of nation-states. He illustrates that a nation is most of all an "imagined community" because "the members of even the smallest nation will never know most of their fellow-members, meet them, or even hear of them" (6).

Yet, even without face-to-face contact the nation-state's members still feel connected to one another (Anderson 6). This "deep, horizontal comradeship", as Anderson calls it (7), leads to identification with the nation-state and a sense of groupness among the nation's members. Even though this unity is to a great extent only imagined it regardless makes the nation-state a real entity as can be seen from the huge number of people ready to "not so much kill as willingly die" for it as Anderson puts it (7). This pertains to the "emotional legitimacy" of the nation (Anderson 4) and shows its members' identification with it and their selfunderstanding and social location in the nation. However, Brubaker and Cooper also emphasize that the nation-state is "a powerful 'identifier,' [...] because it has the material and symbolic resources to impose the categories, classificatory schemes, and modes of social counting and accounting with which bureaucrats, judges, teachers, and doctors must work and to which non-state actors must refer" (16). A nation-state, whether one sees it as imagined or not, thus holds a great amount of very real power over its members in that it can identify and categorize, whether they feel particularly emotionally invested in it or not.

When it comes to migration these things get complicated. For a start, if the nation-state and thus a specific territory is seen as a person's home, a migrant must inevitably be homeless because he or she is separated from it. Migrants consequently must be literally displaced and since commonality, connectedness and groupness are joined to the place they left, they are also separated from all familiar social space, which in turn must have a significant impact on their selfunderstanding. In addition, they are confronted with the confusing situations that there are now several nation-states competing in their attempts to categorize and identify. It seems that the crisis of identity, which is so frequently invoked by

13 The exact dating is disputed. Anderson argues for the late eighteenth century. During situates it slightly later in the early nineteenth century. Beck on the other hand links it to the rise of the discipline of sociology and accordingly dates it to the nineteenth and early twentieth century. 
postcolonial theorists is inevitable. As by now has become quite obvious this results from the assumption that identity is necessarily tied to territory. However, contemporary social science shows that there has been a profound change in "social, territorial, and cultural reproduction of group identity" (Appadurai 48) so that old definitions of home and belonging consequently do not apply to "an increasing number" of people anymore (Hannerz 218). This realization follows from a shift in the view of migration because of which the focus is not so much on international migration anymore but on transnational migration and the concomitant changes of nation-states through transnationalism.

\section{Transnationalism}

\subsection{New Perspectives on Migration}

Past migration research used to predominantly analyse the way immigrants adjusted to their new life in the country they emigrated to. Their continuing ties and connections to their country of origin were mostly neglected (Vertovec, "Transnationalism and Identity" 574) or even thought to eventually stop altogether (Glick Schiller, Basch and Szanton Blanc, "From Immigrant" 73; Wong and Satzewich 3). As already touched upon in the previous chapter, sociologists had simply assumed that the "rise of the nation-state" had confined people's social lives "within its borders" (J. Hall 60).

Underlying this assumption was the so-called "container-theory of society" which assumes that each society is enclosed in a separate nation-state just as in a container (Beck, "Globalisierung" 49; my translation). Ludger Pries explains that this theory results from a particular perception of 'space' in sociology in which a distinction is made between "social space" and "geographic space" (3). ${ }^{14}$ According to this, "social space" signifies people's social interactions in their daily lives and their connections to others, whereas "geographic space" describes a particular territory (Pries 3). Sociologists believed that social space was tied to geographic space and as a result "society was conceived as a territorial unity, usually constituted as a nation-state" (Pries 16). Since, in addition, migratory movements were thought to be "unidirectional and one-time changes in location" theorists presumed that if people migrated they left one container for another and necessarily had to break their connections to the old container (Pries 21).

Such a view of migration accordingly did not allow for the possibility of continued involvement in the home country since from such a perspective cultural and social participation is only possible if one is in the place a particular society

14 This is of course only a small fraction of the usage of 'space' in sociology. For a comprehensive overview see Pries 6-20. 
inhabits. As the possibility of return was ignored, the physical separation from a nation-state necessarily meant that the existing connection just stopped. Even though research on migrant diasporas showed that connections to the homeland often remained, they were nevertheless accentuated by feelings of loss and unbelonging. James Clifford thus characterizes diasporas as marked by "a history of dispersal, myths/memories of the homeland, alienation in the host (bad host?) country, desire for eventual return, ongoing support of the homeland, and a collective identity importantly defined by this relationship" (305). ${ }^{15}$ Even though Clifford stresses that not all of these criteria have to apply at the same time (306), it is nevertheless obvious that the relationship to the country left behind is still very important for the diaspora's members and that they feel both non-belonging in their new country and disconnected from the old one to which they wish to return. In Clifford's words, "diaspora communities are 'not-here' to stay" and exist in a state of "living here and remembering/desiring another place" (311). This closely resembles postcolonial critics' view with their emphasis on imaginary homelands which replace the real home country after migration. Yet,as shown above this phantasm proved equally futile and lead to disillusionment on migrants' return. Confronted with these alternatives it is no wonder that migrants were thought to only have the option of either assimilating to their new location or of feeling deterritorialized and alienated.

However, research done in the social sciences since the 1990s shows that this view of migration and its effects upon migrants was not entirely correct. Some of the earliest scholars who noted this were the cultural anthropologists Nina Glick Schiller, Linda Basch and Cristina Blanc-Szanton. Studying the lives of "migrants from Haiti, the eastern Caribbean, and the Philippines" who had migrated to New York, Glick Schiller, Basch and Blanc-Szanton observed that many of these migrants were still - and often to a great extent - involved in the affairs of the countries they had left ("Transnationalism" 2). These continuing ties were manifested in diverse actions such as sending back money to their families, owning property in the sending country, investing money in community building projects or taking part in politics there (Glick Schiller, Basch and Blanc-Szanton, "Transnationalism" 2). In addition, they frequently travelled back and forth between the two countries (Glick Schiller, Basch and Blanc-Szanton, "Transnationalism 3). They were wellestablished in their lives in New York and took part in local politics there as well as in the country they had migrated from (Glick Schiller, Basch and BlancSzanton, "Transnationalism" 3). In such a case one can no longer speak of migrants as exiles who do not fit in with both the sending and the receiving coun-

15 Robert Smith points out that lately the term 'diaspora' has been applied differently "to describe the state of dispersal and connectedness between migrants and their homelands" with no further regard for Clifford's other points (190). 
try. ${ }^{16}$ Glick Schiller, Basch and Blanc-Szanton therefore concluded that the container theory of nation-states did not adequately capture the reality of many migrants' lives and that new research categories were needed ("Transnationalism" 5). They furthermore believed that contemporary migrants can be distinguished from former generations in so far as " $\mathrm{t}]$ heir lives cut across national boundaries and bring two societies into a single social field" (Glick Schiller, Basch and BlancSzanton, "Transnationalism" 1). According to them, contemporary migrants are not simply ordinary immigrants but "transmigrants" who "take actions, make decisions, and feel concerns, and develop identities within social networks that connect them to two or more societies simultaneously" (Glick Schiller, Basch and Blanc-Szanton, "Transnationalism" 1-2). Thus it appears that integration into a new country and transnational connections with the old one are not mutually exclusive practices. In the case of these migrants the connection between social space and geographic space has been weakened.

Other researchers have been quick to critically point out that transnational migration is not an entirely new phenomenon. For example, Christiane Harzig and Dirk Hoerder in their study "Transnationalism and the Age of Mass Migration, 1880 s to 1920 s" prove that transnational activities existed already much earlier among migrants from Europe who migrated to North America. ${ }^{17}$ However, Glick Schiller, Basch and Blanc-Szanton also acknowledge that there was earlier transnational activity, but clarify that the receiving state generally attempted to suppress such actions because they "raised questions about the allegiance and loyalty of immigrants" ("From Immigrant" 80). ${ }^{18}$ Hence, scholars have recently appeared to view transnational migration not as a new phenomenon per se but rather as a new perspective on international migration (Portes and DeWind 10; Vertovec, "Transnationalism and Identity" 576-77). Regardless, in spite of the disagreement about the starting point of the phenomenon it is apparent that it is of far greater extent than originally imagined. In addition, there seems to be a growing consensus that contemporary transnational migration has a different quality because advances in technology make travelling and communication easier (Hannerz 225; Portes and DeWind 10-11; Vertovec, "Migrant Transnationalism" 149-50). The latter makes

16 There are definitely parallels between such behaviour and the behaviour of members of diasporas. However, most of the characteristics of diaspora do not fit: these migrants are not alienated in the host country, there is no dispersal, myth of the homeland and desire for eventual return because the homeland is not something from which they are cut off. Consequently, their "collective identity" (Clifford 305) is not shaped by the experience of dislocation. Lloyd Wong and Vic Satzewich therefore call diasporas "a concomitant of transnationalism" but they encompass additional different aspects (5-6). They also admit that there is a difference in scope between the two (Wong and Satzewich 6), which I will address in the next chapter.

17 Paul Kennedy and Victor Roudometof provide a concise summary of various other critical voices regarding the historical perspective of transnationalism (2-3).

18 In other articles Cristina Blanc-Szanton is listed differently as 'Christina Szanton Blanc'. To avoid confusion, I will continue to refer to her as 'Blanc-Szanton' in the text. 
the means for transnational behaviour accessible to a greater number of people and not only a small elite. Therefore, modern transnational migration is often described as "a phenomenon of ever-greater intensity and scope" (Jackson, Crang and Dwyer 11).

What exactly is considered transnational behaviour differs widely from one approach to the next. While initially the focus was mainly on nation-state transcending connections of migrants, Peggy Levitt and Nina Glick Schiller by now differentiate between four different "traditions" of research in transnationalism which vary widely in scope and focus (183). ${ }^{19}$ The areas of interest in these fields are very diverse and span questions of economic and political incentives for transnational migration, the role of gender in it, its effects on families, the emergence of migrant networks, migrants' assimilation or non-assimilation to the new country, and reactions of sending and receiving countries towards transnational migration, to name only a few of the topics covered (Levitt and Glick Schiller 183-85).

Moreover, the general use of the concept has become even more widespread and has often been used to characterize the behaviour of "all migrants, [...] every ethnic diaspora, [...] all travellers and tourists" as Vertovec complains ("Transnationalism and Identity" 576). It is hardly surprising that the term 'transnationalism' is thus often found in connection with qualifiers such as "over-used" (Vertovec, "Transnationalism and Identity" 576), "elastic" and "stretched" (Wong and Satzewich 2). It seems that almost any kind of action or person can be labelled 'transnational' and as a result the term appears to have been stripped of all meaning at times. To specify my use of the term I will therefore limit myself to one approach to transnationalism in the following which strikes me as particularly useful with regard to aspects of identity formation because of its focus on the reconfiguration of social space.

\subsection{Transnational Social Space}

Transnational migration clearly shows that geographic space and social space are not necessarily congruent anymore. From the beginning, Glick Schiller, Basch and Blanc-Szanton stated that transnational migrants "live in and create a new social and cultural space" ("Transnationalism" 14) and argued that it was necessary to concentrate on transnationalism in terms of "a new field of social relations" to adequately describe the concomitant changes ("Transnationalism" 19). Many others have subsequently taken up this social fields perspective (e.g. Beck, "Globalisierung"; Jackson, Crang and Dwyer; Kennedy and Roudometof; Pries; Vertovec) and recently Levitt and Glick Schiller have attempted to generalize the results of

19 For detailed information and further reading on these different groups see Levitt and Glick Schiller 183-85. Peter Jackson, Philip Crang and Claire Dwyer also offer a compact overview of different forms of and research approaches to transnationalism (8-11). 
this in what they call "a transnational social field perspective on society" (Levitt and Glick Schiller 181). They show that in contrast to the container model of societies with its impermeable borders social fields are:

a set of multiple interlocking networks of social relationships through which ideas, practices, and resources are unequally exchanged, organized, and transformed [...]. Social fields are multidimensional, encompassing structured interactions of differing forms, depth, and breadth that are differentiated in social theory by the terms organization, institution, and social movement. National boundaries are not necessarily contiguous with the boundaries of social fields. (Levitt and Glick Schiller 188)

This perspective allows for greater accuracy in the analysis of migrants' social behaviour, which is not limited by national borders. After all, as Vertovec points out, for transnational migrants "[a]spects of life 'here' and life 'there' [...] are constantly monitored and perceived as complementary aspects of a single space of experience" (Vertovec, "Migrant Transnationalism" 153-54) which could hardly be captured if the focus was solely on particular nation-states. Transnational migrants thus take part in several worlds simultaneously (Harzig 51; Levitt and Glick Schiller 182; Vertovec, "Migrant Transnationalism" 149-50). Accordingly, the social field perspective opens up a new space which does not limit social interactions to either here or there but rather focuses on a state of being both here and there at the same time (Beck, "Globalisierung" 58). ${ }^{20}$ This perceived simultaneity of lives in geographically separated places is one of the most important aspects of this theory.

Moreover, the focus on transnational space does not only offers a new perspective of migrants' lives, but also depicts the wider implications of transnationalism. It becomes apparent that non-migrants are equally affected by these developments and can take part in transnational social space as well through contact with migrants. Much research has been done on this aspect. Hence, Harzig and Hoerder stress that "both worlds overlap in communities of origin, too" because of migrants' continued involvement in their countries of emigration (43). ${ }^{21}$ Transnational migration, for example, generates the development of networks between migrants and non-migrants in the sending country (Hollifield 78; Levitt and Glick Schiller 191; Portes 6). These facilitate migration because they "help to lower the costs and the risks of migration" and also further intensify the linkage of both countries (Hollfield 78).

20 Beck speaks of this space as "etwas Neues, Drittes", a third space, as opposed to the two states of 'here' and 'there' ("Globalisierung" 58). This inevitably evokes Homi Bhabha's concept of the third space which is, however, quite different from Beck's and on which I will elaborate below.

21 This seems to be more pronounced in more recent forms of transnationalism, though, because of technological advances (Harzig and Hoerder 44). 
Research has less focused on the participation of non-migrants in transnational social space in the receiving country. Jackson, Crang and Dwyer emphasize how the existence of minority groups or diasporas can also influence people in the host country through day to day contact and enable them to enter transnational social space. They propagate a very inclusive notion of transnationalism in which one can already temporarily enter transnational space by consuming ethnic food (3). While this may seem far-fetched at first, it can nevertheless imply that there is contact and exchange between a diasporic or transnational population in a country and people who have no migrant background or experience and therefore can be seen as an, albeit minor, transnational occurrence. This aspect is more pronounced in Arjuan Appadurai's theories on global flows. While Appadurai does not hold a transnational view but rather sees the increase of global interconnection as the beginning of the end of nation-states (19), his study on the influence of the media on people's imagination indicates how people are connected transnationally through the media. For Appadurai, the imagination "creates ideas of neighbourhood and nationhood" (7) and shared imaginings result in border-crossing "communit[ies] of sentiment" (8). Similar to Anderson's "imagined communities", Appadurai calls these shared imaginings people's "imagined worlds" which are made up of members all over the world (33). According to this, shared media consumption can unite people who are territorially far apart in common transnational social space. Thus if immigrants watch, for example, a home TV programme while living abroad they become part of "diasporic public spheres" (Appadurai 4). However, such connections are not only imaginary but also bring with them the possibility for real contact with another geographically removed culture.

It must be stressed that not all migrants lead transnational lives (Vertovec, "Transnationalism" 576). Nonetheless, the predicted further increase in international migration and the consolidation of transnational communities is thought to also lead to an exponential rise of transnational migration (Portes 9-10). In addition, although for many people culture and community is still tied to place (Jackson, Crang and Dwyer 6-7) the number of people who will take part in transnational social space, whether they have a background of migration, or not will necessarily also increase since migrants influence their receiving countries (Jackson, Crang and Dwyer 2; Kennedy and Roudometof 5). Social space and geographic space are not congruent anymore for even more people than previously presumed and this number is increasing. Hannerz therefore concludes that " $\mathrm{f}$ ] or a growing number of people, of several kinds, personal border-crossing involvements with different places, cultures, and nations can be central, deeply affecting experiences" (230).

The question that begs to be asked now is how these developments affect people's identities. After all, the orderly state model with clearly demarcated "[i]dentities-borders-orders" that Vertovec had lined out is obviously strongly impacted by this since more and more people lead lives that cut across borders, 
and thereby change orders and identities ("Migrant Transnationalism" 158). Even theories on diasporic communities or imagined homelands do not entirely cover this phenomenon of continued simultaneous involvement in both country of immigration and sending country. Both rootedness in a nation-state and uncertain ideas of home in diasporas thus do not adequately capture the realities of people who live in transnational social spaces for whom questions of identity, home and belonging certainly bring up very different answers.

\section{Transnational Identities}

\subsection{Hybridity}

A long neglected influential concept must finally be acknowledged: hybridity. Especially in postcolonial literary theory one can hardly escape the term, above all when it comes to migrants' identities, which are generally described as hybrid. My only using it sparingly in this thesis therefore needs some explanation. In cultural studies, the concept of hybridity is used to describe the effects on identities in the case of contact between different cultures (Griem 269). It is an attempt to go beyond the conception of cultural identities as absolutes, which is illustrated by the notion of the "third space" which shows how cultures interpenetrate one another and become inextricably intertwined (Griem 269; my translation). This approach is highly influenced by the writings of Homi Bhabha. However, Bhabha's definition of hybridity is quite problematic. As Ania Loomba puts it, it is not only the "most influential" but also the "most controversial in postcolonial studies" (148). Nevertheless, it is inevitable to address it in connection with transnationalism, since hybridity also speaks of the migrant condition in terms of space.

The problem with Bhabha's use of hybridity becomes instantly apparent as soon as one tries to point out how Bhabha defines hybridity since he hardly ever says what it is but mostly just what it does. For him "all forms of culture are continually in a process of hybridity" ("Third Space" 211), and, while different from one another ("Third Space" 209), they are constantly "subject to intrinsic forms of translation" ("Third Space" 210). ${ }^{22}$ As he explains in "The Third Space", when such intrinsically hybrid cultures meet, a hybridizing process starts:

[T] he importance of hybridity is not to be able to trace two original moments from which the third emerges, rather hybridity to me is the third

22 Bhabha defines 'translation' as "a way of imitating, but in a mischievous, displacing sense imitating an original in such a way that the priority of the original is not reinforced but by the very fact that it can be simulated, copied, transferred, transformed, made into a simulacrum and so on: the 'original' is never finished or complete in itself. The 'originary' is always open to translation so that it can never be said to have a totalised prior moment of being or meaning an essence" ("Third Space" 210; emphasis in original). 
space' which enables other positions to emerge. This third space displaces the histories that constitute it, and sets up new structures of authority, new political initiatives, which are inadequately understood through received wisdom. [...] [H]ybridity puts together the traces of certain other meanings or discourses. It does not give them the authority of being prior in the sense of being the original: they are prior only in the sense of being anterior. The process of hybridity gives rise to something different, something new and unrecognisable, a new area of negotiation of meaning and representation. (Bhabha, "Third Space" 211)

According to this, hybridity is a process which leads to the creation of "something new" that does, however, contain some "traces" of what existed before its creation, but is neither one nor the other. Being a mixture of both it is nevertheless neither. For Bhabha, this is how new cultural meaning is produced. An important notion connected with that of hybridity is that of liminality. Hybridity comes into existence in the "third space", which Bhabha also often calls an "'in-between" space ("Location" 2), especially when he refers to contact between nations. When different national cultures, which he stresses are not homogeneous or pure to begin with ("Location" 212), come into contact with one another, they enter into the process of hybridization. This takes place at "the boundary [which] becomes the place from which something begins its presencing" ("Location" 7; emphasis in original). Thus the "boundary" is the place of contact where hybridity is created and consequently the place at which the third space is located.

This boundary is however used in a metaphorical sense and does not denote a "physical location" (Huddart 7). Therefore, the liminal, in-between space of the boundary becomes a "space in which strategies for personal or communal selfhood may be elaborated, a region in which there is a continual process of movement and interchange between different states" (Ashcroft, Griffiths and Tiffin, "Liminality" 130). As Bhabha also assumes that all cultures are constantly changing within during the process of inner translation, the whole concept becomes slightly paradoxical since then everything turns out to be hybrid. One must wonder of how much more use this concept can be once the constructed nature of cultures, identities and nations has been recognized (see also Easthope 346; Griem 269). In addition, Bhabha's purely theoretical approach neglects the very real power of nation-states to identify and categorize, which puts an end to at least some aspects of hybridization when it comes to national identities.

This is made even more problematic by the lack of differentiation of hybridity in Bhabha's theory. As stated, for Bhabha, hybridization occurs whenever there is contact between differences. This clearly does not only apply to collectives such as nations or cultures, but necessarily also affects individuals and especially migrants. Yet, all Bhabha says of such migrants is that they occupy "'in-between' spaces" ("Location" 2) and the spaces of "liminality" ("Location" 321). They are displaced (Bhabha "Location" 13) and lead "unhomely" lives which means that they do not 
entirely belong since they are always located at the border (Bhabha "Location 13). The only characteristic of Bhabha's migrant figure appears to be his displacement. Loomba therefore understandably complains:

$[D]$ espite the accent on hybridity and liminality, Bhabha generalises and universalises the colonial encounter. Thus, ironically, the split, ambivalent, hybrid colonial subject projected in his work is in fact curiously universal and homogeneous - that is to say he could exist anywhere in the colonial world. Hybridity seems to be a characteristic of his inner life (and I use the male pronoun purposely) but not of his positioning. He is internally split and antagonistic, but undifferentiated by gender, class or location. (149$50)^{23}$

Such a use of hybridity can of course only result in generalizations about a wide range of possible different but interrelated phenomena. For example, if it was applied to merely the changes in identity formation through transnational migration there would hardly be any differentiation between the impact it has on different aspects of identity if one only spoke of hybrid identities. I am therefore somewhat reluctant to use the term 'hybridity' as it is imprecise, lacking in meaning and also automatically equates hybridity with displacement. Furthermore, it does not offer any differentiation in the quality of hybridity which makes the concept appear oddly static and the emergence of hybrids inevitable so that terming someone's identity 'hybrid' carries hardly any meaning at all as, on further reflection, everybody's identity is hybrid. It does not seem likely, though, that all those who are caught in cross-cultural or transnational situations would react in the same way to it, so that regarding contemporary migration and its effects, ,transnational' seems to be a more adequate qualifier when speaking of identities.

In addition, the term also reflects the continuing power of nation-states, making it less abstract than hybridity. After all, while identities are no longer solely dependent on the nation-state, and home and belonging are no longer automatically confined to one nation-state, it nevertheless hardly seems that "the nationstate, as a complex modern political form, is on its last legs" as Appadurai claims (19). While the nation-state's influence has surely weakened through transnational behaviour it has not altogether disappeared (Jackson, Crang and Dwyer 11; Wayland 19). The majority of researchers denies the advent of postnational ways of life because after all "people are not deterritorialized but live their lives on earth, in states, and in communities" (Wayland 20; see also Yeoh, Lai, Charney and Kiong 2). True global belonging would only be available to a very small elite who has the pecuniary means to afford constant travelling all over the world (Hedetoft and Hjort xviii). Thus, for the majority the globe is not "something people belong to"

23 While Loomba restricts Bhabha's use of hybridity to the colonial context, it also applies to migrants since Bhabha's later works have become considerably wider in scope and include contemporary problems (Huddart 124 ff.). 
as Hedetoft and Hjort explain (xx; emphasis in original). Accordingly, local attachments cannot simply be ignored like Bhabha does.

\subsection{Changes in Identity Formation}

What then do transnational identities look like? They are no longer confined to a single nation-state, but also not postnational. Therefore, concerning identification and categorization, transnational individuals identify with several nations and cultures, which they feel they belong to. Hannerz accordingly speaks of "'biterritorialization', or 'multiterritorialization"' (220), which Beck very aptly calls "place polygamy" ("Living" 276) thereby emphasizing the feeling of belonging to several places or nations at once. There can now be two or more nation-states who can exercise the power to identify and categorize (or not), which can result in dual or multiple citizenship, which is, however, not practiced in all states (Wayland 26). ${ }^{24}$ Even if it is, it is not without its problems as Levitt and Glick Schiller point out:

First, dual belonging calls into question the very notion of governance because it is not readily obvious which state is ultimately responsible for which aspects of transnational migrants' lives. Where should those who live across borders get health care, pay taxes, or serve in the army? Which state assumes the primary responsibility for migrants' protection and representation? What happens when migrants are sentenced to the death penalty in their host country while the death sentence is prohibited in their country of origin? (204)

These are all very important questions with no readily available answers so far. The nation-state's power to categorize and identify its members is thus somewhat weakened because it is shared and because a specific nation-state's authority is not automatically guaranteed anymore. Nevertheless, Levitt and Glick Schiller look at this not as a loss of power but rather a transformation of the state which now "assumes new functions" (198)..$^{25}$

Self-understanding and social location underwent considerable change, too. While one's social location is not tied to a particular place anymore, people still live in certain places and communities, as emphasized above. However, for transmigrants their social location can differ markedly from one actual location to the next. Levitt and Glick Schiller thus point out the possibility that "individuals occupy different gender, racial, and class positions within different states at the same time" (194). For example, people may be well educated or belong to a high social class in their home country, but nevertheless work in low paid jobs in the host

24 Since citizenship, rights, and participation will not be of great importance in the following, I will not go into detail here. Levitt and Glick Schiller provide a good overview (197-205).

25 See previous note. 
country (Levitt and Glick Schiller 194-95), which would accordingly influence the way they act in these respective social locations. Such cases also indicate that transnational behaviour is not only a phenomenon of elites as postcolonial theorists claim, who can easily switch between countries since they certainly would not experience differences in social location as drastic.

In addition, as one's social location is also influenced by the identification and categorization by others, transmigrants might experience rejection, for example in the form of racism, by not being identified as part of one of the nations or cultures which make up their social space (Glick Schiller, Basch and Blanc-Szanton, "Transnationalism" 18) which would lead to feelings of displacement. Transnational lives can nevertheless also be empowering, especially for those whose countries occupy less privileged positions in the world. They can increase their influence in the home country as their social location can change for the better through migration because it can offer them possibilities to both improve the standing of themselves and their home country economically (Levitt and Glick Schiller 192). It furthermore enables them to advance changes for their benefit in both sending and receiving states (Levitt and Glick Schiller 193).

Furthermore, non-migrants' social location and self-understanding can also be influenced if they are involved in transnational social space. As the examples from the previous chapter have shown such involvement can be quite significant in its influence on the sending country's economy, for example because of money transfers. Additionally, the contact between those who stayed behind and temporarily or permanently - returning migrants leads to the formers' acquaintance with a transnational lifestyle which can have "a powerful impact even on the transnational orientations of those who have never left" (Vertovec, "Migrant Transnationalism" 155). Similarly to Appadurai, Levitt furthermore points out that through the media Western culture has already so much influence on non-Western countries that today's migrants "arrive already partially socialized" to the new country's culture (25).

Transnational migration can even lead to changes in the political structure of both sending and receiving countries. Levitt and Glick Schiller point out the example of governmental structures:

Migrants bring ideas about governance with them that transform hostcountry politics, they reformulate their ideas and practices in response to their experiences with host states, and they communicate these social remittances back to those in their homelands or members of their networks settled in other states. (205)

Such behaviour inevitably influences the social and political structure of both states, which would in turn force non-migrants in the receiving countries to adapt to the changes. In addition, Levitt and Glick Schiller give examples of how transnational migrants influence their host countries to interfere with the domestic 
politics of their country of origin (193). Further influences can be discerned on an interpersonal level because the presence of migrants with different cultural traits can lead to "transculturation" when these differences are incorporated in the place they inhabit (Chan and Ma 12). All of this clearly leads to changes in selfunderstanding, which is linked to one's social location. If the one undergoes a drastic change, the other can hardly remain uninfluenced.

This leaves the aspects of commonality, connectedness and groupness and with it the question of where transnational people belong. As with all of the above, possibilities have also multiplied here. Hence, transnational migrants are described as having "multiple attachments" (Hedetoft and Hjort xvi), "multiple membership and multiple loyalties" (Kastoryano 134). Similarly, Wong describes that they have "deep attachments to more than one "home" (170) while others again stress that the concept of 'home' is not necessarily linked to a specific place any longer (Yeoh, Lai, Charney and Kiong 7). Rather, transmigrants have "a more 'itinerant' or 'portable' notion of 'home"' (Yeoh, Lai, Charney and Kiong 7) just as they "construct and utilize flexible personal and national identities" (Yeoh, Lai, Charney and Kiong 3). Adaptability and multiplicity appear to be the general characteristics of such belongings. Ayse Çağlar sums this up precisely by observing that transnational migrants "weave their collective identities out of multiple affiliations and positionings. They link their cross-cutting belongingness with complex attachments and multiple allegiances to issues, peoples, places and traditions beyond the boundaries of their resident nation-states" (610). Similarly, selfidentification also becomes a more complex issue because transnational migrants "incorporate cultural references from both the place of origin and the place of residence" as Sarah Wayland notes (18). Levitt and Glick Schiller nevertheless stress that such transnational activities do not hinder assimilation into the country of immigration but can occur simultaneously (182).

Moreover, the identities may also change over time. Levitt and Glick Schiller accordingly distinguish between "ways of being" and "ways of belonging" in/to a transnational social field (187). They note that it is possible to be part of a social field but to decide not to "identify with any label or cultural politics associated with that field" (Levitt and Glick Schiller 189). One would then merely be part of the field, but not belong to it and thus be engaged in "ways of being". "Ways of belonging" on the other hand imply that one acts in such a way as to show a "conscious connection" to the field (Levitt and Glick Schiller 189). The emphasis here is on "concrete, visible actions" that signify the belonging to that field (Levitt and Glick Schiller 189). Ways of being and belonging can change over time and also depend on particular situations (Levitt and Glick Schiller 189). For example, a migrant might stay in touch with people in the home country, but not identify with the country at all, and would thus exhibit "transnational ways of being but not belonging" (Levitt and Glick Schiller 189-90). This person can, however, also revert to ways of belonging when they begin to "explicitly recognize this and high- 
light the transnational elements of who they are" (Levitt and Glick Schiller 190). Transnational identities are therefore not "linear or sequential" but can alter over time in their intensity and there are degrees of connection regarding the countries involved (Levitt and Glick Schiller 190). This certainly offers a much more detailed perspective with regard to the identities of those involved than 'hybridity' could by highlighting that becoming transnational is not an event but an intricate process.

So far there have been few critical voices concerning transnational lives. That such networks of complex belongings and allegiances always work smoothly can hardly be expected, though. Satzewich and Wong voice concern that maybe states may not always be positive and accommodating towards transnational activities and wonder if "in an era of shifting global alliances when yesterday's international ally can quickly turn into today's 'rogue state' (and vice versa)" the pursuit of transnational connections may be rather risky (298). A significantly larger group of theorists believe that transnational lifestyles will increase, affect more and more people regardless of their migrant status and thus change societies all over the globe so much that "transnational lifestyles may become not the exception but the rule" (Levitt 4; see also Beck, "Living" 275; Hannerz 230; Hedetoft and Hjort xvi; Wong 170). In such a scenario all nation-states, cultures and lives would eventually become hybrid, in the sense of being mixtures of different influences (Beck, "Living" 280; Chan and Ma 15).

\section{Transnational Identities in Ondaatje's Fiction}

I will start my interpretation of Ondaatje's fiction with a quote that refers back to chapter 2. In an essay on The English Patient Aitor Ibarrola-Armendariz comments on the state of North American literature:

[L]ately the very heart of North American literature has been taken over by a race of postnational authors characterized by their rootlessness and sense of transcultural identity. [...] Rather than seeing their existence divided between their old home and indigenous heritage and a new home in a postimperial order, they prefer to (un)define themselves as belonging to two or more - half-homes simultaneously. Naturally, their literary production is deeply affected by this change in self-perception, so that what we generally encounter in it are groups of uprooted souls, their lives dominated by an all-prevailing sense of dislocation. (37-38)

As above, migrant writing is again seen as dislocated and uprooted and its characters - as well as the author - as having no real home and celebrating their rootlessness. Especially when it comes to Ondaatje's fiction, such a judgement seems unconvincing to me and appears to merely repeat the usual concerns associated with migrant writing without taking a closer look. I will not the deny the existence 
of the typical migrant writing motifs in Ondaatje's books as there certainly are instances when his characters seem unsure of where they belong and who they are and when they feel dislocated. If one approaches these texts with a different focus - on the transnational aspects of the characters' identities - the analysis must result in a quite different interpretation. Through such a lense one can see that in Ondaatje's fiction complex questions of post-, trans-, or simply national belonging, self-understanding, and connectedness are negotiated in subtle yet precise ways that are never uncritical. On the contrary, the texts do not offer simple, clear-cut answers to these issues and by this defy the categories that are usually applied to migrant literature.

In order to capture these aspects of the novels and show how they differ from other forms of migrant writing, I will therefore now analyze them with the help of the results from the previous theoretical part. The different aspects of transnational identities will be pointed out in the migrant characters in Ondaatje's fiction so that it will be possible to examine different approaches to transnational identities that are juxtaposed, compared and contrasted. Special attention will also be paid to the transnational spaces, metaphoric and real, that the characters are located in because repeatedly the use of spaces, their boundaries, dissolution and overlapping in the texts reflects the same questions concerning identities in highly symbolic ways. As a result, the representation of characters' identities in Ondaatje's fiction often almost seems like a direct engagement with the theoretical concerns of transnational studies, relocated to a fictional arena, as the following analysis will show.

\subsection{Anil's Ghost and Running in the Family: Journeying towards Belonging}

Anil's Ghost and Running in the Family do not only share a similar plot revolving around a return journey to the protagonists' country of origin, they are also equally concerned with questions of identity. ${ }^{26}$ Both protagonists, Anil Tissera and Michael Ondaatje, the narrator of Running in the Family, are migrants whose lives have lead them across the boundaries of several nation-states. ${ }^{27}$ However, while this situates both of them in a transnational social field, neither character seems aware of that or particularly interested in a transnational life up to the point when they suddenly feel the need to return. In Levitt and Glick Schiller's terms, they are engaged in transnational ways of being but not belonging. When they eventually do engage in a journey to the country they came from this turns out to be not only a literal journey but also a symbolic one in which they have to relocate the

26 The texts will in the following be abbreviated as $A G$ and $R F$.

27 Running in the Family is by admission of its author a fictionalized account of two journeys to Sri Lanka in 1978 and 1980 (Running in the Family 205-6) so that the narrator must be strictly separated from the author Michael Ondaatje. Unless stated otherwise 'Ondaatje' will refer to the narrator of Running in the Family in chapter 5.1. 
boundaries of their social space in order to establish a transnational mode of belonging. This proves difficult and frustrating though, as crossing the borders of nation-states, even a war-torn one in Anil's case, is much easier than crossing the cultural and historical ones that keep them separated from their past. In addition, crossing into a transnational way of belonging is presented as coming with its own set of difficulties in Anil's Ghost, which makes it (the author) Ondaatje's most critical book concerning transnational identities.

\subsubsection{Dealings with Boundaries}

Initially, the characters Anil and Ondaatje appear to be much alike. Their lives read like ordinary, but rather successful immigration stories. Anil is a renowned scientist, Ondaatje a famous author. Both seem to lead equally successful, welladjusted lives in Western countries. Even their immigration stories sound similar. Ondaatje, having left Sri Lanka at the age of ten for England, later moved on to Canada, where he stayed permanently ( $R F$ 172). Although not much is said in the text of his feelings towards Canada, he appears at home there with friends and family ( $R F$ 22) and there is no mention of alienation and feeling displaced. ${ }^{28}$ As Danuta Woznialis rightly remarks, it is "his other country and the motherland of his children" (278). Similarly, Anil left Sri Lanka to study in England and after that moved on to the United States ( $A G$ 145). When asked about her affiliations, she states, “I live here,' [...] 'In the West." (AG 36). Neither one of them appears to strongly identify with their home country anymore but for different reasons: the beginning of striking differences between these two characters.

Ondaatje matter-of-factly admits that he had "slipped past a childhood [he] had ignored and not understood" (RF 22). This neglect appears to have happened accidentally and is hardly surprising since most of his family crisscrossed the globe repeatedly: "Gilian stayed in Ceylon with me, Christopher and Janet went to England. I went to England, Christopher went to Canada, Gilian came to England, Janet went to America, Gilian returned to Ceylon, Janet returned to England, I went to Canada." (RF 172). They were never again all in the same place together (RF 172). Ondaatje's social space was thus necessarily disconnected from geographic space since his family connections occurred transnationally. With the family scattered, home and belonging appear to be more tied to people than to a particular place, and since only one sister and the estranged father stayed in Ceylon the connection to the country and any sense of connectedness to its culture naturally weakened.

28 There has been much debate concerning the genre of Running in the Family, which I will not go into here. As already mentioned, the book is a partly fictionalized account, but otherwise hard to classify and will therefore here only be referred to as 'text' or 'book'. For discussions of the genre of Running in the Family see Smaro Kamboureli, "The Alphabet of the Self: Generic and Other Slippages in Michael Ondaatje's Running in the Family." 
This is very different from Anil's story as she downright rejects national belonging soon after she has left Sri Lanka. While at first feeling alienated and lost in England and so homesick that she marries another Sri Lankan ( $A G$ 142), little later she deliberately tries to break her connections with Sri Lanka without showing clear reasons for doing so. As long as her parents are alive she still has some feelings of connectedness to Sri Lanka, which are superficial, though: "her only real connection was the new sarong her parents sent her every Christmas (which she dutifully wore), and news clippings of swim meets" ( $A G 10)$. This remnant of belonging to Sri Lankan culture is more obligation than her own freel will, though, since "dutifully" engaging in a cultural practice hardly indicates belonging by choice. She "courted foreignness" ( $A G 54$ ), stopped speaking Sinhala and "turned fully to the place she found herself in" ( $A G$ 145). However, this place is not a country or a culture but science ( $A G$ 145). The scientist community she becomes part of appears to her to be its own "world" with its own culture, which Anil is fascinated with ( $A G$ 147). It is also the only larger group which she connects to emotionally. She admits that she "would always love the clatter and verbal fling of pathologists" ( $A G$ 148), "loved their rituals" (147) and took part in their "old tradition" of listening to music while working ( $A G$ 146). She is clearly very attached to it, identifies with it and probably feels she belongs there.

This scientific community is transnational in its own right since its members come "from all over the world" (AG 36) and are bound together by the same interest. It is what Appadurai would call a "community of sentiment" which exists independent of national boundaries, without any particular affiliation to specific nations (8). This, however, makes it more postnational than transnational as the geographic space of this community seems completely interchangeable as can be seen in Anil's vague responses to where she lives. She feels at home in the world of science, which is not limited to a particular place while admitting her affiliations with nations only in the vaguest terms. She "now travelled with a British passport" (AG 15-16) and resides in the West ( $A G$ 36) but any emotional attachment to a country as a whole that would show that she understands herself as part of it is strangely missing (see also Danyte, qutd. in Woznialis 280). ${ }^{29}$ Thus, while she could be identified as British, her self-understanding would most likely differ. Even when she contemplates returning to the "adopted country of her choice" ( $A G$ 285) at the end of the novel one cannot be quite sure whether she means the country whose passport she carries or the one in which she lives. Her lack of specificity in this perfectly reflects what she says she likes about the West: anonymity ( $A G 72)$.

29 Nevertheless, she feels attached to certain localities, such as Oklahoma, which she loves because of its deserts ( $A G$ 149). This is immediately contrasted with the flowering, green Sri Lankan landscape in which "she could spit on the ground and a bush would leap up" (AG 148). Her love of deserts is thus another instance of deliberate disconnection from Sri Lanka. 
Both characters are thus engaged in transnational ways of being but at first but do not make the deliberate choice of belonging. Indeed, Anil appears to have even moved beyond emotional attachments to countries and national cultures altogether and lives in the postnational space of science without any interest in being transnational. However, both characters change their ways and set out on very different return journeys, running towards their country of origins in Ondaatje's case or starting to hesitantly move in its direction in the case of Anil, which is symbolized in a number of border crossings.

For Ondaatje, the incentive to return is a dream about his father in which he sees him in the jungle surrounded by barking dogs ( $R F$ 21). Waking up, the "bright bone of a dream" still lingers and has long-lasting effects on the narrator:

The noises [of the barking dogs] woke me up I sat up on the uncomfortable sofa and I was in a jungle, hot sweating. Street lights bounced off the snow and into the room through the hanging vines and ferns at my friend's window. [...] Tense, not wanting to move as the heat gradually left me, as the sweat evaporated and I became conscious again of the brittle air outside the windows searing and howling through the streets and over the frozen cars hunched like sheep all the way down towards Lake Ontario. It was a new winter and I was already dreaming of Asia. (RF 21-22)

The passage is marked by strong contrasts between heat and cold which are associated with Asia and Canada respectively and point out differences between the countries (see also Pesch 58; Ray 41). It also locates the narrator in a symbolic transnational space in which aspects of Asia and Canada are simultaneously present. After all, the narrator does not remember having been in a jungle in his dream, but in the instance of waking up he "was in a jungle" and with the vines and ferns at the window the jungle appears to invade the Canadian winter. Places which are geographically far apart as well as mutually exclusive elements are suddenly united in the space of the friend's living room.

The moment affects the narrator profoundly and functions like an epiphany that makes him suddenly aware that these contrasts are united in himself as well. As Joanna Saul observes, the passage shows that "[t]he here and there are in constant dialogue, so that the often naturalized relationship between self and place is interrogated. Ondaatje discovers that he is neither 'Sri Lankan' nor 'Canadian' in any straightforward way" (43). I slightly disagree with her on this, however, since the fusion of time (the father's past), place (Sri Lanka and Canada) and contrasting elements (fire, ice) in the familiar space of the living room of all rooms, seem to indicate that the narrator encompasses both. The dream therefore turns into an indicator of his transnational self, which transcends geographic spaces and national boundaries. It is this discovery that starts the narrator's "running" to Asia (RF 22) and in doing this the decision to reconnect with previously neglected aspects of his transnational identity. The passage accordingly not only marks a 
change in his self-understanding but also the beginning of a literal journey to Sri Lanka in order to reconnect with his country of origin in order to understand the newly found transnational self. In addition, the dream is the first of many instances that confront the narrator with various boundaries and their crossing or at least attempts at doing so.

The starting point for Anil's decision to re-connect with her Sri Lankan identity is harder to pin down. Her initial request to go on a human rights investigation to Sri Lanka had been "halfhearted" ( $A G 15)$ and once she arrives she seems to be unsure about how to proceed. Even though Anil has some relatives left in Colombo she decides not to contact them ( $A G$ 10). Moreover, she makes it very clear that she is "not a prodigal" $(A G 10)$ and dislikes being connected to her past as a famous swimmer ( $A G$ 16). By this she refutes any connectedness to the country. ${ }^{30}$ This is also demonstrated in her - erroneous - belief that " $\mathrm{t}[\mathrm{h}] \mathrm{e}$ island no longer held her by the past" ( $A G$ 11). She does not understand herself as Sri Lankan. As Woznialis remarks, "she seems to have decided to go to her motherland as a foreigner" (280). Even though she later admits that she "decided to come back [...] wanted to come back" (AG 200) she attempts to look at Sri Lanka with a "long-distance gaze" $(A G 11)$ and by this acts like she did with regard to her Western countries. Anil appears to have walled herself off from national and therefore also transnational groupness or connectedness and seems unwilling to remove these barriers between herself and the world. Not unfittingly, David Farrier describes the life she led in the West as a "somnambulant existence" because of its utter lack of deep and meaningful connections (84). She seems to be completely oblivious to anything outside the world of science with its sterile labs. She is awoken from this sleep by the resurfacing of long-forgotten memories from her childhood in Sri Lanka, which can be seen as a first boundary crossing experience for her as the memories manage to escape her subconscious. They make her realize that there is, or at least once was, more to her life than just science and she feels that she must face the "background" she had previously ignored and refused to address ( $A G$ 36), which results in her hesitantly changing her selfunderstanding.

\subsubsection{Confusion and Isolation}

As Saul rightly says, there is a "theme of searching [...] at the heart of Running in the Family" (37) and this description certainly also applies to Anil's Ghost. The searches are quite different, though. Ondaatje sets out to discover his family history, and especially the father he hardly knew, to find his "roots" in the country

30 Woznialis points out that when Anil begins to identify with Sri Lanka again in the end she does no longer reject her labelling, even refers to herself as "the swimmer" (AG 270) and thereby "reinstates her old identity" (282). 
(Pesch 57). Anil on the other hand searches for the truth in the war crimes she investigates. However, as Woznialis explains, "Anil's 'getting to the truth' comes to imply a struggle for self-discovery as well" (282). In addition, both quests can also be seen as struggles to overcome the boundaries that separate the characters from past aspects of their lives and show their developing a new more transnational self-understanding.

For Ondaatje, the enterprise seems simple at first since his extended family still offers him a familiar social location in the country. He thus still has a place in Sri Lankan society and can use this to learn about the family's past. It seems only a matter of collecting information through his various aunts that can then be organized into a family history (RF 26). Yet, his search is soon complicated when Ondaatje realizes that in his family "[e]veryone was vaguely related and had Sinhalese, Tamil, Dutch, British and Burgher blood in them going back many generations" ( RF 41) so that it becomes impossible to say for certain were the family's roots lie and what its nationality is. "God alone knows" as one of his relatives once said (RF 41). In addition, Ondaatje realizes that the past he put together from his sources "was part of another lost world" (RF 51) that ended with the decolonization of the island $(R F 53)$ and does not exist in this form anymore. With regard to his parents, Ondaatje furthermore recognizes that "[t]ruth disappears with history and gossip tells us in the end nothing of personal relationships" (RF 53). The past he wanted to get to know eludes him and strongly resembles the image of the "human pyramid" formed by his family members, which he saw in a dream (RF 27). Just as the pyramid naturally walks through the living-room wall, his family is not stopped by the seemingly distinct boundaries between nationalities, countries, truth and lies.

Ondaatje also realizes that present day Sri Lanka is not his home anymore. While several critics have voiced the opinion that Running in the Family is mostly concerned with creating the Ondaatjes' past as indicated in the narrator's continually calling Sri Lanka by its colonial name 'Ceylon' (Kamboureli, "Alphabet" 91; Woznialis 276) this is clearly not the case. Ondaatje likewise also reflects on his position in contemporary Sri Lanka which he encounters in his journeys. For example, in the chapter titled "Monsoon Notebook (i)" he lists impressions of every mundane detail that he sees and notices in run-on sentences:

Watched leopards sip slowly, watched the crow sitting restless on his branch peering about with his beak open. Have seen the outline of a large fish caught and thrown in the curl of a wave, been where nobody wears socks, where you wash your feet before you go to bed, where I watch my sister who alternatively reminds me of my father, mother and brother. Driven through rainstorms that flood the streets for an hour and suddenly evaporate, where sweat falls in the path of this ballpoint, where the jak fruit rolls across your feet in the back of the jeep, where there are eighteen ways 
of describing the smell of durian, where bullocks hold up traffic and steam after the rains. ( $R F$ 69)

He appears to want to write down every impression and sensation he comes across to evoke the atmosphere of the place but by his choice of topics which highlight everyday life reveals how unusual these events have become for him. As Graham Huggan observes, "he mocks his readers, and himself, for playing the part of wide-eyed foreigners" (122). It is clearly not the point of view of someone who feels naturally at home in the place Ondaatje describes but that of an outsider.

Soon, his approach does not stay this humorous but turns to frustration in the chapter called "The Karapothas" which translates as the foreigners ( $R F$ 80). At this point in the text, Ondaatje becomes aware that he is displaced in this country, which is also his homeland and states "I am the foreigner. I am the prodigal who hates the foreigner" ( $R F$ 79). His belonging or lack of belonging to Sri Lanka is paradoxical to him as he believes "[w]e own the country we grow up in, or we are aliens and invaders" (RF 81). He grew up in the country, and nevertheless is also a stranger in it upon his return and consequently a colonizer.

Ajay Heble therefore concludes that Ondaatje is "ex-centric" and assumes that Ondaatje realizes that "he himself is the other" ("Rumours" 189; also Huggan 118-19; Saul 43) which, however, provokes the questions 'Which other?' and 'Where is the centre that he is displaced from?' After all, Ondaatje is not only unable to connect to his family tradition because it existed in the bygone era of Sri Lanka's colonial past. He in addition does not fit into present-day independent Sri Lanka either. He is "other" and "ex-centric" in several ways: as a Canadian in Sri Lanka, as a Ceylonese in Sri Lanka and as both a Canadian and Ceylonese who cannot return to a stable past that would offer a locally fixed sense of belonging because this past was never stable to begin with but subject to many different influences and affiliations. A dichotomy between self and other is hence not possible anymore in his case and a clearly identifiable centre can no longer be located. ${ }^{31}$ Ondaatje's self-understanding is troubled by this because he does not know to which of these he belongs and how he can connect to them.

It is hardly surprising that the two poems following this chapter, "High Flower" and "To Colombo" (RF 87-91), focus on Sri Lankans without a mixed background whose belonging is rooted in place. While Sangeeta Ray complains that the characters are presented as "native subalterns" (43), this does not seem to

31 In her analysis of Anil's Ghost Victoria Cook similarly states, "[Ondaatje's] voice is one of those involved in re-defining the boundaries, speaking from beyond preconceptions of 'the Other' and 'writing back' to 'the West,' and reconfiguring the 'postcolonial' perspective into one of 'transnationalism.' Anil's Ghost provides a forum for the expression of a range of cultural identities - one in which the postcolonial voice does not simply speak from the margins, but is represented as an integrated component of a transnational identity" (8). This clearly applies to all of Ondaatje's fiction. 
be the poems' intent. Their position at this point in the text rather suggests that they function as a melancholic, romanticized image of people whose culture sits in place and who do not have to deal with the problem of being both foreigner and prodigal at the same time. Strikingly, the "brown men" in "To Colombo" "rise knee deep like the earth / out of the earth" ( $R F$ 90). They appear to literally have grown out of the land which Ondaatje envies at this point. These people can connect to the country in a way that Ondaatje and his hybrid family cannot (see also Leon 31). The sentimental mood is only confirmed if one takes a look at the poem "Sweet Like a Crow" preceding the chapter (RF 76-77). It describes a young Sinhalese girl singing so out of tune that her voice is described as sounding, for example, "like someone pulling barbed wire / across a stone courtyard, like a pig drowning" (RF 76). It must take a great amount of romanticizing and sentimentality indeed to construe this noise as even remotely "sweet". The poems accordingly convey Ondaatje's momentary longing for a simpler notion of home and identity resulting from his frustration in establishing a connection to Sri Lanka/Ceylon, not without his typical irony though by overdramatically exaggerating his feelings.

Anil's reconnection with her homeland is similarly difficult and shows a more complicated side of having a transnational identity as she suffers from a conflict of interests. This is best expressed in her inability to use her once native language and her inability or unwillingness to modify her idea of truth. Her reflections on language show a change in her self-understanding: she is upset that she can no longer speak Sinhala because it prevents her from communicating with other Sri Lankans, such as Ananda ( $A G$ 170) and her ayah, Lalitha. The meeting with Lalitha demonstrates this especially well. Because they no longer speak the same language, Anil cannot re-establish their relationship, which leaves both of them feeling isolated: "When Anil let go, the old woman seemed stranded [...]. Anil sat next to Lalitha and held her hand in silence, feeling an ache in herself' ( $A G$ 22). There is a border between them that they cannot cross. Anil is in this instant confronted with the extent of her estrangement from the culture she was born into. Even when she wants to belong to it again, she is unable to, which is especially painful with regard to Lalitha who is Anil's last intimate connection in the country. It is therefore not possible for herself to realign herself to the Sri Lankan part of her identity even though she wishes to.

This is further emphasized by the reaction of Lalitha's granddaughter. She watches the meeting through "stern eyes" ( $A G$ 22) and deliberately excludes Anil by talking to Lalitha in Tamil without bothering to translate for Anil (AG 23). She even pointedly highlights Anil's lack of "connection" to Sri Lanka ( $A G$ 24) and by all this categorizes Anil as an outsider who does not belong there. While this certainly mirrors Anil's self-understanding upon initially arriving on the island, it is now painful because it emphasizes a boundary between her and the woman whom she loves like a mother ( $A G$ 23) and because Anil has finally decided that she wants to cross the boundaries that separate her from Sri Lankan society but is 
unable to. Like Ondaatje, Anil thus becomes a stranger in her homeland and feels equally lost as further comments on her inability to speak Sinhala show: "on this island, she realized she was moving with only one arm of language [...]. There was less to hold on to with that one arm" ( $A G 54)$. Her ability to connect to the social world around her is severely handicapped. As Brenda Glover shows in her analysis of Anil's behaviour in Sri Lanka, her lack of language denies her a whole world (79). This certainly complicates any further attempts to establish transnational ways of belonging - or even being for that matter - because Anil is cut off from a large part of the population.

However, it is important that Anil's problem concerning language is not that she has completely forgotten how to speak Sinhala, but it is "her lack of tone" which makes it impossible for others to understand her ( $A G$ 23). There is no differentiation or nuance in her voice, which makes questions, offers and commands sound the same. This lack of differentiation is also present in other aspects of Anil's behaviour and is her biggest problem when it comes to finding her way in Sri Lankan society. Her attitude towards the concept of truth exemplifies this particularly well. Anil believes that the truth is simple and straightforward: "she had come to expect clearly marked roads to the source of most mysteries. Information could always be clarified and acted upon" ( $A G 54)$. Therefore, when she and her colleague, Sarath, discover the skeleton they dub "Sailor", she immediately thinks that this is an opportunity to accuse the government of a war crime ( $A G$ 51). She entirely overlooks the fact that the social location she is in in war-torn Sri Lanka is very different from her social world in the West and accordingly demands an adjustment of her actions. As Sarath says, "It's different here, dangerous. Sometimes law is on the side of power not truth" ( $A G 44) .{ }^{32}$ Yet, as with her language Anil has only one tone to use, and that is the 'tone' of Western science.

In the course of the investigation this leads to constant tension between her and Sarath who repeatedly accuses her of acting like a "visiting journalist" ( $A G$ 27; see also 44). This does not mean, though, that she is a "stock character in postcolonial fiction: the Europe- or America-returned professional woman struggling to maintain her hard-won status against all odds" (Burton 41). On the contrary, its symbolizes Anil's problem to form transnational ways of belonging because as soon as she takes up the nuanced changeable notion of truth Sarath offers, she is in conflict with her Western self-understanding which is above all dependent on her being a scientist as shown above.

32 Teresa Derrickson, however, remarks, "Lost in this account [...] is a summary of the foreign agenda that is served by initiating a human rights investigation on the island to begin with. As the novel tells us, the president of Sri Lanka only approved of Anil's visit in an attempt to 'placate trading partners in the West' ([AG]16). This statement not only provides insight as to why the Sri Lankan government has taken a sudden interest in the human rights of its people, but it also suggests a dubious reason as to why the United Nations has followed suit" (142). Apparently, the truth is not only influenced by power in Sri Lanka alone. 
Victoria Cook is therefore certainly right to note that "Anil's Ghost provides an examination of identity reflective of the cultural clashes that are an inevitable consequence of such an interweaving of nationalities, histories, and border divisions" (6). With regard to her understanding of truth, to belong to one country makes it impossible to belong to the other. It is impossible for her to identify with both. Thus, while Teresa Derrickson states that "the total exclusion of any other possible outcome in Anil's search for truth in Sri Lanka is somewhat troubling" (140), it is also to some extent understandable since in order to accept different notions of truth Anil would have to become a different person from the one she thinks she is. Having a transnational identity is in Anil's case a much more difficult affair than in Ondaatje's case. She does not merely have to reconnect to her homeland and negotiate a new place in it, she also has to fundamentally change her selfunderstanding. Becoming Sri Lankan again in the current circumstances makes it impossible for her to entirely be "alongside the language of science" ( $A G$ 145) which is extremely problematic for her because it is the only thing that generates a feeling of belonging and home.

\subsubsection{Collapsing Boundaries}

In a somewhat ironic reversal of other forms of migrant writing both Ondaatje and Anil feel most displaced and unsure about who they are only upon their return to their 'homeland' which is by now much less of a home than their Western countries. Yet, for both of them this confused state is not permanent but merely a stage of adjustment on their journey to find ways to break down the boundaries that separate them from the possibility of transnational belonging.

Ondaatje's change in self-understanding begins immediately after the crisis that had left him feeling displaced and unsure of his belongings and its starting point is another poem. In "Women Like You" (RF 92-94), which is significantly subtitled "the communal poem" ( $R F$ 92), the speaker describes the beauty of rock carvings in the shape of women. Admiring them he falls in love with both the women and the surrounding landscape: "Seeing you / I want no other life / and turn around / to the sky / and everywhere below / jungle, waves of heat / secular love" (RF 93). Suddenly, the perspective reverses and the speaker becomes part of the group of women so that "we stand against the sky" (RF 94). To an observer, the speaker thus becomes part of the landscape while the speaker feels a connectedness with the cultural artefact as indicated by his use of 'we'. In a following metafictional moment, he is identified as Ondaatje who says, "I bring you / a flute / from the throat/ of a loon" (RF 94). Ondaatje, the North American bird-singer-poet, offers a poem - a "flute" - to the country and by communicating with it in this way 
writes himself into the country and becomes part of its community. ${ }^{33}$ For the writer, crossing the boundary between fact and fiction, writing himself into the country, as well as into his fiction, turns out to be his route to belonging.

This practice is continued repeatedly throughout the rest of the text, the most noted example of which is a correspondence between the poem "The Cinnamon Peeler" (RF 95-97) and a later scene in which Ondaatje's father gives a cinnamon peeler a ride in his car (RF 187). As the poem starts "If I were a cinnamon peeler", Pesch takes this to mean that "the narrator slips into the role of the cinnamon peeler, but the context reveals that the love poem is also an attempt to become Mervyn's companion in conversation" (68; see also Heble, "Rumours" 199; Snelling 29). ${ }^{34}$ Thus Ondaatje has not only written himself into the Sri Lankan landscape again but also into his father's past. This is further emphasized by the description of the father sitting on the bathroom floor watching ants carrying away page 189 of a book, which corresponds exactly to page 189 of Running in the Family on which the scene is located (Kamboureli, "Alphabet" 90). Saul consequently states, "By fictionalizing his family history, by filling in missing gaps, and by adding his own voice to the versions of others, he is taking some ownership of his past" (51).

Nevertheless, Saul assumes that the fragmented form of the narrative suggests that Ondaatje is not really at home in Sri Lanka: "In the search for some kind of connection or sense of belonging, Ondaatje comes up with numerous ruptures and gaps" (53). However, she overlooks that the different and seemingly separate parts of the text are often intricately related to one another and thereby create some form of textual unity. This is done by the repetition of motifs which function as bridging devices between individual and often widely separated parts of the narrative. The cinnamon peeler has already been mentioned which links the poem

33 This writing of himself into landscape also echoes an earlier description of Ondaatje's grandfather: 'Like some other Ondaatjes, Bampa had a weakness for pretending to be 'English' and, in his starched collars and grey suits, was determined in his customs. [...] It was only in the afternoons when, dressed in sarong and vest, he went out for walks over his property (part of a mysterious treatment for diabetes), that he seemed to become a real part of the landscape around him" ( $R F$ 56). As in the poem blending into landscape signals some form of 'real' connection with one's environment here (see also Leon 33-34).

34 Ray critically remarks that the poem about the cinnamon peeler constructs the "native" as static to contrast him with the Ondaatjes' mobility. She complains, "That this mobility, a benefit enjoyed by voluntary exiles, is often enabled by those exploited and burdened by the current global economy based on international trade is entirely overlooked by Ondaatje in his poem [...]" (Ray 46). I am not convinced of this, though, since the emphasis on the smell of cinnamon relates the poem also to another scene in the book in which Ondaatje tells an anecdote about ship captains who used to sprinkle cinnamon across the ship a few miles off the coast and to ask their passengers to "smell Ceylon". Shortly after this he then continues: "This island was a paradise to be sacked. Every conceivable thing was collected and shipped back to Europe", amongst them "seven kinds of cinnamon" ( $R F$ 81). Ondaatje seems to be more aware of exploitative practices than Ray gives him credit for. 
with the father and the son's doubts about his belonging. Similarly, the initial "bone of a dream" that initiated Ondaatje's journey in Canada (RF 21) comes up again towards the end of the book in the chapter "The Bone" (RF 182). Another example is the wild pig which Ondaatje sees during a trip to the jungle, where he feels so at home in Sri Lanka, that the pig becomes "my wild pig" (RF 142-43; see also Leon 34). The pig conspicuously also is part of the poem "To Colombo" (RF 90) with its emphasis on having roots in the place. The book therefore is not as fragmented as it seems at first but relies strongly on linking devices that make it a unified whole. If the story is taken as a symbol for transnational belonging as Saul takes it, then it also stands for the interconnection of different parts, which are contained in a transnational identity. While " $\mathrm{h}]$ is writing act does not disperse the chaos of the dream that set him running" (Kamboureli, "Alphabet" 87) it turns out to be much less chaotic than it at first appeared.

For Anil a reconciliation of the differences between her countries is not so easily achieved. In her case it is not really possible to belong to both because being part of one group betrays the other. Transnational belonging for her comes with a price. When she in the end identifies with Sri Lanka, and announces in front of a group of government officials "I think you murdered hundreds of us" ( $A G$ 272) she clearly states her affiliation with the country and engages in transnational ways of belonging since she still believes in Western truths. As Sarath observes, her speech is "a citizen's evidence; she was no longer just a foreign authority" ( $A G$ 272). This also turns her into a threat to the authorities, though, and she suffers the consequences. Farrier accordingly points out, "It is important to note that after declaring her commonality with Sri Lanka, Anil is repeatedly strip-searched as she leaves the government building, demonstrating the vulnerability of intimacy, how it can lead to intrusion and deprivation" (90). At this point the boundary between her and Sri Lanka has disappeared, she is now part of it. But by becoming Sri Lakan again she is also stripped of part of her former identity.

Derrickson assumes that after this incident Anil will return to the West and "the story [she] will ultimately tell about the 'truth' of Sri Lanka is a Western story" (136). Her identification with the country does not seem to end with her leaving, however. Her reflections on her time in Sri Lanka show how ambivalent she feels about her newfound connection with her old country. When she remembers a conversation she had with Sarath and his brother Gamini, she ponders:

If she were stepping into another life now, back to the adopted country of her choice, how much would Gamini and the memory of Sarath be a part of her life? Would she talk to intimates about them, the two Colombo brothers? And she in some way like a sister between them, keeping them from mauling each other's worlds? Wherever she might be, would she think of them? ( $A G$ 285) 
This reflection takes place after the events narrated in the novel have ended since Sarath is already dead. Only his "memory" remains whereas Gamini who is alive could in reality be a part of Anil's life. In addition, Anil seems to be still in Sri Lanka and undecided whether she should leave or not. She has not yet disappeared like the hero of Western novels who leaves the country after his job is done and does not care anymore what happens there as Gamini dismissively points out: "So the war, to all purposes, is over. That's enough reality for the West" (AG 286). For Anil, however, the war is not so easily over. Another passage states, "Anil would never get over her time here" ( $A G$ 202). It has deeply influenced her because she feels both Sri Lankan and Western at the end of the novel but in her case, having a transnational identity and identifying with both cultures left her feeling conflicted and uneasy because her experience has shown her that not all differences can be reconciled. She nevertheless does not reject her transnational identity. The text indicates that she returns to the country: "Years later she might see an etching or a drawing and understand something about it, not sure why - unless she were told that the walawwa she lived in had belonged to the artist's family and that the artist had also lived there for a time" ( $A G$ 202). The connection and identification with the country has obviously not stopped even years later. Thus, unlike Ondaatje's, Anil's transnational ways of belonging highlight that transnational identities can be a very complicated and unsettling affair.

\subsection{In the Skin of a Lion: Transformative Space and the Narrative of the Self}

"I will wander through the wilderness" reads the first epigraph of In the Skin of a Lion, and it could hardly capture the novel's main theme better, since this is a story of wanderings, or, in other words, of migration. Almost all characters in the novel engage in some form of migration from the Finnish loggers in Patrick's childhood to Ambrose Small, Clara and, of course, the immigrant community Patrick encounters in Toronto. As in Anil's Ghost the peregrinations and migrations are also journeys towards forming transnational identities during which the characters struggle to find their place in Canadian society and come to terms with their initial feelings of displacement. However, in In the Skin of a Lion forming transnational identities is not only reflected in the characters' migrations but especially in symbolic transformative spaces they are located in.

\subsubsection{Actual and Metaphorical Migrations}

In the Skin of a Lion's theme of migration is most prominently embodied in the characters of Patrick Lewis and Nicholas Temelcoff whose migration experiences act as a foil for one another. While Temelcoff immigrates to Canada from Macedonia, Patrick's move from rural Ontario to Toronto is also presented as an im- 
migration experience when he is explicitly referred to as an "immigrant to the city" (In the Skin of a Lion 53). ${ }^{35}$ Patrick's immigration is further emphasized when he begins to live in Toronto's immigrant quarter in which he is identified as an "alien" (SL 113) so that he becomes a "foreigner in his own country" (Gorjup 92). As Simone Vauthier comments, "By a neat inversion, Patrick Lewis, who by virtue of his birth and native tongue, not to mention gender, belongs to the dominant group, is made an outsider" (72). To Patrick, entering the immigrant community is like metaphorically migrating to another country even though he never left his home country. While Patrick's immigration is thus not entirely real because he does not move from one country to another it certainly is an entering into transnational social space.

As a result, both Patrick and Temelcoff find themselves in socially and culturally different places and initially struggle with similar questions of identity, which are mostly expressed through their use of language (see also Bölling 214; Schumacher 13; Stolar 127-28; Vauthier 71). They cannot connect to the new communities surrounding them at first because they lack the language to do so and are isolated from others. This is expressed in both characters' unawareness of the people surrounding them. So Temelcoff believes no one can hear or see him while he works on the bridge ( $S L$ 42), just as for Patrick his neighbours in Toronto's immigrant quarter are merely "dark blinds on his street, their street" (SL 113). Consequently, this "linguistic and cultural exile" (Gorjup 92) leads to an impaired self-understanding, which can be seen in Temelcoff's being described as having "no portrait of himself" (SL 42) while Patrick is "new even to himself" (SL 54). They are not sure anymore who they are and where they belong. There is certainly no sense of developing transnational identities here but on the contrary a strong sense of general dislocation, which is in line with traditional forms of migrant writing except that strangely a character who is not a real migrant is also affected by this.

There has been much criticism of the equation of Patrick's and Temelcoff's situations, especially since Patrick, in an attempt to become part of the immigrant community, conceals his identity as a Canadian and does not speak around the English-speaking overseers at work (SL 136). Therefore, some have pointed out that Patrick is in a privileged position because he has a choice not to speak while the immigrants' inability to communicate is involuntary because they do not know English (Bölling 214; Vauthier 73). Others are offended that Patrick feels "deliriously anonymous" (SL 112) in his exile, which they see as self-imposed whereas for the immigrants it is a harsh reality from which they cannot escape (Kamboureli, "Culture" 49). Dennis Duffy consequently argues that the immigrants' anonymity makes them "disenfranchised" and "vulnerable" to the authorities (134) and Jody Mason accuses Ondaatje of "effac[ing] important differences

35 In the Skin of a Lion will from now on be abbreviated as SL. 
among kinds of travel and degrees of agency" (75). According to her, Temelcoff and Patrick's travels are "clearly radically different" (Mason 70) because Patrick has "greater agency than any of the other migrant characters in the novel" since he was born in Canada (Mason 72). This, however, is not entirely true and their juxtaposition is much more subtle and subversive.

Patrick obviously has more rights and opportunities than the immigrants because he can be categorized as a citizen of the state. The immigrants do not seem to have citizenship which makes them dependent on the goodwill of the authorities. In addition, while the immigrants' inability to speak English certainly poses a disadvantage for them and denies them the means to be heard and thus to establish some sense of connectedness to their new country, Patrick's knowledge of the language theoretically allows him to speak up, connect and become part of the English-speaking majority. Yet, in practice this is not the case and Patrick is as disconnected from his co-nationals as from the immigrants. As Karen Overbye demonstrates, Patrick is generally " 'inexpressive' in his relationships with others" (5) which is mentioned repeatedly in the text when even in situations with English-speaking people Patrick keeps his distance from them. During his relationship with Clara "[h]e liked to sleep separate, in his own world" (SL 65), and he feels that he is always "on the verge" (SL 97). Moreover, there is continued emphasis on the fact that "[th] ere was a wall in him that no one reached" (SL 71), "a terrible horizon in him beyond which he couldn't leap" (SL 157). Like Anil, Patrick is separated from others by a boundary which he cannot cross. His disconnectedness from others is clearly not a "cunning device to conceal his potential for transformation" (Werth 129) but it shows a genuine inability to connect.

When he attempts to overcome this barrier that separates him from others, he uses non-verbal ways of communication instead of speech, but also does not mind his "lack of language" (SL 133). However, this is not because it "precludes [him of] any necessity to reveal himself" as Overbye claims (6), but it rather reflects the only other community he was ever part of before, namely his family whose way of communicating is marked by lack of conversation (Schumacher 5; cf. SL 10). It is only logical then that he does not feel uncomfortable when he is part of a nonspeaking community again. His silence and anonymity very soon make Patrick feel no longer "deliriously anonymous" (SL 112), though, but "utterly alone" when the Macedonians and Finns talk in their own language around him so that he is excluded (SL 115). Therefore Rod Schumacher rightly concludes that "[a]ny feelings of alienation Patrick experiences, either in the wilderness or in Toronto, arise not from some calculated withdrawal from the world, but rather from his inability to use language effectively" (4-5). In order to actually be able to use his theoretically greater agency he would thus just like the immigrants have to learn to use language.

Yet, this does not equalize their situations because unlike the immigrants Patrick does not know how to make the necessary changes and adjustments. $\mathrm{He}$ 
needs to rely on others to make him feel connected. He admits that within him there was "[s]omething hollow, so when alone, when not aligned with another whether it was Ambrose or Clara or Alice - he could hear the rattle within that suggested a space between him and community" (SL 157). While Alice thinks that he can be solitary because he is "self-sufficient" (SL 123), this self-sufficiency clearly is not of much use to him since there are things he is unable to do such as overcoming his sense of displacement that resulted from his (im)migration.

Temelcoff, on the contrary, is well prepared for establishing new connections in Canada, which is not surprising since he is part of a transnational network that helps him deal with the problems of immigration. Thus Temelcoff met others who have migrated even before he left Macedonia and knows that there will be people from his village in Toronto who he can go to for help (SL 46). These, of course, can provide advice since they have been through the same experience. Accordingly, Temelcoff is fully aware of what is needed to be successful and, for example, knows that "[i]f he did not learn the language he would be lost" (SL 46) and quickly finds work in several Macedonian bakeries because of his connections. Patrick, on the other hand, is utterly alone.

This extreme difference between the two characters is illustrated in the novel's use of light and darkness. Raphaël Ingelbien shows that light and darkness in In the Skin of a Lion function as metaphors of which light is connected with consciousness and empowerment whereas darkness stands for powerlessness and alienation (31-33). Temelcoff's transnational connectedness is therefore further highlighted by the description of him as someone who "came to this country like a torch on fire and he swallowed air as he walked forward and he gave out light. Energy poured through him" (SL 149). In addition, light in the novel is also often associated with naming, which in turn "is a necessary step in the process leading to social and cultural recognition" (Ingelbien 34-35). To be able to name something is to be able to identify oneself and others, thereby asserting one's selfunderstanding and also one's place in one's social location. Accordingly, if Temelcoff arrives "like a torch on fire" it indicates that he has already started his process of integration into the host country before his arrival. His social space thus is made up of a transnational network which provides assistance in his migration which then leads to his greater agency, mobility and flexibility and in turn to a higher chance of successful integration.

Patrick on the other hand is not part of such a network and instead lacks connectedness of any kind as shown above. This is strongly reflected in his migration experience which is not only not the same as Temelcoff's but in a way even more difficult. This is again reflected in the use of light and darkness. Contrary to Temelcoff, Patrick is frequently situated in utter darkness (SL 9, 105, 120, 166, 230) and as Ingelbien points out "mainly passive, looking for light without producing any" (34) which stresses his inability to make connections. The metaphor even goes to extremes in Patrick's case because he is not only in the dark, but also asso- 
ciated with blindness. For example, he is described as "a searcher gazing into the darkness of his own country, a blind man dressing the heroine" (SL 157). Hence, while his father once commented that the Finnish loggers of Patrick's childhood "don't know where they are" (SL 133; emphasis in original), Patrick realizes only through prolonged contact with the immigrant community in Toronto that they know more about his native country than he does (SL 157). Knowledge of their rich heritage additionally leads to his awareness that it is him who does not know where he is (Heble, "Putting Together" 241; Schumacher 13). He is further associated with blindness when he attempts to impress Clara by "blindfold[ed]" movement (SL 79), is "guided" by Hana through the immigrant quarter (139) like a blind man who needs to be lead and by his possession of a blind pet iguana (SL 83). All this clearly shows that Temelcoff is much better equipped to adjust to their new situation whereas Patrick is overwhelmed when faced with similar situations. Therefore, if Patrick's and Temelcoff's migrations are compared, Temelcoff's transnational connectedness allows him greater agency, whereas Patrick is unable to act because he has no network to help him. In a subversive move, the immigrant who is usually less advantaged is here portrayed as much better suited to life in a country that is continually changing through technological advances and immigration.

\subsubsection{Transformative Spaces}

In addition to their struggles with language and sight, Temelcoff and Patrick's movement towards transnational identities is also symbolized in the places and spaces they occupy in the narrative. Many critics have noticed that there are highly symbolic spaces in In the Skin of a Lion, which impact those who inhabit them immensely (e.g. Criglington 137-38; Lowry 63-64; Mason 78; Siemerling 97; Spearey 56; Stolar 132; Vauthier 76). The focus is often on the liminal character of such spaces, and an example very often used to demonstrate such a space in the novel is Union Station (Criglington 137-38; Lowry 63-64; Stolar 132).

Batia Stolar analyzes this in detail. When Patrick first comes to Toronto he watches an immigrant who seems caught in the space of the station. The man seems lost and unable to leave and when Patrick returns two days later, the immigrant is still there, "still unable to move from his safe zone, in a different suit, as if one step away was the quicksand of the new world" (SL 54). For this immigrant, "'home' [is] not in the immigrant communities but at - and in - the border" (Stolar 132) which "offers what no other place in the city can: a meeting point between these two extremes", that is between inside and outside (Stolar 132). This makes Union Station a literal description of Bhabha's third space. It is a space that is neither here nor there but in-between, a boundary from which something new can be created. And as correspondingly, "[s]omewhat paradoxically, the immi- 
grant, like Union Station itself, is simultaneously static and mobile, inside yet outside the city" (Stolar 132) he ought also be able to create something new.

However, the liminal space of Union station is also clearly very constrictive because even though the immigrant in theory is both inside and outside, he is in reality neither as a station is usually a transitional space and not a space to stay permanently. The passage emphasizes that there are real binaries and boundaries in the world which cannot be so easily hybridized. Accordingly, the immigrant is caught in a no man's land between stable points that is not hospitable at all. It isolates the immigrant, who has no connections, no belonging and no identity that can be attributed to him. As Stolar notes, "there is little that is known about [him]" and he is characterized by a "lack of specificity" (132). Inhabiting such a space can hardly be a positive experience because the immigrant is literally displaced from the world and, in addition, seems - probably as a result from his being in this place - rather mad, since he constantly shouts without addressing anyone: "The man's eyes burned through everyone who at first received his scream personally" (SL 54). Bhabha's notion of the third space which "gives rise to something different, something new" ("Third Space" 211) is undermined in this passage as the novel suggests that a permanent state of liminality is frightening and not desirable. The immigrant seems to blend into non-existence because he cannot be identified, cannot even identify himself and as a result is completely powerless and helpless.

This message is also emphasized in the liminal spaces Patrick and Temelcoff occupy. Thus, during the construction of the Bloor Street Viaduct, Temelcoff can be seen working not only on the bridge, but mostly below it, hanging suspended in "all that space" (SL 35) between the unfinished bridge and the river below, "lost to that community of men on the bridge" (SL 39). While Meredith Criglington comments that "the lyrical descriptions celebrat[e] the dignity, skill, and grace of Nicholas Temelcoff on the bridge" (139), the horror of his job is equally shown. One memorable description of his stepping over the edge "into the clean air" (SL 42) is located right next to a description of silent films in which a blindfolded Chaplin is about to step over the edge of a balcony and the narrator states, "These comedies are nightmares. The audience emits horrified laughter" (SL 43). The similarity of these two scenes and their close proximity to one another suggest a deliberate connection between them, especially considering previous instances of this ordering strategy, such as the use of cinnamon in Running in the Family. ${ }^{36}$ The narrator's comment on Chaplin must accordingly also be applied to Temelcoff. His disconnected state in the empty space under the bridge is not only literally dangerous but also symbolic in terms of his isolation and disconnection in the process of integrating into his new country.

36 See page 318 , note 34 . 
This space also has transformative effects in a metaphorical sense. It is a stage that has to be passed through to get somewhere else, to start a new life. Accordingly, the next time Temelcoff is mentioned in the narrative after the episode on the bridge, he is integrated into his new life in Toronto's immigrant community and is no longer the silent, unconnected immigrant mentioned in the previous chapter. Susan Spearey generalizes such spaces in In the Skin of a Lion and explains:

Ondaatje's vision of order is one of constant reformulation, one that depends on the diverse and multifarious range of individuals and communities in any given space, and one that involves the dialectical play of powers within and between the boundaries which divide these groups. In the process of such dialectical play, as in migration and metamorphosis, the disorientation caused by the shifting of parameters enables reorientation, reformulation. Existence in liminal areas in which contexts or frameworks of order become unclear allows for revision of such order. (56)

These liminal spaces thus change the "order" and "boundaries" they come in touch with as well as the people who inhabit them which is clearly reminiscent of the way transnational social spaces come into existence. After all, they are a result of the revision of what Vertovec calls the "identities-orders-borders" of nationstates ("Migrant Transnationalism" 158). Yet, it also shows the difference between transnational space and liminal space because permanently being in the latter will still lead to displacement and exile as in Bhabha's notion of liminality, which the example of the immigrant in union station suggests. As with Bhabha's third space, there is constant change and constant hybridization, which does not allow for stability that would make identification possible and would also preclude agency as the example of the immigrant in Union Station showed. Hence, this space also has to be left at some point since otherwise the "images of metamorphosis" (Spearey 48) which occur in it will never end and prevent connections to others as well as a somewhat coherent self-understanding. After all, for any kind of belonging and groupness, there needs to be commonality and connectedness. Commonality among people can hardly persist if a person never stops metamorphosing for even a moment. Liminality then becomes a space between a person and community that excludes the liminal subject from what surrounds the liminal space.

However, if this space is merely passed through, it leads to changes, "reformulation" and "revision" which for the migrant figures of the novel results in the formation of transnational social spaces and transnational identities that encompass the originals as well as change them. ${ }^{37}$ For the novel's characters, passing

37 Criglington (134), Winfried Siemerling (97) and Spearey (56) all mention the transformative effect the liminal space between bridge and river has on Alice who starts a new life after her fall from the bridge. None of them relates it to Temelcoff, though. Notably, her fall will also eventually result in the friendship with Temelcoff and thereby her introduction to the immigrant 
through liminal space is thus a period of adjustment, which allows them to change in such a way that they can connect to their new environment, which will, however, also be modified through these spaces. ${ }^{38}$

This is illustrated well in the character of Patrick. He, too, occupies transformative spaces repeatedly, of which I will only focus on two here, the Island of the Blind and Union Station. While the island may at first not seem like a particularly liminal space, it is nevertheless in an in-between location because on the one hand it is land, but on the other hand it is disconnected from the mainland and surrounded by water. Patrick's being on it illustrates his continuing lack of belonging. It echoes John Donne's "No man is an island, entire of itself; every man is a piece of the continent, a part of the main" (1305). Patrick, however, is depicted as such an island in his disconnection from all community. Unlike Temelcoff, Patrick unsurprisingly has to pass through several transformative spaces until he finally changes and becomes able to connect to his surroundings. The scene of the Island of the Blind is very evocative in this respect, because it highlights the theme of blindness usually associated with Patrick. On the island he is able to see, but lacks other senses that are needed there and relies on a blind woman he meets on the island to guide him through it (SL 168-71). He is thereby still separate from the community surrounding him in this space. As a result, this transformative space cannot change Patrick either: the woman symbolically blinds him before he leaves by covering his eyes with her hands (SL 170) so that Patrick is not transformed but returns to the mainland still unable to see.

His transformation finally takes place almost at the end of the storyline when he returns from prison and passes through Union Station, in a passage which is charged with allusions to all the things that kept him from connecting throughout:

A group of redcaps were standing with three large cages full of dogs, all of whom were barking like aristocrats claiming to be wrongly imprisoned. [Patrick] went up to the cages. They were anxious with noise. He had come from a place where a tin cup against a cell wall was the sole form of protest. He got closer to the cages, looked into the eyes which saw nothing, the way his own face in prison had looked in a metal mirror.

He was still crouched when the redcaps wheeled the cages down the ramp. On his knees in Union Station. He felt like the weight on the end of a plumb-bob hanging from the very centre of the grand rotunda, the absolute

community and its transnational space. It is likely also the moment of Temelcoff's transformation because "he sees the landscape as something altered" after that night (SL 48).

38 Regarding this, Sergio Perosa offers an interesting analysis of how the immigrants' work at "linking devices" (185) such as the bridge leads to changes in the structure of the city and turns it into a space that is "suited for new nomads, internal as well as external nomads, rather than settlers" and makes Toronto a place of "interchange and integration" (186). It symbolizes how the influence of liminal, transformative spaces can affect its surroundings. 
focus of the building. Slowly his vision began to swing. He turned his head to the left to the right to the left, discovering the horizon. (SL 210).

In this moment Patrick becomes aware of everything that has separated him from others all along. His silence is contrasted with the noise of the dogs and he sees his blindness reflected in their eyes. He now begins to see and recognizes the horizon, which clearly evokes the "terrible horizon in him beyond which he couldn't leap" (SL 157) but is now able to. With the beginning of the following paragraph "[h] moved tentatively into the city" thereby crossing the "horizon" and once he arrives in Temelcoff's bakery, Temelcoff greets him with "[t]he grip of the world" (SL 210) so that Patrick, too, has finally reached a state of connectedness.

\subsubsection{Narrating the Self}

Another last step is needed for both characters to finally develop transnational identities: the awareness of their multiple connections and affiliations which will lead to a change in their self-understanding. This last change occurs through the use of narrative through which Patrick and Temelcoff will narrate their transnational selves. In the scene that gave the novel its title, Alice tells Patrick of a play in which a number of actresses took turns playing the central character. To demonstrate whose turn it was, they passed around a storyteller's coat decorated with skins. The narrator comments, "Each person had their moment when they assumed the skins of wild animals, when they took responsibility for the story" (SL 157). Speaking and telling stories is thus a sign of power and agency and taking up the skin and narrating a story is a symbolic act to identify as the hero of the play. A similar act also occurs in both Temelcoff and Patrick's final deliberate identification with their transnational identities and ways of life. After all, the act of publicly speaking and telling one's story equates to identification with it and shows a character's self-understanding which in Patrick and Temelcoff's case is made up of references from multiple places and cultures. By telling their stories these two will then identify with their transnational selves.

So far, both Patrick and Temelcoff have found ways to connect to their new environments and are both equally part of a transnational social field: Patrick, the native Canadian, is integrated into the immigrant community and Temelcoff, the immigrant, in addition also is "a citizen here, in the present, successful with his own bakery" (SL 149). However, both characters are only engaged in ways of being without emphasizing their transnational belonging. The text stresses that "Nicholas Temelcoff never looks back. He will drive the bakery van over the bridge with his wife and children and only casually mention his work there" (SL 149). Criglington therefore assumes that " $[\mathrm{w}] \mathrm{ith}$ his immigrant's desire to integrate, Nicholas has repressed his old identity" (135). He has hardly suppressed it, though, since he still lives in the immigrant part of town and accordingly still is 
part of that community (SL 210). Nevertheless, he does not seem to highlight his connections very much because he is too busy forging new belongings to pay much attention to the old ones. As he says, "That was all he had time for in those years. Language, customs, family, salaries" (SL 149). Nonetheless he is still located in transnational space, which is cleverly depicted in his use of and history with the bridge. Criglington thus points out, "Nicholas Temelcoff, the focal character in 'The Bridge' chapter, personifies the bridging metaphor" (134). He can literally be seen to link and travel back and forth between two worlds. Yet, by not emphasizing this he is only engaged in ways of being a part of transnational space.

However, Temelcoff changes during the course of the novel and eventually develops ways of belonging, and he does so through narrative. This change is induced by Patrick who finds out that Temelcoff worked on the bridge and confronts him with his past thereby giving Temelcoff a "gift" which for him is an "arrow into the past, [that] shows him the wealth in himself, how he has been sewn into history. Now he will begin to tell stories" (SL 149; see also Criglington 135). In taking up the narrative, Temelcoff then begins to tell the story of his 'self', and reinforces his transnational self-understanding in the process. He thereby changes from merely being transnational to transnational ways of belonging since taking up the narrative is also a statement that identifies him with his past and his Macedonian heritage.

Similarly, Patrick's being part of the immigrant community is at first merely a matter of being but turns into ways of belonging also, which nevertheless has its setbacks and takes much longer than Temelcoff's. Criglington states that "Patrick is adopted by the immigrant community in Toronto's east end, and he in turn takes charge of Hana as his adoptive daughter" (147), the symbolic value of which is even further emphasized by Branko Gorjups' fitting assessment of Hana as "the symbolic daughter of the entire community" (94). Even though adopting Hana is a significant statement that aligns Patrick with his new 'country' of the immigrant community in ways of belonging, he cannot entirely belong to it until he is able to articulate it through language. Accordingly, there is a doubleness to his adoption of Hana, which is linked to his use of language. He at first tells Alice that he wants to "look after Hana [...]. More formally" (SL 158) but eventually cannot accomplish what is necessary by this quasi adoption of the girl. Ingelbien shows that after Alice's death Patrick relapses into silence as symbolized in his return to darkness (35; see also Schumacher 15). Patrick clearly has not yet learned to produce light of his own and relies on others to connect him to a community.

Accordingly, he cannot take up the responsibility for either his story or Hana's because he has not yet discovered a voice of his own. Strikingly, he leaves Hana with Temelcoff when he goes off to burn down the Muskoka hotel, knowing full well that he will probably be caught and imprisoned so that he will be unable to fulfil his responsibility as her father (SL 211). Only when he manages to find a voice and pass the space between him and community at the end of the novel, is 
he finally able to announce to Clara "I am her father" (SL 218) which formalizes the adoption of both Patrick and Hana. It is also at this point that he takes up the lion's skin and becomes a story teller who on their journey to Marmora tells her the story that is contained in the novel as the frame indicates: "This is a story that a young girl gathers in a car during the early hours of the morning" (SL 1; emphasis in original). It is a story that locates Patrick in the immigrant community and as well introduces Hana to her heritage (Criglington 132; Gorjup 94; Overbye 12). It also altogether emphasizes the transnational lives of father and daughter by highlighting their various affiliations and belongings and the fusion of different nationalities in their family.

In addition to this, Stolar points out that telling Hana the story of her community also turns Patrick into a "spokesperson" for the immigrants (128). She further states, "The political force of the revolutionary immigrant is thus transferred to the English voice that has been naturalized an immigrant voice by virtue of his choice of urban residence and employment" (128). She fails to see that Patrick is only able to use his "English voice" because he has finally learned to use language effectively. Yet, the story of his learning the language doubles back to the immigrants because Patrick begins to learn to use language through Alice when she introduces him into the community. Alice's connection to the immigrant community, however, in turn started by the bond formed between her and Temelcoff on the night she fell from the bridge when she became his "twin" (SL 49). Patrick would not be able to be the person he is at the end of the novel had it not been for the influence of the immigrant community in his life. Patrick's becoming a representative of the immigrant community thus becomes another instance in which "the whole idea of socio-cultural centrality is undermined" in the novel (Vauthier 72) since the Canadian protagonist of the novel is only able to act when he is no longer purely Canadian. There is hence no longer just one dominant homogeneous national culture, which dictates the behaviour of minorities and forces them to assimilate to its order but the immigrant minorities can be seen to change their host country from within and to be much better suited to living in such heterogeneous nations (see also Werth 127). Accordingly, the national space of In the Skin of a Lion's Canada becomes a transnational space in which the formation of transnational identities is possible.

\subsection{The English Patient: Transnational Dreams}

The English Patient just as In the Skin of a Lion makes abundant use of symbolic spaces to depict its characters' identities while also applying the fusion of boundaries characteristic of Anil's Ghost and Running in the Family. As Ondaatje's most famous and therefore most thoroughly researched novel, there are a plethora of different opinions concerning its stance towards the interplay between nations and 
identities. For example, while some comment that it undermines the idea of nation-states' power as a source of identity (Burcar 99; Papayanis 223), others emphasize how it provides an image of life in a postnational world (Delbaere 49; Ibarrola-Armendariz 41; Kella 92). Others again claim that the latter is then destroyed by the continuing power of imperial nation-states in a reaffirmation of nation-states' power (Burcar 109; Goldman 190). Consequently, it is also argued that the novel eventually negates the idea of identities that cut across national boundaries and reasserts national belonging (Kemp 151; Turcotte 70). A thorough analysis of its use of spaces and its dissolution of boundaries will reveal quite different results. These are emphasized by a comparison of Kip and the English patient who are the novel's two central migrant figures and who are much more different than they initially appear. Through this the novel also comments on transnational identities and ways of life and the chances of their survival in a world dominated by nation-states.

\subsubsection{Two Transnational Spaces: the Villa and the Desert}

Two transnational spaces figure prominently in the novel: the Italian villa community, made up of Hana, Kip, Caravaggio and the English patient, and the African desert explorers' community which the patient recalls in his memory. Both groups constantly negotiate questions of nationality and belonging which as in In the Skin of a Lion are expressed through the relationship between its characters and the spaces they inhabit. The community in the desert and in the villa seem models for transnational connectedness at first. The characters in the villa coexist peacefully without negating their cultural and national differences (see also Younis, "Race" 55-56). They are thus not separated from their past as Jeanne Delbaere claims (49) and have not "shed the clothing of their countries" either (Papayanis 235) but on the contrary still feel strongly connected to the places they left behind. Hana frankly states her affiliation with "Upper America" (The English Patient 81) (39 $^{2}$ and is clearly very attached to Canada for which she feels homesick (EP 135). Kip similarly freely admits to his Indian heritage (EP 81) and, for example, continues to wear his turban, which connects him to his religion and through it to his home in India (EP 79). All of them share the common experience of migration and are equally scarred by the war in which they all were involved and can thus relate to one another despite being of different nationalities.

Yet, they do not only tolerate each other's differences, they also actively attempt to transcend national and cultural affiliations by collapsing the boundaries between their countries. Hana wishes she could take Kip to Canada to show him her world there (EP 137) and, "[d]uring the verbal nights, they travel his country

39 Henceforth EP. 
of five rivers" (EP 288) together, Kip not only envisions but narrates into existence a life for him and Hana in India:

He guides her into the great gurdwara, removing her shoes, watching as she washes her feet, covers her head. What they enter was built in 1601, desecrated in 1757 and built again immediately. In 1830 gold and marble were applied. 'If I took you before morning you would see first of all the mist over the water. Then it lifts to reveal the temple in light. You will already be hearing the hymns of the saints - Ramananda, Nanak and Kabir. Singing is at the centre of worship. You hear the song, you smell the fruit from the temple gardes - pomegranates, oranges. The temple is a haven in the flux of life, accessible to all. It is the ship that crossed the ocean of ignorance.'

They move through the night, they move through the silver door to the shrine where the Holy Book lies under a canopy of brocades. The ragis sing the Book's verses accompanied by musicians. [...] Kip walks her beside a pool to the tree shrine where Baba Gujhaji, the first priest of the temple, is buried. (EP 288)

Kip's description of his India collapses all boundaries of distance and time. It is not an imagined future, which he and Hana could one day share, but it is a space they inhabit immediately as the use of the present tense indicates. Kips "guides her" and watches "as she washes her feet", and while his account of the river and the singing is at first something she "would" hypothetically hear, it soon switches to a present that seems to envelop Hana as well who can also "hear the song" and "smell the fruit". Together they "move" through a place, which is geographically far away but simultaneously present for them in Italy, "in [Kip's] tent, in 1945, where their continents met in a hill town" (EP 239). It is a perfect symbolic representation of a transnational social space which is at the same time both here and there. Caravaggio and the English patient are likewise equally enamoured with this idea of connectivity since Caravaggio wishes for Kip and Hana to be married (EP 284) and the patient sees in Kip a fellow "international bastard" who lives independent of national boundaries (EP 188).

Instances of simultaneity and fusion of spaces abound throughout the description of the villa and additionally reflect this theme. Like its inhabitants it is "in near ruins" (EP 29). There are holes in its walls (EP 12) and some walls are altogether missing (EP 14). Nevertheless, the house "had adapted itself to this wound, accepting the habits of weather, evening stars, the sound of birds" (EP 12). The boundary between inside and outside has thus become blurred and the villa seems to encompass both at the same time. It is as if the trompe l'oeil that covers the patient's room (EP 33) has become real in the space of the opened up villa as its walls have become "interchangeable with living gardens" (Papayanis 235). Kip's tent in the villa's garden likewise presents a fusion of spaces since it is both a mere tent and also almost a part of Kip's body, "a khaki wing he folds over himself 
during the night" (EP 135). It is his "world" (EP 135), and as Elizabeth Kella observes (100), Kip even symbolically sleeps half inside, half outside his tent (EP 81) which locates him simultaneously in his private world in the tent and the world surrounding it.

Similarly, the desert is another "in-between space $[\ldots]$ where the concept of national enclosures and imperial boundaries collapses" (Burcar 103). The patient explains that "it is easy to lose a sense of demarcation" there (EP 20) because "nothing was strapped down or permanent, everything drifted" (24). The desert, too, is a "trompe l'oeil", both real and at the same time a painting of "time and water" (EP 257) which makes it possible for the community of desert explorers to reconcile irreconcilable differences there. Thus they can be in the oxymoronic state of being "desert European[s]" (EP 260), simultaneously belonging to both the desert and Europe. Like the inhabitants of the villa they can likewise be "planetary strangers" (EP 259; see also EP 49): different but nevertheless connected in the same "system" (EP 79). Both communities are therefore connected by a sense of transnational groupness.

However, for all its emphasis on connectedness, the novel from the start points out the inevitable destruction of these two transnational spaces, which is foreshadowed long before the war and the dropping of the atomic bombs. The atmosphere in both the desert and the villa constantly stresses the illusionary nature of both spaces. At times they appear like the magical landscape of fairy tales in which - in the case of the villa - characters from books come alive as when Kim's entrance into the villa community seems to Hana as if he has stepped out of Kipling's Kim (EP 117) after "those long nights of reading and listening" (EP 118). The patient's "talk[ing] in his circuitous way" (EP 95) in addition portrays him as a storyteller who imagines stories such as "the half-invented world of the desert" (EP 160). It is made clear that he does not care about "the outside world" (EP 152), namely reality, which is especially apparent in the patient's description of the desert.

The patient's desert is an otherworldly, mystic place filled with eclipses and the "half-darkness of the covered sun" in which power is drawn "into his body from the universe" while he is surrounded by the eerie sounds of "wind chimes" (EP 9) and clinking glass bottles through which one can see "translated light - blues and other colours shivering in the haze and sand" (EP 10). At times he is not even sure if this is dream or reality (EP 24). ${ }^{40}$ In any case, both places seem more like fantasy structures than reality and bear little resemblance to their real counterparts which is unsurprisingly emphasized by descriptions of the villa as a "miniature world" (EP 49) which just as the desert community is separated from the outside world (EP 42; 118; 156). These places appear to exist in and of themselves, com-

40 One could argue that the patient is at this stage somewhat delusional because of the burns he suffered in the plane crash but his obsession with the dream-like, invented character of the desert can be found even before that. See for example EP 261-62. 
pletely cut off from the world that surrounds them. However, if they are not part of the real world they cannot really be transnational spaces, which would require an overlap of spaces that cannot take place if their boundaries/separateness are insisted upon. There is a logical breach at the centre of both transnational spaces and communities which reveals all transnational connectedness to be only a dream, which like the patient's trompe l'oeil only seems true in moonlight (EP 33).

This leaves an apparent paradox since on the one hand the desert and the villa clearly are described as transnational spaces but on the other hand they are characterized in a way that makes their existence impossible. The narrative perspective of these passages clears up the confusion. Hence, the emphasis on the villa's separateness from all other communities is mainly voiced from Hana's perspective or a description of Hana's behaviour. She is the one who feels "secure in the miniature world she had built" (EP 49; my emphasis) and not unlike her father, Patrick Lewis, she is characterized by a certain degree of blindness. She can be seen "closing her eyes against the world around her" because she cannot take the trauma in the war hospitals around her any longer (EP 51). Furthermore, her obsession with the English patient further stresses her desire to escape reality. She wants to "throws herself out of the world to love a ghost" (EP 47) because "[t]here was something about him she wanted to learn, grow into, and hide in" (EP 54). That she has succeeded in this wish becomes apparent in her way of talking about the villa. By describing it as a world of its own, she likens it to the patient's description of the desert and thereby admits that she has taken up his perspective of these transnational spaces. This is completely at odds with the model of transnational connectedness Kip expresses as shown above. This clash introduces a destructive potential into the space of the villa. It can best be seen in the patient's and Kip's approaches to cross-national situations which, upon closer inspection, are radically different from each other.

\subsubsection{Kip and the Patient as Contrasting Migrant Figures}

The English patient and Kip at first seem to be very similar characters since both are migrants whose lives span several countries. Kip with his Indian background does not only identify with India as seen above but also with England because in colonial India he was brought up with traditions from both countries (EP 301) and during his time in England he started "to love the English" (EP 202). Likewise, the patient appears to be connected to several cultures and nations. In addition to English, he can speak German and appears as equally familiar with the cultures of England and the rest of Europe (EP 101) as with the tribes of the North African desert (EP 144). As Rufus Cook sums it up, "So extensive is his learning that he seems to transcend time, place, and ethnic origin; he feels equally at home among the English, the Bedouin, and the ancient Greeks or Egyptians" 
(45). However, he claims to have forgotten his nationality because of his accident (EP 6) and consequently cannot be named or identified (EP 102).

The patient nevertheless stresses the similarities between himself and Kip, and there are certainly many. In addition to their shared migrant background, they are both equally self-sufficient (EP 134, 252), they value their independence above all (EP 135, 253) and are defined by the skill of their respective professions (EP 116, 255). Kip is furthermore enthralled by the patient's encyclopaedic knowledge which leads to their frequent discussions of a diverse range of topics, for example the defusing of bombs (EP 95). Because of this Kip is repeatedly found sitting on the patient's bed, which leads the latter to liken this scene to a painting by Caravaggio, David with the Head of Goliath. The painting shows David gazing at the face of Goliath, in which David's face is supposedly modelled after the young Caravaggio and Goliath has the face of Caravaggio in his old age. The patient concludes, "Kip is my David" (EP 123) and sees his younger self reflected in the sapper (see also Kella 109), thereby stressing the similarities he sees between them.

Nevertheless, there are also striking differences between them which the patient and Kip, too, initially fail to see. Kip clearly attempts to lead a transnational life, which can be discerned in the description of his time in England. After initial difficulties and alienation (EP 199), he joins Suffolk's team and "stepped into a family, after a year abroad, as if he were the prodigal returned, offered a chair at the table, embraced with conversations" (EP 201-2). Even though other English people do not recognize him as an equal and categorize him as 'other', thereby stressing that for them he does not belong to their nation (EP 209, 225), the relationship with Suffolk and his group is marked by respect and acceptance. Markedly, throughout the chapter "In Situ" which recounts his experiences in England, he is not called 'Kip' as in the rest of the novel, but by his real name 'Singh' which consequently highlights his Indianness but does not thereby distance him from the English around him. ${ }^{41}$ On the contrary, this is the chapter in his life in which he is most accepted into English society and actually feels he belongs there as part of Suffolk's family. ${ }^{42}$ After Suffolk's death and Kip's departure from England his identification with the country does not change: "Kirpal Singh had been befriended, and he would never forget it" (EP 199). Nonetheless he is always aware

41 Towards the end of the chapter, Miss Morden calls him Kip once (EP 215) but as was stated before, "Lord Suffolk and his demolition team took to calling him by his nickname, which he preferred to the English habit of calling people by their surname" (EP 94). The narrator's usage of Kip's real name clearly emphasizes a different, more accepting attitude towards Kip's difference without attempting to familiarize him by "translat[ing] [him] into a salty English fish" (EP 93-94). Likewise, he is also referred to as Kirpal Singh a few times towards the novel's end after he has rejected any idea of transnational belonging and has re-established his national identity (EP 305, 307).

42 The emphasis on the respect for Kip's difference expressed through the use of his real name is strikingly absent in the transnational space of the villa. 
of his "invisibility" to most English people which results in the self-sufficiency he shares with the English patient (EP 209).

His desire to affiliate with England does not solely stem from his friendship with Suffolk, though. As Younis explains he began to "love the English at an early stage" and does not view them merely as colonizers even though his family is negatively affected by the colonization of India ("Nationhood" 5). After all, his brother is in jail as a consequence of his anti-colonial resistance (EP 287-88). Nevertheless, Kip "seems to have a more fluid sense of the relation between nation and identity [and] seems to reject the stark binarism that characterizes a number of accounts of the relationship between colonial expansion and post-colonial affirmations of independence" (Younis, "Nationhood" 5). Thus, he defends his choice to fight in an English war even though he is Asian and Asia is colonized by the English. For Kip loyalties are a much more differentiated matter: "Japan is part of Asia, I say, and the Sikhs have been brutalized by the Japanese in Malaya. But my brother ignores that" (EP 230). He defiantly struggles to defend his transnational self-understanding, even if it means that he has to disagree with his family.

The patient on the contrary may have forgotten his nationality but he certainly has not forgotten his hatred of the very concept of nations. During his time in the desert he develops a strong desire to "Erase the family name! Erase nations!" by which he claims people are deformed (EP 148). As a consequence he reconfigures the formerly transnational space of the desert into a postnational "pure zone" (EP 262) devoid of all markers of nationality and belonging. He states:

The desert could not be claimed or owned - it was a piece of cloth carried by winds, never held down by stones, and given a hundred shifting names long before Canterbury existed, long before battles and treaties quilted Europe and the East. Its caravans, those strange rambling feasts and cultures, left nothing behind, not an ember. All of us, even those with European homes and children in the distance, wished to remove the clothing of our countries. It was a place of faith. We disappeared into landscape. Fire and sand. (EP 147-148)

This is the place in which, according to the patient, the former desert Europeans become "their best selves" (EP 262), which are "nationless" (EP 147) and their "own invention[s]" (EP 262). The postnational idyll lined out here, however, must be considered very critically because by turning the desert into a postnational space, the patient denies the existence of the histories and cultures of its inhabitants who, according to him, "left nothing behind". His behaviour has consequently been described as "arrogantly Eurocentric" (Kemp 143) and "a form of grotesque narcissism" (Shin 218). In addition, the patient refuses to notice that not everyone shares his naive view of the desert and that his charting of it will inevitably be used for imperial pursuits, which makes him responsible for its destruction (Papayanis 223). The ones who attempt to be postnational are as a result 
portrayed as being able to cause just as much harm as those with a nationalist agenda. The patient's postnational dreams clearly fail to grasp that even if he tries to disassociate himself from nationality, nation-states nonetheless possess great power which must be reckoned with.

Nevertheless, the patient's view of an idyllic nationless world is "seductive" (Goldman 185) and both Hana and Kip fall under its spell. As shown above, Hana subscribes to the patient's idea of communities which are separated from the world and in sharing his dream of postnationality becomes his "true heir" (Papyanis 236). Kip comes to regard him as a father figure: he "believed in the burned man and the meadows of civilisation he tended" (EP 313). This makes it easy for postnational thoughts to slip into the villa community and erode its transnational potential just as the community in the desert was destroyed. Through this, the text makes an adamant statement that hiding from the world and effacing differences is not an answer to the question of how to reconcile national differences. This is also distinctly represented in the character of the patient. As Cook remarks, the patient is the "most thoroughly negated or nullified character in the novel" and turns into "a synonym for absence or anonymity" (R. Cook 46). This is not a result of his absorbing too many cultures (R. Cook 46), though, but on the contrary a result of his rejection of all affiliations and connections. Even the patient understands this towards the end: "He is exhausted not from the desert but from solitude" (EP 187). To be postnational then is to be isolated and reduced to nothingness. Thus the patient's postnational dream ultimately is dismissed as a dangerous delusion (see also Smyrl 15).

Kip's painful recognition of this is symbolized in his final scene with the patient. After he heard of the dropping of the atomic bombs on Asia he confronts the patient in a manner which resembles their previous conversations and thus their pairing as David and Caravaggio. However, this time he points his rifle at him and watches him through it, undecided as to whether he should shoot him (EP 302-3). In a reversal of the former scene it is now Goliath who shows David his future, which is filled with death as the burned patient clearly resembles the dead in Hiroshima and Nagasaki (see also Kella 109-10). Postnational behaviour is thus portrayed as inevitably resulting in destruction. In addition, Kip's accusation that the bombs would never have been dropped on a white nation (EP 304) furthermore emphasizes that even transnational belonging is not possible for Kip because, as before, he would not be accepted in England as a colonial and nonwhite person. He will always be identified and categorized as the other who does not belong there. As Delbaere points out, the scene emphasizes "the precariousness of human efforts to do away with the carcans of nations and races and to rechart the world in terms of a global community" (55). At this point in the novel, both transnational and postnational identities are rendered impossible. 


\subsubsection{Transnational Illusions?}

So far, the novel offers a grim perspective on the formation of transnational identities. The promising initial transnational connections in the novel have turned out to be illusions. Any trace of transnational sentiments that had been left in Kip immediately disappears upon his hearing of the news of the atomic bombs. He is "separate from the world" (EP 301) in the patient's room, which is "crowded now with the world" (EP 303). The two worlds mentioned here clearly stand for two very different things. Kip is exiled from one of these worlds, the villa community, and arrives in the other, in his real world again which is dominated by conflict between nations and cultures. Brutally confronted with real life he can no longer remain part of the postnational villa community and realizes that any connectedness on his part to a Western nation will ultimately be denied so that he must leave. In fact, he seems already partly gone while he still occupies the villa's space, which is conveyed by frequent references to Kip's body surrounding the immediate news of the bomb. Hana remembers the "line of movement Kip's body followed out of her life", she hears "a scream emerge from his body" (EP 300) and can see that "his brown face is weeping" (EP 301). The Kip who travelled with her to India in his mind is no longer there, though. He seems split, his mind and personality already elsewhere while only his body remains.

This is further emphasized by his reassertion of a purely Indian identity. He can no longer be connected to several nations and realizes that he is no longer Kip but "Kirpal Singh and he does not know what he is doing here" (EP 305). As a consequence, he rejects his British uniform in favour of traditional Indian clothes (EP 305) and finally leaves. The breach seems irrevocable as his return journey indicates that he can no longer occupy transnational spaces. Having been fascinated with churches and Christian art throughout the novel, he can now no longer enter the church he wants to revisit, "unable to enter the intimacy of a home" (EP 310). Thus the community is disbanded: Kip has left, the patient dies and with him his postnational ideals, and Caravaggio and Hana return to Canada. It seems as if the possibility of transnationality has only been an illusion (see also Kella 102).

It is important to note that the novel does not end like that. Delbaere stresses that an attempt at some reconciliation is already made through the novel's use of intertextuality during Kip's journey home. Riding on his motorcycle he cannot shake off the image of the patient who seems to sit in front of him and sings Isaiah to him. She explains, "[t] he words that 'shall not depart out of [Kip's] mouth' (p. 294) are those of Isaiah who, as we know, prophesied the recovery of the garden in which the wolf would dwell with the lamb and the leopard with the kid" (Delbaere 55-56; emphasis in original). There is still hope that differences can be reconciled which is further affirmed in the unbroken connection between Hana and Kip (see also Papayanis 237). Younis sums up the novel's sentiment precisely: 
[T]wo nations, two nationalities, meet and the space of the intersection is transformed, for the result is memorable and affirmative. The implication is touching and unexpected: despite the evolution of their lives as individuals and family persons, the things that they shared have a quiet and sustaining vitality and an undiminished, secret life that bridges worlds, countries, and modes of being.

The novel suggests ultimately that Kip and Hana are not alone; that the secret connection between them is irrevocable. In this way, the novel's end suggests, once again, to be sure, that it is the things that bring two nationalities or two people together, and not the things that separate them, that are ultimately of the greatest value. ("Nationhood" 7)

A new transnational space is created which allows Hana and Kip to again collapse space and time as during their time in Italy and this space is so strong that it is almost possible to physically connect across the boundaries of Hana and Kip's nation-states as symbolized through Kip's catching the glass Hana drops in Canada as well as his daughter's fork in India (EP 321). Thus, transnationalism is not ultimately rejected in the novel but tentatively but nevertheless hopefully reaffirmed. The transnational space that was opened up in the villa community was not an illusion, but a dream of a future in which transnational identities become possible. It seems to echo the ending of Forster's A Passage to India. As with the friendship between Aziz and Fielding, the message for Kip and Hana's younger selves is "No, not yet,' [...] 'No, not there." (Forster 288). However, it is not Kip who connects with Hana in this passage but Kirpal (EP 321) and as the use of Kip's real name emphasizes, only when both parties have equal rights and there is no attempt to level out the differences between them can there be a connectedness that will not discriminate against one of them. The novel therefore distinctly rejects a postnational view of the world but on its last pages returns to the vision of transnational identities from the start, yet under more hopeful auspices.

\subsection{Divisadero: Piecing Together Imagined Worlds}

With Divisadero, the theme of transnational identities and the spaces in which they exist at first glance appears to have come to an abrupt halt. Even the usual focus on connectivity that figured so prominently in Ondaatje's previous fiction appears to be missing. The narrative diverges and splits into two seemingly very different, unconnected narrative strands: the novel's first part is concerned with the lives of Anna, Claire and Coop in California, their traumatic separation after Anna's father tried to kill Coop, her boyfriend, Claire and Coop's eventual reunion and Anna's moving to France to investigate the life of the fictional writer Lucien Segura. The second and third parts leave this storyline altogether - except for a few brief 
glimpses of Anna's life in France - and focus on the life of Lucien Segura. Subjectwise, this latest of Ondaatje's novels is not as expressly concerned with the formation of transnational identities as the texts previously analyzed. Yet, I am going to read it as an outlook on the further development of these issues in Ondaatje's fiction. Reviewers have called Divisadero "oblique, glancing and frustratingly inconclusive" (Parker) and "a more stubbornly eclectic Ondaatje book than most" (Maslin). Taken at face value it certainly is but a more thorough analysis reveals such astonishing parallels that Divisadero might well be seen as a dissolution of boundaries taken to extremes.

\subsubsection{Anna's Journey}

While Divisadero seems radically different from Ondaatje's other novels, this latest book shares a common motif with the previous ones: a journey. As shown above, journeys in the other texts, however, are not only literal journeys of the characters but contain an additional deeper, symbolic meaning. Considering this, Anna's travelling to France deserves special attention since in Ondaatje's fiction a journey never appears to express a mere change in location. Unusually, on the surface Anna's voyage does not offer much in terms of the transnational connectedness or any connectedness for that matter - which figures so prominently in the other books I have analyzed. Even though the novel's protagonist travels to another country, her journey is just that: a journey. As she says, she "came to France [...] to research the life and the work of Lucien Segura" (Divisadero 135) ${ }^{43}$ which does not convey an intent to stay permanently. On the contrary, she makes it clear that this is not "her real world" (D 66). Yet, it is hard to say what Anna's real world is if one considers her life up to the point of her arrival in France. In terms of plot, she got estranged from her family, ran away, studied French at university ( $D$ 89) and eventually became a professor of French Literature ( $D$ 88). Home or belonging are accordingly difficult to define for her.

Interestingly, from the beginning Anna does not only surround herself by everything French but also uses it as an escape from real life. Thus she pretends to be a "French girl" on her flight from home (D 144) by not speaking English to the man who gives her a lift in his car $(D$ 147). While this could be explained as a mere attempt to advert unwanted conversation, the influence of French culture on her life becomes more substantial later on. As her constant references to French literature show, she clearly sees her life reflected through these books. For example, she compares her Californian history to Balzac (D 13), a practice which she continues during her stay in France, likening the landscape of Europe to Stendhal ( $D$ 77). Fiction seems to be part of her reality and as present as the landscape sur-

43 From now on abbreviated as $D$. 
rounding her which already represents an instance of if not dissolution, then certainly a weakening of the boundaries between reality and fiction.

This is especially striking since Anna also speaks of her belief that "we live permanently in the recurrence of our own stories, whatever story we tell" (D 136). Considering that she is a writer who presently works on researching the story of Lucien Segura's life, this comment certainly suggests a deeper meaning: what if she does exactly this with Lucien's life? This suspicion is further supported by several of her remarks that she enjoys "hid[ing] in a stranger's landscape" (D 75) in order to escape the violence of her past. It appears that she does exactly this while living in Segura's house in France.

Her mentioning of the "small fictional street" Hugo supposedly created for the fictional character "Jean Valjean to slip into, in which to hide from pursuers" ( $D$ 142) mirrors her behaviour. While this could be merely another instance of the abundance of references to French literature that line her narrative, her following mentioning of the street she lives on in San Francisco nevertheless introduces another element of doubt concerning the truthfulness of her story. One cannot help but wonder whether she really lives on Divisadero Street or if this is her fictional street. It would be convenient indeed if she lived on a street named after "the Spanish word for 'division,' the street that at one time was the dividing line between San Francisco and the fields of the Presidio. Or it might derive from the word divisar, meaning "to gaze at something from a distance" (D 142). Especially since she further comments: "It is what I do with my work, I suppose. I look into the distance for those I have lost, so that I see them everywhere. Even here in Dému, where Lucien Segura existed" (D 143). It would be a huge coincidence if a character who is scarred by and distanced from her past accidentally turned up on a street that fittingly reflected their behaviour with the additional benefit of describing their style of work, especially since many parts of her narrative shed similar moments of doubt on her reliability as a narrator.

Considering Ondaatje's careful structuring of his novels and the significance of even the smallest details, I cannot believe that this is done without some deliberation. Such a 'coincidence' does indeed fit perfectly with Ondaatje's tendency to dilute boundaries since it effectively blurs the line between fact and fiction and leaves the reader uncertain of what can be trusted anymore. After all, the address on Divisadero Street is one of the few pieces of information that is actually available about Anna. ${ }^{44}$ If she does not really live there and it is merely a metaphoric description of the way she leads her life, Divisadero Street could also describe her state of mind while being in France and reflecting on her past which is territorially and geographically distanced in California. The novel's structure certainly supports such a reading as the following chapter will detail.

44 She even changed her name but does not tell us her new one as the framing passages before the first chapter indicates. 


\subsubsection{Everything Is Collage}

Even though Divisadero's title suggests a division, the novel's halves are nevertheless intricately connected through a string of recurring motifs. Parts of one storyline constantly turn up in one another: the blue table of Anna's boyfriend reappears in Lucien's house in France ( $D$ 30; 70; 93; 239); the flags Anna gives to Coop are suddenly present when he is almost beaten to death by the poker players as well as when he and Claire meet his former friends ( $D$ 132; 161); Stendhal's The Red and the Black is used as a chapter heading for Coop's story in Tahoe (D 39), additionally mentioned in the narrative strand that follows Anna's life in France (D 77), while Claire and Coop accidentally meet again after years of not having seen one another in a club called "The Stendhal" ( $D$ 106). There are many more of these examples, which finely sew together the different parts of Divisadero. The lives of Anna, Claire and Coop are thus not as absent from the second half of the book as it seemed at first.

This leaves the question of why this is done. In any case, it reflects the motto that "everything is collage" which is twice mentioned by Anna during the narration of her youth (D 16-17). It also evokes her similar quotation that "everything is biographical" (D 16) and her occupation with "piec[ing] together the landscapes [Segura] had written about" (D 144). With all this emphasis on piecing together and collages, mixed with the inevitable reference to French literature - Stendhal and the notion that everything is also biographical it is not far-fetched to conclude that maybe Anna is the one who does the piecing.

Further close parallels between the events in Anna's youth and the life of Segura strengthen this perception additionally. Segura is characterized as someone who "lived mostly an imaginary life" and preferred the company of fictional characters in troubled times ( $D$ 173). At one point he finds a journal by his wife that leads to his realization that he did not know her at all ( $D$ 223) just like Anna begins to understand that she did not know her sister at all after having read her diary (D 138-9). Additionally, a number of scholarly remarks in the parts that are not narrated in first person by Anna could indicate that she, being a scholar, narrated these parts as well, including the life of Segura. What narrator would otherwise mention that they "have recently been reading, in a monograph a haunting thing" (D 142) or reflect on "Sanskrit poetics" (D 152)?

Together with her conviction that "[ $\mathrm{t}]$ he third-person voice protects us" and that "sometimes we enter art to hide within it" ( $D$ 142), the probability that all storylines are narrated by Anna is further strengthened. Her admission that "we live with those retrievals from childhood [...] making up a single monologue" ( $D$ 136) finally seems to sum up and explain the strange structure of this novel. Anna would hence be seen as the novel's narrator who invents or at least strongly influ- 
ences the other storylines. ${ }^{45}$ Having lost her home and her family she tries to imagine them in the space of the novel in which she is constantly linked to and connected with them across geographical and temporal distances. The novel can then be seen as her imagined world. However, even this conclusion is by no means certain since, after all, Anna also in a striking passage reflects upon a story of how one twin can absorb another in the womb: "And perhaps this is the story of twinship. I have smuggled myself away from who I was, and what I was. But am I the living twin in the story of our family? Or is it Claire? Who is the stilled one?" (D 141).

The only thing that can be said with certainty about Divisadero is that it is filled with uncertainty. Meaning is always open and infinite as everything in the novel seems interconnected. The longer one tries to separate the different parts, the closer they stick together. In the space of the novel all boundaries are blurred and everything is part of the other. This might make it a "stubbornly eclectic" book, to quote Maslin again, but it also makes it a rather fitting illustration of the transnational condition as 'Anna' certainly seems to simultaneously take part in all the different parts of the book.

\section{Conclusion}

Michael Ondaatje's fiction and transnational conceptions of space appear to suit one another rather well when it comes to the depiction of characters' identities. Ondaatje's description of the spaces of identity in which different nations and cultures are joined in boundary-transgressing unity precisely echoes transnationalism's perspective on the simultaneous experience of here and there of transnational lives.

Nevertheless, Ondaatje's works do not only accentuate the positive experiences of transnational identities but also address their difficulties, such as the problem of different belief systems - for example in Anil's Ghost - which suppress the successful formation of transnational identities. Touching upon a similar concern, the rejection of migrants in the country of immigration is a topic in The English Patient. The texts can therefore not be seen as a simple celebration of multicultural or postnational ways of life, but reflect the challenges many contemporary migrants are faced with in a nuanced way: all stories are marked by a strong desire to unite spaces and transcend boundaries, no matter how successful they are in achieving it and thus seem to echo contemporary forms of life and identities

45 Since already near the beginning some form of omniscience and all-encompassing presence is associated with, or better self-attributed to Anna ( $D$ 27), it would not be surprising to take up this perspective again while speculating about the lives of those she lost. She certainly thinks she "can imagine most things about Claire accurately" (D 139) even though she has not seen her in almost 20 years. 
which are not bound by the borders of nation-states. The focus on transnationalism is even present in Ondaatje's latest novel, which is hardly concerned with migration at all: in Divisadero the same concerns are addressed, even though the novel appeared completely opposed to transnational theories at first.

As my analysis of the texts has shown, theories on the phenomenon of transnational migration describe the nature of identities in Ondaatje's fiction much more fittingly than the usual postcolonial concepts of liminality and hybridity. Reading these texts from such a perspective brings out the finer points and subtleties that all his fictional works contain. The clear-cut categories usually applied to Ondaatje's writing cannot (un)cover these aspects and are not able to do the texts justice because they do not pay attention to the complex and detailed way the issue of transnational identities is dealt with in them. Hardly surprising, these ordinarily used categories are at times even downright rejected in the texts, such as in In the Skin of a Lion. It appears that Ondaatje's fiction strives to go beyond ordinary categories. Given Ondaatje's long-standing interest in the topic, starting with Running in the Family in 1982 up to Divisadero in 2007, the novels undoubtedly do not address a quickly passing trend in the perspective on migration but rather seem to reflect a different form of migration. I therefore conclude that Ondattje's fiction can be described as a different form of migrant writing altogether. It would now be interesting to compare other migrant literature to it to see if this is the beginning of a new development in migrant writing or just a singular occurrence. 


\section{Bibliography}

Primary Literature

Achebe, Chinua. Things Fall Apart. New York: Anchor, 1994.

Desai, Kiran. The Inheritance of Loss. London: Penguin, 2006.

Donne, John. "Meditation 17." The Norton Anthology of English Literature. 8th ed. Vol. 1. Ed. Stephen Greenblatt and M.H. Abrams. New York: Norton, 2006. 1305-1306.

Forster, E.M. A Passage to India. London: Penguin, 1979.

Kunzru, Hari. Transmission. New York: Plume, 2005.

Ondaatje, Michael. Anil's Ghost. London: Picador, 2000.

- Divisadero. New York: Knopf, 2007.

- The English Patient. London: Bloomsbury, 1992.

- Running in the Family. New York: Vintage, 1993.

- In the Skin of a Lion. New York: Vintage, 1997.

Roy, Arundhati. The God of Small Things. London: Flamingo, 1998.

Secondary Literature

“About Migration." International Organization for Migration. 4 June 2009. http://www.iom.int/jahia/Jahia/lang/en/pid/3.

Anderson, Benedict. Imagined Communities. Rev. ed. London: Verso, 2006.

Appadurai, Arjun. Modernity at Large: Cultural Dimensions of Globalization. $7^{\text {th }}$ ed. Public Worlds 1. Minneapolis: U of Minnesota P, 2005.

Ashcroft, Bill, Gareth Griffiths and Helen Tiffin. The Empire Writes Back: Theory and Practice in Post-colonial Literatures. $2^{\text {nd }}$ ed. London: Routledge, 2003.

- "Exile." Key Concepts in Post-Colonial Studies. London: Routledge, 1998. 92-94.

- "Liminality." Key Concepts in Post-Colonial Studies. London: Routledge, 1998. 13031.

Barry, Peter. Beginning Theory: An Introduction to Literary and Cultural Theory. $2^{\text {nd }}$ ed. Manchester: MUP, 2002.

Beck, Ulrich. " Living Your Own Life in a Runaway World: Individualisation, Globalisation and Politics." Globalization: Critical Concepts in Sociology. Vol. IV Culture and Identity. Ed. Roland Robertson and Kathleen E. White. London: Routledge, 2003. 272-80.

- Was ist Globalisierung? Irrtümer des Globalismus - Antworten auf Globalisierung. $6^{\text {th }}$ ed. Frankfurt a.M.: Suhrkamp, 1999. 
Bhabha, Homi K. The Location of Culture. Routledge Classics. London: Routledge, 2004.

- "The Third Space." Interview with Jonathan Rutherford. Identity: Community, Culture, Difference. Ed. Jonathan Rutherford. London: Lawrence and Wishart, 1990. 207-21.

Boehmer, Elleke. Colonial and Postcolonial Literature: Migrant Metaphors. $2^{\text {nd }}$ ed. Oxford: OUP, 2005.

Bölling, Gordon. History in the Making: Metafiktion im neueren anglokanadischen historischen Roman. Heidelberg: Winter, 2006.

Bowers, Maggie Ann. "Global, National and Local Identities: The Transformative Effects of Migrant Literatures." International Migration and Security: Opportunities and Challenges. Ed. Elspeth Guild and Joanne van Selm. London: Routledge, 2005. 147-56.

Brennan, Timothy. "The National Longing for Form." Nation and Narration. Ed. Homi K. Bhabha. London: Routledge, 1990. 44-70.

Brubaker, Rogers and Frederick Cooper. "Beyond 'Identity." Theory and Society 29.1 (2000): 1-47.

Burcar, Lilijana. "Re-Mappig Nation, Body and Gender in Michael Ondaatje's The English Patient." The Flesh Made Text Made Flesh: Cultural and Theoretical Returns to the Body. Ed. Zoe Detsi-Diamanti, Katerina Kitsi-Mitakou and Effie Yiannopoulou. New York: Peter Lang, 2007. 99-110.

Burton, Antoinette. "Archive of Bones: Anil's Ghost and the Ends of History." The Journal of Commonwealth Literature 38 (2003): 39-56.

Çağlar, Ayse S. "Constraining Metaphors and the Transnationalisation of Spaces in Berlin." Journal of Ethnic and Migration Studies 27.4 (2001): 601-13.

Castles, Stephen and Mark J. Miller. The Age of Migration: International Population Movements in the Modern World. New York: Guilford Press, 1993.

Chambers, Iain. Migrancy, Culture, Identity. London: Routledge, 1994.

Chan, Joseph M. and Eric Ma. "Transculturating Modernity: A Reinterpretation of Cultural Globalization." In Search of Boundaries: Communication, Nation-States and Cultural Identities. Ed. Joseph M. Chan and Bryce T. McIntyre. Advances in Communication and Culture. Westport, CT: Ablex, 2002. 3-18.

Clifford, James. "Diasporas.” Cultural Anthropology 9.3 (1994): 302-38.

Cook, Rufus. "Being and Representation in Michael Ondaatje's The English Patient." ARIEL 30.4 (1999): 35-49.

Cook, Victoria. "Exploring Transnational Identities in Ondaatje's Anil's Ghost." Comparative Cultural Studies and Michael Ondaatje's Writing. Ed. Steven Tötösy de Zepetnek. West Lafayette: Purdue UP, 2005. 6-15. 
Criglington, Meredith. "The City as Site of Counter-Memory in Anne Michael's Fugitive Pieces and Michael Ondaatje's In the Skin of a Lion." Essays on Canadian Writing 81 (2004): 129-51.

Delbaere, Jeanne. "'Only Re-Connect': Temporary Pacts in Michael Ondaatje's The English Patient." The Contact and the Culmination. Ed. Marc Delrez and Bénédicte Ledent. Liège: Liège Language and Literature: 1997. 45-56.

Derrickson, Teresa. 'Will the 'Un-truth' Set You Free? A Critical Look at Global Human Rights Discourse in Michael Ondaatje's Anil's Ghost.” Literature Interpretation Theory 15 (2004): 131-52.

Duffy, Dennis. "A Wrench in Time: A Sub-Sub-Librarian Looks beneath the Skin of a Lion." Essays on Canadian Writing 53 (1994): 125-40.

During, Simon. "Literature - Nationalism's Other? The Case for Revision." Nation and Narration. Ed. Homi K. Bhabha. London: Routledge, 1990. 138-53.

Easthope, Anthony. "Bhabha, Hybridity and Identity." Textual Practice 12.2 (1998): 341-48.

Farrier, David. "Gesturing Towards the Local: Intimate Histories in Anil's Ghost." Journal of Postcolonial Writing 41:1 (2005): 83-93.

Getachew, Mahlete-Tsigé. "Marginalia: Black Literature and the Problem of Recognition." Write Black, Write British: From Postcolonial to Black British Literature. Herford: Hansib, 2005. 323-45.

Glick Schiller, Nina, Linda Basch and Cristina Blanc-Szanton. "Transnationalism: A New Analytic Framework for Understanding Migration." Towards a Transnational Perspective on Migration: Race, Class, Ethnicity, and Nationalism Reconsidered. Ed. Nina Glick Schiller, Linda Basch and Cristina Blanc-Szanton. Annals of the New York Academy of Sciences 645. New York: The New York Academy of Sciences, 1992. 1-24.

Glick Schiller, Nina, Linda Basch and Christina Szanton Blanc. "From Immigrant to Transmigrant: Theorizing Transnational Migration." Migration and Transnational Social Spaces. Ed. Ludger Pries. Aldershot: Ashgate, 1999. 73-105.

"Global Estimates." International Organization for Migration. 4 June 2009. <http://www.iom.int/jahia/Jahia/about-migration/facts-and-figures/globalestimates-and-trends $>$.

Glover, Brenda. "'Unanchored to the World': Displacement and Alienation in Anil's Ghost and the Prose of Michael Ondaatje." CRNLE Journal (2000): 75-80.

Godard, Barbara. "Notes from the Cultural Field: Canadian Literature from Identity to Hybridity." Essays on Canadian Writing 72 (2000): 209-47.

Goldman, Marlene. "War and the Game of Representation in Michael Ondaatje's The English Patient." Re-Constructing the Fragments of Michael Ondaatje's Works / La diversité d'construite et reconstruite de l'auvre de Michael Ondaatje. Ed. Jean-Michel Lacroix. Paris: Presses de la Sorbonne Nouvelle, 1999. 181-93. 
Gorjup, Branko. "Michael Ondaatje's Reinvention of Social and Cultural Myths: In the Skin of a Lion." Acta Neophilologica 22 (1989): 89-95.

Griem, Julika. "Hybridität." Metəler Lexikon Literatur- und Kulturtheorie: Ansätz̨e, Personen, Grundbegriffe. Ed. Ansgar Nünning. Stuttgart: Metzler, 2004. $269-70$.

Hall, John A. "Transatlantic Images of Belonging." The Postnational Self: Belonging and Identity. Ed. Ulf Hedetoft and Mette Hjort. Public Worlds 10. Minneapolis: U of Minnesota P, 2002. 53-65.

Hall, Stuart. "Cultural Identity and Diaspora." Identity: Community, Culture, Difference. Ed. Jonathan Rutherford. London: Lawrence and Wishart, 1990. 222-37.

Hannerz, Ulf. "Where We Are and Who We Want to Be." The Postnational Self: Belonging and Identity. Ed. Ulf Hedetoft and Mette Hjort. Public Worlds 10. Minneapolis: U of Minnesota P, 2002. 217-32.

Harzig, Christiane and Dirk Hoerder. "Transnationalism and the Age of Mass Migration, 1880s to 1920s." Transnational Identities and Practices in Canada. Ed. Vic Satzewich and Lloyd Wong. Vancouver: UBC Press, 2006. 35-51.

Heble, Ajay. "Putting Together Another Family: In the Skin of a Lion, Affiliation, and the Writing of Canadian (Hi)stories." Essays on Canadian Writing 56.1 (1995): 236-54.

- "'Rumours of Topography': The Cultural Politics of Michael Ondaatje's Running in the Family." Essays on Canadian Writing 53 (1994): 186-203.

Hedetoft, Ulf and Mette Hjort. Introduction. The Postnational Self: Belonging and Identity. Ed. Ulf Hedetoft and Mette Hjort. Public Worlds 10. Minneapolis: U of Minnesota P, 2002. vii-xxxii.

Hollifield, James. "The Emerging Migration State." Rethinking Migration: New Theoretical and Emperical Perspectives. Ed. Alejandro Portes and Josh DeWind. New York and Oxford: Berghahn Books, 2007. 62-89.

Horatschek, Annegreth. "Kollektive Identität." Metzler Lexikon Literatur- und Kulturtheorie: Ansätz̨e, Personen, Grundbegriffe. Ed. Ansgar Nünning. Stuttgart: Metzler, 2004. 276-77.

Huddart, David. Homi K. Bhabha. Routledge Critical Thinkers. Abingdon: Routledge, 2006.

Huggan, Graham. "Exoticism and Ethnicity in Michael Ondaatje's Running in the Family." Writing Ethnicity: Cross-Cultural Consciousness in Canadian and Québécois Literature. Ed. Winfried Siemerling. Toronto: ECW, 1996. 116-27.

Ibarrola-Armendariz, Aitor. "Boundary Erasing: Postnational Characterization in Michael Ondaatje's The English Patient." Tricks With a Glass: Writing Ethnicity in Canada. Ed. Rocío G. Davis and Rosalía Baena. Cross/Cultures 46. Amsterdam: 2000. 37-57. 
Ingelbien, Raphaël. "A Novelist's Caravaggism: Michael Ondaatje’s In the Skin of a Lion." The Guises of Canadian Diversity: New European perspectives = Les masques de la diversité canadienne. Ed. Jaumain Serge and Marc Manfort. Cross/Cultures 19. Amsterdam: Rodopi, 1995. 27-37.

Innes, C.L. The Cambridge Introduction to Postcolonial Literatures in English. Cambridge: CUP, 2007.

Iyer, Pico. "A New Kind of Mongrel Fiction." Rev. of Divisadero, by Michael Ondaatje. The New York Review of Books 54.11 (2007).

Jackson, Peter, Philip Crang and Claire Dwyer. "Introduction: The Spaces of Transnationality." Transnational Spaces. Ed. Peter Jackson, Philip Crang and Claire Dwyer. Transnationalism 6. London: Routledge, 2004. 1-23.

Kamboureli, Smaro. "The Alphabet of the Self: Generic and Other Slippages in Michael Ondaatje's Running in the Family." Reflections: Autobiography and Canadian Literature. Ed. K.P. Stich. Ottawa: U of Ottawa P, 1988. 79-91.

- "The Culture of Celebrity and National Pedagogy." Home-Work: Postcolonialism, Pedagogy \& Canadian Literature. Ed. Cynthia Sugars. Reappraisals: Canadian Writers 28. Ottawa: U of Ottawa P, 2004. 35-55.

Kastoryano, Riva. "Citizenship and Belonging: Beyond Blood and Soil." The Postnational Self: Belonging and Identity. Ed. Ulf Hedetoft and Mette Hjort. Public Worlds 10. Minneapolis: U of Minnesota P, 2002. 120-36.

Kella, Elizabeth. Beloved Communities: Solidarity and Difference in Fiction by Michael Ondaatje, Toni Morrison, and Joy Kogawa. Studia Anglistica Upsaliensia 110. Uppsala: Uppsala University Library, 2000.

Kemp, Mark A. R. "Italy and the Ruins of Western Civilization: Michael Ondaatje's The English Patient.” NEML A Italian Studies 21 (1997): 131-55.

Leon, Carol. "Diaspora Space: The Practice of Biography in Michael Ondaatje's Running in the Family." Sri Lanka Journal of the Humanities 27-28.1-2 (2001-02): 24-37.

Levitt, Peggy and Nina Glick Schiller. "Conceptualizing Simultaneity: A Transnational Social Field Perspective on Society." Rethinking Migration: New Theoretical and Emperical Perspectives. Ed. Alejandro Portes and Josh DeWind. New York: Berghahn Books, 2007. 181-218.

Levitt, Peggy. The Transnational Villagers. Berkeley: UCP, 2001.

Lisle, Debbie. The Global Politics of Contemporary Travel Writing. Cambridge, CUP: 2006.

Löfgren, Orvar. "The Nationalization of Anxiety: A History of Border Crossings." The Postnational Self: Belonging and Identity. Ed. Ulf Hedetoft and Mette Hjort. Public Worlds 10. Minneapolis: U of Minnesota P, 2002. 250-74.

Loomba, Ania. Colonialism/Postcolonialism. 2nd ed. London: Routledge, 2005. 
Lowry, Glen. "The Representation of 'Race' in Ondaatje's In the Skin of a Lion." Comparative Cultural Studies and Michael Ondaatje's Writing. Ed. Steven Tötösy de Zepetnek. West Lafayette: Purdue UP, 2005. 62-72.

Maslin, Janet. "Strands May Be Delicate, but They're All Connected." Rev. of Divisadero, by Michael Ondaatje. The New York Times 11 June 2007. 8 April 2008. http://www.nytimes.com/2007/06/11/books/11masl.html?scp=4\& $\mathrm{sq}=$ divisadero $\% 20$ ondaatje\&st $=\mathrm{cse}>$

Mason, Jody. "'The Animal out of the Desert': The Nomadic Metaphysics of Michael Ondaatje's In the Skin of a Lion." Studies in Canadian Literature 31.2 (2006): 66-87.

McLeod, John. Beginning Postcolonialism. Manchester: MUP, 2000.

Mukherjee, Arun P. "The Poetry of Michael Ondaatje and Cyril Dabydeen: Two Responses to Otherness." The Journal of Commonwealth Literature 20.1 (1985): 49-67.

Overbye, Karen. "Remembering the Body: Constructing the Self as Hero in In the Skin of a Lion." Studies in Canadian Literature 17.2 (1992): 1-13.

Papayanis, Marylin Adler. Writing in the Margins: The Ethics of Expatriation from Lawrence to Ondaatje. Nashville: Vanderbilt UP, 2005.

Parker, Peter. Rev. of Divisadero, by Michael Ondaatje. Times Online 23 September 2007. 8 April $2008<$ http://entertainment.timesonline.co.uk/tol/arts_and_ entertainment/books/fiction/article2500258.ece>

Perosa, Sergio. "Michael Ondaatje's In the Skin of a Lion and the Building of Cities." Imagination and the Creative Impulse in the New Literatures in English. Ed. M.-T. Bindella and G.V. Davis. Cross/Cultures 9. Amsterdam: Rodopi, 1993. 18189.

Pesch, Josef. "Mediation, Memory and a Search for the Father: Michael Ondaatje's Running in the Family." Zeitschrift für Anglistik und Amerikanistik: A Quarterly of Language, Literature and Culture 45.1 (1997): 556-71.

Portes, Alejandro and Josh DeWind. "A Cross-Atlantic Dialogue: The Progress of Research and Theory in the Study of International Migration." Rethinking $M i$ gration: New Theoretical and Emperical Perspectives. Ed. Alejandro Portes and Josh DeWind. New York: Berghahn Books, 2007. 3-26.

Pries, Ludger. "New Migration in Transnational Spaces." Migration and Transnational Social Spaces. Ed. Ludger Pries. Aldershot: Ashgate, 1999. 1-35.

Ray, Sangeeta. "Memory, Identity, Patriarchy: Projecting a Past in the Memoirs of Sara Suleri and Michael Ondaatje.” Modern Fiction Studies 39.1 (1993): 37-58.

Renan, Ernest. "What is a Nation?" Nation and Narration. Ed. Homi K. Bhabha. London: Routledge, 1990. 8-22.

Rushdie, Salman. Imaginary Homelands: Essays and Criticism 1981-91. London: Granta Books, 1992. 
Said, Edward W. Culture and Imperialism. New York: Vintage, 1993.

Satzewich, Vic and Lloyd Wong. "Conclusion: Directions for Future Research." Transnational Identities and Practices in Canada. Ed. Vic Satzewich and Lloyd Wong. Vancouver: UBC Press, 2006. 296-98.

Saul, Joanna. Writing the Roaming Subject: The Biotext in Canadian Literature. Toronto: U of Toronto P, 2006.

Schiffauer, Werner, Gerd Baumann, Riva Kastoryano and Steven Vertovec. Civil Enculturation: Nation-State, Schools and Ethnic Difference in Four European Countries. New York: Berghahn, 2004.

Schumacher, Rod. "Patrick's Quest: Narration and Subjectivity in Michael Ondaatje's In the Skin of a Lion." Studies in Canadian Literature 21.2 (1996): 1-21.

Shin, Andrew. "The English Patient's Desert Dream." Lit: Literature Interpretation Theory 18.3 (2007): 213-35.

Siemerling, Winfried. "Oral History and the Writing of the Other in Ondaatje's In the Skin of a Lion." Comparative Cultural Studies and Michael Ondaatje's Writing. Ed. Steven Tötösy de Zepetnek. West Lafayette: Purdue UP, 2005. 92-103.

Smith, Robert. "Reflections on Migration, the State and the Construction, Durability and Newness of Transnational Life." Migration and Transnational Social Spaces. Ed. Ludger Pries. Canadiana 1. Aldershot: Ashgate, 1999. 187-219.

Smyrl, Shannon. 'The Nation as 'International Bastard': Ethnicity and Language in Michael Ondaatje's The English Patient.” SCL/ÉLC 28.2 (2003): 9-38.

Snelling, Sonia. "A Human Pyramid': An (Un)Balancing Act of Ancestry and History in Joy Kogawa's Obasan and Michael Ondaatje's Running in the Family." Journal of Commonwealth Literature 32.1 (1997): 21-33.

Spearey, Susan. "Mapping and Masking: The Migrant Experience in Michael Ondaatje's In the Skin of a Lion." The Journal of Commonwealth Literature 29.2 (1994): 45-60.

Stolar, Batia Boe. "Building and Living the Immigrant City: Michael Ondaatje's and Austin Clarke's Toronto." Downtown Canada: Writing Canadian Cities. Ed. Justin D. Edwards and Douglas Ivison. Toronto: U of Toronto P, 2005. 12241.

Turcotte, Gerry. "Venturing into Undiscoverable Countries: Reading Ondaatje, Malouf, Atwood \& Jia in an Asia-Pacific Context." Australian-Canadian Studies 15.2-16.1 (1997-98): 65-72.

United Nations. "Estimated Number of International Migrants at Mid-Year." United Nations. 2006. 12 February 2009. < http://esa.un.org/migration/index. asp?panel $=1>$. Path: Estimated number of international migrants at mid-year (both sexes); World. 
- "International Migrants as a Percentage of the Population." United Nations. 2006. 12 February 2009. <http://esa.un.org/migration/index.asp?panel=1>. Path: International Migrants as a percentage of the population: World.

Vauthier, Simone. "A Story of Silence and Voices: Michael Ondaatje's In the Skin of a Lion." Multiple Voices: Recent Canadian Fiction: Proceedings of the $4^{\text {th }}$ International Symposium of Brussels Centre for Canadian Studies 29 November - 1 December 1989. Ed. Jeanne Delbaere. Sydney: Dangaroo P, 1990. 69-90.

Vertovec, Steven. "Migrant Transnationalism and Modes of Transformation." Rethinking Migration: New Theoretical and Emperical Perspectives. Ed. Alejandro Portes and Josh DeWind. New York: Berghahn Books, 2007. 149-79.

- "Transnationalism and Identity." Journal of Ethnic and Migration Studies 27.4 (2001): 573-82.

Wayland, Sarah V. "The Politics of Transnationalism: Comparative Perspectives." Transnational Identities and Practices in Canada. Ed. Vic Satzewich and Lloyd Wong. Vancouver: UBC Press, 2006. 18-34.

Werth, Wolfgang. "Immigration and Acculturation in Michael Ondaatje's In the Skin of a Lion." Wandering Selves: Essays on Migration and Multiculturalism. Ed. Michael Porsche and Christian Berkemeier. Arbeiten zur Amerikanistik 29. Essen: Die Blaue Eule, 2001. 125-33.

White, Paul. "Geography, Literature and Migration." Writing across Worlds: Literature and Migration. Ed. Russel King, John Connel and Paul White. London: Routledge, 1995. 1-19.

Wong, Lloyd and Vic Satzewich. "Introduction: The Meaning and Significance of Transnationalism." Transnational Identities and Practices in Canada. Ed. Vic Satzewich and Lloyd Wong. Vancouver: UBC Press, 2006. 1-15.

Wong, Lloyd L. "Home away from Home? Transnationalism and the Canadian Citizenship Regime." Communities across Borders: New Immigrants and Transnational Cultures. Ed. Paul Kennedy and Victor Roudometof. Transnationalism 5. London: Routledge, 2002. 169-81.

Woznialis, Danuta. "Identity as an Open-Ended Process: Michael Ondaatje's Works." Dabai ir Dienos 32 (2002): 267-90.

Yeoh, Brenda S.A., Karen P.Y. Lai, Michael W. Charney and Tong Chee Kiong. "Approaching Transnationalisms." Approaching Transnationalisms: Studies on Transnational Societies, Multicultural Contacts, and Imaginings of Home. Ed. Brenda S. A. Yeoh, Michael W. Charney and Tong Chee Kiong. Boston: Kluwer, 2003. $1-12$.

Younis, Raymond Aaron. "Nationhood and Decolonization in The English Patient." Canadian Journal of Film Studies / Revue canadienne d'études cinématographiques 6.1 (1997): 2-9

- "Race, Representation and Nationhood." Australian-Canadian Studies 15.2-16.1 (1997-98): 43-63. 


\section{„Göttinger Schriften zur Englischen Philologie“: Zum Konzept der Reihe}

Die Reihe „Göttinger Schriften zur Englischen Philologie“ umfasst Schriften zur Forschung aus den Disziplinen englische, amerikanische und postkoloniale Literatur- und Kulturwissenschaft, englische Fachdidaktik, englische Sprache, Literatur und Kultur des Mittelalters, Linguistik des Englischen. Veröffentlicht werden können:

- im Rahmen des 1. Staatsexamens für das Lehramt an Gymnasien verfasste Zulassungsarbeiten (Staatsarbeiten), die mit ,sehr gut' benotet wurden bzw. die mit ,gut' benotet und entsprechend überarbeitet wurden, so dass sie zum Zeitpunkt der Veröffentlichung mit ,sehr gut' bewertet werden könnten;

- im Rahmen des Magisterexamens verfasste Zulassungsarbeiten (Magisterarbeiten), die mit ,sehr gut ${ }^{6}$ benotet wurden bzw. die mit ,gut benotet und entsprechend überarbeitet wurden, so dass sie zum Zeitpunkt der Veröffentlichung mit ,sehr gut ${ }^{6}$ bewertet werden könnten;

- im Rahmen des BA-Studiengangs (Zwei-Fächer-Bachelor-Studiengang) verfasste Abschlussarbeiten (Bachelor-Arbeiten), die mit ,sehr gut ${ }^{6}$ benotet wurden bzw. die mit ,gut ${ }^{`}$ benotet und entsprechend überarbeitet wurden, so dass sie zum Zeitpunkt der Veröffentlichung mit ,sehr gut' bewertet werden könnten;

- im Rahmen der einschlägigen MA-Studiengänge (Master of Arts / Master of Education) verfasste Abschlussarbeiten (Master-Arbeiten), die mit ,sehr gut' benotet wurden bzw. die mit ,gut ${ }^{6}$ benotet und entsprechend überarbeitet wurden, so dass sie zum Zeitpunkt der Veröffentlichung mit ,sehr gut bewertet werden könnten.

Zusätzlich können in der Reihe Sammelbände beispielsweise mit den Arbeitsergebnissen aus Kolloquien oder Workshops veröffentlicht werden. Die Werke werden auf Deutsch oder Englisch publiziert. 
How do we see ourselves? How do we see each other? Questions of identity feature largely in our everyday lives: Advertisements try to sell us things to improve our lives because "they fit us". A particular set of clothes is turned into a brand which a group of people uses to identify who belongs to them and who does not. In literature, too, questions of belonging somewhere - to a group, to a people, to a nation - are discussed widely, though this is sometimes not apparent from the very outset. In this volume, four essays discuss questions of identity and gender, of identity and nationality in English, Irish and Canadian/Sri Lankan texts ranging from the early nineteenth to the twentyfirst century. 